\title{
Advanced Sorbent Development Program \\ Development of Sorbents for Moving-Bed and Fluidized-Bed Applications
}

Volume I: Development of Sorbents for Moving-Bed Applications

Final Report

By

R.E. Ayala

V.S. Venkataramani

September 1998

Work performed under Contract No.: DE-AC21-94MC31089

September 30, 1994 to September 30, 1998

For

U.S. Department of Energy

Federal Energy Technology Center

Morgantown, West Virginia

By

GE Corporate Research and Development

P.O. Box 8

Schenectady, New York 12301

E-mail: Raul.Ayala@crd.ge.com 


\section{DISCLAIMER}

This report was prepared as an account of work sponsored by an agency of the United States Government. Neither the United States Government nor any agency thereof, nor any of their employees, makes any warranty, express or implied, or assumes any legal liability or responsibility for the accuracy, completeness, or usefulness of any information, apparatus, product, or process disclosed, or represents that its use would not infringe privately owned rights. Reference herein to any specific commercial product, process, or service by trade name, trademark, manufacturer, or otherwise does not necessarily constitute or imply its endorsement, recommendation, or favoring by the United States Government or any agency thereof. The views and opinions of authors expressed herein do not necessarily state or reflect those of the United States Government or any agency thereof. 


\begin{abstract}
The integrated gasification combined cycle (IGCC) power system using high-temperature coal gas cleanup is one of the most promising advanced technologies for the production of electric power from coal in an environmentally acceptable manner. Unlike conventional low-temperature cleanup systems that require costly heat exchangers, high-temperature coal gas cleanup systems can be operated near $482-538^{\circ} \mathrm{C}\left(900-1000^{\circ} \mathrm{F}\right)$ or higher, conditions that are a closer match with the gasifier and turbine components in the IGCC system, thus resulting is a more efficient overall system.
\end{abstract}

GE is developing a moving-bed, high-temperature desulfurization system for the IGCC power cycle in which zinc-based regenerable sorbents are currently being used as desulfurization sorbents. Zinc titanate and other proprietary zinc-based oxides are being considered as sorbents for use in the Clean Coal Technology Demonstration Program at Tampa Electric Co.'s (TECo) Polk Power Station. Under cold startup conditions at TECo, desulfurization and regeneration may be carried out at temperatures as low as $343^{\circ} \mathrm{C}\left(650^{\circ} \mathrm{F}\right)$, hence a versatile sorbent is desirable to perform over this wide temperature range. A key to success in the development of high-temperature desulfurization systems is the matching of sorbent properties for the selected process operating conditions, namely, sustainable desulfurization kinetics, high sulfur capacity, and mechanical durability over multiple cycles. Additionally, the sulfur species produced during regeneration of the sorbent must be in a form compatible with sulfur recovery systems, such as sulfuric acid or elemental sulfur processes.

The overall objective of this program is to develop regenerable sorbents for hydrogen sulfide removal from coal-derived fuel gases in the temperature range $343-538^{\circ} \mathrm{C}\left(650-1000^{\circ} \mathrm{F}\right)$. Two categories of reactor configurations are being considered: moving-bed reactors and fluidized-bed (bubbling and circulating) reactors. In addition, a cost assessment and a market plan for large-scale fabrication of sorbents were developed. As an optional task, long-term bench-scale tests of the best moving-bed sorbents were conducted.

Starting from thermodynamic calculations, several metal oxides were identified for potential use as hot gas cleanup sorbents using constructed phase stability diagrams and laboratory screening of various mixed-metal oxide formulations. Modified zinc titanates and other proprietary metal oxide formulations were evaluated at the bench scale and many of them found to be acceptable for operation in the target desulfurization temperature range of $370^{\circ} \mathrm{C}\left(700^{\circ} \mathrm{F}\right)$ to $538^{\circ} \mathrm{C}\left(1000^{\circ} \mathrm{F}\right)$ and regeneration temperatures up to $760^{\circ} \mathrm{C}\left(1400^{\circ} \mathrm{F}\right)$. Further work is still needed to reduce the batch-to-batch repeatability in the fabrication of modified zinc titanates for larger scale applications.

The information presented in this Volume 1 report contains the results of moving-bed sorbent development at General Electric's Corporate Research and Development (GE-CRD). A separate Volume 2 report contains the results of the subcontract on fluidized-bed sorbent development at the Institute of Gas Technology (IGT). 


\section{ACKNOWLEDGMENTS}

Special thanks to all the people who, over the years, contributed in one way or another to the fruitful completion of this multiyear contract. Our sincere appreciation to all those who provided technical insights and managerial guidance at various points in the program. At the risk of forgetting to acknowledge individually each and all of the contributors, the help of the following individuals was particularly appreciated:

- E. Gal and S. Bevan at GE Environmental Services, Inc. (GEESI), and S.G. Kimura, D. Najewicz, and N. Shilling, at GE-CRD who reviewed the project through the years and gave useful advice and guidance.

- T. Chuck and K. McEvoy, who diligently performed most of the tests in the laboratory at GE-CRD. Also A.H. Furman, A. Feitelberg and the technical staff of the GE-CRD pilot plant, who collaborated in the pilot plant and gathered data on the performance of zinc titanates during the 200-hr Test 8 in 1996.

- J. Swisher, E\&A Associates, and the Illinois Clean Coal Institute for providing GE-CRD with the samples of ICCI-2C sorbent for bench evaluation within this program

- M. Wise and W. Goyette of Chemetals, Inc., who provided samples of zinc-manganese sorbents for evaluation at GE-CRD.

- R. Gupta and the technical staff at Research Triangle Institute, who performed the independent 50cycle long-term testing of GE-UCI zinc titanate sorbents in their bench-reactor facilities.

- The authors also acknowledge the helpful discussions with Mr. D. Cicero, DOE's Program Contracting Office Representative, for the support and review of this contract work over the years, as well as the rest of the staff at the U.S. Dept. of Energy, Federal Energy Technology Center, who funded this project under Contract DE-AC21-94MC31089. 


\section{TABLE OF CONTENTS}

ABSTRACT

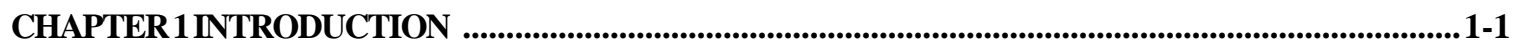

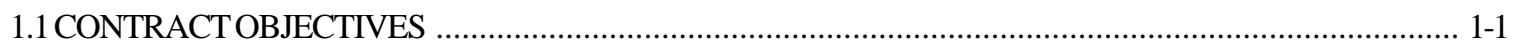

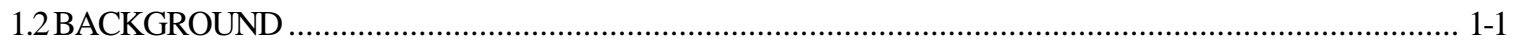

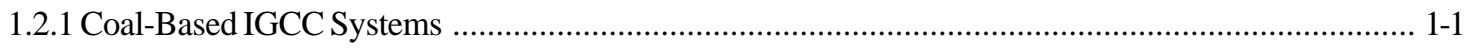

1.2.2 High-Temperature Desulfurization Systems …................................................................ 1-3

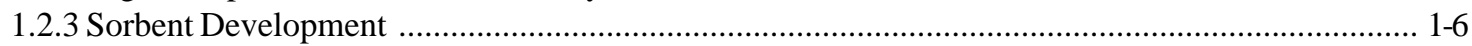

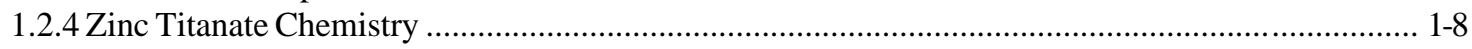

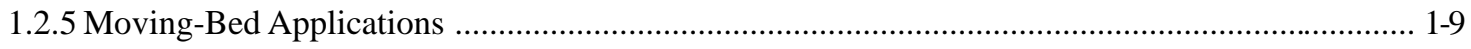

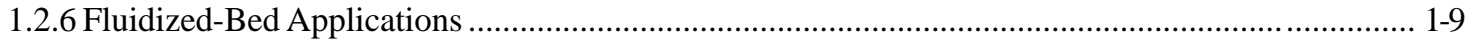

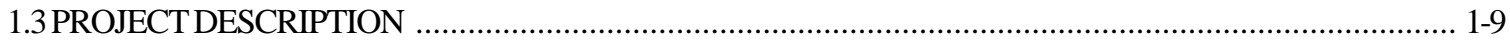

CHAPTER 2 EXPERIMENTAL PROCEDURES ...............................................................................2 2-1

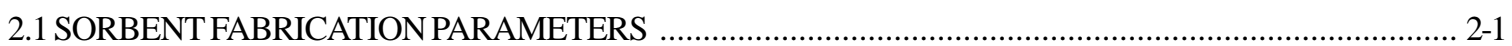

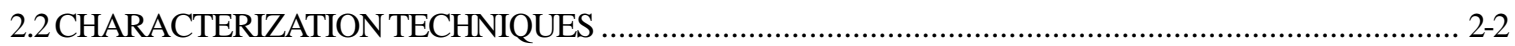

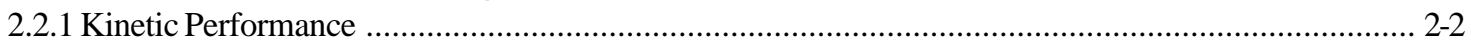

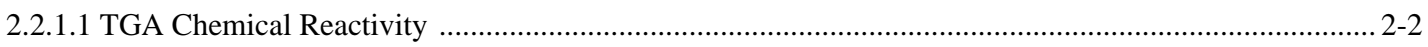

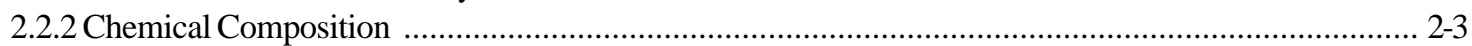

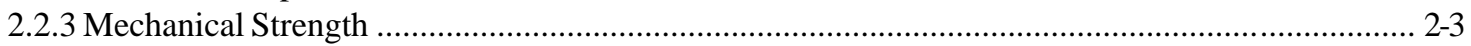

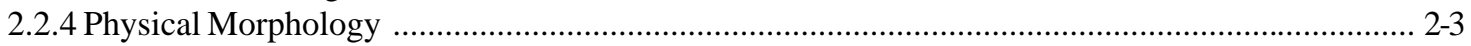

2.2.4.1 Pore Size Distribution by Mercury Porosimetry ...................................................................... 2-3

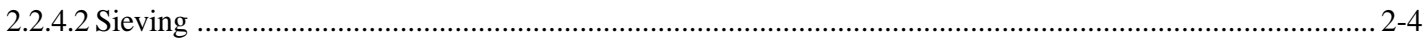

2.3 PROVISION OF BENCH-SCALE REACTOR (TASK 3) ................................................................... $2-4$

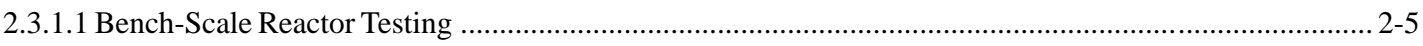

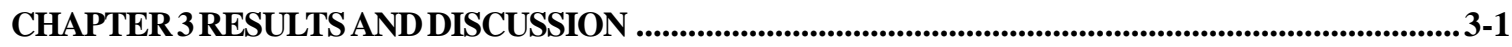

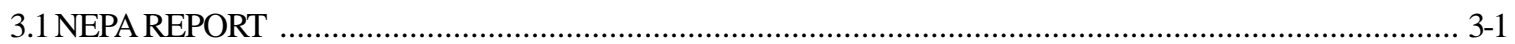

3.2 EVALUATION OF METAL OXIDES AS REGENERABLESORBENTS .......................................... 3-1

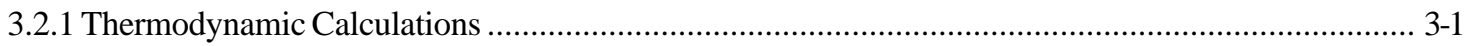

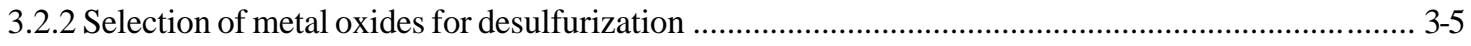

3.3 SORBENT PREPARATION AND BENCH REACTOR TESTING ................................................... 3-7

3.3.1 Testing of UCI-GE Zinc Titanate Sorbents ..................................................................... 3-7

3.3.2 Screening of Sorbents Containing Mixed-Metal Oxides ..................................................... 3-7

3.3.3 Evaluation of Molybdenum-Containing Zinc Titanate Sorbents ........................................... 3-9

3.3.3.1 Screening of laboratory formulations at GE-CRD ....................................................................... 3-9

3.3.3.2 50-cycle of Bench Test at Research Triangle Institute .............................................................. 3-11

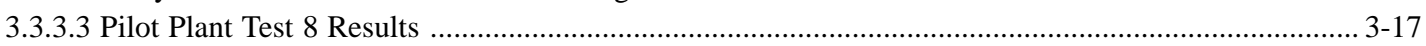

3.3.3.4 Zinc titanate structure determination after sulfidation/regeneration cycles ........................................ 3-20 
3.3.3.5 Regeneration of Mo-doped zinc titanate formulations at higher pressure and

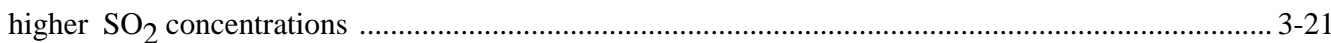

3.3.4 Modified Zinc Titanates (MZT's) with additives ................................................................ 3-27

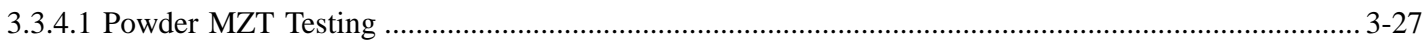

3.3.4.2 Pelletized MZT Sorbent Testing ….................................................................................... 3-31

3.3.4.2.1 Mechanical durability of fresh pelletized sorbents .............................................................. 3-31

3.3.4.2.2 Desulfurization and regeneration characteristics ............................................................... 3-32

3.3.4.2.3 Sulfate formation during regeneration ........................................................................... 3-36

3.3.4.2.4 Temperature range of desulfurization of single pellets ....................................................... 3-36

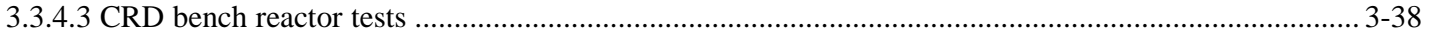

3.3.4.3.1 Mechanical durability of cycled formulations .................................................................. 3-43

3.3.4.3.2 Bench-scale extended multicycle tests at GE-CRD ............................................................ 3-45

3.3.4.3.3 Desulfurization and Regeneration performance at $371^{\circ} \mathrm{C}\left(700{ }^{\circ} \mathrm{F}\right)$ temperatures ....................... 3-48

3.3.4.4 RTI's Independent Bench Evaluation ................................................................................ 3-51

3.3.5 Evaluation of Chemetals Manganese Oxide Sorbents ............................................................ 3-54

3.3.6 Evaluation of ICCI-2C Zinc Titanate Sorbent ................................................................... 3-62

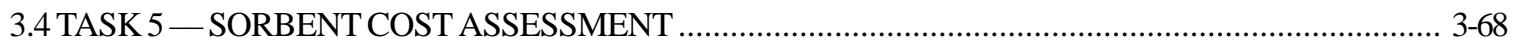

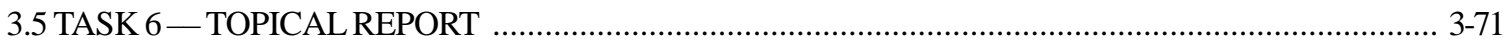

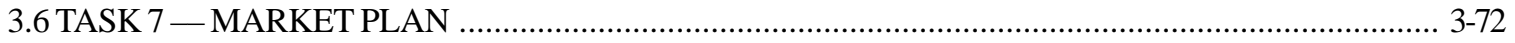

CHAPTER 4 CONCLUSIONS

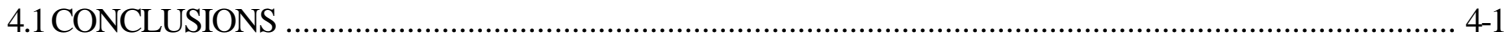

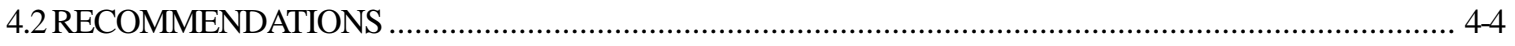




\section{LIST OF TABLES}

Table 2-1 Gas Compositions (vol \%) used in TGA tests .................................................................2-2

Table 2-2 Simulated Coal Gas Composition for Bench-Scale Testing ..............................................2-6

Table 3-1 List of metal components for sorbent screening …................................................ 3-6

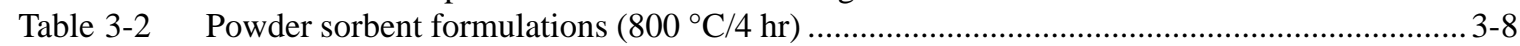

Table 3-3 Zinc/titanium formulations with various additives ...................................................... 3-8

Table 3-4 Powder mixed-metal oxides formulations .............................................................. 3-9

Table 3-5 Gas compositions for 50-cycle test ................................................................. 3-13

Table 3-6 Target test conditions during absorption ........................................................ 3-13

Table 3-7 Sulfur loading of zinc titanate sorbent ........................................................... 3-15

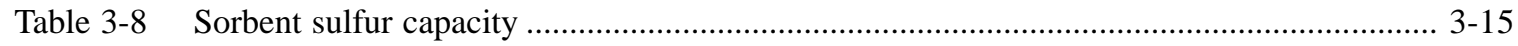

Table 3-9 Attrition results of zinc titanate bench tests at RTI .................................................... 3-17

Table 3-10 Major structure of Mo-doped zinc titanate by XRD ...................................................... 3-20

Table 3-11 GE Modified Zinc Titanate Formulations .................................................................. 3-27

Table 3-12 Properties of the first round of pelletized fresh samples ............................................. 3-31

Table 3-13 Mechanical properties of the second round of zinc titanate formulations ...................... 3-32

Table 3-14 Target test conditions during absorption in bench tests ......................................... 3-38

Table 3-15 Test conditions in the GE-CRD reactor system during quadrant bench tests .................... 3-39

Table 3-16 Formulations loaded into bench quadrant tests at GE-CRD ....................................... 3-40

Table 3-17 Attrition and sulfur results on 5th regeneration samples from quadrant bench test \#1 ...... 3-43

Table 3-18 Attrition and sulfur results on 5th regeneration samples from quadrant bench test \#2 ....... 3-44

Table 3-19 Bench-Scale Extended testing of MZT-I1 ....................................................... 3-47

Table 3-20 Preliminary results of screening tests at RTI on MZT-R1 .......................................... 3-53

Table 3-21 XRD Analysis of CST939 sorbent …....................................................................... 3-56

Table 3-22 Bench-Scale Test Parameters for Chemetals CST-939 Sorbent ........................................ 3-60

Table 3-23 Residual sulfur of ICCI-2C samples after bench-scale testing at GE-CRD ........................ 3-60

Table 3-24 Relative cost of metal oxides for sorbent fabrication .................................................... 3-68

Table 4-1 List of metal components for sorbent screening ......................................................... 


\section{LIST OF FIGURES}

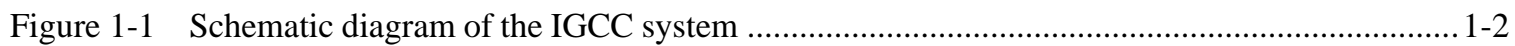

Figure 1-2 Schematic diagram of the GE-CRD pilot plant ................................................................... 1-4

Figure 2-1 Schematic diagram of the gas flow system in the bench-scale reactor ...................................2-5

Figure 3-1 $\mathrm{H}_{2} \mathrm{~S}$ equilibrium concentration in fuel gas (Texaco) with various oxides ...............................3-3

Figure 3-2 $\mathrm{H}_{2} \mathrm{~S}$ equilibrium concentration in fuel gas (U-GAS) with various oxides ..............................3-3

Figure 3-3 Phase stability diagrams for Zn-S-O, Mo-S-O, Cu-S-O, and Mn-S-O systems ......................... 3-4

Figure 3-4 Phase stability diagrams for Co-S-O, Fe-S-O, W-S-O, and Ce-S-O systems ............................. 3-5

Figure 3-5 $\mathrm{H}_{2} \mathrm{~S}$ breakthrough curve for the simultaneous bench reactor testing of four formulations

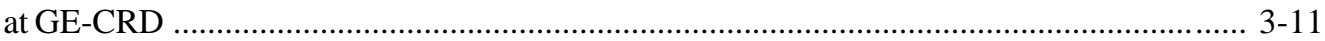

Figure 3-6 Envelope of breakthrough curves for zinc titanate screening at GE-CRD .......................... 3-11

Figure 3-7 ASTM attrition results on sorbents after the 20th regeneration in bench screening

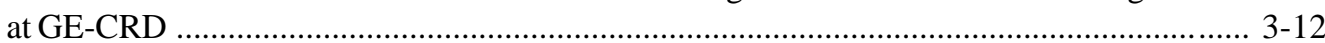

Figure 3-8 Pellet distribution after ASTM attrition test (20th. regeneration) ....................................... 3-12

Figure 3-9 TGA sulfur capacity of sorbents after 20-cycles ........................................................ 3-12

Figure 3-10 $\mathrm{H}_{2} \mathrm{~S}$ breakthrough curves for 50-cycle test of zinc titanate at RTI .................................... 3-14

Figure 3-11 Envelope of breakthrough curves for zinc titanate testing at RTI ................................... 3-14

Figure 3-12 TGA sulfur capacity of powdered samples after 50 cycles of testing at RTI ....................... 3-16

Figure 3-13 TGA reactivity of T-3121 zinc titanate pellets after 50 cycles of bench tests at RTI ........ 3-16

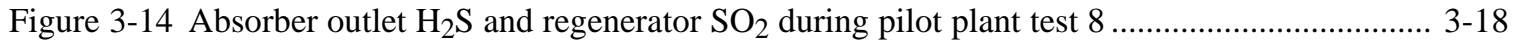

Figure 3-15 TGA reactivity of T-2594M zinc titanate pellets after 200 hours of pilot plant Test 8

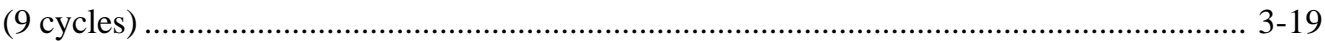

Figure 3-16 $\mathrm{H}_{2} \mathrm{~S}$ breakthrough curves for T-2594M when regeneration under regeneration with $\mathrm{SO}_{2}$

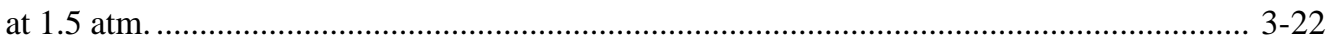

Figure 3-17 Envelope of $\mathrm{H}_{2} \mathrm{~S}$ breakthrough curves for T-2594M when regenerating under $\mathrm{SO}_{2}$

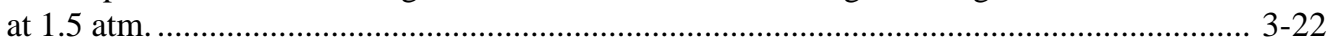

Figure 3-18 $\mathrm{H}_{2} \mathrm{~S}$ breakthrough curves for T-2594M with regeneration performed with $\mathrm{SO}_{2}$ at 3 atm. . 3-23

Figure 3-19 Envelope of $\mathrm{H}_{2} \mathrm{~S}$ breakthrough curves for T-2594M with regeneration performed with $\mathrm{SO}_{2}$ at $3 \mathrm{~atm}$.

Figure 3-20 $\mathrm{H}_{2} \mathrm{~S}$ breakthrough curves for T-2594M with regeneration performed with $\mathrm{SO}_{2}$ at $5 \mathrm{~atm}$ and $704{ }^{\circ} \mathrm{C}$ (cycles $\left.1-5\right)$ or $760^{\circ} \mathrm{C}\left(1400{ }^{\circ} \mathrm{F}\right)($ cycles 6-8) ............................................... 3-24

Figure 3-21 Envelope of $\mathrm{H}_{2} \mathrm{~S}$ breakthrough curves for T-2594M with regeneration performed with $\mathrm{SO}_{2}$ at $5 \mathrm{~atm}$ and $704{ }^{\circ} \mathrm{C}\left(1300{ }^{\circ} \mathrm{F}\right)$ (cycles 1-5) or $760{ }^{\circ} \mathrm{C}\left(1400{ }^{\circ} \mathrm{F}\right)$ (cycles 6-8) ...... 3-24

Figure 3-22 $\mathrm{H}_{2} \mathrm{~S}$ breakthrough curves for T-2594M with regeneration performed with $\mathrm{SO}_{2}$ at $5 \mathrm{~atm}$

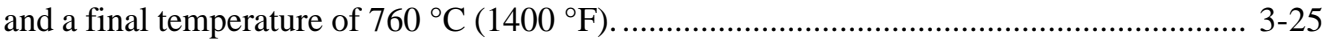

Figure 3-23 Envelope of $\mathrm{H}_{2} \mathrm{~S}$ breakthrough curves for T-2594M with regeneration performed with $\mathrm{SO}_{2}$ at 5 atm and a final $\mathrm{N}_{2}$ decomposition temperature of $760{ }^{\circ} \mathrm{C}\left(1400{ }^{\circ} \mathrm{F}\right)$............ 3-25

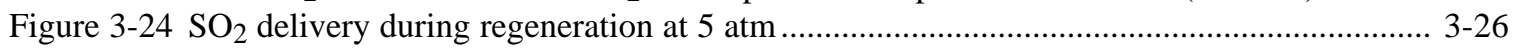

Figure 3-25 TGA chemical reactivity of ZT9607 zinc titanate ........................................................... 3-29

Figure 3-26 TGA Chemical reactivity of ZT9603 zinc titanate without stabilizer ................................ 3-29

Figure 3-27 TGA reactivity of a zinc titanate with a phase stabilizer ................................................ 3-30

Figure 3-28 TGA reactivity of powder modified zinc titanates at $482{ }^{\circ} \mathrm{C}, 3 \% \mathrm{H}_{2} \mathrm{~S}$, and $1 \mathrm{~atm}$............ 3-30

Figure 3-29 TGA Reactivity of PP4114 zinc titanate at $482^{\circ} \mathrm{C}\left(900^{\circ} \mathrm{F}\right)$......................................... 3-33

Figure 3-30 TGA Reactivity of PP4118 zinc titanate at $482{ }^{\circ} \mathrm{C}\left(900{ }^{\circ} \mathrm{F}\right)$........................................ 3-33

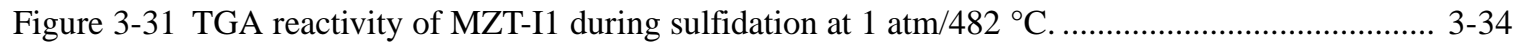

Figure 3-32 TGA reactivity of MZT-O1 during sulfidation at $1 \mathrm{~atm} / 492{ }^{\circ} \mathrm{C}$..................................... 3-34

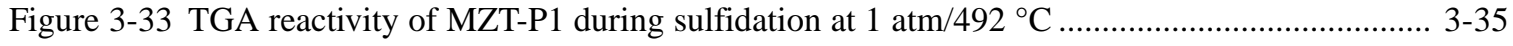

Figure 3-34 TGA reactivity of MZT-R1 during sulfidation at $1 \mathrm{~atm} / 492{ }^{\circ} \mathrm{C}$........................................ 3-35

Figure 3-35 TGA reactivity of MZT-G1 during sulfidation at $1 \mathrm{~atm} / 492{ }^{\circ} \mathrm{C}$...................................... 3-36

Figure 3-36 TGA weight gain due to sulfate formation during regeneration of the pelletized modified zinc titanates at $1 \mathrm{~atm}$ and $718^{\circ} \mathrm{C}\left(1325^{\circ} \mathrm{F}\right)$................................................... 3-37

Figure 3-37 TGA reactivity of MZT-R1 zinc titanate as a function of temperature ............................... 3-37 
Figure 3-38 Breakthrough curves during absorption for the modified zinc titanate sorbents

(Quadrant Bench Test \#1) .................................................................................... 3-40

Figure 3-39 Temperatures profiles for the four sorbents tested under the Quadrant Bench Test \#1........ 3-41

Figure 3-40 Temperatures profiles for the four sorbents tested under the Quadrant Bench Test \#1 ........ 3-42

Figure 3-41 Breakthrough curves for T-2594M zinc titanate with regeneration at 5 atm and $8 \% \mathrm{SO}_{2}$ in the regeneration gas

Figure 3-42 Outlet $\mathrm{H}_{2} \mathrm{~S}$ concentration from the pilot plant absorber using T-2594M during Test 8 (1995)

Figure 3-43 Attrition resistance ratios of zinc titanate formulations after 5 cycles of bench-scale testing (Quadrant Bench Test \#1) .................................................................................... 3-44

Figure 3-44 Breakthrough curves of MZT-I1 for the first 10 cycles of screening ................................. 3-45

Figure 3-45 Breakthrough curves of MZT-I1 after the first 10 cycles of screening .............................. 3-46

Figure 3-46 Envelope of the breakthrough curves at $120 \mathrm{~min}$ of absorption for MZT-I1 ...................... 3-46

Figure 3-47 $\mathrm{H}_{2} \mathrm{~S}$ breakthrough curves for absorption by MZT-R1 at $371^{\circ} \mathrm{C}\left(700^{\circ} \mathrm{F}\right)$.......................... 3-48

Figure 3-48 Temperature profiles during regeneration of MZT-R1 at $371{ }^{\circ} \mathrm{C}\left(700{ }^{\circ} \mathrm{F}\right)$

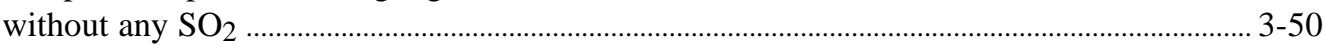

Figure 3-49 Temperature profiles during regeneration of MZT-R1 at $371{ }^{\circ} \mathrm{C}\left(700{ }^{\circ} \mathrm{F}\right)$ with $10 \% \mathrm{SO}_{2}$ added $3-50$

Figure 3-50 Breakthrough curves for MZT-R1 sorbent for 5-cycles in screening bench tests performed at RTI

Figure 3-51 Breakthrough curves for MZT-I1 sorbent for 5-cycles in screening bench tests performed at RTI

Figure 3-52 Breakthrough curves for MZT-I1 sorbent for 13 cycles in screening bench tests performed at RTI

Figure 3-53 Mechanical Strength of Chemetals Sorbents $3-54$

Figure 3-54 First sulfidation on CST 939 manganese oxide sorbent in a TGA .................................... 3-55

Figure 3-55 TGA regeneration profile of CST-939 sorbent powder at $1350{ }^{\circ} \mathrm{F}$ and $2 \% \mathrm{O}_{2} \ldots \ldots \ldots \ldots \ldots \ldots \ldots . . . . . . . .3-56$

Figure 3-56 Equilibrium diagram for the system Mn-O-S at $550{ }^{\circ} \mathrm{C}\left(1022^{\circ} \mathrm{F}\right)$................................... 3-57

Figure 3-57 Second TGA absorption of CST-939 sorbent powder at $100{ }^{\circ} \mathrm{F}$ and $3 \% \mathrm{H}_{2} \mathrm{~S}$.

Reductive regeneration started at $\sim 50$ min. $\mathrm{H}_{2} \mathrm{~S}$ introduced at 125 minutes .................... 3-57

Figure 3-58 First absorption of CST 10255-171-3 sorbent .......................................................... 3-58

Figure 3-59 Chemetals CST-939 breakthrough curves .................................................................. 3-61

Figure 3-60 Sulfur species evolved during Reductive Regeneration \#1 ............................................... 3-61

Figure 3-61 Sulfur species evolved during Reductive Regeneration \#2 ............................................... 3-62

Figure 3-62 Breakthrough curves of ICCI-2C during bench testing at GE-CRD .................................. 3-63

Figure 3-63 Envelope of the breakthrough curves for bench testing of ICCI-2C at GE-CRD ............... 3-64

Figure 3-64 TGA Reactivity of ICCI-2C samples from the gas inlet location ....................................... 3-65

Figure 3-65 TGA Reactivity of ICCI-2C samples from the gas outlet location ..................................... 3-65

Figure 3-66 Temperature history of ICCI-2C during bench-scale absorptions and regenerations ......... 3-66

Figure 3-67 Sorbent makeup cost versus percent sorbent makeup ........................................................... 3-69 


\section{EXECUTIVE SUMMARY}

\section{BACKGROUND}

The integrated gasification combined cycle (IGCC) power system using high-temperature coal gas cleanup is one of the most promising advanced technologies for the production of electric power from coal in an environmentally acceptable manner. Unlike conventional low-temperature cleanup systems that require costly heat exchangers, high-temperature coal gas cleanup systems can be operated near $482-538^{\circ} \mathrm{C}\left(900-1000{ }^{\circ} \mathrm{F}\right)$ or higher, conditions that are a closer match with the gasifier and turbine components in the IGCC system, thus resulting in a more efficient overall system.

GE is developing a moving-bed, high-temperature desulfurization system for the IGCC power cycle in which zinc-based regenerable sorbents are currently being used as desulfurization sorbents. Zinc titanate and other proprietary zinc-based oxides are being considered as sorbents for use in the Clean Coal Technology Demonstration Program at Tampa Electric Co.'s (TECo) Polk Power Station. Under cold startup conditions at TECo, desulfurization and regeneration may be carried out at temperatures as low as $343^{\circ} \mathrm{C}\left(650^{\circ} \mathrm{F}\right)$; hence a versatile sorbent is desirable to perform over this wide temperature range. A key to success in the development of high-temperature desulfurization systems is the matching of sorbent properties for the selected process operating conditions, namely, sustainable desulfurization kinetics, high sulfur capacity, and mechanical durability over multiple cycles. Additionally, the sulfur species produced during regeneration of the sorbent must be in a form compatible with sulfur recovery systems, such as sulfuric acid or elemental sulfur processes.

\section{OBJECTIVES}

The overall objective of this program is to develop regenerable sorbents for hydrogen sulfide removal from coal-derived fuel gases in the temperature range $343-538^{\circ} \mathrm{C}\left(650-1000{ }^{\circ} \mathrm{F}\right)$. Two categories of reactor configurations are being considered: moving-bed reactors and fluidized-bed (bubbling and circulating) reactors. In addition, a cost assessment and a market plan for large-scale fabrication of sorbents were developed. As an optional task, long-term bench-scale tests of the best moving-bed sorbents were conducted.

The information presented in this Volume 1 report contains the results of moving-bed sorbent development at General Electric's Corporate Research and Development (GE-CRD). A separate Volume 2 report contains the results of the subcontract on fluidized-bed sorbent development at the Institute of Gas Technology (IGT). 


\section{ACCOMPLISHMENTS}

- Thermodynamic equilibrium calculations were performed for metal oxides under desulfurization conditions to determine the predicted desulfurization efficiency from coal gases in the temperature range $343-538^{\circ} \mathrm{C}$. Phase stability diagrams were constructed for oxidative regeneration conditions of the same metal oxides. From an initial list of twenty metal oxides, the number of viable candidates was reduced to six desulfurization and three structural components for laboratory evaluation. This work complements previous thermodynamic calculations of desulfurization at temperatures from $500{ }^{\circ} \mathrm{C}$ to $800{ }^{\circ} \mathrm{C}$ available in the literature.

- Evaluation of molybdenum-containing zinc titanate was performed from laboratory and bench scale to pilot plant $(4500 \mathrm{~kg})$ to correlate desulfurization reactivity and mechanical durability of sorbents and determine operating costs after scale up. The optimized formulation achieved $99 \% \mathrm{H}_{2} \mathrm{~S}$ removal from coal gas in the pilot plant and produced $8 \% \mathrm{SO}_{2}$ in the regeneration gas stream over 200 hours of operation.

- To expand the temperature operating window of zinc titanates from $482^{\circ} \mathrm{C}$ down to $343^{\circ} \mathrm{C}$, metal additives were used to produce various formulations, such as MZT-R1, which are capable of desulfurization and regeneration without preconditioning at least down to $371^{\circ} \mathrm{C}\left(700^{\circ} \mathrm{F}\right)$, conditions that are representative of cold startup at TECo's Polk Power Station HGCU demonstrationscale system.

- Two types of proprietary sorbents supplied by external vendors (ICCI-2C sorbent from E\&A Associates/Illinois Clean Coal Institute, and various zinc-manganese sorbents from Chemetals) were evaluated at GE-CRD's bench reactor to qualify for additional long-term testing.

- Sorbent operating costs for a commercial power plant using a moving-bed HGCU system were calculated. Guidelines for raw materials cost, fabrication costs, and replacement or makeup costs were calculated using a sorbent total operating cost of $0.16-0.2$ cents/ $/ \mathrm{kWh}$ for a typical $250 \mathrm{MW}$ IGCC power plant. A market plan, including recommendations for sorbent fabrication in commercial scale and identification of various vendors for the fabrication of the identified zinc titanate and proprietary sorbents, was established.

\section{RESULTS AND CONCLUSIONS}

The following results and conclusions were drawn from the evaluation of metal oxides from thermodynamic and kinetic principles in order to identify sorbent formulations suitable for fabrication and laboratory evaluation:

- A literature review of past work and screening thermodynamic calculations of metal oxides identified twenty metal oxides that had the potential for use in hot gas desulfurization systems in the temperature range of 343 to $538^{\circ} \mathrm{C}$. These were considered for further experimental evaluation.

- Thermodynamic equilibrium diagrams of $\mathrm{H}_{2} \mathrm{~S}_{(\mathrm{g})}$ over metal oxides were constructed as a function of temperature to determine the maximum sulfur removal possible at the given temperature range. Two 
coal gas fuel compositions were chosen: oxygen-blown, entrained-flow gasifier and air-blown, fluidized-bed gasifier. Of the twenty metal oxides initially considered, manganese, molybdenum, cobalt, zinc, and copper oxides were identified as having the low equilibrium $\mathrm{H}_{2} \mathrm{~S}$ and the required kinetic rates to desulfurize coal gas to the target of less than $25 \mathrm{ppm}_{2} \mathrm{~S}$.

- Corresponding phase stability diagrams of the metal sulfides in oxidative regeneration gases were also constructed to identify the regeneration capabilities of the promising desulfurization metal oxides. Zinc, copper, iron and molybdenum among others were the metals that thermodynamically and kinetically exhibited promising characteristics for regeneration at temperatures compatible with the desulfurization range chosen. Manganese required a higher temperature of regeneration than the others but still could be considered for evaluation.

- Three categories of metal oxides were considered for evaluation: (1) main components for desulfurization, (2) secondary components for desulfurization, chemical stability additives, or porosity modifiers, and (3) structural components to maintain mechanical durability of the pellets.

- The following table summarizes the metal oxides that were identified in each of the three categories as potential candidates for laboratory fabrication and evaluation.

\section{List of metal components for sorbent screening.}

\begin{tabular}{ccc}
\hline Main Component & Secondary Component & Structural Component \\
\hline $\mathrm{Zn}$ & $\mathrm{Fe}, \mathrm{Cu}, \mathrm{Mo}, \mathrm{Co}$ & $\mathrm{Ti}, \mathrm{Zr}, \mathrm{Ce}$ \\
$\mathrm{Fe}$ & $\mathrm{Cu}$ & $\mathrm{Ti}, \mathrm{Zr}$ \\
$\mathrm{Ce}$ & $\mathrm{Mo}$ & $\mathrm{Ti}, \mathrm{Zr}$ \\
$\mathrm{Cu}$ & $\mathrm{Mn}$ & $\mathrm{Ti}, \mathrm{Zr}$ \\
\hline
\end{tabular}

The following conclusions can be drawn from the sorbent fabrication and experimental evaluation of UCI-GE zinc titanates:

- Molybdenum-containing zinc titanate (at 2\% equivalent molybdenum oxide) exhibited a good combination of chemical and mechanical properties during laboratory testing at GE-CRD. Further testing at RTI's facilities during 1996 showed that requirements at that time for chemical reactivity and sulfur loading were exceeded at the target levels of $50 \%$ of theoretical. The mechanical ASTM attrition loss was well below the target level for the fresh material ( $0.7 \%$ vs. $4 \%$ target) although the same ASTM attrition loss after 50 cycles was higher at $7.4 \%$ versus the target of $5 \%$. Higher levels of attrition resistance would be required ultimately for this sorbent to be economically viable in commercial systems.

- The same molybdenum-containing formulation studied in the laboratory was also tested for 200 hours of continuous operation in the GE-CRD pilot plant under Test 8 in September 1998 to determine the correspondence in performance between bench-scale conditions in the laboratory and pilot plant operation. The pilot plant makeup losses were measured at 1.7 and $0.3 \%$ for the 200 -hr cycled sorbent under conditions of two different mesh sizes of the vibrating screen that 
removes the sorbent fines. These results are better than the 7.4\% ASTM attrition loss measured after 50 cycles in the laboratory, indicating that the large-scale operation is less severe and the cost of sorbent replacement or makeup in the pilot plant is less than predicted from ASTM tests. With respect to desulfurization performance in the GE-CRD pilot plant, close to $99 \%$ sulfur removal (30-40 ppm dry residual $\mathrm{H}_{2} \mathrm{~S}$ in the clean gas) was obtained while simultaneously achieving the target sulfur loading on the sorbent for TECo and $\mathrm{SO}_{2}$ production during regeneration. The results at the three levels of testing indicate that the flow of information and technology transfer from laboratory to pilot plant is technically consistent and prediction of larger pilot-plant scale operation is possible from laboratory and bench test results.

- Several formulations of modified zinc titanates (MZT's) were pelletized to aim at improvements in mechanical durability over the previously tested molybdenum-containing zinc titanate formulations. Two rounds of formulations containing additives were prepared. Although the first round of formulations was disappointingly weak in mechanical strength, the second round of pelletization included two formulations, MZT-I1 and MZT-R1, which exhibited improved characteristics. Both presented better mechanical durability with negligible degradation with respect to the fresh formulation, but only MZT-R1 was capable of meeting the requirements of sulfur loading of $0.11 \mathrm{~g}$ of sulfur $/ \mathrm{cm}^{3}$ of bed $\left(6.7 \mathrm{lb} / \mathrm{ft}^{3}\right)$ at the low temperatures of operation $\left(370^{\circ} \mathrm{C}, 700^{\circ} \mathrm{F}\right)$.

- Batch-to-batch repeatability in the fabrication of MZT's, however, is still an issue. ASTM attrition loss of different batches of fresh MZT-R1 prepared for testing at GE-CRD and RTI ranged from 0.7 to $2.0 \%$. This batch-to-batch variability in the attrition resistance of fresh samples is large compared to the corresponding changes in attrition loss, typically less than $1 \%$, that occur over repetitive testing. Further refinements to the formulation of MZT compositions will require better control in the pelletization procedures.

- Testing at RTI for 13 cycles at bench-scale conditions showed that the two MZT sorbents considered (MZT-R1 and MZT-I1) can desulfurize and regenerate at conditions resembling those encountered at the TECo plant, namely, desulfurization in the range $373-482^{\circ} \mathrm{C}\left(700-900^{\circ} \mathrm{F}\right)$ and regeneration up to $760^{\circ} \mathrm{C}\left(1400^{\circ} \mathrm{F}\right)$. In spite of these positive results, more work is needed to circumvent the impending degradation of the pellets over a higher number of cycles.

The following conclusions can be drawn from the testing of proprietary sorbents in the GE-CRD pressurized bench-scale reactor system:

- Several formulations of zinc oxide/manganese oxide sorbents provided by Chemetals (Baltimore, Maryland) were evaluated at GE-CRD for mechanical durability (attrition and crush strength) and chemical reactivity.

- Evaluation of Chemetals manganese-containing zinc-based sorbents suggested that improvements in mechanical strength can be brought about by the manganese component to the sorbent. Given that manganese by itself cannot remove $\mathrm{H}_{2} \mathrm{~S}$ to as low levels as zinc-based sorbents can, the combination gives a synergistic advantage of deep desulfurization and added mechanical strength. However, improvements in the fabrication procedures aimed at increasing attrition resistance of the manganese-zinc pellets are necessary to compete against other zinc-containing sorbents in durability.

- Evaluation of ICCI-2C sorbent was carried out at GE-CRD with the purpose of evaluating the reactivity and durability of the sorbent in pelletized forms. ASTM attrition losses after 13 cycles of bench testing (range 1.89-2.09\%) were comparable to that of the fresh sorbent (2.16\%), suggest- 
ing that this sorbent is a potential candidate for long-term use. All testing was performed at $482{ }^{\circ} \mathrm{C}$ for absorption and regeneration; evaluation at lower temperatures is still needed to confirm suitability for low-temperature operation down to $343^{\circ} \mathrm{C}$.

- ICCI-2C is capable of operating under pilot plant conditions (1.5-atm regeneration) provided an activation step of three to five cycles is carried out in the absence of $\mathrm{SO}_{2}$ during regeneration. Evaluation at higher generation pressures (i.e., 7 atm), as in the TECO demonstration plant, will require additional bench-scale testing before confirming the suitability of the sorbent for those conditions.

- With respect to the economics of operating a moving-bed HGCU system, a reasonable target for the sorbent operating cost to a utility company is 0.1 to 0.2 cents $/ \mathrm{kWh}$. To operate below this target and be commercially viable, the sorbent makeup rate must be less than 0.16 to $0.2 \%$ at a sorbent purchase price of \$3-5/lb to make the moving-bed HGCU systems feasible. Higher sorbent prices or higher make-up rates make the HGCU system commercially less attractive. Currently, sorbent manufacturers consider these sorbent sale prices achievable in commercial quantities.

\section{RECOMMENDATIONS}

The development of zinc titanates, whether in the form of molybdenum-added formulations or modified zinc titanates (MZT's), has reached a level of understanding that makes them suitable for commercial applications. Evaluation of desulfurization reactivity at the laboratory, bench-scale, and pilot-plant facilities has shown that zinc titanates and proprietary sorbents can easily meet the target levels of $99 \%$ desulfurization of coal gases in the temperature range of 343 to $538^{\circ} \mathrm{C}$.

A significant issue that still remains with the use of zinc titanates is the capability to control the fabrication procedures that result in predictable sorbent mechanical properties, particularly the ASTM attrition resistance. To date, variations from batch to batch have a spread that is comparable to the changes observed during testing over five to fifteen cycles. It is recommended that a program be undertaken with commercial sorbent suppliers aimed at understanding and minimizing the variability in the physical morphology and mechanical properties of the pelletized sorbents.

For the case of Chemetals manganese-zinc sorbents, given that addition of zinc oxide decreased the attrition resistance of the pure manganese sorbents, a study of the production methods and mixing variability is also needed.

For the case of ICCI-2C sorbents, a study is needed on the operability of the sorbent at temperatures in the range 343 to $482^{\circ} \mathrm{C}$ to determine if the chemical reactivity is sufficient to operate a commercial system at the desired sulfur loadings. In addition, methods should be investigated that decrease the level of conditioning or activation that is currently required over the first three to five cycles.

Overall the technology of manufacturing pelletized sorbents for desulfurization in moving-bed applications has reached a high level of maturity that makes it possible to assess current sorbent performance in laboratory and bench-scale systems and correlate with pilot-scale performance. Extrapolation of these performance parameters is still necessary when going to commercial scale systems, since no data have been generated at these scales. 


\section{Chapter 1 INTRODUCTION}

\subsection{CONTRACT OBJECTIVES}

The overall objective of this program is to develop regenerable sorbents for hydrogen sulfide removal from coal-derived fuel gases in the temperature range $343-538^{\circ} \mathrm{C}\left(650-1000{ }^{\circ} \mathrm{F}\right)$. Two categories of reactor configurations are being considered: fixed-bed/moving-bed reactors and fluidized-bed (bubbling and circulating) reactors. In addition, a cost assessment and a market plan for large-scale fabrication of sorbents will be developed. As an optional task, long-term bench-scale tests (up to 100 cycles) of the best fixed-bed/moving-bed and fluidized-bed sorbents will be conducted.

The sorbents must have chemical characteristics that permit cyclic regeneration over many cycles without a drastic loss of activity. They must also have physical characteristics that are compatible with the selected reactor (e.g., moving bed vs. fluidized bed), and which remain acceptable during absorption and regeneration. The sorbents must be capable of reducing the hydrogen sulfide level in the fuel gas to less than $20 \mathrm{ppmv}$ in the specified temperature range and pressures in the range of 1 to 20 atmospheres.

\subsection{BACKGROUND}

\subsubsection{Coal-Based IGCC Systems}

Global power generation markets have shown a steady penetration of gas turbine/combined cycle technology into oil- and gas-fired applications as the technology has matured. The low cost, improved reliability, and efficiency advantages of combined cycles can now be used to reduce the cost of electricity and meet environmental acceptance of fuels other than natural gas such as coal, heavy oil, petroleum coke, and waste products.

According to Holt, ${ }^{1}$ coal and lignite account for approximately 3400 gigatons of oil equivalents (Gtoe), or $76 \%$, of the total recoverable fossil fuel reserves in the world, which is estimated at 4400 Gtoe. In contrast, natural gas is only 220 Gtoe or $5 \%$ of the total recoverable fossil fuel reserves. Unconventional oils (including heavy crudes, natural bitumen, and oil shale) account for $14 \%$ of the total, while conventional oil represents an additional 5\%. From these figures, it is clear that coal and lignites account for a large percentage of total recoverable fossil fuel reserves in the world and, as such, will have an important role in the future of energy usage and power generation worldwide.

Several technologies have been proposed to convert coal to electricity, including combustion (atmospheric and pressurized), liquefaction, and gasification. Several reviews of gasification are available in the literature ${ }^{2,3}$ that provide details on the status of various technologies for coal utilization. Within gasification, the Integrated Gasification Combined-Cycle (IGCC) is now 
moving towards being a commercial technology. In the global marketplace, this shift is being demonstrated using various gasification technologies to produce a clean fuel for the combined cycle. Early plants in the 1980's demonstrated the technical/environmental features and suitability for power generation. Economics, however, were disappointing until advances in gas turbine technology were first used in the early 1990's. Since 1993, a number of IGCC projects have taken off for commercial application in the mid- to late-1990's. These applications utilize seven different gasification technologies to meet specific project needs. ${ }^{4}$

In power generation technology, the combined cycle consists of the gas turbine cycle (Brayton cycle) and the steam turbine cycle (Rankine cycle). The combination of the two results in a more efficient configuration than either of the two cycles taken separately.

The major components of the coal-based IGCC cycle, shown in schematic form in Figure 1-1, are:

- Coal handling and gasification

- Gas cleanup

- Gas turbine cycle

- Steam turbine cycle (including the heat recovery steam generator, HRSG)

In practice there are many other sub-elements of the IGCC configuration that support the operation of the major components enumerated above.

When integrating gas cleanup systems with the gasification cycle it is necessary to match conditions of the gasifier exit coal gas with the operating conditions of downstream equipment (i.e., gas cleanup systems and gas turbine fuel inlet conditions). With respect to gas cleanup systems for IGCC operation, two temperature regions have been reported ${ }^{3}$ : the low-temperature region below $300{ }^{\circ} \mathrm{C}$ and the high-temperature region above $300{ }^{\circ} \mathrm{C}$.

In the low-temperature cleanup (LTCU) range, also called cold gas cleanup (CGCU), the gas coming from the gasifier is typically cleaned of particulate matter and sulfur species such as $\mathrm{H}_{2} \mathrm{~S}$,

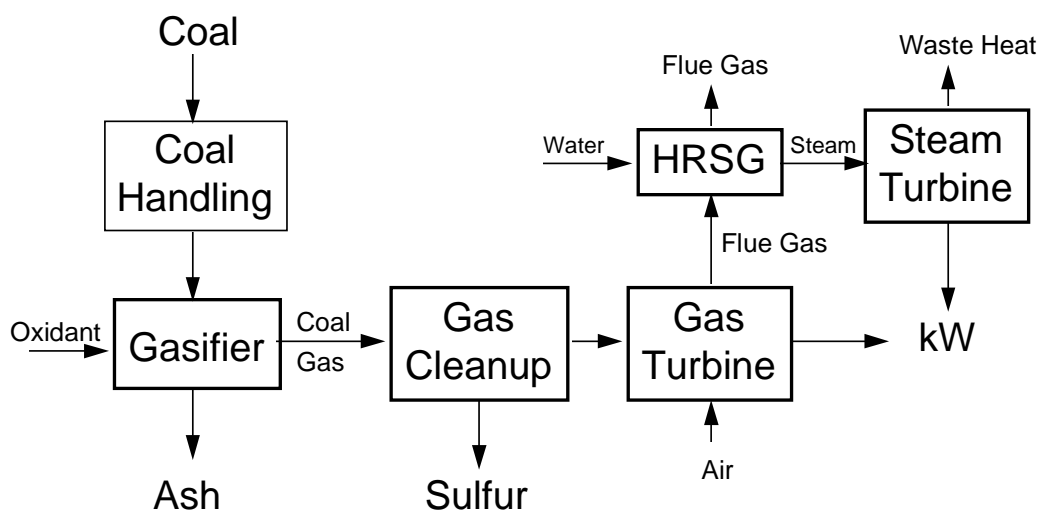

Figure 1-1. Schematic diagram of the IGCC system 
$\mathrm{COS}$, and $\mathrm{CS}_{2}$, at temperatures below $300{ }^{\circ} \mathrm{C}$. Generally, CGCU systems operate around 20$100{ }^{\circ} \mathrm{C}$, with some that include cryogenic stages that require sub-zero temperatures. CGCU systems are proven technologies and commercially available. The main limitation is that they are energy intensive, and are parasitic processes to the high cycle efficiencies desired from IGCC or any other system.

In the high-temperature cleanup (HTCU) range, also called hot gas cleanup (HGCU), the gas from the gasifier is cleaned of particulate matter, sulfur species, and other contaminants at temperatures above $400{ }^{\circ} \mathrm{C}$. HGCU technologies are at various stages of development or in the early stages of commercialization. High-temperature desulfurization is typically accomplished using throwaway calcium-based sorbents or regenerable mixed-metal oxide sorbents. Cost, removal efficiency, and operability determine the advantages of one type of sorbent over the other. The performance of regenerable mixed-metal oxide sorbents for HGCU desulfurization will be solely discussed in this report.

IGCC power systems using HGCU are one of the most promising advanced technologies for the production of electric power from coal in an environmentally acceptable manner. In conventional cleanup systems, costly heat exchangers are necessary to cool down the gases for cleaning. Unlike these conventional low-temperature cleanup systems, where the coal gas from the gasifier has to be cooled down from $500-1100{ }^{\circ} \mathrm{C}\left(932-2012^{\circ} \mathrm{F}\right)$ to below $149^{\circ} \mathrm{C}\left(300{ }^{\circ} \mathrm{F}\right)$, hightemperature coal gas cleanup systems can be operated at near $482-538{ }^{\circ} \mathrm{C}\left(900-1000{ }^{\circ} \mathrm{F}\right)$ or higher, i.e., at conditions compatible with the gasifier and turbine components in the IGCC system. The result is a more efficient overall system. ${ }^{5-7}$ A review of high-temperature desulfurization technology has been given by Thambimuthu ${ }^{3}$, and economic analyses and optimization in various gas stream cleanup systems have been published by Buchanan. ${ }^{8}$

Coal gas desulfurization to sufficiently low levels at elevated temperatures is now recognized as crucial to efficient and economic coal utilization in Integrated Gasification-Combined Cycle (IGCC) systems. The implementation of hot coal gas desulfurization heavily relies on the development of regenerable sorbent materials that have high sulfur capacity and can efficiently remove $\mathrm{H}_{2} \mathrm{~S}$ (from several thousand ppmv levels down to a few ppmv) over many cycles of sulfidation/regeneration. Structural stability and good mechanical strength are also desirable features in a sorbent. Not surprisingly, only a few metal oxides can meet these stringent requirements.

A recent international conference ${ }^{9}$ focused on new developments of coal-based IGCC systems and high-temperature desulfurization systems. A review of the status of application of IGCC technology to power generation throughout the world ${ }^{10}$ and an assessment of coal gasification processes as related to sorbent development ${ }^{4}$ are given in the conference proceedings.

\subsubsection{High-Temperature Desulfurization Systems}

The research and development for high-temperature desulfurization of fuel gases has been sponsored primarily by the Federal Energy Technology Center (FETC, formerly Morgantown Energy Technology Center, METC) of the United States Department of Energy (U.S. DOE). ${ }^{11}$ Fixed-bed systems, fluidized-bed systems, moving-bed systems, and transport reactor systems for 
hot gas desulfurization are being pursued under DOE/FETC contracts and are described in the literature. $^{12}$

Fluidized-bed systems ${ }^{13,77}$ are also under development with DOE/FETC sponsorship. They have an advantage over fixed-bed systems in that better temperature control can be achieved during regeneration because of better gas-solid mixing. However, sorbents are subject to higher levels of attrition in a fluidized bed, and stronger sorbent materials are necessary. A variation of the fluidized bed concept is being pursued by the transport reactor design of M.W. Kellogg. ${ }^{14}$

GE is developing a moving-bed, high-temperature desulfurization system for integrated gasification combined-cycle (IGCC) power systems in which zinc-based regenerable sorbents are currently being used as desulfurization sorbents. ${ }^{15-18}$ Design and analysis of moving-bed reactors has been pursued over several years ${ }^{19,20}$ based on mathematical analyses available in the literature. ${ }^{21}$ Zinc titanates and various other zinc-based oxides are being considered as sorbents for use in the Clean Coal Technology Demonstration Program at Tampa Electric Co.'s Polk Power Station. A key to success in the development of high-temperature desulfurization systems is the matching of sorbent properties for the selected process operating conditions, namely, sustainable desulfurization kinetics, sulfur capacity, and mechanical durability over multiple cycles.

A schematic of the GE-CRD pilot plant, or Process Evaluation Facility (PEF), is shown in Figure 1-2. The GE/Lurgi fixed bed, pressurized air-/steam-blown gasifier is shown on the left. The lowBtu coal gas is directed from the gasifier to the primary cyclone located immediately downstream of the gasifier (to collect entrained particles), through a circulating fluidized bed (CFB) hydrogen chloride removal vessel, then to the HGCU system.

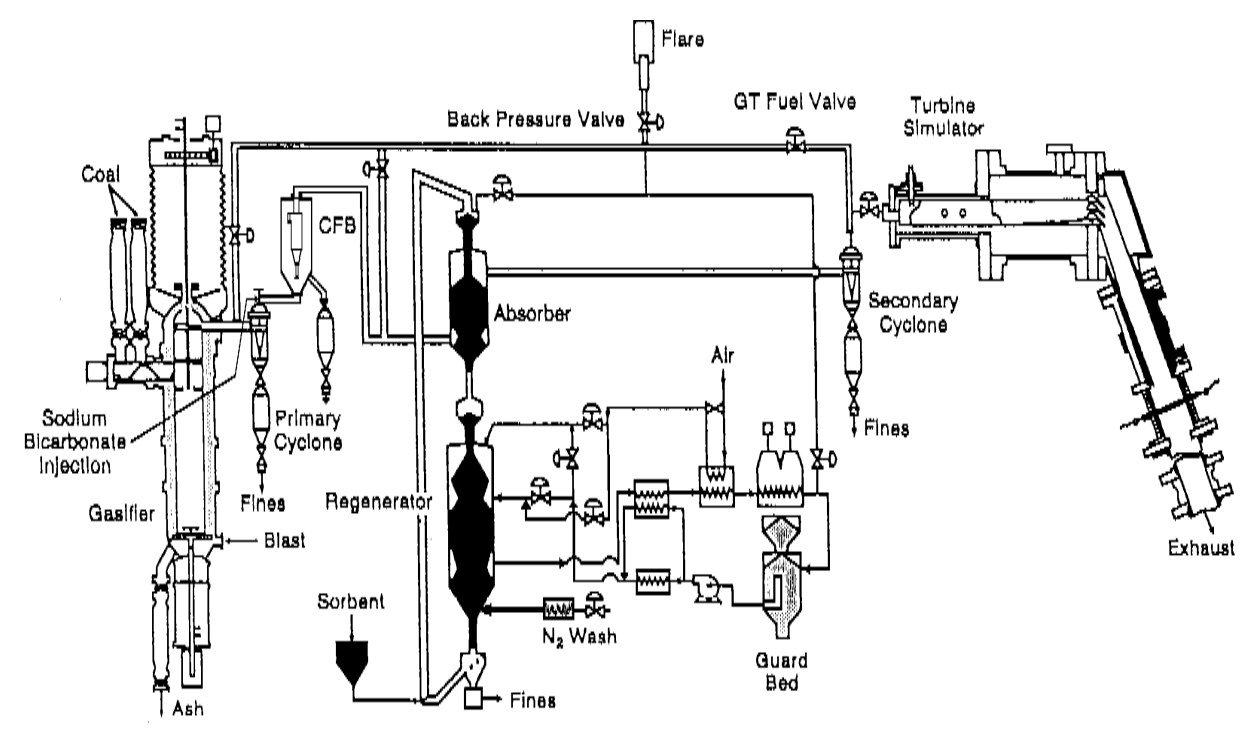

Figure 1-2. Schematic diagram of the GE-CRD pilot plant. 
The HGCU system consists of high-efficiency cyclones to collect entrained particles, a movingbed absorber containing the metal oxide sorbent to remove sulfur compounds, a moving-bed regenerator to oxidize the sulfided sorbent back to its original oxide form, a regenerator gas recycle system, and a solids transport system. A secondary cyclone is located downstream of the absorber, and the cleaned fuel can be directed either to the combustion test stand or to the system flare.

In GE's moving-bed, HGCU system configuration zinc-based metal oxide sorbents are currently being used as regenerable desulfurization sorbents. During normal operation, the sorbent moves by gravity across the absorber and in countercurrent direction to the flow of gases. In the process, the sulfur species in the coal gas are removed to very low levels (approximately 10-50 ppmv) while the sorbent reacts to form metal sulfides. The sulfided sorbent moves down by gravity slowly and leaves the bottom of the absorber vessel through a lockhopper and continues to move down by gravity to the regenerator, which is also a slow moving bed. The sulfided sorbent is then regenerated at nearly atmospheric pressure in three stages of varying oxygen concentrations with the evolution of $\mathrm{SO}_{2}$.

The ability to regenerate and recycle the sorbent is essential for economically viable hot coal gas desulfurization. The regeneration step is a highly exothermic oxidation process requiring careful temperature control. Too high a temperature (above $800{ }^{\circ} \mathrm{C}$ ) sinters and destroys the sorbent structure and reduces its ability to absorb sulfur in consecutive absorption steps. Low temperature, high $\mathrm{SO}_{2}$ and $\mathrm{O}_{2}$ result in sulfate formation and a lower sulfur removal efficiency. In order to effectively control the reaction and achieve a complete regeneration, the regenerator reactor is divided into three zones or stages. As the sorbent proceeds in a controlled atmosphere with varying oxygen concentrations, $\mathrm{SO}_{2}$ is evolved. Sorbent movement in the regenerator is controlled by a rotary valve at its bottom.

The moving-bed regeneration produces an off-gas with a high enough $\mathrm{SO}_{2}$ concentration (up to $10-12 \%$ ) suitable for direct production of sulfuric acid or elemental sulfur. The regeneration gas recycle loop is designed as an internal diluent that reduces the oxygen concentration in the air to the desired levels without the use of costly externally provided diluents such as steam or nitrogen. Using recycle rather than external inert diluent also enriches the $\mathrm{SO}_{2}$ concentration of the product stream. The heat exchangers in the recycle loop are designated to control the temperature of the regenerator inlet streams. The gas cooler removes the heat generated during the regeneration reaction by cooling the recycle gas stream. In a commercial system, the gas cooler will be replaced by a steam generator.

GE has patented the moving-bed process to utilize mixed metal oxide sorbents to remove sulfur from a high-temperature fuel gas stream and regenerate the sorbent for reuse while producing a byproduct stream suitable for the recovery of sulfur ${ }^{22,23}$.

Mixed-metal oxide sorbents have been studied quite extensively in the past, including various types of zinc titanates (e.g., $\mathrm{Zn}_{2} \mathrm{TiO}_{4}$ and $\left.\mathrm{Zn}_{2} \mathrm{Ti}_{3} \mathrm{O}_{8}\right)^{24-27,13}$ or as combinations of other metal oxides such as nickel, copper, manganese, cobalt, tin, and others; see for instance. ${ }^{28-32}$ Proprietary zinc-based sorbents, such as Phillips Petroleum Company's Z-Sorb ${ }^{\mathrm{TM}}$ III sorbent and METC sorbents, have also been tested both in the laboratory as well as in pilot-plant scale. ${ }^{33-35}$ 


\subsubsection{Sorbent Development}

Over the last two decades a number of studies have been reported on high-temperature $\mathrm{H}_{2} \mathrm{~S}$ removal, primarily using various transition metal oxides as regenerable sorbents. ${ }^{36-42}$ The sorbent most intensively studied in the 1980's was iron oxide, which yields equilibrium $\mathrm{H}_{2} \mathrm{~S}$ concentrations in the few hundred ppm range for a composition representative of low-Btu coalderived gas and temperatures of above $500{ }^{\circ} \mathrm{C}$. While the sulfidation kinetics of iron oxide are very good, ${ }^{38}$ this sorbent cannot be used for single-stage coal gas desulfurization to reduce the $\mathrm{H}_{2} \mathrm{~S}$ content of the fuel gas down to a few ppm of sulfur.

Zinc oxide has been used as a non-regenerable sorbent in "guard beds" protecting catalyst beds from trace sulfur impurities. More recently, zinc oxide has also been investigated as a regenerable sorbent. ${ }^{39-46}$ The thermodynamic equilibrium for sulfidation of $\mathrm{ZnO}$ is quite favorable, yielding desulfurization down to a few $\mathrm{ppm} \mathrm{H}_{2} \mathrm{~S}$. The sulfidation kinetics of $\mathrm{ZnO}$, however, are slower ${ }^{47}$ compared to those of pure iron oxide, and the regenerability of $\mathrm{ZnO}$ is restricted above $700{ }^{\circ} \mathrm{C}$ by the loss of surface area and the formation of zinc sulfate at low regeneration temperatures.

In the late 1980's, it was shown that certain mixed oxides have superior properties compared to single oxides for hot gas cleanup. ${ }^{43-45,48-54}$ A compound of zinc and iron oxides, zinc ferrite, $\mathrm{ZnFe}_{2} \mathrm{O}_{4}$, developed by DOE/METC was tested at the pilot stage for desulfurization of low-Btu gases. ${ }^{55-57}$ Physical durability of the zinc ferrite sorbent in long-term testing precluded further use at that time, but recent work suggests that improved performance can be obtained with new preparation techniques. ${ }^{58}$

Because of the apparent limitations of the zinc ferrite sorbent, many investigators have been conducting research to develop a superior mixed metal oxide sorbent. ${ }^{42-45,59-63}$

Earlier experimental studies that pioneered the use of mixed-metal oxides were performed at the Massachusetts Institute of Technology (MIT), ${ }^{64-66}$ Research Triangle Institute (RTI), ${ }^{67} 68$ Electrochem, ${ }^{69}$ U.S. Dept. of Energy/Morgantown Energy Technology Center (DOE/METC), ${ }^{70}$ (now Federal Energy Technology Center, FETC) and the Institute of Gas Technology (IGT). ${ }^{71}$ Mixed-metal oxide sorbents have been studied in the past both as straight zinc titanates, (e.g., $\mathrm{Zn}_{2} \mathrm{TiO}_{4}$ and $\left.\mathrm{Zn}_{2} \mathrm{Ti}_{3} \mathrm{O}_{8}\right)^{72}$ or as combinations of oxides of vanadium, copper, manganese, cobalt, and others; see for instance. ${ }^{65}$

Work on zinc titanates such as $\mathrm{ZnTiO}_{3}, \mathrm{Zn}_{2} \mathrm{TiO}_{4}$, and $\mathrm{Zn}_{2} \mathrm{Ti}_{3} \mathrm{O}_{8}{ }^{44},{ }^{45}$ has shown that titanium oxide is a better alternative to iron oxide additives in terms of the higher stability of the titanates over the ferrite compounds of zinc, and their similar sulfidation equilibria. With zinc titanates, the sulfidation temperature has been shown to extend to $700{ }^{\circ} \mathrm{C}$, and sintering of the $\mathrm{ZnO}$ was greatly reduced. Although zinc titanate has also shown better attrition resistance than zinc ferrite in pilot tests, this sorbent also suffers gradual loss of reactivity in long-term cyclic operation, resulting in high fresh sorbent makeup rate to maintain the desired level of desulfurization. ${ }^{73,74}$ Other mixed metal oxides such as copper-based and cobalt-based sorbents have also been investigated ${ }^{75-78}$ however, the research has been limited to laboratory-scale equipment. 
Although higher temperature application offers better overall process efficiency, the stringent requirement for sulfur removal efficiency at temperatures above $538{ }^{\circ} \mathrm{C}\left(1000{ }^{\circ} \mathrm{F}\right)$ limits the choice of the sorbents to a few metal oxides (based on thermodynamic equilibrium), that have been shown to have other limitations as described earlier. The thermodynamic equilibria of many metal oxides significantly improve as the temperature decreases, making many metal oxide sorbents suitable for hot gas cleanup application in the temperature range of $343-538{ }^{\circ} \mathrm{C}(650$ $\left.1000^{\circ} \mathrm{F}\right)$. Although the initial chemical reactivities of the sorbents generally decrease with decreasing temperature, the lower thermal stress incurred can lead to better sorbent reactivity after a large number of cycles, reducing the sorbent replacement cost. In general, the benefit to be gained by lower temperature application may outweigh the slight loss of efficiency, resulting in lower overall cost of electricity. However, no extensive study has been done on the development of advanced sorbents for the lower temperature application. The reactions occurring during desulfurization of coal gases and regeneration of the sulfided sorbents have been

described before in many sources. ${ }^{13-79}$ More recent studies of sorbent development can be found in the literature. ${ }^{12}$

Outside of the United States, work on sorbent development has been very prolific, particularly in western European countries such as the Netherlands, ${ }^{80,81}$ England, and Spain. ${ }^{82}$

In order for a metal oxide to be considered suitable for high-temperature desulfurization, the material must exhibit desirable properties in the following areas:

1. Rate of $\mathrm{H}_{2} \mathrm{~S}$ absorption and low equilibrium $\mathrm{H}_{2} \mathrm{~S}$ achievable in the gas phase

2. Ease of regeneration of the sulfide species formed during absorption

3. Likelihood of sulfate formation and ease of sulfate decomposition

4. Metal/sorbent evaporation and temperature of incipient evaporation

5. Formation of low-melting eutectic phases

6. Reduction to metal during absorption due to highly reducing coal gases

7. Interactions between active metal oxide, stabilizers, and support with other components and contaminants in coal gas (e.g., $\mathrm{H}_{2}$, alkali metals, halogens)

8. Sulfur loading of metal oxide and sulfur loading capacity limitations

9. Disposal of spent sorbent metals and deleterious effects of volatilized sorbent metals to other IGCC components (e.g., turbine)

10. Cost of support and/or cost of active metal oxide

The feasibility of operating a moving-bed high-temperature desulfurization system in an economically competitive and technically feasible manner currently restricts its use to a temperature window between $400-750{ }^{\circ} \mathrm{C}\left(752-1472{ }^{\circ} \mathrm{F}\right)$ and pressures above 10 atmospheres 
during absorption. Operation below $400{ }^{\circ} \mathrm{C}$ does not take full advantage of higher system efficiency compared to low-temperature cleanup systems, while operation above $750{ }^{\circ} \mathrm{C}$ requires a tradeoff between more sophisticated material properties/higher capital costs and reliability of process operation. Although this window of operation may expand in the future, these current boundaries of operation are considered realistic.

Preliminary to the preparation of mixed-metal oxide sorbents under this program, a review of the literature was done to identify pure metal oxides and combinations of metal oxides that had been evaluated in the past for high-temperature desulfurization of coal gases. ${ }^{27}$ Given the degree of advanced development of zinc-based sorbents and the need to minimize secondary undesired reactions (as described in items 1-10 above), it was decided to focus first on the optimization of zinc titanate sorbents.

\subsubsection{Zinc Titanate Chemistry}

When calcining mixtures of $\mathrm{ZnO}$ and $\mathrm{TiO}_{2}$ powders at high temperature, three crystalline structures of zinc titanate may form depending on the ratio of zinc to titanium: $\mathrm{ZnTiO}_{3}$, $\mathrm{Zn}_{2} \mathrm{Ti}_{3} \mathrm{O}_{8}$, or $\mathrm{Zn}_{2} \mathrm{TiO}_{4}$. The highest zinc-to-titanium molar ratio zinc titanate, $\mathrm{Zn}_{2} \mathrm{TiO}_{4}$, would be the most desired crystalline phase from the point of view of its higher sulfur capacity. For this case, the overall reaction occurring during $\mathrm{H}_{2} \mathrm{~S}$ absorption from coal gases is as follows:

$$
\mathrm{Zn}_{2} \mathrm{TiO}_{4}+2 \mathrm{H}_{2} \mathrm{~S} \Rightarrow 2 \mathrm{ZnS}+\mathrm{TiO}_{2}+2 \mathrm{H}_{2} \mathrm{O}
$$

A secondary reaction that may take place during desulfurization is the reduction of zinc titanate by hydrogen and carbon monoxide to zinc metal, with the subsequent loss of $\mathrm{Zn}$ caused by evaporation. Zinc metal evaporation becomes significant if desulfurization above $732{ }^{\circ} \mathrm{C}$ $\left(1350{ }^{\circ} \mathrm{F}\right)$ under dry conditions (i.e., low $\mathrm{H}_{2} \mathrm{O}$ content in the coal gas) is desired ${ }^{68}$ Since the GE moving-bed system carries out $\mathrm{H}_{2} \mathrm{~S}$ absorption around $482-538^{\circ} \mathrm{C}\left(900-1000{ }^{\circ} \mathrm{F}\right)$, zinc metal evaporation is not a concern. When regeneration is carried out under dry conditions in the presence of diluted air, the following reaction takes place:

$$
2 \mathrm{ZnS}+\mathrm{TiO}_{2}+3 \mathrm{O}_{2} \Rightarrow \mathrm{Zn}_{2} \mathrm{TiO}_{4}+2 \mathrm{SO}_{2}
$$

In addition to the regeneration reaction, zinc sulfate formation may occur during regeneration, favored below $650{ }^{\circ} \mathrm{C}\left(1200^{\circ} \mathrm{F}\right)$, and at high $\mathrm{O}_{2}$ and $\mathrm{SO}_{2}$ concentrations.

$$
\mathrm{ZnO}+\mathrm{SO}_{2}+\frac{1}{2} \mathrm{O}_{2} \Rightarrow \mathrm{ZnSO}_{4}
$$

Zinc sulfate formation is undesirable because the sulfate occupies more volume than the sulfides in the pores (producing internal pellet stresses) and decomposes during subsequent absorption, releasing $\mathrm{SO}_{2}$. Zinc sulfate thermally decomposes in the range of $600{ }^{\circ} \mathrm{C}\left(1112{ }^{\circ} \mathrm{F}\right)^{83}$ to $740{ }^{\circ} \mathrm{C}$ $\left(1364^{\circ} \mathrm{F}\right) .^{84}$ These decomposition temperatures increase at higher concentrations of $\mathrm{SO}_{2}$ and $\mathrm{O}_{2}$. Hence, a regeneration scheme in which the temperature is appropriate to minimize zinc sulfate formation or maximize decomposition is desired. 


\subsubsection{Moving-Bed Applications}

Moving-bed systems have been developed by GE. ${ }^{85}$ Although the sorbent materials move slowly between the absorber and regenerator vessels, the level of deterioration at process conditions requires the material to be mechanically durable. Sorbent formulations prepared for moving-bed systems must have mechanical durability and exhibit satisfactory desulfurization kinetics at 538 ${ }^{\circ} \mathrm{C}\left(1000{ }^{\circ} \mathrm{F}\right) ;{ }^{34}$ however, larger-scale demonstration systems such as the Tampa Electric Co.'s Polk Station will operate at lower temperatures, close to $482{ }^{\circ} \mathrm{C}\left(800-900{ }^{\circ} \mathrm{F}\right)$. Hence, development of sorbents with reactivity in this middle temperature range of 343 to $538^{\circ} \mathrm{C}(650$ $1000^{\circ} \mathrm{F}$ ) is important for moving-bed systems.

\subsubsection{Fluidized-Bed Applications}

Although the fixed-bed approach using metal oxides has been shown to reduce the $\mathrm{H}_{2} \mathrm{~S}$ content of the cleaned gas to very low levels, the operation is not continuous. It also suffers from operational problems and requires large-scale high temperature valves. To overcome these problems, US DOE has sponsored fluidized-bed as well as moving-and fixed-bed hot gas desulfurization research in recent years. The fluidized-bed approach offers advantages over the moving- and fixed-bed reactors because of its ability to control the reactor temperature during the highly exothermic regeneration step.

The key characteristic of concern in the fluidized-bed application is maintenance of the physical integrity of the sorbent during the chemical transformations associated with absorptionregeneration. Testing appears to verify that excessive attrition results primarily from the changes in composition during transformation and not from mechanical forces. ${ }^{7374}$ The extreme temperature and severe chemical conditions of air/steam regeneration are deleterious to many inorganic support materials and sorbent compounds. A sorbent suitable for fluidized-bed application must, therefore, have both good thermodynamic equilibrium and initial chemical reactivity in the range of $343{ }^{\circ} \mathrm{C}-538^{\circ} \mathrm{C}$, as well as acceptable long-term physical and chemical durability with a reasonable cost of production.

The application of fluidized beds to hot gas desulfurization will be dealt with in detail in the second volume of this report which summarizes the subcontract program developed at the Institute of Gas Technology.

\subsection{PROJECT DESCRIPTION}

The proposed program is divided into several tasks:

Task 1 - NEPA Report

Task 2 - Sorbent Preparation

Task 3 - Provision of Bench Unit 
Task 4 - Bench Testing

Task 5 - Sorbent Cost Assessment

Task 6 - Topical Report

Task 7 - Market Plan

Task 8 - Long-Term Testing (option)

In Task 1, the information required for preparation of a NEPA report by DOE was provided. In Task 2, several sorbents suitable for fixed-/moving-, and fluidized-bed applications were fabricated. Three classes of materials were used: zinc-based materials (e.g., zinc titanates), advanced metal oxide (non-zinc) materials, and proprietary materials from external vendors. Selection of non-proprietary materials was based on thermodynamic and laboratory evaluation of powder materials. GE-CRD, IGT, and Prof. M. Flytzani-Stephanopoulos (consultant, Tufts University) were involved in identifying and screening the chemical compositions of the sorbents. Pelletization (for moving/fixed beds) and granulation (for fluidized beds) was conducted on the promising materials using suitable binders and pore formers. Standard techniques (extrusion and calcination) were used to modify the morphology of the formed materials. GE-CRD focused on moving/fixed-bed applications, while IGT focused on fluidizedbed applications.

Commercial sorbent and catalyst developers pelletized or agglomerated the final formulations for bench testing according to recommendations by GE-CRD and IGT. In Task 3, the moving/fixedbed bench reactor at GE-CRD and the fluidized-bed reactor at IGT were refurbished for use. In Task 4, the eight most promising sorbents that passed screening under Task 2 were tested for ten cycles of absorption and regeneration each in the GE-CRD moving/fixed-bed bench reactor and IGT fluidized-bed reactor, and the properties of the used materials were compared against those of the fresh sorbents. In Task 5, a sorbent cost assessment was performed to determine costs and sensitivity of costs for raw materials, fabrication, disposal, or recycle. In Task 6, a Topical Report was prepared summarizing the results obtained in the program. In Task 7, a Market Plan was considered jointly with the commercial sorbent manufacturers and users to develop a strategy for commercialization and benefits to IGCC technologies.

Finally as an optional task, Task 8 was proposed for testing of a minimum of two formulations, one for moving/fixed-bed systems and the other for fluidized-bed systems for extended number of cycles (up to 100 cycles) to assess durability and chemical reactivity in the corresponding bench-scale reactor configurations.

The information presented in this Volume 1 report details the results on moving-bed sorbent development at GE-CRD. The work performed at IGT on fluidized-bed sorbents under a subcontract from GE-CRD will be presented under Volume 2 of this final contract report. 


\section{REFERENCES: CHAPTER 1}

${ }^{1}$ Holt, N. 1995. World Market: A Survey of Opportunities for Advanced Coal-Fired Systems. In Proceedings of the Coal-Fired Power Systems 95 - Advances in IGCC and PFBC Review Meeting, p. 5. DOE/METC-95/1018. NTIS/DE95009732. Springfield, Va.: National Technical Information Service.

${ }^{2}$ Takematsu, T. and Maude, C. 1991. Coal Gasification for IGCC Power Generation. IEACR/37. IEA Coal Research, London, 1991.

${ }^{3}$ Thambimuthu, K.V. 1993. Gas Cleaning for Advanced Coal-Based Power Generation. IEACR/53, March 1993. IEA Research, London.

${ }^{4}$ Ayala, R.E. 1996. Assessment of Coal Gasification Processes - Relevance to Sorbent Development. In Desulfurization of Hot Coal Gas. Proceedings of the NATO/Advanced Study Institute Conference - Desulfurization of Hot Coal Gas with Regenerable Metal Oxide Sorbents: New Developments, KuLadasi, Turkey, July 7-19 1996. A. Atimtay (ed.) NATO ASI Series. Series G Ecological Sciences Vol. 42. pp. 41-56. Springer Verlag, Berlin. August 1998. ISBN 3-540-64726-0.

${ }^{5}$ Rath, L.K., G.T. Lee, and P.H. Le. 1994. IGCC System Studies. In Proceedings of the Coal-Fired Power Systems 94 - Advances in IGCC and PFBC Review Meeting, p. 66. DOE/METC-94/1008. NTIS/DE94012252. Springfield, Va.: National Technical Information Service.

${ }^{6}$ Droog, H.A., A. Delwel, and R. Assink. 1993. Comparison of High-Temperature Gas Treatment Options with LowTemperature Gas Treatment in IGCC's following Entrained Flow Gasification. In Proceedings 12th EPRI Conference on Gasification Power Plants.San Francisco, CA, Oct 27-29, 1993

${ }^{7}$ Corman, J.C. 1986. System Analysis of Simplified IGCC Plants, Topical Report. U.S. Dept of Energy, DOE/ET/14928-2233.

${ }^{8}$ Buchanan, T.L., H.T. Chen, M.G. Klett, M.D. Rutkowski, and R. Zaharchuk. 1994. Optimization of Gas Stream Cleanup in Three IGCC Systems. Final Report to the U.S. Department of Energy/Morgantown Energy Technology Center by Gilbert/Commonwealth, Inc. Contract DE-AC01-88FE61660. March 1994.

9 Atimtay, A. (ed.) Proceedings of the NATO/Advanced Study Institute Conference - Desulfurization of Hot Coal Gas with Regenerable Metal Oxide Sorbents: New Developments, Kusadasi, Turkey, July 7-19, 1996. NATO ASI Series. Series G Ecological Sciences Vol. 42. Springer Verlag, Berlin. August 1998. ISBN 3-540-64726-0.

${ }^{10}$ Ayala, R.E. Application of IGCC Technology to Power Generation. In Proceedings of the NATO/Advanced Study Institute Conference - Desulfurization of Hot Coal Gas with Regenerable Metal Oxide Sorbents: New Developments, Kusadasi, Turkey, July 7-19, 1996. NATO ASI Series. Series G Ecological Sciences Vol. 42. pp. 75-102. Springer Verlag, Berlin. August 1998. ISBN 3-540-64726-0.

${ }^{11}$ Bossart, S.J., D.C. Cicero, C.M. Zeh, and R.C. Bedick. 1990. Gas Stream Cleanup. Technology Status Report. DOE/METC-91/0273. NTIS/DE91002037. Springfield, Va.: National Technical Information Service.

${ }^{12}$ McDaniel, H.M, D.J. Mollot, and V.K. Venkataraman. 1995. editors. In Proceedings of the Advanced Coal-Fired Power Systems '95 Review Meeting, Vol I and II. DOE/METC-95/1018. NTIS/DE95009732. Springfield, Va.: National Technical Information Service.

${ }^{13}$ Gangwal, S.K., and R.P. Gupta, 1993. Enhanced Durability of Desulfurization Sorbents for Fluidized-Bed Applications. In Proceedings of the Coal-Fired Power Systems 93 - Advances in IGCC and PFBC Review Meeting, p. 146-157. DOE/METC-93/6131. NTIS/DE93000289. Springfield, Va.: National Technical Information Service.

${ }^{14}$ Gangwal, S.K., R.P. Gupta, W.M. Campbell, G.B. Henningsen . 1995. Zinc Titanate tests in Transport Reactor. In Proceedings of the Advanced Coal-Fired Power Systems '95 Review Meeting, Vol I, p 215. DOE/METC95/1018. NTIS/DE95009732. Springfield, Va.: National Technical Information Service.

${ }^{15}$ Furman, A.H., R. Ayala, A. Feitelberg, M. Lacey, and S. Bevan. 1998. Integrated Operation of a Pressurized Fixed-Bed Gasifier and Hot Gas Desulfurization System. CD ROM. Final Report to the U.S. Department of Energy/Federal Energy Technology Center, Morgantown, WV, under contract DE-AC21-87MC23170. March 1998. 
${ }^{16}$ Bevan, D.J. Najewicz, R.E. Ayala, A. Feitelberg, and A. Furman. 1995. Integrated Operation of a Pressurized Gasifier, Hot Gas Desulfurization System and Turbine Simulator. In Proceedings of the Advanced Coal-Fired Power Systems '95 Review Meeting, Vol I , pp. 187-201. DOE/METC-95/1018. NTIS/DE95009732. Springfield, Va.: National Technical Information Service.

${ }^{17}$ Bevan, S., D.J. Najewicz, E. Gal, A.H. Furman, R. Ayala, and A. Feitelberg. 1994. Integrated Operation of a Pressurized Gasifier, Hot Gas Desulfurization System and Turbine Simulator. In Proceedings of the Coal-Fired Power Systems 94 - Advances in IGCC and PFBC Review Meeting, p. 222. DOE/METC-94/1008. NTIS/DE94012252. Springfield, Va.: National Technical Information Service.

${ }^{18}$ Cook, C.S., R. Hamilton, E. Gal, A.H. Furman, and R. Ayala. 1991. Integrated Operation of a Pressurized FixedBed Gasifier and Hot Gas Desulfurization System. In Proceedings of the Eleventh Annual Gasification and Gas Stream Cleanup Systems Contractors Review Meeting, ed. V.K. Venkataraman, L.K. Rath, J.W. Martin, and R.C. Bedick. Vol 1.p. 45. DOE/METC-91/6123. NTIS/DE92001102. Springfield, Va.: National Technical Information Service.

${ }^{19}$ R.E. Ayala and B.M. Kim, "Modeling and Analysis of Moving-Bed Hot-Gas Desulfurization Processes," Environ. Prog., 8, 19 (1989).

${ }^{20}$ Ayala, R.E. 1991. Enhanced Durability of High Temperature Desulfurization Sorbents for Moving-Bed Applications. Base Program: Development and Testing of Zinc Ferrite Sorbents. Topical Report. DOE/MC/250033045. NTIS/DE92001121. Springfield, Va.: National Technical Information Service.

${ }^{21}$ Westerterp, K.R., W.P.M van Swaaij, and A.A.C.M. Beenackers. 1984. Chemical Reactor Design and Operation. Wiley, New York.

${ }^{22}$ Gal, E. 1991. System for Removal of Sulfur Compounds from Gases and for Regenerating Spent Sorbents, U.S. patent 5,026,528, June 25, 1991. Also U.S. patent 4,857,285, August 1989.

${ }^{23}$ Ayala, R.E. and E. Gal. 1995. Process and Apparatus for Generating Elemental Sulfur and Reusable Metal Oxide from Spent Metal Sulfide Sorbents, U.S. patent 5,401,475, March 28, 1995.

${ }^{24}$ Ayala, R.E., V.S. Venkataramani, J. Abbasian, and A.H. Hill. 1995b. Advanced Low-Temperature Sorbents. In Proceedings of the Advanced Coal-Fired Power Systems '95 Review Meeting, Vol I, pp 407-416. DOE/METC95/1018 Vol. 1. NTIS/DE95009732. Springfield, Va.: National Technical Information Service.

${ }^{25}$ Ayala, R.E. T.L. Chuck, and R.P. Gupta. 1995a. . Moving-Bed Sorbents. In Proceedings of the Advanced CoalFired Power Systems '95 Review Meeting, Vol II , pp 591-600. DOE/METC-95/1018 Vol 2. NTIS/DE95009733. Springfield, Va.: National Technical Information Service.

${ }^{26}$ Ayala, R.E., T. Chuck, E. Gal, and R.P. Gupta. 1994. Development of High Temperature Desulfurization Sorbents for Moving-Bed Systems. In Proceedings of the Coal-Fired Power Systems 94 -Advances in IGCC and PFBC Review Meeting, p. 637. DOE/METC-94/1008. NTIS/DE94012252. Springfield, Va.: National Technical Information Service.

${ }^{27}$ Ayala, R.E. 1993. Enhanced Durability of High-Temperature Desulfurization Sorbents for Moving-Bed Applications. Option 2 Program: Development and Testing of Zinc Titanate Sorbents. Contract DE-AC2188MC25003. Topical Report. Springfield, Va.: National technical Information Service.

${ }^{28}$ Gasper-Galvin, L.D., J.H. Swisher, and K Hammerbeck. 1994. Characterization and Fixed-Bed Testing of a Nickel-Based Hot Gas Desulfurization Sorbent. In Proceedings of the Coal-Fired Power Systems 94 -Advances in IGCC and PFBC Review Meeting, p. 308. DOE/METC-94/1008. NTIS/DE94012252. Springfield, Va.: National Technical Information Service.

${ }^{29}$ Gasper-Galvin, L.D., and A.T. Atimtay. 1989. Novel Supported Hot Gas Desulfurization Sorbents: Zinc Oxide on Zeolite. In Proceedings of the Ninth Annual Gasification and Gas Stream Cleanup Systems Contractor's Review Meeting. ed. R.A. Johnson, and T.P. Dorchak. Vol 2, pp 563. DOE/METC-89/6107. NTIS/DE89011707. Springfield, Va.: National Technical Information Service. 
${ }^{30}$ Gasper-Galvin, L.D., and A.T. Atimtay. 1991. Zeolite Supported Copper Sorbents for Hot Gas Desulfurization. Paper 82f presented at the 1991 AIChE Summer National Meeting, Pittsburgh, PA, August. 18-21, 1991.

${ }^{31}$ Hepworth, M.T., and R. Ben-Slimane. 1994. Hot Gas Desulfurization with Manganese-Based Sorbents. In Proceedings of the Coal-Fired Power Systems 94 - Advances in IGCC and PFBC Review Meeting, p. 337. DOE/METC-94/1008. NTIS/DE94012252. Springfield, Va.: National Technical Information Service.

${ }^{32}$ Karpuk, M.E, R.J. Copeland, D. Feinber, D. Wickham, B. Windecker, and J. Yu. 1994. High Temperature Hydrogen Sulfide Removal with Stannic Oxide. In Proceedings of the Coal-Fired Power Systems 94 -Advances in IGCC and PFBC Review Meeting, p. 444. DOE/METC-94/1008. NTIS/DE94012252. Springfield, Va.: National Technical Information Service.

${ }^{33}$ Everitt, C.E., and S.J. Monaco. 1994. Data Summary Report for M.W. Kellogg Z-Sorb Sorbent Tests (Z-Sorb-01, Z-Sorb-02, Z-Sorb-03). Final Topical Report. Contract DE-AC21-90MC26328. Report No. 33FF-R93-003.

${ }^{34}$ Gangwal, S.K., R.P. Gupta, G.P. Khare, G.A. Delzer, and D.H. Kubicek. 1994. Fluidization Studies using Phillips Z-SORB Sorbent. In Proceedings of the Coal-Fired Power Systems 94 -Advances in IGCC and PFBC Review Meeting, p. 654. DOE/METC-94/1008. NTIS/DE94012252. Springfield, Va.: National Technical Information Service.

${ }^{35}$ Siriwardane, R.V., U. Grimm, J. Poston, and S. Monaco. 1994. Desulfurization Sorbent Development at the Morgantown Energy Technology Center. In Proceedings of the Coal-Fired Power Systems 94 -Advances in IGCC and PFBC Review Meeting, p. 662. DOE/METC-94/1008. NTIS/DE94012252. Springfield, Va.: National Technical Information Service.

36 "MERC — Hot Gas Cleanup Process," Final Report, MERC/SP-78/2, Morgantown, W.V., 1978.

${ }^{37}$ Joshi, D., Olson, T. H., Hayes, M. L. and Shah, "Hot Low-Btu Producer Gas Desulfurization in Fixed-Bed of Iron Oxide-Fly Ash," APCI Final Report to DOE, Contr. No. FE-77-2757-3, 1979.

${ }^{38}$ Tamhankar, S. S., Hasatani, M. and Wen, C. Y., Chem. Eng. Sci. 36, 1181-1191 (1981).

${ }^{39}$ Grindley, T. and Steinfeld, G., "Development and Testing of Regenerable Hot Coal Gas Desulfurization Sorbents," Final Report No. DOE/MC/16545-1125, 1981.

${ }^{40}$ Jalan, V. and Wu, D., "High Temperature Desulfurization of Fuel Gases for Molten Carbonate Fuel Cell Power Plants," Paper presented at the National Fuel Cell Seminar, San Diego, CA, July 14-16, 1980.

${ }^{41}$ In Proceedings of the Advanced Coal-Based and Environmental Systems '96 Review. CD ROM. U.S. Dept. of Energy, Morgantown Energy Technology Center (METC). Morgantown, WV.

${ }^{42}$ In Proceedings of the Advanced Coal-Based and Environmental Systems '97 Conference. CD ROM. U.S. Dept. of Energy, Federal Energy Technology Center. Pittsburgh, PA 15236.

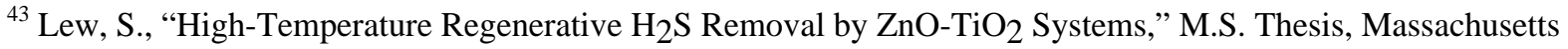
Institute of Technology, January 1987.

${ }^{44}$ Flytzani-Stephanopoulos, M. et al., Final Report to DOE, DOE/MC22193-2582, October 1987.

${ }^{45}$ Lew, S., Jothimurugesan, K. and Flytzani-Stephanopoulos, M., Ind. Eng. Chem. Res. 28,535 (1989).

${ }^{46}$ Siriwardane, R.V., J.A. Poston, and K. Hammerbeck. Testing and Analysis of METC10 Sorbent. In Proceedings of the Advanced Coal-Based and Environmental Systems '97 Conference. CD ROM. U.S. Dept. of Energy, Federal Energy Technology Center. Pittsburgh, PA 15236.

${ }^{47}$ Westmoreland, P. R., Gibson, J. B. and Harrison, D. P., Env. Sci. Tech. 11 (5), 488-491 (1977).

${ }^{48}$ Grindley, T. and Steinfeld, G., "Zinc Ferrite as Hydrogen Sulfide Absorbent," 3rd Ann. Contr. Mtg. on Contaminant Control in Coal-Derived Gas Streams, Rp. No. DOE/METC/84-6, 1983. 
${ }^{49}$ Anderson, G. L. et al., "Development of Hot Gas Cleanup System for Integrated Coal Gasification/Molten Carbonate Fuel Cell Plants," Final Report, No. DOE/MC/19403-1816, 1985.

${ }^{50}$ Flytzani-Stephanopoulos, M., Tamhankar, S. S., Sharma, P. K. and Gavalas, G. R., "Novel Sorbents for HighTemperature Regenerative $\mathrm{H}_{2} \mathrm{~S}$ Removal," Jet Propulsion Laboratory Final Report No. DOE/MC/20417-1898, October 1985.

${ }^{51}$ Tamhankar, S. S., Bagajewicz, M., Gavalas, G. R., Sharma, P. K. and Flytzani-Stephanopoulos, M., Ind. Eng. Chem. Proc. Des. Dev. 25, 429-437 (1986).

${ }^{52}$ Flytzani-Stephanopoulos, M. et al., High-Temperature Regenerative Removal of $\mathrm{H}_{2} \mathrm{~S}$ by Porous Mixed Oxide Sorbents, ACS Div. Fuel Chem. Preprints 30, 16-25 (1985).

${ }^{53}$ Flytzani-Stephanopoulos, M., Lew, S. and Sarofim, A. F., "Mechanistic and Kinetic Studies of High-Temperature Coal Gas Desulfurization Sorbents," Quarterly Report to DOE/PETC, DOE/PC88927-1, December 1988.

${ }^{54}$ Focht, G. D., Ranade, P. V., Harrison, D. P., "High-Temperature Desulfurization Using Zinc Ferrite: Reduction and Sulfidation Kinetics," Chemical Engineering Science, 43, (11) 3005-3013, 1988.

55 Smith, K. J., Haldipur, G. B. and Lucas, J. L., "KRW Process Development Coal Gasification/Hot Gas Cleanup," Proceedings, 7th Ann. Gasification and Gas Stream Cleanup Systems Contr. Rev. Mtg. DOE/METC-87/6079, 2, 668, June 1987.

${ }^{56}$ Wu, T. C., Kassman, J. S. and Robin, A. M., "Integration and Testing of Hot Desulfurization and Entrained Flow Gasification for Power Generation Systems," Proceedings of 9th Ann. Gasification and Gas Stream Cleanup Systems Contr. Rev. Mtg., Morgantown, WV, June 1989, DOE/METC-89/6107, 1, 25-36.

${ }^{57}$ Cook, C.S., E. Gal, A.H. Furman, and R.E. Ayala. Integrated Operation of a Pressurized Fixed-Bed Gasifier and Hot Gas Desulfurization System. In Proceedings of the Twelfth Annual Gasification and Gas Stream Cleanup Systems Contractors Meeting. U.S. Department of Energy, Morgantown Energy Technology Center, Morgantown, WV. DOE/METC-92/6128 (DE93000228).

${ }^{58}$ Copeland, R.J., M. Cesario, D.A. Feinberg, J. Sibold, and B. Windecker. Highly Attrition Resistant Moving-Bed Zinc Ferrite (Titanate) Sorbent. In Proceedings of the Advanced Coal-Based and Environmental Systems '97 Conference. CD ROM. U.S. Dept. of Energy, Federal Energy Technology Center. Pittsburgh, PA 15236.

${ }^{59}$ Gavalas, G. R., Patrick, U., Jothimurugeson, Kandaswami, Flytzani-Stephanopoulas, Maria, "High-Temperature

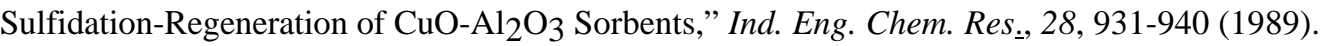

${ }^{60}$ Gangwal, S. K., Harkins, W. M., Stronger, J. M., Bossart, S. J., “Testing of Novel Sorbents for H2 Removal From Coal Gas," Environmental Progress, 8, (1) 26 (1989).

${ }^{61}$ Portzer, J.W., A.S. Damle, and S.K. Gangwal. Hot-Gas Desulfurization with Sulfur Recovery. In Proceedings of the Advanced Coal-Based and Environmental Systems '97 Conference. Paper CD ROM. U.S. Dept. of Energy, Federal Energy Technology Center. Pittsburgh, PA 15236.

${ }^{62}$ Flytzani-Stephanopoulos, M., Lew, S. and Sarofim, A. F., "Hot Gas Desulfurization by Zinc Oxide-Titanium Dioxide Regenerable Sorbents," ACS - Division of Fuel Chemistry Preprints of Papers. Presented at 199th ACS Nat'l Mtg., Boston, MA, Vol. 35 (1), p. 77, April 1990.

${ }^{63}$ Patrick, V., Gavalas, G. R., Flytzani-Stephanopoulos, M. and Jothimurugesan, K., Ind. Eng. Chem. Res. 28, $931-$ $940,1989$.

${ }^{64}$ Flytzani-Stephanopoulos, G.R. Gavalas, and S.S. Tamhankar. 1984. Novel Sorbents for High Temperature Regenerative $\mathrm{H}_{2} \mathrm{~S}$ Removal. Topical Report prepared by Jet Propulsion Laboratory, California Institute of Technology, Pasadena, CA, to U.S Dept. of Energy. DOE/MC-87/20407-2. JPL F-1750. July 1984.

${ }^{65}$ Flytzani-Stephanopoulos, M, K. Johtimurugesan, S. Lew, G.R. Gavalas, and V. Patrick. 1987. Detailed Studies of Novel Regenerable Sorbents for High-Temperature Coal-Gas Desulfurization. In Proceedings of the Seventh Annual Gasification and Gas Stream Cleanup Systems Contractor's Review Meeting. ed. M. Ghate, K. Markel, L. 
Jarr, S. Bossart, Vol 1, p. 726. DOE/METC-87/6079. NTIS/DE87006496. Springfield, Va.: National Technical Information Service.

${ }^{66}$ Lew S., M, K. Johtimurugesan, and Flytzani-Stephanopoulos. 1989. High-Temperature $\mathrm{H}_{2} \mathrm{~S}$ Removal from Fuel Gases by Regenerable Zinc Oxide-Titanium Dioxide Sorbents. Ind. Eng. Chem. Res. 28, 535 (1989).

${ }^{67}$ Gangwal, S.K., and Harkins, S.M. 1987. Bench-Scale Testing of Novel High-Temperature Desulfurization Sorbents. In Proceedings of the Seventh Annual Gasification and Gas Stream Cleanup Systems Contractor's Review Meeting. ed. M. Ghate, K. Markel, L. Jarr, S. Bossart, Vol 2, p. 749. DOE/METC-87/6079. NTIS/DE87006496. Springfield, Va.: National Technical Information Service.

${ }^{68}$ Gangwal, S.K., and Harkins, S.M. 1988. Bench-Scale Testing of Novel High-Temperature Desulfurization Sorbents. In Proceedings of the Eighth Annual Gasification and Gas Stream Cleanup Systems Contractor's Review Meeting. ed. V.P. Kothari, J.R. Longanbach, Vol 1, pp 103. DOE/METC-88/6092. NTIS/DE88010253. Springfield, Va.: National Technical Information Service.

${ }^{69}$ Jalan, V., M. Desai, and F. Brown. 1989. Copper-Based Sorbents for Hot Gas Cleanup. In Proceedings of the Ninth Annual Gasification and Gas Stream Cleanup Systems Contractor's Review Meeting. ed. R.A. Johnson, and T.P. Dorchak. Vol 2, pp 541. DOE/METC-89/6107. NTIS/DE89011707. Springfield, Va.: National Technical Information Service.

${ }^{70}$ Grindley, T. 1991. Lab-Scale Sorbent Development. In Proceedings of the Eleventh Annual Gasification and Gas Stream Cleanup Systems Contractor's Review Meeting. ed. V.K. Venkataraman, L.K. Rath, J.W. Martin, and R.C. Bedick. Vol 2, p. 516. DOE/METC-91/6123. NTIS/DE92001102. Springfield, Va.: National Technical Information Service.

${ }^{71}$ Anderson, G.L., and F.O. Berry. 1987. Development of a Hot Gas Cleanup System. In Proceedings of the Seventh Annual Gasification and Gas Stream Cleanup Systems Contractors Review Meeting, Vol 2. p. 642. DOE/METC87/6079. NTIS/DE87006496. Springfield, Va.: National Technical Information Service.

${ }^{72}$ Woods, M.C., K.E. Leese, S.K. Gangwal, D.P. Harrison, and K. Jothimurugesan. 1989. Reaction Kinetics and Simulation Models for Novel High-Temperature Desulfurization Sorbents. Final report. DOE/METC/24160-2671. NTIS/DE89000950. Springfield, Va.: National Technical Information Service.

73 "Desulfurization of Hot Coal Gas in Fluidized-Bed With Regenerable Sorbents," J. Abbasian, K. Salo and W. Mojtahedi. Paper submitted for publication in Fuel Processing Technology, 1993.

74 "High Temperature Fuel Gas Desulfurization in Fluidized-Bed With Zinc Titanate," W. Mojtahedi, K. Salo, J. Abbasian, J. R. Wangerow and F. S. Lau. Paper presented at the AIChE Annual Meeting, St. Louis, 1993.

${ }^{75}$ Abbasian, J., Hill, A. H., and Wangerow, J. R., "Development of Novel Copper Based Sorbent for Hot Gas Cleanup," Final Technical Report, September 1, 19909-August 31, 1992, prepared by Institute of Gas Technology for Center for Research on Sulfur in Coal.

${ }^{76}$ Abbasian, J., Rehmat, A., Stephanopoulous, M.F., and Hu, Z., "Development of Novel Copper-Based Sorbent for Hot Gas Cleanup." Paper presented at the 1992 AIChE Spring National Meeting, New Orleans, LA.

${ }^{77}$ Abbasian, J., R.B. Slimane, J.R. Wangerow, and M.K. Zarnegar, Advanced Low-Temperature Sorbents for FluidBed Applications. CD ROM. U.S. Dept. of Energy, Federal Energy Technology Center. Pittsburgh, PA 15236.

${ }^{78}$ Anderson, G. A., et. al., "Development of a Hot Gas Cleanup System for Integrated Coal Gasification/Molten Carbonate Fuel Cell Power Plant,” Final Report Prepared by Institute of Gas Technology for U.S. DOE/METC.

${ }^{79}$ Westmoreland, P.W., and D. P. Harrison. 1976. Evaluation of Candidate Solids for High-Temperature Desulfurization of Low-Btu Gases. Env. Sci. Tech., 10, 659 (1976).

${ }^{80}$ Moulijn, J.A.; W.J.W. Bakker, J.C.P. van Rossen, and J.P. Janssens. 1996. Sulfiding Mechanisms in Absorption of $\mathrm{H}_{2} \mathrm{~S}$ by Solids. Also Performance Analysis of Manganese-Based Sorbents in Hot Gas Desulfurization. In Proceedings of the NATO/Advanced Study Institute Conference - Desulfurization of Hot Coal Gas with Regenerable Metal Oxide Sorbents: New Developments, KuEadasi, Turkey, July 7-19, 1996. 
${ }^{81}$ Van der Ham, A.G.J. van der Ham, R.H. Venderbosch, W. Prins, and W.P.M. van Swaaij. Desulfurization Processes of Fue Gas and Stage-wise Desulfurization. Also Effect of Reactor Parameters on Sulphidation/Regeneration Performance. In Proceedings of the NATO/Advanced Study Institute Conference Desulfurization of Hot Coal Gas with Regenerable Metal Oxide Sorbents: New Developments, Ku乏adasi, Turkey, July 7-19, 1996

${ }^{82}$ García, E; C. Ibarra, J.V. Cilleruelo, M. Pineda, and J.M. Palacios. 1997. Kinetic Study of High Temperature Removal of $\mathrm{H}_{2} \mathrm{~S}$ by Novel Metal Oxide Sorbents. Ind. Eng. Chem. Res., 1997, 36, 846-853.

${ }^{83}$ Wheast, R.C., and M.J. Astle, 1978. CRD Handbook of Chemistry and Physics. CRD Press, Inc. West Palm Beach, Florida, 33409.

${ }^{84}$ Perry, H.R., and C.H. Chilton. 1973. Chemical Engineer's Handbook. 5th. Edition. McGraw-Hill, New York.

${ }^{85}$ Ayala, R.E., V.S. Venkataramani, and T.L. Chuck. Hot Gas Desulfurization using Moving-Bed Reactor. In Proceedings of the Advanced Coal-Based and Environmental Systems ' 97 Conference. CD ROM. U.S. Dept. of Energy, Federal Energy Technology Center. Pittsburgh, PA 15236. 


\section{Chapter 2 \\ EXPERIMENTAL PROCEDURES}

\subsection{SORBENT FABRICATION PARAMETERS}

Two different types of sorbents were evaluated for moving-bed applications in the current program:

- Zinc-based sorbents, particularly zinc titanates

- Non-zinc sorbents, particularly proprietary formulations

Testing of zinc-based sorbents included zinc titanates prepared for GE by United Catalysts, Inc. (UCI), and ICCI zinc titanates prepared by UCI for E\&A Associates and the Illinois Clean Coal Technology Institute (ICCI). Non-zinc sorbents included manganese-based Chemetals Inc. sorbents. Because of the proprietary nature of the preparation procedures for most sorbents, the fabrication parameters for the formulations tested in this program will not be presented here.

Zinc titanate sorbents prepared for GE by United Catalysts, Inc., (UCI) were rounded 3-5-mm pellets. The rounded pellets were used to screen a number of chemical formulations for chemical performance in desulfurization to achieve a desired balance of mechanical properties (crush strength and attrition resistance) and chemical properties. The details of the preparation procedure are proprietary to UCI, but in general, the procedure involves mixing of the metal oxide powders followed by forming into shape and calcining at high temperature so that the mixed-metal oxide structure is created by solid-state reactions. The rounding procedure, when used in addition to extrusion, produces stronger pellets and has been described before and shown to aid in the preparation of sorbents more suitable for moving-bed applications. ${ }^{1,2}$.

For all zinc titanate formulations, calcination time and temperature were varied as necessary to achieve the best combination of chemical and mechanical properties. Pellet size was held constant at $5 \mathrm{~mm}$ whenever comparisons of reactivity were being made. When calcining mixtures of $\mathrm{ZnO}$ and $\mathrm{TiO}_{2}$ powders at high temperature, three crystalline structures of zinc titanate may form depending on the ratio of zinc to titanium: $\mathrm{ZnTiO}_{3}, \mathrm{Zn}_{2} \mathrm{Ti}_{3} \mathrm{O}_{8}$, or $\mathrm{Zn}_{2} \mathrm{TiO}_{4}$. The highest zincto-titanium molar ratio zinc titanate, $\mathrm{Zn}_{2} \mathrm{TiO}_{4}$, would be the most desired crystalline phase for its higher sulfur capacity. However, other phases could also be desirable in principle if they provide higher strength to the calcined sorbent pellet.

More information on the properties of the sorbents will be given in the results section for each sorbent.

Several guidelines were used to assess sorbent performance and to identify superior formulations for moving-bed systems. Among the guidelines, a formulation had to meet mechanical strength requirements (crush strength and attrition resistance), chemical reactivity requirements (as measured by single-pellet thermo-gravimetric analysis, (TGA)), and pellet physical morphology requirements (size, shape, and pore structure). 


\subsection{CHARACTERIZATION TECHNIQUES}

\subsubsection{Kinetic Performance}

\subsubsection{TGA Chemical Reactivity}

Chemical reactivity of single-pellet sorbent samples was determined by measuring pellet sulfur capacity and regenerability in a thermogravimetric analyzer (TGA). The rate of sulfidation or regeneration was determined indirectly by relating pellet weight gained or lost as a function of time. Details of the procedure have been described before ${ }^{1}$.

The TGA is a Perkin Elmer balance having a capacity of up to $100 \mathrm{~g}$, and capable of measuring weight changes with an accuracy of $\pm 1 \mu \mathrm{g}$. Typical gas compositions used for sulfidation and regeneration are shown in Table 2-1. The sulfidation gas compositions could simulate oxygenblown, entrained-bed gasifier gas or air-blown, fixed-bed gasifier gas; the regeneration gas composition did not include purposely any $\mathrm{SO}_{2}$ in the feed in order to achieve the highest level of regeneration and measure the true regeneration to oxide in the absence of zinc sulfate formation. The test procedure consists of a 30-minute reduction at $482-538^{\circ} \mathrm{C}\left(900-1000{ }^{\circ} \mathrm{F}\right)$ in clean reducing gas (i.e., no $\mathrm{H}_{2} \mathrm{~S}$ ) prior to each sulfidation. Sulfidation is then conducted at the selected temperature with $3 \% \mathrm{H}_{2} \mathrm{~S}$ for both the half-cycle (i.e., sulfidation) runs and the $1 \frac{1}{2}$-cycle (i.e., sulfidation-regeneration-sulfidation) runs. Tests are conducted for a minimum of three hours or until no weight change occurs.

After full sulfidation, oxidative regeneration is carried out at $677^{\circ} \mathrm{C}\left(1250{ }^{\circ} \mathrm{F}\right)$ with $4 \% \mathrm{O}_{2}$ in $\mathrm{N}_{2}$. At this point the run is interrupted, if necessary, to remove one pellet from the screen for characterization of pore size distribution. The remaining pellets are then subjected to a second reduction and sulfidation prior to termination of the run. All tests were conducted at $1 \mathrm{~atm}$ pressure, except for a few conducted at higher pressure elsewhere to cross-correlate results via partial pressures of $\mathrm{H}_{2} \mathrm{~S}$. All of the sample pellets for testing were selected to be of nearly equivalent size so that the comparison of reaction rates would be meaningful.

Table 2-1. Gas Compositions (vol \%) used in TGA tests

\begin{tabular}{lccc}
\hline & $\begin{array}{l}\text { Simulated } \\
\text { air-blown } \\
\text { gasifier gas }\end{array}$ & $\begin{array}{l}\text { Simulated } \\
\mathrm{O}_{2} \text {-blown } \\
\text { gasifier gas }\end{array}$ & Regeneration gas \\
\hline $\mathrm{H}_{2}$ & 15.0 & 25.1 & \\
$\mathrm{CO}$ & 8.0 & 60.9 & \\
$\mathrm{CO}_{2}$ & 11.0 & 3.0 & \\
$\mathrm{H}_{2} \mathrm{O}$ & 30.0 & 3.0 & \\
$\mathrm{H}_{2} \mathrm{~S}$ & 3.0 & 3.0 & \\
$\mathrm{~N}_{2}$ & 33.0 & 5.0 & 96.0 \\
$\mathrm{O}_{2}$ & & & 4.0 \\
\hline
\end{tabular}




\subsubsection{Chemical Composition}

Chemical composition analyses were conducted on both fresh sorbents and sorbents extracted from the bench-scale reactor system after multicycle testing. Analyses concentrated on the determination of the elemental composition, solid crystalline phase composition, and microstructure.

The crystalline phase composition of the sorbent was determined using x-ray diffraction (XRD). The instrument used for analysis is a Rigaku $\theta / \theta$ automated diffractometer with a 43-position sample changer. The lower detection limit for most constituents is of the order of $1 \%$ to $3 \%$. Quantitative average elemental analysis of whole pellets was determined by inductively coupled plasma (ICP) atomic emission spectroscopy; qualitative and quantitative elemental analyses for whole pellets was determined by $\mathrm{x}$-ray fluorescence (XRF) spectrometry. The average content of total carbon and total sulfur in single pellets was determined by total carbon and total sulfur analyses by Commercial Testing and Engineering, Co. (CTE, South Holland, Illinois) using a LECO induction furnace analyzer. Sulfate sulfur was also determined at CTE following the ASTM D2492 procedure.

\subsubsection{Mechanical Strength}

The mechanical strength of sorbents, crush strength, and attrition resistance were measured at GE-CRD or at the sorbent supplier site. Crush strength is defined as the maximum dead-weight load a pellet withstands on compression prior to fracture; for rounded pellets, the crush strength is presented as force per pellet since the contact area between the flat plates and the ellipsoidal pellet is not easily measured and varies depending on the pellet aspect ratio. Crush strength (i.e., deadweight load) was measured by subjecting single pellets to an increasing load between two plates in an Instrom tester until breakage occurred, and the measured force was averaged over a minimum of 20 pellets.

Attrition tests were performed at ambient temperature in a rotating cylinder, and the weight loss of sorbent on attrition was measured according to a modified ASTM D4058-81 method, "Attrition and Abrasion of Catalysts and Catalysts Carriers." Modifications of the test apparatus to withstand high temperature have been described previously. ${ }^{3}$ In this study, attrition resistance

is defined as $100 \%$ minus the ASTM percent loss on attrition. Percent loss on attrition is defined in the above ASTM D4058-81 method by calculating the percent difference in measured weight of the sample retained in a No. $20(850 \mu \mathrm{m})$ ASTM sieve before and after rotating the cylinder at $60 \mathrm{rpm}$ for 30 minutes. The word attrition will be used in this report as being equivalent to the definition of percent loss on attrition, as defined in the ASTM D4058-81 method.

\subsubsection{Physical Morphology}

\subsubsection{Pore Size Distribution by Mercury Porosimetry}

Pellet pore size distributions, including the calculation of median pore diameter (MPD) (i.e., diameter at 50\% intrusion) and specific pore volume (SPV) (i.e., pore or void volume per unit 
mass of sorbent), were determined using a Micromeritics (Model AutoPore 9220II) mercury porosimeter or equivalent. Measurement of pore size distributions for selected formulations are presented in this report. This information is not given for proprietary sorbents.

\subsubsection{Sieving}

Sieving was performed using ASTM standard sieves in order to determine the size distribution of solids before and after attrition tests. Pellet size classification was divided into three categories: whole pellets, broken pellets, or aggregates (i.e., those particles or pellet pieces larger than 20 mesh but smaller than whole pellets), and fines (i.e., powder material below $850 \mu \mathrm{m}$, or 20 mesh). This classification allowed us to quantify the degree of degradation that whole pellets had experienced by fracture or other means even if not resulting in the formation of fines less than 20 mesh as defined by the ASTM D4058-81 test.

\subsection{PROVISION OF BENCH-SCALE REACTOR (TASK 3)}

Relatively minor hardware modifications were made to the reactor system at GE-CRD under Task 3. The bench reactor had been commissioned and tested under a previous DOE-sponsored sorbent development contract. ${ }^{2}$ Figure 2-1 shows the gas flow system of the bench reactor. Most changes or enhancements were in the automation of data acquisition, handling, and analysis. A significant change attempted in the gas flowing system was the addition of a recirculation loop (shown as a dashed line). The purpose was to simulate the recycling of regeneration gases, which concentrates the $\mathrm{SO}_{2}$ to $8-10 \%$. High $\mathrm{SO}_{2}$ levels are beneficial for sulfur recovery systems, such as sulfuric acid production, because the production then runs without external heat input. Unfortunately, the recirculation pump was not capable of delivering the desired flow rate at the temperatures $\left(400{ }^{\circ} \mathrm{C}\right.$ or higher) and pressures $(5 \mathrm{~atm})$ of interest. After many attempts, the recirculation loop operation was still unreliable and we reverted back to a single-pass regeneration system where the $\mathrm{SO}_{2}$ is introduced directly into the feed stream.

In addition, the bench-scale reactor system was also modified to automate the data acquisition module. In particular, the acquisition and logging of direct readings of thermocouple temperature were switched from a central VAX computer system to a personal computer running the software LabView for Windows. All PC hardware and software additions to the bench unit were provided by GE from internal funding at no charge to the government contract. Data from temperature and flow rate measuring instrumentation is processed in the PC and stored in the hard disk for future

off-line analysis using spreadsheet programs. Previously, retrieval of temperature data during the run required mounting of a disk tape, downloading it as ASCII files, and then importing the data into a PC. 


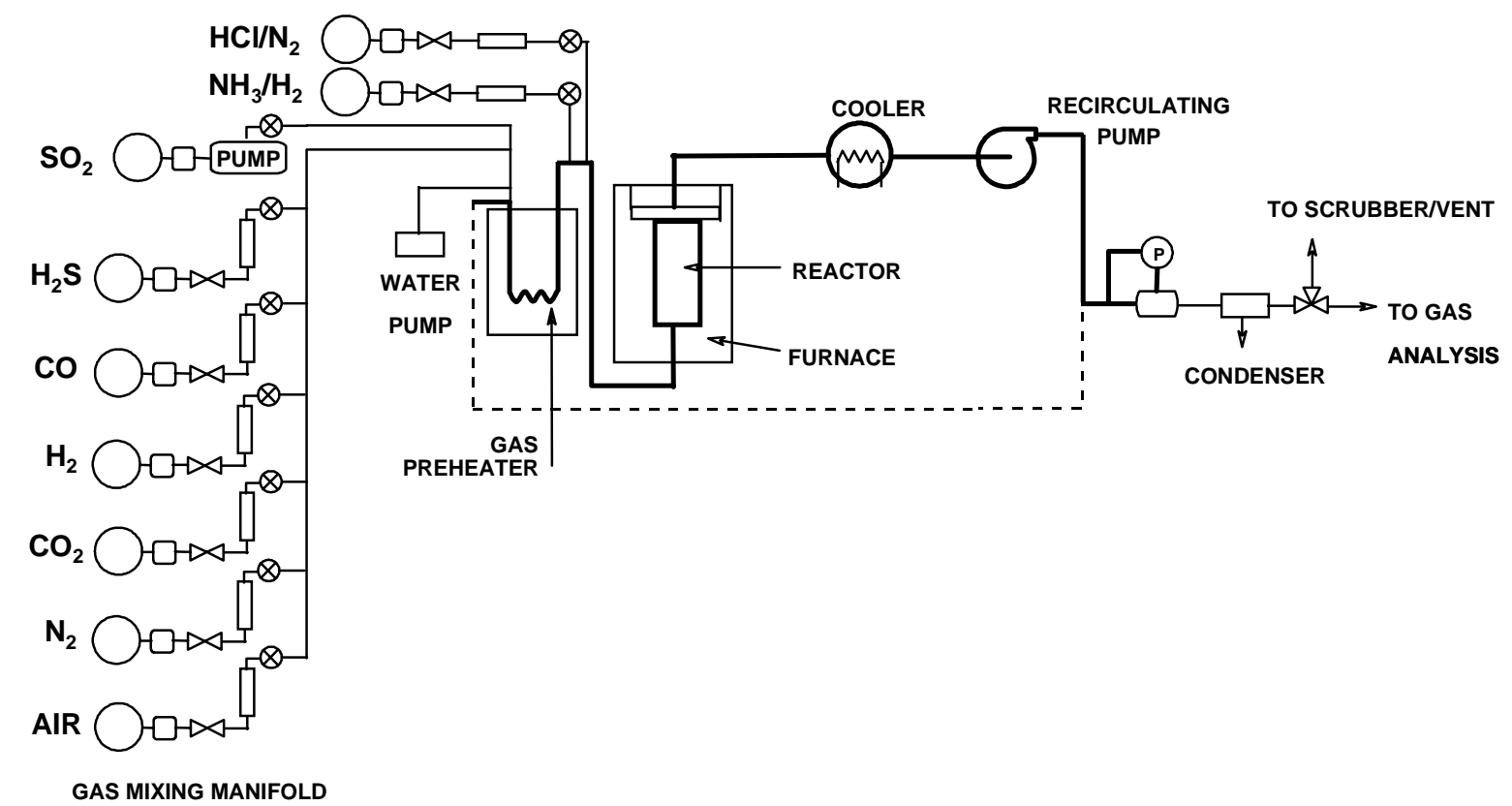

Figure 2-1. Schematic diagram of the gas flow system in the bench-scale reactor

\subsubsection{Bench-Scale Reactor Testing}

In addition to TGA tests, chemical reactivity was also determined by measuring sorbent sulfur loading (defined as grams of sulfur absorbed per $100 \mathrm{~g}$ of fresh sorbent) in fresh and in cycled (i.e., spent) samples from the bench-scale reactor. Only formulations that exhibited a good balance of chemical and mechanical performance as fresh pellets were selected for further cyclic testing in a bench-scale reactor system.

The important aspect of the bench-scale testing is that both absorption and regeneration are conducted in a packed-bed reactor simulating the time/temperature environment in which the sorbent would be exposed in a typical full-scale moving-bed system. Absorption was carried out at $482{ }^{\circ} \mathrm{C}\left(900^{\circ} \mathrm{F}\right)$ using the gas composition shown in Table 2-2, which is similar to that of an oxygen-blown gasifier. The $1 \% \mathrm{H}_{2} \mathrm{~S}$ concentration used is artificially high in order to accelerate the rate of sulfur loading and reduce testing time. 


\section{Table 2-2. Simulated Coal Gas Composition for Bench-Scale Testing}

\begin{tabular}{ll}
\hline Component & $(\%)$ \\
\hline $\mathrm{CO}$ & 39 \\
$\mathrm{CO}_{2}$ & 10 \\
$\mathrm{H}_{2}$ & 30 \\
$\mathrm{H}_{2} \mathrm{O}$ & 20 \\
$\mathrm{H}_{2} \mathrm{~S}$ & 1 \\
$\mathrm{~N}_{2}$ & 0 \\
\hline
\end{tabular}

The oxidative regeneration was carried out between $343-538{ }^{\circ} \mathrm{C}\left(700-1000{ }^{\circ} \mathrm{F}\right)$, depending on the test, up to $677^{\circ} \mathrm{C}\left(1250^{\circ} \mathrm{F}\right)$ or higher. Oxygen concentration was between $1-8 \%$ oxygen during the early phases of regeneration in order to keep the peak temperatures below $760{ }^{\circ} \mathrm{C}\left(1400{ }^{\circ} \mathrm{F}\right)$ during the final phase of regeneration. This scheme of regeneration was intended to simulate the temperature rise of the sorbent bed (triggered by the exothermic oxidation reaction) in the largescale system. Several variations of the bench reactor test procedures were depending on the test. More details of the test conditions are provided in the results section so that the reader can follow the procedural information closer to the test results.

\section{REFERENCES: CHAPTER 2}

\footnotetext{
${ }^{1}$ Ayala, R.E. 1993.Enhanced Durability of High-Temperature Desulfurization Sorbents for Moving-Bed Applications. Option 2 Program: Development and Testing of Zinc Titanate Sorbents. Topical Report, Contract DEAC21-88MC25003 US Department of Energy, Morgantown Energy Technology Center. Morgantown, West Virginia.

${ }^{2}$ Ayala, R.E and T.L. Chuck. 1996. Enhanced Durability of High-Temperature Desulfurization Sorbents for Moving-Bed Applications. Option 3 Program: Development and Testing of Additional Zinc Titanate Sorbents. Topical Report, Contract DE-AC21-88MC25003 US Department of Energy, Morgantown Energy Technology Center. Morgantown, West Virginia.

${ }^{3}$ Ayala, R.E. 1991.Enhanced Durability of High-Temperature Desulfurization Sorbents for Moving-Bed Applications. Base Program: Development and Testing of Zinc Ferrite Sorbents. Topical Report, DOE/MC/250033045. NTIS/DE920001121. Contract DE-AC21-88MC25003 US Department of Energy, Morgantown Energy Technology Center. Morgantown, West Virginia.
} 


\section{Chapter 3}

\section{RESULTS AND DISCUSSION}

Results are being presented in each of the following sections according to technical topic (e.g., testing of modified zinc titanates) rather than by program task (as described in Section 1.3 Project Description). The task to which each of the technical topics belongs is referenced within the text. This approach was taken since it is more logical for the reader to follow from beginning to end a technical topic (e.g., development of a given sorbent) that was carried out across several tasks rather than to follow simultaneously several topics presented in sequential task order.

\subsection{NEPA REPORT}

The information necessary for the DOE to prepare a National Environmental Program Assessment (NEPA) report was submitted by GE-CRD and the subcontractor IGT to DOE as per contract requirements. The NEPA information fulfilled the requirements for completion of Task 1. The reports included, as a minimum, detailed information on the environmental impact that the execution of the experimental tasks would have on the environment in the areas of:

- land use

- air quality

- water resources/water quality

- solid waste and hazardous materials

- other areas (energy requirements, noise level, impact on vegetation and animals, visual resources, historical/cultural resources

\subsection{EVALUATION OF METAL OXIDES AS REGENERABLE SORBENTS}

\subsubsection{Thermodynamic Calculations}

Before undertaking the actual preparation of new sorbent formulations under Task 2-Sorbent Preparation and Characterization, it was deemed necessary to review the literature and perform thermodynamic equilibrium calculations for $\mathrm{H}_{2} \mathrm{~S}$ removal by metal oxides in equilibrium with the corresponding sulfided solid phases. The literature review was previously summarized in Section 1.2, Background. The thermodynamic calculations were performed as part of Task 2 - Sorbent Preparation and Characterization.

Results were evaluated in view of the program objectives considering that most of these previous studies concentrated in the temperature range $538-704^{\circ} \mathrm{C}\left(1000-1300^{\circ} \mathrm{F}\right)$ for sulfidation, rather than in the range of $343-538^{\circ} \mathrm{C}\left(650-1000^{\circ} \mathrm{F}\right)$. Consequently, some materials that were considered by previous authors to be of secondary importance in the upper temperature range may show reasonable reactivity and absence of secondary undesired reactions to be competitive in the lower temperature range.

Model calculations of equilibrium between $\mathrm{H}_{2} \mathrm{~S}_{(\mathrm{g})}$ and metal sulfides had been performed in the past by Westmoreland et al. ${ }^{1}$ with emphasis on desulfurization at temperatures above $500{ }^{\circ} \mathrm{C}$. In this program, the emphasis is on desulfurization at below $538^{\circ} \mathrm{C}\left(1000^{\circ} \mathrm{F}\right)$ using two particular coal gasifier gas 
compositions: an oxygen-blown, entrained-flow gasifier (similar to Texaco gasifier being used at the Tampa Electric Co.'s Polk Power Station), and an air-blown, fluidized-bed gasifier gas (such as the UGas gasifier). Calculations on oxygen-blown, entrained flow gasifier coal gas were performed at GECRD since the Tampa Electric Co.'s Polk Plant uses a Texaco gasifier and a moving-bed HGCU system. On the other hand, those for an air-blown, fluidized bed U-Gas gasifier were performed by the subcontractor IGT with the end goal of coupling the gasifier with a fluidized bed desulfurization system.

The thermodynamic $\mathrm{H}_{2} \mathrm{~S}$ equilibrium concentrations in simulated fuel gases (Texaco and U-GAS gasifiers) for a number of potential metal oxides were calculated at elevated temperatures (i.e., $350^{\circ}$ $550^{\circ} \mathrm{C}$ ) and pressure (20 bar). Calculations were performed on a personal computer using the thermodynamic calculation package and database HSC Chemistry for Windows software. Calculations were based on the minimization of the Gibbs free energy of formation and suppressing secondary reactions that change the gas composition (e.g., solid carbon deposition, and methane formation equilibria for the case of coal gases). The metal oxides considered for this analysis included copper, zinc, iron, nickel, tin, cobalt, molybdenum, manganese, and tungsten. The number of moles of the fuel gas and the solid oxides was selected to correspond to $50 \%$ sorbent conversion during sulfidation. Based on the available data, certain restrictions were imposed on formation of a number of species (such as carbon deposition) so as to better simulate the actual environment of a dynamic, kinetically constrained equilibria coal gasifier.

The results of these analyses are presented in Figure 3-1 for the Texaco fuel gas. Better $\mathrm{H}_{2} \mathrm{~S}$ removal (i.e., lower equilibrium $\mathrm{H}_{2} \mathrm{~S}$ concentrations) can be obtained by all of the metal oxides considered at lower temperatures. For this program, a target of less than 25 ppm equilibrium $\mathrm{H}_{2} \mathrm{~S}$ is acceptable for HGCU sorbent development. For comparison, Figure 3-2 presents the corresponding results for UGAS fuel gas performed at IGT, indicating that calculated $\mathrm{H}_{2} \mathrm{~S}$ equilibrium concentrations are only slightly affected by the fuel gas composition of these two gasifiers. Furthermore, because of the lower temperature range (e.g., $350^{\circ}-550^{\circ} \mathrm{C}$ ) considered in this study, a large number of metal oxides are capable of reducing the $\mathrm{H}_{2} \mathrm{~S}$ level of the fuel gases to below $20 \mathrm{ppmv}$ for IGCC application. It should be noted that the $\mathrm{H}_{2} \mathrm{~S}$ equilibrium for copper oxide is the lowest (e.g., below $0.1 \mathrm{ppmv}$ ). If reduction to metallic copper is prevented while in the reduced form, metallic copper is still an acceptable candidate below $400^{\circ} \mathrm{C}$. On the other hand, kinetic considerations must also be included prior to selecting a metal oxide as being a superior desulfurization agent for HGCU development. The above argument is the reason for testing several types of sorbents in this program (e.g., modified zinc titanates and proprietary sorbents).

In addition to constructing $\mathrm{H}_{2} \mathrm{~S}$ equilibrium diagrams for reducing gases (i.e., coal gas), phase stability diagrams for oxidizing gas atmospheres (i.e., regeneration gases) were constructed using similar algorithms based on minimization of the Gibbs free energy of the system. The phase stability of metals under regeneration gases containing $\mathrm{SO}_{2}$ and $\mathrm{O}_{2}$ is important during regeneration because spalling and pellet deterioration occur more often as a result of metal sulfate formation. Figure 3-3 shows the stability of four metals as a function of the $\log$ partial pressure of $\mathrm{O}_{2}$ and $\mathrm{SO}_{2}$ (in atms). For gas compositions containing approximately 0.02 atm of $\mathrm{O}_{2}$ and 0.5 to 0.1 atm $\mathrm{SO}_{2}$ (typical of atmospheric regeneration gases in the moving-bed system), the thermodynamically stable phase of copper is copper sulfate, while the thermodynamically stable form of molybdenum is the oxide. For most pure oxides, including zinc oxide, the metal sulfate is the stable form under oxidizing gas conditions at temperatures around 500$700{ }^{\circ} \mathrm{C}$, depending on $\mathrm{SO}_{2}$ and $\mathrm{O}_{2}$ concentration. Of course, thermodynamic predictions do not take 


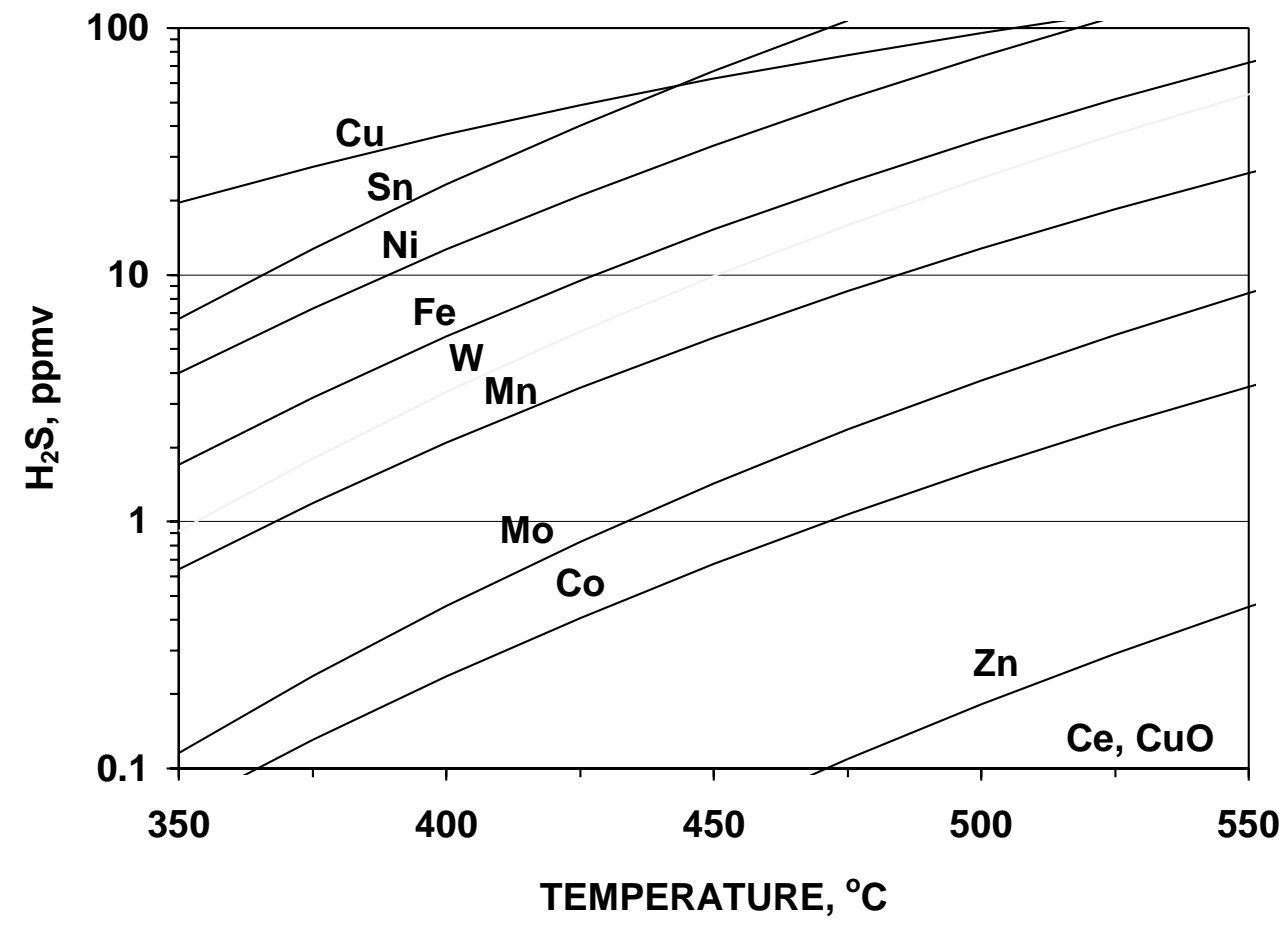

Figure 3-1. $\mathrm{H}_{2} \mathrm{~S}$ equilibrium concentration in fuel gas (Texaco) with various oxides

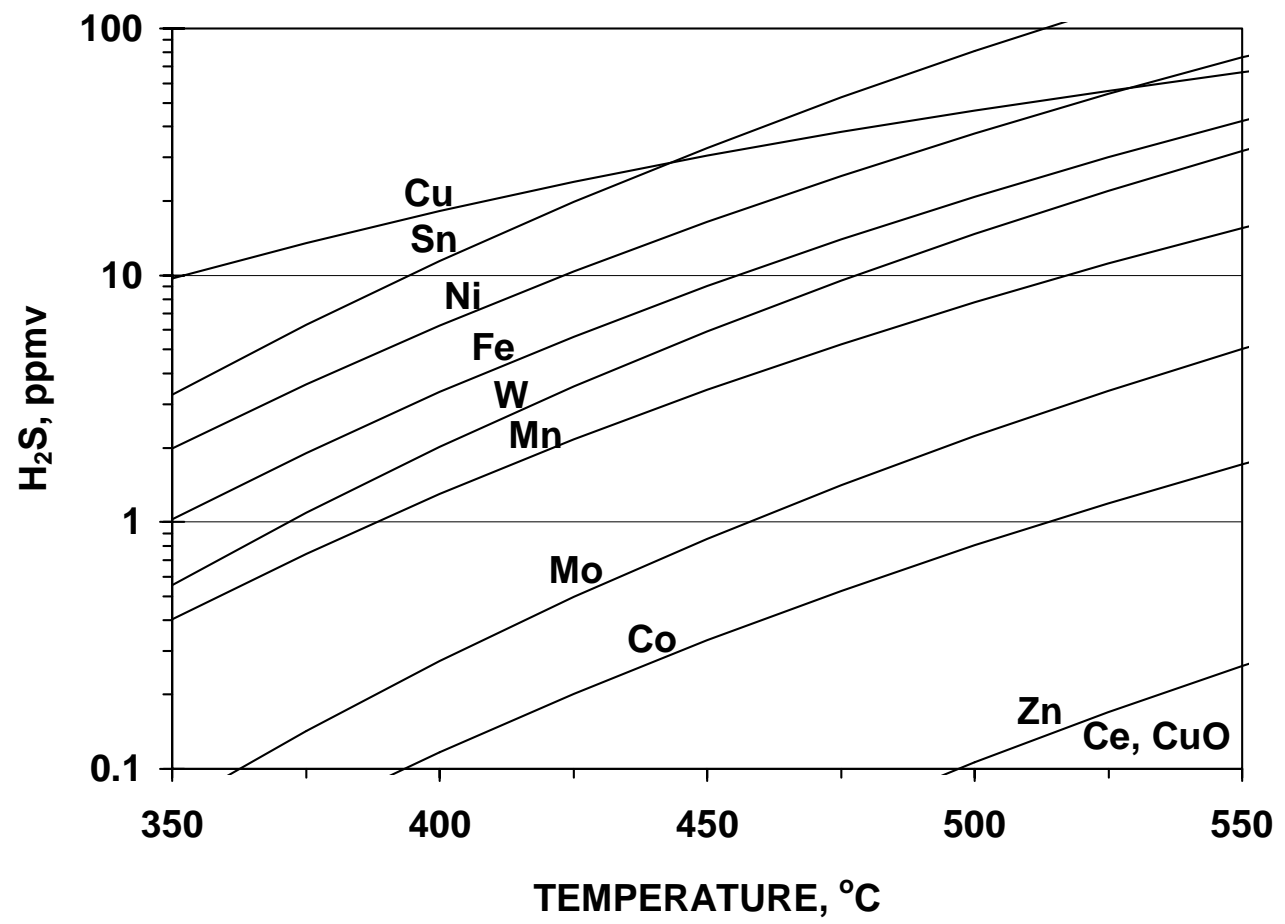

Figure 3-2. $\mathrm{H}_{2} \mathrm{~S}$ equilibrium concentration in fuel gas (U-GAS) with various oxides 

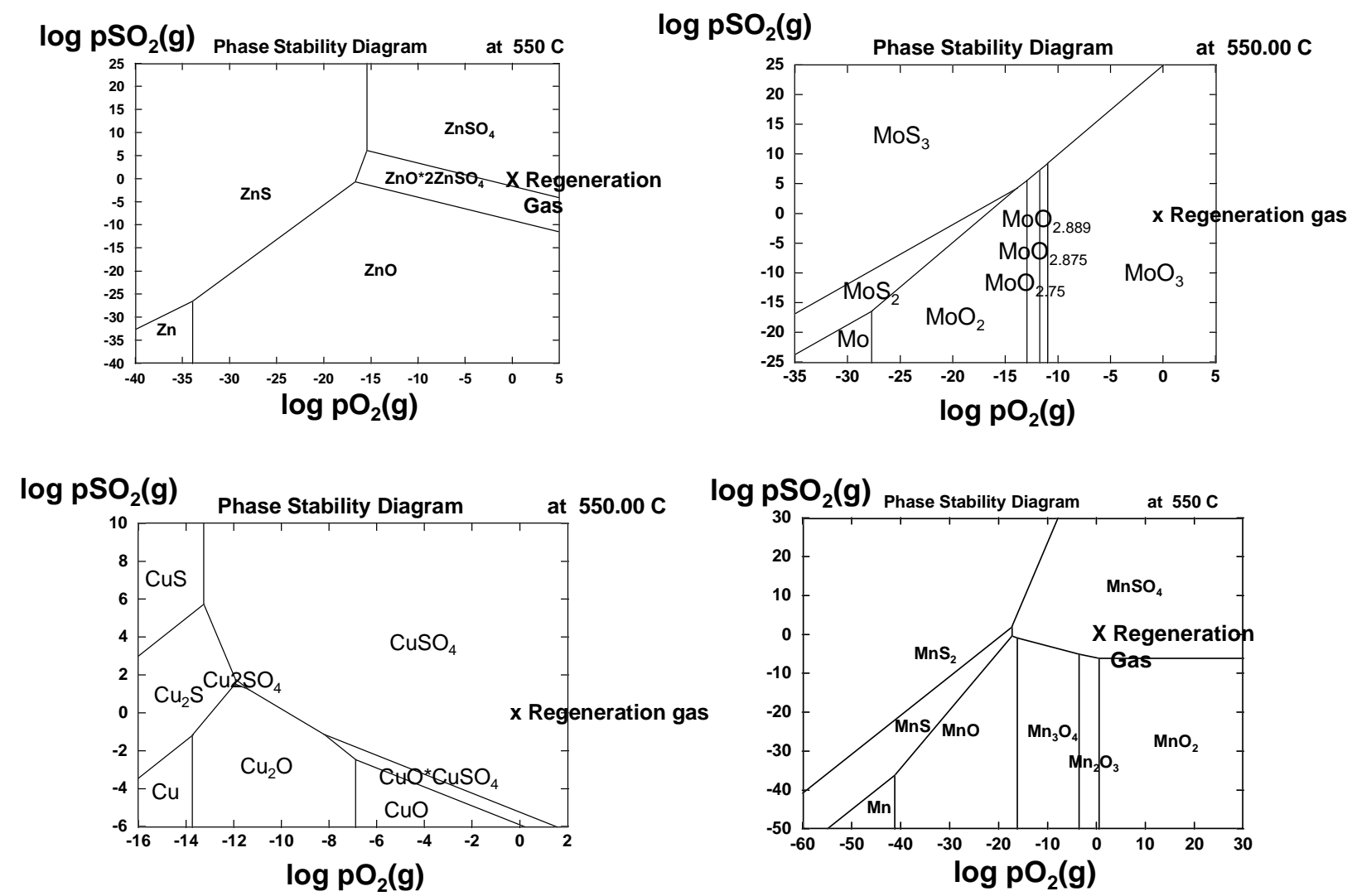

Figure 3-3. Phase stability diagrams for Zn-S-O (upper left), Mo-S-O (upper right), Cu-S-O (lower left), and Mn-S-O (lower right) systems.

into account the rate of approach to equilibrium (i.e., kinetic rates), and hence experimental data is still needed to confirm the extent of formation of the predicted species. Nevertheless, thermodynamics allows the investigator to determine if formation of certain compounds is infeasible. Other phase stability diagrams for cobalt, iron, tungsten, and cerium are presented below in Figure 3-4.

The diagram for zinc has been well studied in the literature and was used as a corroboration of the predictions of our calculation methodology. The diagram for cobalt is particularly interesting in that two cobalt sulfide species are possible, giving the sorbent a potential for several levels of sulfidation. 

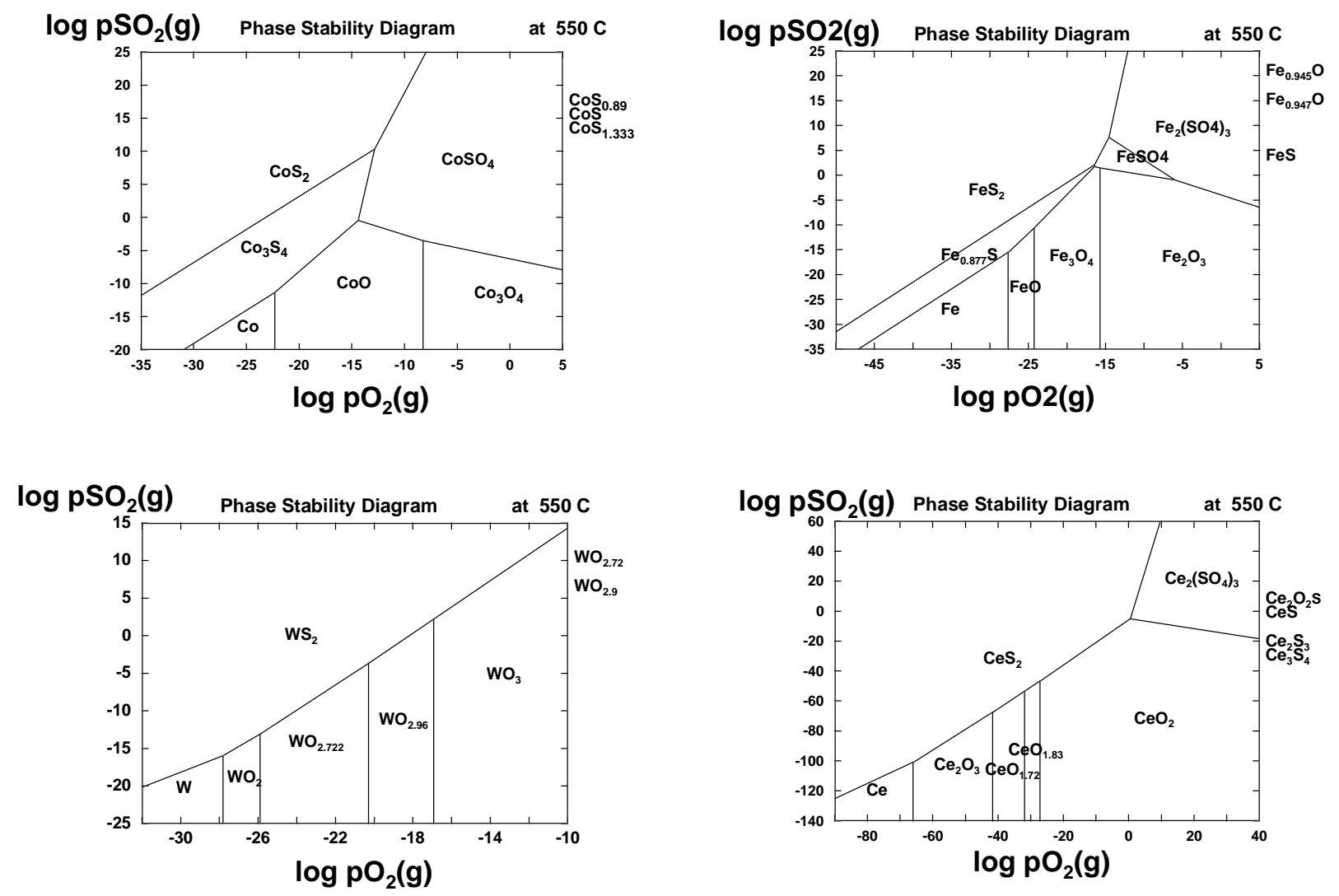

Figure 3-4. Phase stability diagrams for Co-S-O (upper left), Fe-S-O (upper right), W-S-O (lower left), and Ce-S-O (lower right) systems.

\subsubsection{Selection of Metal Oxides for Desulfurization}

Various meetings among the program participants were held to identify new sorbent formulations for the current program. The selection of metal oxides for sorbents fell under three categories:

- Zinc-based sorbents

- Non-zinc sorbents

- Proprietary formulations

The main criteria for selection were based on:

1. High desulfurization capability: thermodynamic equilibria and fast reaction kinetics in the temperature range of $343-538^{\circ} \mathrm{C}\left(650-1000^{\circ} \mathrm{F}\right)$.

2. Minimization of undesired reactions under reducing gas conditions (e.g., interactions with $\mathrm{HCl}$, $\mathrm{CO}$, and $\mathrm{H}_{2}$, catalysis of gas phase reactions).

3. Ease of regeneration capability: thermodynamic stability and fast reaction kinetics compatible with the desulfurization temperature range.

4. Minimization of undesired reactions under oxidizing gas conditions (e.g., sulfate formation, hydrothermal stability) 
From the initial screening of metals, the following metals were ruled out immediately: $\mathrm{Ba}, \mathrm{Ca}, \mathrm{Sr}$, and $\mathrm{V}$. The main reason was the lack of sulfidation of their oxide forms in the desired range of $340-550^{\circ} \mathrm{C}$ $\left(\sim 650-1000^{\circ} \mathrm{F}\right)$ or incompatibility with turbine operation (i.e., high-temperature corrosion by vanadium compounds).

The process of selection of metal oxides for desulfurization identified the following metals as being potentially useful for our study: $\mathrm{Zn}, \mathrm{Cu}, \mathrm{Co}, \mathrm{Fe}, \mathrm{Ce}, \mathrm{Mo}, \mathrm{Mn}, \mathrm{Sn}, \mathrm{W}, \mathrm{Ni}$. It was agreed that many of these metals have weaknesses when considered as pure metal oxides, but become useful when used in combination with others (e.g., $\mathrm{Cu}-\mathrm{Mo}$, and $\mathrm{Zn}$-Mo systems). $\mathrm{Zn}, \mathrm{Cu}, \mathrm{Fe}, \mathrm{Ce}$, and Mo were ranked as being the most useful, hence worth further evaluation. Sn and Ni were ranked as being less desirable than the others and probably will not be considered before the others. Sn has one of the highest $\mathrm{H}_{2} \mathrm{~S}$ vapor pressures and its sintering temperatures are relatively low, which may affect the regeneration process conditions, typically done from 500 to $700^{\circ} \mathrm{C}$. More information on thermodynamic properties is needed on the $\mathrm{W}$ system to proceed forward with an evaluation.

The next step was consideration of the relative compositions in formulations. The metals still considered as useful at that point were divided into three functional groups:

- Main components for desulfurization

- Secondary components for desulfurization, chemical stability, or porosity modifier

- Structural component to maintain mechanical durability

Given these characteristics, the following matrix was developed (Table 3-1) for consideration both at GE-CRD and at IGT. Up to this point, the selection of metal oxides is a general method that is equally applicable to moving beds as well as fluidized beds, transport beds or any other HGCU process configuration operating in the prescribed temperature regime.

$\mathrm{Zn}, \mathrm{Fe}, \mathrm{Ce}$, and $\mathrm{Cu}$ were selected to be the next generation of most promising metals for use as main components. Secondary components will be added to the main components to satisfy most of the evaluation criteria (criteria 1-4 in the previous page), and a structural component will be needed to maintain morphological and mechanical durability. The relative amounts of each component were outlined in a test matrix.

It is important to emphasize that the selection of useful metals was made keeping in mind both (1) shortterm goals (such as providing for support in the selection of the TECO sorbents in the next year) and (2) long-term goals (such as providing for laboratory evaluation of the next generation sorbents), where other larger scale systems may be scheduled for operation.

Table 3-1. List of metal components for sorbent screening

\begin{tabular}{ccc}
\hline Main Component & Secondary Component & Structural Component \\
\hline $\mathrm{Zn}$ & $\mathrm{Fe}, \mathrm{Cu}, \mathrm{Mo}, \mathrm{Co}$ & $\mathrm{Ti}, \mathrm{Zr}, \mathrm{Ce}$ \\
$\mathrm{Fe}$ & $\mathrm{Cu}$ & $\mathrm{Ti}, \mathrm{Zr}$ \\
$\mathrm{Ce}$ & $\mathrm{Mo}$ & $\mathrm{Ti}, \mathrm{Zr}$ \\
$\mathrm{Cu}$ & $\mathrm{Mn}$ & $\mathrm{Ti}, \mathrm{Zr}$ \\
\hline
\end{tabular}


The cost of purchasing raw materials was also considered in the evaluation of the relative merit of the various metal oxides. A more detailed analysis of cost of raw materials will be presented in Section 3.4-Sorbent Cost Assessment. Costs were kept in mind when developing formulations, but it was considered too early to make decisions whether to use or not to use an oxide just because of its price, since the relative amounts of secondary components may be too small (e.g., $<1 \%)$ to have a significant impact on the cost of the sorbent and yet have a tremendous impact on the durability of the material.

After the outline of the metal oxides suitable for desulfurization in the desired range of $343-538^{\circ} \mathrm{C}$ $\left(650-1000^{\circ} \mathrm{F}\right)$ was completed, the task of sorbent preparation in the laboratory was divided into moving-bed and fluidized-bed applications.

\subsection{SORBENT PREPARATION AND BENCH REACTOR TESTING}

\subsubsection{Testing of UCI-GE Zinc Titanate Sorbents}

UCI and GE have developed over the years several formulations of zinc titanate sorbents with additives that exhibit desirable properties for desulfurization and regeneration of fuel coal gases. In the following sections, a description of the results on molybdenum-containing zinc titanates (Section 3.3.3, Evaluation of Molybdenum-Containing Zinc Titanate Sorbents) and modified zinc titanates (MZT) (Section 3.3.4, Modified Zinc Titanates (MZT's) with additives) will be presented. Various aspects of the information contained within this report are subject to one or more patents issued in the name of the General Electric Company ${ }^{1-4}$ and are referenced in this report so that the reader can understand the technical background and framework for the development of HGCU moving-bed sorbents within this program.

\subsubsection{Screening of Sorbents Containing Mixed-Metal Oxides}

Once it was decided to start the experimental work on sorbent preparation and characterization, two objectives were defined for the moving-bed applications:

1. To develop an accelerated program of less than a year for screening molybdenum-containing zinc titanates in order to select a sorbent for testing in Run 8 of the GE pilot plant in September 1995.

2. To develop a longer-term program emphasizing development of mixed-metal oxides, including zinc titanates and other non-zinc sorbents, for moving-bed systems.

Phase diagrams of molybdenum in zinc titanate suggest that the presence of molybdenum lowers the minimum temperature needed for the formation of the zinc titanate structure from the zinc and titanium oxide components. Information available in the literature suggests that molybdenum is a good "fluxing" agent. For this reason, calcination temperature for zinc titanates containing molybdenum was explored in more detail (Table 3-2).

Additional samples of reformulated zinc titanate were prepared where the ratio of zinc to titanium, as well as the presence of bentonite binder, was varied (Table 3-3). The addition of zinc and titanium cations in various forms of starting materials was done with the purpose of substituting the cationic sites in tetrahedral and octahedral sites in the inverse spinel structure of zinc titanate that will add either mechanical strength to the lattice or resistance to overoxidation of zinc to zinc sulfate compounds during regeneration. 
Table 3-2. Powder sorbent formulations $\left(800^{\circ} \mathrm{C} / 4 \mathrm{hr}\right)$

\begin{tabular}{cc}
\hline Formulation ID & Chemical Structure \\
\hline GEMZT-1 & $\mathrm{Zn}_{2} \mathrm{Ti}_{0.983} \mathrm{Mo}_{0.017} \mathrm{O}_{4}$ \\
GEMZT-2 & $\mathrm{Zn}_{2} \mathrm{Ti}_{0.966} \mathrm{Mo}_{0.034} \mathrm{O}_{4}$ \\
GEMZT-3 & $\mathrm{Zn}_{2} \mathrm{Ti}_{0.9575} \mathrm{Mo}_{0.0425} \mathrm{O}_{4}$ \\
GEMZT-4 & $\mathrm{Zn}_{2} \mathrm{Ti}_{0.949} \mathrm{Mo}_{0.051} \mathrm{O}_{4}$ \\
GEMZT-5 & $\mathrm{Zn}_{2} \mathrm{Ti}_{0.915} \mathrm{Mo}_{0.0425} \mathrm{O}_{4}$ \\
GEMZT-6 & $\mathrm{Zn}_{2} \mathrm{Ti}_{0.93825} \mathrm{Mo}_{0.0425} \mathrm{O}_{4}$ \\
GEMZT-7 & $\mathrm{Zn}_{1.9575} \mathrm{Ti}_{0.9575} \mathrm{Mo}_{0.0425} \mathrm{O}_{4}$ \\
GEMZT-8 & $\mathrm{Zn}_{1.8725} \mathrm{Ti} \mathrm{Mo}_{0.0425} \mathrm{O}_{4}$ \\
GEMZT-9 & $\mathrm{Zn}_{2.0425} \mathrm{Ti}_{0.9120} \mathrm{Mo}_{0.0425} \mathrm{O}_{4}$ \\
\hline
\end{tabular}

Table 3-3. Zinc/Titanium formulations with various additives

\begin{tabular}{cc}
\hline Formulation ID & Chemical Structure \\
\hline MZT-23 & $(32.60 \%) \mathrm{ZnO}, 16 \% \mathrm{TiO}_{2},(0.97 \%) \mathrm{MoO}_{3} *$ \\
MZT-24 & $(50 \%) \mathrm{Zn}_{2} \mathrm{TiO}_{4}, 1 \% \mathrm{MoO}_{3}{ }^{*}$ \\
MZT-25 & $(50 \%) \mathrm{Zn}_{2} \mathrm{TiO}_{4}, 1 \% \mathrm{MoO}_{3}$ \\
MZT-26 & $(32.60 \%) \mathrm{ZnO}, 16 \% \mathrm{TiO}_{2},(1.12 \%) \mathrm{MoO}_{3} / \mathrm{ZnO}$ \\
MZT-27 & $(50 \%) \mathrm{Zn}_{2} \mathrm{TiO}_{4},(1.15 \%) \mathrm{MoO}_{3} / \mathrm{ZnO}$ \\
MZT-28 & $(32.60 \%) \mathrm{ZnO}, 16 \% \mathrm{TiO}_{2},(0.97 \%) \mathrm{MoO}_{3}$ \\
MZT-29 & $(16 \%) \mathrm{ZnO},(16 \%) \mathrm{TiO}_{2},(0.64 \%) \mathrm{MoO}_{3} *$ \\
\hline
\end{tabular}

All samples contain approximately $10 \%$ solution of polyvinyl alcohol for porosity enhancement. Samples marked with a * contain bentonite at around 1-1.5\% bentonite. Comparison of performance between samples containing bentonite and those without will provide indication of the effect on strength.

In addition to zinc titanate sorbents containing molybdenum additives, several other mixed-metal oxides have been prepared and calcined (Table 3-4). The replacement of zinc and titanium cations is being done with the purpose of substituting the cationic sites in tetrahedral and octahedral sites in the inverse spinel structure of zinc titanate with atoms $(\mathrm{Ce}, \mathrm{Cu}, \mathrm{Fe}$, etc.) that will add either mechanical strength to the lattice or resistance to overoxidation of zinc to zinc sulfate compounds. Results on the reactivity of these powder formulations was assessed by TGA tests. 
Table 3-4. Powder mixed-metal oxides formulations

\begin{tabular}{cc}
\hline Formulation ID & Chemical Structure \\
\hline MZT-1 & $\mathrm{Zn}_{2} \mathrm{TiO}_{4}$ \\
MZT-2 & $\mathrm{Zn}_{1.985} \mathrm{Ti}_{0.985} \mathrm{Fe}_{0.03} \mathrm{O}_{4}$ \\
MZT-3 & $\mathrm{Zn}_{1.97} \mathrm{Fe}_{0.03} \mathrm{TiO}_{4}$ \\
MZT-4 & $\mathrm{Zn}_{2} \mathrm{Fe}_{0.03} \mathrm{Ti}_{0.97} \mathrm{O}_{4}$ \\
MZT-5 & $\mathrm{Zn}_{2} \mathrm{Fe}_{0.03} \mathrm{Ti}_{0.97} \mathrm{O}_{4}$ \\
MZT-6 & $\mathrm{Zn}_{2} \mathrm{Sn}_{0.05} \mathrm{Ti}_{0.95} \mathrm{O}_{4}$ \\
MZT-7 & $\mathrm{Zn}_{1.97} \mathrm{Fe}_{0.05} \mathrm{TiO}_{4}$ \\
MZT-8 & $\mathrm{Zn}_{2} \mathrm{SnO}_{4}$ \\
MZT-9 & $\mathrm{Cu}_{2} \mathrm{SnO}_{4}$ \\
MZT-11 & $\mathrm{ZnCuTiO}_{4}$ \\
MZT-12 & $\mathrm{ZnCuSnO}_{4}$ \\
MZT-13 & $\mathrm{Ce}_{2} \mathrm{CuTiO}_{4}$ \\
\hline
\end{tabular}

\subsubsection{Evaluation of Molybdenum-Containing Zinc Titanate Sorbents}

Three levels of testing were performed on molybdenum-doped zinc titanate: laboratory screening at GECRD, long-term (50-cycle) bench-scale testing at RTI, and pilot plant testing (200-hr, Test 8) at the GE-CRD pilot plant. The purpose of the screening tests at GE-CRD was to improve the addition and composition of molybdenum in order to enhance performance in scheduled pilot plant tests (Test 8, September 1995). The laboratory work was performed in support of the DOE-sponsored Clean Coal Technology Program at Tampa Electric Co's (TECO) Polk Power Station, where a demonstrationscale moving-bed HGCU system has been built. Previous work had identified the usefulness of molybdenum-addition to zinc titanate for HGCU in moving-bed reactor configurations. For instance, the presence of molybdenum oxide in small quantities promotes quicker rearrangement and reconstitution of the zinc titanate structure over multiple cycles than in the case of straight zinc titanates.

\subsubsection{Screening of laboratory formulations at GE-CRD}

Several formulations of Mo-containing zinc titanate sorbents were extruded, rounded, and calcined by United Catalysts Inc. (UCI) during early 1995. From attrition test results, the most promising four formulations having higher attrition resistance were selected for bench-scale screening over twenty cycles. The screening for chemical reactivity over multiple cycles of absorption and regeneration of four molybdenum-doped zinc titanate formulations was performed using a the $7-\mathrm{cm}(2.75 \mathrm{in}$.) ID fixed-bed bench reactor at GE-CRD described previously in this report. One modification to the bench reactor was introduced for these tests: the cross sectional area of the reactor was divided into four quadrants, 
and each quadrant was filled with a different zinc titanate formulation. This modification allowed simultaneous testing of up to four formulations under identical conditions of time and gas flow rate.

The four formulations tested ranged in molybdenum content from $0 \%$ (formulation $\mathrm{A}$ ) to $1.5 \%$ (formulation B) to $2.0 \%$ (formulations $\mathrm{C}$ and D). Formulations $\mathrm{C}$ and $\mathrm{D}$ differed in the calcination history (i.e., calcination temperature and/or time). Absorption and regeneration were performed at 5 atm each, since the GE-CRD reactor does not have the capability to operate at $20 \mathrm{~atm}$. Absorption was performed at $482{ }^{\circ} \mathrm{C}$ using a simplified coal gas composition similar to that of an oxygen-blown gasifier with high $\mathrm{H}_{2} \mathrm{~S}$ $\left(39 \% \mathrm{CO}, 10 \% \mathrm{CO}_{2}, 30 \% \mathrm{H}_{2}, 20 \% \mathrm{H}_{2} \mathrm{O}, 1 \% \mathrm{H}_{2} \mathrm{~S}\right)$. Regeneration was performed between $482{ }^{\circ} \mathrm{C}$ and $760{ }^{\circ} \mathrm{C}$ using $1-4 \% \mathrm{O}_{2}$ in nitrogen. At the end of the 20 cycles, the sorbent bed was unloaded for chemical and reactivity analysis of the pellets.

Figure 3-5 shows the outlet $\mathrm{H}_{2} \mathrm{~S}$ concentration (i.e., the $\mathrm{H}_{2} \mathrm{~S}$ breakthrough curve) of the composite four-formulation test. The $\mathrm{H}_{2} \mathrm{~S}$ concentration prior to breakthrough was less than $200 \mathrm{ppm}$ (dry), indicating good desulfurization reactivity (i.e., $99.84 \%$ sulfur removal in 60 minutes) and well beyond the target desulfurization of $50 \mathrm{ppm}$ (dry) residual $\mathrm{H}_{2} \mathrm{~S}$ in the gas phase.

Figure 3-6 shows the envelope of breakthrough curves (at the 200 ppm outlet $\mathrm{H}_{2} \mathrm{~S}$ ) taking the highest breakthrough time ( $2 \mathrm{hr}$ for absorption 1$)$ as being $100 \%$ of initial sorbent performance. These resulting breakthrough measurements are the composite of the four formulations being tested in parallel in the same reactor (to make exposure conditions comparable). All absorptions showed $\mathrm{H}_{2} \mathrm{~S}$ levels below 20 ppm prior to breakthrough. The results were very promising, with about $80 \%$ capacity maintained from cycles ten to twenty. In addition, the convergence of the envelope of breakthrough curves as we went from 10 to 20 cycles suggests that the level of regeneration improved as we adjusted the operating conditions from each previous cycle's results. The four sorbents were unloaded, and pellet quality (absence of hairline cracks) was better when molybdenum was present.

Figures 3-7 through 3-9 show the properties of the fresh and cycled samples. Some conclusions that were drawn from those figures are:

- All formulations A, B, C, and D met the ASTM attrition test criterion for fresh pellets (i.e., <4\% ASTM attrition loss), but formulations B and D did not meet the ASTM attrition criterion for longterm operation (i.e., <5\% ASTM attrition) simulated moving-bed operation (Figure 3-7). Formulation $\mathrm{C}$ had the lowest ASTM attrition for both the fresh (0.7\%) and after 20 accelerated cycles $(2.2 \%)$.

- The distribution of broken pellets and whole pellets after the ASTM attrition tests in the 20th regeneration samples is shown in Figure 3-8. Formulation $\mathrm{C}$ again fares better than the other three formulations tested.

- Sulfur capacity of the pellets was compared as fresh and after 20 cycles (Figure 3-9). Formulation C comfortably exceeded the minimum sulfur capacity required for TECO: $6.7 \mathrm{lb}$ sulfur/ $\mathrm{ft}^{3}$ bed (107 kg sulfur $/ \mathrm{m}^{3}$ bed), or approximately $3.2 \% \mathrm{wt}$. gain on TGA sulfidation for a bulk density of $100 \mathrm{lb} / \mathrm{ft}^{3}\left(1603 \mathrm{~kg} / \mathrm{m}^{3}\right)$. Weight gain for formulation $\mathrm{C}$ was more than twice the minimum.

Overall, formulation C (containing $2 \%$ equivalent molybdenum oxide) exhibited the best combination of desired properties for long-term operation and was recommended for preparation and testing for longterm (50 cycles) at RTI's bench-scale reactor system and in the GE pilot plant Test 8. 


\subsubsection{50-Cycle Bench Test at Research Triangle Institute}

In support of the effort for the selection of sorbent for the Tampa Electric Co's Polk Station, a subcontract was issued by GE-CRD to Research Triangle Institute to conduct an independent 50-cycle benchscale test on one selected zinc titanate formulation for the screening tests at GE-CRD. The test would provide information on the long-term chemical reactivity and mechanical durability of the pelletized sorbent when operated at a pressure of 20 atm during absorption and 7 atm during regeneration. GECRD's bench reactor has capability only up to $7 \mathrm{~atm}$. The selected sorbent for 50 -cycle testing was

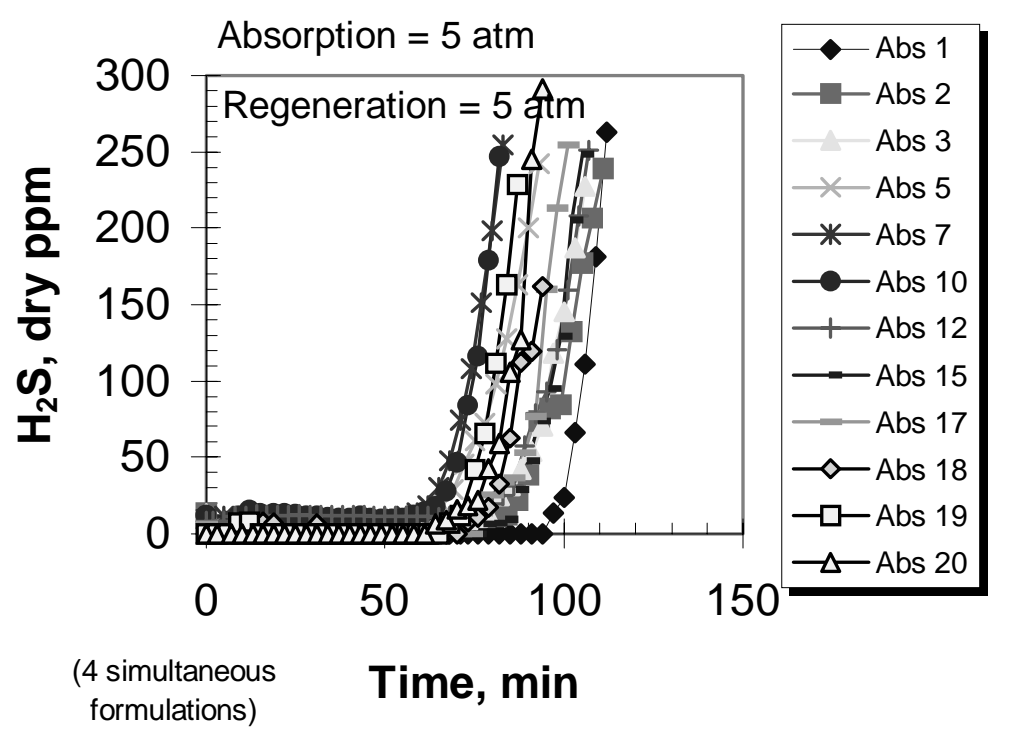

Figure 3-5. $\mathrm{H}_{2} \mathrm{~S}$ breakthrough curve for the simultaneous bench reactor testing of four formulations at GE-CRD

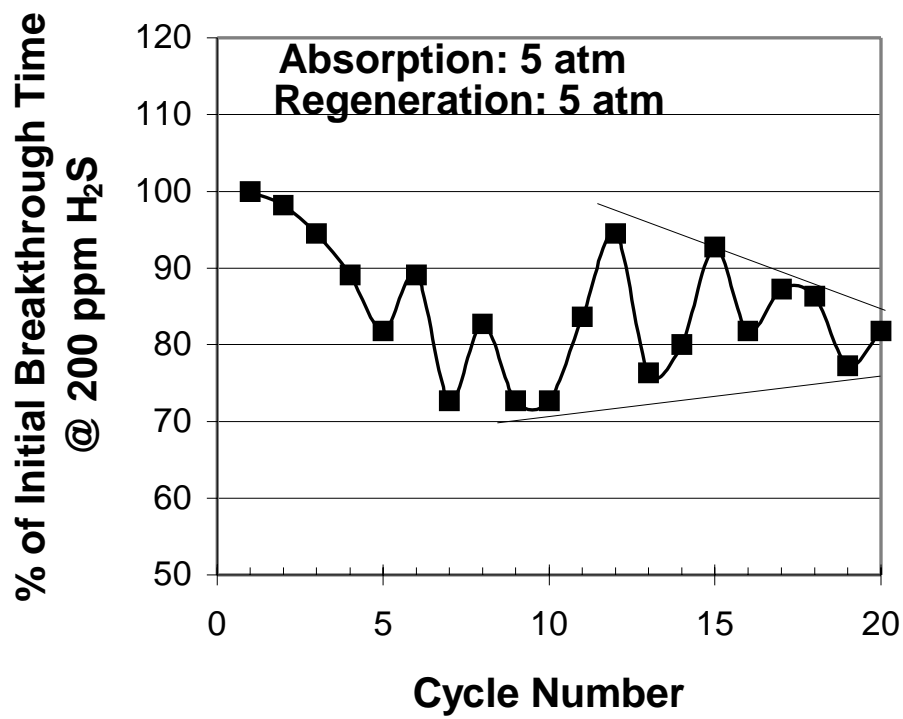

Figure 3-6. Envelope of breakthrough curves for zinc titanate screening at GE-CRD 


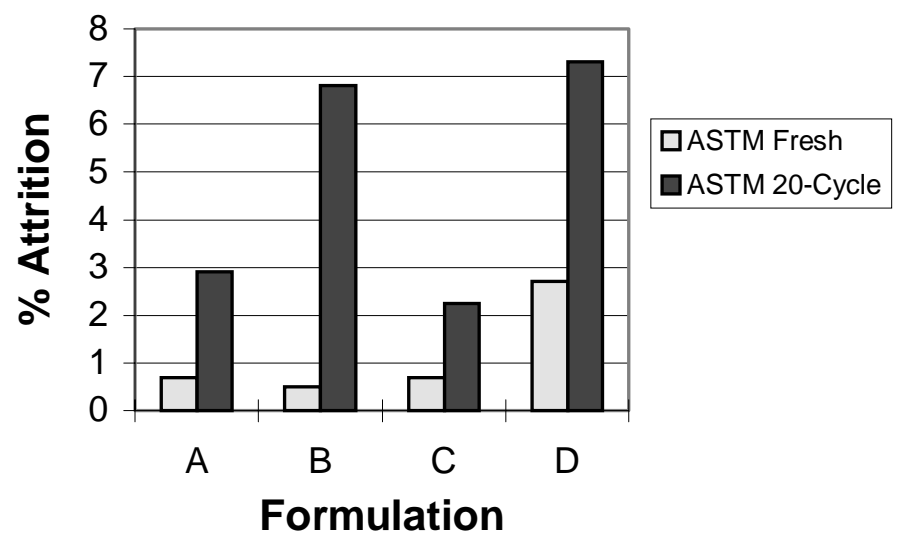

Figure 3-7. ASTM attrition results on sorbents after the 20th regeneration in bench screening at GE-CRD

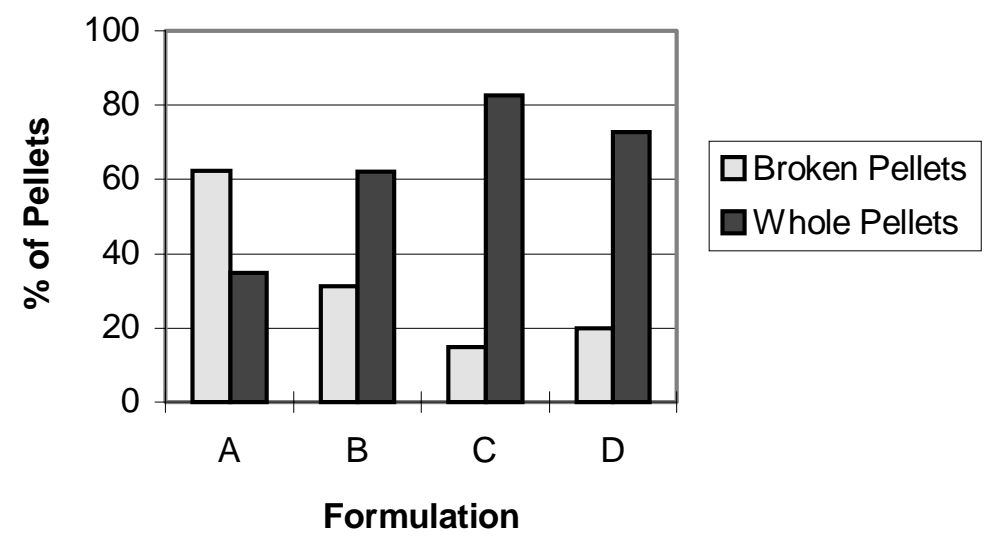

Figure 3-8. Pellet distribution after ASTM attrition test (20th regeneration)

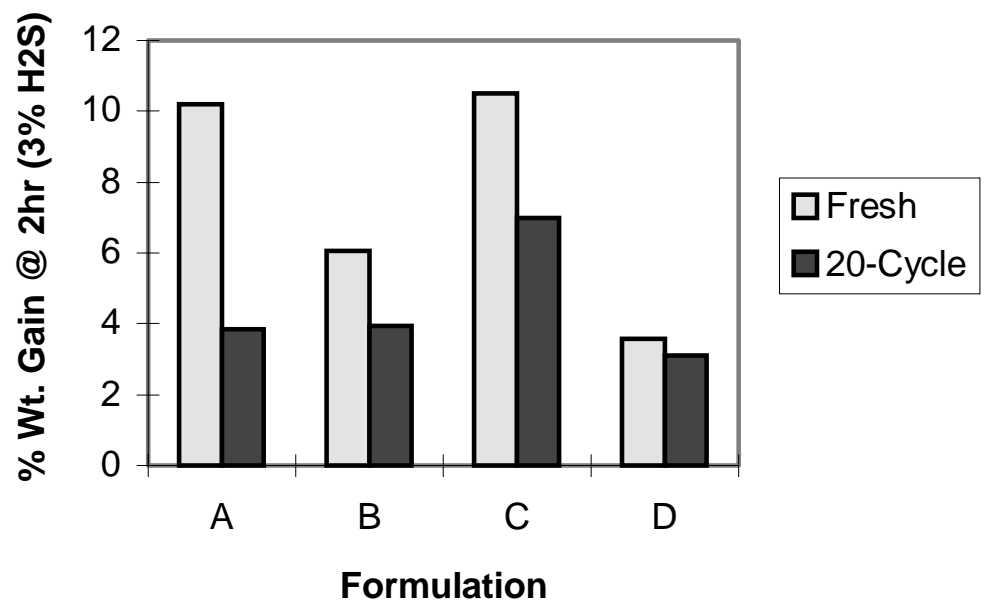

Figure 3-9. TGA sulfur capacity of sorbents after 20 cycles 
Formulation C, previously shown in Figures 3-7 and 3-8, which exhibited low ASTM attrition and high sulfur loading in the GE-CRD screening tests. The sorbent was fabricated again by UCI under similar calcinations conditions and designated as formulation PP2131. The testing at RTI proceeded according to the test protocol written at GE-CRD to provide uniformity in test procedures for the development of moving-bed sorbents. Conditions for the testing are shown in Table 3-5 and Table 3-6.

The bed volume was adjusted to obtain the desired gas space velocity, meet the requirement of sulfur loading at the gas inlet location, meet the $200 \mathrm{ppmv}$ breakthrough in a reasonable time $(<5 \mathrm{hr})$, and meet the test schedule for completion of the 50 cycles. Test conditions during absorption (Table 3-6) follow the TECO conditions, except for the reduced pressure (20 atm vs. $30 \mathrm{~atm}$ ) and definition of breakthrough (200 ppmv vs. less than $50 \mathrm{ppmv}$ ). The reduced pressure is a result of limitations in the existing hardware; the definition of breakthrough was selected for ease of measurement and for historical comparisons. Regeneration was conducted at 7 atm and between $482{ }^{\circ} \mathrm{C}$ and $760{ }^{\circ} \mathrm{C}$.

Figure 3-10 shows the raw data of the breakthrough curves for PP3121 zinc titanate. Pre-breakthrough $\mathrm{H}_{2} \mathrm{~S}$ concentrations were below the detection limit $\left(<5 \mathrm{ppm}_{2} \mathrm{~S}\right)$, suggesting good desulfurization kinetics and thermodynamics. Target desulfurization is less than 50 ppmv for the Polk Station hot gas cleanup system. A gradual decrease in reactivity that stabilizes at about 40 minutes is observed due to aging of the pellet structure.

Figure 3-11 shows the corresponding envelope of the breakthrough curves at the $200 \mathrm{ppm}$ level. The bed performance stabilizes to a constant level as the number of cycles increases. This result suggests that steady state operation can be achieved, and loss in bed capacity is not a linear process with number of cycles. Hence, extrapolation of bed performance to longer number of cycles is possible. In practice,

Table 3-5. Gas compositions for 50-cycle test

\begin{tabular}{l|cc}
\hline & Absorption & Regeneration \\
\hline $\mathrm{CO}$ & Balance & \\
$\mathrm{CO}_{2}$ & 10 & \\
$\mathrm{H}_{2}$ & 20 & \\
$\mathrm{H}_{2} \mathrm{O}$ & 20 & Balance \\
$\mathrm{N}_{2}$ & 16.3 & \\
$\mathrm{H}_{2} \mathrm{~S}$ & 2.0 & $0-4$ \\
$\mathrm{O}_{2}$ & & \\
\hline
\end{tabular}

Table 3-6. Target test conditions during absorption

\begin{tabular}{l|c}
\hline Parameter & Operating Condition \\
\hline Desired Sorbent Sulfur Loading & $\begin{array}{c}96.2 \mathrm{~g} \mathrm{~S} / \text { liter of bed }\left(6-7 \mathrm{lb} \mathrm{S} / \mathrm{ft}^{3} \text { of bed }\right) \\
\text { at the gas inlet location }\end{array}$ \\
$\mathrm{H}_{2} \mathrm{~S}$ Breakthrough point & $200 \mathrm{ppm}$ \\
Gas space velocity & $\geq 2000 \mathrm{hr}^{-1}(\mathrm{STP})^{*}$ \\
Pressure & $20 \mathrm{~atm}$ \\
Temperature & $482{ }^{\circ} \mathrm{C}\left(900{ }^{\circ} \mathrm{F}\right)$ \\
\hline
\end{tabular}

* STP (standard temperature and pressure is defined at $20^{\circ} \mathrm{C}$ and $1 \mathrm{~atm}$ ). 


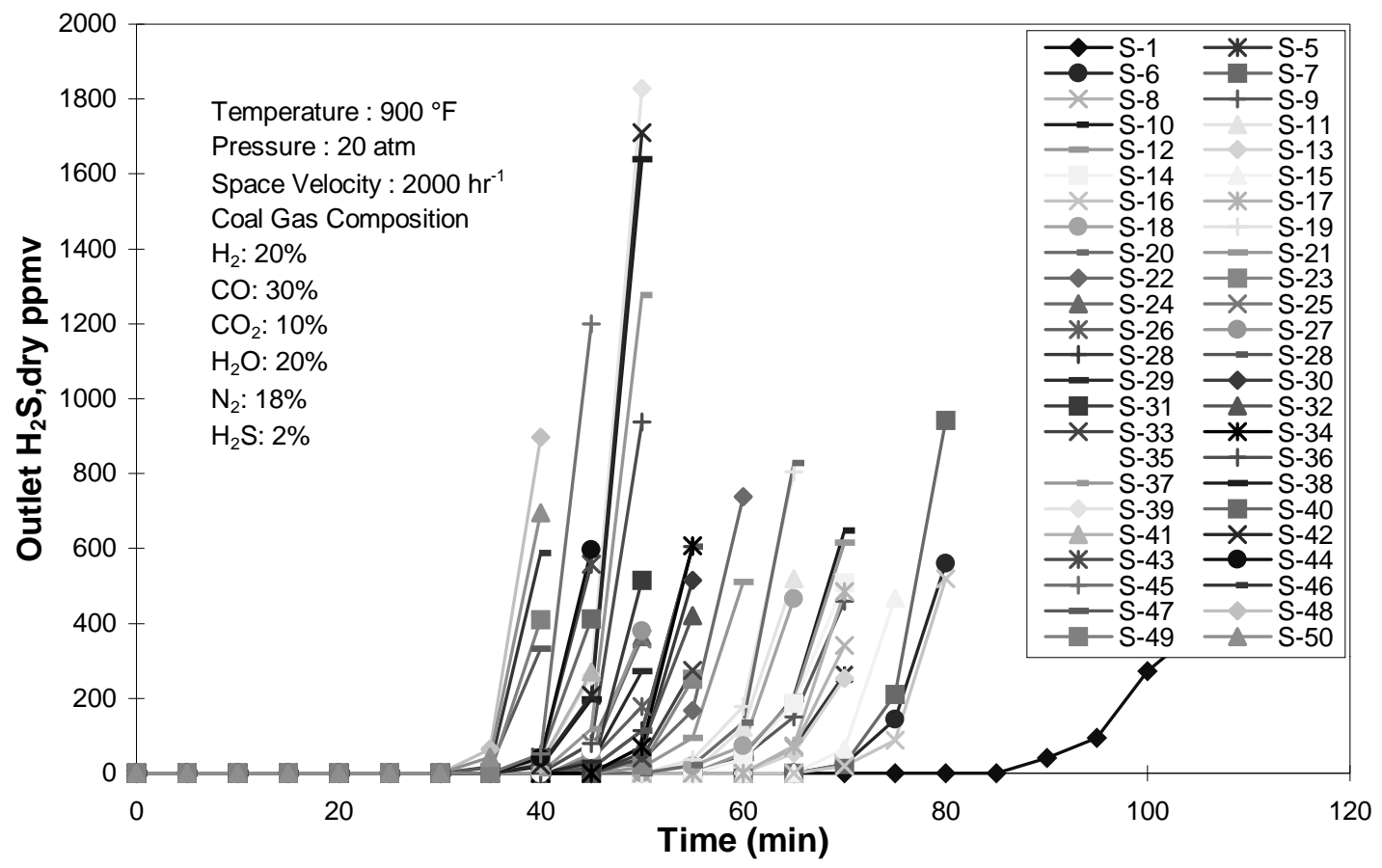

Figure 3-10. $\mathrm{H}_{2} \mathrm{~S}$ Breakthrough Curves for 50-Cycle Test of Zinc Titanate at RTI

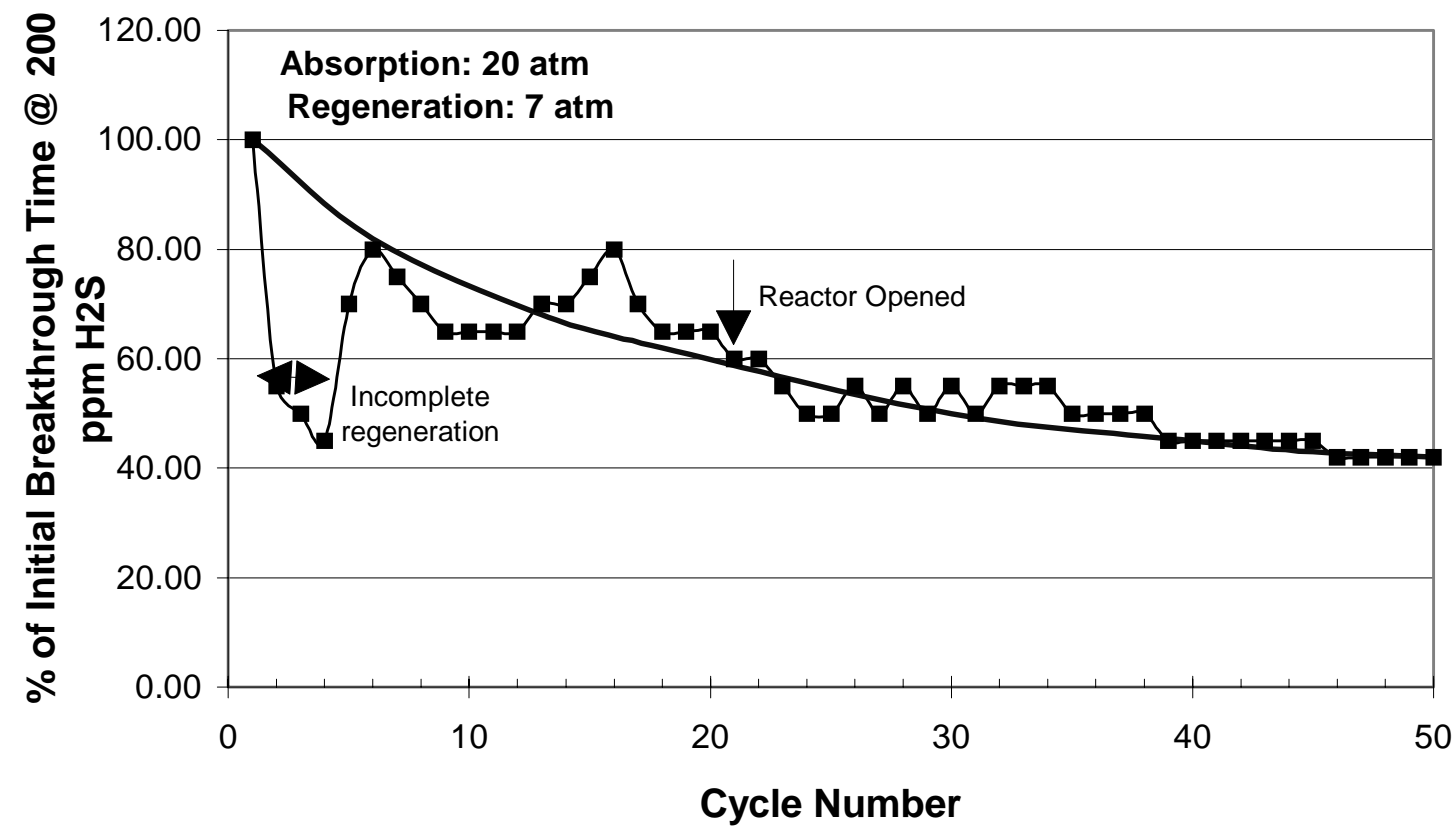

Figure 3-11. Envelope of breakthrough curves for zinc titanate testing at RTI 
the location of the y-axis stable point (as \% of initial breakthrough time) can be adjusted by modifying the actual operating conditions (e.g., temperature and flow rate).

Table 3-7 shows a comparison of sulfur loading for the fresh and cycled sorbents. The target sulfur loading depends on current bulk density as the sorbent densifies upon cycling. Sulfur loadings were measured by a thermogravimetric analyzer (TGA) as regenerable sulfide on gas inlet location samples. Sulfur measurements by the induction furnace (LECO) method were performed for reference and agreed with the TGA measurements.

Given that the 60-minute absorption at cycle 21 resulted in below target sulfur loading, the absorption time was increased to keep loading within target range. Overall, the target sulfur loading at the gas inlet location was maintained over the 50 cycle test.

In addition to the current sulfur loadings on the pelletized sorbent at the end of selected sulfidations, the measurement of total sulfur capacity available in the powder was also made by TGA, and is shown in Table 3-8 and in Figure 3-12. Samples were in powder form to determine the intrinsic reactivity of the oxide while minimizing pore diffusion mass transfer resistances across the pellets. Poisoning, sulfate accumulation, formation of inert zinc phases, and other chemical considerations could all contribute to the loss of chemical reactivity of the sorbent over a period of time, regardless of pellet pore structure or pellet integrity. A sorbent is considered acceptable for long-term operation if its sulfur capacity is retained at $50 \%$ or higher of its initial (i.e., theoretical) capacity -in other words, if the sorbent decreases its capacity by no more than a factor of two at the end of fifty cycles.

The rate of sulfur loading on the powder sorbents as a function of time is given by the TGA curves presented in Figure 3-12. A standard GE TGA test was performed at $1 \mathrm{~atm} / 538^{\circ} \mathrm{C} / 3 \% \mathrm{H}_{2} \mathrm{~S}$ for 2 hours.

Table 3-7. Sulfur loading of zinc titanate sorbent

\begin{tabular}{l|c}
\hline Bed Capacity & $\begin{array}{c}\text { \% Sulfur Capacity by GE TGA Test } \\
\text { (At 2-hr exposure) }\end{array}$ \\
\hline Target: as \% of theoretical after 50 cycles & $50 \%$ \\
Fresh & $95 \%$ \\
After 21 cycles & $60 \%$ \\
After 50 cycles & $55 \%$ \\
After 50 cycles (at 3-hr exposure) & $62 \%$ \\
\hline
\end{tabular}

Table 3-8. Sorbent sulfur capacity

\begin{tabular}{l|c}
\hline Bed Capacity & $\begin{array}{c}\text { \% Sulfur Capacity by GE TGA Test } \\
\text { (At 2-hr exposure) }\end{array}$ \\
\hline Target: as \% of theoretical after 50 cycles & $50 \%$ \\
Fresh & $95 \%$ \\
After 21 cycles & $60 \%$ \\
After 50 cycles & $55 \%$ \\
After 50 cycles (at 3-hr exposure) & $62 \%$ \\
\hline
\end{tabular}




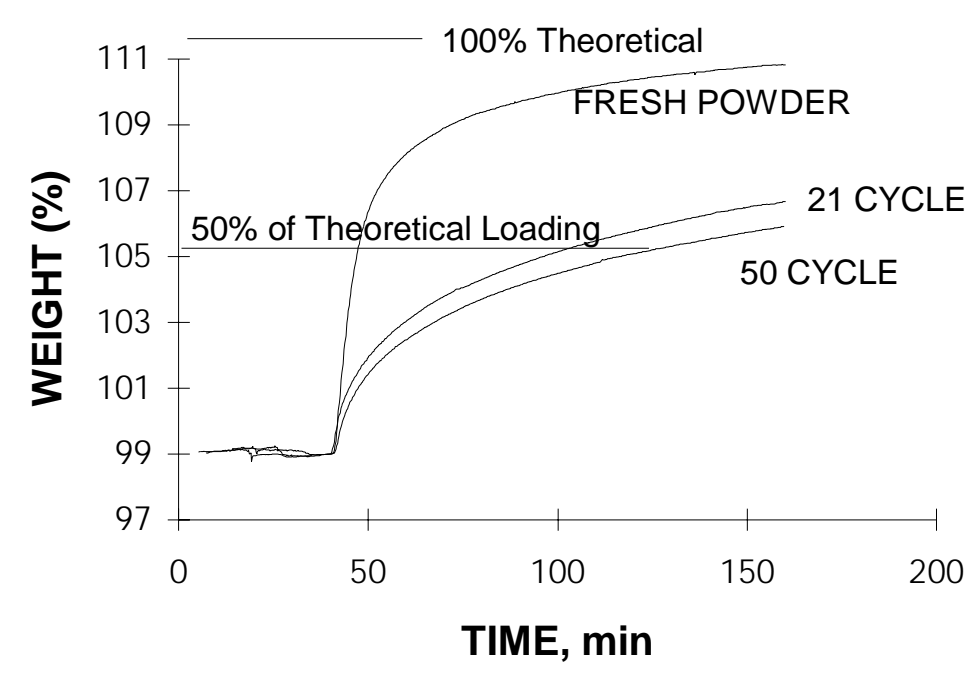

\section{Figure 3-12. TGA sulfur capacity of powdered samples after 50 cycles of testing at RTI}

After the standard 2-hr TGA test, the 50-cycle powder sample was allowed to sulfide for 1 additional hour to determine if sorbent was saturated at that point. The measured sulfur capacity was higher $(62 \%$ of theoretical) after one additional hour of sulfidation, confirming that the target sulfur loading requirement was exceeded comfortably and that further capacity was still available in the sorbent. All samples exceeded the acceptance requirement for sulfur capacity, as shown in Table 3-8.

A comparison of TGA reactivities between powder and pelletized samples would answer the question if the pellet porosity, or pellet integrity, was retained to a reasonable extent. Figure 3-13 shows the single-pellet TGA reactivity of the sorbent after 50-cycle bench tests at RTI . The drop in the weight gain due to sulfur absorption indicates a measurable decrease in the reactivity of the pelletized sorbent. The qualitative behavior in reactivity is similar between the powder and the pelletized samples after 50

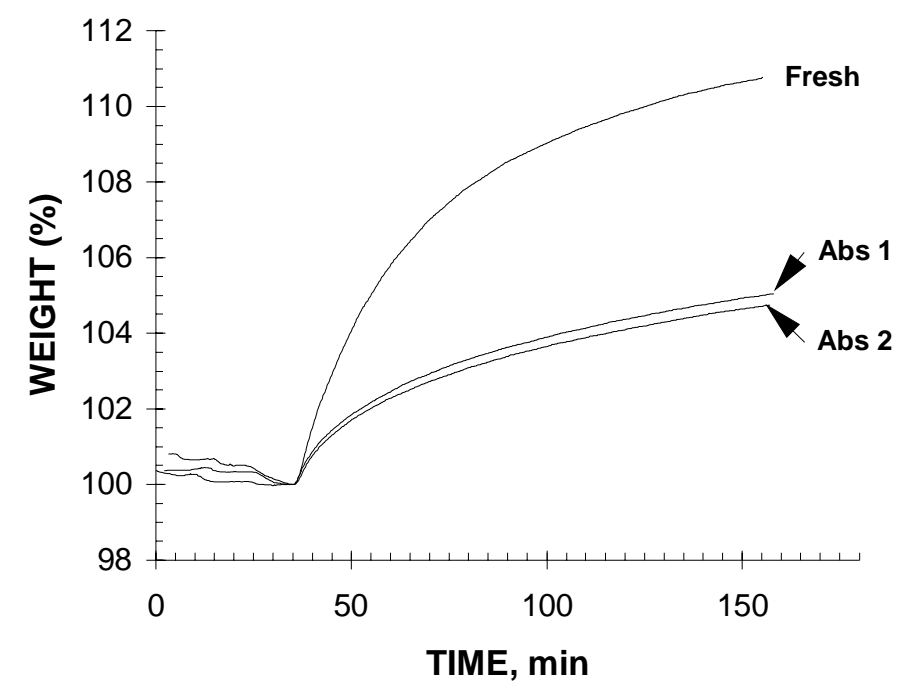

Figure 3-13. TGA reactivity of T-3121 zinc titanate pellets after 50 cycles of bench tests at RTI 
cycles of testing. This suggests that the loss in reactivity is a result of chemical degradation and not pore blinding in the pellets. The most likely reason for chemical degradation is, of course, zinc sulfate formation given that the regeneration at RTI was conducted at high pressure (i.e., $7 \mathrm{~atm}$ ).

In addition to measuring the chemical reactivity of the cycled sorbent, the mechanical performance was also measured by ASTM D4058-81 attrition tests (Table 3-9).

\section{Table 3-9. Attrition Results of Zinc Titanate Bench Tests at RTI}

\begin{tabular}{l|c}
\hline Sample Source & ASTM (D4058-81) Attrition Loss, \% \\
\hline Target: Fresh sorbent & $<4 \%$ \\
Fresh & $0.7 \%$ \\
After 50 cycles: Target & $<5 \%$ \\
After 50 cycles: gas inlet location & $8.0 \%$ \\
After 50 cycles: gas outlet location & $6.9 \%$ \\
After 50 cycles: average & 7.4 \\
\hline
\end{tabular}

The attrition loss for the fresh sorbent was well below the initial target of $4 \%$ by the ASTM method. The target for the fresh sorbent is as defined in the performance specifications for pilot plant sorbent procurement. The attrition loss for the 50-cycle sorbent was above the target value. Given the fact that the chemical reactivity was satisfactory and exceeded the minimum requirements but the attrition was above target, the performance suggests that the sorbent should be regenerated preferably below 7 atm, so that the rate of sulfate formation is minimized. Also, the sorbent should be calcined differently to further increase pellet strength at the expense of lower reactivity. As we have stated in the past, calcination conditions determine a balance of reactivity and strength: the higher the reactivity (because of higher pellet porosity) the lower the pellet strength and the higher the ASTM attrition.

Overall, the PP3121 molybdenum-containing zinc titanate sorbent formulation exceeded minimum specifications of reactivity, sulfur capacity, $\mathrm{H}_{2} \mathrm{~S}$ equilibrium removal levels, and initial attrition losses. An improvement in the attrition resistance at the 50th cycle (i.e., 50th regeneration) is still desirable for regeneration at $7 \mathrm{~atm}$ of pressure. Currently regeneration pressure should be conducted at $5 \mathrm{~atm}$ or below as the GE-CRD tests. In order to correlate any laboratory data with actual plant operation during evaluation of future sorbent formulations, a batch of this same zinc titanate composition was recommended for fabrication and testing at the GE-CRD pilot plant.

\subsubsection{Pilot Plant Test 8 Results}

Formulation PP3121, tested at RTI for fifty cycles, was again fabricated by UCI as a $6,400 \mathrm{~kg}$ batch $(\sim 14,000 \mathrm{lb})$ (designation T-2594M) for testing in the GE-CRD pilot plant during Test 8 in September 1995. From the point of view of sorbent development, the purpose of the pilot plant testing was to collect data on the scaling factors of chemical reactivity and sorbent mechanical durability between laboratory tests and larger-scale systems. A second objective was to measure the manufacturability of large sorbent batches given laboratory target specifications.

Figure 3-14 shows the absorber outlet $\mathrm{H}_{2} \mathrm{~S}$ during operation of the GE-CRD pilot plant (Test 8) using the zinc titanate sorbent developed in the current sorbent program. Complete results of the pilot plant 


\section{TEST 8: ABSORBER OUTLET $\mathrm{H}_{2} \mathrm{~S}$}

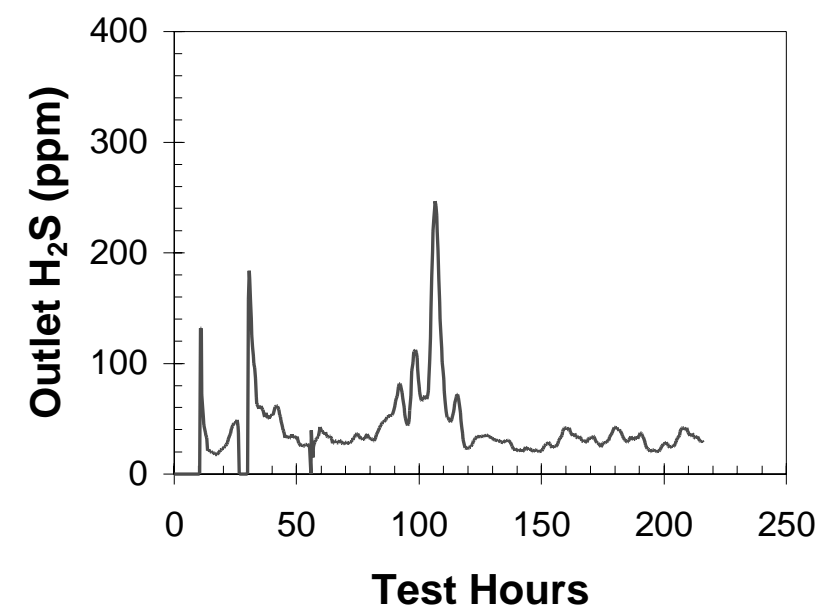

TEST 8 REGENERATOR $\mathrm{SO}_{2}$

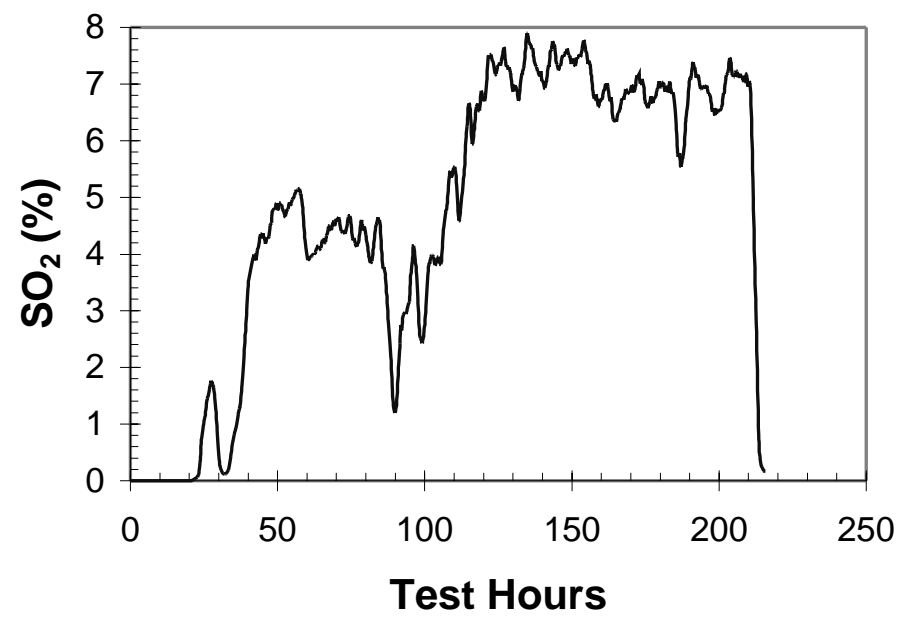

Figure 3-14. Absorber outlet $\mathrm{H}_{2} \mathrm{~S}$ and regenerator $\mathrm{SO}_{2}$ production during pilot plant test 8

Test 8 were presented in a separate GE report to DOE. ${ }^{5}$ Absorption was carried out at 20 atm and close to $480^{\circ} \mathrm{C}\left(\sim 900^{\circ} \mathrm{F}\right)$. After some initial excursions in the desulfurization performance during the first 100 hours, the sorbent and hardware were made to operate in integrated fashion, with close to $99 \% \mathrm{H}_{2} \mathrm{~S}$ removal (from $3500 \mathrm{ppmv}$ dry to $30-40 \mathrm{ppmv}$ dry), while simultaneously achieving desired sorbent net sulfur loading in the absorber and stable $\mathrm{SO}_{2}$ production in the regeneration loop. $\mathrm{SO}_{2}$ production was increased during the second half of the test by adjusting the regeneration operating conditions $\left(\mathrm{O}_{2}\right.$ concentration and bed temperature profiles). These encouraging pilot plant results proved the soundness of the scale-up method used from laboratory to pilot-plant tests. The attrition loss in the pilot plant test was measured at $1.7 \%$ under one set of conditions (i.e., a V-Wire screen in the regenerator fines separator) and $0.3 \%$ loss under another set of conditions after the test (i.e., a $1 \mathrm{~mm} \mathrm{x}$ $1 \mathrm{~mm}$ square mesh screen at the same location). These measured pilot plant attrition losses compare favorably with the ASTM attrition losses of approximately $7 \%$ measured in the laboratory, indicating 
that the large-scale operation is less severe and the cost of sorbent replenishment is less than predicted from ASTM tests alone. No corresponding scaling factors are currently available from pilot plant to the TECO demonstration plant, and these will have to be measured under comparable operating conditions of the vibrating screen at the outlet of the regenerator.

Figure 3-15 presents the reactivity of the pelletized T-2594M zinc titanate sorbent as fresh and after 200 hours of operation during Test 8 . The reactivity of the 200 -hr regenerated sample was somewhat lower than that of the fresh. Note that the reactivity of the fresh sorbent tested at RTI is different from that of the fresh sorbent tested under Test 8. The RTI material was made more reactive but less strong, and it was fabricated before the formulation T-2549M for the pilot plant test, when it was adjusted to correct some of the strength. Moreover, the loss in reactivity of the sorbent tested in the pilot plant Test 8 for $200 \mathrm{hr}$ ( 10 cycles, 1.5 -atm regeneration) was less than that measured for its corresponding formulation in the RTI tests (50 cycles, 7-atm regeneration).

Although the pilot plant batch T-2594M was not prepared at the same time and with the same scale equipment as the laboratory formulations screened at GE-CRD (formulations A-D) and RTI (PP3121), it was still encouraging that a formulation with lower performance in the laboratory performed acceptably in reactivity and initial attrition in the pilot plant operation.

In conclusion, three levels of testing were performed on molybdenum-doped zinc titanate: laboratory screening at GE-CRD, long-term (50-cycle) bench-scale testing at RTI, and pilot plant testing (200-hr, Test 8) at the GE-CRD pilot plant. The results indicate that the flow of information and technology transfer from laboratory to pilot plant is consistent and prediction of large-scale system operation is possible from laboratory and bench test results.

Test 8 in the pilot plant confirmed the acceptability of molybdenum-doped zinc titanate for desulfurization in a moving-bed system to target levels in commercial plants. Test 8 also suggested that higher levels of attrition resistance would be required for this sorbent to be economically viable during long-term use in commercial systems. To address some of these operational needs for Mo-doped zinc titanate, further efforts in the laboratory concentrated in several areas:

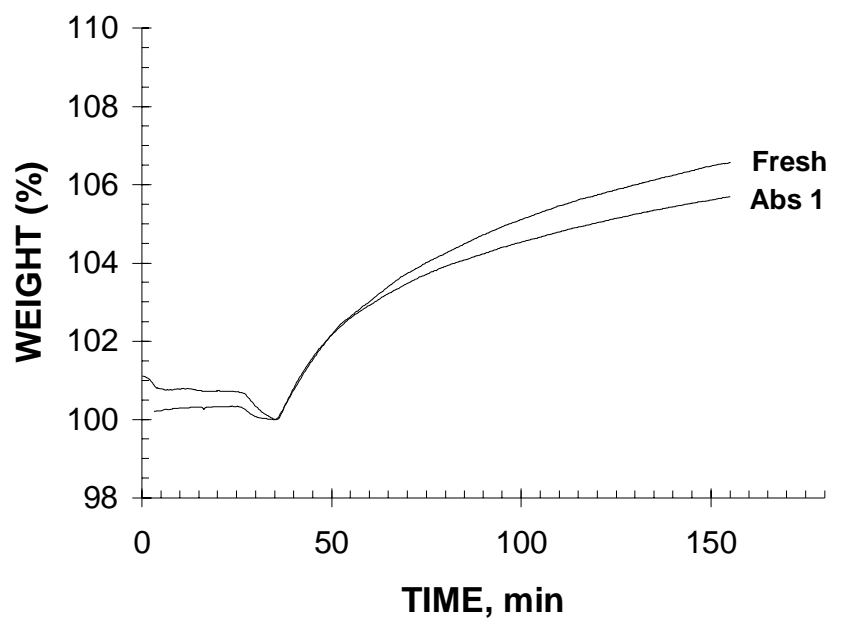

Figure 3-15. TGA reactivity of T-2594M zinc titanate pellets after 200 hours of pilot plant Test 8 ( 9 cycles) 
- Determination of the zinc titanate structure reconstitution after several sulfidation/regeneration cycles (Section 3.3.2.4, Zinc titanate structure determination after sulfidation/regeneration cycles).

- Regeneration of zinc titanate in the presence of $10 \% \mathrm{SO}_{2}$ in the regeneration gases at regeneration pressures of 1.5, 3, and 5 atm (Section 3.3.2.5, Regeneration of Mo-doped zinc titanate formulations at higher pressure and higher $\mathrm{SO} 2$ concentrations).

- Development of zinc titanate powder formulations containing additives for higher desulfurization rates below $482^{\circ} \mathrm{C}\left(900^{\circ} \mathrm{F}\right)$ and pelletized formulations for higher attrition resistance (Section 3.3.3, Modified Zinc Titanates (MZT's) with additives).

\subsubsection{Zinc titanate structure determination after sulfidation/regeneration cycles}

One of the practical questions that needs to be answered about the performance of zinc titanates with added mixed-metal oxide is whether the $\mathrm{Zn}_{2} \mathrm{TiO}_{4}$ crystal structure reforms after undergoing transformations between sulfided and regenerated states. In other words, whether there will be free zinc oxide and titanium dioxide phases present after repetitive cycling of the zinc titanate sorbents and, if so, whether this phenomenon is a potential source of weakening of the pellet mechanical structure. Several tests were conducted in the laboratory to study this question further.

X-ray diffraction patterns were taken from several zinc titanate sorbents after several levels of sulfidation to determine the extent of reconstitution of the zinc titanate, $\mathrm{Zn}_{2} \mathrm{TiO}_{4}$, structure after sulfidation. All regenerations were carried out at a maximum temperature of approximately $718^{\circ} \mathrm{C}\left(1325^{\circ} \mathrm{F}\right)$. Table 3-10 presents the results of sorbent regenerated in the laboratory Regardless of the prior level of sulfidation (e.g., 10, 25, 50, 75\%), zinc titanate always reconstitutes to $\mathrm{Zn}_{2} \mathrm{TiO}_{4}$ structure, at least above the level of detection by XRD ( 3-5 wt \%). Results of sulfided sorbent from the laboratory show that, in addition to $\mathrm{ZnS}$, there is the presence of the $\mathrm{ZnTiO}_{3}$ structure, suggesting that the sorbent never has free zinc oxide, $\mathrm{ZnO}$, available for reaction with $\mathrm{HCl}$ or $\mathrm{SO}_{2}$ during operation to form undesirable solid chlorides or sulfates. The pilot plant samples shown in Table 3-10 also show that the sorbent leaving the regenerator is not fully oxidized because there is some residual $\mathrm{ZnS}$ present, but the regenerated zinc is present in the form of $\mathrm{Zn}_{2} \mathrm{TiO}_{4}$, and the $\mathrm{ZnS}$ can be regenerated completely to $\mathrm{Zn}_{2} \mathrm{TiO}_{4}$.

Table 3-10. Major structure of Mo-doped zinc titanate by XRD

\begin{tabular}{lcc}
\hline Zinc titanate & $\begin{array}{c}\text { \% of Theoretical } \\
\text { Sulfidation }\end{array}$ & $\begin{array}{c}\text { Major Crystal } \\
\text { Structure }\end{array}$ \\
\hline 2nd. Regeneration sorbent & $10 \%$ & $\mathrm{Zn}_{2} \mathrm{TiO}_{4}$ \\
2nd. Regeneration sorbent & $25 \%$ & $\mathrm{Zn}_{2} \mathrm{TiO}_{4}$ \\
2nd. Regeneration sorbent & $50 \%$ & $\mathrm{Zn}_{2} \mathrm{TiO}_{4}$ \\
2nd. Regeneration sorbent & $75 \%$ & $\mathrm{Zn}_{2} \mathrm{TiO}_{4}$ \\
2nd. Sulfidation sorbent & $75 \%$ & $\mathrm{ZnS}^{\mathrm{ZnTiO}_{3}}$ \\
Pilot Plant Test 8 (sample 95-8R91, & $25 \%$ & $\mathrm{ZnS}+\mathrm{Zn}_{2} \mathrm{TiO}_{4}$ \\
200-hr regenerator) & & $\mathrm{Zn}_{2} \mathrm{TiO}_{4}$ \\
Above sample after TGA exposure & $25 \%$ & \\
to $\mathrm{O}_{2}$ at $704{ }^{\circ} \mathrm{C}\left(1300^{\circ} \mathrm{F}\right) / 1 \mathrm{hr}$ & & \\
\hline
\end{tabular}




\subsubsection{Regeneration of Mo-doped zinc titanate formulations at higher pressure and higher $\mathrm{SO}_{2}$ concentrations}

Work during the month of September focused on analyzing cyclic testing of zinc titanate in the presence of $10 \% \mathrm{SO}_{2}$ in the regeneration gases at pressures of $1.5,3$, and 5 atm and regeneration temperatures below $700{ }^{\circ} \mathrm{C}$. The objective of these tests was to determine the effect of sulfate accumulation or the rate of sulfide oxidation on the effective bed capacity during absorption and over multiple cycles.

In the following plots (Figure 3-16 to Figure 3-23) we will show the outlet $\mathrm{H}_{2} \mathrm{~S}$ concentrations versus time (i.e., the $\mathrm{H}_{2} \mathrm{~S}$ breakthrough curves) and the envelope of the breakthrough curves (at the $200 \mathrm{ppm}$ $\mathrm{H}_{2} \mathrm{~S}$ point) for each curve at $1.5,3$, and $5 \mathrm{~atm}$. Absorptions were performed at $900{ }^{\circ} \mathrm{F}$ with $1 \% \mathrm{H}_{2} \mathrm{~S}$ in simulated oxygen-blown gasifier coal gases. All regenerations were conducted in the presence of up to $12 \% \mathrm{SO}_{2}$ with no previous activation or preconditioning required. Regenerations were carried out until the $\mathrm{O}_{2}$ climbed to $0.1 \%$ or higher in the effluent gases. The maximum temperature during regeneration was maintained below $704^{\circ} \mathrm{C}\left(1300^{\circ} \mathrm{F}\right)$ and typically between $650-700^{\circ} \mathrm{C}$ except when otherwise noted. Hence, the bed performance at a given absorption is the result of either the residual sulfide or the sulfate formed and accumulated during previous regenerations.

As shown in Figure 3-16 and Figure 3-17, there is a gradual loss in bed capacity when regenerating at $1.5 \mathrm{~atm}$ and below $1300^{\circ} \mathrm{F}$ (cycles 1-4). When conditions were changed, i.e., temperature or regeneration time, the sulfur loading and the breakthrough time increased for the bed during absorption number 5 . This curve showed the effect of regeneration temperature on sulfate decomposition.

For the case of regeneration at 3 atm (Figure 3-18 and Figure 3-19), the loss of sulfur reactivity is less than in the case of regeneration at $1.5 \mathrm{~atm}$ during the first few cycles because the temperature at the gas outlet location of the bed had been monitored more closely and maintained near $700^{\circ} \mathrm{C}\left(1300^{\circ} \mathrm{F}\right)$, rather than near $650^{\circ} \mathrm{C}\left(1210^{\circ} \mathrm{F}\right)$. There is still a leveling off of the breakthrough time by the fifth absorption.

Similarly, Figure 3-20 and Figure 3-21 show the case of regeneration at 5 atm and demonstrate that regeneration below $704^{\circ} \mathrm{C}\left(1300^{\circ} \mathrm{F}\right)$ still results in a gradual loss of sulfur capacity in the bed (cycles 1-5). However, when the temperature of regeneration was increased to $760^{\circ} \mathrm{C}\left(1400^{\circ} \mathrm{F}\right)$, or slightly above $760^{\circ} \mathrm{C}$ as in cycles 6 to 8 , there was upward trend in the breakthrough times, suggesting that a steady level of performance had been achieved or that the sulfur capacity loss in previous cycles could be regained via zinc sulfate decomposition. This set of conditions is a good indicator that suggests pressurized regeneration at $5 \mathrm{~atm}$ can be achieved, but the level of control of regeneration may be very difficult.

Figure 3-22 and Figure 3-23 show the similar case when all the first five cycles were performed with regeneration temperatures as high as $760^{\circ} \mathrm{C}\left(1400^{\circ} \mathrm{F}\right)$. The downward trend is still present, but the trend stabilizes for cycles 5 and above. Samples were taken for sulfur analysis at the end of five cycles. The sulfur content of the sorbent, prior to the $\mathrm{N}_{2}$ sulfate decomposition step, indicated that there was a $2.16 \%$ residual sulfide (considered to be high) and a $1.28 \%$ sulfate sulfur (considered to be relatively low). The fact that there was residual sulfide suggests that the regeneration time was not long enough to complete regeneration in the presence of $\mathrm{SO}_{2}$, which is known to slow down the net oxidation rate of sulfide. The fact that the $\mathrm{O}_{2}$ was shut off at low levels of breakthrough $\left(<1 \% \mathrm{O}_{2}\right)$ during regeneration, as it will be shown later, confirms the supposition of incomplete oxidation. Hence, the regeneration at 
T2594M ZINC TITANATE

(Regeneration @ 1.5 Atm., >5\% SO2)

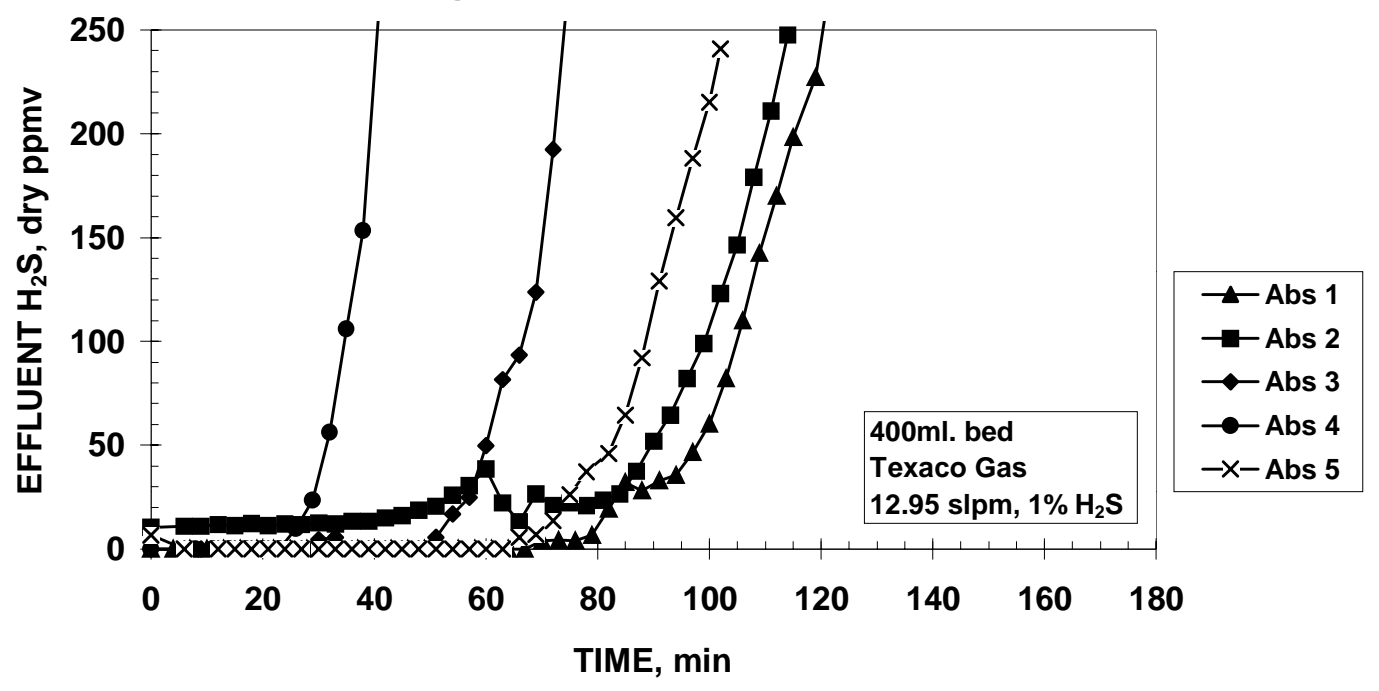

Figure 3-16. $\mathrm{H}_{2} \mathrm{~S}$ breakthrough curves for $\mathrm{T}-2594 \mathrm{M}$ when regeneration under regeneration with $\mathrm{SO}_{2}$ at 1.5 atm.

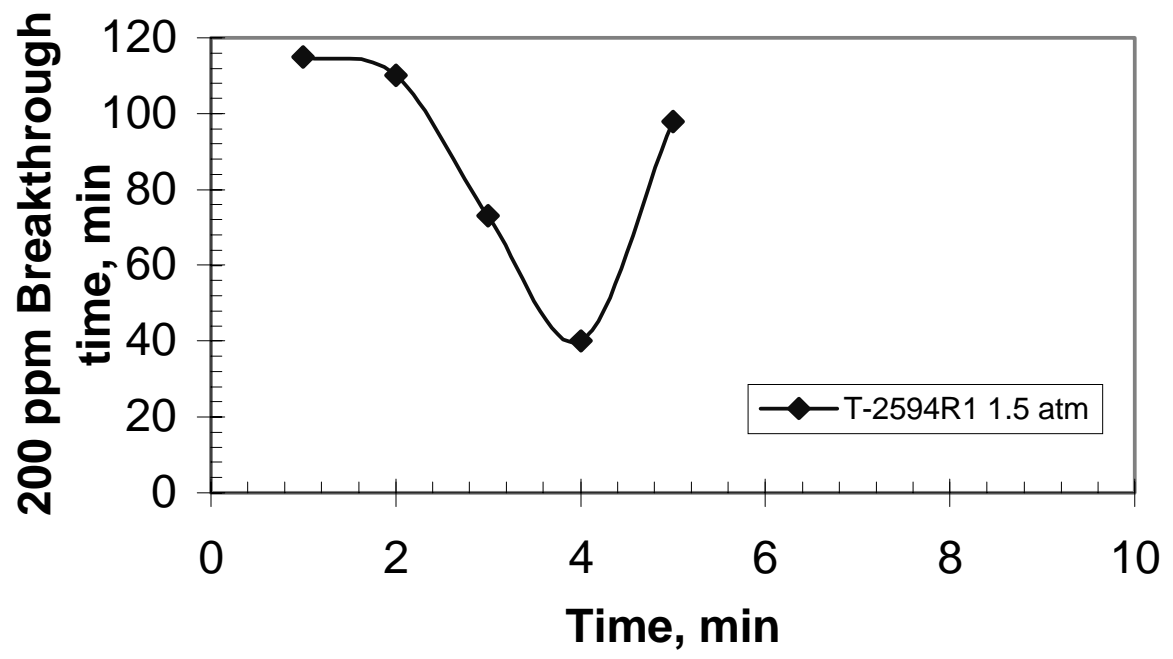

Figure 3-17. Envelope of $\mathrm{H}_{2} \mathrm{~S}$ breakthrough curves for T-2594M when regenerating under $\mathrm{SO}_{2}$ at $1.5 \mathrm{~atm}$. 
T2594M ZINC TITANATE

(Regeneration @ 3 Atm., >5\% SO2)

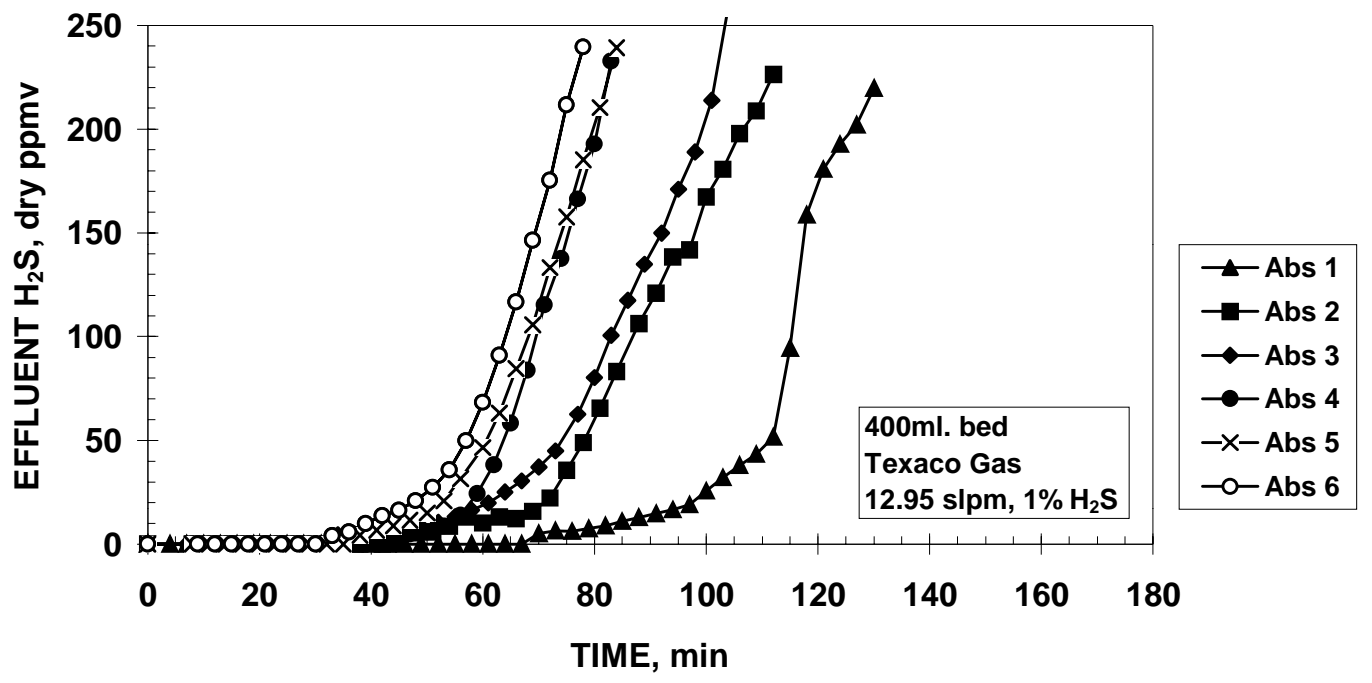

Figure 3-18. $\mathrm{H}_{2} \mathrm{~S}$ breakthrough curves for $\mathrm{T}-2594 \mathrm{M}$ with regeneration performed with $\mathrm{SO}_{2}$ at 3 atm.

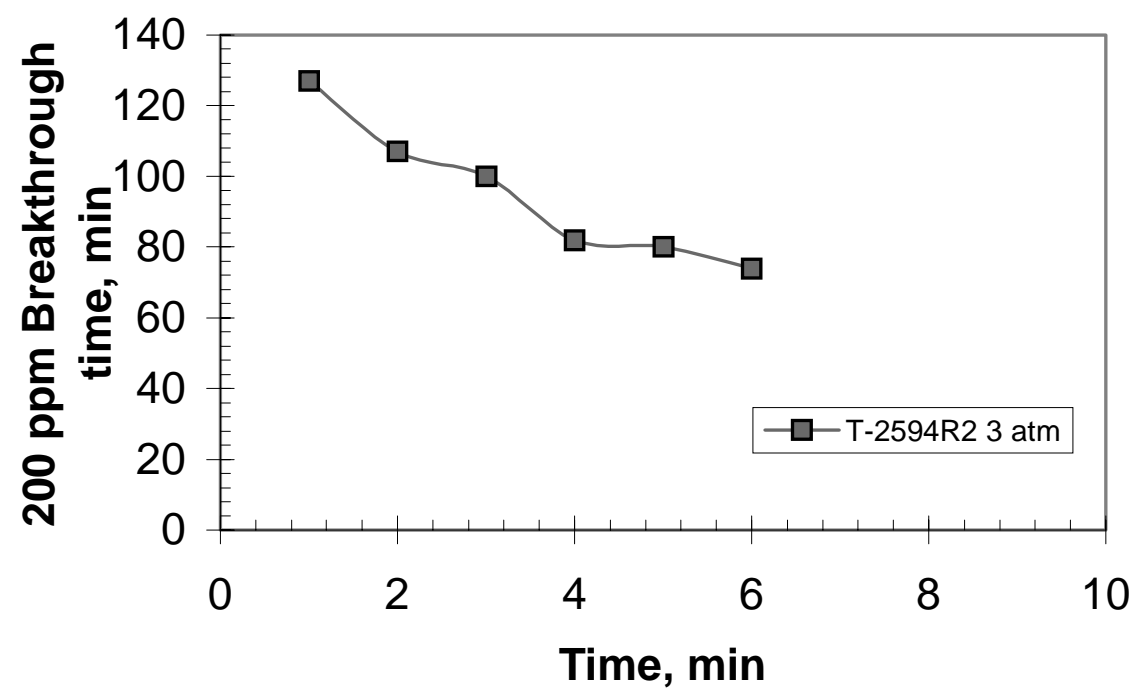

Figure 3-19. Envelope of $\mathrm{H}_{2} \mathrm{~S}$ breakthrough curves for T-2594M with regeneration performed with $\mathrm{SO}_{2}$ at 3 atm. 
T2594M ZINC TITANATE

(Regeneration @ 5.0 Atm., >5\% SO2)

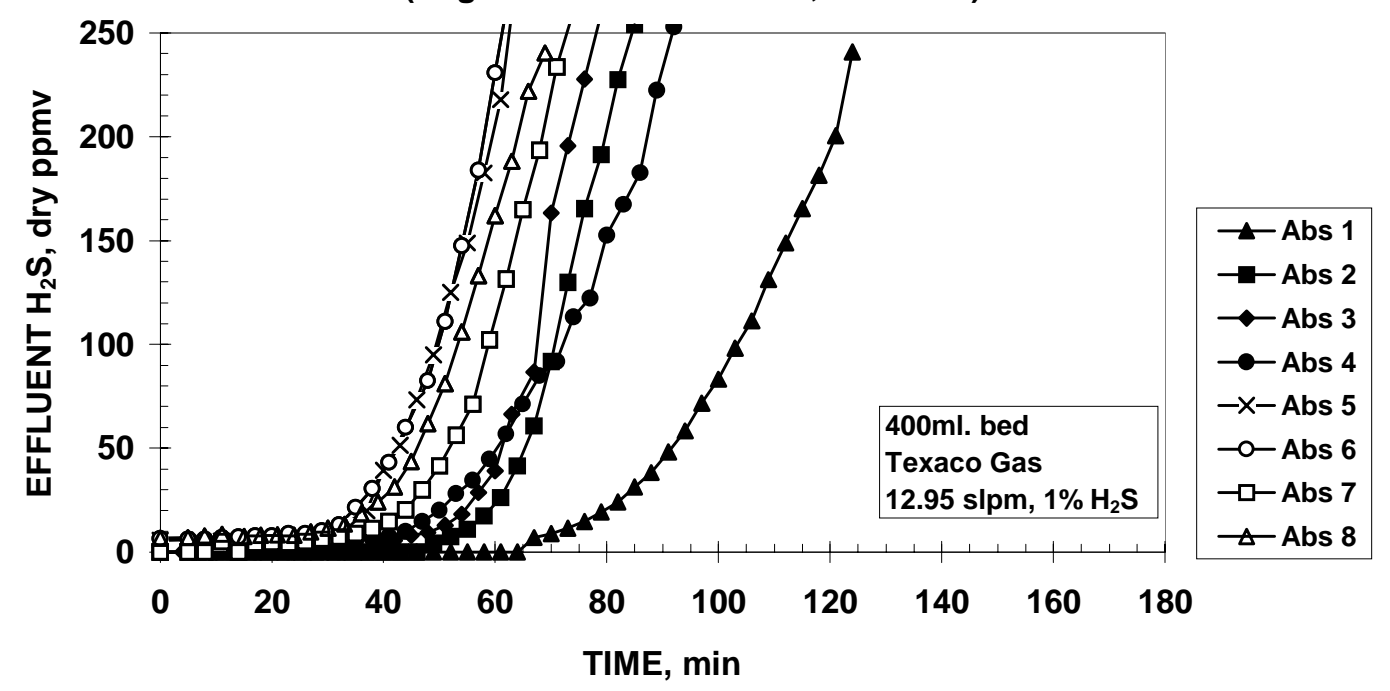

Figure 3-20. $\mathrm{H}_{2} \mathrm{~S}$ breakthrough curves for $\mathrm{T}-2594 \mathrm{M}$ with regeneration performed with $\mathrm{SO}_{2}$ at 5 atm and $704^{\circ} \mathrm{C}\left(\right.$ cycles 1-5) or $760{ }^{\circ} \mathrm{C}\left(1400{ }^{\circ} \mathrm{F}\right)($ cycles 6-8).

Envelope of Breakthrough times

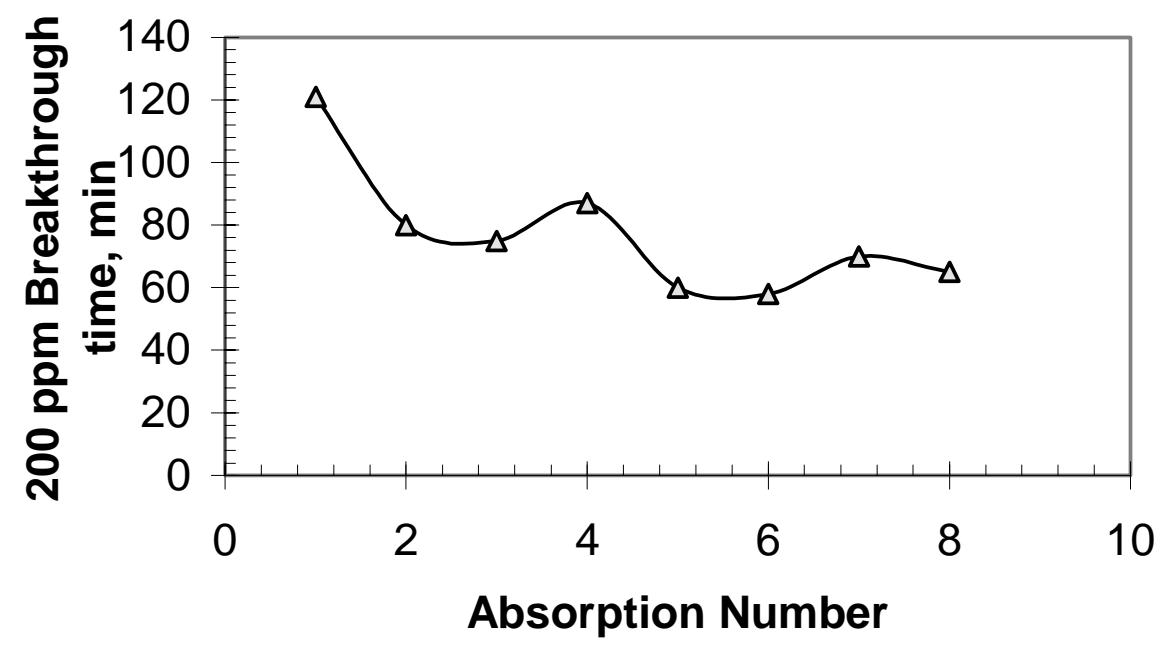

Figure 3-21. Envelope of $\mathrm{H}_{2} \mathrm{~S}$ breakthrough curves for T-2594M with regeneration performed with $\mathrm{SO}_{2}$ at 5 atm and $704^{\circ} \mathrm{C}\left(1300{ }^{\circ} \mathrm{F}\right)(\operatorname{cycles} 1-5)$ or $760{ }^{\circ} \mathrm{C}\left(1400{ }^{\circ} \mathrm{F}\right)$ (cycles 6-8). 


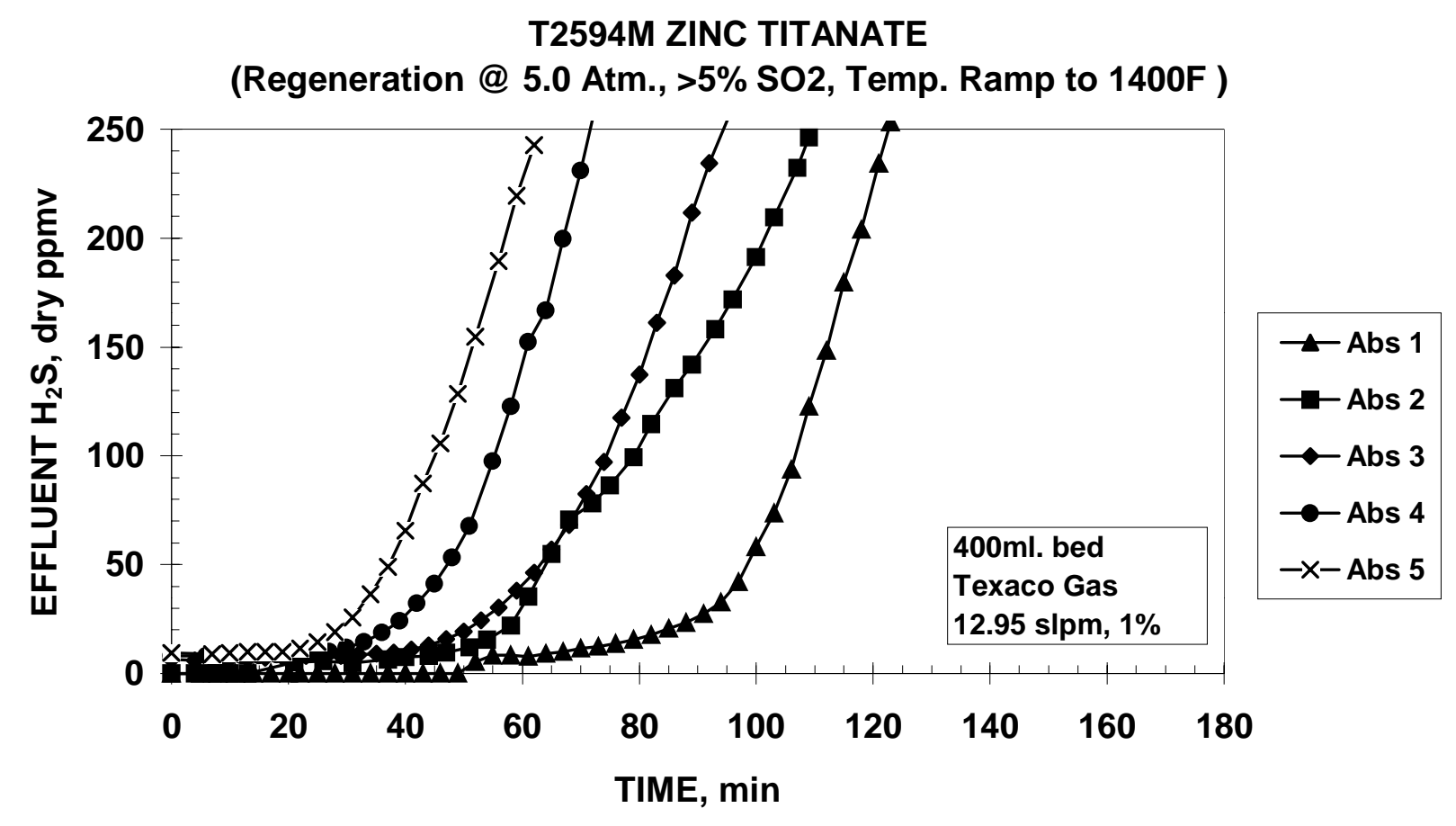

Figure 3-22. $\mathrm{H}_{2} \mathrm{~S}$ breakthrough curves for $\mathrm{T}-2594 \mathrm{M}$ with regeneration performed with $\mathrm{SO}_{2}$ at $5 \mathrm{~atm}$ and a final temperature of $760^{\circ} \mathrm{C}\left(1400{ }^{\circ} \mathrm{F}\right)$.

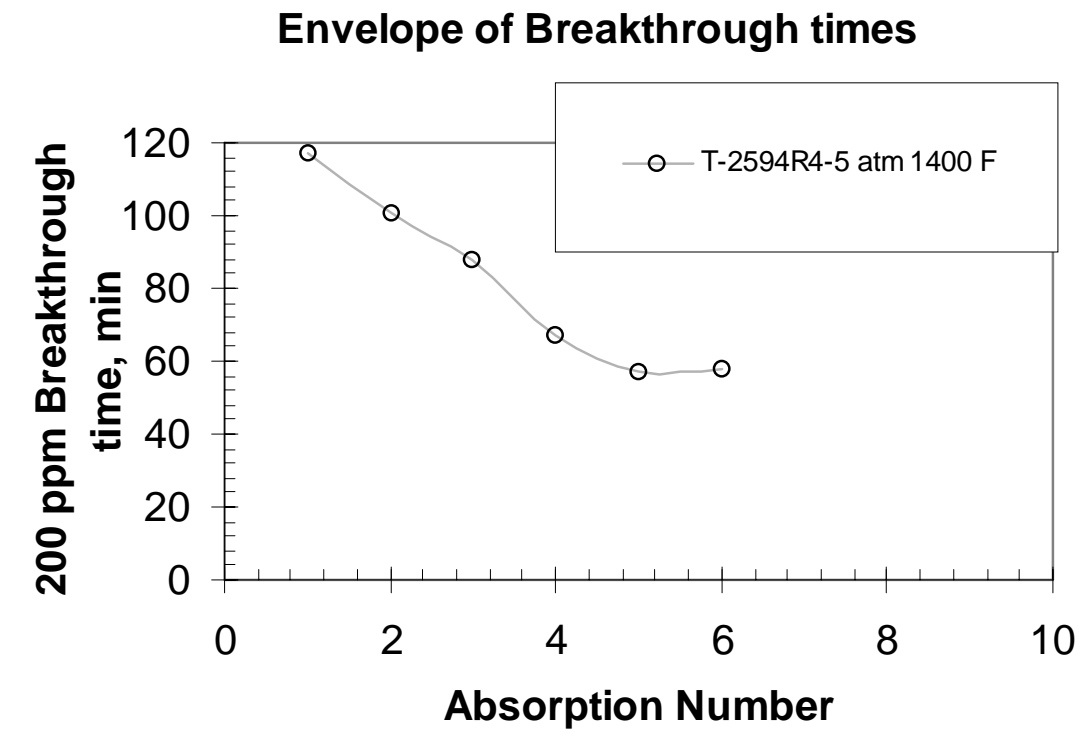

Figure 3-23. Envelope of $\mathrm{H}_{2} \mathrm{~S}$ breakthrough curves for $\mathrm{T}-2594 \mathrm{M}$ with regeneration performed with $\mathrm{SO}_{2}$ at $5 \mathrm{~atm}$ and a final $\mathrm{N}_{2}$ decomposition temperature of $760{ }^{\circ} \mathrm{C}\left(1400{ }^{\circ} \mathrm{F}\right)$. 
$704^{\circ} \mathrm{C}\left(1400^{\circ} \mathrm{F}\right)$ kept low sulfate levels in the sorbent, which is beneficial, but should have been carried out longer in the presence of $\mathrm{O}_{2}$ to complete the zinc sulfide oxidation.

Addition of $\mathrm{SO}_{2}$ from compressed gas cylinders to a pressurized bench-scale reactor system is somewhat complicated because at the high flow rates needed, only liquefied $\mathrm{SO}_{2}$ can be used. To show that the level of control maintained on regeneration experiments was acceptable, Figure 3-24 shows the $\mathrm{SO}_{2}$ concentrations delivered at $5 \mathrm{~atm}$ regeneration, as planned for TECO. The $\mathrm{SO}_{2}$ delivery system at pressure was able to keep up with the flow rate of sulfur dioxide needed for the bench reactor system and deliver $10 \% \mathrm{SO}_{2}$. In some other cases (not shown), however, the fluctuations in inlet $\mathrm{SO}_{2}$ were high (from $10 \pm 3 \%$ ) due to flashing of the liquid $\mathrm{SO}_{2}$ as it was delivered to the hot system. We have taken measures to minimize these fluctuations, and future tests will probably be within narrower limits of $\mathrm{SO}_{2}$ fluctuations. In general, it was easier to control the $\mathrm{SO}_{2}$ delivered at higher pressures than at lower pressures, where flashing and cavitation of the liquid $\mathrm{SO}_{2}$ pump were observed.

The same Figure 3-24 shows the outlet $\mathrm{O}_{2}$. A typical regeneration time was stopped at 200 minutes or less, when the oxygen concentration had broken through at the reactor exit from 0 to $0.5-0.7 \% \mathrm{O}_{2}$. Since the initial absorption times were around 120 minutes, the regeneration should perhaps have been carried out up to 240 minutes, or twice the absorption times to prevent sulfide accumulation.

REGENERATION \#2 @ 5 ATM.

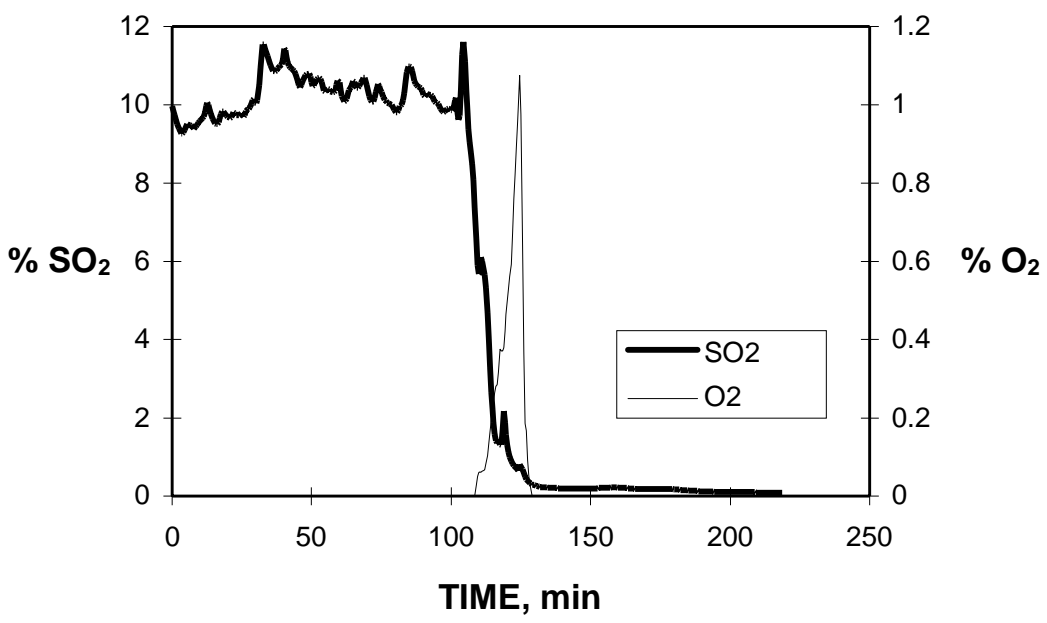

Figure 3-24. $\mathrm{SO}_{2}$ delivery during regeneration at 5 atm 


\subsubsection{Modified Zinc Titanates (MZT's) with Additives}

Introduction of additives other than molybdenum into the zinc titanate structure was also pursued at GECRD. These zinc titanates were called modified zinc titanates (MZT's). The tests were performed with two major objectives in mind:

1. To increase the strength of the $\mathrm{Zn}_{2} \mathrm{TiO}_{4}$ sorbent pellets, which in the past have exhibited various degrees of mechanical performance in long-term pilot plant tests (phase-stability modifiers)

2. To increase the lower limit of operation during desulfurization from $482{ }^{\circ} \mathrm{C}$ down towards $343^{\circ} \mathrm{C}$ (desulfurization-rate additives). This need for sustained reactivity at temperatures below $482^{\circ} \mathrm{C}$ $\left(900^{\circ} \mathrm{F}\right)$ exists because of the lower actual gasifier coal gas temperatures currently being delivered by the Texaco gasifier at the HGCU demonstration plant at TECO.

The initial tests on MZT's were performed using powders to ascertain that the presence of additives would not cause negative interactions with the desulfurization reactivity and sulfur removal capacity of $\mathrm{Zn}_{2} \mathrm{TiO}_{4}$. Once proper reactivity was determined, the existing powders were pelletized to obtain durable formulations to withstand operation over multiple cycles.

\subsubsection{Powder MZT Testing}

Evaluation of the modified zinc titanates (MZT) was first performed to ascertain that the presence of additives in powders would not have a negative effect on the desulfurization reactivity, sulfur removal capacity, and regenerability of zinc titanate. For instance, the structure in zinc titanate is less likely to form zinc chloride compounds during sulfidation than pure zinc oxide; however, additives to the zinc titanate could potentially react with $\mathrm{HCl}_{(\mathrm{g})}$ in the coal gas and promote formation of metal chlorides; these metal chlorides would be undesirable because they are carried to the regenerator where they decompose and are released as $\mathrm{HCl}_{(\mathrm{g})}$ during regeneration, affecting the sulfur recovery system. The second part of the testing involved pelletizing the formulations and assessing the mechanical characteristics (attrition and crush strength) of the fresh and reacted sorbents.

Approximately 30 powder formulations were prepared during 1996 to assess chemical reactivity. Table 3-11 presents the designation of a few of the powder formulations that were prepared with promising desulfurization and regeneration properties. Details of formulation compositions are covered in the GE patent literature reported in Section 3.3.1.

Table 3-11. GE modified zinc titanate formulations

\begin{tabular}{lll}
\hline $\begin{array}{l}\text { Formulation } \\
\text { Number }\end{array}$ & $\begin{array}{l}\text { GE } \\
\text { Designation }\end{array}$ & \multicolumn{1}{c}{ Comment } \\
\hline 1 & ZT9601 & reference plain zinc titanate \\
2 & ZT9602 & molybdenum additive \\
3 & ZT9603 & desulfurization additive \\
4 & ZT9606 & strengthening additive \\
5 & ZT9607 & phase stability additive \\
6 & ZT9608 & phase stability additive \\
7 & ZT9605 & phase stability additive \\
8 & ZT9604 & Mo + stabilizing additive \\
\hline
\end{tabular}


Formulations 1 and 2 are the standard plain zinc titanate $\left(\mathrm{Zn}_{2} \mathrm{TiO}_{4}\right)$ without additives and zinc titanate with molybdenum additive. These two were fabricated again to provide a comparison baseline. Formulation 3 contains additives to increase the desulfurization capability in the temperature range 343-482 ${ }^{\circ} \mathrm{C}$, which is currently the operating coal gas temperature of the Texaco gasifier coal gas at TECO. Formulation 4 contains an additive for strength. In the past (Test 8 of the pilot plant), the existing zinc titanate (as in formulation No. 2) performed very well in terms of reactivity, but the attrition rate was higher after $200 \mathrm{hr}$ of operation than commercially desired.

Chemical reactivity of sorbents was assessed using a thermogravimetric analyzer (TGA). In a TGA test, the weight of a powder or pellet sample hanging from the microbalance is monitored as a function of time. The weight gain is proportional to the extent of reaction in the sample. For pure zinc titanate $\left(\mathrm{Zn}_{2} \mathrm{TiO}_{4}\right)$, the complete sulfidation reaction (26\% wt/wt sulfur on the sorbent) corresponds to a weight gain of $12.6 \%$. Of course, addition of inerts and binders reduces the weight gain observed at saturation, but reproducibility of the weight changes through multiple cycles of absorption and regeneration is the key parameter in sorbent development. In a typical TGA reactivity test, the pellets are exposed to simulated clean coal gas (without $\mathrm{H}_{2} \mathrm{~S}$ ) for the first 30 minutes at 1 atm and $482{ }^{\circ} \mathrm{C}$ to establish a weight baseline. Then, $3 \% \mathrm{H}_{2} \mathrm{~S}$ is introduced during absorption (also called sulfidation) to check for weight changes during the reaction. A regeneration with 2-4\% $\mathrm{O}_{2}$ can follow the sulfidation, when the weight should return to its base value. Repetitive cycles of sulfidation and regeneration can be carried out in a multiple cycle test. A typical example of a TGA powder formulation with a phase stability additive (ZT9607) is shown in Figure 3-25, where no loss in reactivity is observed between the first and the second absorptions, indicating hydrothermal stability of the sorbent in the absence of confounding sulfidation weight changes. A horizontal baseline is measured in the first 30 minutes of each absorption, and essentially no loss in reactivity is observed between the first and the second absorptions. Standard conditions for TGA sulfidation tests at GE are $3 \% \mathrm{H}_{2} \mathrm{~S}$ in simulated coal gases at $482{ }^{\circ} \mathrm{C}$ and $1 \mathrm{~atm}$.

Figure 3-26 presents the reactivity of ZT9603 zinc titanate. This formulation has desulfurization additives and no phase stabilizers. Some initial loss in capacity is observed, either due to sulfate formation or structure densification (e.g., loss of surface area).

Figure 3-27 shows the performance of ZT9606 zinc titanate with a phase stabilizer. The fact that the two absorptions are very close together suggest that there is little surface area loss between cycles.

TGA tests show that the reactivity of the top five formulations is satisfactory during the initial screening, i.e., that the strengthening and desulfurization enhancing additives are not detrimental to the desulfurization and regeneration of the sorbents. Figure 3-28 shows the TGA curves for the first sulfidation of several of the formulations obtained at $482{ }^{\circ} \mathrm{C}, 1 \mathrm{~atm}$, and $3 \% \mathrm{H}_{2} \mathrm{~S}$ in the simulated coal gas. The theoretical capacity of the modified zinc titanate powders is between $10 \%$ and $12 \%$ weight gain, so all the curves exhibit a normal behavior of weight gain to close to saturation after the two hour test (theoretical for these zinc titanates is approximately $12.6 \%$ ). Differences in the total sulfur capacity among the sorbents are a result of differences in the zinc titanate initial concentration in the formulation. Also, none of the formulations lose or gain weight prior to introduction of $\mathrm{H}_{2} \mathrm{~S}$ ( 0 to 40 minutes), which indicates a (hydrothermally) stable crystal structure in the presence of $\mathrm{H}_{2}$ and $\mathrm{CO}$ in the simulated coal gas.

After completion of the reactivity tests on powder formulations, UCI was requested to pelletize these formulations to test their mechanical properties (attrition resistance and crush strength) at GE-CRD. 


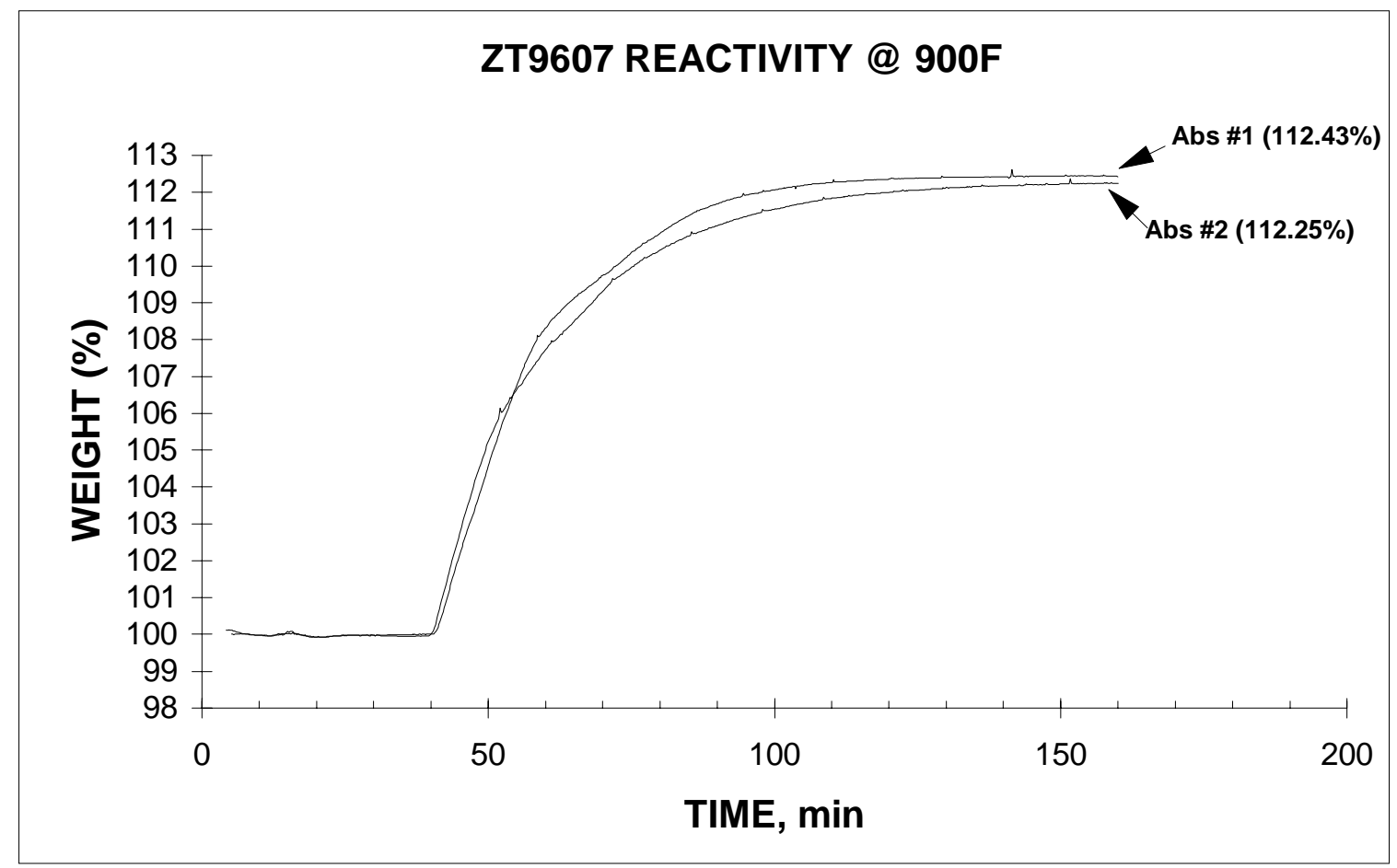

Figure 3-25. TGA Chemical reactivity of ZT9607 zinc titanate

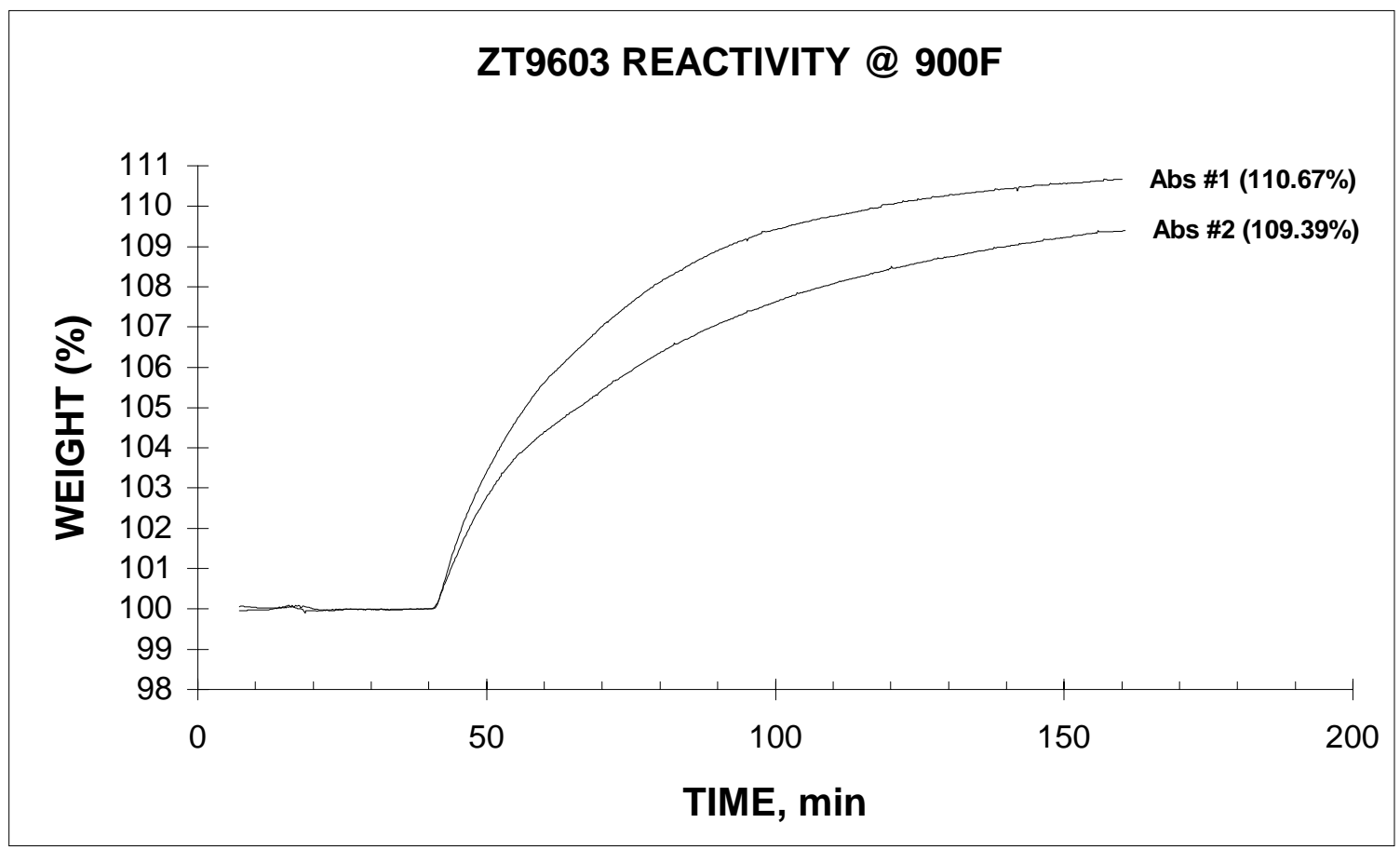

Figure 3-26. TGA Chemical reactivity of ZT9603 zinc titanate without stabilizer 


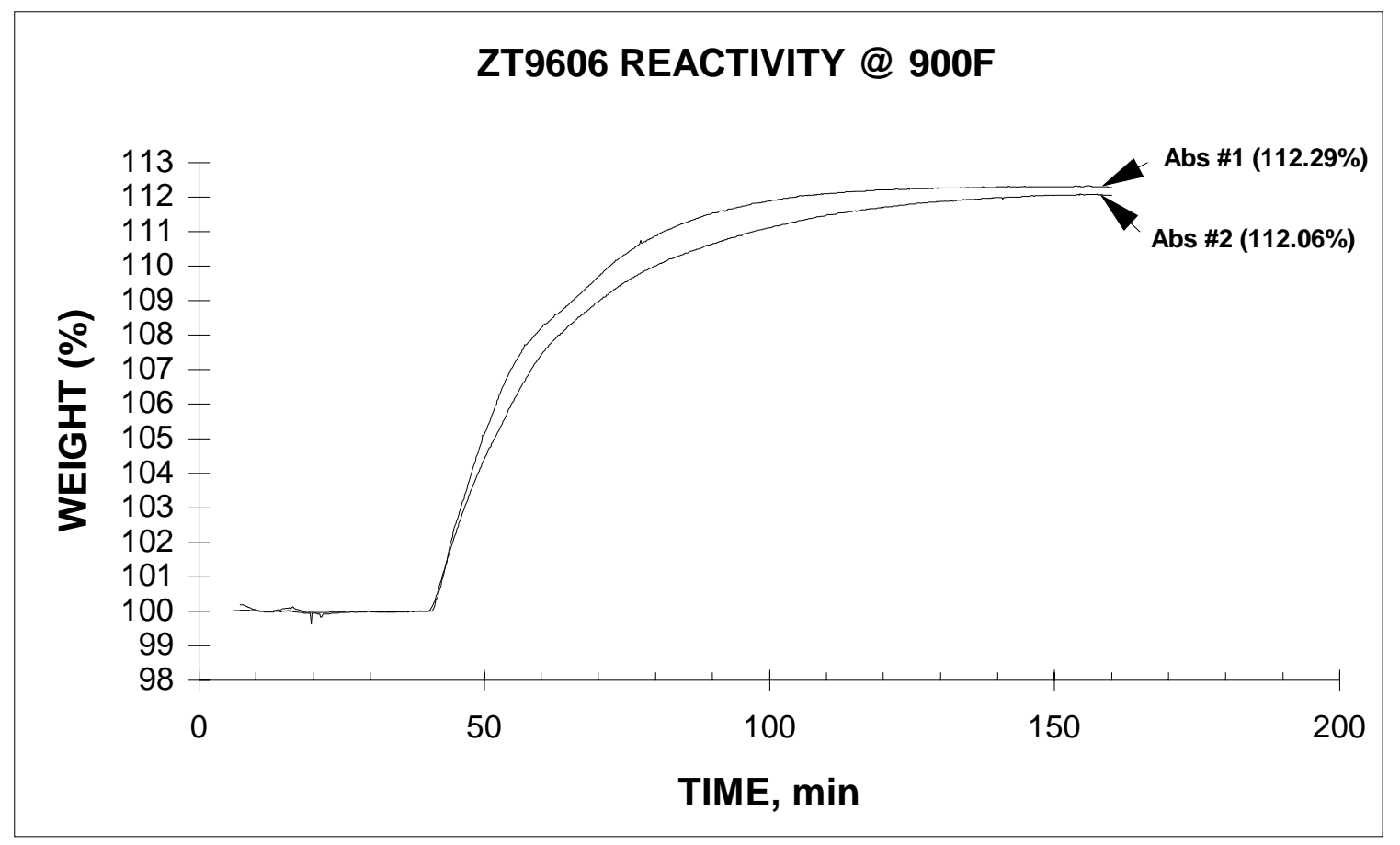

Figure 3-27. TGA reactivity of a zinc titanate with a phase stabilizer

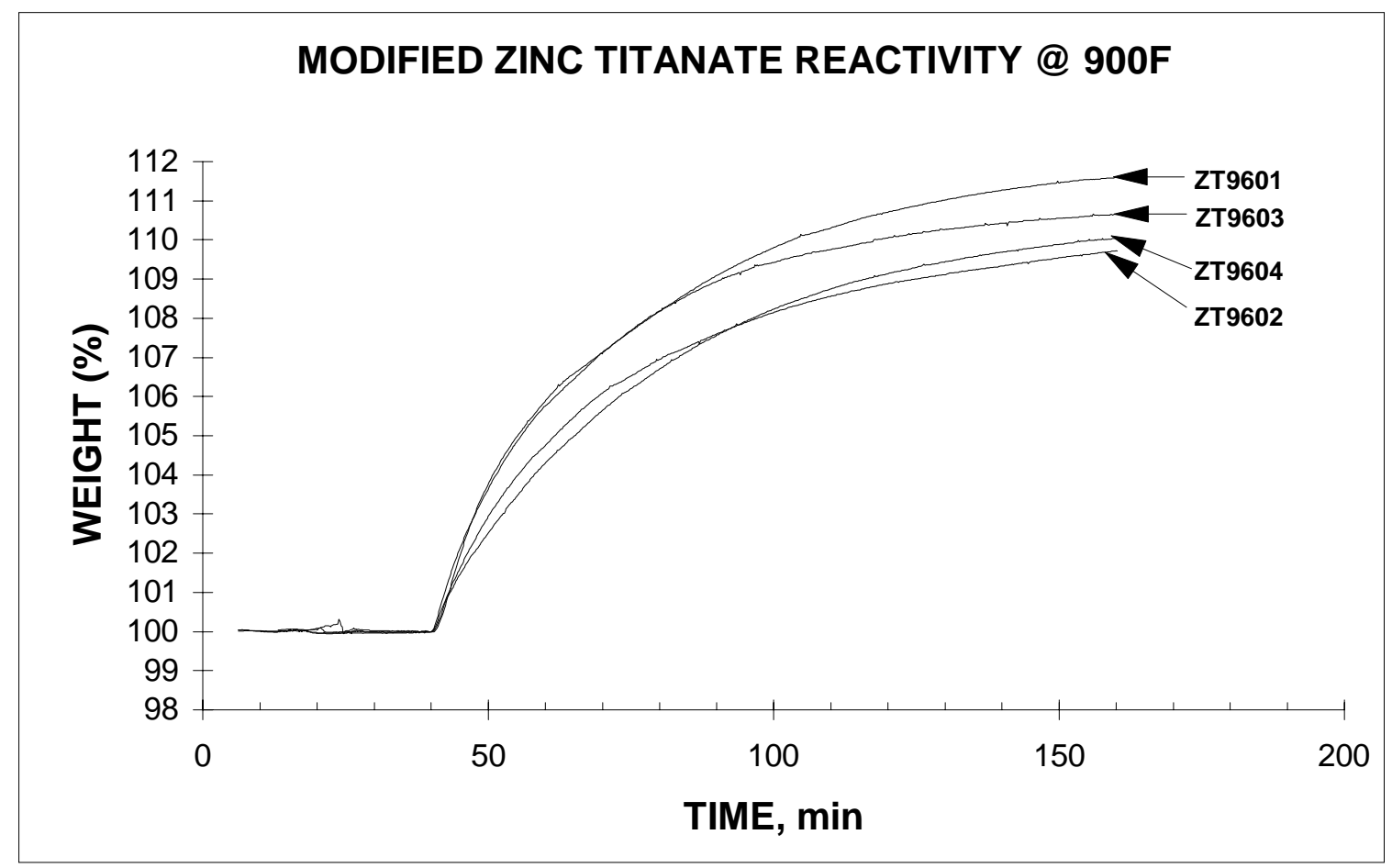

Figure 3-28. TGA reactivity of powder modified zinc titanates at $482{ }^{\circ} \mathrm{C}, 3 \% \mathrm{H}_{2} \mathrm{~S}$, and 1 atm. 


\subsubsection{Pelletized MZT Sorbent Testing}

Having evaluated the chemical performance of powder MZT sorbents, we proceeded to pelletize those formulations that exhibited satisfactory chemical performance. The purpose of the pelletization studies at UCI was to improve the mechanical durability of zinc titanate sorbent formulations by adjusting the pelletization conditions (i.e., time, temperature, pore modifiers, and binders) that would result in an improved overall (chemical and mechanical) performance of the previously tested powdered formulations. Typically, mechanically strong pellets have low reactivities, and highly reactive pellets tend to be soft. A balance between the two properties is usually necessary to achieve optimum performance in moving-bed applications.

The following key areas of sorbent performance were considered for comparison among pelletized formulations:

- mechanical durability (attrition and crush strength) of fresh and cycled sorbents

- desulfurization and regeneration characteristics during normal operation

- sulfate formation tendency during regeneration

- temperature range of desulfurization.

All modified zinc titanate formulations were tested as received from UCI. No interim conditioning or activation of the pellets was necessary prior to testing at GE-CRD. Pelletization procedures are proprietary to UCI.

\subsection{Mechanical durability of fresh pelletized sorbents}

Several formulations of modified zinc titanate sorbents were extruded, formed, and calcined by UCI. The resulting pellets had a 3-4 mm diameter and were ellipsoidal in shape. The first round of pelletized zinc titanate formulations was received for evaluation at GE-CRD in January 1997 (Table 3-12). Crush strength was acceptable (i.e., greater than $3 \mathrm{lb} /$ pellet or $1.36 \mathrm{~kg} / \mathrm{pellet}$ ) and TGA reactivity was also reasonable (discussed in the next section). However, ASTM attrition for most of the fresh formulations was above the target value of less than $4 \%$.

Given that pelletization of modified zinc titanates in the first round fell short of exceeding the target mechanical strength (i.e., ASTM attrition less than 4\%), preparation of a second round of formulations with the same compositions was undertaken again at UCI. This time, pelletization procedures were

Table 3-12. Properties of the first round of pelletized fresh samples

\begin{tabular}{lcccc}
\hline Formulation & $\begin{array}{c}\text { Density, } \\
\text { lb/ft } \\
\text { (sp. gravity) }\end{array}$ & $\begin{array}{c}\text { Crush Strength, } \\
\text { lb/pellet } \\
\text { (kg/pellet) }\end{array}$ & $\begin{array}{c}\text { ASTM Attrition, } \\
\%\end{array}$ & $\begin{array}{c}\text { Presence of broken } \\
\text { granules after ASTM } \\
\text { attrition tests }\end{array}$ \\
\hline PP-4114 & $83.1(1.33)$ & $6.5(2.9)$ & 1.32 & No \\
PP-4115 & $84.3(1.61)$ & $5.9(2.7)$ & 10.85 & No \\
PP-4116 & $88.4(1.42)$ & $5.1(2.3)$ & 16.15 & No \\
PP-4117 & $78.4(1.26)$ & $4.6(2.1)$ & 8.64 & Yes \\
PP-4118 & $80.3(1.29)$ & $3.9(1.8)$ & 5.22 & Yes \\
\hline
\end{tabular}


tailored to the particular extrusion characteristics of the formulations. The objective for preparation of a second round of formulations was to obtain $2 \%$ or less ASTM attrition loss, or half the maximum acceptable for a fresh sorbent.

Table 3-13 shows the physical properties of the second round of fresh sorbents. The crush strength values are higher than those measured in the first round (Table 3-12), and well above the minimum of 3 $\mathrm{lb} /$ pellet needed to prevent pellet crushing under its own bed weight. ASTM attrition loss values were lower than those in Table 3-12 and, except for formulation MZT-G1, achieved the internal target of less than or equal to $2 \%$, which is half of the $4 \%$ ASTM attrition loss target for evaluation in pilot plant operation.

Table 3-13. Mechanical properties of the second round of zinc titanate formulations

\begin{tabular}{lllcc}
\hline UCI ID & GE ID & $\begin{array}{l}\text { Density, lb./ft } \\
\text { (sp. gravity) }\end{array}$ & $\begin{array}{c}\text { Crush Strength, } \\
\text { lb/pellet } \\
\text { (Kg/pellet) }\end{array}$ & $\begin{array}{c}\text { ASTM Attrition \%, } \\
\text { (GE-CRD) }\end{array}$ \\
\hline PP-4195 & MZT-P1 & $64.0(1.03)$ & $8.3(3.8)$ & 1.0 \\
PP-4197 & MZT-R1 & $63.6(1.02)$ & $4.9(2.2)$ & 2.0 \\
PP-4198 & MZT-G1 & $61.5(0.99)$ & $4.8(2.2)$ & 2.5 \\
PP-4199 & MZT-I1 & $61.0(0.98)$ & $6.0(2.7)$ & 1.96 \\
PP-4248 & MZT-O1 & $65.2(1.04)$ & $5.4(2.4)$ & 0.91 \\
\hline
\end{tabular}

\subsection{Desulfurization and regeneration characteristics}

TGA chemical reactivity tests were conducted at GE-CRD on the pelletized sorbent formulations in two rounds of production by UCI. Typical reactivity performance of two of the formulations prepared during the first round of pelletization are shown in Figure 3-29 and Figure 3-30. TGA reactivity tests were conducted using the standard conditions at GE-CRD $\left(482{ }^{\circ} \mathrm{C}, 1 \mathrm{~atm}, 3 \% \mathrm{H}_{2} \mathrm{~S}\right.$ in simulated coal gases). A weight gain due to sulfur absorption of at least $5 \%$ in 2 hours is considered acceptable sulfur capture performance. The first 30-35 minutes correspond to exposure to simulated clean coal gas without $\mathrm{H}_{2} \mathrm{~S}$ (i.e., reductive regeneration) to establish a weight baseline. Note that the pellet weight is stable during the 30-minute reductive regeneration step, indicating that the metal oxides used in MZT's do not react with clean coal gas.

However, since the mechanical durability, attrition in particular, was low in these first round formulations, these formulations are considered weak and not as desirable for further testing.

Chemical reactivity of the pellets produced in the second round of formulations (previously shown in Table 3-13) was also tested. Figure 3-31 shows the typical weight gain during absorption for the first two cycles of MZT-I1, while Figure 3-32 shows the corresponding weight gain of MZT-O1. Again, the first 30 minutes correspond to exposure to simulated clean coal gas (without $\mathrm{H}_{2} \mathrm{~S}$ ) to establish a weight baseline. An acceptable weight gain is 5\% above the stable initial baseline in the first 2 hours. This weight gain corresponds to the operating point for the moving-bed system (i.e., $96 \mathrm{~g}$ of sulfur/liter of bed) for these formulations. Both formulations met this requirement. MZT-I1 is slightly more stable than MZT-O1 since the difference in sulfur loading against time for repetitive absorptions is more predictable. The difference in behavior between the two formulations is probably a result of different chemical compositions and preparation method. 


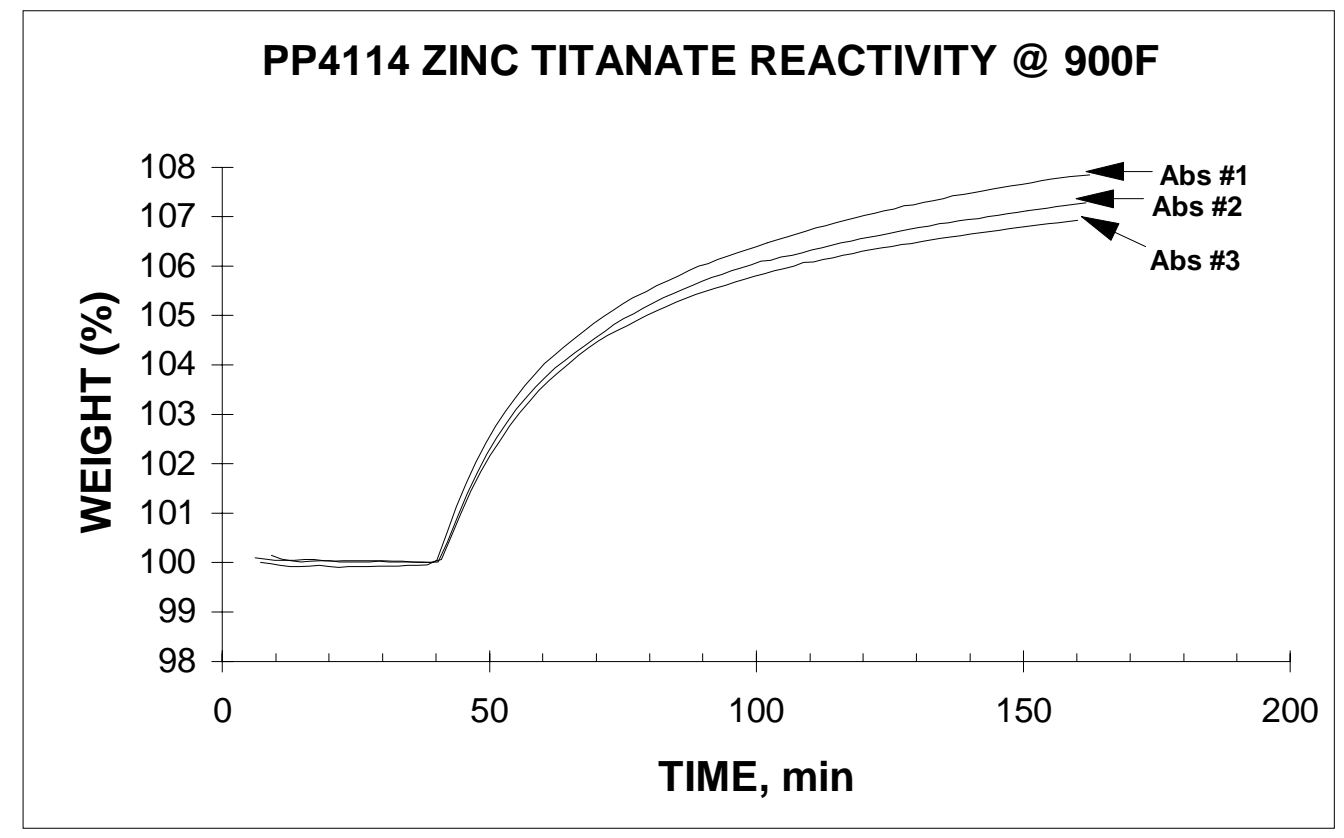

Figure 3-29. TGA Reactivity of PP4114 zinc titanate at $482{ }^{\circ} \mathrm{C}\left(900{ }^{\circ} \mathrm{F}\right)$

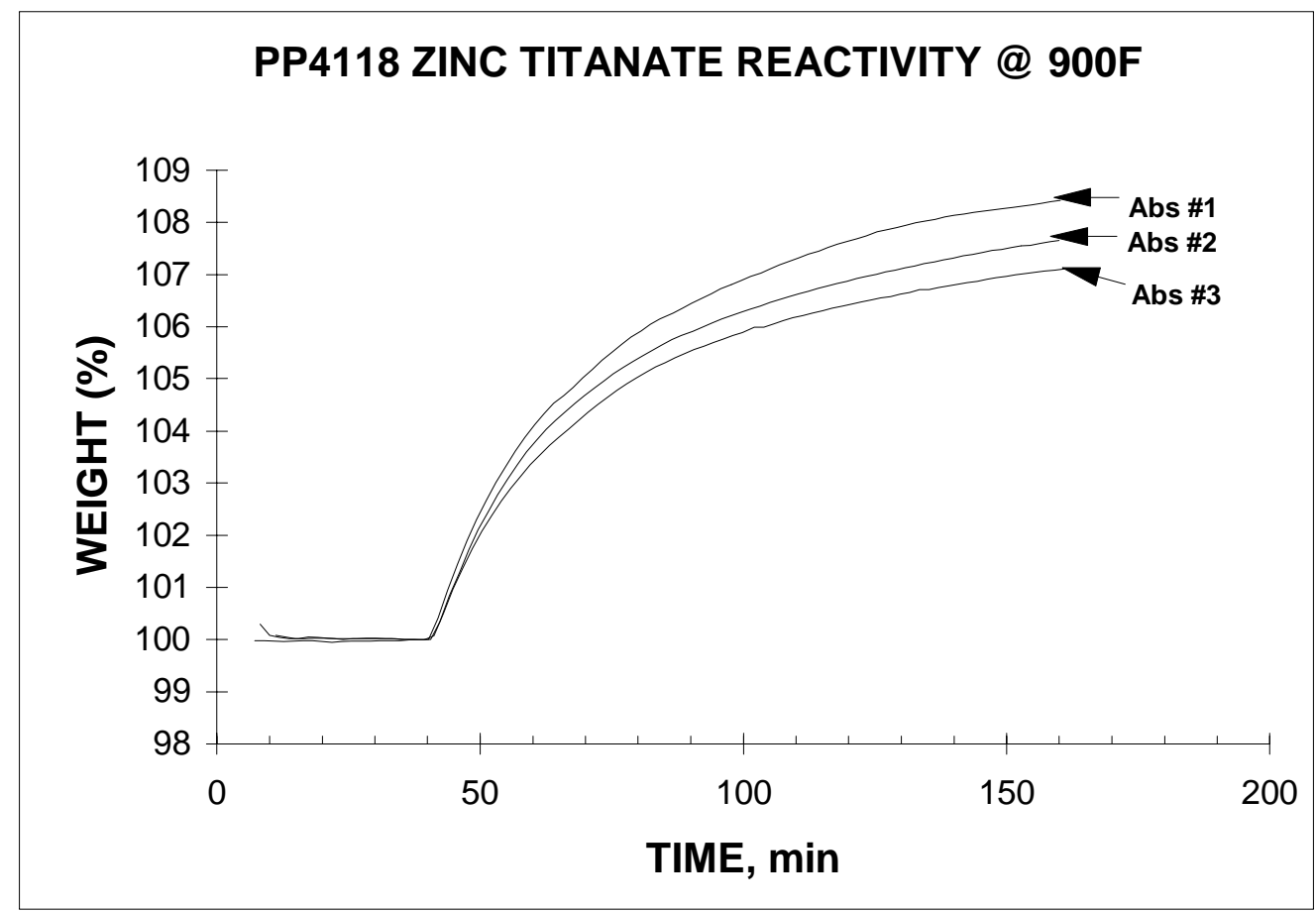

Figure 3-30. TGA Reactivity of PP4118 zinc titanate at $482{ }^{\circ} \mathrm{C}\left(900{ }^{\circ} \mathrm{F}\right)$ 


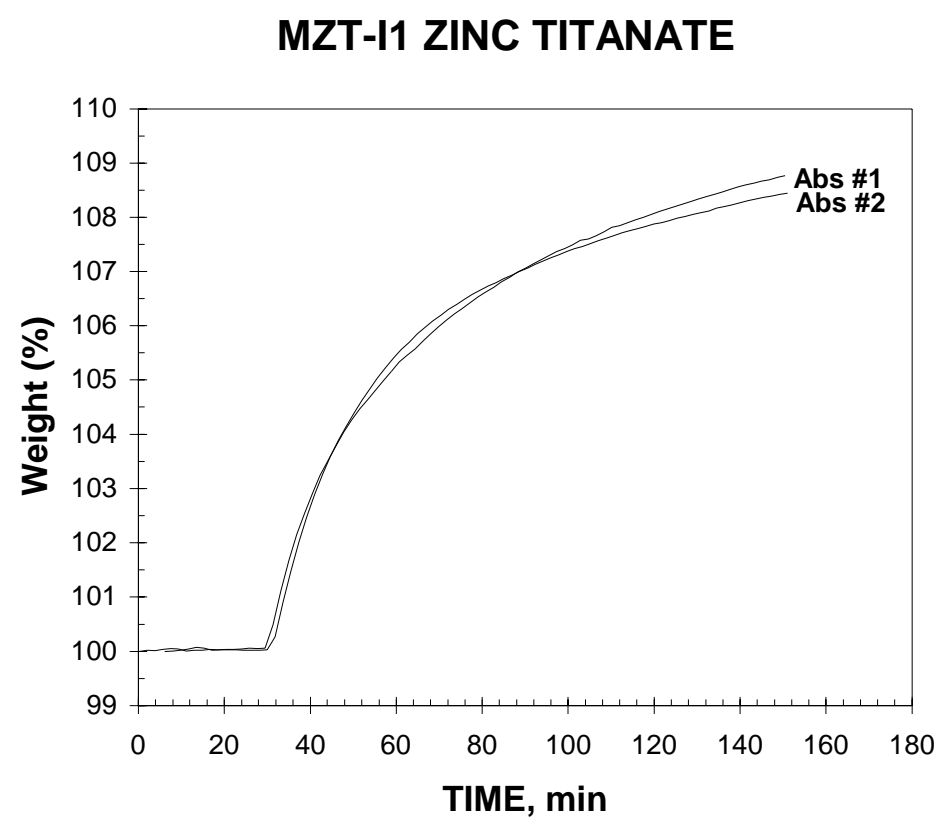

Figure 3-31. TGA reactivity of MZT-I1 during sulfidation at $1 \mathrm{~atm} / 482{ }^{\circ} \mathrm{C}$.

\section{MZT-01 ZINC TITANATE}

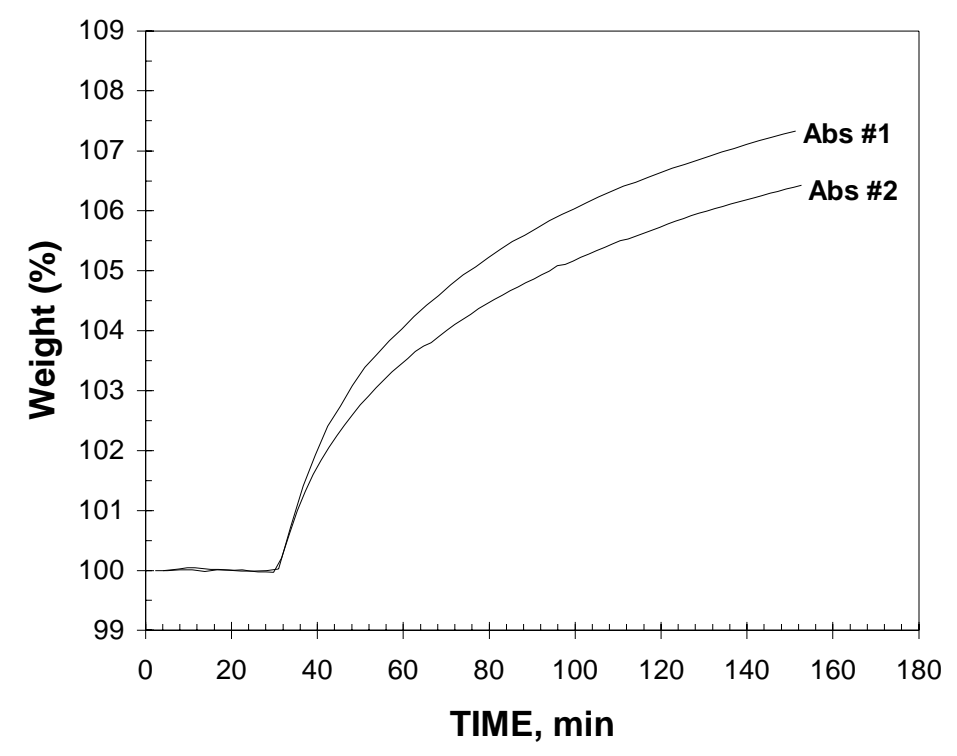

Figure 3-32. TGA reactivity of MZT-O1 during sulfidation at $1 \mathrm{~atm} / 492{ }^{\circ} \mathrm{C}$ 
Performance for the other formulations is shown in Figure 3-33 to Figure 3-35.

Overall, the chemical reactivity as well as the mechanical durability of the fresh MZT's prepared under the second round was acceptable for further testing in the bench-scale reactor.

\section{MZT-P1 ZINC TITANATE}

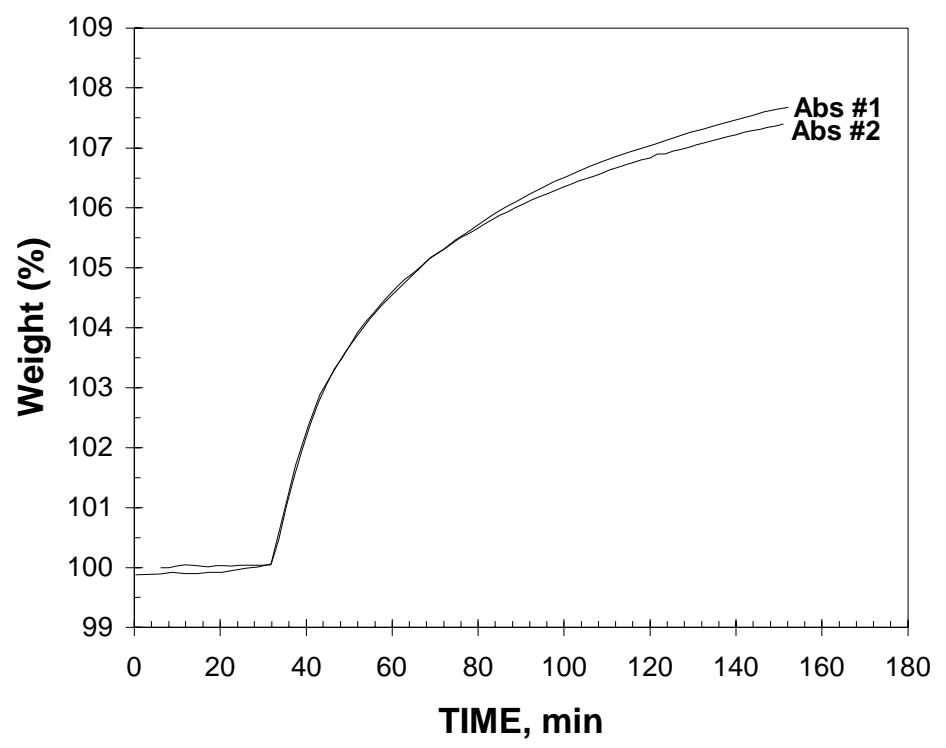

Figure 3-33. TGA reactivity of MZT-P1 during sulfidation at $1 \mathrm{~atm} / 492{ }^{\circ} \mathrm{C}$

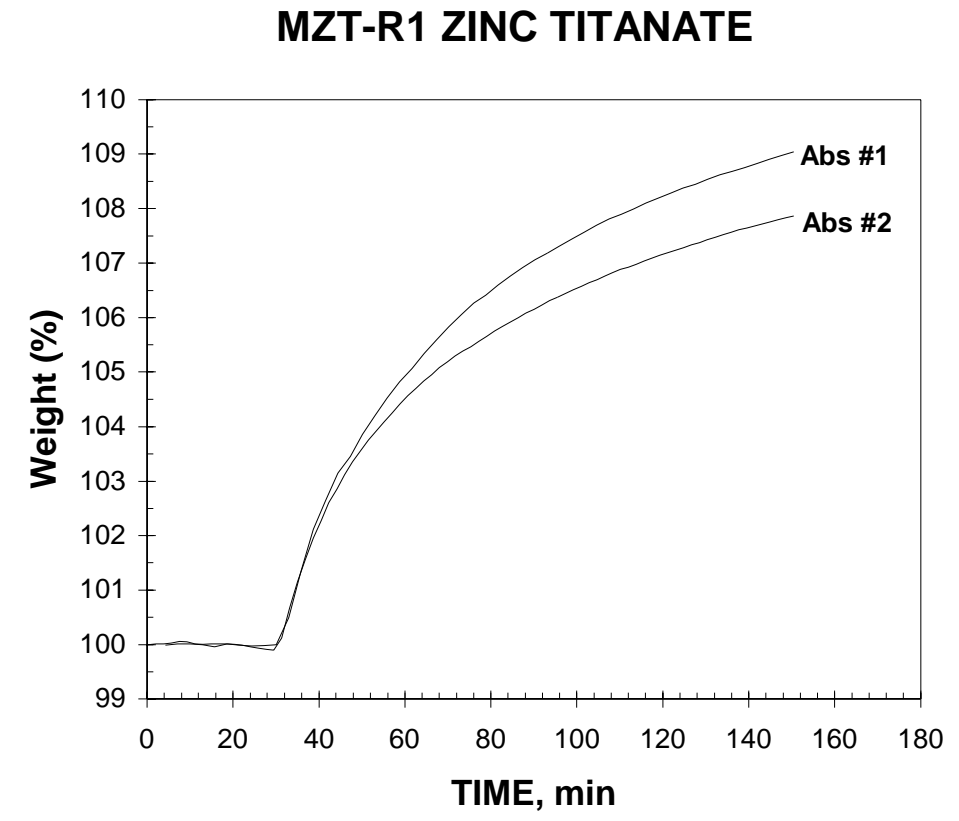

Figure 3-34. TGA reactivity of MZT-R1 during sulfidation at $1 \mathrm{~atm} / 492{ }^{\circ} \mathrm{C}$ 


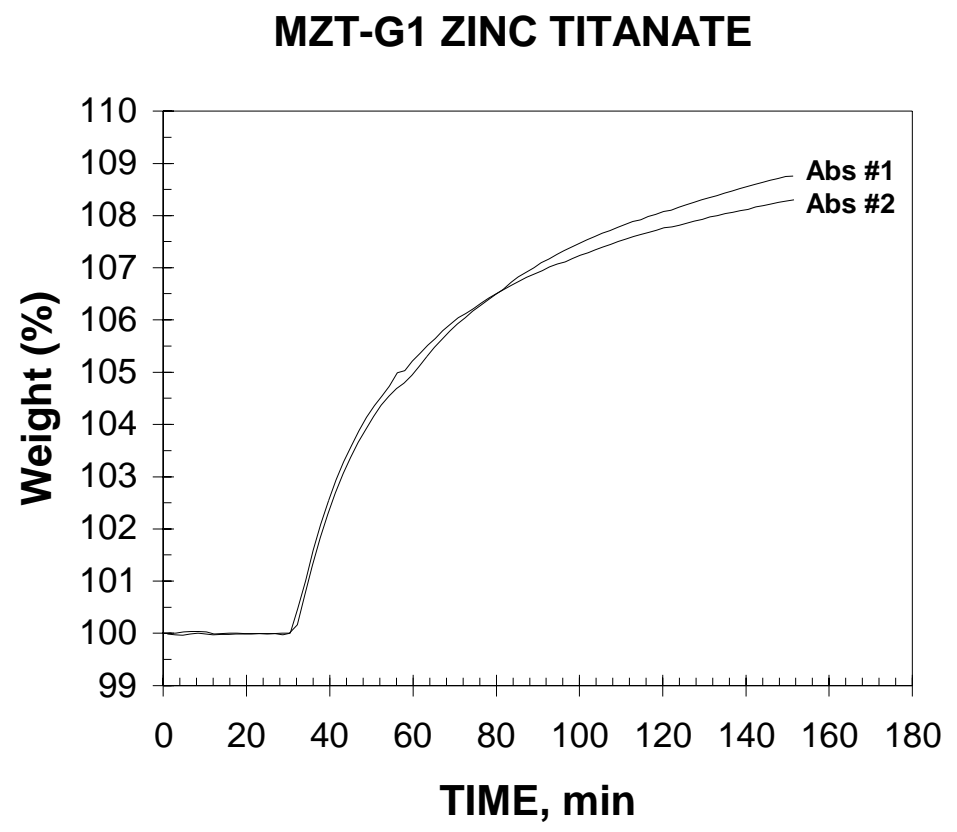

Figure 3-35. TGA reactivity of MZT-G1 during sulfidation at $1 \mathrm{~atm} / 492{ }^{\circ} \mathrm{C}$

\subsection{Sulfate formation during regeneration}

Dry regeneration of zinc-based sorbents with diluted air produces sulfur dioxide, which is used as a starting material for sulfuric acid production or elemental sulfur. However, sulfur species may remain in the sorbent as residual solid zinc sulfates. The presence of zinc sulfates is highly undesirable because it reduces the sulfur capacity of the sorbent in subsequent cycles and eventually cannot be removed from the sorbent even with thermal treatment. Accumulation of sulfates reduces porosity and future reactivity of the pellets. The TGA weight gain of the sorbent pellets due to sulfate formation in the presence of oxidizing regeneration gases is presented in Figure 3-36. After establishing a baseline steady weight of the sorbent at $718^{\circ} \mathrm{C}\left(1325^{\circ} \mathrm{F}\right)$ under nitrogen for twenty minutes, the sorbent was exposed to a gas containing $5 \% \mathrm{SO}_{2}, 2 \% \mathrm{O}_{2}$ at $718^{\circ} \mathrm{C}\left(1325^{\circ} \mathrm{F}\right)$ and $1 \mathrm{~atm}$. Higher weight gains are indicative of detrimental faster rates of sulfate formation for the sorbent in the 2 hour exposure time. Plain zinc titanate (MZT-P1) (i.e., zinc titanate with no additives) has the higher sulfate formation tendency, while those with additives have a reduced tendency. Lower zinc sulfate formation tendencies are beneficial because they minimize sorbent deterioration.

\subsection{Temperature range of desulfurization of single pellets}

In order for a sorbent to be useful in HGCU operation, it has to be able to desulfurize coal gas in reasonable times, i.e., have a chemical reactivity for sulfur species compatible with practical reactor size, not only at steady state but also during transient startup/shutdown operations. Typical startup and shutdown operations for an absorber require operation at lower temperatures (below 482 ${ }^{\circ} \mathrm{C}$ ). Off-design operation may also require operation at lower temperatures for extended periods of time. For these reasons, sulfur absorption tests were performed in the TGA to compare the rate of reaction of zinc titanate sorbents as a function of temperature. 


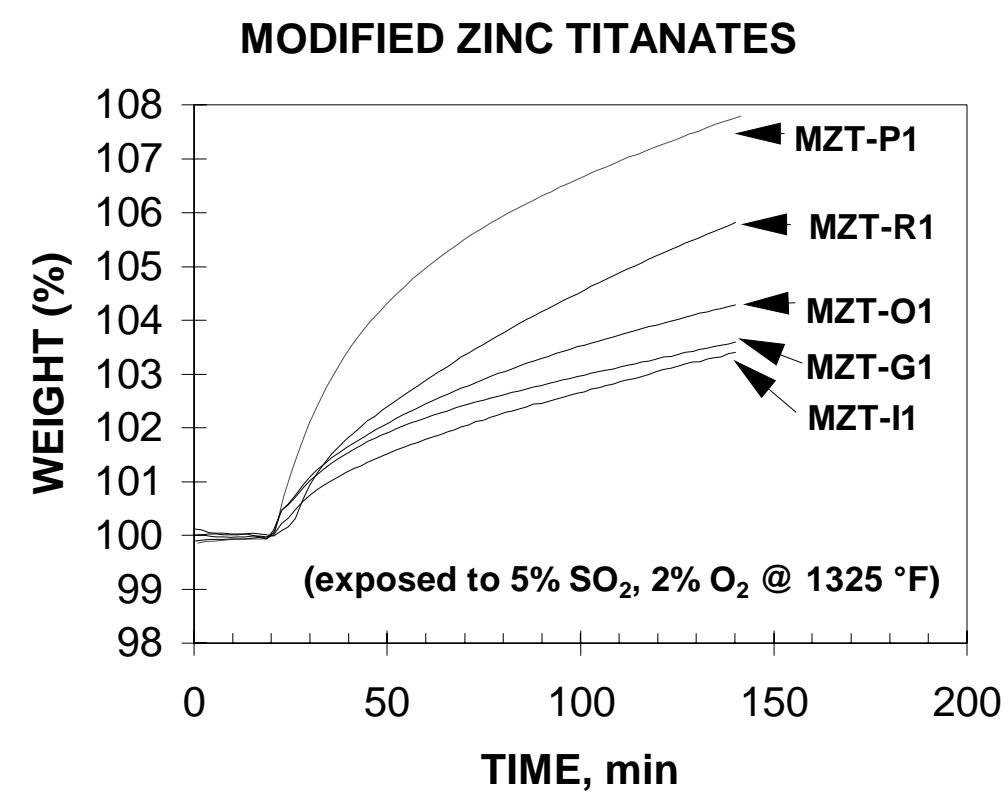

Figure 3-36. TGA weight gain due to sulfate formation during regeneration of the pelletized modified zinc titanates at $1 \mathrm{~atm}$ and $718^{\circ} \mathrm{C}\left(1325{ }^{\circ} \mathrm{F}\right)$

Figure 3-37 shows the TGA performance of MZT-R1 formulation in the range $371-482{ }^{\circ} \mathrm{C}(700-900$ $\left.{ }^{\circ} \mathrm{F}\right)$. After setting a baseline initial sample weight under simulated coal gases without $\mathrm{H}_{2} \mathrm{~S}$, the $\mathrm{H}_{2} \mathrm{~S}$ was started at 30 minutes. The desulfurization rate of the sorbent results in a weight gain as the zinc component of zinc titanate goes from the oxide form to the sulfide form. A typical normal operating condition (NOC) in a moving-bed reactor requires a sulfur loading of $96.2 \mathrm{~g}$ of sulfur/liter of bed. This target is shown as a horizontal line at the equivalent weight percentage versus time in Figure 3-37 and labeled TECo NOC. For the chosen TGA test (at $1 \mathrm{~atm}, 3 \% \mathrm{H}_{2} \mathrm{~S}$ ) to be a good predictor of sulfur loading in a moving-bed reactor, the target sulfur loading in the TGA must be accomplished in 2 hours of test time.

MZT-R1 ZINC TITANATE

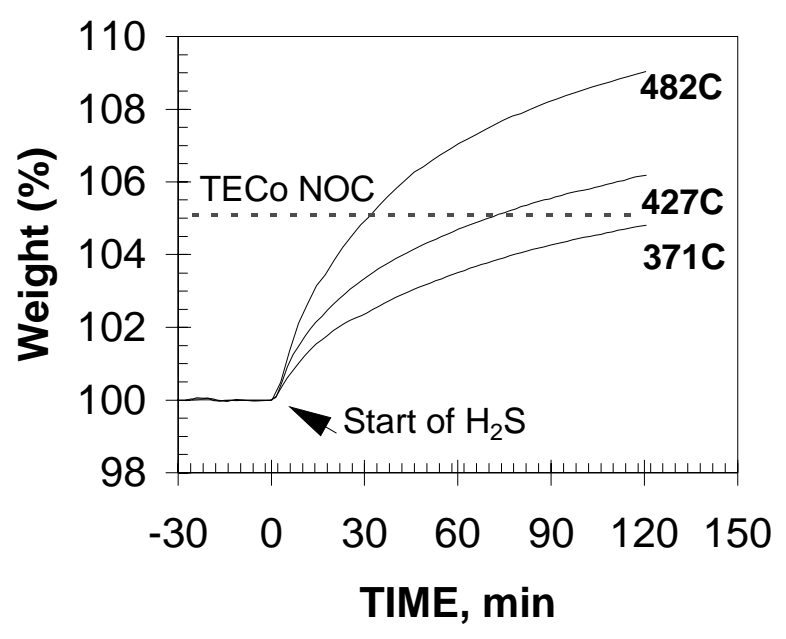

Figure 3-37. TGA reactivity of MZT-R1 zinc titanate as a function of temperature. 
It can be seen from Figure 3-37 that the sulfur loading at the TECo NOC (normal operating conditions) can be achieved with MZT-R1 by operation as low as approximately $371^{\circ} \mathrm{C}\left(700^{\circ} \mathrm{F}\right)$. This performance suggests a window of about $200^{\circ} \mathrm{F}$ below the NOC, albeit being considered off-design conditions. Other sorbent formulations were evaluated for operation at temperatures below $482{ }^{\circ} \mathrm{C}$, but their performance was not as good as that of MZT-R1.

\subsubsection{CRD bench reactor tests}

The evaluation of MZT's TGA chemical reactivity and mechanical durability in small amounts of fresh pellets was followed by bench-scale testing of five of the most promising formulations at GE-CRD. The bench tests provided information on the bed desulfurization performance and attrition resistance of the bed as a whole over multiple cycles of operation. These tests on MZT's were conducted under the optional Task 8 - Long-Term Testing.

The bench screening was performed using the $7-\mathrm{cm}$ (2.75 in.) inside diameter fixed-bed bench reactor at GE-CRD. The cross sectional area of the reactor was divided into four quadrants, and each quadrant was filled with a different sorbent formulation. In this way, all four formulations were exposed for the same period of time to the same flow rates, gas compositions, and baseline temperatures during the test.

Target conditions for desulfurization bench tests that apply to any sorbent under development are summarized in Table 3-14. As much as possible, these bench test conditions are expected to approximate the design steady-state operation of the TECo moving-bed demonstration plant. However, laboratory or bench reactor systems operating under fixed-bed configurations may not be able to satisfy simultaneously all the conditions of a large-scale moving-bed system. Two major exceptions were taken in the laboratory testing protocol: the outlet $\mathrm{H}_{2} \mathrm{~S}$ at TECo is expected to be less than $50 \mathrm{ppmv}$ at steady state rather than the $200 \mathrm{ppm}$ breakthrough level, and the absorption pressure at TECo will be $30 \mathrm{~atm}$ instead of $20 \mathrm{~atm}$.

Typical test conditions maintained during screening in the bench-scale reactor at CRD are presented in Table 3-15. At the end of the multiple cycles, typically five cycles of absorption and regeneration, the sorbent was removed from the reactor and the ASTM D-4058-81 attrition test performed on samples in each of the quadrants. By following this procedure, data were collected on the composite desulfurization performance (i.e., the $\mathrm{H}_{2} \mathrm{~S}$ breakthrough curves) and individual mechanical durability of each of the sorbents.

Table 3-14. Target test conditions during absorption in bench tests

\begin{tabular}{l|c}
\hline Parameter & Operating Condition \\
\hline Desired Sorbent Sulfur Loading & $96.2 \mathrm{~g} \mathrm{~S} /$ liter of bed $\left(6-7 \mathrm{lb} . \mathrm{S} / \mathrm{ft}^{3}\right.$ of bed $)$ \\
& at the gas inlet location \\
$\mathrm{H}_{2} \mathrm{~S}$ Breakthrough point & $200 \mathrm{ppm}$ \\
Gas space velocity & $\geq 2000 \mathrm{hr}^{-1}(\mathrm{STP})^{*}$ \\
Pressure & $20 \mathrm{~atm}$ \\
Temperature & $482^{\circ} \mathrm{C}\left(900{ }^{\circ} \mathrm{F}\right)$ \\
\hline
\end{tabular}

* STP (standard temperature and pressure) is defined at $20{ }^{\circ} \mathrm{C}$ and $1 \mathrm{~atm}$. 
The reactor bed typically accommodated up to 0.51 of sorbent. In the so-called quadrant tests, the bed volume was adjusted to obtain the desired gas space velocity, meet the requirement of sulfur loading at the gas inlet location, meet the $200 \mathrm{ppmv}$ breakthrough in a reasonable time $(<5 \mathrm{hr})$, and meet the current test schedule for screening. Test conditions during absorption (Table 3-15) followed the TECo guidelines for bench tests (Table 3-14), except for the reduced pressure (5 atm at CRD vs. 20 atm for preferred bench tests and $30 \mathrm{~atm}$ at TECo) and definition of breakthrough ( $200 \mathrm{ppmv}$ in bench tests vs. less than $50 \mathrm{ppmv}$ in the TECo plant). The chosen reduced pressure during absorption is a result of limitations in the existing GE-CRD bench hardware; a preferred condition for bench tests is $20 \mathrm{~atm}$ during absorption. The definition of breakthrough at $200 \mathrm{ppm}$ rather than at $50 \mathrm{ppm}$ was selected for ease of measurement and for historical comparisons. Regeneration was conducted at 5 atm and between $482^{\circ} \mathrm{C}$ and $760{ }^{\circ} \mathrm{C}$. The acceptable regeneration pressure range is 5 to $7 \mathrm{~atm}$.

Two quadrant bench tests, for a total of 8 formulations, were performed as presented in Table 3-16. In addition to the five new formulations prepared during 1997 at UCI, an old formulation from 1995, T$2565 \mathrm{M}$, was loaded in the quadrant test \#2 to be able to compare old and new methods of fabrication.

Figure 3-38 presents the composite $\mathrm{H}_{2} \mathrm{~S}$ breakthrough curves for four formulations in the quadrant bench test \#1 (formulations MZT-I1, MZT-G1, MZT-O1, and MZT-R1). The only potential difference in test conditions is that each sorbent may produce a different temperature rise above the baseline during regeneration, which would be characteristic to each sorbent; however, the exposure time was the same for all four sorbents in both absorption and regeneration modes.

Typical temperatures during regeneration during the first quadrant bench Test \#1 are presented in Figure 3-39. The three temperatures shown correspond to the gas inlet, middle section, and gas outlet locations of each of the quadrants in the reactor bed. At time zero the oxygen and $\mathrm{SO}_{2}$ were introduced to the bed. As the exothermic regeneration started and the temperatures rose by $28^{\circ} \mathrm{C}\left(50^{\circ} \mathrm{F}\right)$, the set point in the heating furnace was increased to $621^{\circ} \mathrm{C}\left(1150^{\circ} \mathrm{F}\right)$ to simulate the adiabatic operation of a

Table 3-15. Test conditions in the GE-CRD reactor system during quadrant bench tests

\begin{tabular}{|c|c|c|c|c|}
\hline Test Gas Composition & Absorption & $\begin{array}{c}\text { Reductive } \\
\text { Regeneration }\end{array}$ & $\begin{array}{c}\text { Oxidative } \\
\text { Regeneration }\end{array}$ & Nitrogen Purge \\
\hline $\mathrm{CO}$ & 38.6 & 39.0 & & \\
\hline $\mathrm{CO}_{2}$ & 5.7 & 5.7 & & \\
\hline $\mathrm{H}_{2}$ & 34.7 & 35.1 & & \\
\hline $\mathrm{H}_{2} \mathrm{O}$ & 20.0 & 20.2 & & \\
\hline $\mathrm{H}_{2} \mathrm{~S}$ & 1.0 & & & \\
\hline $\mathrm{O}_{2}$ & & & $2-5 \%$ & \\
\hline $\mathrm{SO}_{2}$ & & & $8 \%$ & \\
\hline $\mathrm{N}_{2}$ & & & balance & \\
\hline Pressure, atm & $5 \mathrm{~atm}$ & $5 \mathrm{~atm}$ & $5 \mathrm{~atm}$ & $1-5 \mathrm{~atm}$ \\
\hline Sorbent Bed & $482{ }^{\circ} \mathrm{C}$ & $482{ }^{\circ} \mathrm{C}$ & $482-704{ }^{\circ} \mathrm{C}$ & \\
\hline Temperature & & & & \\
\hline $\begin{array}{l}\text { Space velocity } \\
\left(\mathrm{STP}, 25^{\circ} \mathrm{C}, 1 \mathrm{~atm}\right)\end{array}$ & $2000 \mathrm{~h}^{-1}$ & $2000 \mathrm{~h}^{-1}$ & $1000 \mathrm{~h}^{-1}$ & $750 \mathrm{~h}^{-1}$ \\
\hline Reaction time, min & $120 \mathrm{~min}$ & $60 \mathrm{~m}$ in & $180 \mathrm{~min}$ & \\
\hline
\end{tabular}


Table 3-16. Formulations loaded into bench quadrant tests at GE-CRD

\begin{tabular}{cc}
\hline Quadrant bench test \#1 & Quadrant bench test \#2 \\
\hline MZT-G1 & MZT-P1 \\
MZT-O1 & T-2564M \\
MZT-R1 & MZT-R1 \\
MZT-I1 & MZT-I1 \\
\hline
\end{tabular}

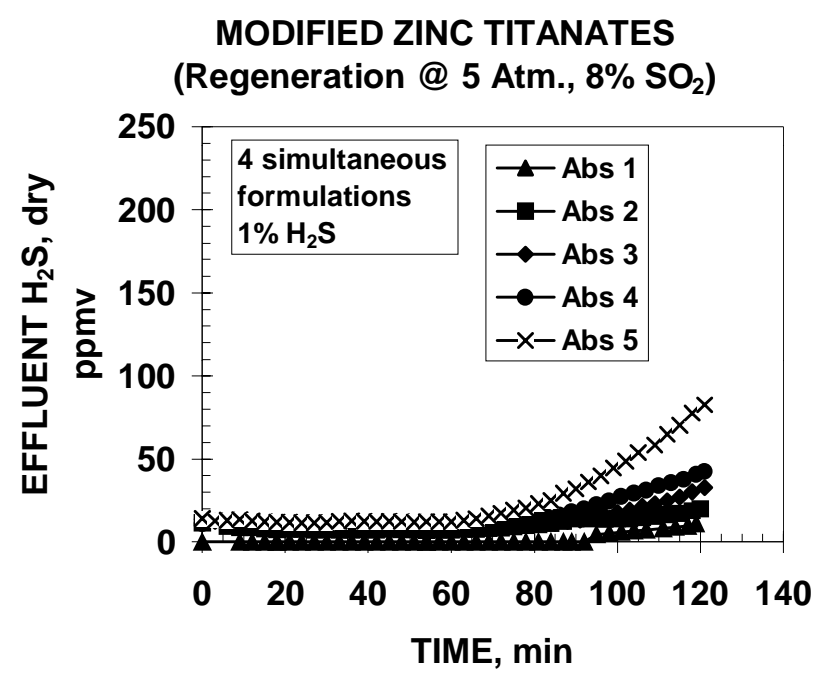

Figure 3-38. Breakthrough curves during absorption for the modified zinc titanate sorbents (Quadrant Bench Test \#1)

larger scale pilot plant system, where radiation towards the walls from the center of the bed is small due to the presence of the surrounding pellets that also undergo oxidation at the same time. Note that a temperature rise was observable at $482^{\circ} \mathrm{C}$ (gas inlet location). Because of the location of the heating elements in the bench furnace, the gas outlet location always runs cooler at about $462^{\circ} \mathrm{C}$. Most peak temperatures were maintained below $704^{\circ} \mathrm{C}\left(1300^{\circ} \mathrm{F}\right)$. As far as we can tell, there is no significant difference among the temperature profiles for each of the formulations from cycle 1 to cycle 5: all maximum temperatures were maintained below $704^{\circ} \mathrm{C}$. 

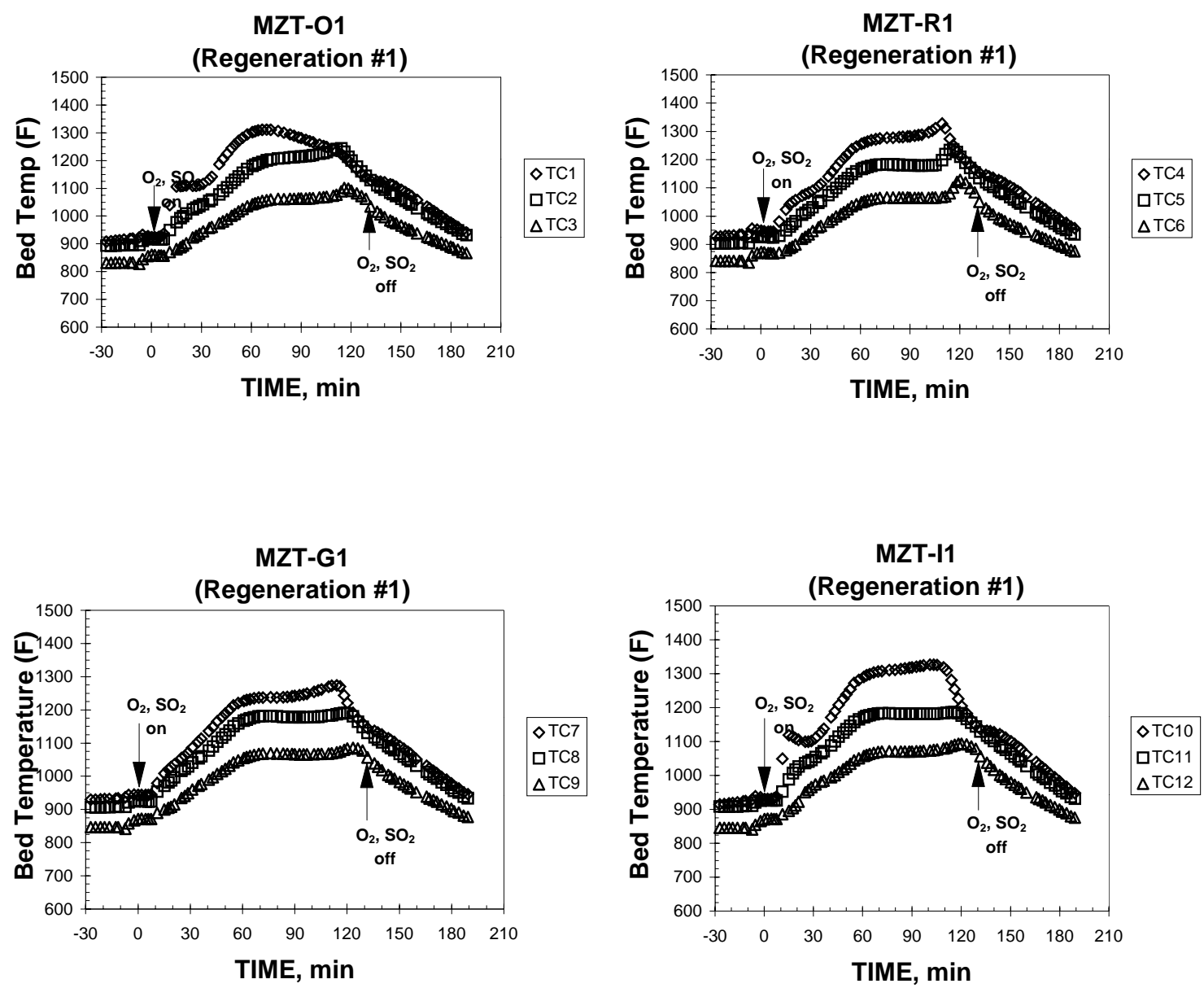

Figure 3-39. Temperatures profiles for the four sorbents tested under the Quadrant Bench Test \#1.

The corresponding temperature profiles for MZT-I1 and MZT-R1 for the quadrant bench test \#2 are shown in Figure 3-40 for the first (top) and fifth (bottom) regenerations. All regeneration profiles are similar in shape and suggest that the regeneration rates shown are within the requirements for regeneration of all formulations tested.

As a last issue on desulfurization performance of MZT's, we needed to compare the relative desulfurization rate of the modified zinc titanates (Figure 3-38) with respect to a prior baseline T-2594M zinc titanate formulation tested in the pilot plant (Figure 3-41). Figure 3-41 is the plot of corresponding breakthrough curves for the molybdenum-doped T-2594M zinc titanate at similar conditions of bench tests using $8 \% \mathrm{SO}_{2}$ in the regeneration. The breakthrough sulfur capacity of MZT's is higher than that of T-2594M, suggesting an improvement in the formulation performance. Figure 3-42 shows again the corresponding operation of the same T-2594M in the GE moving-bed pilot plant Test \#8 (September 1995 ) when the sorbent desulfurization performance (99\% sulfur removal) was satisfactory in both in bench tests and actual pilot plant operation. 
MZT-I1

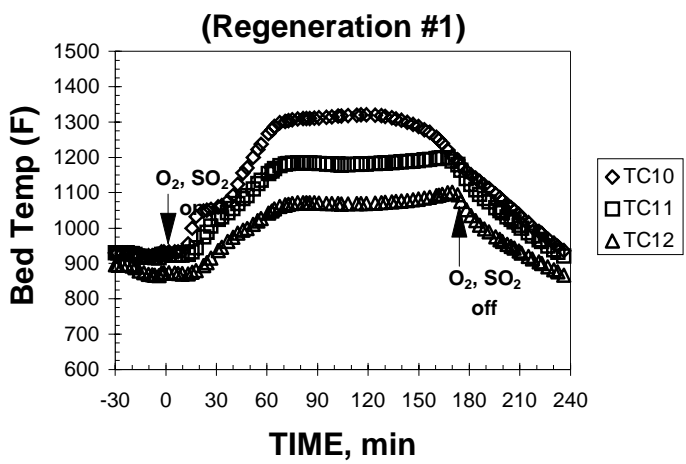

MZT-I1

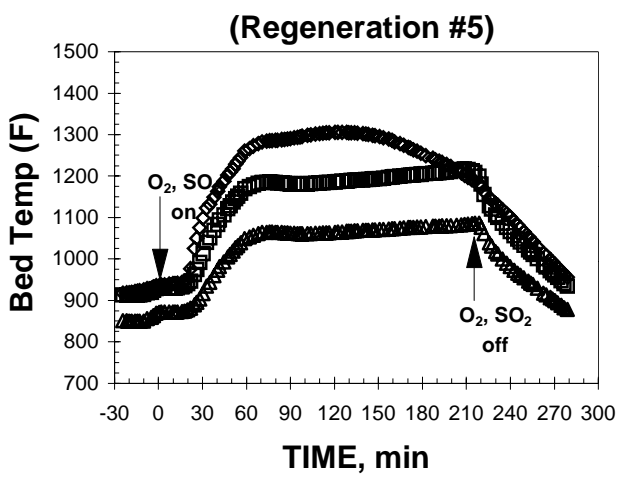

MZT-R1

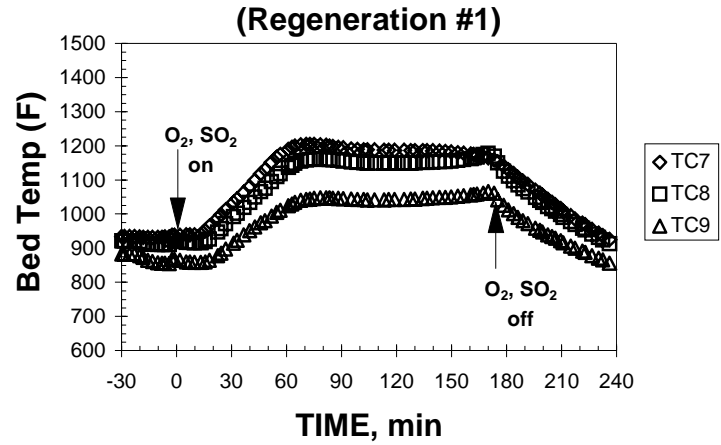

MZT-R1

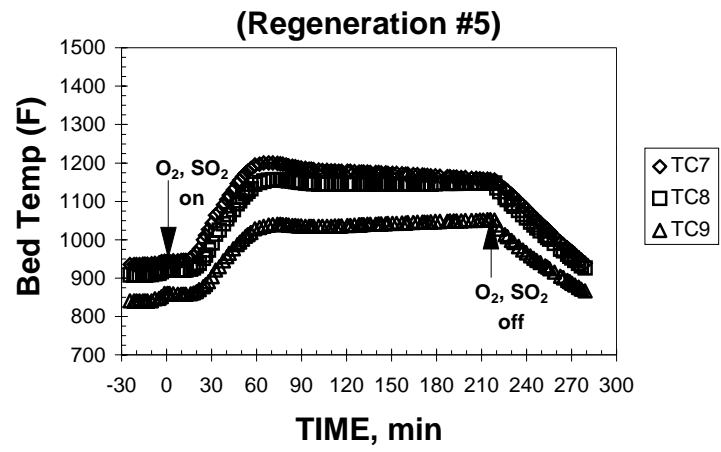

Figure 3-40. Temperatures profiles for the four sorbents tested under the Quadrant Bench Test \#1.

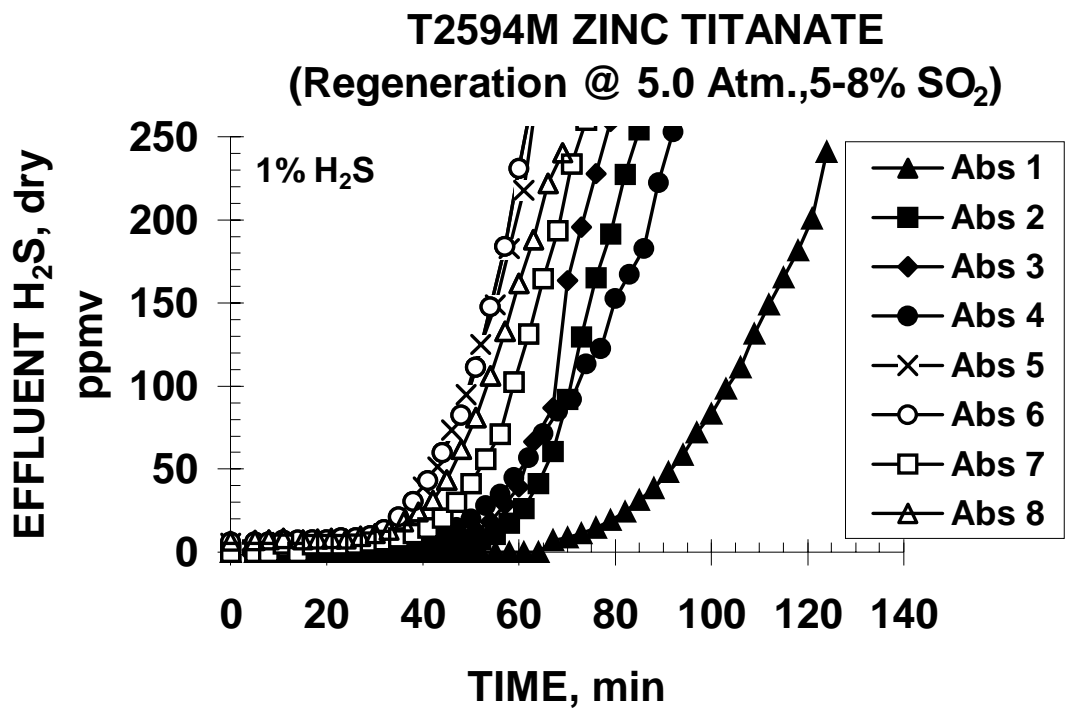

T2594r3.xls

Figure 3-41. Breakthrough curves for T-2594M zinc titanate with regeneration at $5 \mathrm{~atm}$ and $8 \% \mathrm{SO}_{2}$ in the regeneration gas 


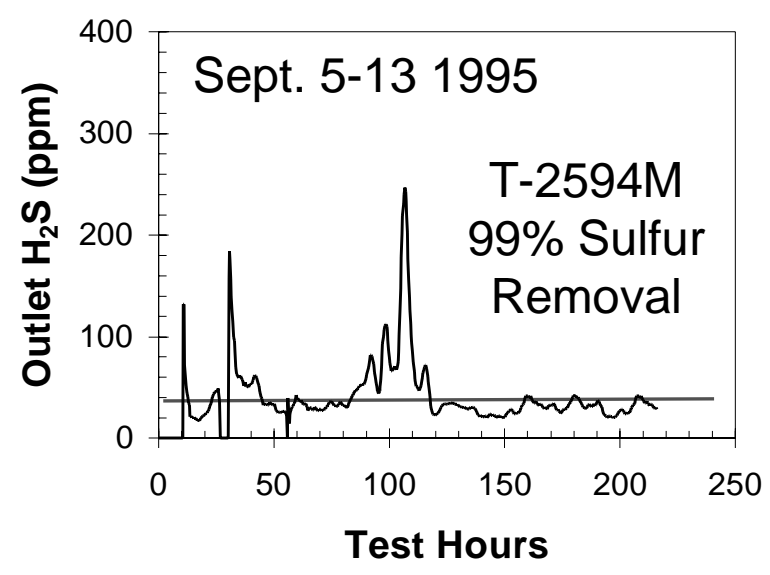

Figure 3-42. Outlet $\mathrm{H}_{2} \mathrm{~S}$ concentration from the pilot plant absorber using T-2594M during Test 8 (1995)

Since T-2594M had satisfactory desulfurization in the pilot plant absorber (99\% desulfurization efficiency, Figure 3-42), we can expect improved performance of the modified zinc titanates over T$2594 \mathrm{M}$ in pilot plant tests. The conclusion from the testing of pelletized MZT's is that an improvement in desulfurization kinetics was achieved in the laboratory over previous zinc titanates and this improvement could be expected to carry over to larger-scale systems.

\subsection{Mechanical durability of cycled formulations}

Table 3-17 presents the results of attrition and residual sulfide and sulfate on cycled sorbents after the $5^{\text {th }}$ regeneration for the four formulations tested in the quadrant bench test \#1 (formulations MZT-I1, MZT-G1, MZT-O1, and MZT-R1). Figure 3-43 presents the corresponding attrition results as attrition ratios. The attrition ratio is defined as the percent ASTM attrition loss in the final state $\left(5^{\text {th }}\right.$ regeneration) divided by the ASTM percent attrition loss in the fresh state. Samples were taken from the gas inlet location, where the highest sulfidation and regeneration levels are experienced by the sorbent. In addition, the corresponding attrition ratio for the baseline T-2594M is presented also. The attrition ratio was used in the chart to highlight the relative degradation of the pellets. For instance, an attrition ratio of 1.0 represents no degradation in the sorbent over the test duration. An attrition ratio less than 1 means that the sorbent became stronger in its final state while an attrition ratio greater than 1 means that the

Table 3-17. Attrition and sulfur results on 5th regeneration samples from quadrant bench test \#1

\begin{tabular}{ccccc}
\hline & MZT-O1 & MZT-R1 & MZT-G1 & MZT-I1 \\
\hline Attrition-Fresh & $0.91 \%$ & $2.0 \%$ & $2.5 \%$ & $1.96 \%$ \\
Attrition After 5 cycles & $1.53 \%$ & $2.0 \%$ & $2.74 \%$ & $1.83 \%$ \\
Sulfide Sulfur Content & $<0.1 \%$ & $<0.1 \%$ & $<0.1 \%$ & $<0.1 \%$ \\
Sulfate Sulfur Content & $2.90 \%$ & $0.22 \%$ & $3.80 \%$ & $0.23 \%$ \\
\hline
\end{tabular}




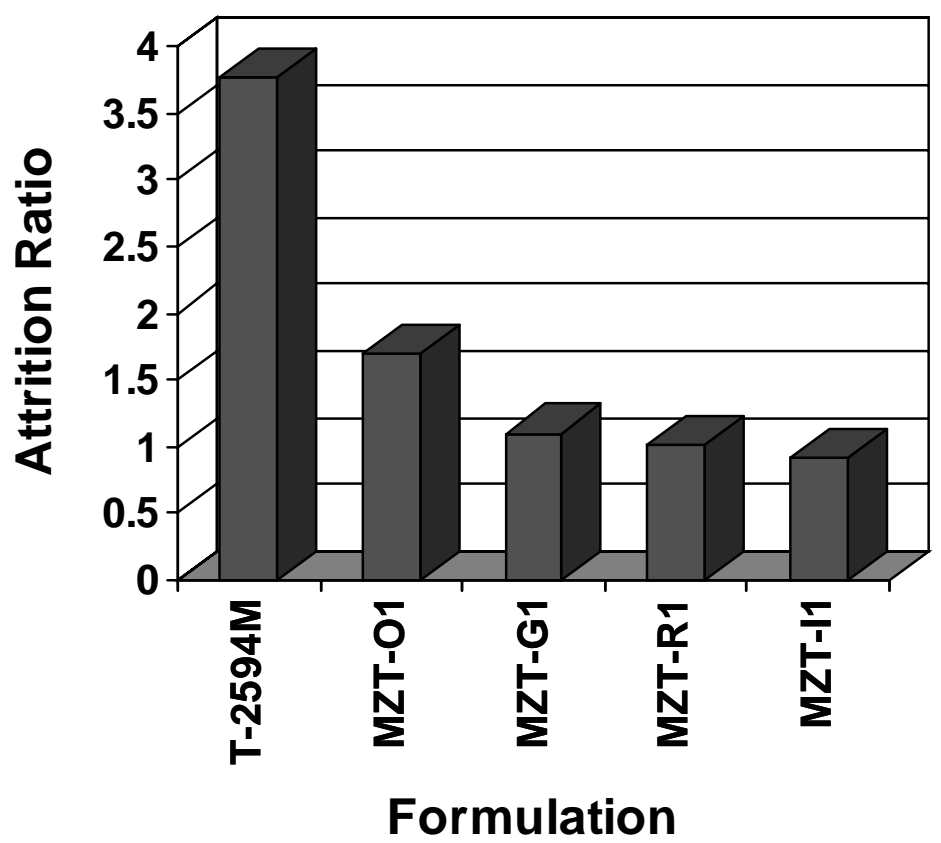

Figure 3-43. Attrition resistance ratios of zinc titanate formulations after 5 cycles of bench-scale testing (Quadrant Bench Test \#1)

sorbent experienced a degradation (i.e., weakening) in attrition resistance. The absolute values of the ASTM attrition losses were in the range 1 to $2.7 \%$.

A second quadrant bench test was also performed on a different batch of each of the formulation compositions MZT-I1 and MZT-R1 along with a sample of the baseline T-2594M zinc titanate and a zinc titanate without additives, MZT-P1 (Table 3-18). In addition to attrition measurements, sulfur measurements by TGA at GE and at Commercial Testing and Engineering (CTE) are presented in the same table. This second batch of MZT-I1 and MZT-R 1 behaved quite differently from the first batch tested in quadrant test\#1 (Table 3-17). Even though the attrition ratios of the MZTs were again lower than those of the base formulation T-2594M, the magnitude of the values for the batches used in the quadrant bench test \#2 was higher than those for batches in quadrant bench test\#1. A similar behavior was observed in the scaling up of fabrication of molybdenum-containing zinc titanates. After discussions with UCI, it was concluded that variations from batch to batch in the production process had repercussions in the sorbent's ability to maintain its mechanical strength during testing.

Table 3-18. Attrition and sulfur results on 5th regeneration samples from quadrant bench test \#2

\begin{tabular}{ccccc}
\hline & MZT-P1 & T2594M & MZT-R1 & MZT-I1 \\
\hline Attrition-Fresh & $1.0 \%$ & $0.46 \%$ & $2.0 \%$ & $2.0 \%$ \\
Attrition After 5 cycles & $5.23 \%$ & $2.64 \%$ & $7.08 \%$ & $8.19 \%$ \\
Sulfide Sulfur Content & $<0.1 \%$ & $2.74 \%$ & $1.54 \%$ & $0.45 \%$ \\
& & & $(1.45 \%$ CTE $)$ & $(0.93 \%$ CTE $)$ \\
Sulfate Sulfur Content & $4.95 \%$ & $2.66 \%$ & $4.35 \%$ & $4.0 \%$ \\
& & & $(4.85 \%$ CTE $)$ & $(4.33 \%$ CTE) \\
\hline
\end{tabular}


The main conclusion of the mechanical durability tests of MZT's is that the mechanical durability of the top formulations is approaching targets for commercial operation. However, fabrication variability from batch to batch of the same formulation suggests that more work is needed to understand the pelletization factors that contribute to sustainable durability over extended testing. The chemistry of desulfurization and regeneration is well understood, but the quality control of the pelletization process should still be improved. The best two formulations, MZT-R1 and MZT-I1, were considered for further testing in 25cycle bench tests at RTI as part of the qualification of sorbents for TECo's $2^{\text {nd }}$ sorbent fill.

\subsection{Bench-scale extended multicycle tests at GE-CRD}

Following the five-cycle quadrant tests at GE-CRD, 17 cycles of normal bench tests at GE-CRD were run on sorbent MZT-I1 in an attempt to determine best operating conditions for regeneration of the sorbent in the desired temperature range. These tests were performed after the results of the screening in quadrant tests were analyzed. Figure 3-44 and Figure 3-45 present the $\mathrm{H}_{2} \mathrm{~S}$ in the bed effluent as a function of time for 17 cycles on MZT-I1, and Table 3-19 shows the corresponding history of the sorbent operating conditions for absorption and regeneration. Given that it is somewhat difficult to see the trends in $\mathrm{H}_{2} \mathrm{~S}$ from cycle to cycle, the results are also plotted as the envelope of the $\mathrm{H}_{2} \mathrm{~S}$ concentrations at $2 \mathrm{hr}$ (120 min) of operation in Figure 3-46. Note that absorptions 7, 9, and 11 were very low in effluent $\mathrm{H}_{2} \mathrm{~S}$, suggesting a reversal of the upward trend seen in other cycles. This reversal is a result of the higher temperature of operation, $732^{\circ} \mathrm{C}\left(1350^{\circ} \mathrm{F}\right)$, in the previous regeneration (Table 3-19). As mentioned above, there is a very strong correlation in the maximum average temperature of regeneration $\left(732^{\circ} \mathrm{C}\right.$ ) and the subsequent $\mathrm{H}_{2} \mathrm{~S}$ concentration at 120 minutes of absorption. Each of the three regenerations where the bed temperature was allowed to rise and stay at $732{ }^{\circ} \mathrm{C}$ resulted in a lower $\mathrm{H}_{2} \mathrm{~S}$ in the following absorption.

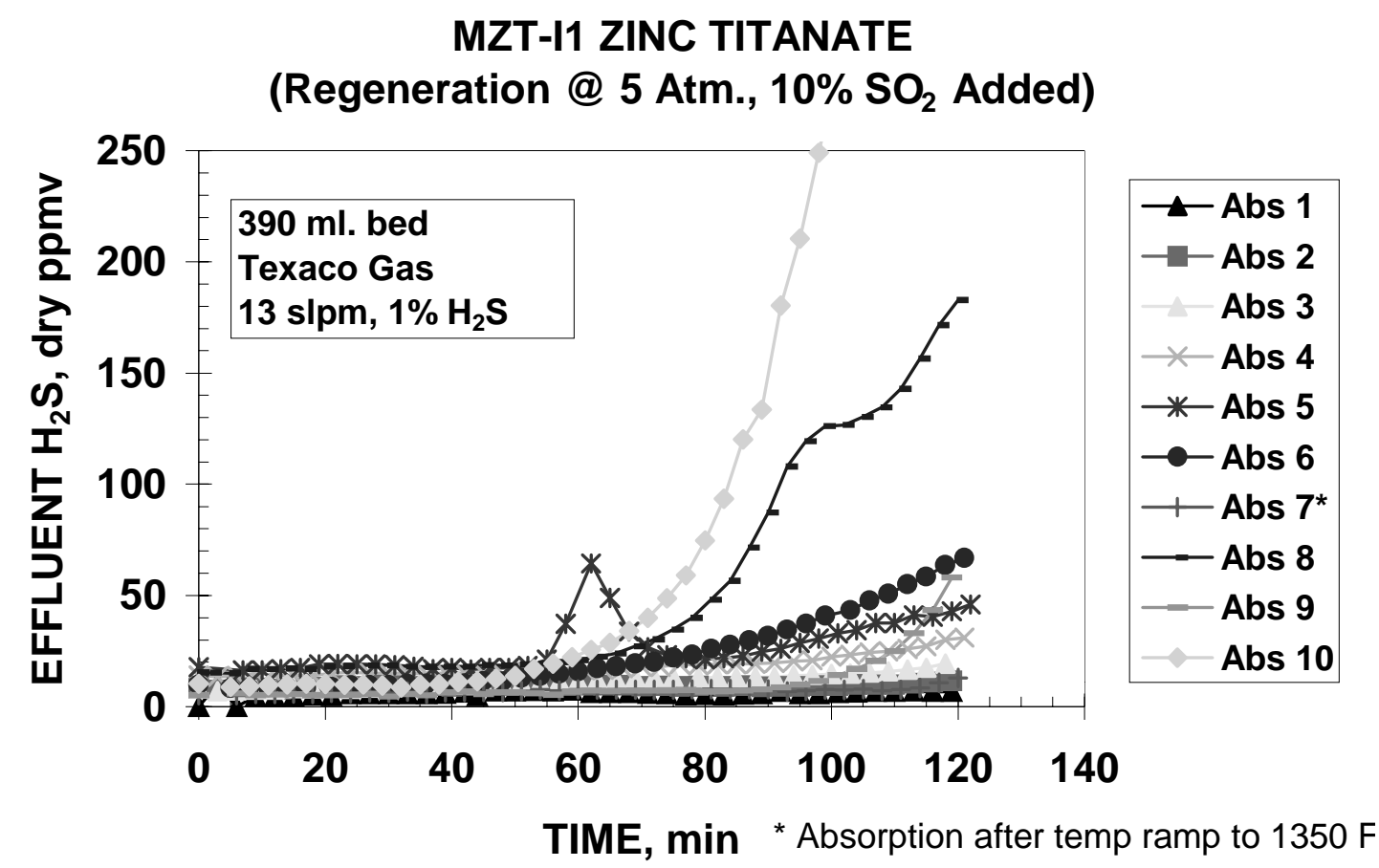

Figure 3-44. Breakthrough curves of MZT-I1 for the first 10 cycles of screening 


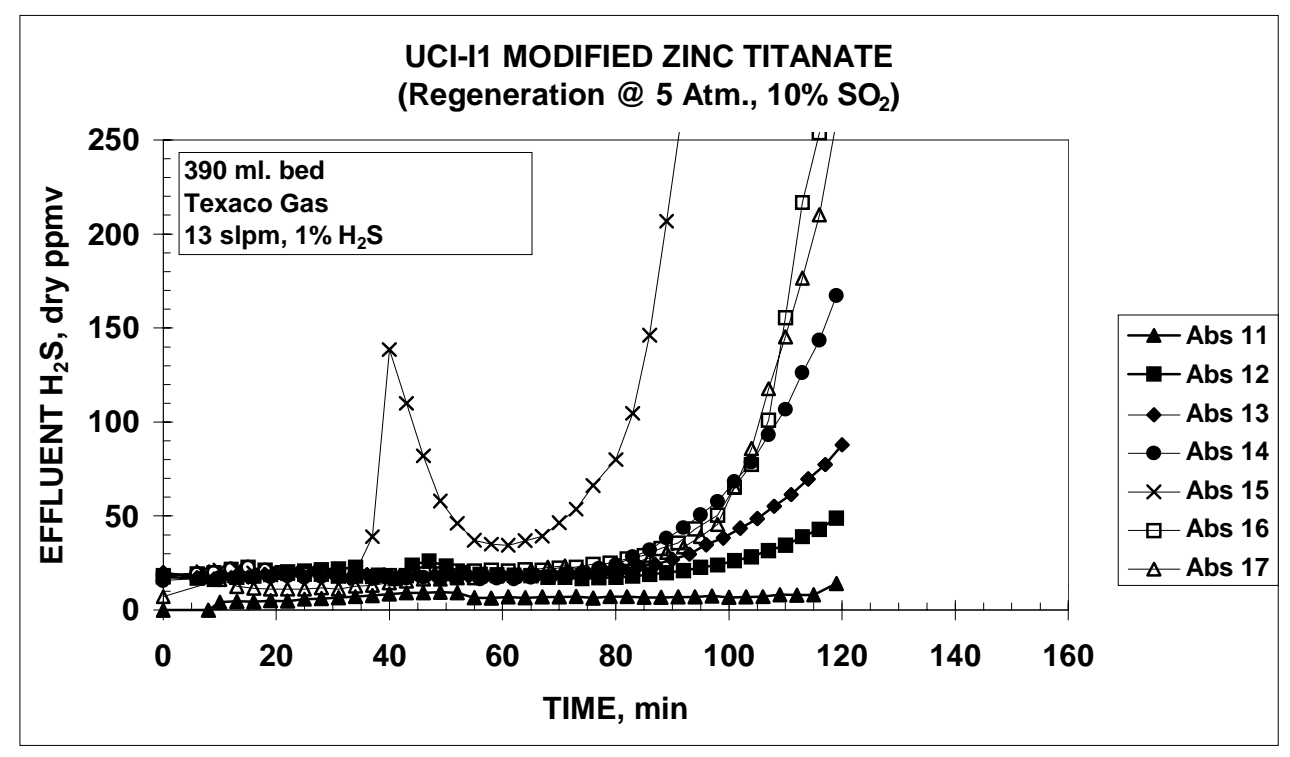

Figure 3-45. Breakthrough curves of MZT-I1 after the first 10 cycles of screening

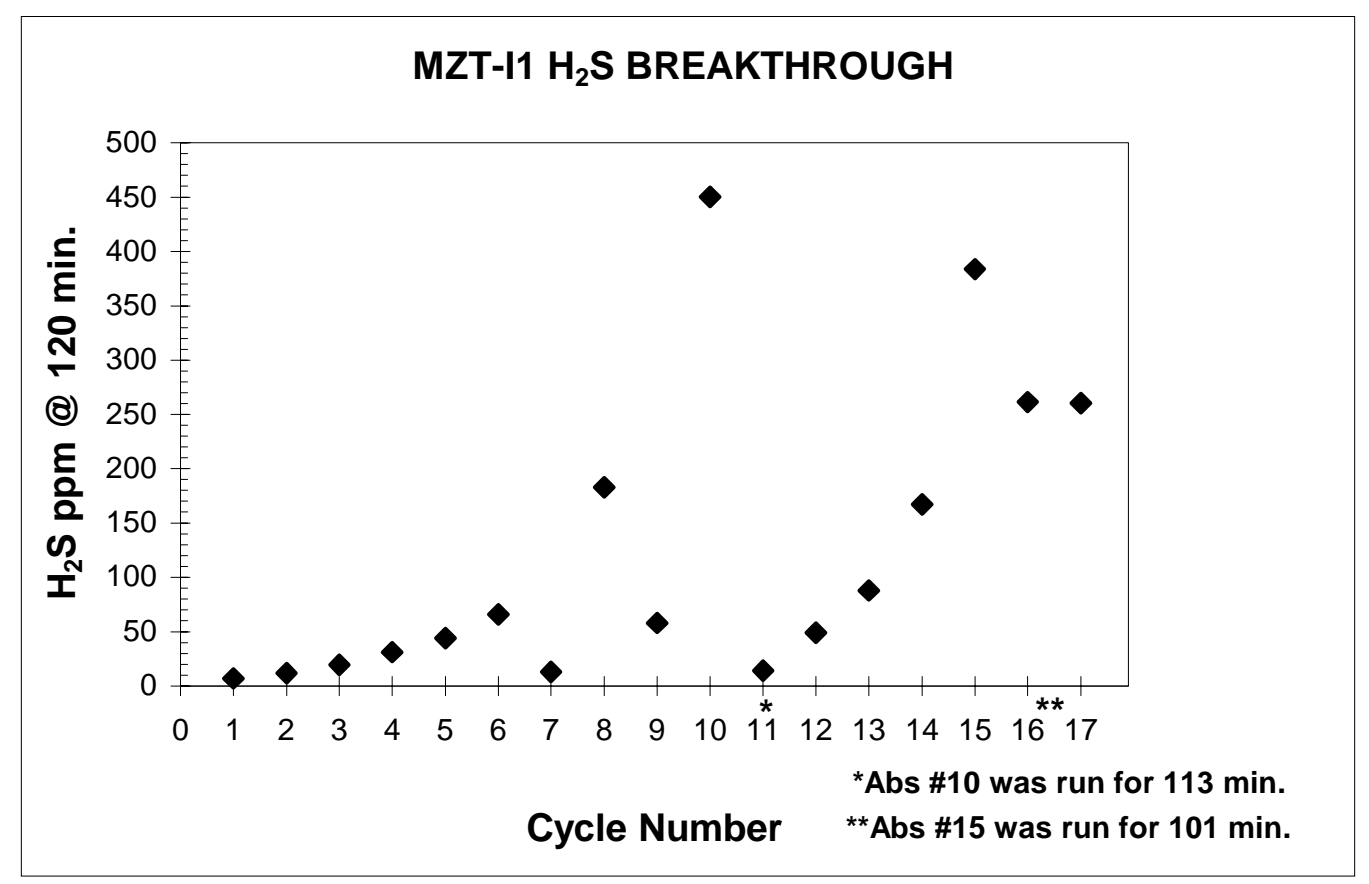

Figure 3-46. Envelope of the breakthrough curves at $120 \mathrm{~min}$ of absorption for MZT-I1 
Table 3-19. Bench-scale extended testing of MZT-I1

\begin{tabular}{|l|c|c|c|c|c|c|}
\hline \multicolumn{1}{|c|}{ Cycle } & $\mathbf{1}$ & $\mathbf{2}$ & $\mathbf{3}$ & $\mathbf{4}$ & $\mathbf{5}$ & $\mathbf{6}$ \\
\hline SULFIDATION & & & & & & \\
\hline $\begin{array}{l}\text { Reductive Regeneration } \\
\text { Duration (min.) }\end{array}$ & 26 & 60 & 60 & 60 & 60 & 60 \\
\hline Temperature $\left({ }^{\circ} \mathrm{C}\right)$ & & & & & & \\
\hline Pressure (atm) & 482 & 482 & 482 & 482 & 482 & 482 \\
\hline Space Velocity $\left(\mathrm{hr}^{-1}\right)$ & 5 & 5 & 5 & 5 & 5 & 5 \\
\hline Inlet $\mathrm{H}_{2}$ S Concentration (ppmv) & 2,000 & 2,000 & 2,000 & 2,000 & 2,000 & 2,000 \\
\hline $\mathrm{H}_{2}$ S Exposure Time (min.) & 10,000 & 10,000 & 10,000 & 10,000 & 10,000 & 10,000 \\
\hline REGENERATION & 120 & 120 & 120 & 120 & 120 & 120 \\
\hline Temperature $\left({ }^{\circ} \mathrm{C}\right)$ & & & & & & \\
& $482-$ & $482-$ & $482-$ & $482-$ & $482-$ & $482-$ \\
\hline Time of Regeneration(min.) & 621 & 621 & 621 & 635 & 649 & 649 \\
\hline Temp Ramp to $732{ }^{\circ} \mathrm{C}$ & 172 & 232 & 245 & 253 & 259 & 230 \\
\hline Pressure $($ atm) & no & no & no & no & no & yes \\
\hline Space Velocity (hr $\left.{ }^{-1}\right)$ & 1,000 & 1,000 & 1,000 & 1,000 & 1,000 & 1,000 \\
\hline $\mathrm{O}_{2}$ Concentration $($ vol\%) in Feed & $5-2.5$ & $5-2.5$ & $5-2.5$ & $5-2.5$ & $5-2.0$ & $5-2.0$ \\
\hline SO $_{2}$ concentration (vol\%) in Feed & 10 & 10 & 10 & 10 & 10 & 10 \\
\hline
\end{tabular}

\begin{tabular}{|l|c|c|c|c|}
\hline \multicolumn{1}{|c|}{ Cycle } & $\mathbf{7}$ & $\mathbf{8}$ & $\mathbf{9}$ & $\mathbf{1 0}$ \\
\hline SULFIDATION & & & & \\
\hline $\begin{array}{l}\text { Reductive Regeneration } \\
\text { Duration (min.) }\end{array}$ & 66 & 117 & 48 & 60 \\
\hline Temperature ( $\left.{ }^{\circ} \mathrm{C}\right)$ & & & & \\
\hline Pressure (atm) & 482 & 482 & 482 & 482 \\
\hline Space Velocity $\left(\mathrm{hr}^{-1}\right)$ & 5 & 5 & 5 & 5 \\
\hline Inlet $\mathrm{H}_{2}$ S Concentration (ppmv) & 2,000 & 2,000 & 2,000 & 2,000 \\
\hline $\mathrm{H}_{2} \mathrm{~S}$ Exposure Time (min.) & 10,000 & 10,000 & 10,000 & 10,000 \\
\hline REGENERATION & 120 & 120 & 120 & 113 \\
\hline Temperature $\left({ }^{\circ} \mathrm{C}\right)$ & $482-538$ & $482-649$ & $482-649$ & $482-649$ \\
\hline Time of Regeneration (min.) & 158 & 210 & 210 & 210 \\
\hline Temp Ramp to 732 ${ }^{\circ} \mathrm{C}$ & no & yes & no & no \\
\hline Pressure (psig) $^{-1}$ ) & 59 & 59 & 59 & 59 \\
\hline $\left.\mathrm{Space} \mathrm{Velocity} \mathrm{(hr}^{-1}\right)$ & 1,000 & 1,000 & 1,000 & 1,000 \\
\hline $\mathrm{O}_{2}$ Concentration (vol\%) in Feed & $5-2.5$ & $5-2.0$ & $5-2.0$ & $5-2.0$ \\
\hline $\mathrm{SO}_{2}$ concentration (vol\%) in Feed & 10 & 10 & 10 & 10 \\
\hline
\end{tabular}

\begin{tabular}{|l|c|c|c|c|c|}
\hline \multicolumn{1}{|c|}{ Cycle } & $\mathbf{1 3}$ & $\mathbf{1 4}$ & $\mathbf{1 5}$ & $\mathbf{1 6}$ & $\mathbf{1 7}$ \\
\hline SULFIDATION & & & & & 60 \\
\hline $\begin{array}{l}\text { Reductive Regeneration } \\
\text { Duration (min.) }\end{array}$ & 60 & 60 & 60 & 60 & 682 \\
\hline Temperature $\left({ }^{\circ} \mathrm{C}\right)$ & 482 & 482 & 482 & 482 & 482 \\
\hline Pressure(atm) & 5 & 5 & 5 & 5 & 5 \\
\hline Space Velocity $\left(\mathrm{hr}^{-1}\right)$ & 2,000 & 2,000 & 2,000 & 2,000 & 2,000 \\
\hline $\begin{array}{l}\text { Inlet } \mathrm{H}_{2} \mathrm{~S} \text { Concentration } \\
\text { ppmv) }\end{array}$ & 10,000 & 10,000 & 10,000 & 10,000 & 10,000 \\
\hline $\mathrm{H}_{2}$ S Exposure Time (min.) & 120 & 120 & 120 & 120 & 120 \\
\hline REGENERATION & & & & & \\
\hline Temperature $\left({ }^{\circ} \mathrm{C}\right)$ & $482-621$ & $482-621$ & $482-649$ & $482-649$ & $607-732$ \\
\hline Time of Regeneration(min.) & 145 & 232 & 245 & 253 & 259 \\
\hline Temp Ramp to 732 ${ }^{\circ} \mathrm{C}$ & no & no & no & no & no \\
\hline Pressure (psig) & 59 & 59 & 59 & 59 & 59 \\
\hline Space Velocity (hr $^{-1}$ ) & 2,000 & 1,000 & 1,000 & 1,000 & 1,000 \\
\hline $\begin{array}{l}\mathrm{O}_{2} \text { Concentration (vol\%) in } \\
\text { Feed }\end{array}$ & $3-1.5$ & $5-3.0$ & $3-2.0$ & $3-2.0$ & $5-2.0$ \\
\hline $\begin{array}{l}\text { SO } \\
\text { Feed concentration (vol\%) in }\end{array}$ & 10 & 10 & 10 & 10 & 10 \\
\hline
\end{tabular}


These results of bench-scale testing of MZT-I1 were used as a basis for planning screening tests at Research Triangle Institute facilities to be discussed later. These screening tests were performed at higher pressure (20 atm) absorption and the same (5-7 atm) pressure regeneration as those performed at GE-CRD. Current hardware at GE-CRD precludes testing at pressures above 7 atm, so testing at RTI approximated more closely the absorption step at TECo at $30 \mathrm{~atm}$.

Before proceeding with the results of the extended testing at RTI, the data on desulfurization and regeneration of sorbents at lower temperatures near $370^{\circ} \mathrm{C}\left(700^{\circ} \mathrm{F}\right)$ will be presented next.

\subsection{Desulfurization and regeneration performance at $371{ }^{\circ} \mathrm{C}\left(700{ }^{\circ} \mathrm{F}\right)$ temperatures}

Part of the analysis of the long-term data for bench testing required data on operation at lower temperatures, namely absorption and regeneration as low as $371^{\circ} \mathrm{C}\left(700^{\circ} \mathrm{F}\right)$. To satisfy this requirement, a series of tests were performed where the absorption of $\mathrm{H}_{2} \mathrm{~S}$ and the regeneration of the sorbent were initiated at $371{ }^{\circ} \mathrm{C}$, simulating the startup operation of the TECO system. This simulation of low gas and sorbent temperature represents the case of cold startup at the large TECO system, where the temperatures of the piping and the temperatures of both the gas and the sorbent flowing into the reaction vessels may be lower than the design case of $900^{\circ} \mathrm{F}\left(482^{\circ} \mathrm{C}\right)$ and currently running at about $371^{\circ} \mathrm{C}\left(700^{\circ} \mathrm{F}\right)$. If proven, the inability of a sorbent to desulfurize and regenerate properly from the very first cycle at low temperatures would be a stumbling block for its consideration in the TECO HGCU system. In addition, any preconditioning necessary on a sorbent would cause significant difficulties to implement in large scale. Figure 3-47 shows the $\mathrm{H}_{2} \mathrm{~S}$ breakthrough curves at $700^{\circ} \mathrm{F}$ for the first and second absorptions of MZT-R1 sorbent. As the porosity of the sorbent increases after the first cycle, so does the reactivity of the sorbent bed. This behavior is common in many sorbents and is desirable for startup operations.

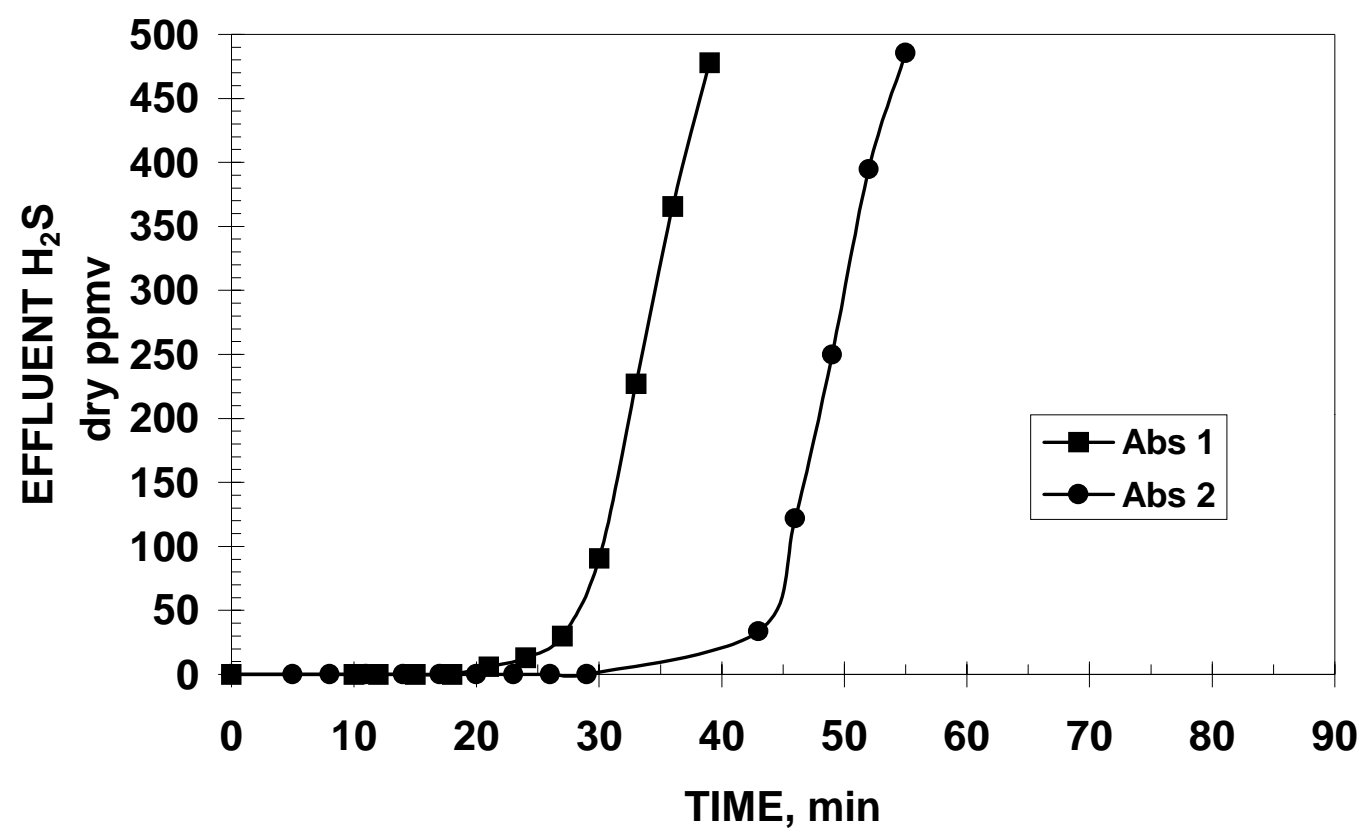

Figure 3-47. $\mathrm{H}_{2} \mathrm{~S}$ breakthrough curves for absorption by MZT-R1 at $371{ }^{\circ} \mathrm{C}\left(700{ }^{\circ} \mathrm{F}\right)$ 
When conducting absorption at $371^{\circ} \mathrm{C}\left(700^{\circ} \mathrm{F}\right)$, the bed reactivity is $1 / 2$ of that at $900{ }^{\circ} \mathrm{F}$ under the same conditions. The bed sulfur capacity is still the same. This means that operation with coal gas at 371 ${ }^{\circ} \mathrm{C}\left(70{ }^{\circ} \mathrm{F}\right)$ will require taking a lower flow of coal gas or moving sorbent at higher sorbent transfer rate to keep the outlet $\mathrm{H}_{2} \mathrm{~S}$ below acceptable limits. In practice, a combination of both techniques could be used to temporarily operate during startup and transient conditions.

Figure 3-48 shows the temperature profile of the first regeneration of MZT-R1 sorbent at $371{ }^{\circ} \mathrm{C}(700$ ${ }^{\circ} \mathrm{F}$ ) when the regenerant gas does not contain any recycled $\mathrm{SO}_{2}$. This condition of zero sulfur dioxide in the gas would be typical to the very early stages of startup, when the recycled gas has zero $\mathrm{SO}_{2}$ from the oxidation of zinc sulfide. Twenty minutes after the oxygen is added, the rate of reaction is high enough to produce an exotherm from $371^{\circ} \mathrm{C}\left(700^{\circ} \mathrm{F}\right)$ to about $593^{\circ} \mathrm{C}\left(1100^{\circ} \mathrm{F}\right)$. This exotherm of $222^{\circ} \mathrm{C}$ is sufficient to initiate the heating of the bed in the moving-bed system. In these laboratory tests, where there is no sorbent movement, the reaction exotherm starts to die out after 50 minutes. When added heat to the bed via the external heating furnace is provided, a second exotherm appears with a maximum temperature close to $805^{\circ} \mathrm{C}\left(1480^{\circ} \mathrm{F}\right)$. The observed regeneration rates in Figure 3-48 are sufficient to move a large-scale operation from startup at $371^{\circ} \mathrm{C}$ to steady-state operation at controlled temperature conditions in the range of $480-790^{\circ} \mathrm{C}$.

Figure 3-49 shows the equivalent regeneration temperature data for MZT-R1 for the case where 10\% $\mathrm{SO}_{2}$ was present in the regenerant gas and both the gas and sorbent temperatures were initially at 371 ${ }^{\circ} \mathrm{C}\left(700{ }^{\circ} \mathrm{F}\right)$. This condition of $10 \% \mathrm{SO}_{2}$ is representative of a transient operation when a temporary shutdown has allowed the gases and sorbent to cool off but the recycle gas continues to be circulated around the loop. Again, there is an initial exotherm where the sorbent rises in temperature from $371{ }^{\circ} \mathrm{C}$ $\left(700^{\circ} \mathrm{F}\right)$ to around $593^{\circ} \mathrm{C}\left(1100^{\circ} \mathrm{F}\right)$. This time, however, there is a slight delay in the onset of the first exotherm, and some temperatures in the middle of the bed (TC4) are still rising after 70 minutes.

Both cases show that this sorbent is capable of cold startup conditions at $371{ }^{\circ} \mathrm{C}\left(700^{\circ} \mathrm{F}\right)$ even in the presence of $10 \% \mathrm{SO}_{2}$ during regeneration. The actual reactor internal diameter is 2-7/8 in. instead of the standard $2 \mathrm{in}$. reactors used under other DOE tests, so that the actual linear velocity of the gas is $1 / 2$ of that in a standard bench reactor. The implication is that lower space velocities may be required during startup and transient operation of the regenerator to produce an exotherm and bring the system towards the higher temperature steady-state operation. Current large-scale systems like TECo do not have a lower limit constraint on the flow of gases to the regenerator so that the tests performed here can be translated directly to the larger systems.

Overall, cold startup of a large-scale system like TECo is possible using modified zinc titanates and lower space velocities to prevent premature breakthrough in the absorber and to maintain a temperature exotherm in the regenerator so that the system can be brought up to higher $\left(482^{\circ} \mathrm{C}\right)$ steady-state baseline operation. Sorbent MZT-R1 is particularly suited for lower temperature operation down to at least $371^{\circ} \mathrm{C}$. 


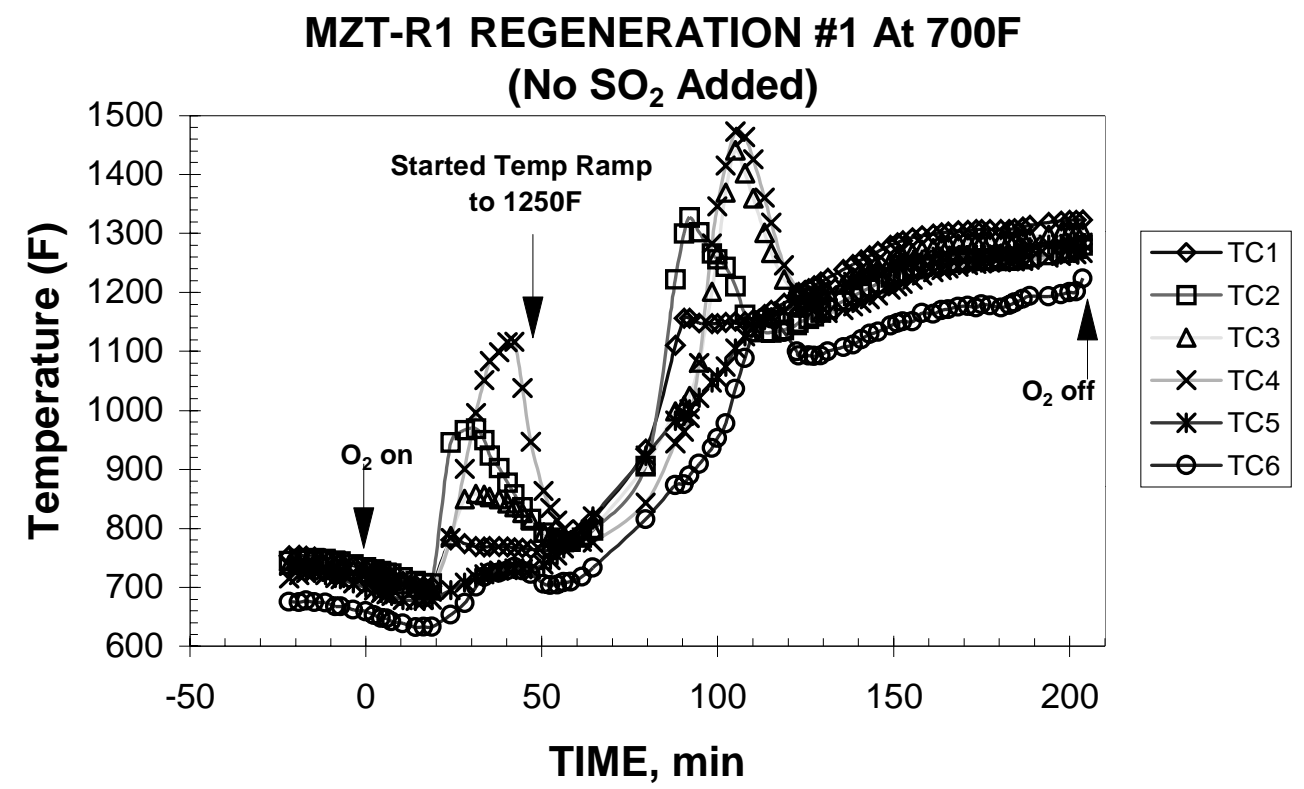

Figure 3-48. Temperature profiles during regeneration of MZT-R1 at $371{ }^{\circ} \mathrm{C}\left(700{ }^{\circ} \mathrm{F}\right)$ without any $\mathrm{SO}_{2}$

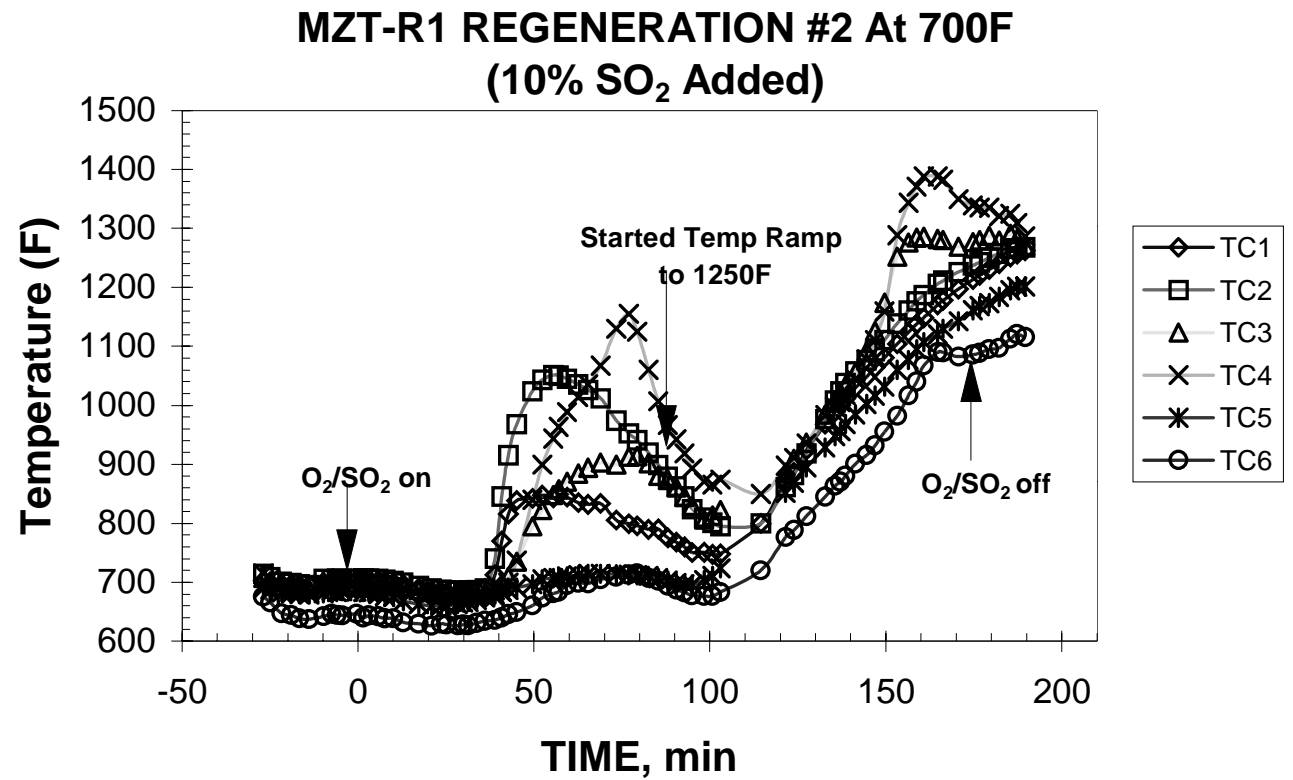

Figure 3-49. Temperature profiles during regeneration of MZT-R1 at $371{ }^{\circ} \mathrm{C}\left(700{ }^{\circ} \mathrm{F}\right)$ with $10 \% \mathrm{SO}_{2}$ added 


\subsubsection{RTI's Independent Bench Evaluation}

Given the satisfactory performance of two of the modified zinc titanate formulations, MZT-R1 and MZT-I1, during the screening process at GE-CRD, the two formulations were further screened in independent bench tests at Research Triangle Institute (RTI). One of them (MZT-R1) was further tested through 13 cycles of absorption and regeneration. Tests at RTI were under a separate DOE-sponsored program. Since the funding for the independent testing at RTI was not disbursed from this program but rather directly from DOE, only a summary of the major results will be given in this report.

By August 1997, MZT-R1 had undergone a preliminary 5-cycle screening test at RTI to check various operating conditions for the future long-term testing. Figure 3-50 presents the $\mathrm{H}_{2} \mathrm{~S}$ breakthrough curves during absorption at $20 \mathrm{~atm}$ for MZT-R1.

Figure 3-51 shows the corresponding curves for MZT-I1. Both sets of curves at 20 atm are comparable to those obtained at GE-CRD at 5-atm absorption during preliminary multiple cycle tests. Table 320 presents the results during the bench screening at RTI. MZT-I1 is a sorbent formulation that does not have additives for operation at lower temperatures around $371^{\circ} \mathrm{C}$. On the other hand, it exhibited higher mechanical strength. These preliminary results suggest that the modified zinc titanate formulations MZT-R1 and MZT-I1 are potential candidates for further evaluation in long-term tests. Both formulations were considered initially for screening tests at $382^{\circ} \mathrm{C}$. However, given that MZT-R1 showed better regenerability in screening tests at $371^{\circ} \mathrm{C}\left(700^{\circ} \mathrm{F}\right)$ at GE-CRD (Figure 3-49) and at RTI's preliminary scouting tests, MZT-R1 was chosen to test operation up to 25 cycles of bench testing.

A new larger batch sample was obtained from UCI for the tests at RTI. Reproducibility of the fabrication of MZT-R1 was somewhat questionable because the same formulation prepared under two small batches several months apart yielded results of $0.7 \%$ and $2.0 \%$ in ASTM attrition resistance. The batch-to-batch variability is significant compared to the typical range of attrition resistance measured in good fresh sorbents, about 1 to $4 \%$ attrition resistance.

Figure 3-52 shows the $\mathrm{H}_{2} \mathrm{~S}$ breakthrough curves for the 13 cycles performed at RTI. Testing was stopped at 13 cycles instead of 25 cycles to inspect the pellets and collect pellet samples. Even though the reactivity of the sorbent was still acceptable, some visual degradation of the mechanical properties was measured. Hairline cracks were observed in some of the pellets. Attrition resistance was over 10\% in some samples extracted from the bed, and hence, it was decided to discontinue testing until further analyses were available. The loss in mechanical durability was ascribed to these major areas:

- Batch-to-batch variability observed in the pelletization, as explained in the paragraphs above. In addition, variability within the batch also has an impact in the overall batch performance, particularly when attrition losses of about $1 \%$ are considered significant.

- The level of sulfate formation/decomposition during the testing. RTI's testing at $5 \mathrm{~atm}$ during regeneration is a more severe requirement on a sorbent than regeneration at lower pressures. Pore structure of the sorbent must be optimized to accommodate changes in the crystal structure between sulfidation and regeneration.

Overall, the testing at RTI showed that the two sorbents considered can desulfurize and regenerate at conditions resembling those to be encountered at the TECO plant, namely, desulfurization in the range $373-482^{\circ} \mathrm{C}\left(700-900^{\circ} \mathrm{F}\right)$ and regeneration up to $760^{\circ} \mathrm{C}\left(1400^{\circ} \mathrm{F}\right)$. Nonetheless, more work is 
MZT-R1 Scoping Test at RTI

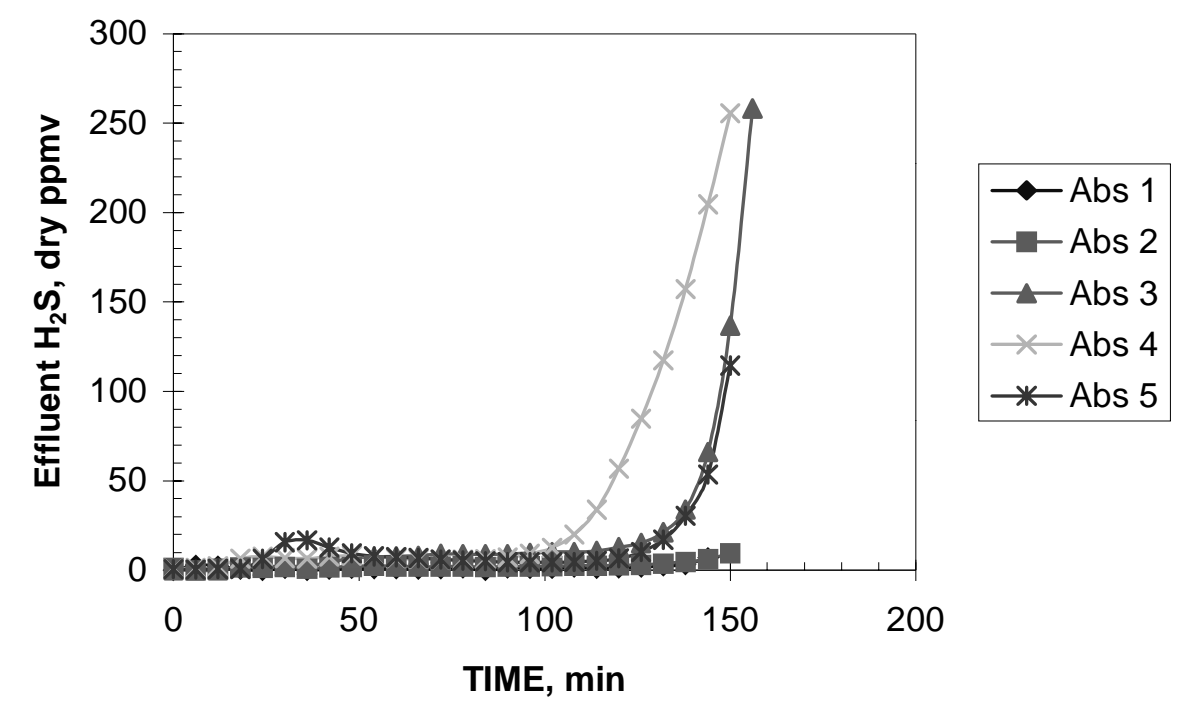

Figure 3-50. Breakthrough curves for MZT-R1 sorbent for 5 cycles in screening bench tests performed at RTI.

\section{MZT-I1 Scoping Test at RTI}

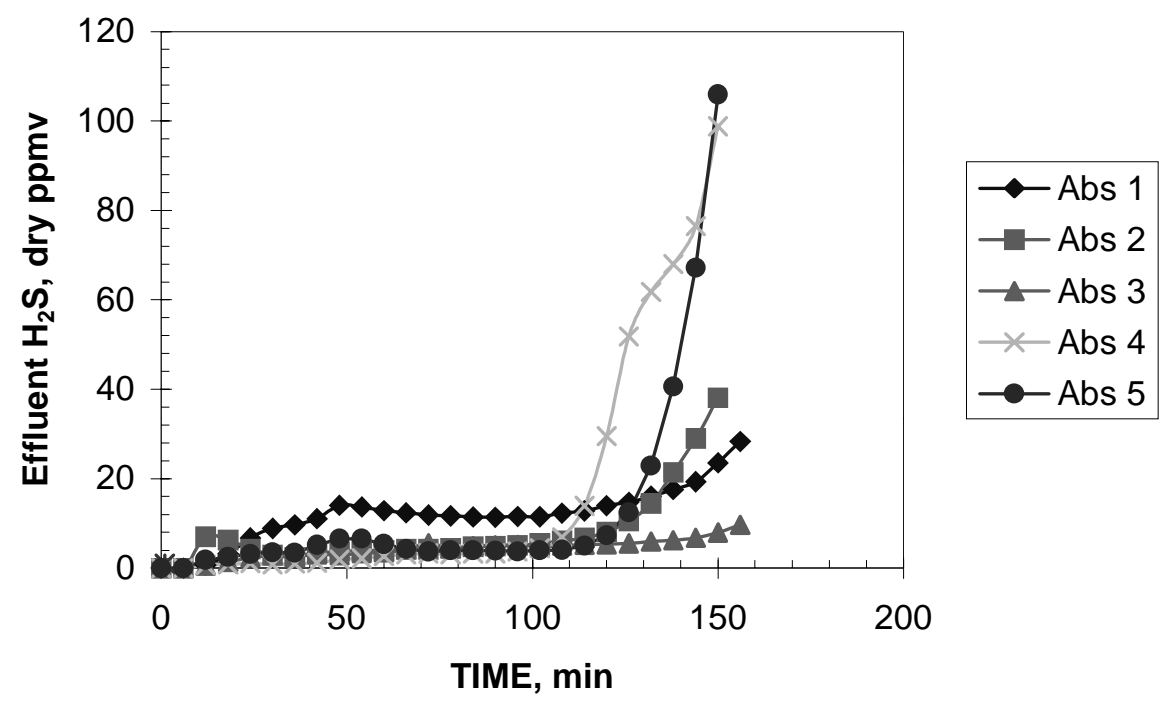

Figure 3-51. Breakthrough curves for MZT-I1 sorbent for 5 cycles in screening bench tests performed at RTI. 
Table 3-20. Preliminary results of screening tests at RTI on MZT-R1

\begin{tabular}{lcc}
\hline Parameter & 25-Cycle Bench Test Targets & Results after 5 cycles \\
\hline Absorption Temperature & $482{ }^{\circ} \mathrm{C}\left(900^{\circ} \mathrm{F}\right)$ & $482{ }^{\circ} \mathrm{C}\left(900^{\circ} \mathrm{F}\right)$ \\
Base Regeneration Temp. & $343-538^{\circ} \mathrm{C}$ & $482{ }^{\circ} \mathrm{C}\left(900^{\circ} \mathrm{F}\right)$ \\
& $\left(650-1000^{\circ} \mathrm{F}\right)$ & and $371{ }^{\circ} \mathrm{C}\left(700^{\circ} \mathrm{F}\right)$ \\
Reg. Pressure & $5-7 \mathrm{~atm}$ & $5 \mathrm{~atm}$ \\
Fresh ASTM attrition loss & $<4 \%$ & $2 \%$ \\
25-cycle ASTM attrition loss & $<5 \%$ & $\mathrm{~N} / \mathrm{A}$ \\
Net Sulfur Loading & $>0.11 \mathrm{~g} \mathrm{~S} / \mathrm{cc} \mathrm{bed}$ & $0.11 \mathrm{~g} \mathrm{~S} / \mathrm{cc}$ bed \\
& $\left(6.7 \mathrm{lb} . \mathrm{S} / \mathrm{ft}^{3} \mathrm{bed}\right)$ & $\left(6.7 \mathrm{lb} . \mathrm{S} / \mathrm{ft}^{3} \mathrm{bed}\right)$ \\
\hline
\end{tabular}

Breakthrough Curves for MZT-R1 Sorbent

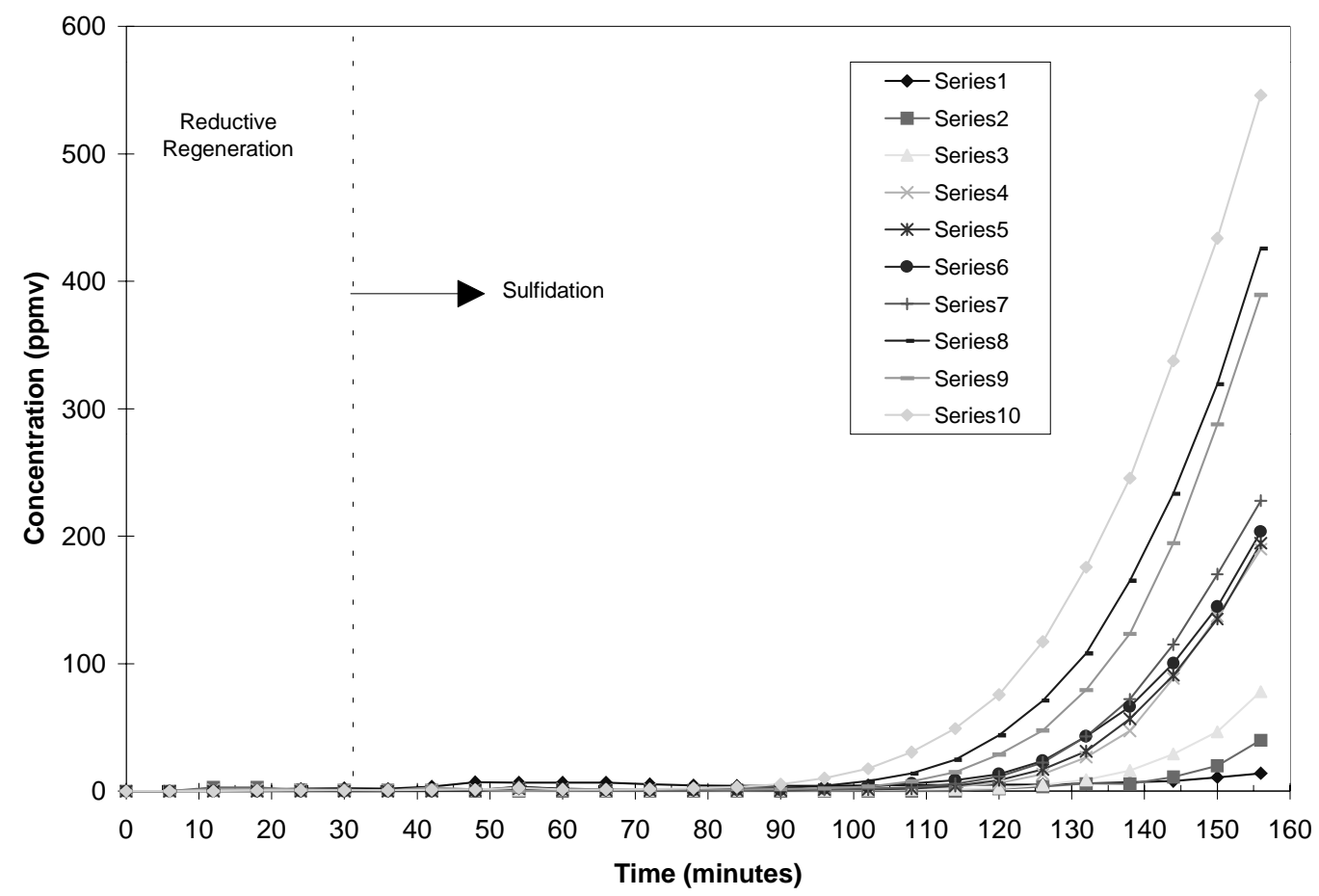

Figure 3-52. Breakthrough curves for MZT-I1 sorbent for 13 cycles in screening bench tests performed at RTI.

needed to control the batch to batch variability and to circumvent the impending degradation of the pellets over a higher number of cycles.

A more complete study is needed jointly with the sorbent manufacturers to control pelletization variability before resuming long-term testing of MZTs. 


\subsubsection{Evaluation of Chemetals' Manganese Oxide Sorbents}

Several formulations of zinc oxide/manganese oxide sorbents provided by Chemetals (Baltimore, Maryland) were evaluated at GE-CRD for mechanical durability (attrition and crush strength) and chemical reactivity. Our interest in manganese-based sorbents is in their potential use in high-temperature desulfurization of coal gases where a sorbent of higher strength properties is desired. Figure 3-53 shows the mechanical durability of three sorbents provided by Chemetals. CST-939 is a pure manganous oxide sorbent which exhibits a high crush strength and low ASTM attrition. The other two sorbents contain various amounts of zinc oxide; unfortunately, the ASTM attrition loss increases and the crush strength decreases with respect to the pure manganous oxide sorbents. The drive for adding zinc oxide is to circumvent the limitations of manganese oxides, namely, higher equilibrium values of $\mathrm{H}_{2} \mathrm{~S}$ during desulfurization and higher propensity to form sulfates. For our sorbent procurement specifications, attrition losses less than $4 \%$ and crush strength greater than $10 \mathrm{lb} /$ pellet $(4.5 \mathrm{~kg} / \mathrm{pellet})$ are acceptable for consideration in pilot scale tests.

Before testing desulfurization and regeneration of manganese oxide sorbent pellets, we tested powders of the pelletized sorbents to accelerate the sulfur uptake and regeneration characteristics in the absence of pore diffusion rate limitations. A first sulfidation on powder using a thermogravimetric analyzer (TGA) was performed, and a $12.6 \%$ weight gain over 2 hours of exposure to sulfidation gases (3\% $\mathrm{H}_{2} \mathrm{~S}, 482^{\circ} \mathrm{C}, 1 \mathrm{~atm}$ ) was measured that showed similar desulfurization characteristics to previous sorbents (Figure 3-54). The first 40 minutes were exposure to reducing gases, which then were followed by addition of $\mathrm{H}_{2} \mathrm{~S}$ to measure the weight gain during sulfidation. If we consider that the sorbent as received is mostly $\mathrm{Mn}_{2} \mathrm{O}_{3}$, then there may be two reactions taking place in the system:

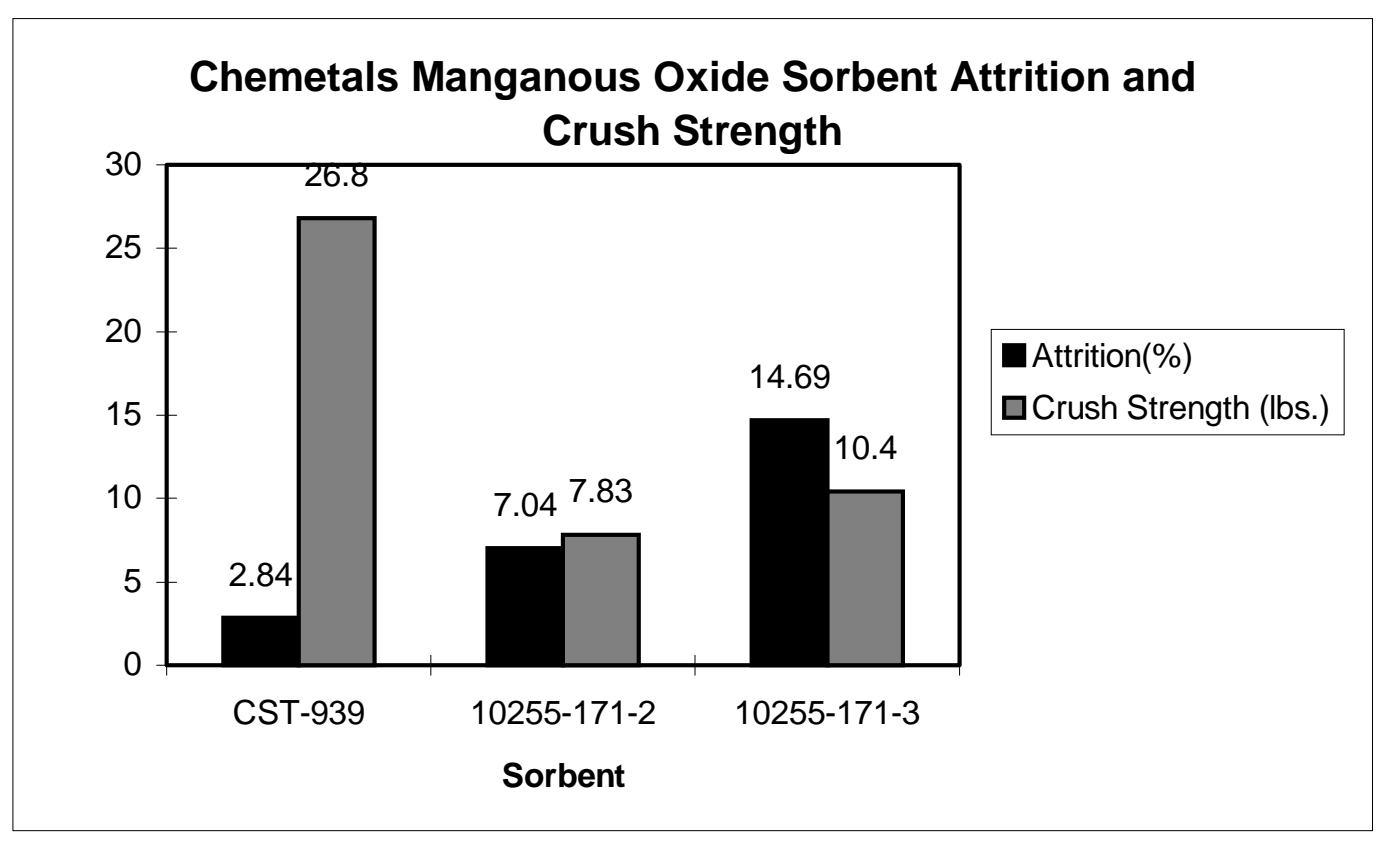

Figure 3-53. Mechanical strength of chemetals sorbents 


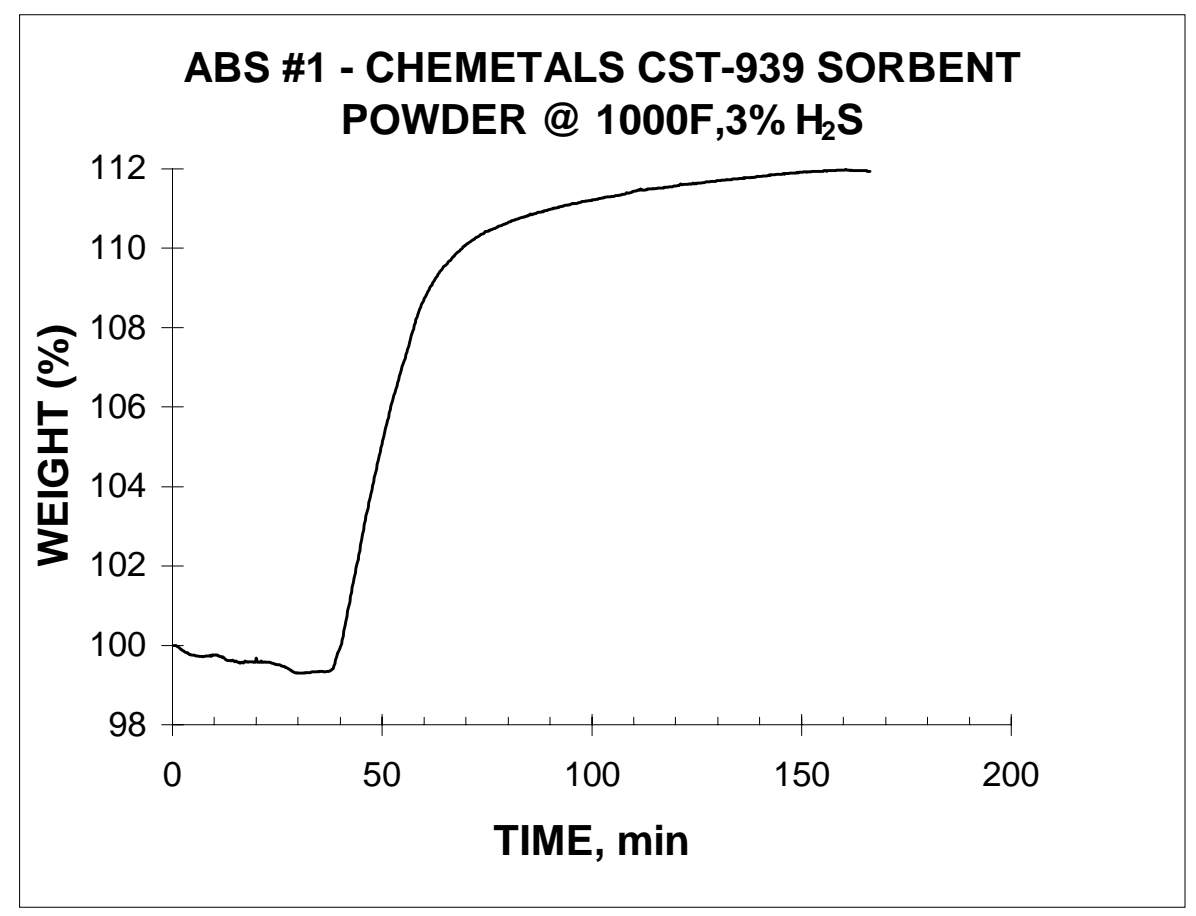

Figure 3-54. First sulfidation on CST 939 manganese oxide sorbent in a TGA

$$
\begin{array}{lr}
\mathrm{Mn}_{2} \mathrm{O}_{3}+\mathrm{H}_{2} \rightarrow 2 \mathrm{MnO}+\mathrm{H}_{2} \mathrm{O} & \Delta \mathrm{W}=-10.2 \% \\
\mathrm{MnO}+\mathrm{H}_{2} \mathrm{~S} \rightarrow \mathrm{MnS}+\mathrm{H}_{2} \mathrm{O} & \Delta \mathrm{W}=+22.6 \% \\
\hline \mathrm{Mn}_{2} \mathrm{O}_{3}+2 \mathrm{H}_{2} \mathrm{~S}+\mathrm{H}_{2} \rightarrow 2 \mathrm{MnS}+3 \mathrm{H}_{2} \mathrm{O} & \Delta \mathrm{W}=+10.3 \%
\end{array}
$$

One reaction is the reduction of the oxide Equation (1), the other is the sulfidation of $\mathrm{MnO}$, Equation (2). The net weight gain, $\Delta \mathrm{W}$, is $+11.3 \%$ in the overall reaction, Equation (3). This weight gain was measured and is shown in Figure 3-54, supporting our supposition of simultaneous oxide reduction by $\mathrm{H}_{2}$ and sulfidation by $\mathrm{H}_{2} \mathrm{~S}$.

Figure 3-55 shows the regeneration profile of Chemetals CST-939 sorbent powder at $732{ }^{\circ} \mathrm{C}(1350$ ${ }^{\circ} \mathrm{F}$ ) and $2 \% \mathrm{O}_{2}$. In principle, the sample weight should have decreased during regeneration, but instead, the weight first decreases and then increases. The observed behavior is suspected to be a result of first oxidation from sulfide to manganous oxide (which corresponds to a weight loss) followed by further oxidation from manganous oxide to manganic oxide (which corresponds to a weight gain).

Table 3-21 presents the major crystalline phases in the CST939 sorbent after the first sulfidation and regeneration reactions. These transformations by themselves have no direct negative effect on the sorbent operation, as long as the mechanical properties of the sorbent are not negatively impacted. 


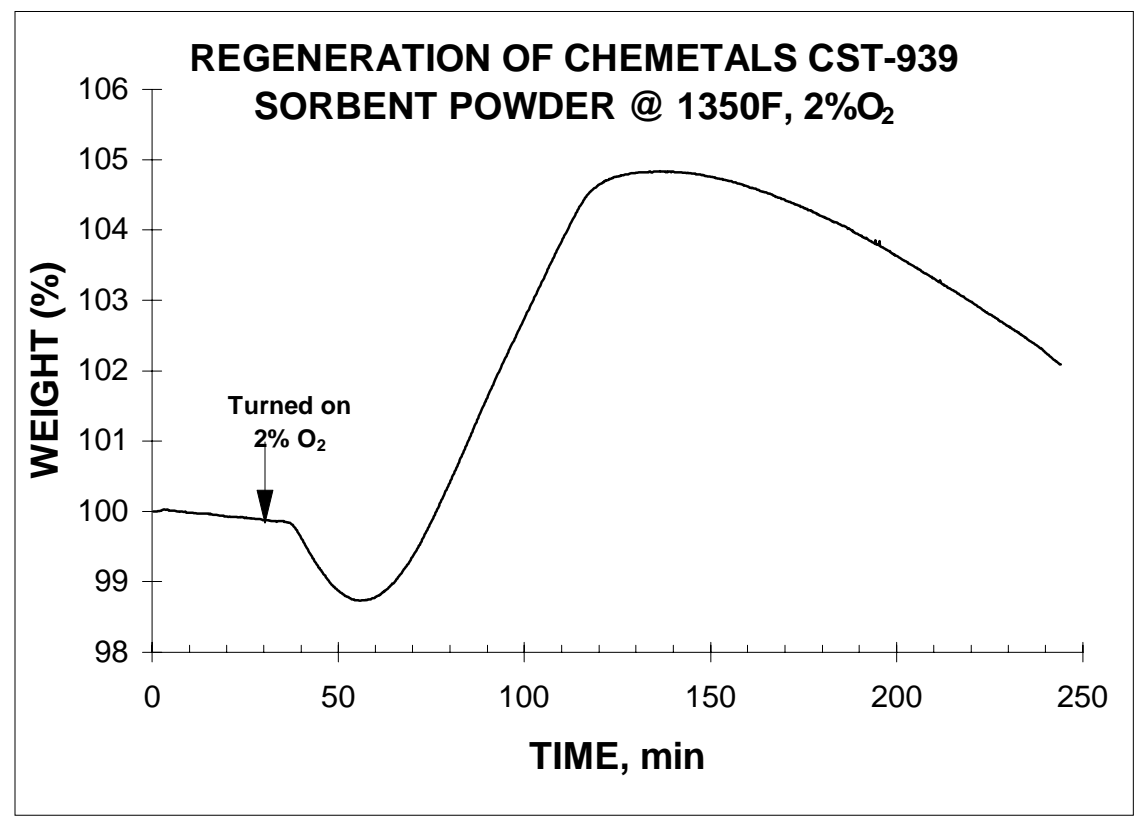

Figure 3-55. TGA regeneration profile of CST-939 sorbent powder at $1350{ }^{\circ} \mathrm{F}$ and $2 \% \mathrm{O}_{2}$

Table 3-21. XRD Analysis of CST939 sorbent

\begin{tabular}{ll}
\hline Sorbent sample & XRD Phases detected \\
\hline Fresh & $\mathrm{MnO}$ \\
After First Absorption & $\mathrm{MnS}, \mathrm{MnO}$ \\
After First Regeneration & $\mathrm{MnO}$ (major), $\mathrm{Mn}_{3} \mathrm{O}_{4}$ (major), \\
& $\mathrm{MnOS}$ (minor) \\
\hline
\end{tabular}

Further analyses were performed to rule out if a significant formation of sulfur species could have remained or formed, which would also produce a weight gain. The amount of MnOS was found to be between 1 and $2 \%$ after the first regeneration, based on XRD analysis, and it is unlikely to account for the approximately $5 \%$ to $6 \% \mathrm{wt}$ gain observed in Figure 3-55. We are uncertain if any molybdenum sulfate was formed, but manganese sulfate is a thermodynamically stable species at these conditions of regeneration. Figure 3-56 shows the phase stability diagram for the system $\mathrm{Mn}-\mathrm{S}-\mathrm{O}$ at $500{ }^{\circ} \mathrm{C}$, and the approximate point of operation during thermogravimetric analysis (TGA) tests is marked with an X. Sulfate concentrations of typically less than $1 \%$ are necessary in zinc oxide sorbents to avoid sorbent spalling or pore plugging due to sulfate formation. At this point, it is not known what the sulfate limit is for manganese oxide-based sorbents.

After the first regeneration under $\mathrm{O}_{2}$ was performed, a second sulfidation was carried out. Figure 3-57 presents the second sulfidation of CST-939. Fifty minutes of exposure to $\mathrm{N}_{2}$ were first done to obtain a steady horizontal baseline. The reducing gases $\left(\mathrm{CO}, \mathrm{H}_{2}\right)$ and other simulated coal gas components 


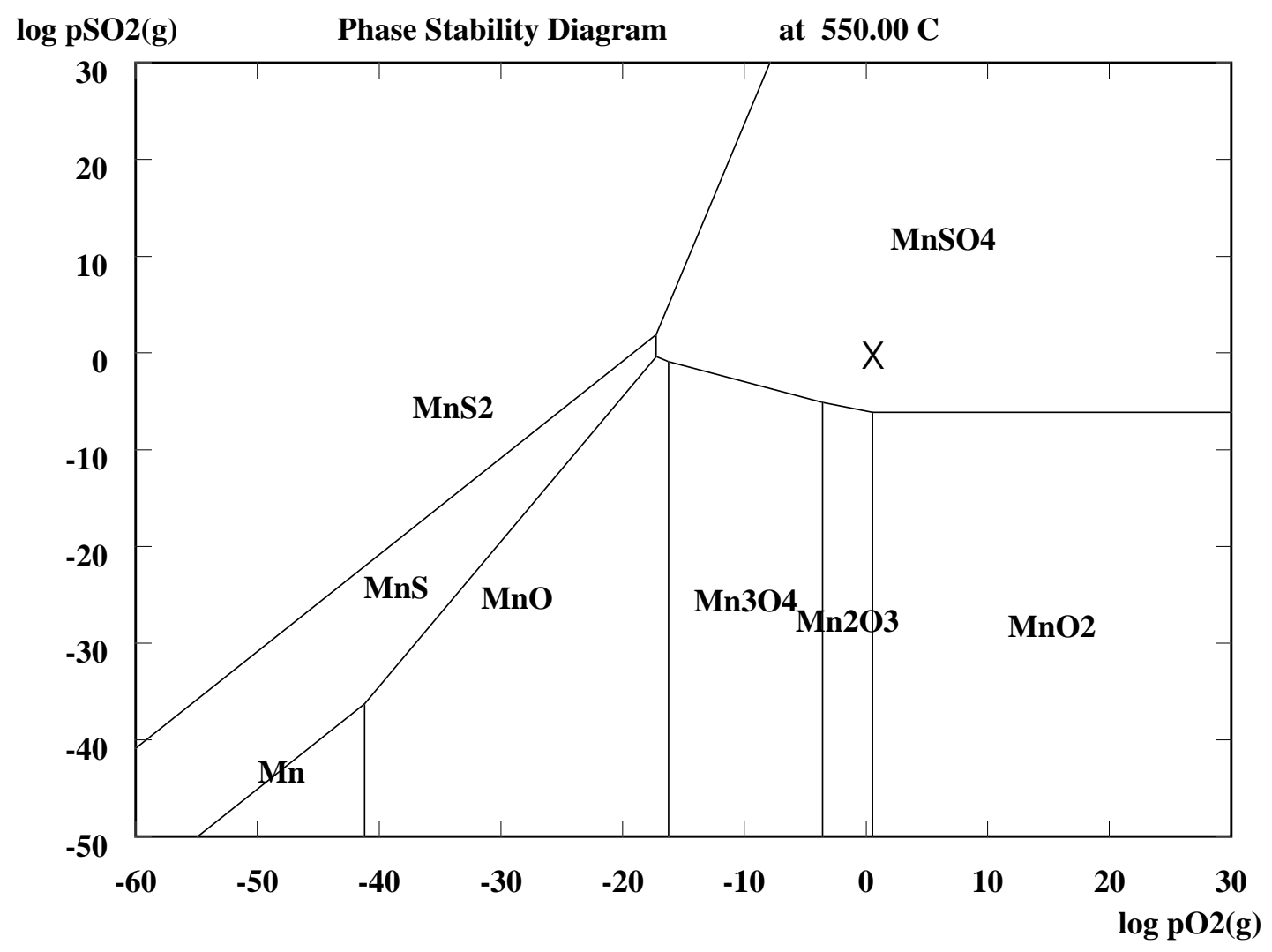

Figure 3-56. Equilibrium diagram for the system $\mathrm{Mn}-\mathrm{O}-\mathrm{S}$ at $550{ }^{\circ} \mathrm{C}\left(1022{ }^{\circ} \mathrm{F}\right)$

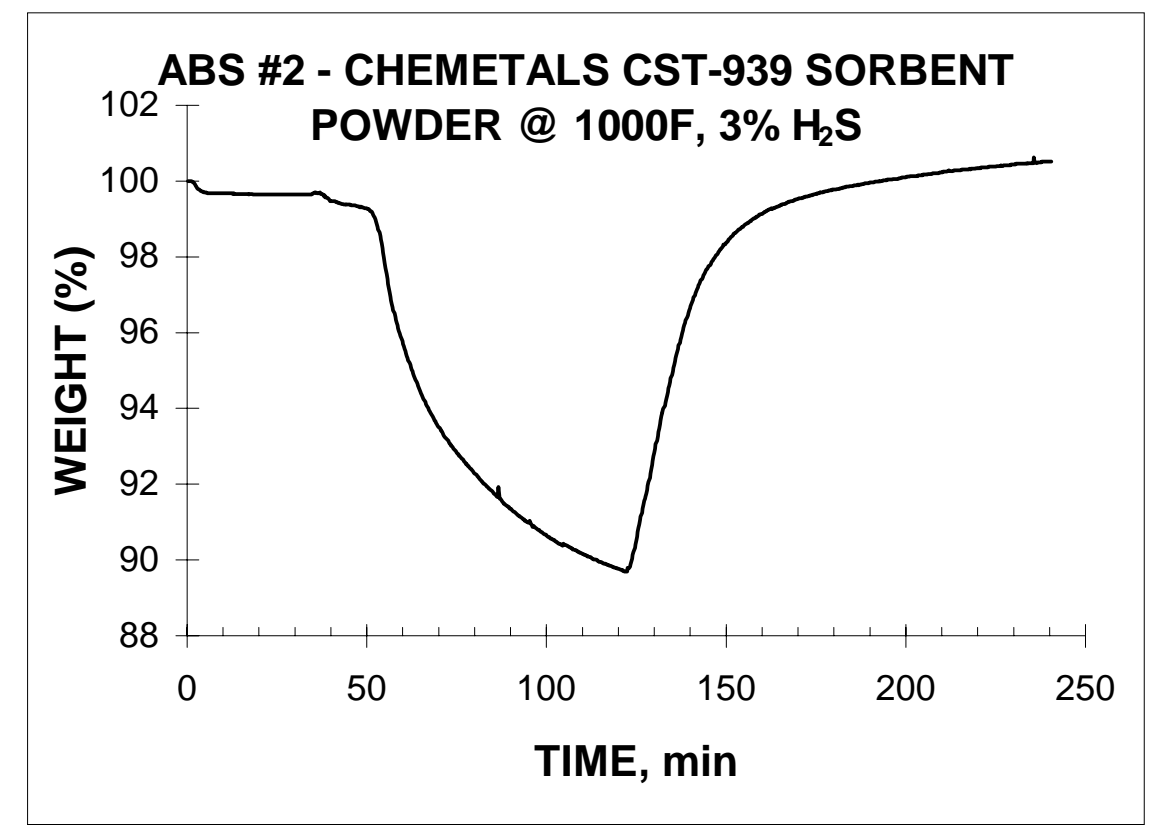

Figure 3-57. Second TGA absorption of CST-939 sorbent powder at $1000{ }^{\circ} \mathrm{F}$ and $3 \% \mathrm{H}_{2} \mathrm{~S}$. Reductive regeneration started at $\sim 50 \mathrm{~min}$. $\mathrm{H}_{2} \mathrm{~S}$ introduced at 125 minutes 
were introduced, and a $10 \%$ weight loss was measured. This weight loss is ascribed to the reaction $\mathrm{Mn}_{2} \mathrm{O}_{3}->\mathrm{MnO}$ (theoretical weight loss of 11.3\%). After a total time of 125 minutes, the $\mathrm{H}_{2} \mathrm{~S}$ was introduced to carry out the sulfidation reaction. A weight gain of $10.8 \%$ was obtained, which is slightly less than the $12.6 \%$ weight gain during the first sulfidation.

Having checked the reactivity of powder samples, tests were continued on whole pellets instead of powders. The first absorption of CST-939 pellets exhibited a standard weight gain curve upon sulfidation. The weight gain was again $12.6 \%$, which is acceptable.

The observed performance of CST-939, containing manganous oxide but no zinc, is acceptable for desulfurization. However, thermodynamic calculations predict that manganese oxides will have an equilibrium $\mathrm{H}_{2} \mathrm{~S}$ concentration that may be as high as 100 times that of zinc oxide at $450-500{ }^{\circ} \mathrm{C}$. Consequently the level of desulfurization of coal gases that can be achieved with manganese sorbents may not be as favorable. Addition of zinc oxide to the manganese obviates this limitation, but the loss in mechanical strength may represent a problem for keeping sorbent losses due to attrition low. If tests of manganese sorbents with zinc oxide showed lower attrition, they would be highly promising for larger scale use.

Figure 3-58 shows the first absorption of CST 10255-171-3 sorbent containing approximately 6\% zinc oxide in its structure. The weight gained during sulfidation is comparable to that of the pure manganese oxide, suggesting there are not negative interactions between zinc and manganese oxides as far as desulfurization reactivity is concerned. Further tests, of course, would be needed to determine if regeneration is affected.

Pure manganese oxide by itself cannot be used for our moving-bed application at TECO because manganese oxide requires regeneration above $816^{\circ} \mathrm{C}\left(1500^{\circ} \mathrm{F}\right)$, which is outside of the allowable temperature window for safe operation at the TECO HGCU demonstration plant, as dictated by the ASTM standards for the materials of construction. Also, pure manganese components will not remove

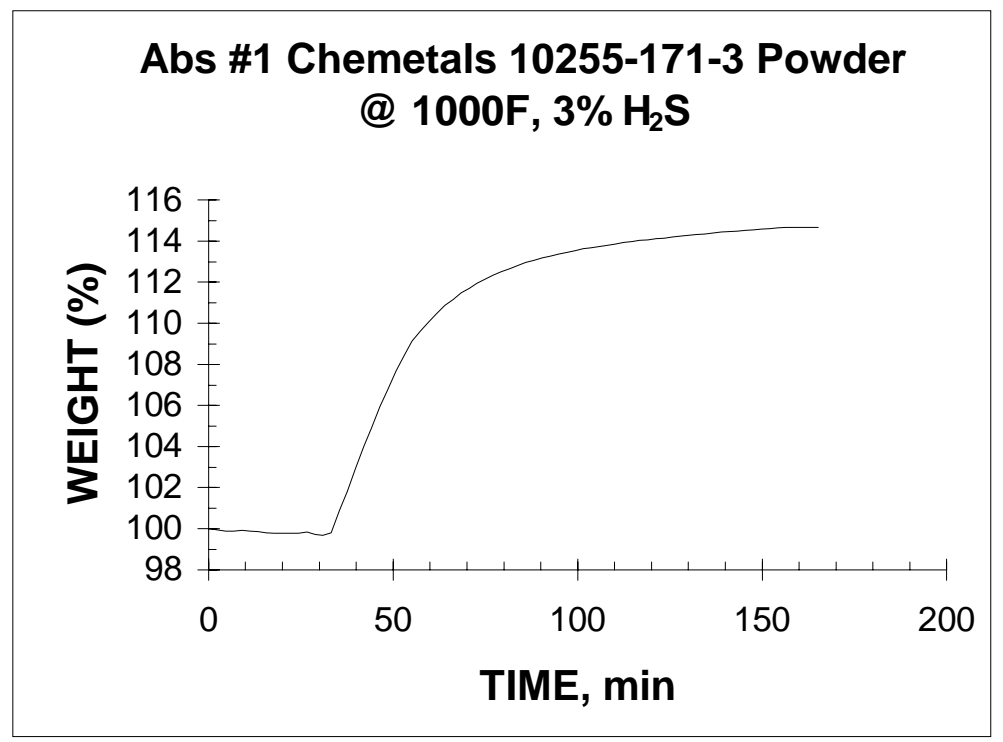

Figure 3-58. First absorption of CST 10255-171-3 sorbent 
$\mathrm{H}_{2} \mathrm{~S}$ in coal gas to low levels comparable to zinc-based sorbents as predicted by the thermodynamic calculations described earlier. At about $500{ }^{\circ} \mathrm{C}$, the equilibrium vapor pressure of $\mathrm{H}_{2} \mathrm{~S}$ in coal gas over $\mathrm{ZnO}$ is $0.1 \mathrm{ppm}$; the corresponding vapor pressure over manganese compounds is about $10 \mathrm{ppm}$, or a factor of 100 higher than that for zinc oxide. This higher equilibrium vapor pressure is somewhat of a limitation for large-scale operations, where $\mathrm{H}_{2} \mathrm{~S}$ equilibrium levels are generally not achievable over long-term operation. As mentioned before, combination of zinc oxide/manganese oxide, with proper attrition resistance, could be a viable avenue for regeneration and operation below $816^{\circ} \mathrm{C}$.

Chemetals manganous oxide sorbent CST-939 was tested in the bench-scale reactor using the procedure described below.

Test Procedure: The sorbent was subjected to 3 cycles of absorption and regeneration. The parameters for each step in a cycle are shown in Table 3-22. The test procedure was as follows:

Cycle 1:

(a) The sorbent was exposed to reductive regeneration conditions for 30 minutes to verify that the $\mathrm{H}_{2} \mathrm{~S}$ baseline was 0 ppm.

(b) The sorbent was exposed to absorption gas conditions until 200 ppmv (dry) $\mathrm{H}_{2} \mathrm{~S}$ was detected in the reactor effluent gas.

(c) The sorbent was exposed to regeneration gas conditions until the $\mathrm{O}_{2}$ concentration in the reactor effluent gas reached approximately $4 \%$. ( $\mathrm{No} \mathrm{SO}_{2}$ was added to the regeneration gas during Cycle 1).

(d) The $\mathrm{O}_{2}$ was turned off and the sorbent bed temperature was ramped to $700{ }^{\circ} \mathrm{C}$ and held there for 1 hour (Temperature Ramp conditions).

Cycle 2:

(a) The sorbent was exposed to reductive regeneration conditions for 2 hours (Reductive Regeneration \#1).

(b) The sorbent was exposed to absorption gas conditions until 200 ppmv (dry) $\mathrm{H}_{2} \mathrm{~S}$ was detected in the reactor effluent gas.

(c) The sorbent was exposed to regeneration gas conditions until the $\mathrm{O}_{2}$ concentration in the reactor effluent gas reached approximately $4 \%$. During this cycle, $8 \% \mathrm{SO}_{2}$ was added to the regeneration gas.

(d) The $\mathrm{O}_{2}$ and $\mathrm{SO}_{2}$ were turned off and the sorbent bed temperature was ramped to $1300^{\circ} \mathrm{F}$ and held there for 1 hour (Temperature Ramp conditions).

Cycle 3:

(a) The sorbent was exposed to reductive regeneration conditions for $21 / 2$ hours (Reductive Regeneration \#2).

(b) The sorbent was exposed to absorption gas conditions until $200 \mathrm{ppmv}$ (dry) $\mathrm{H}_{2} \mathrm{~S}$ was detected in the reactor effluent gas. 
Table 3-22. Bench-scale test parameters for Chemetals CST-939 sorbent

\begin{tabular}{|c|c|c|c|c|c|}
\hline \multirow[b]{2}{*}{ Test gas composition } & Absorption & $\begin{array}{c}\text { Reductive } \\
\text { Regeneration }\end{array}$ & $\begin{array}{l}\text { Regeneration } \\
\text { Cycle 1 }\end{array}$ & $\begin{array}{c}\text { Regeneration } \\
\text { Cycles 2\&3 }\end{array}$ & $\begin{array}{c}\text { Temperature } \\
\text { Ramp }\end{array}$ \\
\hline & \multirow{3}{*}{$\begin{array}{c}38.6 \% \\
57 \%\end{array}$} & \multirow[b]{2}{*}{$39.0 \%$} & \multirow[b]{2}{*}{ - } & \multirow[b]{2}{*}{-} & \multirow[b]{2}{*}{-} \\
\hline $\mathrm{CO}$ & & & & & \\
\hline $\mathrm{CO}_{2}$ & & $5.7 \%$ & - & - & - \\
\hline $\mathrm{H}_{2}$ & $34.7 \%$ & $35.1 \%$ & - & - & - \\
\hline $\mathrm{H}_{2} \mathrm{O}$ & $20.0 \%$ & $20.2 \%$ & - & - & - \\
\hline $\mathrm{H}_{2} \mathrm{~S}$ & $1.0 \%$ & $0 \%$ & - & - & - \\
\hline $\mathrm{O}_{2}$ & - & - & $2 \%-5 \%$ & $2 \%-5 \%$ & - \\
\hline $\mathrm{SO}_{2}$ & - & - & $0 \%$ & $8 \%$ & - \\
\hline $\mathrm{N}_{2}$ & - & - & balance & balance & $100 \%$ \\
\hline Pressure (absolute) & $5 \mathrm{~atm}$. & 5 atm. & $1.5 \mathrm{~atm}$. & $1.5 \mathrm{~atm}$. & $1.5 \mathrm{~atm}$. \\
\hline $\begin{array}{l}\text { Sorbent Bed } \\
\text { Temperature }\end{array}$ & $482^{\circ} \mathrm{C}$ & $482^{\circ} \mathrm{C}$ & $482^{\circ} \mathrm{C}-718^{\circ} \mathrm{C}$ & $482^{\circ} \mathrm{C}-718^{\circ} \mathrm{C}$ & $704^{\circ} \mathrm{C}$ \\
\hline Flow Rate & 13 slpm & $12.8 \mathrm{slpm}$ & $5 \mathrm{slpm}$ & $5 \mathrm{slpm}$ & $5 \mathrm{slpm}$ \\
\hline Space Velocity & $1950 \mathrm{hr}^{-1}$ & $1920 \mathrm{hr}^{-1}$ & $750 \mathrm{hr}^{-1}$ & $750 \mathrm{hr}^{-1}$ & $750 \mathrm{hr}^{-1}$ \\
\hline \multicolumn{6}{|c|}{$\begin{array}{ll}\text { Sorbent Bed Volume } & 400 \mathrm{ml} .(733.05 \mathrm{gms}) \\
\end{array}$} \\
\hline
\end{tabular}

(c) The sorbent was exposed to regeneration gas conditions until the $\mathrm{O}_{2}$ concentration in the reactor effluent gas reached approximately $4 \%$. During this cycle, $8 \% \mathrm{SO}_{2}$ was added to the regeneration gas.

(d) The $\mathrm{O}_{2}$ and $\mathrm{SO}_{2}$ were turned off and the sorbent bed temperature was ramped to $700{ }^{\circ} \mathrm{C}$ and held there for 1 hour (Temperature Ramp conditions).

Results

Figure 3-59 shows the $\mathrm{H}_{2} \mathrm{~S}$ breakthrough curves for the three absorption cycles. While the sulfidation capacity of the sorbent is high (demonstrated by the relatively high breakthrough times), the sorbent has a high residual sulfur content after being regenerated. This is indicated by the high baseline $\mathrm{H}_{2} \mathrm{~S}$ before absorptions 2 and 3 (19 ppm and 48 ppm respectively) and the amount of each sulfur species evolved during the reductive regeneration of the sorbent (Figure 3-60 and Figure 3-61). The addition of 8\% $\mathrm{SO}_{2}$ during regeneration resulted in a significant increase in residual sulfur after regeneration.

Analysis for residual sulfur in CST-939 indicated that regeneration at the chosen conditions was not sufficient to oxidize the sulfur from the sorbent (Table 3-23).

Table 3-23. Sulfur analysis of Chemetals CST-939 sorbent after regeneration 3

\begin{tabular}{llc}
\hline & Fresh & After $3^{\text {rd }}$. Regeneration \\
\hline$\%$ Total Sulfur - Gas inlet & 0.15 & 4.68 \\
$\%$ Total Sulfur - Gas outlet & 0.15 & 1.70 \\
$\%$ Sulfate Sulfur - Gas inlet & 0.05 & 0.39 \\
\% Sulfate Sulfur - Gas outlet & 0.05 & 1.63 \\
\hline
\end{tabular}




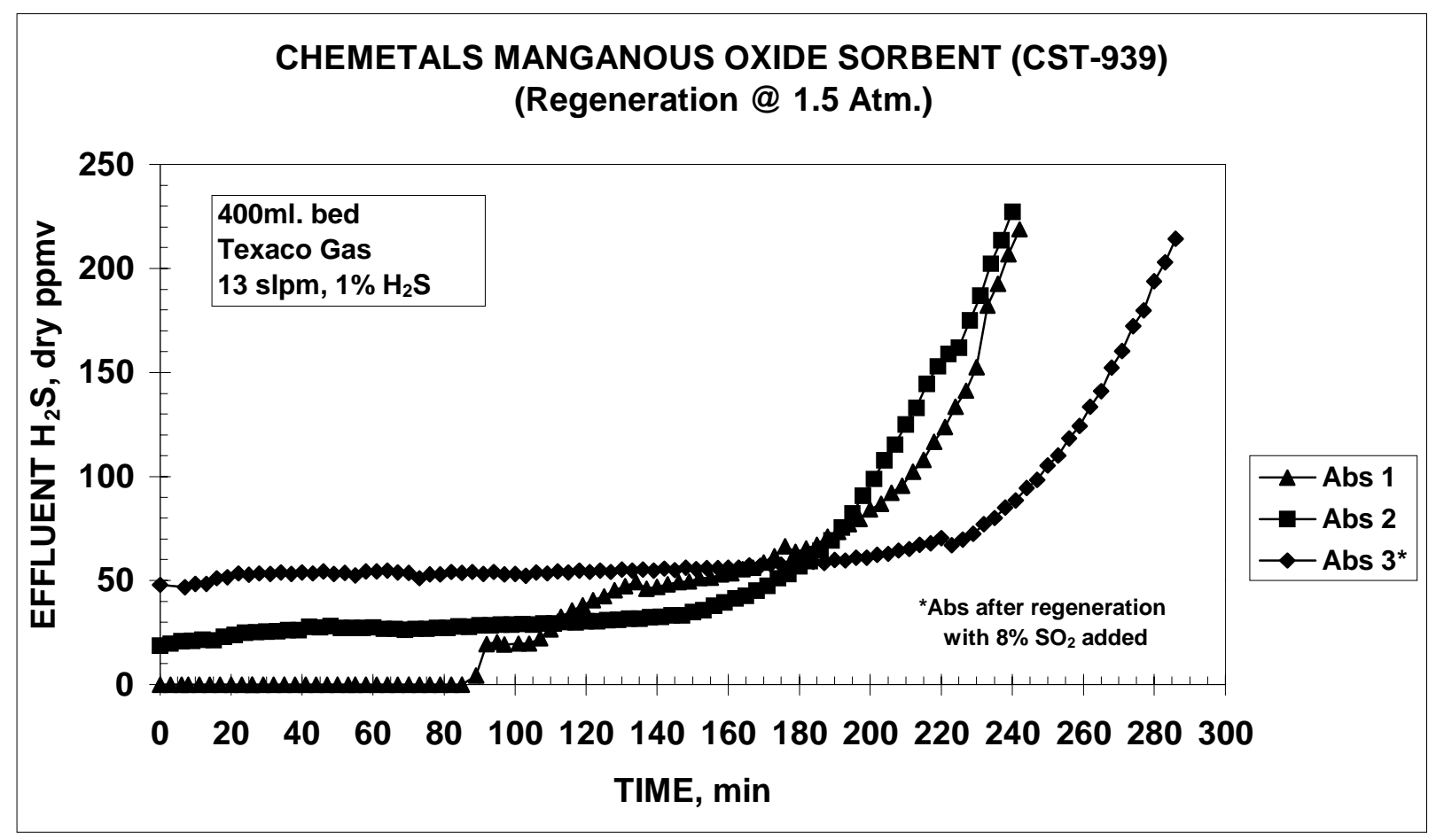

Figure 3-59. Chemetals CST-939 breakthrough curves

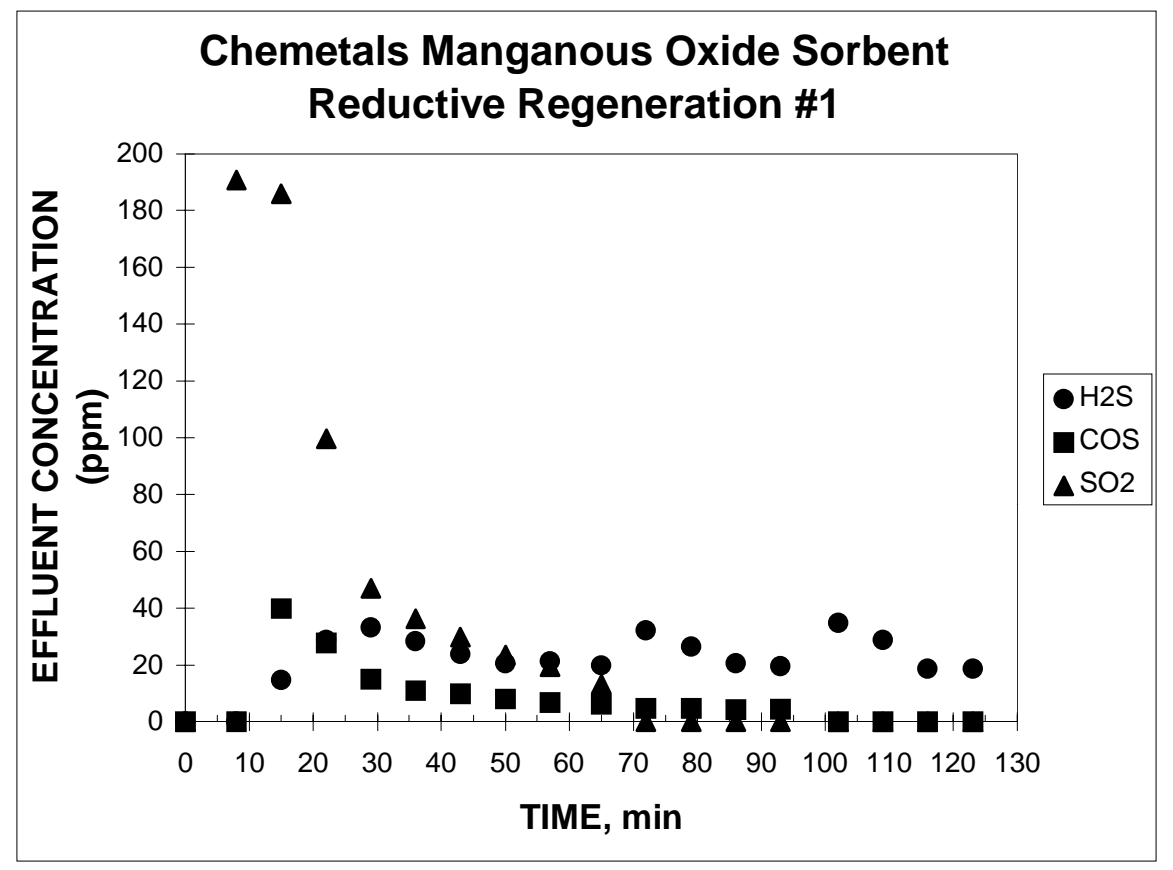

Figure 3-60. Sulfur species evolved during Reductive Regeneration \#1. 


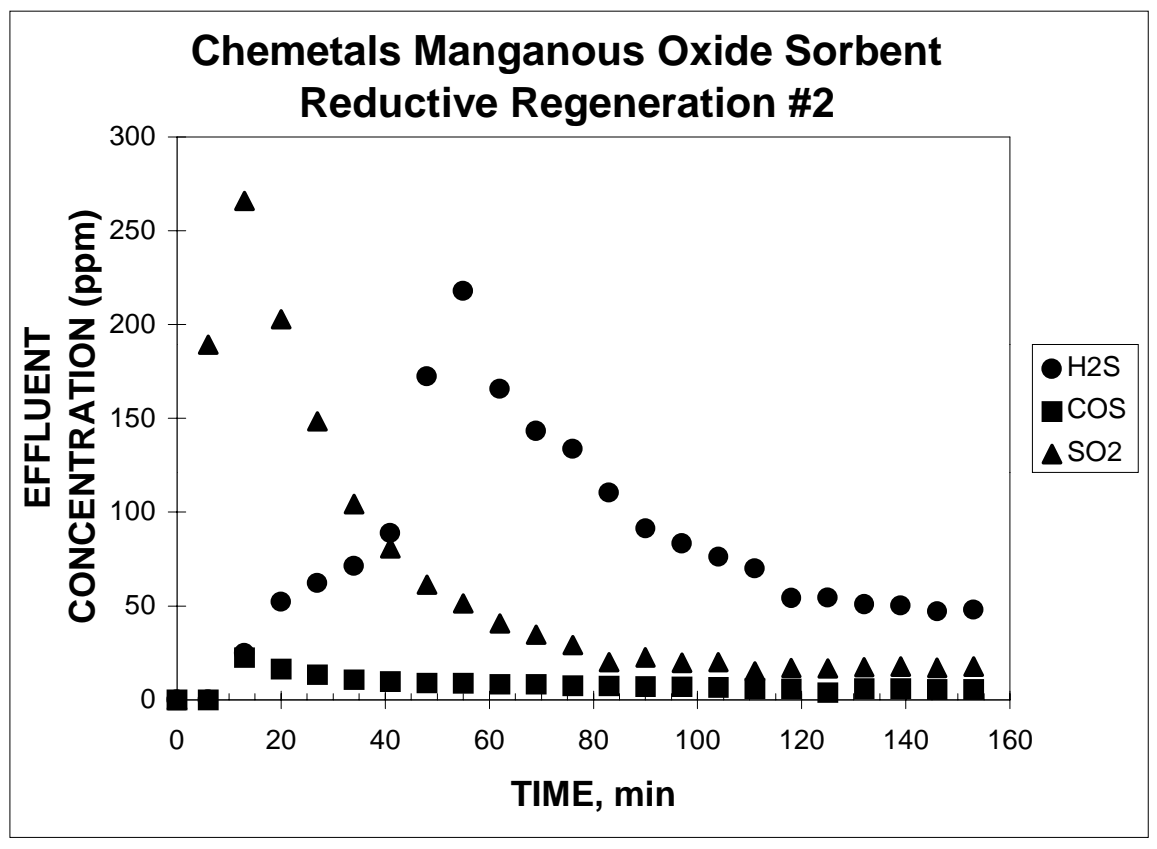

Figure 3-61. Sulfur species evolved during Reductive Regeneration \#2.

Evaluation of manganese-containing sorbents suggested that improvements in mechanical strength can be brought about by the manganese component of the sorbent. Given that manganese by itself cannot remove $\mathrm{H}_{2} \mathrm{~S}$ to as low levels as zinc-based sorbents can, the combination of the two may give a synergistic advantage. However, improvements in the attrition resistance of the manganese-zinc pellets are necessary to compete against other zinc-containing sorbents in durability.

\subsubsection{Evaluation of ICCI-2C Zinc Titanate Sorbent}

Testing of the Illinois Clean Coal Institute's ICCI2-C sorbent, as provided by Dr. J. Swisher from Southern Illinois University (SIU), was completed during 1996 as a parallel effort in the testing of proprietary sorbents. The zinc titanate-based sorbent was found to be acceptable for pilot plant testing (where regeneration is performed at a lower pressure of $1.5 \mathrm{~atm}$ ). A summary of the results for lowpressure regeneration, simulating pilot plant regeneration, is presented below.

Testing of ICCI-2C was carried out at GE-CRD under the bench-scale conditions of absorption at 5.0 atm and regeneration at 1.5 atm with $0 \%, 1 \%$, and $10 \% \mathrm{SO}_{2}$. Activation is defined as the process of treating the sorbent to a procedure of time, temperature, and gas composition so that its reactivity towards desulfurization increases to an acceptable level for large-scale use. The sulfur capacity of ICCI-2C is lower than other fully active sorbents, because of its lower zinc content (i.e., around 15\% $\mathrm{ZnO}$ ), and the reactivity is somewhat lower also, presumably because of its lower accessible surface area or porosity. Nonetheless, these two limitations can be circumvented in the moving-bed system by adjusting upwards the sorbent movement rate so that the sulfur removal per unit time remains constant. 
Figure 3-62 shows the $\mathrm{H}_{2} \mathrm{~S}$ breakthrough curves for the three test periods of regeneration with $0 \% \mathrm{SO}_{2}$ (cycles 1-5), $1 \% \mathrm{SO}_{2}$ (cycles 7-10), and 10\% $\mathrm{SO}_{2}$ (cycles 11-13) in the regeneration gas. There is a gradual activation of the sorbent after the third cycle that becomes complete by the fifth cycle. As with any other sorbent, some of the reactivity is decreased in the presence of $\mathrm{SO}_{2}$ regeneration. Absorptions were conducted at $482{ }^{\circ} \mathrm{C}, 5 \mathrm{~atm}$, and $1 \% \mathrm{H}_{2} \mathrm{~S}$ in the inlet gas. The gas composition simulated that of an oxygen-blown gasifier (i.e., high $\mathrm{CO}, \mathrm{H}_{2}$ concentration).

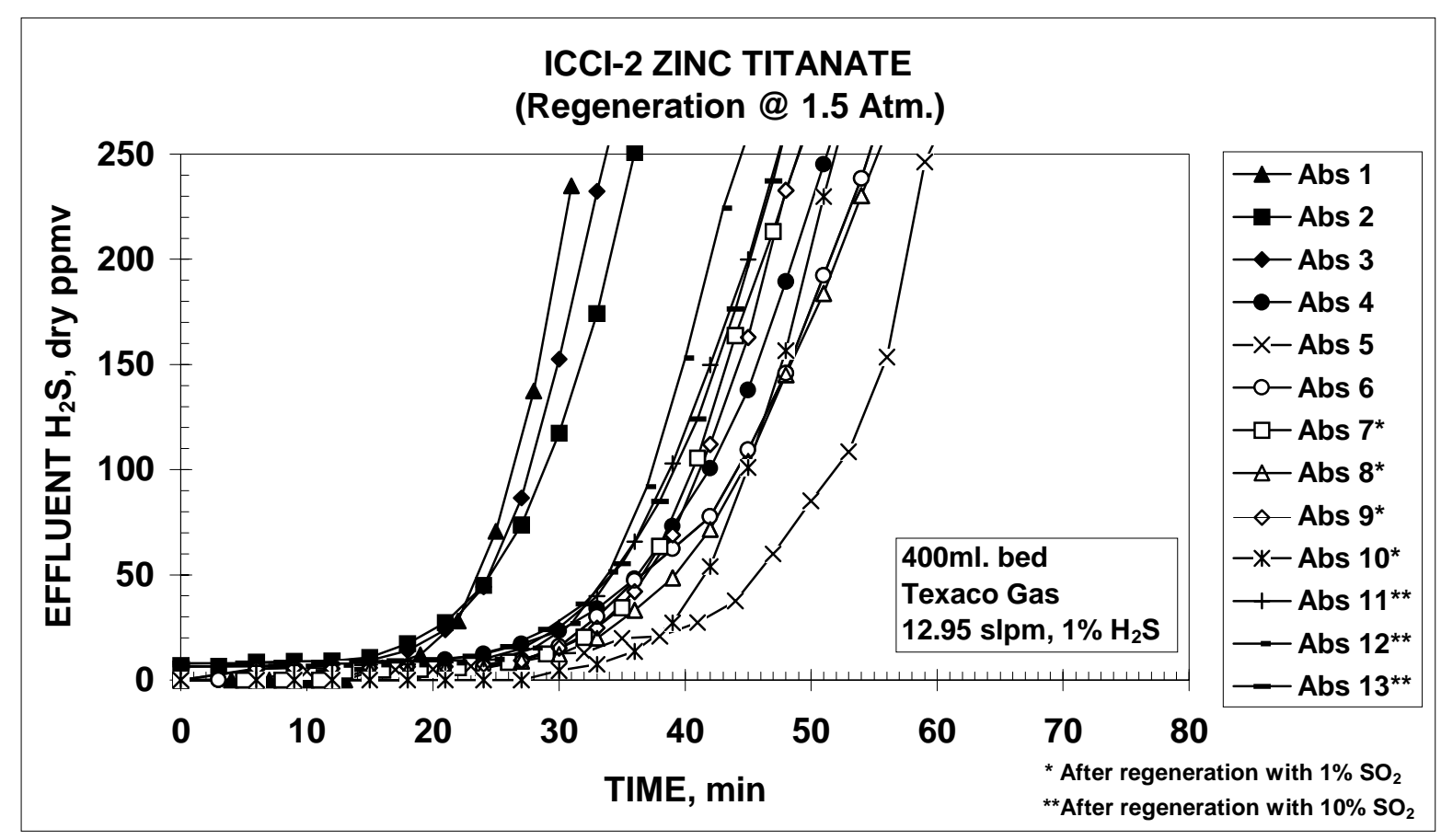

Figure 3-62. Breakthrough curves of ICCI-2C during bench testing at GE-CRD

Since it is sometimes somewhat difficult to see the trend in breakthrough times for multiple cycles shown in the same plot, an alternate approach to present the results is by plotting the "envelope" curve of the breakthrough curves versus cycle number. For each breakthrough curve, we take the time taken to reach $200 \mathrm{ppmv}_{2} \mathrm{~S}$ in the outlet gas for a given absorption and plot that time versus cycle number. Presentation of the data in this form is usually much easier when trying to determine how fast a sorbent is losing reactivity.

Figure 3-63 shows the envelope of the breakthrough curves from Figure 3-62, taken at the $200 \mathrm{ppm}$ $\mathrm{H}_{2} \mathrm{~S}$ point. You can see more clearly that the sorbent was very active by cycle 5 , and upon introduction of $\mathrm{SO}_{2}$, it slightly decreases in reactivity, and stabilizes at about $80 \%$ of its highest activity for $1 \% \mathrm{SO}_{2}$ and slightly lower for $10 \% \mathrm{SO}_{2}$. 


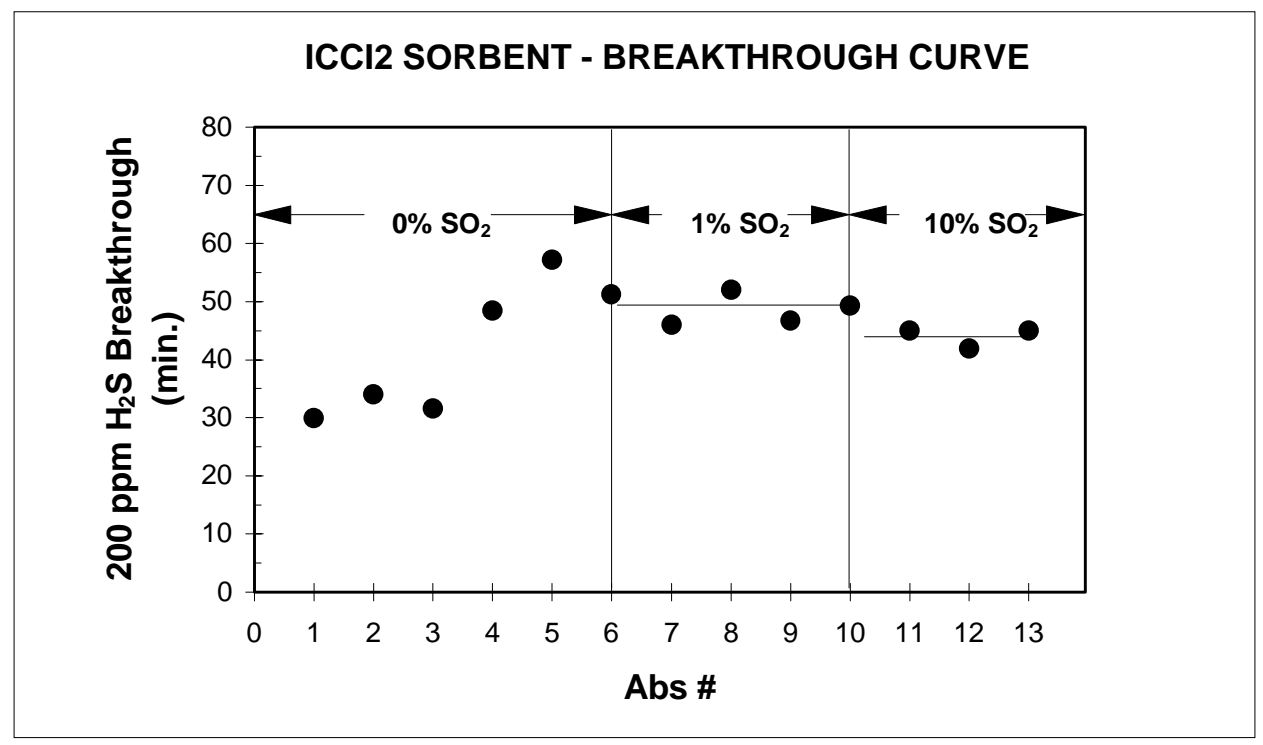

Figure 3-63. Envelope of the breakthrough curves for bench testing of ICCI-2C at GE-CRD

Figure 3-64 and Figure 3-65 show the TGA curves of samples extracted after the highest activation point (cycle 5) and after cycles with $10 \% \mathrm{SO}_{2}$ (cycle 13). The effect of $\mathrm{SO}_{2}$ on sorbent reactivity is small and not a major barrier. The weight gain due to sulfur loading is about 3-3.5\% wt or about 6 to $7 \%$ wt sulfur loading on the sorbent over 2 hours of exposure to $\mathrm{H}_{2} \mathrm{~S}$. For comparison, this amount is lower than other sorbents, which typically exhibit a $10-15 \%$ wt sulfur loading in the same time interval at full activation. Because the moving-bed absorber maintains performance by adjusting the sorbent movement rate, the lower reactivity of ICCI- $2 \mathrm{C}$ can be compensated by moving sorbent faster at the expense of (perhaps) higher sorbent mass loss per unit time of operation due to attrition.

Regeneration was started at $482{ }^{\circ} \mathrm{C}, 5 \% \mathrm{O}_{2}, 1000 \mathrm{~h}^{-1}$ space velocity. The main objective of this bench testing was to show the ability of the sorbent to regenerate when the inlet gas temperature is $482{ }^{\circ} \mathrm{C}$ as in pilot plant operation. As the temperature of the bed rose to $700^{\circ} \mathrm{C}$, the $\mathrm{O}_{2}$ concentration was reduced to $4 \% \mathrm{O}_{2}$ and the furnace temperature increased to $620^{\circ} \mathrm{C}$ to simulate the movement of the sorbent in a moving-bed system from the inlet location to a location further down the bed, where the gas temperature is higher. Once the temperatures in the bed decreased from $700^{\circ} \mathrm{C}$ to about $650{ }^{\circ} \mathrm{C}$, the oxygen concentration was adjusted again to maintain the temperatures high (this time simulating the second stage of regeneration in the pilot plant). When $\mathrm{O}_{2}$ breakthrough at the gas outlet was measured, the $\mathrm{O}_{2}$ and $\mathrm{SO}_{2}$ (if any) were shut off in the inlet gas and the nitrogen purge at $700{ }^{\circ} \mathrm{C}$ started for 1 hour.

Figure 3-66 presents the bed temperatures versus time as a function of bed location for the first regeneration. Odd numbered temperatures are measured along the center line of the bed. TC1 is the gas inlet location while TC7 is the gas outlet location at the center location. Even numbered temperatures represent wall temperatures at the same plane as the center temperatures. 


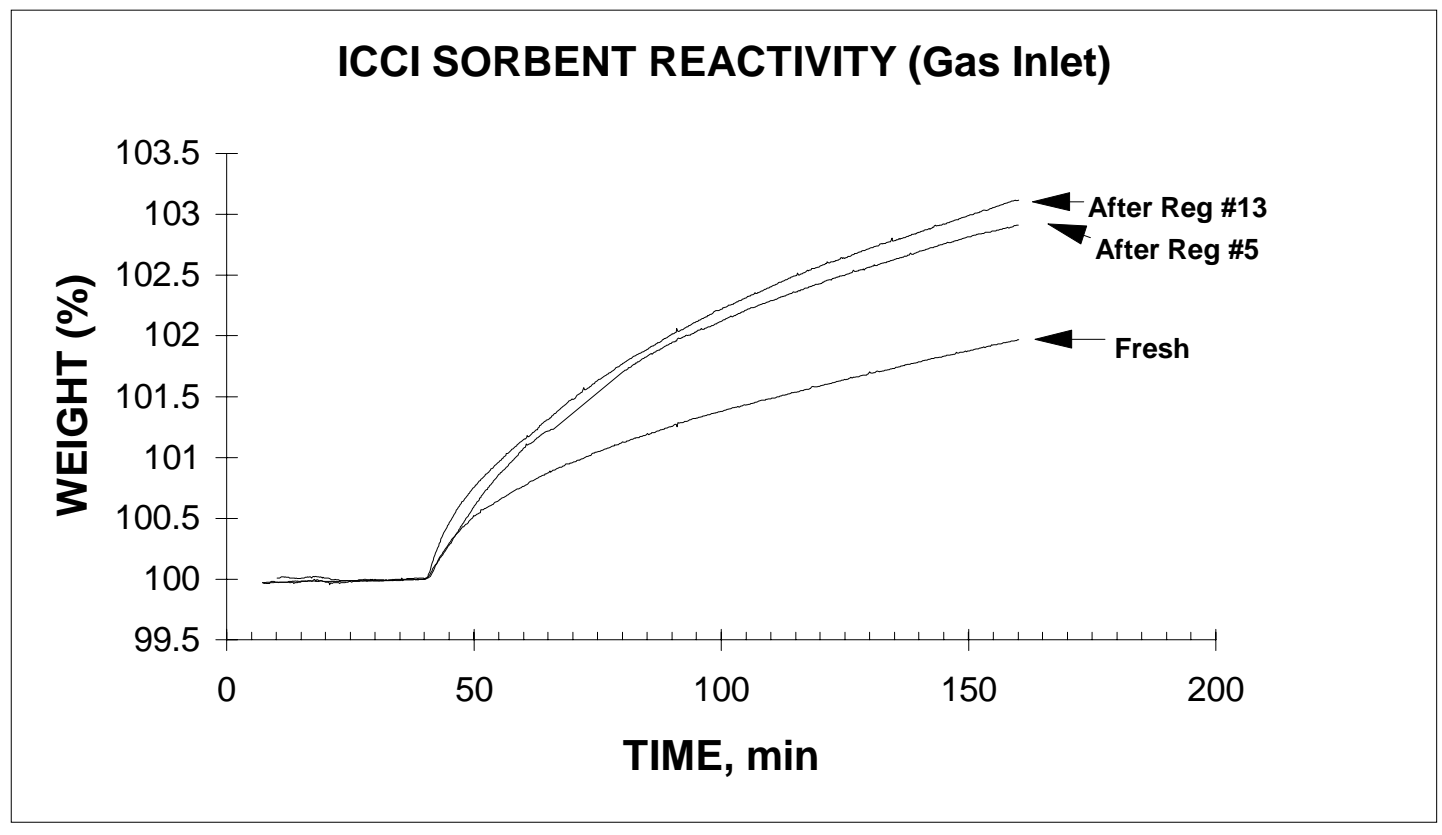

Figure 3-64. TGA Reactivity of ICCI-2C samples from the gas inlet location

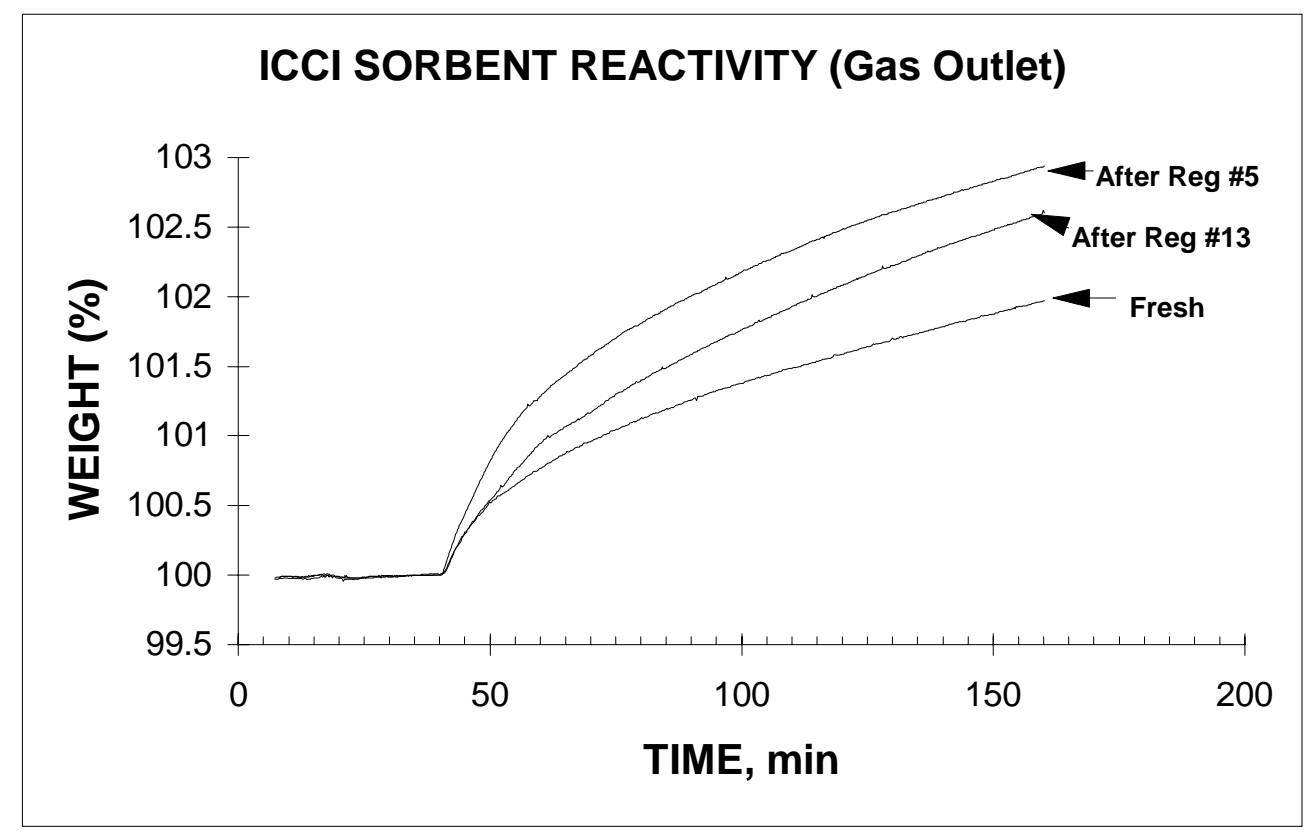

Figure 3-65. TGA Reactivity of ICCI-2C samples from the gas outlet location 


\section{Bench Screening Test of ICCl-2C Bed Temperatures}

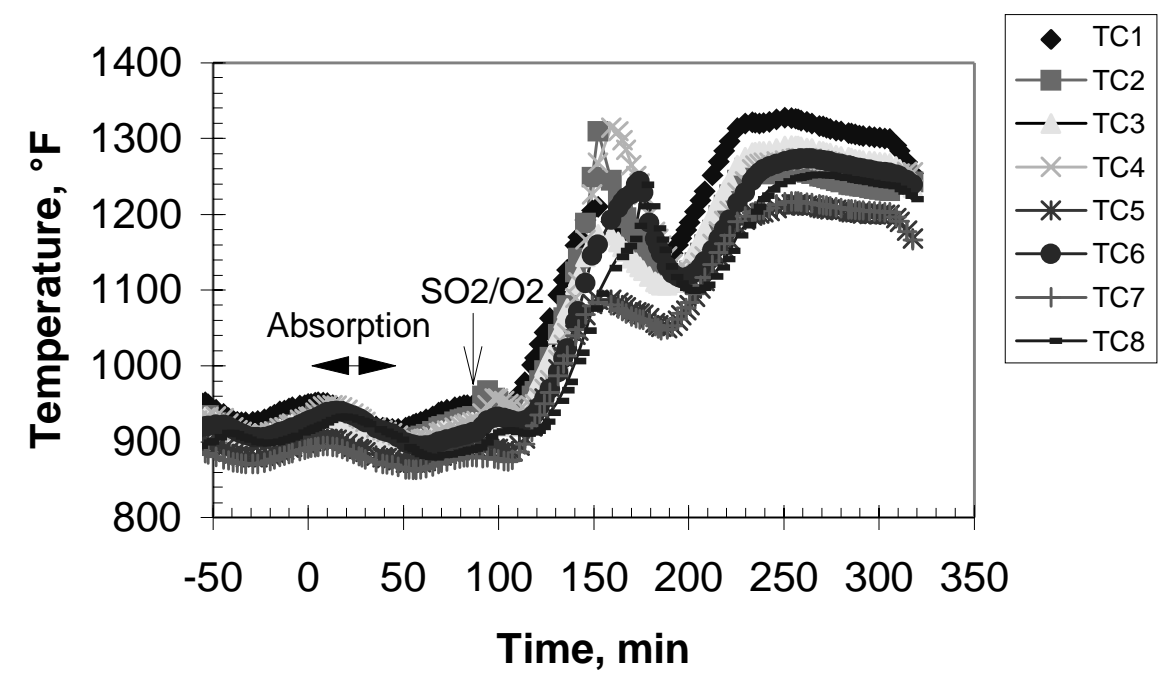

Figure 3-66. Temperature history of ICCI-2C during bench-scale absorptions and regenerations

Table 3-23 below shows the residual total sulfur and sulfate at both gas inlet and gas outlet locations for samples after the 5th regeneration and after the 13th regeneration. The amounts of residual sulfate and residual total sulfur are very minimal (values below $0.5 \%$ is acceptable). As expected, the presence of $\mathrm{SO}_{2}$ slows down the rate of regeneration, as given by the higher amounts of residual total sulfur in the sample. All sulfur analyses of the sorbents are acceptable for operation.

Table 3-23. Residual sulfur of ICCI-2C samples after bench-scale testing at GE-CRD

\begin{tabular}{c|c|c|c|}
\hline \multicolumn{4}{c|}{ ICCI2 SORBENT - Bench-Scale Test } \\
\hline & Fresh & After 5th Regeneration & After 13th Regeneration \\
\hline \% Total Sulfur & & & .66 \\
Gas Inlet & .08 & .16 & .26 \\
Gas Outlet & .08 & .16 & .16 \\
\hline \% Sulfate Sulfur & & & .04 \\
Gas Inlet & .05 & .14 & .14 \\
Gas Outlet & .05 & & \\
\hline
\end{tabular}


Finally, the attrition of the samples was also measured, as given below:

ASTM attrition:

- Fresh Sorbent: $2.16 \%$

- Gas inlet location, 13 th regeneration: $1.89 \%$

- Gas outlet location, 13th regeneration: $2.09 \%$

For comparison, other sorbents exhibit ASTM attrition values of around 0.7 to $1 \%$ for fresh sorbent. ICCI-2C's attrition is approximately double. However, the advantage of one material over the other for TECO operation (i.e., where regeneration is done under $\mathrm{SO}_{2}$ at 5-7 atm) can only be given by the more extensive testing protocol, i.e., the 25 cycle test under pressurized conditions of regeneration in the presence of $\mathrm{SO}_{2}$. ICCI-2C is capable of operating under pilot plant conditions (1.5-atm regeneration) provided an activation step for three to five cycles in the absence of $\mathrm{SO}_{2}$ during regeneration is carried out. Evaluation at higher generation pressures (i.e., $7 \mathrm{~atm}$ ), as in the TECO demonstration plant, will require additional laboratory testing before confirming the suitability of the sorbent for those conditions. 


\subsection{TASK 5 - SORBENT COST ASSESSMENT}

In the process of screening formulations for sorbent development, it is important not only to analyze the sorbent performance from a technical standpoint (desulfurization and regeneration characteristics) but also from the point of view of the potential cost associated with the operation of a commercial hot gas cleanup system using a moving-bed sorbent. The important cost areas in determining the total operating cost associated with the sorbent itself are:

- purchase of the sorbent

- replacement or makeup during operation

- disposal of the spent material

The cost assessment was initiated early in the program and concurrently in the cost assessment with the thermodynamic equilibrium calculations of Task 2 -Sorbent Preparation. The first item in the cost assessment is the purchase cost of the sorbent, which includes the price of raw materials and the fabrication cost at a vendor. We looked at the order-of-magnitude purchase price of raw metal oxides for sorbent fabrication in commercial quantities (i.e., more than 100,000 lb/year). Table 3-24 shows the relative costs of the metal oxides identified under Task 2 as being potentially usable for sorbent fabrication. If a sorbent is to be fabricated inexpensively and be competitive in price with either a straight zinc titanate (with no additives) or a supported zinc oxide on an inert substrate, the cost of raw materials cannot exceed $\$ 2-3 / \mathrm{lb}$.

From Table 3-24 we can see that major desulfurization components, i.e., those oxides that will perform the bulk of the desulfurization duty, must be in the lower categories of the cost scale, namely, less than $\$ 2 / \mathrm{lb}$. Zinc oxide can be obtained from about $\$ 0.50 / \mathrm{lb}$ for relatively low purity up to about $\$ 2 / \mathrm{lb}$ for high purity/high surface area grades. Manganese oxides and copper oxides can be purchased in large quantities for about $\$ 2 / \mathrm{lb}$, so they also can be used as starting materials for bulk desulfurization. Oxides in the medium-to-high price range such as zirconium oxide can be used as strengthening materials (since the desulfurization activity is practically zero) but in smaller quantities, less than $50 \%$ of the composition, in order to keep raw material prices down.

In addition, raw metal oxides that cost $\$ 7-10 / 1 b$ can only be used as additives in small amounts $(<10 \%)$ to a major desulfurization component, so that the price increases by less than $\$ 1 / \mathrm{lb}$ only. Because target

Table 3-24. Relative cost of metal oxides for sorbent fabrication

\begin{tabular}{|l|c|c|}
\hline$<\mathbf{\$ 1 / l b}$ & $\mathbf{\$ 2 - \$ 6 / l b ~}$ & $\mathbf{\$ 7 - \$ 1 0 / l b}$ \\
\hline $\mathrm{ZnO} \rightarrow$ & $\leftarrow \mathrm{ZnO}$ & $\mathrm{V}_{2} \mathrm{O}_{5}$ \\
$\mathrm{TiO}_{2}$ & $\mathrm{NiO}$ & $\mathrm{MoO}_{3}$ \\
& $\mathrm{MnO}_{2}$ & $\mathrm{Cr}_{2} \mathrm{O}_{3}$ \\
& $\mathrm{CuO}$ & $\mathrm{CoO}$ \\
& & $\mathrm{CeO}_{2}$ \\
& & $\leftarrow \mathrm{ZrO}_{2} \rightarrow$ \\
\hline
\end{tabular}


prices for commercial quantities of moving-bed sorbents are in the range of $\$ 3-5 / \mathrm{lb}$, the expensive metal oxides like molybdenum seem to be viable only as secondary additives. For instance, current zinc titanate with molybdenum additive uses two to three percent molybdenum in order to keep target costs within reach.

The second item in the initial purchase cost is the fabrication cost. From discussions with various sorbent suppliers, the cost of converting the raw materials into a formed (pelletized) sorbent formulation adds about $\$ 1 / \mathrm{lb}$ for the current fabrication techniques. These pelletization techniques are considered proprietary or trade secrets so no details are available in the public domain.

After the initial purchase cost, the second category in the total operating cost assessment of sorbents included the cost associated with the replacement or makeup cost of the sorbent. The sorbent makeup is dictated by the necessary removal of the sorbent from the moving-bed system either because of fines production (by attrition or pellet degradation that increases the pressure drop across the bed) or a loss in chemical reactivity of the sorbent (that requires faster sorbent movement across the absorber to maintain a given level of desulfurization performance). The removal of sorbent fines is done after each cycle through a vibrating screen at the bottom of the regenerator.

The basis for calculating the replacement or makeup cost for a moving-bed system is the current TECo Polk Power Station I configuration for the entire plant:

- $250 \mathrm{MW}$ (net) electricity production

- 2000 ton (dry)/day of coal with $2.45 \%$ sulfur and $4.5 \%$ moisture in the coal

- $7 \%$ sulfur loading per pound of sorbent and $100 \%$ sulfur removal from the coal fuel

Figure 3-67 presents the sorbent makeup cost, in cents per kWh versus the percent sorbent makeup as a function of purchase cost. Since the sorbent moves continuously in a loop between the absorber and the regenerator vessels in the moving-bed system, the sorbent makeup is defined as the percentage of

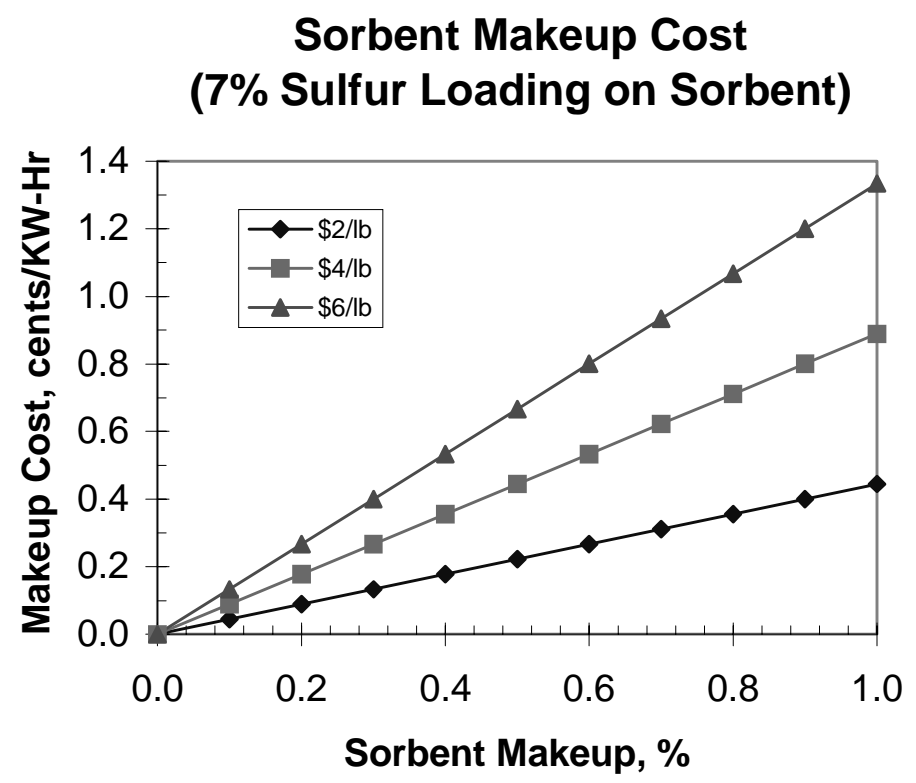

Figure 3-67. Sorbent makeup cost versus percent sorbent makeup. 
the total material circulated in pounds divided by the amount removed through the vibrating screen, also in pounds. Therefore, if the sorbent makeup cost that a utility company is willing to accept is defined and the purchase cost per pound is available from a sorbent supplier, then the allowable sorbent makeup rate (as a percentage of the circulated amount) is defined. For instance, if the utility company will accept a makeup cost of 0.1 to 0.2 cents/ $\mathrm{kWh}$ and the sorbent supplier quotes a selling price range of $\$ 3-\$ 5 /$ $\mathrm{lb}$, then a makeup rate of 0.16 to $0.2 \%$ is acceptable to make the system economically viable at the commercial scale.

Acceptable sorbent candidate formulations for moving beds have an initial ASTM attrition loss of 1-2\% or less. The ASTM attrition loss measured in laboratory tests has been observed to be up to 10 times higher than the actual makeup rates measured in the pilot plant. If this ratio holds for commercial-scale systems, the actual makeup rate will be about $0.1-0.2 \%$ for fresh material, which is in agreement with the sample calculation of 0.16 to $0.2 \%$ presented above using Figure 3-67. Market conditions will eventually determine the target ASTM attrition rates for acceptability of a given sorbent formulation.

The third category in the total operating cost assessment of sorbents includes the disposal cost of the spent sorbent. The cost of disposal will be directly related to whether or not the material can be classified as non-hazardous and suitable for landfilling. Past samples of sorbents from the GE-CRD pilot plant have been analyzed and passed landfill requirements as non-hazardous materials under RCRA requirements.

Various reclaimers have been contacted by GE-CRD in the past under the pilot plant program, and various arrangements have been made for disposal of relatively small quantities of zinc titanates and zinc-based sorbents. For larger shipments (about 30,000 lb), the reclaimer has paid \$20/ton for the spent sorbent material. For large commercial quantities (greater than 100,000 lb), it is expected that a positive revenue can be realized by the utility for selling the material to the metal ore reclaimer. The chemical composition will influence strongly the selling price. For the purpose of estimation of the operating costs for this task, no credit is given for the sale of the spent sorbent material since geographic market conditions vary widely across the U.S.

Consequently, for a sorbent development program for moving-bed applications, the general guidelines to keep the sorbent costs low and aim at meeting commercial operation targets should be:

- Bulk desulfurization components should be less than $\$ 2 / \mathrm{lb}$.

- Sorbent makeup rates should be about $0.1-0.2 \%$ in commercial systems when the purchase price range is $\$ 3-5 / 1 b$ and the acceptable operating cost for the utility company is in the range of 0.1-0.2 cents/kWh.

- A positive revenue stream is expected if the spent sorbent can be sold as non-hazardous, landfillable material under RCRA guidelines. 


\subsection{TASK 6 - TOPICAL REPORT}

This topical report includes a summary of all the technical information generated during the course of the contract from September 1994 to date. In addition to the monthly technical reports, the following annual technical reports were submitted to DOE to summarize the annual technical progress of the project:

- 1994 Annual Technical Report (September 1994-November 1994)

- 1995 Annual Technical Report (December 1994 to November 1995)

- 1996 Annual Technical Report (December 1995 to November 1996)

- 1997 Annual Technical Report (December 1996 to November 1997) 


\subsection{TASK 7 - MARKET PLAN}

The market plan for the development of moving-bed sorbents was centered around potential sorbent suppliers for three formulations:

1. modified zinc titanates (MZT's)

2. ICCI-2C sorbent

3. zinc-manganese oxide sorbents

Fabrication of modified zinc titanates was conducted at UCI in the performance of this contract program. To develop technical formulations that could be manufactured in commercial quantities (greater than 100,000 lb/yr), UCI committed to provide technical support in the development of the large-scale technique for extruding and forming MZT's at their facilities in Louisville, Kentucky. Fabrication of zinc titanate compositions is protected in part by previous patent positions at GE developed during the course of the years in sorbent development. The know-how of pelletization and forming comes from UCI's industrial experience in the granulation, pelletization, and forming of commercial catalysts and specialty chemicals. A secrecy agreement was signed between GE and UCI and is in place to protect UCI's industrial experience in the market place. This relationship of patented zinc titanate compositions and proprietary fabrication techniques is in place to move forward quickly in response to market conditions that require manufacture of large quantities of sorbents.

As the testing at TECo's Polk Station proceeds with the current sorbent formulations, and if a request is received from DOE and TECo's project management, UCI and GE are in a position to consider fabrication of 100,000 lb. of zinc titanate sorbents. Market conditions, scheduling of production, raw materials costs, and other external factors will determine the timing and final cost of the delivered product, but it is anticipated that the target sorbent cost of $\$ 3-5 / \mathrm{lb}$ can be met. A potential market development risk for commercialization of moving-bed sorbents in the future is the uncertainty about the size of the near-term market for coal-based IGCC power generation in the U.S. Several alternate sorbent manufacturers had been polled by GE over the years for upgrading of their facilities to prepare for demonstration- and commercial-scale production of desulfurization sorbents, and a recurring question revolves around the certainty in the predicted near-future market for coal-based IGCC in the US.

Several other sorbent manufacturers are interested in forming partnerships to market moving-bed sorbents, but, because of their smaller current production size, response to a sudden opening in the IGCC/HGCU market would take several years for them to upgrade their production facilities and respond to market requests for new sorbents.

In parallel to the position of modified zinc titanates, E\&A Associates has also developed a proprietary position with UCI to offer ICCI-2C sorbent in support of moving-bed sorbents at TECo. As actual process conditions for steady-state desulfurization in the demonstration-scale TECo plant develop, ICCI-2C is an alternate sorbent path for moving-bed sorbent development towards commercial systems.

With respect to the evaluation of manganese-based sorbents, it is believed that a feasible program plan could be implemented where Chemetals optimizes the chemical composition and mechanical strength of manganese-zinc based sorbents and GE focuses on the kinetic characteristics of the desulfurization performance. Potential applications of the manganese-based sorbents for moving-bed systems would be 
a third-generation sorbent fill for the Clean Coal Technology Demonstration Plants. A development plan would still be necessary for the marketing of commercial quantities of zinc-manganese sorbents.

Evaluation of manganese-containing sorbents suggested that improvements in mechanical strength can be brought about by the manganese component of the sorbent. Given that manganese by itself cannot remove $\mathrm{H}_{2} \mathrm{~S}$ to as low levels as zinc-based sorbents can, the combination of both zinc and manganese oxides may give a synergistic advantage that either of the two metals taken alone cannot provide. However, improvements in the attrition resistance of the manganese-zinc pellets in larger scale production are necessary to compete in durability against other zinc-containing sorbents.

\section{REFERENCES: CHAPTER 3}

1 Gal, E.1991 System for Removal of Sulfur Compounds from Gases and for Regenerating Spent Sorbents, U.S. patent 5,026,528, June 25, 1991. Also U.S. patent 4,857,285, August 1989.

2 Ayala, R.E. and E. Gal. 1995. Process and Apparatus for Generating Elemental Sulfur and Reusable Metal Oxide from Spent Metal Sulfide Sorbents, U.S. patent 5,401,475, March 28, 1995.

3 Ayala, R.E. Molybdenum-Based Additives to Mixed-Metal Oxides for Use in Hot Gas Cleanup Sorbents for the Catalytic Decomposition of Ammonia in Coal Gases. U.S. Patent 5,188,811. Feb. 23, 1993.

4 Ayala, R.E.; T.L. Chuck; and V.S. Venkataramani. Hot Coal Gas Desulfurization. US Patent 5,753,198. May 19, 1998.

5 Furman, A.H., R. Ayala, A. Feitelberg, M. Lacey, and S. Bevan. 1998. Integrated Operation of a Pressurized Fixed-Bed Gasifier and Hot Gas Desulfurization System. CD ROM. Final Report to the U.S. Department of Energy/Federal Energy Technology Center, Morgantown, WV, under contract DE-AC21-87MC23170. March 1998. 


\section{Chapter 4}

\section{CONCLUSIONS AND RECOMMENDATIONS}

\subsection{CONCLUSIONS}

The following conclusions can be drawn from the evaluation of metal oxides from thermodynamic and kinetic principles in order to identify sorbent formulations suitable for fabrication and laboratory evaluation:

- A literature review of past work and screening thermodynamic calculations of metal oxides identified twenty metal oxides that had the potential for use in hot gas desulfurization systems in the temperature range of 343 to $538^{\circ} \mathrm{C}$. These were considered for evaluation.

- Thermodynamic equilibrium diagrams of $\mathrm{H}_{2} \mathrm{~S}_{(\mathrm{g})}$ over metal oxides were constructed as a function of temperature to determine the maximum sulfur removal possible at the given temperature range. Two coal gas fuel compositions were chosen: oxygen-blown, entrained-flow gasifier and air-blown, fluidized-bed gasifier. Of the twenty metal oxides initially considered, manganese, molybdenum, cobalt, zinc, and copper oxides were identified as having the low equilibrium $\mathrm{H}_{2} \mathrm{~S}$ and the required kinetic rates to desulfurize coal gas to the target of less than $25 \mathrm{ppm} \mathrm{H}_{2} \mathrm{~S}$.

- Corresponding phase stability diagrams of the metal sulfides in oxidative regeneration gases were also constructed to identify the regeneration capabilities of the promising desulfurization metal oxides. Zinc, copper, iron and molybdenum among others were the metals that thermodynamically and kinetically exhibited promising characteristics for regeneration at temperatures compatible with the desulfurization range chosen. Manganese required a higher temperature of regeneration than the others but still could be considered for evaluation.

- Three categories of metal oxides were considered for evaluation: (1) main components for desulfurization, (2) secondary components for desulfurization, chemical stability additives, or porosity modifiers, and (3) structural components to maintain mechanical durability of the pellets.

- Table 4-1 summarizes the metal oxides that were identified in each of the three categories as potential candidates for laboratory fabrication and evaluation.

The following conclusions can be drawn from the sorbent fabrication and experimental evaluation of UCI-GE zinc titanates:

Table 4-1. List of metal components for sorbent screening.

\begin{tabular}{ccc}
\hline Main Component & Secondary Component & Structural Component \\
\hline $\mathrm{Zn}$ & $\mathrm{Fe}, \mathrm{Cu}, \mathrm{Mo}, \mathrm{Co}$ & $\mathrm{Ti}, \mathrm{Zr}, \mathrm{Ce}$ \\
$\mathrm{Fe}$ & $\mathrm{Cu}$ & $\mathrm{Ti}, \mathrm{Zr}$ \\
$\mathrm{Ce}$ & $\mathrm{Mo}$ & $\mathrm{Ti}, \mathrm{Zr}$ \\
$\mathrm{Cu}$ & $\mathrm{Mn}$ & $\mathrm{Ti}, \mathrm{Zr}$ \\
\hline
\end{tabular}


- Molybdenum-containing zinc titanate (at 2\% equivalent molybdenum oxide) exhibited a good combination of chemical and mechanical properties during laboratory testing at GE-CRD. Further testing at RTI's facilities during 1996 showed that requirements at that time for chemical reactivity and sulfur loading were exceeded at the target levels of $50 \%$ of theoretical. The mechanical ASTM attrition loss was well below the target level for the fresh material ( $0.7 \% \mathrm{vs.} 4 \%$ target) although the same ASTM attrition loss after 50 cycles was higher at $7.4 \%$ versus the target of $5 \%$. Higher levels of attrition resistance would be required ultimately for this sorbent to be economically viable in commercial systems.

- The same molybdenum-containing formulation studied in the laboratory facilities was also tested for 200 hours of continuous operation in the GE-CRD pilot plant under Test 8 in September 1995 to determine the correspondence in performance between bench-scale conditions in the laboratory and pilot plant operation. The pilot plant makeup losses were measured at 1.7 and $0.3 \%$ for the 200-hr cycled sorbent under conditions of two different mesh sizes of the vibrating screen that removes the sorbent fines. These results compare favorably with the 7.4\% ASTM attrition loss measured after 50 cycles in the laboratory, indicating that the large-scale operation is less severe and the cost of sorbent replacement or makeup in the pilot plant is less than predicted from ASTM tests. With respect to desulfurization performance in the GE-CRD pilot plant, close to $99 \%$ sulfur removal (30-40 ppm dry $\mathrm{H}_{2} \mathrm{~S}$ in the clean gas) was obtained while simultaneously achieving the target sulfur loading on the sorbent for TECo and steady $\mathrm{SO}_{2}$ production during regeneration. The results at the three levels of testing indicate that the flow of information and technology transfer from laboratory to pilot plant is technically consistent and prediction of larger pilot-plant scale operation is possible from laboratory and bench test results.

- Several formulations of modified zinc titanates (MZT's) were pelletized to aim at improvements in mechanical durability over the previously tested molybdenum-containing zinc titanate formulations. Two rounds of formulations containing additives were prepared. Although the first round of formulations was disappointingly weak in mechanical strength, the second round of pelletization included two formulations, MZT-I1 and MZT-R1, which exhibited improved characteristics. Both presented better mechanical durability with negligible degradation with respect to the fresh formulation, but only MZT-R1 was capable of meeting the requirements of sulfur loading of $0.11 \mathrm{~g}$ of sulfur $/ \mathrm{cm}^{3}$ of bed $\left(6.7 \mathrm{lb} / \mathrm{ft}^{3}\right)$ at the low temperatures of operation $\left(370^{\circ} \mathrm{C}, 700{ }^{\circ} \mathrm{F}\right)$.

- Batch-to-batch repeatability in the fabrication of MZT's, however, is still an issue. ASTM attrition loss of different batches of fresh MZT-R1 prepared for testing at GE-CRD and RTI ranged from 0.7 to $2.0 \%$. This batch-to-batch variability in the attrition resistance of fresh samples is large compared to the corresponding changes in attrition loss, typically less than $1 \%$, that occur over repetitive testing. Further refinements to the formulation of MZT compositions will require better control in the pelletization procedures.

- Testing at RTI for 13 cycles at bench-scale conditions showed that the two MZT sorbents considered (MZT-R1 and MZT-I1) can desulfurize and regenerate at conditions resembling those to be encountered at the TECo plant, namely, desulfurization in the range $373-482^{\circ} \mathrm{C}\left(700-900{ }^{\circ} \mathrm{F}\right)$ and regeneration up to $760^{\circ} \mathrm{C}\left(1400^{\circ} \mathrm{F}\right)$. In spite of these positive results, more work is needed to circumvent the impending degradation of the pellets over a higher number of cycles. 
The following conclusions can be drawn from the testing of proprietary sorbents in the GE-CRD pressurized bench-scale reactor system:

- Several formulations of zinc oxide/manganese oxide sorbents provided by Chemetals (Baltimore, Maryland) were evaluated at GE-CRD for mechanical durability (attrition and crush strength) and chemical reactivity.

- Evaluation of Chemetals manganese-containing zinc-based sorbents suggested that improvements in mechanical strength can be brought about by the manganese component to the sorbent. Given that manganese by itself cannot remove $\mathrm{H}_{2} \mathrm{~S}$ to as low levels as zinc-based sorbents can, the combination gives a synergistic advantage of deep desulfurization and added mechanical strength. However, improvements in the fabrication procedures aimed at increasing attrition resistance of the manganese-zinc pellets are necessary to compete against other zinc-containing sorbents in durability.

- Evaluation of ICCI-2C sorbent was carried out at GE-CRD with the purpose of evaluating the reactivity and durability of the sorbent in pelletized forms. ASTM attrition losses after 13 cycles of bench testing (range 1.89-2.09\%) were comparable to that of the fresh sorbent (2.16\%), suggesting that this sorbent is a potential candidate for long-term use. All testing was performed at $482{ }^{\circ} \mathrm{C}$ for absorption and regeneration; evaluation at lower temperatures is still needed to confirm suitability for low-temperature operation down to $343^{\circ} \mathrm{C}$.

- ICCI-2C is capable of operating under pilot plant conditions (1.5-atm regeneration) provided an activation step of three to five cycles is carried out in the absence of $\mathrm{SO}_{2}$ during regeneration. Evaluation at higher generation pressures (i.e., $7 \mathrm{~atm}$ ), as in the TECO demonstration plant, will require additional bench-scale testing before confirming the suitability of the sorbent for those conditions.

- With respect to the economics of operating a moving-bed HGCU system, a reasonable target for the sorbent operating cost to a utility company is 0.1 to 0.2 cents $/ \mathrm{kWh}$. To operate below this target and be commercially viable, the sorbent makeup rate must be less than 0.16 to $0.2 \%$ at a sorbent purchase price of $\$ 3-5 / \mathrm{lb}$ to make the moving-bed HGCU systems feasible. Higher sorbent prices or higher make-up rates make the HGCU system commercially less attractive. Currently, sorbent manufacturers consider these sorbent prices achievable in commercial quantities. 


\subsection{RECOMMENDATIONS}

The development of zinc titanates, whether in the form of molybdenum-added formulations or modified zinc titanates (MZT's), has reached a level of understanding that makes them suitable for commercial applications. Evaluation of desulfurization reactivity at the laboratory, bench-scale, and pilot-plant facilities has shown that zinc titanates and proprietary sorbents can easily meet the target levels of $99 \%$ desulfurization of coal gases in the temperature range of 343 to $538^{\circ} \mathrm{C}$.

A significant issue that still remains with the use of zinc titanates is the capability to control the fabrication procedures that result in predictable sorbent mechanical properties, particularly the ASTM attrition resistance. To date, variations from batch to batch have a spread that is comparable to the changes observed during testing over five to fifteen cycles. It is recommended that a program be undertaken with commercial sorbent suppliers aimed at understanding and minimizing the variability in the physical morphology and mechanical properties of the pelletized sorbents.

For the case of Chemetals manganese-zinc sorbents, given that addition of zinc oxide decreased the attrition resistance of the pure manganese sorbents, a study of the production methods and mixing variability is also needed.

For the case of ICCI-2C sorbents, a study is needed on the operability of the sorbent at temperatures in the range 343 to $482^{\circ} \mathrm{C}$ to determine if the chemical reactivity is sufficient to operate a commercial system at the desired sulfur loadings on the sorbent. In addition, methods should be investigated that decrease the level of conditioning or activation that is currently required over the first three to five cycles.

Overall the technology of manufacturing pelletized sorbents for desulfurization in moving-bed applications has reached a maturity that makes it possible to assess current sorbent performance in laboratory and bench-scale systems and correlate with pilot-scale performance. Extrapolation of these performance parameters is still necessary when going to commercial scale systems, since no data have been generated at those scales. Future advances in moving-bed technology will require data on the mechanical and chemical performance of TECo's Polk Station hot gas cleanup demonstration plant. 


\title{
Advanced Sorbent Development Program \\ Development of Sorbents for Moving-Bed and Fluidized-Bed Applications
}

Volume II: Development Of Sorbents For Fluidized-Bed Applications

Final Technical Report

\author{
By \\ Javad Abbasian \\ Rachid B. Slimane \\ Brett E. Williams \\ Minoo K. Zarnegar \\ James R. Wangerow \\ Andy H. Hill
}

Work Performed as a Subcontract to GE Corporate Research and Development Under Contract No. DE-AC21-94MC31089

September 30, 1994 - March 31, 2000

For

U.S. Department of Energy

Office of Fossil Energy

National Energy Technology Laboratory

P.O. Box 880

Morgantown, WV 26507-0880

By

Institute of Gas Technology

1700 S. Mt. Prospect Rd

Des Plaines, IL 60018-1804

March 2000 


\section{DISCLAIMER}

This report was prepared as an account of work sponsored by the United States Government. Neither the United States nor the National Energy Technology Laboratory (NETL), nor any of their employees, makes any warranty, expressed or implied, or assumes any legal liability or responsibility for the accuracy, completeness or usefulness of any information, apparatus, product, or process disclosed, or represents that its use would not infringe privately owned rights. Reference herein to any specific commercial product, process, or service by trade name, mark, manufacturer, or otherwise, does not necessarily constitute or imply its endorsement, recommendation, or favoring by the United States Government or any agency thereof. The views and opinions of authors expressed herein do not necessarily state or reflect those of the United States Government or any agency thereof.

This report will be available to the public from the National Technical Information Service, U.S. Department of Commerce, 5285 Port Royal Road, Springfield, VA 22161; phone orders accepted at (703) 487-4650. 


\section{ACKNOWLEDGEMENT}

We express our appreciation to the Department of Energy, National Energy Technology Laboratory (NETL) and General Electric Corporate Research and Development (GE-CRD) for financial support under Contract DE-AC21-94MC31089 "Advanced Sorbent Development." We also thank GE-CRD Project Manager Dr. Raul Ayala and DOE/NETL Project Managers, Mr. Daniel C. Cicero and Mr Suresh C. Jain, for providing technical support and guidance during the course of this project. 


\section{EXECUTIVE SUMMARY}

This report is submitted to the United States Department of Energy in fulfillment of the contractual requirements for the project titled, 'Advanced Sorbent Development', under agreement number DE-AC21-94MC31089.

The overall objective of this program was to develop regenerable sorbents for use in the temperature range of 343 to $538^{\circ} \mathrm{C}\left(650\right.$ to $\left.1000^{\circ} \mathrm{F}\right)$ to remove hydrogen sulfide $\left(\mathrm{H}_{2} \mathrm{~S}\right)$ from coal-derived fuel gases in a fluidized-bed reactor.

The goal was to develop sorbents that are capable of reducing the $\mathrm{H}_{2} \mathrm{~S}$ level in the fuel gas to less than $20 \mathrm{ppmv}$ in the specified temperature range and pressures in the range of 1 to 20 atmospheres. The sorbents are expected to have chemical characteristics that permit cyclic regeneration over many cycles without a drastic loss of activity, as well as physical characteristics that are compatible with the fluidized bed application.

The initial principal criterion used for sorbent formulation was based on thermodynamic equilibrium calculations to limit the choice of the active sorbent metal oxides to those that can meet the stringent requirement of removing $\mathrm{H}_{2} \mathrm{~S}$ to below 20 ppmv in the temperature range of 343 to $538^{\circ} \mathrm{C}\left(650\right.$ to $\left.1000^{\circ} \mathrm{F}\right)$ and at 20 bar pressure. The main criteria imposed for selection of potential metal oxides in this study were: (a) favorable thermodynamic equilibrium in the temperature range of 350 to $550^{\circ} \mathrm{C}$; (b) minimization of undesired reactions under reducing gas conditions, such as interactions with $\mathrm{HCl}, \mathrm{CO}$, and $\mathrm{H}_{2}$, and catalysis of gas phase reactions; (c) feasibility and ease of complete conversion of metal sulfide to oxide (i.e., regeneration); and (d) minimization of undesired reactions under regeneration conditions, such as sulfate formation and hydrothermal instability. Based on these criteria, only the sorbents based on oxides of copper $(\mathrm{Cu})$, iron $(\mathrm{Fe})$, manganese $(\mathrm{Mn})$, and zinc $(\mathrm{Zn})$ were considered in this research program.

During the course of this program, three different sorbent preparation approaches were investigated. These research approaches were designated as Method I, Method II, and Method III. The sorbent formulations that exhibited higher attrition resistance than a baseline UCI-4169 sorbent were evaluated for their sulfidation reactivity in a packed-bed reactor. The regenerability of those sorbent formulations that achieved high levels of conversion during the first cycle were each evaluated in a $1 \frac{1}{2}$ cycle test. The sorbent formulations that exhibited good reactivity and regenerability in the moderate temperature range of 350 to $538^{\circ} \mathrm{C}$ were further evaluated in multi-cycle testing.

Method I concentrated on the preparation of highly dispersed metal oxide sorbent formulations using refractory supports/dispersants, which are themselves highly resistant to sintering and deterioration. The rationale was that these low-capacity sorbents would have a high probability of maintaining good chemical reactivity and physical stability with cycling. A total of 66 sorbent formulations were prepared using Method I. These sorbents were evaluated in packed-bed reactor. 
Attempts were then made to improve the sulfur capacity of the prepared sorbents, using the same sorbent preparation technique. However, most of the sorbent formulations prepared with this approach lacked sufficient strength and/or reactivity toward $\mathrm{H}_{2} \mathrm{~S}$, necessitating an alternative sorbent preparation technique to be utilized.

In order to achieve sorbent stability at the highest possible effective sulfur capacity, secondary efforts were devoted to the preparation of sorbents having higher sulfur capacity and mechanical strength. This was accomplished by extending the application of a pelletization technique previously developed for the formulation of spherical pellets (dia. $=3-10 \mathrm{~mm}$ ) to the preparation of highly attrition-resistant granular sorbents (dia. $=50$ to $850 \mu \mathrm{m}$ ). A total of 113 sorbent formulations were prepared using Method II. The parameters considered in preparing the sorbents included selection of the primary reactive metal oxide, primary reactive metal oxide concentration, selection of the primary support material (matrix), ratio of primary reactive oxide to support material, selection and concentration of secondary reactive metal oxides, selection and concentration of inorganic binders, selection and concentration of organic binders, initial high temperature processing, and induration/calcination condition.

Based on the results of evaluation of sorbents prepared by the traditional Method II, the following conclusions are drawn:

- Fe-based sorbents: No sorbent based on iron oxide was found to have sufficient reactivity in the moderate temperature range.

- Mn-based sorbents: Encouraging results were obtained with sorbents based on manganese oxide; however, their regeneration necessitates very high temperatures that cannot be accommodated by current desulfurization systems requiring regeneration ignition temperatures of about $550^{\circ} \mathrm{C}$.

- Zn-based sorbents: The results obtained with zinc-based sorbents prepared using Method II suggest that although excellent effective sulfur capacity and $\mathrm{H}_{2} \mathrm{~S}$ removal efficiency can be achieved in the moderate temperature range of 350 to $550^{\circ} \mathrm{C}$, using traditional sorbent preparation techniques such as solid oxide mixing, coprecipitation, etc., may not be suitable for development of effective sorbents with sufficient attrition resistance required for a demanding commercial application, such as the Piñon Pine transport reactor.

- Cu-based sorbents: Only sorbents based on copper oxide were found to possess the best combination of high attrition resistance and sulfidation reactivity, sulfur removal efficiency, and pre-breakthrough conversion in the moderate temperature range of 350 to $550^{\circ} \mathrm{C}$.

Given the results obtained, two zinc-based sorbents (IGTSS-314B, IGTSS-325A), one manganese-based sorbent (IGTSS-057), and one copper-based sorbent (IGTSS-179) were selected for the bench-scale fluidized-bed tests in the high-pressure reactor. 
The bench-scale high-pressure fluidized-bed tests were conducted with the selected sorbent in the bubbling fluidized-bed regime at $10 \mathrm{~atm}$ pressure at $450{ }^{\circ} \mathrm{C}$. The results of these tests indicated that the copper-based IGTSS-179 was the only sorbent that could satisfy both the high attrition resistance and the high reactivity requirements for the transport reactor application. However, because fluidization of copper-based sorbents in the reducing fuel gas environment at low superficial velocities of bubbling fluidized-bed appeared to be problematic, additional efforts were directed toward further evaluation of copper-based sorbents in fluidized-bed reactors. These efforts resulted in the development of IGTSS-326A and IGTSS-345B sorbents, which exhibited improved fluidization behavior compared to the IGTSS-179 sorbent.

Given the results obtained with the sorbents prepared by the conventional Method II, there was a need for an alternative sorbent preparation approach that have been shown to produce mechanically strong, porous solids with median pore diameters in the range of interest. Review of the literature identified sol-gel processing as a promising technique for development of more effective sorbents.

In the sol-gel approach of Method III, a stable sol is first prepared from a titania precursor (alkoxide and/or powder). The required amount of a zinc precursor (zinc nitrate hexahydrate) is then added to bring the zinc oxide content to the desired level. The resulting solution is then well mixed to disperse the reactive oxide, thickened, dried, and finally calcined at the desired temperature for a predetermined period.

Eleven (11) $\mathrm{ZnO}$-based sorbent formulations were prepared using a modified solgel approach (Method III). These sorbents exhibited unique properties that are unattainable by conventional sorbent preparation methods. This method eliminates the need for excessively high thermal treatment temperatures to impart the required physical strength and has made possible the achievement of the challenging combination of high reactivity (desirable pore size distribution and high surface area), high attrition resistance, and regenerability at lower temperature.

Based on the results obtained with this sorbent preparation technique, three zincbased sorbents (i.e., IGTSS-353, IGTSS-354, and IGTSS-360) demonstrated high chemical reactivity, regenerability at lower temperatures, and attrition resistance properties far exceeding the stringent requirement of the transport reactor application.

Based on the results obtained in this program, three sorbent formulations were selected as potentially-suitable candidates for the transport reactor application. These sorbents included the copper-based IGTSS-326A, the mixed copper-and zinc-based IGTSS-345B, and the zinc-based IGTSS-354.

Although high reactivity, superior attrition resistance, and excellent durability were demonstrated for a number of sorbents, in order to move these leading sorbents towards the IGCC demonstration stage at the Piñon Pine facility, the U.S. DOE, the M. W. Kellogg (MWK), and the Sierra Pacific Power Company (SPPC) require that the 
sorbent be produced by a commercial sorbent manufacturer and its effectiveness evaluated according to a precise test protocol developed by USDOE/NETL.

Arrangements were made, under a confidentiality agreement, with United Catalyst, Inc. (UCI) to prepare 10 pounds of each of IGTSS-326A and IGTSS-345B according to IGT's preparation procedure, but using a spray-drying technique. A similar arrangement was also made with Contract Materials Processing, Inc. (CMP) to produce 20 pounds of IGTSS-354 sorbent. The commercially-produced sorbents were evaluated for their attrition resistance, chemical reactivity, and fluidization behavior.

Comparison of the attrition resistance properties of the IGTSS-326A and IGTSS$345 \mathrm{~B}$ produced at IGT and UCI indicated that the spray-dried sorbents produced by UCI have significantly higher attrition resistance than those produced at IGT, both significantly exceeding the requirement for the transport reactor application. However, particle size analysis of the commercially-produced IGTSS-354 sorbent (produced by CMP) indicated that $100 \%$ of its particles are smaller than 45 microns. The attrition resistance of this commercially produced material could not be determined by the ASTM 5757-95 technique because essentially all the materials are elutriated from the unit.

The effective sulfur capacities of the commercially-produced sorbents were also determined in the packed-bed reactor for comparison with those produced at IGT. The results indicated that the effective sulfur capacities of all commercially-produced sorbents are lower than those produced at IGT. In the case of IGTSS-326A and IGTSS-345B sorbents the effective sulfur capacities of the sorbents produced by UCI are only slightly lower than those produced at IGT. Despite the small particle size of the commerciallyproduced IGTSS-354 (produced by CMP), this sorbent exhibited significantly lower reactivity and sulfur capacity, compared to those obtained with the sorbent produced at IGT, which should be attributed to the production technique used by CMP.

The commercially-produced IGTSS-326A and IGTSS-345B sorbents were also evaluated for their fluidization behavior. However, fluidization of both of these spraydried sorbents under bubbling fluidized-bed conditions continued to be problematic. Efforts were directed toward determination of the ranges of operating conditions under which acceptable fluidization behavior can be maintained. The parameters investigated included reduction/sulfidation temperature $\left(300\right.$ to $\left.550^{\circ} \mathrm{C}\right)$, composition of reduction/sulfidation gas, and superficial gas velocity $(20$ to $45 \mathrm{~cm} / \mathrm{s})$. The results obtained and observations made suggest that in the range of gas velocities employed, achieving desirable fluidization behavior with the commercially-produced copper-based IGTSS-326A and IGTSS-345B sorbents alone, after undergoing reduction or simultaneous reduction/sulfidation, is also problematic. The fluidization behavior of the sorbents improved with increasing gas velocities, and may be expected to be problemfree at the much higher gas velocities prevailing in the transport reactor. However, because of the limitation of the batch reactor used in this project, higher gas velocities could not be used and it was not possible to determine the gas velocity beyond which good sorbent fluidization can be maintained during sulfidation. 
Based on all the results obtained in this program, the $\mathrm{ZnO}$-based sorbents produced by sol-gel technique developed in this program exhibited the best attrition resistance that significantly exceeds the requirement for the transport reactor application. Furthermore, these sorbents showed excellent reactivity, regenerability at lower temperatures, and long-term durability.

To ensure successful commercialization of sol-gel based sorbents, the preparation technique should be modified to make it more economical and readily adaptable to a large-scale production. Therefore, at the completion of this program, these efforts are continuing under the sponsorship of the Illinois Clean Coal Institute in coordination with DOE/NETL. 


\section{TABLE OF CONTENTS}

PROGRAM OBJECTIVE

Page No

1

BACKGROUND

DESULFURIZATION/REGENERATION REACTOR CONSIDERATIONS 3

THERMODYNAMIC AND PRACTICAL CONSIDERATIONS 8

Desulfurization (Sulfidation) Considerations $\quad 8$

$\begin{array}{ll}\text { Regeneration Considerations } & 14\end{array}$

$\begin{array}{ll}\text { EXPERIMENTAL SECTION } & 17\end{array}$

Method I 17

Method II 18

Pelletization Procedure $\quad 19$

Method III $\quad 22$

Introduction $\quad 22$

EXPERIMENTAL APPROACH AND PROCEDURES 24

Preliminary Screening of Prepared Sorbents $\quad 24$

Chemical Analysis and Physical Characterization $\quad 25$

ASTM Attrition Resistance Procedure $\quad 27$

Attrition Unit Performance Verification 28

HPTGA System Description and Testing Procedures $\quad 30$

Ambient Pressure Packed-/Fluidized-Bed Reactor 33

Bench-Scale High- Pressure /High- Temperature Reactor (HPTR) 35

$\begin{array}{ll}\text { RESULTS AND DISCUSSION } & 38\end{array}$

$\begin{array}{ll}\text { Sorbents Prepared with Method I } & 38\end{array}$

Sorbents Prepared with Method II $\quad 48$

Comparison of Attrition Resistance $\quad 57$

Bench-Scale Testing in the High-Pressure Reactor 59

Further Efforts with Copper-Based Sorbents 63

Sorbents Prepared by Sol-Gel Technique (Method III) 67

$\begin{array}{ll}\text { Sorbent Characterization } & 69\end{array}$

Comparison of Attrition Resistance 69

Evaluation of Chemical Reactivity, Regenerability, and Durability 72

SORBENT PRODUCTION BY COMMERCIAL MANUFACTURERS 82

CONCLUSIONS AND RECOMMENDATIONS $\quad 87$

REFERENCES $\quad 91$ 


\section{LIST OF FIGURES}

Figure 1. Schematic Diagrams of Different Types of Hot Gas Cleanup Systems for IGCC Application

Figure 2. High Temperature High Pressure Sulfur Removal Subsection of 7 Enviropower's $15 \mathrm{MW}_{\text {th }}$ Pressurized Gasification Pilot Plant

Figure 3. $\mathrm{H}_{2} \mathrm{~S}$ Concentration in Fuel Gas in Equilibrium with Various Metal Oxides (UGAS)

Figure 4. $\mathrm{H}_{2} \mathrm{~S}$ Concentration in Fuel Gas in Equilibrium with Various Oxides (Texaco)

Figure 5. Superimposed Stability Diagrams for $\mathrm{Cu}, \mathrm{Fe}, \mathrm{Mn}$, and $\mathrm{Zn}$ Oxides as a Function of Temperature and $\mathrm{CO}_{2}$ to $\mathrm{CO}$ Ratio

Figure 6. Oxide/Sulfate Equilibria for a Number of Metal Systems at $750^{\circ} \mathrm{C}$

Figure 7. Phase Stability Diagram for the Cu-S-O System

Figure 8. Phase Stability Diagram for the Mo-S-O System 16

Figure 9. Pelletizer Used for the Production of Spherical Pellets and Granules from Fine 20 Powders

Figure 10. Experimental Arrangement for Preliminary Attrition Resistance Evaluation of Sorbents

Figure 11. Preliminary Attrition Resistance of Baseline Sorbent (UCI-4169 Zinc Titanate) 26

Figure 12. Schematic Diagram of the Three-Hole Attrition Resistance Measurement Unit 28

Figure 13. Comparison of AJI Results of FCC Catalyst at Different Facilities 29

Figure 14. Comparison of Attrition Results of Different Materials at IGT and ANRF 29

Figure 15. Schematic Diagram of the Overall Arrangement of the High-Pressure 31 Thermogravimetric Analyzer (HPTGA)

Figure 16. Schematic Diagram of HPTGA Reaction Chamber Details

Figure 17. Schematic Diagram of the Packed-Bed Reactor Unit 


\section{LIST OF FIGURES (CONT.)}

Figure 18. Schematic Diagram of the High-Pressure/High-Temperature Reactor (HPTR) 37 Unit

Figure 19. $\mathrm{H}_{2} \mathrm{~S}$ Breakthrough Curves for UCI-4169 Zinc Titanate Sorbent 38

Figure 20. $\mathrm{H}_{2} \mathrm{~S}$ Breakthrough Curves for CuCr-1 Sorbent 39

Figure 21. $\mathrm{H}_{2} \mathrm{~S}$ Breakthrough Curves for CuCr-2 Sorbent $\quad 40$

Figure 22. Effect of Temperature on Effective Sorbent Conversion 40

Figure 23. Effect of Temperature on Maximum Space Velocity 41

Figure 24. Effect of Temperature on Maximum Effective Sulfur Capacity 42

Figure 25. Conversions for Sorbent IGTSS-1 at $350^{\circ} \mathrm{C} \quad 43$

Figure 26. $\mathrm{H}_{2} \mathrm{~S}$ Breakthrough Curves for Sorbent IGTSS-1 at $350^{\circ} \mathrm{C} 43$

Figure 27. Conversions for Sorbent IGTSS- 11 at $450^{\circ} \mathrm{C}$

Figure 28. $\mathrm{H}_{2} \mathrm{~S}$ Breakthrough Curves for Sorbent IGTSS-11 at $450^{\circ} \mathrm{C} \quad 44$

Figure 29. $\mathrm{H}_{2} \mathrm{~S}$ Breakthrough Curves for IGTSS-6 Sorbent at $350^{\circ} \mathrm{C}$

Figure 30. Fractional Conversion of IGTSS-6 Sorbent in Successive Cycles at $350^{\circ} \mathrm{C} \quad 46$

Figure 31. Conversions for Sorbents with Higher Theoretical Sulfur Capacities 47

Figure 32. Effect of Fresh Sorbent Activation Method on Sulfidation Performance of $\quad 50$ IGTSS-122 Sorbent at $450^{\circ} \mathrm{C}$

Figure 33. Effect of Sorbent Activation on Reactivity and Effective Sulfur Capacity $\quad 50$

Figure 34. $\mathrm{H}_{2} \mathrm{~S}$ Breakthrough Curves for the Baseline UCI-4169 Zinc Titanate Sorbent 51

Figure 35. $\mathrm{H}_{2} \mathrm{~S}$ Breakthrough Curves for the IGTSS-122 Sorbent 51

Figure 36. $\mathrm{H}_{2} \mathrm{~S}$ Breakthrough Curves for the IGTSS-314B Sorbent 52

Figure 37. $\mathrm{H}_{2} \mathrm{~S}$ Breakthrough Curves for the IGTSS-325A Sorbent 53

Figure 38. Comparison of Sulfidation Performance of IGTSS- 057 Sorbent at $450^{\circ} \mathrm{C}$ and 54 $350^{\circ} \mathrm{C}$ 


\section{LIST OF FIGURES (CONT.)}

Figure 39. $\mathrm{H}_{2} \mathrm{~S}$ Breakthrough Curves for the IGTSS-057 Sorbent

Figure 40. $\mathrm{H}_{2} \mathrm{~S}$ Breakthrough Curves for the IGTSS-179 Sorbent at $450^{\circ} \mathrm{C}$

Figure 41. $\mathrm{H}_{2} \mathrm{~S}$ Breakthrough Curves for the IGTSS-179 Sorbent at $350^{\circ} \mathrm{C} \quad 56$

Figure 42. Effective Capacity for Sulfur of a Commercial Zinc Titanate Sorbent (UCI- 56 4169) as a Function of Desulfurization Temperature

Figure 43. $\mathrm{H}_{2} \mathrm{~S}$ Breakthrough Curves for the IGTSS-326A Sorbent at $450^{\circ} \mathrm{C}$

Figure 44. Comparison of Attrition Results of Different Sorbents 58

Figure 45. $\mathrm{H}_{2} \mathrm{~S}$ Breakthrough Curves for the UCI-4169 Sorbent in High-Pressure Bench- 61 Scale Fluidized-Bed Reactor

Figure 46. $\mathrm{H}_{2} \mathrm{~S}$ Breakthrough Curves for the IGTSS-314B Sorbent in High-Pressure 61 Bench-Scale Fluidized-Bed Reactor

Figure 47. $\mathrm{H}_{2} \mathrm{~S}$ Breakthrough Curves for the IGTSS-325A Sorbent in High-Pressure 62 Bench-Scale Fluidized-Bed Reactor

Figure 48. $\mathrm{H}_{2} \mathrm{~S}$ Breakthrough Curves for the IGTSS-057 Sorbent in High-Pressure 62 Bench-Scale Fluidized-Bed Reactor

Figure 49. $\mathrm{H}_{2} \mathrm{~S}$ Breakthrough Curves for the IGTSS-179 Sorbent in High-Pressure 63 Bench-Scale Fluidized-Bed Reactor

Figure 50. Attrition Resistance of New and Conventional ZnO-Based Sorbents (5-hr Loss)

Figure 51. Attrition Resistance of Selected Sorbents ( $2^{\text {nd }}$ hr Only $)$

Figure 52. Attrition Resistance of Selected Sorbents 71

Figure 53. Sulfidation Performance of IGTSS-349 Sorbent 73

Figure 54. Performance of IGTSS-353 Sorbent 74

Figure 55. Performance of IGTSS-353 Following Different Regeneration Temperatures 74

Figure 56. Regeneration of IGTSS-353 at Different Temperatures 75

Figure 57. Performance of IGTSS-354 Sorbent 76 


\section{LIST OF FIGURES (CONT.)}

Figure 58. Sulfur Balance in a Typical Sulfidation/Regeneration Cycle 76

Figure 59. Effect of Steam on Regenerability of IGTSS-354 Sorbent 77

Figure 60. Effect of Temperature on Regenerability of IGTSS-354 Sorbent 78

Figure 61. Performance of IGTSS-354 Sorbent (2 ${ }^{\text {nd }}$ Batch) 78

Figure 62. Performance of IGTSS-354 Sorbent in Fluidized-Bed Reactor 79

$\begin{array}{ll}\text { Figure 63. Performance of IGTSS-357 Sorbent } & 79\end{array}$

Figure 64. Performance of IGTSS-359 Sorbent $\quad 80$

Figure 65. Temperature and $\mathrm{SO}_{2}$ Profiles during Regeneration of IGTSS-359 Sorbent 81

Figure 66. Performance of IGTSS-360 Sorbent $\quad 81$

Figure 67. Comparison of Attrition Resistance of Sorbents Produced by IGT and Commercial Manufacturer

Figure 68. Comparison of Effective Sulfur Capacities of Sorbents Produced by IGT and Commercial Manufacturers 


\section{LIST OF TABLES}

Table 1. Simplified Compositions of Three Industrial Fuel Gases, Vol\% 11

Table 2. Breakdown of Sorbent Formulations by Main Reactive Component (Method I) 18

Table 3. Breakdown of Sorbent Formulations by Main Reactive Component (Method II) 22

Table 4. Simulated Fuel Gas Composition for Sorbent Evaluation 35

Table 5. Chemical Analysis Results of Fresh Sorbents (Method II) 48

Table 6. Physical Characteristics of Selected Sorbents (Method II) 49

Table 7. Data Summary for IGT's Leading Copper-Based Sorbents (Method II) 58

Table 8. Operating Conditions for Evaluation of Selected Sorbents in the Bench-Scale 60 High-Pressure Reactor

Table 9. Simplified Composition of KRW Fuel Gas, Vol\% 64

Table 10. Physical and Chemical Properties of Copper-Based Sorbents Investigated 65

Table 11. Attrition Resistance Indices for Various Sorbents 67

Table 12. Zinc-Based Sorbents Prepared using Sol-Gel Approach (Method III) 68

Table 13. Physical Characteristics of Selected Sorbents $\quad 69$

Table 14. Ranges of Operating Parameters $\quad 72$ 


\section{PROGRAM OBJECTIVE}

The overall objective of this program was to develop regenerable sorbents for use in the temperature range of 343 to $538^{\circ} \mathrm{C}\left(650\right.$ to $\left.1000^{\circ} \mathrm{F}\right)$ to remove hydrogen sulfide $\left(\mathrm{H}_{2} \mathrm{~S}\right)$ from coalderived fuel gases in a fluidized-bed reactor.

The goal was to develop sorbents that are capable of reducing the $\mathrm{H}_{2} \mathrm{~S}$ level in the fuel gas to less than 20 ppmv in the specified temperature range and pressures in the range of 1 to 20 atmospheres. The sorbents are expected to have chemical characteristics that permit cyclic regeneration over many cycles without a drastic loss of activity, as well as physical characteristics that are compatible with the fluidized bed application.

\section{BACKGROUND}

U.S. coals have a very variable sulfur content; low in the eastern (Appalachian) fields and in the western sub-bituminous deposits and too high in the mid-western basin deposits. The major reserves that are most readily accessible to industry and population centers are the midwestern coals of Illinois, Western Kentucky, Indiana, and Iowa. Unfortunately, these coals have sulfur levels that are too high for direct utilization. Therefore, sulfur removal must be accomplished prior to combustion, during combustion, or by post-combustion processing of the exhaust stream. With the ever-increasing limitations on $\mathrm{SO}_{2}$ emissions, even most low-sulfur coals will eventually require some treatment at sometime in their utilization. The sulfur in coal is typically about equally divided between its occurrence as the mineral component (pyrite-FeS $\mathrm{S}_{2}$ ) or as a sulfur-containing compound in the organic portion. Of these, the inorganic component is most readily removed via fine grinding, for liberation and separation via physical techniques. Current coal gasification technology relies on removal of some of the relatively easy inorganic fraction during coal cleaning (ash removal) and anticipates that the major removal will occur during or after gasification.

Coal gas desulfurization to sufficiently low levels at elevated temperatures and pressures is now recognized as crucial to efficient and economic coal utilization in Integrated GasificationCombined Cycle (IGCC) systems. The implementation of hot coal gas desulfurization heavily relies on the development of regenerable sorbent materials that have high sulfur capacity and can efficiently remove $\mathrm{H}_{2} \mathrm{~S}$ (from several thousand ppmv levels down to a few ppmv) over many cycles of sulfidation/regeneration. Structural stability and good mechanical strength are also desirable features in a sorbent. Not surprisingly, only a few metal oxides can meet these stringent requirements.

The research and development for high-temperature desulfurization of fuel gases has been sponsored primarily by the National Energy Technology Laboratory (NETL, formerly known as FETC or METC) of the United States Department of Energy (U.S. DOE). Over the last two decades a number of studies have been reported on high-temperature $\mathrm{H}_{2} \mathrm{~S}$ removal, primarily using various transition metal oxides as regenerable sorbents. ${ }^{1-5}$ The sorbent most intensively studied is iron oxide, which yields equilibrium $\mathrm{H}_{2} \mathrm{~S}$ concentrations in the few hundred ppm range for a composition representative of low-Btu coal-derived fuel gas at temperatures 
above $500^{\circ} \mathrm{C}$. While the sulfidation kinetics of iron oxide are very good, ${ }^{3}$ this sorbent cannot be used for single-stage coal gas desulfurization to reduce the $\mathrm{H}_{2} \mathrm{~S}$ content of the fuel gas down to the required level of a few ppmv of sulfur.

Zinc oxide has been used as a non-regenerable sorbent in "guard beds" to protect catalysts from trace sulfur impurities. More recently, zinc oxide has also been investigated as a regenerable sorbent. ${ }^{4-8}$ The thermodynamic equilibrium for sulfidation of $\mathrm{ZnO}$ is quite favorable, yielding desulfurization down to a few ppmv $\mathrm{H}_{2} \mathrm{~S}$. The sulfidation kinetics of $\mathrm{ZnO}$, however, is slower ${ }^{9}$ compared to that of iron oxide, and the regenerability of $\mathrm{ZnO}$ is restricted by the loss of surface area at high temperatures $\left(>750^{\circ} \mathrm{C}\right)$ and the formation of zinc sulfate at low regeneration temperatures $\left(<650^{\circ} \mathrm{C}\right)$.

Reduction and sulfidation take place simultaneously when the sorbent is contacted with the hot fuel gas. Regeneration can be conducted with air or air-steam mixtures. When reaction and diffusion rates are sufficiently rapid, the sorbent sulfur capacity and the extent of desulfurization are determined by thermodynamics alone. With many sorbents, however, the rates of reaction, pore diffusion, or diffusion in the product layer, limit sorbent capacity and the extent of cleanup under practical conditions. Such is the case with some commercial $\mathrm{ZnO}$ sorbents where the reported conversions at breakthrough have been less than $20 \%$ in packed-bed applications. The larger molar volume of the product zinc sulfide $\left(\mathrm{ZnS}=24.4 \mathrm{~cm}^{3} / \mathrm{mol}\right)$ compared to that of the reactant zinc oxide $\left(\mathrm{ZnO}=14.4 \mathrm{~cm}^{3} / \mathrm{mol}\right)$ causes pore plugging, limiting access to the interior of the sorbent.

It was shown in previous studies that certain mixed oxides have superior properties compared to single oxides for hot gas cleanup. ${ }^{6-8,10-16}$ A compound of zinc and iron oxides, zinc ferrite $\left(\mathrm{ZnFe}_{2} \mathrm{O}_{4}\right)$, developed by DOE/NETL reached pilot-stage testing for desulfurization of low-Btu gases. ${ }^{17-19}$ However, physical durability of the zinc ferrite sorbent in long-term testing was shown to be inadequate for IGCC application.

Because of the limitations of the zinc ferrite sorbent, investigations were directed towards development of alternative mixed metal oxide sorbents. ${ }^{6-8,11-13,20-26}$ Work on zinc titanates, such as $\mathrm{ZnTiO}_{3}, \mathrm{Zn}_{2} \mathrm{TiO}_{4}$, and $\mathrm{Zn}_{2} \mathrm{Ti}_{3} \mathrm{O}_{8},{ }^{6-8,24}$ showed that titanium oxide is a better alternative to iron oxide additives in terms of the higher stability of the titanates over the ferrite compounds of zinc, and their similar sulfidation equilibria. With zinc titanates, the sulfidation temperature was shown to extend to $700^{\circ} \mathrm{C}$ and sintering of the $\mathrm{ZnO}$ was greatly reduced. Although zinc titanate was shown to have better attrition resistance than zinc ferrite in pilot tests, this sorbent was also shown to suffer from gradual loss of reactivity in long-term cyclic operation, resulting in high fresh sorbent makeup rates to maintain the desired level of desulfurization. ${ }^{27,28}$ Other mixed metal oxides such as copper-based and cobalt-based sorbents have also been investigated, ${ }^{29-32}$ however, the research has been limited to laboratory-scale equipment.

Although the overall process efficiency improves with increasing temperature, recent studies indicated that desulfurization system components become prohibitively expensive at operating temperatures above $538^{\circ} \mathrm{C}$ and that the overall IGCC process efficiency gains at higher desulfurization temperatures may not be sufficient to justify operation at temperatures above $538^{\circ} \mathrm{C} .^{33}$ Furthermore, the stringent requirement for sulfur removal efficiency at temperatures 
above $538^{\circ} \mathrm{C}\left(1000^{\circ} \mathrm{F}\right)$ limits the choice of sorbents to a few metal oxides (based on thermodynamic equilibrium), that have been shown to have other limitations, as described earlier. The thermodynamic equilibria of many metal oxides significantly improve as temperature decreases, making many metal oxide sorbents suitable for hot gas cleanup applications in the temperature range of 343 to $538^{\circ} \mathrm{C}\left(650\right.$ to $\left.1000^{\circ} \mathrm{F}\right)$. Although the initial chemical reactivities of the sorbents generally decrease with decreasing temperature, the lower thermal stress incurred can lead to better sorbent reactivity after a large number of cycles. In general, the benefit to be gained by lower temperature application may outweigh the slight loss of efficiency due to lower temperature application, resulting in lower overall cost of electricity. However, up to the time this project was initiated, no extensive study had been done on the development of advanced sorbents for the lower temperature application. This program aimed at the development of regenerable sorbents suitable for desulfurization of coal-derived gases in the temperature range of 343 to $538^{\circ} \mathrm{C}\left(650\right.$ to $\left.1000^{\circ} \mathrm{F}\right)$ in a fluidized-bed reactor.

\section{DESULFURIZATION/REGENERATION REACTOR CONSIDERATIONS}

The desulfurization reactor can have a fixed-bed, a moving-bed, a transport reactor, or a bubbling fluidized-bed reactor design. Schematic diagrams of these types of desulfurization reactors are shown in Figure 1. Depending on process conditions and the application intended, each of these reactor configurations offers advantages, but also has limitations. A general comparison of these reactor configurations as well as their implications in the context of the development of regenerable sorbents for the moderate temperature range of 343 to $538^{\circ} \mathrm{C}$ ( 650 to $1000^{\circ} \mathrm{F}$ ) is provided below.

The fixed bed desulfurization reactor system (Figure 1(a)) consists of two reactors. While one of these reactors is used to remove $\mathrm{H}_{2} \mathrm{~S}$ from the coal gas, the sulfided sorbent in the second reactor is regenerated. In normal operation, desulfurization is continued until the $\mathrm{H}_{2} \mathrm{~S}$ content of the cleaned coal gas exceeds the desired level, at which time the coal gas stream is directed toward the other reactor containing regenerated sorbent. Fixed-bed operation is not continuous, suffers from operational problems, and requires expensive large-scale high temperature valves for switching the gas streams between the two reactors. In addition, because both reactors are used for sulfidation as well as regeneration, the materials of construction for both reactors should be capable of handling both reducing and oxidizing environments, increasing the cost of construction and maintenance of fixed-bed reactor systems.

The fixed-bed design has been shown to have high gas cleaning efficiency, reducing the $\mathrm{H}_{2} \mathrm{~S}$ content of the cleaned coal gas to very low levels. Fixed-bed operation also offers high sorbent utilization, and because of minimal movement of the sorbent, the requirement for sorbent crush strength is not very stringent. However, because of the large size of the pellets used in this reactor configuration, highly reactive sorbents are required to achieve high levels of desulfurization efficiency. Furthermore, in fixed-bed reactors, highly exothermic reactions, such as metal sulfide oxidation reactions during regeneration, result in significant temperature excursions, leading to severe sorbent decrepitation problems. 
As shown in Figure 1(b), in the moving-bed configuration, the sulfided sorbent is continuously removed from the sulfidation reactor and fed to a second reactor for regeneration. The sulfided sorbent is continuously replaced with regenerated sorbent. In the sulfidation reactor, the sorbent is sulfided as a result of removing sulfur-bearing species (mainly $\mathrm{H}_{2} \mathrm{~S}$ ) from the fuel gas. In the regeneration reactor, the captured sulfur in the sulfided sorbent is burned off with air/steam mixtures and the reactivity of the sorbent is restored to enable its re-use in the cyclic desulfurization process. Consequently, both the crush strength and attrition resistance of the sorbent and its sorption capacity after repeated cycling are of critical importance. Compared to the fixed-bed reactor system, the moving-bed approach offers advantages in continuous operation and eliminates the need for expensive large-scale high temperature gas switching valves. Furthermore, because each reactor is specifically used for either sulfidation or regeneration, the requirement for materials of construction is not as exigent.

The moving-bed system was, in recent years, under development at General Electric. This hot gas desulfurization system was developed to remove sulfur, particulates, and halogens from high-temperature fuel gas streams using regenerable mixed metal oxide sorbents suitable for moving-bed applications. The moving-bed hot gas desulfurization system also reached the demonstration stage by the Tampa Electric Company in one of the major Clean Coal Technology Demonstration Programs in the U.S. Similar to the fixed-bed system, the moving-bed approach employs sorbents in the form of pellets and has been shown to achieve high desulfurization efficiency and sorbent utilization. Although the sorbents move slowly between the sulfidation and regeneration reactors, the sorbent is required to be mechanically durable to minimize sorbent losses in the desulfurization process. To minimize temperature excursions during regeneration and resulting sorbent decrepitation, the GE moving-bed system employs a complicated multiple oxygen feeding system, which achieves a relatively constant and high concentration of sulfur dioxide $\left(\mathrm{SO}_{2}\right)$ in the regeneration product gas.

The transport reactor system (Figure 1(c)) employs dilute-phase fluid-bed reactors similar to the fluid catalytic cracking unit in an oil refinery. In this system, the sorbent is continuously circulated between a sulfidation riser reactor and a standpipe at a very high circulation rate, while a slip stream of the sorbent is circulated between the sulfidation and the regeneration reactors. The transport reactor system, which has been developed by the M. W. Kellogg Company, is being demonstrated at the Piñon Pine Power Project by the Sierra Pacific Power Company, in another major project in the Clean Coal Technology Demonstration Programs in the U.S.

In general, the residence time in the sulfidation reactor is significantly shorter than that in the regeneration reactor to ensure complete regeneration of the sorbent. Accordingly, the linear velocities of the solids during sulfidation are significantly higher than those during regeneration. This reactor design has been shown to successfully reduce the $\mathrm{H}_{2} \mathrm{~S}$ content of the coal gas to acceptable levels for IGCC application at $538^{\circ} \mathrm{C}\left(1000^{\circ} \mathrm{F}\right)$. Because the sorbent in this reactor system is in dilute phase, temperature excursions are avoided even when pure air is used for regeneration. In the transport reactor system, the coal gas residence time in the sulfidation reactor is in the range of 1 to 10 seconds. Given that the sulfidation reactor is operating as a dilute fluid-bed reactor, it requires a highly reactive sorbent to achieve the required high level of desulfurization efficiency. This is in part accomplished by employing sorbents in the form of small granules (i.e., dp $<200 \mu \mathrm{m}$ ). The sorbent utilization in the transport reactor system is 
dependent on the rate of circulation of the solids. However, because of the high solid velocities in this system, the attrition rate of the sorbent must be extremely small to minimize sorbent elutriation from the reactor. Furthermore, the high sorbent circulation rate between the sulfidation reactor and the regeneration reactor requires that the sorbent be capable of initiating regeneration at the sulfidation temperature and that the regeneration is carried out at a temperature that is not significantly higher than that of sulfidation.

The bubbling fluidized-bed desulfurization reactor system (Figure 1(d)) consists of two dense phase bubbling fluid-bed reactors. The overall design of this continuous reactor system is much simpler than both the moving-bed and the transport reactor systems discussed above. While sulfidation can be carried out in a single reactor (compared to the more sophisticated transport reactor design), unlike the moving-bed system, it does not require complicated multiple oxygen feeding systems to prevent temperature excursions in the regeneration reactor. Therefore, the bubbling fluidized bed reactor system offers a good compromise between the moving-bed and the transport reactor systems.

A pilot plant scale bubbling fluidized-bed high temperature desulfurization reactor system has been successfully operated since 1990 by Enviropower, Inc. (now Carbona) in Finland, demonstrating its suitability for hot gas desulfurization in the context of the IGCC process. Because of IGT's experience with the fluidized-bed systems and coal gasification processes, IGT was involved during the design, construction, and operation of this desulfurization system. Sulfidation and regeneration are carried out in two side-by-side fluidizedbed reactors at this pilot plant, as shown in Figure 2, employing zinc titanate sorbents in the 100$300 \mu \mathrm{m}$ size range. The test results showed that very high sulfur removal efficiency can be achieved. The contact with real coal gas containing impurities such as gasification fines, alkali and trace metals, $\mathrm{HCl}$, and ammonia, had no detrimental effect on the physical or chemical properties of the sorbents tested. It must be noted the sorbent formulations used were identified by IGT researchers after screening several sorbents in a pressurized batch fluidized-bed reactor and subjecting the sorbents to "life-cycle" sulfidation/regeneration tests.

In the bubbling fluidized-bed design, because of its excellent solid mixing and heat transfer characteristics, both the sulfidation and the regeneration reactors operate isothermally, eliminating the problem with temperature excursions. Furthermore, because of the low sorbent circulation rate between the two reactors, the sulfidation and regeneration reactors can be operated at significantly different temperatures.

In the bubbling fluidized bed reactor system, the sorbent is transferred between the reactors by gravity and/or an external lift line; however, the sorbent circulation rates are much closer to those of the moving-bed system. Therefore, the requirement on the physical durability of the sorbent is not as stringent as the requirement on sorbents used in the transport reactor system. To maintain desirable bubbling fluidization behavior in the two reactors, the sorbent in this reactor system is in granular form, generally in the particle size range of 100 to $600 \mu \mathrm{m}$. Although similar to the transport reactor system the coal gas residence time is in the range of 1 to 10 seconds, because the solids are in dense phase, the requirement on the reactivity is not as exigent as is the case with transport reactors. 


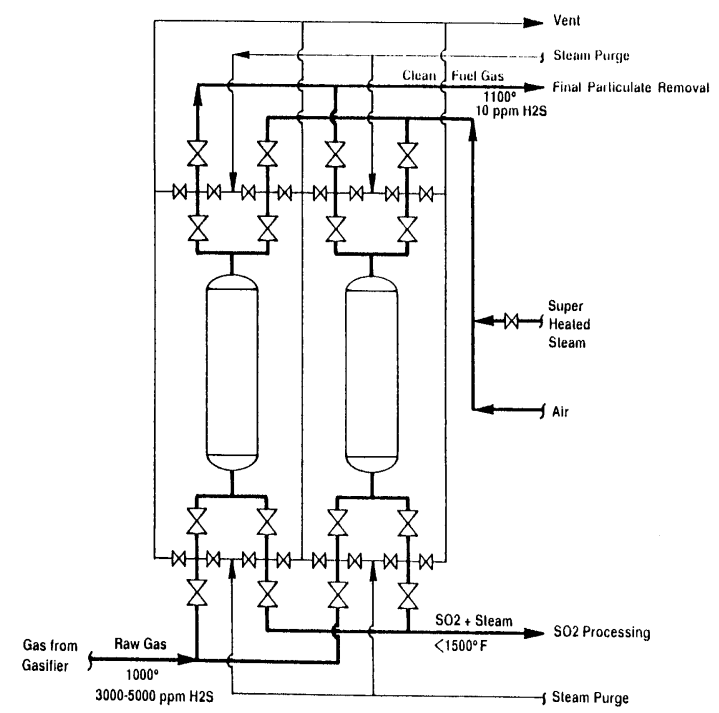

(a) Dual Fixed-Bed Zinc Ferrite Process $^{(34)}$

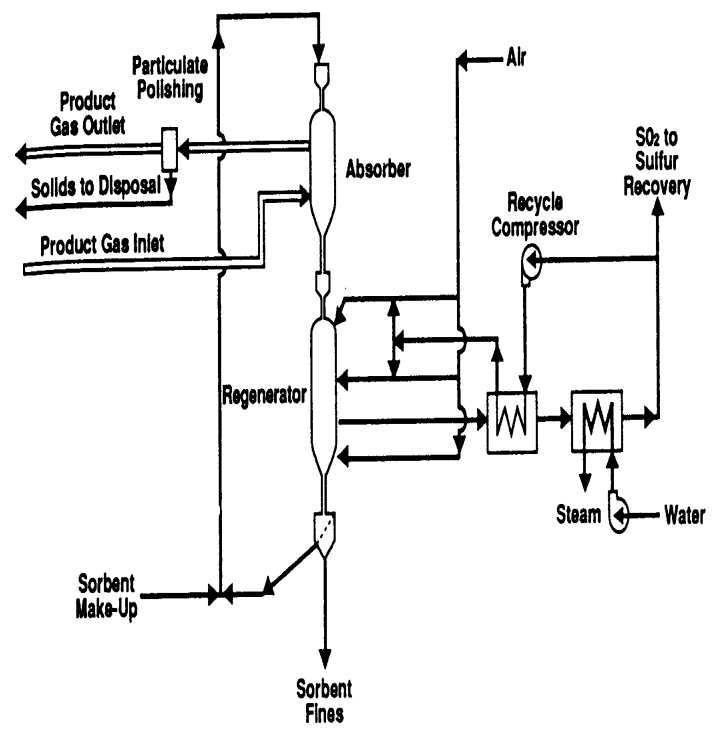

(b) Schematic Diagram of a Moving-Bed Hot Gas Cleanup System ${ }^{(35)}$

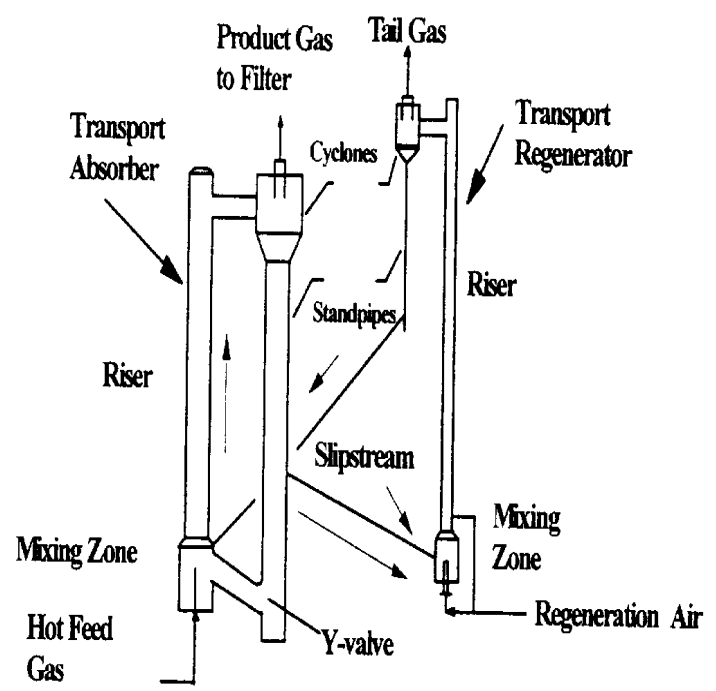

(c) Simplified Process Flow Diagram of the HGD Unit for Sierra Pacific ${ }^{(36)}$

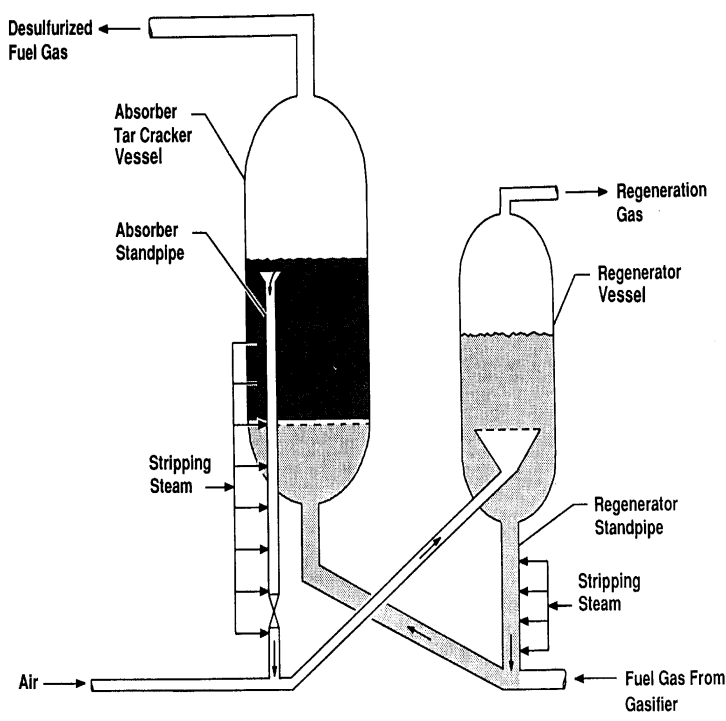

(d) Two-Vessel Fluid-Bed Absorber/Regenerator Concept ${ }^{(37)}$

Figure 1. Schematic Diagrams of Different Types of Hot Gas Cleanup Systems for IGCC Application 


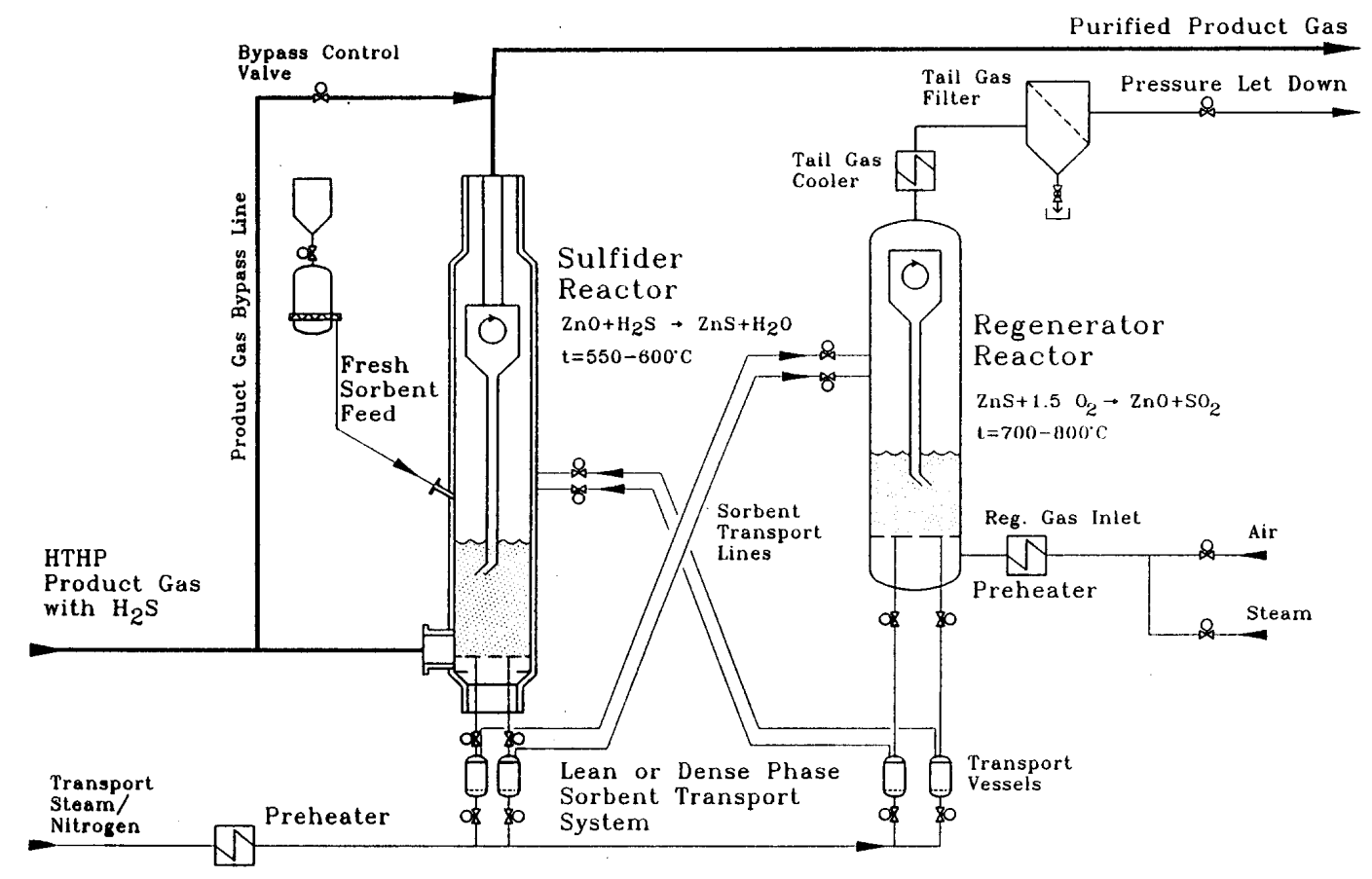

Figure 2. High Temperature High Pressure Sulfur Removal Subsection of
Enviropower's $15 \mathrm{MW}_{\text {th }}$ Pressurized Gasification Pilot Plant ${ }^{(38)}$

Although the fluidized-bed reactor configuration is quite suitable for desulfurization of coal-derived fuel gases using regenerable metal oxide-based sorbents in the moderate temperature range of 343 to $538^{\circ} \mathrm{C}\left(650\right.$ to $\left.1000^{\circ} \mathrm{F}\right)$, in recent years, the transport reactor has gained more and more acceptance as a suitable reactor system for carrying out desulfurization/regeneration reactions. As mentioned above, this reactor configuration is similar to that of a bubbling fluidized-bed reactor; however, the attrition resistance requirement of the sorbent is significantly more stringent. In addition, sorbents for the transport reactor must also be regenerable at lower temperatures.

Work in the early part of this project was directed towards the development of regenerable sorbents for the fluidized-bed application in general. However, because the only remaining Clean Coal Technology Demonstration Program relies on the transport reactor technology for hot fuel gas desulfurization, work in the latter part of this program was directed toward development of sorbents for the specific desulfurization application in the transport reactor system. 


\section{THERMODYNAMIC AND PRACTICAL CONSIDERATIONS}

\section{$\underline{\text { Desulfurization (Sulfidation) Considerations }}$}

The initial principal criterion used for sorbent formulation was based on thermodynamic equilibrium calculations to limit the choice of the active sorbent metal oxides to those that can meet the stringent requirement of removing $\mathrm{H}_{2} \mathrm{~S}$ to below 20 ppmv in the temperature range of 343 to $538^{\circ} \mathrm{C}\left(650\right.$ to $\left.1000^{\circ} \mathrm{F}\right)$ and at 20 bar pressure.

The pioneering work on the selection, based on thermodynamic considerations alone, of metal oxides for $\mathrm{H}_{2} \mathrm{~S}$ removal from fuel gases was performed over 20 years ago by Westmoreland et. al. ${ }^{9,39}$ In one study, Westmoreland and Harrison ${ }^{39}$ screened the high-temperature desulfurization potential of 28 solids, primarily metal oxides. They concluded that 11 candidate solids based upon the metals $\mathrm{Fe}, \mathrm{Zn}, \mathrm{Mn}, \mathrm{Cu}, \mathrm{Mo}, \mathrm{V}, \mathrm{Ca}, \mathrm{Sr}$, $\mathrm{Ba}, \mathrm{Co}$, and $\mathrm{W}$ showed thermodynamic feasibility for high-temperature desulfurization. In a following study, Westmoreland et al. ${ }^{9}$ determined the initial rates for the reaction between $\mathrm{H}_{2} \mathrm{~S}$ and $\mathrm{MnO}, \mathrm{CaO}, \mathrm{ZnO}$, and $\mathrm{V}_{2} \mathrm{O}_{3}$ in a thermo-balance reactor over the temperature range of 300 to $800^{\circ} \mathrm{C}$. The relative magnitude of reaction rates determined were found to decrease in the order $\mathrm{MnO}>\mathrm{CaO} \cong \mathrm{ZnO}>\mathrm{V}_{2} \mathrm{O}_{3}$.

In this investigation, we re-evaluated a number of potentially-suitable metal oxides for their capability to remove $\mathrm{H}_{2} \mathrm{~S}$ from fuel gases. The thermodynamic $\mathrm{H}_{2} \mathrm{~S}$ concentrations in two simulated fuel gases (i.e., U-GAS and Texaco) upon equilibration with each of these metal oxides were calculated at elevated temperatures (i.e., 350$550^{\circ} \mathrm{C}$ ) and pressure (20 bar). The metal oxides considered in this analysis included copper, zinc, iron, nickel, tin, cobalt, molybdenum, manganese, and tungsten. The number of moles of the fuel gas and the solid oxides were selected to correspond to $50 \%$ sorbent conversion during sulfidation. Moreover, based on available data, certain restrictions were imposed on the formation of a number of species to better simulate the actual environment.

The results of these analyses are presented in Figures 3 and 4 for the U-GAS and Texaco fuel gases, respectively. It should be noted that fuel gases produced by U-GAS and KRW have similar compositions. The results indicate that the calculated $\mathrm{H}_{2} \mathrm{~S}$ equilibrium is not significantly affected by the fuel gas composition. Furthermore, because of the lower temperature range (e.g., $350-550^{\circ} \mathrm{C}$ ), a large number of metal oxides are capable of reducing the $\mathrm{H}_{2} \mathrm{~S}$ level of the fuel gases to below $20 \mathrm{ppmv}$ as required by the IGCC application. 


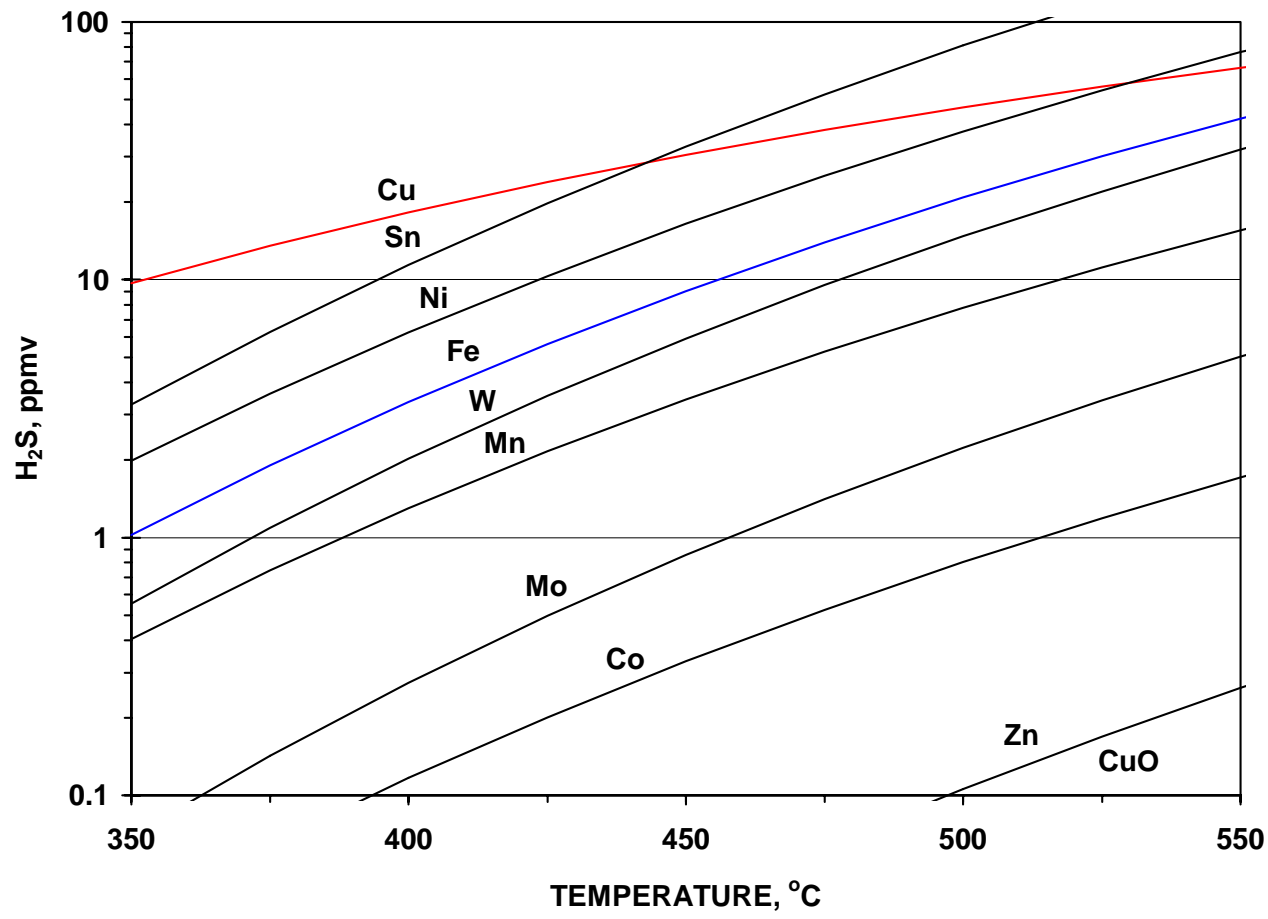

Figure 3. $\mathrm{H}_{2} \mathrm{~S}$ Concentration in Fuel Gas in Equilibrium with Various Metal Oxides (U-GAS)

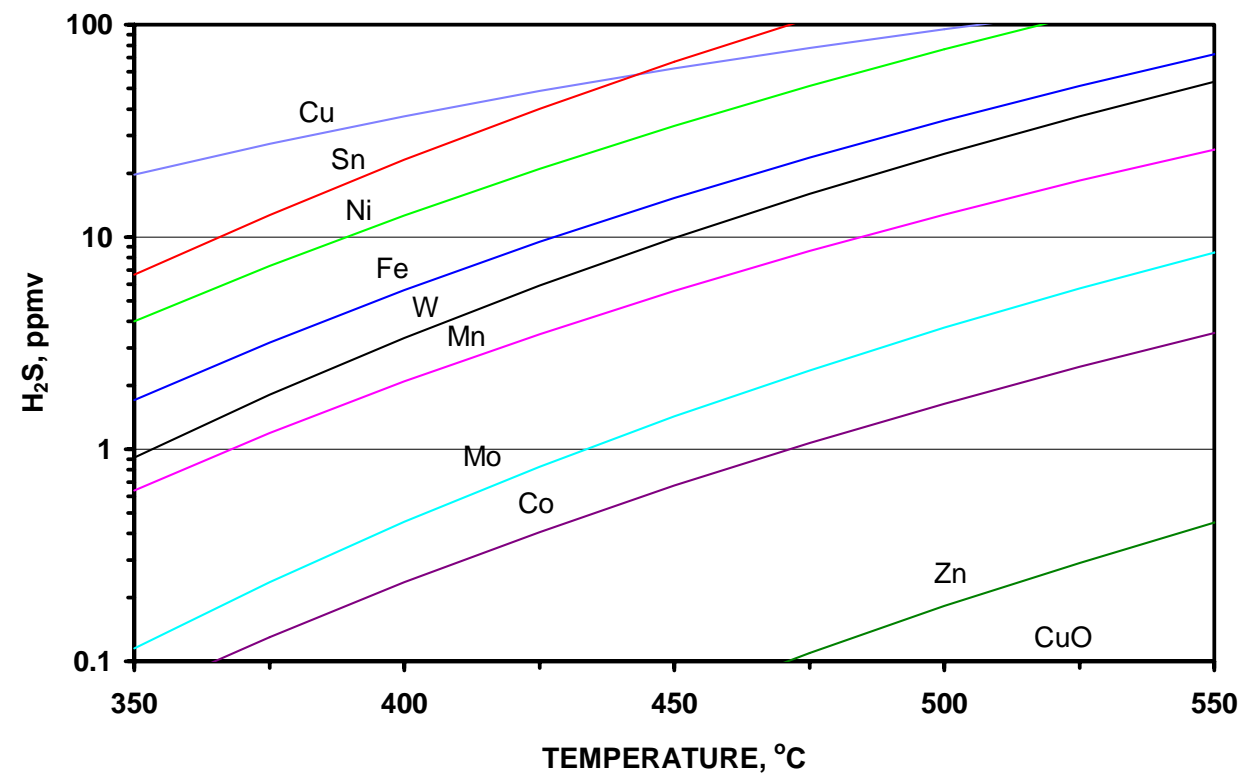

Figure 4. $\mathrm{H}_{2} \mathrm{~S}$ Concentration in Fuel Gas in Equilibrium with Various Oxides (Texaco) 
In addition to using high pressure, the thermodynamic calculations in this investigation took into account several practical issues. The main criteria imposed for selection of potential metal oxides in this study were: (a) favorable thermodynamic equilibrium in the temperature range of 350 to $550^{\circ} \mathrm{C}$; (b) minimization of undesired reactions under reducing gas conditions, such as interactions with $\mathrm{HCl}, \mathrm{CO}$, and $\mathrm{H}_{2}$, and catalysis of gas phase reactions; (c) feasibility and ease of complete conversion of metal sulfide to oxide (i.e., regeneration); and (d) minimization of undesired reactions under regeneration conditions, such as sulfate formation and hydrothermal instability. From the initial screening of metals considered, this study ruled out $\mathrm{Ba}, \mathrm{Ca}, \mathrm{Sr}$, and $\mathrm{V}$ mainly because of their lack of sulfidation in the desired range of 350 to $550^{\circ} \mathrm{C}$ or incompatibility with turbine operation.

Combination of findings from the above studies identified the following list of metals as being potentially useful for developing metal oxide-based sorbents for fuel gas desulfurization in the moderate temperature range: $\mathrm{Fe}, \mathrm{Cu}, \mathrm{Mn}, \mathrm{Zn}, \mathrm{Mo}, \mathrm{Co}$, and $\mathrm{W}$. Both molybdenum and tungsten oxides have good desulfurization potential; however, they are temperature-limited because of possible carbide formation. ${ }^{40}$ Cobalt exhibits similar behavior to that of copper in its tendency to reduce to the metallic form in fuel gas atmospheres. However, compared to copper oxide, desulfurization with cobalt oxide is more temperature-limited and becomes less efficient with increasing temperature. In addition, cobalt sulfide requires significantly higher temperature for regeneration than copper sulfide (refer to Figure 6). For these reasons, only those sorbents based on oxides of copper $(\mathrm{Cu})$, iron $(\mathrm{Fe})$, manganese $(\mathrm{Mn})$, and zinc $(\mathrm{Zn})$ have been considered in this research program.

Figure 5 represents predominance area diagrams for $\mathrm{Cu}, \mathrm{Fe}, \mathrm{Mn}$, and $\mathrm{Zn}$ oxides as a function of temperature and $\mathrm{CO}_{2}$ to $\mathrm{CO}$ ratio in the gas phase. Each line in Figure 5 represents a boundary below which the lower oxide (or elemental metal) is stable. Two fuel gas equilibrium compositions (Shell and Texaco) are superimposed on Figure 5 as indicated in the legend. The simplified compositions of the Shell, Texaco, and U-GAS are provided in Table 1. The Shell gas represents a highly reducing fuel gas, while the Texaco gas is typical of slightly reducing coal-derived fuel gases. The U-GAS composition is in the middle range and is provided here because it was employed during packed-bed screening tests (see Experimental Section).

Figure 5 is useful in predicting, among other things, the stable oxide form under prevailing fuel gas conditions, and therefore, the governing equilibrium reaction for sulfidation. It is seen that $\mathrm{Cu}, \mathrm{Fe}_{3} \mathrm{O}_{4}, \mathrm{MnO}$, and $\mathrm{ZnO}$ are the stable forms of the oxides considered in this program. The implications from this figure are as follows: For the $\mathrm{Cu}$ system, the stable form is elemental $\mathrm{Cu}$ which is not necessarily undesirable from the standpoint of desulfurization efficiency, but may be undesirable because it leads to agglomeration of metallic copper accompanied by low surface area and poor kinetics. Effective desulfurization may be achieved by combining copper oxide $\left(\mathrm{CuO}\right.$ or $\left.\mathrm{Cu}_{2} \mathrm{O}\right)$ with a suitable inert oxide to significantly diminish its reduction rate in the fuel gas environment. If that is realized, it is very desirable to develop a copper-based sorbent mainly because of its high sulfur removal efficiency (i.e., $<1 \mathrm{ppmv}$ ) that may be required 
in very sulfur-intolerant applications such as fuel cells. Lower desulfurization temperatures favor the stability of copper-based sorbents against complete reduction, thus increasing the likelihood of developing effective sorbents based on this oxide. Stabilization of copper oxide against complete reduction has been discussed in more detail in a recent publication by Abbasian and Slimane. ${ }^{41}$ In a more recent investigation by the same authors, ${ }^{42}$ the development of effective copper-based sorbents for the moderate temperature range of 350 to $550^{\circ} \mathrm{C}$ is described in detail; a brief summary is also provided in this report.

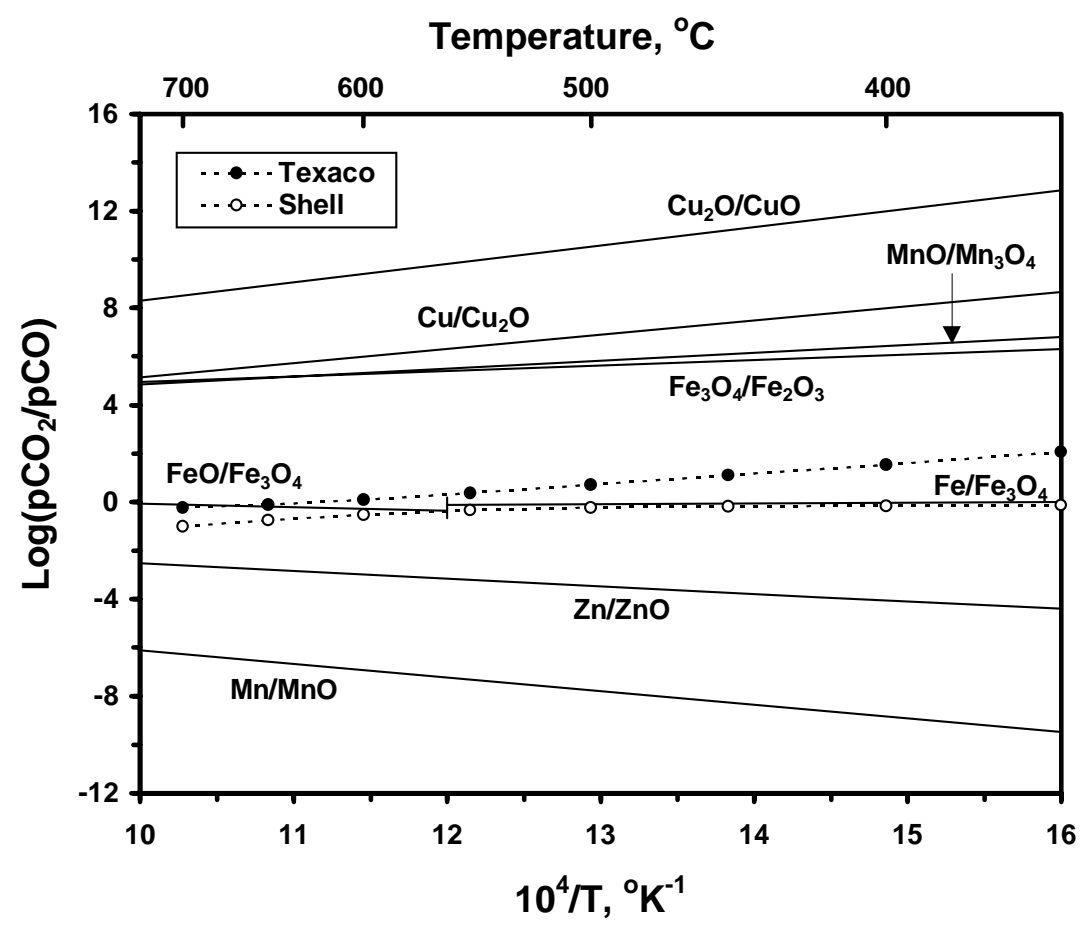

Figure 5. Superimposed Stability Diagrams for $\mathrm{Cu}, \mathrm{Fe}, \mathrm{Mn}$, and $\mathrm{Zn}$ Oxides as a Function of Temperature and $\mathrm{CO}_{2}$ to $\mathrm{CO}$ Ratio

Table 1. Simplified Compositions of Three Industrial Fuel Gases, Vol\%

\begin{tabular}{|l|c|c|c|}
\hline Component & $\begin{array}{c}\text { Texaco (Entrained-bed; } \\
\text { Air-blown) }\end{array}$ & Shell & U-GAS \\
\hline $\mathrm{CO}$ & 15.2 & 64 & 20 \\
$\mathrm{CO}_{2}$ & 8.3 & 0.8 & 10 \\
$\mathrm{H}_{2}$ & 10.7 & 31.6 & 10 \\
$\mathrm{H}_{2} \mathrm{O}$ & 10.7 & 1.5 & 10 \\
$\mathrm{H}_{2} \mathrm{~S}$ & 0.5 & 1.4 & 0.5 \\
$\mathrm{~N}_{2}$ & 54.6 & 0.7 & 49.5 \\
\hline
\end{tabular}


For the Fe system, the stable form of iron in the temperature range considered is either $\mathrm{Fe}$ or $\mathrm{Fe}_{3} \mathrm{O}_{4}$, depending on the reducing power of the fuel gas. A higher oxidation state of a reactive oxide (i.e., $\mathrm{Fe}_{3} \mathrm{O}_{4}$ ) results in more efficient $\mathrm{H}_{2} \mathrm{~S}$ removal. In addition, research ${ }^{43}$ has shown that $\mathrm{Fe}_{3} \mathrm{O}_{4}$ is significantly more reactive with $\mathrm{H}_{2} \mathrm{~S}$ than $\mathrm{Fe}$ and therefore, it follows that an iron-based sorbent is most suitable for a low reducing power fuel gas (a low-Btu gas). Moreover, as will be discussed subsequently, Fe-based sorbents require the lowest temperature, among the oxides considered in this investigation, for complete oxidative regeneration without sulfate formation. Therefore, since regeneration of iron sulfide to iron oxide may be conducted at a lower temperature than is required by other metal oxide systems, the use of an iron-based sorbent appears to be the best approach to achieve an energetically viable cyclic sulfidation/regeneration process in the moderate temperature range of 350 to $550^{\circ} \mathrm{C}$.

Reported works in the literature of Kawasaki Heavy Industries (KHI), ${ }^{44}$ Sasaoka et al., ${ }^{45}$ Hasatani et al., ${ }^{46}$ and Fuda et al. ${ }^{47}$ in Japan; Van der Wal ${ }^{48}$ and De Wild et al. ${ }^{49}$ in the Netherlands; and Patrick et al. ${ }^{50}$ in the United States offer clear indications that a sorbent based on iron oxide may be suitable for desulfurization applications at moderate temperatures.

For the $\mathrm{Mn}$ system, $\mathrm{MnO}$ is the stable form of manganese both in very reducing atmospheres as well as in those that are only slightly reducing. This fact remains true even at much higher temperatures $\left(>750^{\circ} \mathrm{C}\right)$, making Mn-based sorbents exceptionally suitable for the desulfurization of highly reducing gases (such as Shell gas) at high temperatures. Given the requirement for temperatures greater than $750^{\circ} \mathrm{C}$ for oxidative regeneration (to avoid sulfate formation), manganese-based sorbents are uniquely qualified not only for highly reducing conditions, but also for operation of desulfurization and regeneration reactors at the same temperature. Such an arrangement would eliminate the costs associated with cooling of fuel gases emanating from a fluid-bed gasifier, for example, and their subsequent heating during cyclic operation in potential commercial applications.

There are also indications in the literature that it may be feasible to develop effective manganese-based sorbents for the moderate temperature range of 350 to $550^{\circ} \mathrm{C}$. For example, in one study Wakker et al. ${ }^{51}$ prepared mixed oxide supported sorbents such as aluminates of $\mathrm{Mn}$ and $\mathrm{Fe}, \mathrm{MnAl}_{2} \mathrm{O}_{4}$ and $\mathrm{FeAl}_{2} \mathrm{O}_{4}$, for evaluation in the temperature range of 400 to $800^{\circ} \mathrm{C}$. Although these supported sorbents have a low sulfur capacity, the results obtained in this study indicated that the manganese-based sorbent in particular was capable of reducing the $\mathrm{H}_{2} \mathrm{~S}$ level of the simulated coal gas to $<20 \mathrm{ppmv}$ at $400^{\circ} \mathrm{C}$ through repeated sulfidation/regeneration cycles.

However, as discussed above for the case of a transport reactor application, the high temperature requirement for regeneration may not be readily accommodated since the disparity between sulfidation and regeneration temperatures cannot be large. Approaches alternative to oxidative regeneration will have to be devised to permit regeneration of manganese-based sorbents at lower temperatures. 
For the $\mathrm{Zn}$ system, the stable form is $\mathrm{ZnO}$ in the moderate temperature range considered. As can be seen in Figure 5, at higher temperatures the tendency of $\mathrm{ZnO}$ to reduce increases, resulting in elemental $\mathrm{Zn}$. The reduction of $\mathrm{ZnO}$ and the subsequent vaporization of elemental zinc have been reported to be problematic, limiting the applicability of $\mathrm{Zn}$-based sorbents to $650^{\circ} \mathrm{C}$. As previously mentioned, these issues have been addressed by moving away from pursuing zinc ferrite and focusing instead on the more stable zinc titanate. As pointed out by Swisher, ${ }^{52}$ however, it is important to realize that the use of titania was for the purpose of compounding zinc oxide, thereby enhancing its stability against reduction and improving its high temperature performance. However, such a practice may not be an attractive option for the moderate temperature range of 350 to $550^{\circ} \mathrm{C}$ since compounding of zinc oxide reduces its chemical reactivity. Therefore, since reduction of zinc oxide and subsequent volatilization of metallic zinc are no longer an issue in the moderate temperature range considered in this research program, the use of other suitable support materials, in addition to titania, was investigated to explore the possibility of incorporating zinc oxide in a formulation that would offer acceptable reactivity.

Research on the development of regenerable sorbents based on zinc oxide has been extensive. It is not the subject of this report to provide a comprehensive review, as this has been done in numerous publications. Briefly, as mentioned earlier, initially work focused on extending the applicability of zinc-based sorbents to higher and higher temperatures. However, because of the tendency of zinc oxide to reduce and the high vapor pressures of metallic zinc at these high temperatures, losses of zinc have been reported. As pointed out earlier, this problem was addressed through the compounding of $\mathrm{ZnO}$ with titanium oxide $\left(\mathrm{TiO}_{2}\right)$, resulting in an improvement in temperature operability up to $725^{\circ} \mathrm{C}$.

With the shift in interest to desulfurization temperatures in the range of 343 to $538^{\circ} \mathrm{C}\left(650\right.$ to $\left.1000^{\circ} \mathrm{F}\right)$, several approaches have been taken to enhance the reactivity of zinc-based sorbents. Swisher, for example, indicated the compounding of $\mathrm{ZnO}$ with $\mathrm{TiO}_{2}$ is accompanied by lower reactivity and stressed the need to investigate alternative supports. ${ }^{52}$ Researchers at the Research Triangle Institute (RTI) proceeded by imparting improvement to earlier versions of zinc-based sorbents that were originally developed for the higher temperature range (i.e., $>550^{\circ} \mathrm{C}$ ). One such sorbents, ZT-4, for example, was developed by a granulation technique for fluidized-bed applications in the higher temperature range and was tested at the pilot-scale level. ${ }^{53}$ However, when tested under transport reactor mode, this sorbent was found to suffer attrition problems. ${ }^{54}$ A spraydried version of ZT-4, designated as CMP-107, was also reported to exhibit an attrition rate that was twice the target value for the transport reactor design at the Piñon Pine plant. $^{54}$ These results underscore the difficulty of improving sorbent attrition to meet transport reactor requirements, while maintaining practical chemical reactivity. RTI, however, reports success in achieving this intricate combination through the use of a proprietary inorganic binder in a formulation designated as EX-SO3. ${ }^{54}$ Thorough evaluation of this sorbent, however, is still awaiting the readiness of the Piñon Pine facility. 


\section{$\underline{\text { Regeneration Considerations }}$}

Of immediate interest to oxidative regeneration of sulfided metal oxide sorbents are equilibrium relations in systems of the type $\mathrm{Me}-\mathrm{S}-\mathrm{O}$, where $\mathrm{Me}$ designates any metal. The primary concern is whether or not sulfate will form during regeneration. The main oxide/sulfate and sulfate/basic or trivalent sulfate equilibria at $750^{\circ} \mathrm{C}$ for a number of metals with promising desulfurization potential are compared in Figure 6. Oxides shown have the form $\mathrm{MeO}, \mathrm{Me}_{3} \mathrm{O}_{4}$, or $\mathrm{Me}_{2} \mathrm{O}_{3}$; while three types of sulfates can be distinguished: simple sulfate $\left(\mathrm{MeSO}_{4}\right)$, trivalent sulfate $\left(\mathrm{Me}_{2}\left(\mathrm{SO}_{4}\right)_{3}\right)$, and basic sulfate $\left(\mathrm{MeO} \bullet \mathrm{MeSO}_{4}\right)$. Data for all systems were obtained from reference 55. For each system considered, there is a definite relation between the $\mathrm{O}_{2}$ and the $\mathrm{SO}_{2}$ partial pressures in the regeneration product gas, defined by the stoichiometry of the regeneration reaction.

As shown in Figure 6, at ambient pressure, iron trivalent sulfate $\left(\mathrm{Fe}_{2}\left(\mathrm{SO}_{4}\right)_{3}\right)$ has the least thermodynamic stability while manganese sulfate $\left(\mathrm{MnSO}_{4}\right)$ is the most stable among the systems considered for this analysis. At a given $\mathrm{O}_{2}$ content in the regeneration feed gas, this translates into more stable sulfates requiring higher temperatures to minimize or prevent sulfate formation during oxidative regeneration. The metal systems considered can be ranked in order of descending thermodynamic stability of sulfates as follows $\mathrm{Mn}>\mathrm{Co}>\mathrm{Zn}>\mathrm{Ni}>\mathrm{Cu}>\mathrm{Fe}$. It is evident from Figure 6 that copper-based sorbents are clearly superior to zinc-based sorbents from the standpoint of sulfate formation during oxidative regeneration. The reduced stability of copper sulfate is, in fact, used to advantage during the regeneration of copper-based sorbents for $\mathrm{SO}_{2}$ removal from flue gases. ${ }^{56}$ Sulfate formation has been considered as one of the most serious challenges facing the commercialization of zinc-based sorbents. In the case of copperbased sorbents, sulfate prevention is of potential technical importance since copper sulfate is reduced to metal at a fairly moderate temperature $\left(350-400^{\circ} \mathrm{C}\right) .{ }^{57}$

Phase stability diagrams for reducing gas atmospheres (i.e., coal gases) and oxidizing gas atmospheres (i.e., regeneration gases) can also be readily constructed using a commercial thermodynamic software package, ${ }^{58}$ that predicts the stability of chemical species based on minimization of the Gibbs free energy of the system. The phase stability of metal oxides under regeneration gases containing $\mathrm{SO}_{2}$ and $\mathrm{O}_{2}$ is important because spalling and pellet deterioration has been found to occur more often as a result of metal sulfate formation. Figures 7 and 8 show the stability of copper and molybdenum oxides, respectively, as a function of the log partial pressure of $\mathrm{O}_{2}$ and $\mathrm{SO}_{2}$. For gas compositions containing approximately $2 \mathrm{vol} \% \mathrm{O}_{2}$ and 10 to $50 \mathrm{vol} \% \mathrm{SO}_{2}$, (typical of atmospheric regeneration gases in the moving-bed system) the thermodynamically stable phase of copper is copper sulfate, while the thermodynamically stable form of molybdenum is the oxide. For most pure oxides, including zinc oxide, metal sulfate is the stable form under oxidizing gas conditions at temperatures in the range of $500-700^{\circ} \mathrm{C}$, depending on $\mathrm{SO}_{2}$ and $\mathrm{O}_{2}$ concentrations. Obviously, thermodynamic predictions do not take into account the rate of approach to equilibrium (i.e., kinetic rates) and hence experimental data are still needed to confirm the extent of formation of the predicted species. Nevertheless, thermodynamics allows the investigator to determine if formation of certain compounds is favored and offers a good tool to guide the experimental work. 


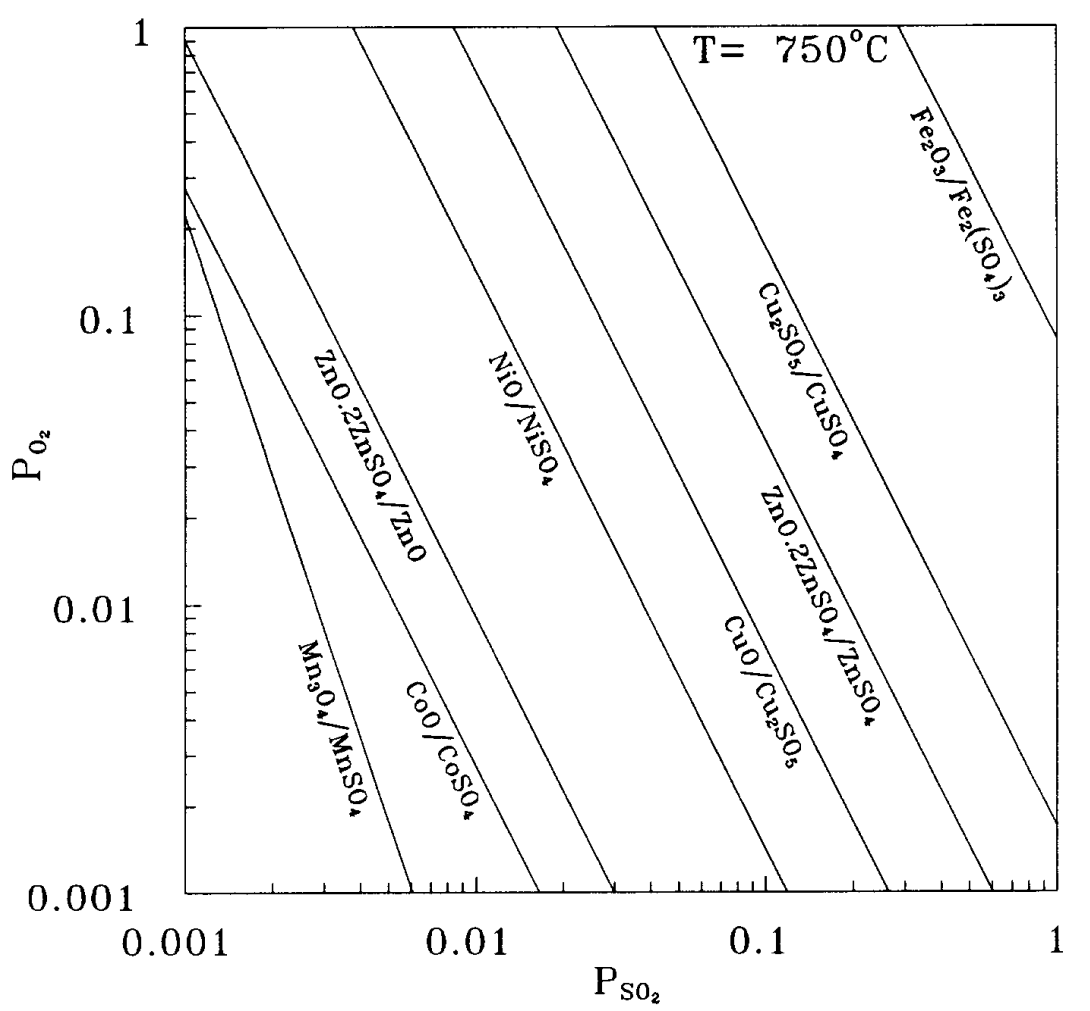

Figure 6. Oxide/Sulfate Equilibria for a Number of Metal Systems at $750^{\circ} \mathrm{C}$

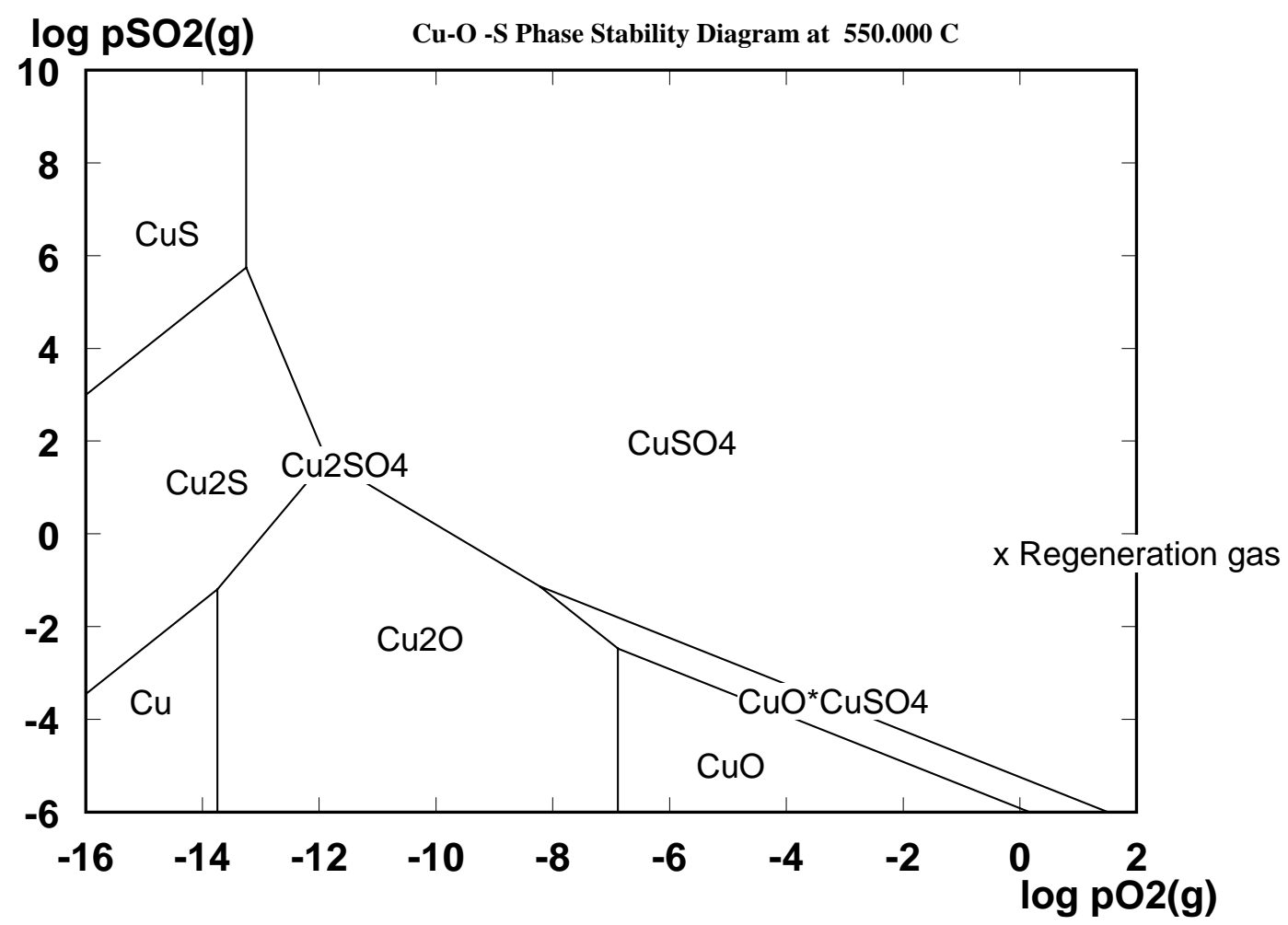

Figure 7. Phase Stability Diagram for the Cu-S-O System 


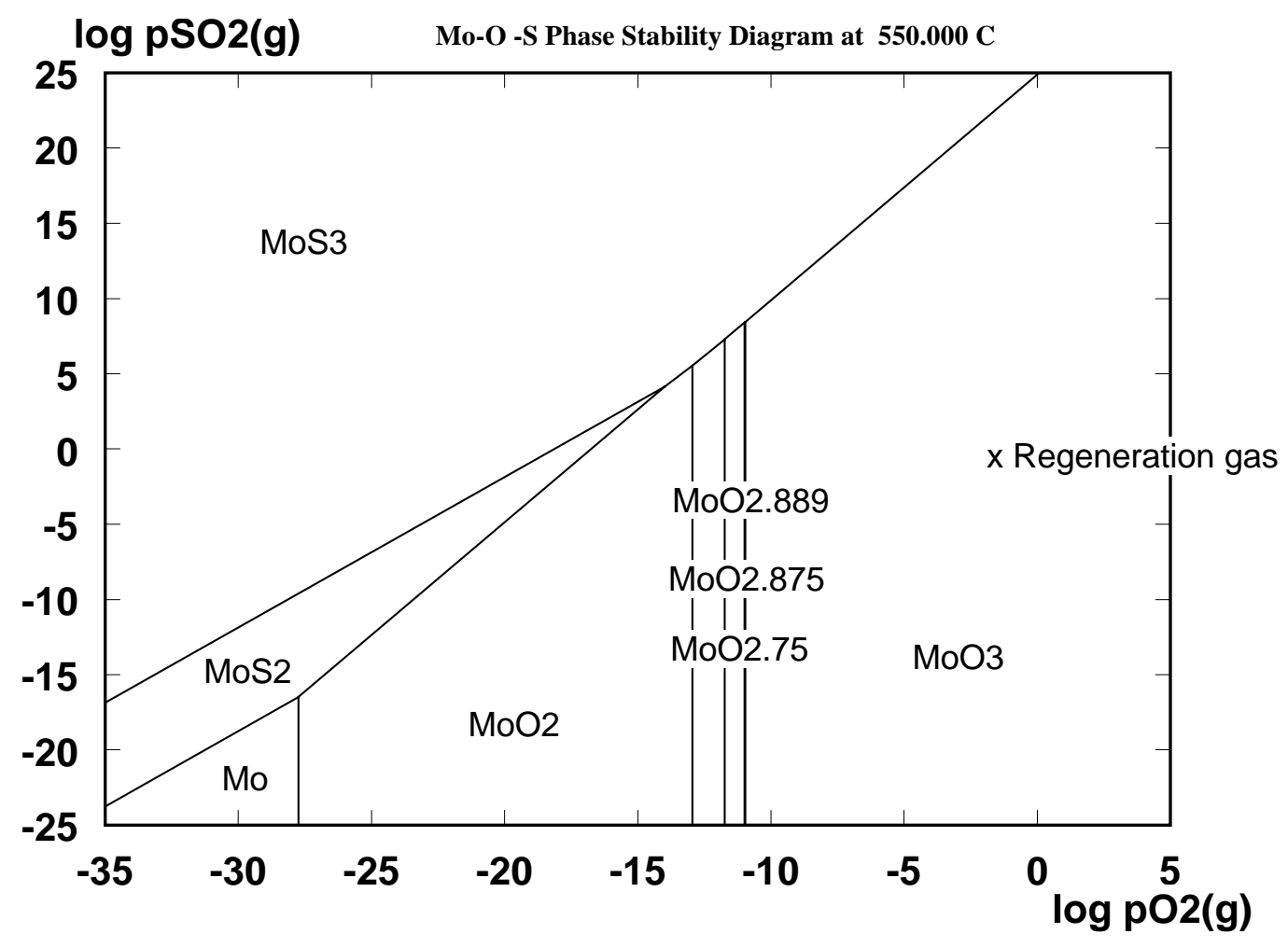

Figure 8. Phase Stability Diagram for the Mo-S-O System 


\section{EXPERIMENTAL SECTION}

Over the period of performance of this program, three different sorbent preparation approaches were investigated. These research approaches are referred to as Method I, Method II, and Method III. Method I was utilized early in this program, but soon after the work focused on sorbents prepared using Method II. The bulk of the work in this program was carried out on sorbents prepared using Method II. Method III was developed during the last year of the program, and made possible the achievement of the unique combination of high sorbent reactivity, very high attrition resistance, and regenerability at lower temperature. Each of these sorbent preparation techniques is described separately below.

\section{Method I:}

The rationale for Method I is that although high theoretical sorbent capacity and high initial reactivity are desired, both of these factors were not deemed crucial in developing a sorbent that would have acceptable long-term physical and chemical durability, as well as sufficient effective sulfur capacity. This latter parameter is equal to the theoretical sorbent capacity times the sorbent conversion at breakthrough. A sorbent with a lower theoretical capacity for sulfur, but much higher reactivity, may have equivalent overall effective capacity to a sorbent with higher theoretical capacity, but considerably lower reactivity. Therefore, if the higher reactivity of a sorbent with a lower theoretical capacity can be maintained or stabilized over a very large number of cycles, then the fresh sorbent makeup rate in an actual desulfurization process can be reduced, thereby reducing the overall cost of hot gas cleanup.

Given the above considerations, a number of low-capacity sorbents were prepared and evaluated early in this investigation. This initial approach concentrated on the preparation of highly dispersed metal oxide sorbent formulations using refractory supports/dispersants which are themselves highly resistant to sintering and deterioration. The rationale was that these low-capacity sorbents would have a high probability of maintaining good chemical reactivity and physical stability with cycling. The sorbent preparation method utilized metal oxides that are available as water-soluble salts, watersoluble as well as insoluble support materials, and a proprietary material that was added in controlled quantities to promote metal oxide dispersion. ${ }^{59}$ The sorbent preparation procedure for Method I is summarized below.

For metal oxides that are available as water-soluble salts, the non-reactive metal salt (i.e., support/dispersant) was completely dissolved in de-ionized water. The reactive metal oxide salt was then added to the solution along with a proprietary additive. The mixture was heated until it turned very viscous and dried overnight at $125^{\circ} \mathrm{C}$. The dried mixture was calcined at the desired temperature for a pre-determined period. The resulting calcined sorbent was ground to the desired size range for preliminary attrition resistance evaluation and testing in the appropriate reactor. 
For water-soluble reactive metal oxides and water-insoluble support/dispersant materials, the reactive metal oxide salt was first completely dissolved in an amount of deionized water equal to the porosity of the support/dispersant material. An appropriate amount of the proprietary additive was then added gradually with slight heating and stirring until complete dissolution. The support/dispersant material was added in controlled quantities to the solution, which was then brought to $75^{\circ} \mathrm{C}$ with moderate stirring. Heating and stirring was continued until the solution turned very viscous. The resulting material was then dried overnight at $125^{\circ} \mathrm{C}$, calcined at the desired temperature for a pre-determined period, and ground to the desired size range for preliminary attrition resistance evaluation and testing in the appropriate reactor.

A total of 66 sorbent formulations were prepared using Method I. The breakdown of the formulations prepared according to the reactive metal oxide employed is provided in Table 2. Based on results of earlier work at IGT, copper oxide-based sorbents were regarded as the best candidates for the moderate temperature application, and accordingly, most of the sorbents prepared using Method I were based on copper oxide, as shown in Table 2.

Table 2. Breakdown of Sorbent Formulations by Main Reactive Component (Method I)

\begin{tabular}{l|c}
\hline Reactive Metal Oxide & No. of Formulations Prepared \\
\hline $\mathrm{CuO}$ & 39 \\
$\mathrm{Fe}_{2} \mathrm{O}_{3}$ & 17 \\
$\mathrm{ZnO}$ & 10 \\
\hline
\end{tabular}

The sorbents prepared using Method I were found to exhibit high reactivity toward $\mathrm{H}_{2} \mathrm{~S}$ along with acceptable durability in multi-cycle testing, as described in the "Results" section of this report. Attempts were then made to improve the sulfur capacity of the prepared sorbents, using the same sorbent preparation technique. However, most of the sorbent formulations prepared with this approach lacked sufficient strength and/or reactivity toward $\mathrm{H}_{2} \mathrm{~S}$, necessitating an alternative sorbent preparation technique to be utilized.

\section{Method II:}

In order to achieve sorbent stability at the highest possible effective sulfur capacity, secondary efforts were devoted to the preparation of sorbents having higher sulfur capacity and mechanical strength. This was accomplished by extending the application of a pelletization technique previously developed for the formulation of spherical pellets (dia. $=3-10 \mathrm{~mm})^{60,61}$ to the preparation of highly attrition-resistant granular sorbents $($ dia. $=50$ to $850 \mu \mathrm{m}$ ). This sorbent manufacturing technique was applied to prepare over 100 formulations of $\mathrm{Cu}-, \mathrm{Fe}-, \mathrm{Mn}-$, and $\mathrm{Zn}$-based sorbents suitable for fluidized-bed application. The experimental procedure for Method II is described below. 
For each sorbent formulation, the initial step involves weighing the desired amounts of components, slightly dry-mixing the components in a bottle before adding sufficient quantities of de-ionized water to make a slurry. Vigorous wet mixing is accomplished using a vibro-mill for one to two hours. The vibro-mill is enclosed in a solid, lined wooden box for safety as well as sound-proofing. The well-mixed slurry is then removed from the mixer and dried overnight in an oven. The resulting dry solid mixture is then calcined in a furnace for about two hours at $500-550^{\circ} \mathrm{C}$. The resulting "cake" is transferred to a ball mill and allowed to disintegrate overnight. The fine material is then screened with the fraction finer than 850 microns (20 mesh) being designated as ready for pelletization. The rest of the material is ground further until it passes through the 20-mesh screen.

\section{Pelletization Procedure:}

The mixed powder is fed to a pelletizer, along with a fine spray of water to form spherical pellets (i.e., 2-5 $\mathrm{mm}$ in diameter) or granular sorbents (i.e., 100-850 $\mu \mathrm{m}$ ). The granular and spherical sorbents are dried to impart green strength for further handling. The dried sorbents are then indurated at high temperature to obtain the desired combination of physical properties such as crush strength and porosity.

Pelletization is accomplished using a balling unit or pelletizer, as shown in Figure 9 , consisting of a 20 -inch tire mounted on a platform with adjustable inclination and rotation speed. Usually, a 40 to $60^{\circ}$ inclination to the horizontal and a rotational speed of 30 to $50 \mathrm{rpm}$ are used during pelletization. Initially, the tire interior is moistened and then wiped clean. About $7 \%$ by weight of the prepared feed in the form of fines is slowly sprinkled into the rotating tire. When seeds begin to form (as evinced by micro-pellets), moisture is added in discrete increments (of about $0.1 \%$ by weight of the original solids) via a finely atomized hand-held sprayer (spray droplets 5 to 15 microns in diameter) along with additional fines to allow the seeds to grow. After growth, the seeds are removed and screened to pass a 6-mesh screen, and the fines are returned to the tire.

This procedure is continued until approximately one-third of the original feed (which is set aside) is converted to agglomerates which would ideally range in size from 2 to $5 \mathrm{~mm}$ in diameter. At this point, the feed is divided into three portions. In the subsequent pellet making operation, a portion of the seeds are returned to the tire and sprayed with the above fine spray of water until the glistening point is noted. This glistening point is a visual observation of a shiny reflective surface appearance on pellets, which originally appeared as "flat", i.e., non-glossy. Fines are then added in small increments to cause the seeds to grow.

The rate of addition of fines is controlled so as to avoid sticking and also to promote the free-rolling of the pellets. Too slow a rate of addition causes the seeds to stick together; whereas, too rapid an addition causes the formation of unnecessary new seeds in competition with the desired growth of the original seeds. Immediately after this procedure of addition of the fines, water is sprayed once again to bring the pellets to the glistening point. This procedure of spraying pellets to the glistening point and the 
subsequent addition of fines is repeated until the pellets grow to the desired final size. At this point, the pellets are removed from the pelletizer and screened; the fraction in the desired size range is stored in dessiccators pending evaluation of their strength and appearance, and the undersize pellets are returned to the tire for further growth.

The pellets are then dried to a constant weight at $110^{\circ} \mathrm{C}$ and then indurated. Induration is conducted in air and involves heating from room temperature to the desired induration temperature and held there for a predetermined period.

These pellets will then be crushed and screened to a particle size range of -40 +140 mesh (100 to $500 \mu \mathrm{m})$ and the resulting attrition-resistant granules will be stored pending further evaluation.

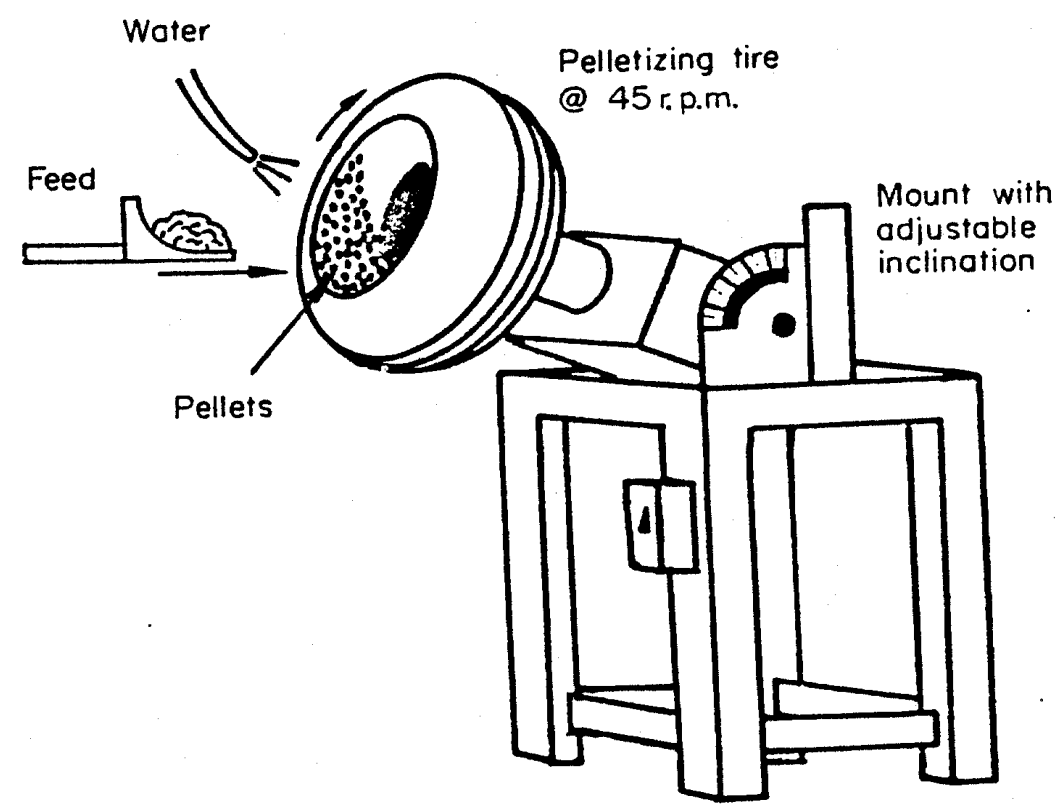

Figure 9. Pelletizer Used for the Production of Spherical Pellets and Granules from Fine Powders

A systematic approach was used to prepare a large number of sorbent formulations for screening in packed-bed and thermogravimetric analysis (TGA) reactors to ultimately identify the most promising sorbent formulations for high-pressure fluidized-bed application in the temperature range of 350 to $550^{\circ} \mathrm{C}$. A total of 113 sorbent formulations were prepared using Method II in this program and the various parameters considered in preparing the sorbents included:

- Selection of the primary reactive metal oxide: Copper oxide $(\mathrm{CuO})$, iron oxide $\left(\mathrm{Fe}_{2} \mathrm{O}_{3}\right)$, manganese oxide $\left(\mathrm{Mn}_{2} \mathrm{O}_{3}\right)$, and zinc oxide $\left.(\mathrm{ZnO})\right)$ were used. The breakdown of formulations prepared according to the reactive metal oxide employed is provided in Table 3. As seen in this table, the bulk of sorbents prepared was based 
on zinc oxide, consistent with much of related literature and the expectation of developing suitable sorbents based on this oxide.

- Primary reactive metal oxide concentration: This determines the theoretical sulfur capacity of the sorbent. The prepared sorbents had nominal sulfur capacities ranging from 10 to $42 \mathrm{~g} \mathrm{~S} / 100 \mathrm{~g}$ of sorbent. Lower-capacity sorbents were prepared to investigate the possibility of enhancing their reactivity through high dispersion of active oxides.

- Selection of the primary support material (matrix): This depends on the reactive metal oxide employed: titania $\left(\mathrm{TiO}_{2}\right)$, alundum (an impure form of alumina), $\gamma-\mathrm{Al}_{2} \mathrm{O}_{3}$, $\alpha-\mathrm{Al}_{2} \mathrm{O}_{3}$, manganese oxide $\left(\mathrm{Mn}_{2} \mathrm{O}_{3}\right)$, silica $\left(\mathrm{SiO}_{2}\right)$, zirconia $\left(\mathrm{ZrO}_{2}\right.$ and $\left.\mathrm{ZrCO}_{3}\right)$, chromia $\left(\mathrm{Cr}_{2} \mathrm{O}_{3}\right)$, magnesium titanium oxide $\left(\mathrm{MgTiO}_{3}\right)$, magnesium zirconium oxide $\left(\mathrm{MgZrO}_{3}\right)$, and calcium sulfate $\left(\mathrm{CaSO}_{4}\right)$ were used both singly and in combination.

- Ratio of primary reactive oxide to support material: In particular, the possibility of enhancing sorbent reactivity at moderate temperatures by employing support material, in excess of the amount required to form the most stable compound, was explored. This approach was previously reported to have led to the development of a promising sorbent for moving-bed applications. ${ }^{62}$

- Selection and concentration of secondary reactive metal oxides: These were employed as a means of enhancing sorbent reactivity via structural modification and also to possibly reduce the temperature required for proper regeneration. The oxides employed included $\mathrm{MoO}_{3}, \mathrm{NiO}, \mathrm{Fe}_{2} \mathrm{O}_{3}$, and $\mathrm{Mn}_{2} \mathrm{O}_{3}$. This latter oxide was used both alone and in combination with alumina, in cases where it was necessary to tie up $\mathrm{Mn}_{2} \mathrm{O}_{3}$ in the form of the non-reactive manganese aluminate $\left(\mathrm{MnAl}_{2} \mathrm{O}_{4}\right)$.

- $\quad$ Selection and concentration of inorganic binders: These were employed to initially promote pelletization/granulation of the raw mixture and then enhance the green strength of the prepared pellets/granules. Bentonite was used in quantities ranging from 1 to $5 \%$ by weight. The choice of bentonite as a generic inorganic binder was made to explore the possibility of enhancing sufficient physical strength to the sorbent without the requirement for excessive thermal treatment temperatures and without adversely affecting its reactivity.

- Selection and concentration of organic binders: Examples of these binders include dextrin and carbon graphite and they were also used as a means to promote pelletization/granulation, but more importantly to enhance sorbent porosity by burn off during high temperature processing of green pellets/granules.

- Initial high temperature processing: This step was applied to initial raw mixed materials and prepared green pellets/granules. This step was usually carried out at a moderate temperature as a pre-granulation conditioning step to further promote the uniformity of the initial sorbent powdery mixture. 
- Induration/calcination: This is the final phase of sorbent preparation and consists of heating the dried and/or calcined sorbents to a high temperature and holding for a predetermined duration. Proper sorbent induration is critical to its physical properties including attrition resistance, crush strength, porosity, and surface area. A wide range of temperatures ranging from 750 to $1200{ }^{\circ} \mathrm{C}$ was investigated with the different sorbents prepared. The induration time was also varied from 2 to 15 hours to explore the possibility of optimizing sorbent properties by induration at higher temperatures and shorter times, and at lower temperatures and longer times.

Table 3. Breakdown of Sorbent Formulations by Main Reactive Component (Method II)

\begin{tabular}{l|c}
\hline Reactive Metal Oxide & No. of Formulations Prepared \\
\hline $\mathrm{CuO}$ & 7 \\
$\mathrm{Fe}_{2} \mathrm{O}_{3}$ & 5 \\
$\mathrm{Mn}_{2} \mathrm{O}_{3}$ & 10 \\
$\mathrm{ZnO}$ & 91 \\
\hline
\end{tabular}

\section{Method III:}

\section{$\underline{\text { Introduction }}$}

The sorbents of Method II were prepared in bulk form using the conventional technique of solid-oxide mixing followed by granulation. Similar to other sorbents prepared with other conventional techniques, such as co-precipitation followed by extrusion, granulation, or spray drying, physical strength is imparted to these sorbents through high temperature treatment, referred to in this report as calcination or induration. Due to sintering effects, the desirable sorbent characteristics, such as surface area, porosity, and pore size distribution were found to diminish with increasing calcination temperature, adversely affecting the reactivity of the sorbent. Moreover, because the reactivity of a sorbent undergoes an Arrhenius-type decrease with decreasing temperature, this trade-off between sorbent mechanical strength and chemical reactivity presented more of a challenge in the moderate temperature range of 343 to $538^{\circ} \mathrm{C}(650$ to $1000^{\circ} \mathrm{F}$ ) that has been the focus of this investigation and is currently of industrial interest.

The need for an alternative sorbent preparation approach stemmed from the results obtained with sorbents prepared according to Method II, and the need to develop sorbents suitable for demonstration at in the Piñon Pine Clean Coal Demonstration facility. ${ }^{54,63}$ Results from this part of the investigation are discussed in detail in this report, but are also summarized in a recent publication by the authors. ${ }^{64}$ This investigation cast doubt on the feasibility of formulating an effective bulk sorbent based on zinc oxide, using conventional sorbent preparation techniques such as co-precipitation and solid oxide mixing, for a demanding commercial desulfurization application, particularly in transport reactors. These sorbent preparation techniques require very high thermal treatment temperatures to impart physical strength, and as a result, they often produce sorbents with low reactivity. The results obtained indicated non-titania sorbents 
based on $\mathrm{ZnO}$ showed no improvement over zinc titanate. Moreover, it has been shown that even when chemical reactivity is compromised significantly, the minimum attrition resistance requirement for the transport reactor is not met. Because sorbents based on zinc oxide have undergone significant development and are best suited for desulfurization, especially in the moderate temperature range of current interest (i.e., 350 to $550^{\circ} \mathrm{C}$ ), an alternative sorbent preparation approach was deemed necessary.

This investigation also demonstrated that only sorbents based on copper oxide were found to possess the best combination of high attrition resistance and sulfidation reactivity, sulfur removal efficiency, and pre-breakthrough conversion in the moderate temperature range of 350 to $550^{\circ} \mathrm{C}$. However, sustaining good and uniform fluidization with copper-based sorbents in the reducing environment proved to be difficult because of relatively strong attractive interparticle forces, resulting in sluggishness and ultimately complete defluidization of the sorbent bed. The fluidization behavior of copper-based sorbents has been shown to improve with increasing gas velocities or upon mixing with other non-copper sorbents. Therefore, good fluidization behavior can be expected at the much higher gas velocities prevailing in the transport reactor. Unfortunately, because of the limitations of bubbling fluidized-bed batch systems and laboratory equipment, the suitability of this class of sorbents for the transport reactor applications could not be demonstrated.

Encouraging results were also obtained with sorbents based on manganese oxide, which were found to combine the advantages of high sulfur capacity and high reactivity in the moderate temperature range, without any requirement for sorbent pre-conditioning or activation. However, their regeneration necessitates very high temperatures $\left(>750^{\circ} \mathrm{C}\right)$ that cannot be accommodated by current desulfurization systems requiring regeneration ignition temperatures of about $550^{\circ} \mathrm{C}$. Further research on alternative regeneration approaches is needed to reduce the disparity between temperatures for sulfidation and regeneration for manganese-based sorbents.

No sorbent based on iron oxide, prepared with Method II, was found to have sufficient reactivity in the moderate temperature range.

Given the desirable properties offered by $\mathrm{ZnO}$, however, further investigation of zinc-based sorbents as potentially suitable desulfurizing agents in the moderate temperature range is warranted. Moreover, $\mathrm{ZnO}$ has a demonstrated capability of being sufficiently reactive at "low" temperatures; for example, $\mathrm{ZnO}$ is used in a commercial application as a once-through sorbent for desulfurizing natural gas at temperatures below $316^{\circ} \mathrm{C} .{ }^{52}$ Also, a number of zinc oxide-containing sorbents specifically formulated for sulfur removal are commercially-available and are used routinely in industry to protect sulfur sensitive catalysts, such as ammonia synthesis and methanation catalysts. ${ }^{65}$ For these reasons, secondary efforts have been geared towards employing alternative sorbent preparation techniques that have been shown to produce mechanically strong, porous solids with median pore diameters in the range of interest. Review of the literature identified sol-gel processing as a promising method, as substantiated below. 
Sol-gel processing is defined broadly as the preparation of ceramic materials by preparation of a sol, gelation of the sol, and removal of the solvent. ${ }^{66}$ The sol is a colloidal suspension of solid particles in a liquid and may be produced from inorganic or organic precursors. For example, common precursors for aluminum oxide include inorganic salts such as $\mathrm{Al}\left(\mathrm{NO}_{3}\right)_{3}$ and organic compounds such as $\mathrm{Al}\left(\mathrm{OC}_{4} \mathrm{H}_{9}\right)_{3}$. The latter is an example of an alkoxide, the class of precursors widely used in sol-gel research because they react readily with water (i.e., hydrolysis reaction). Gels have a huge interfacial area, typically $300-1000 \mathrm{~m}^{2} / \mathrm{g}$, and this enormous area serves as a driving force to bring about sintering at exceptionally low temperatures, compared to ordinary ceramic materials. Therefore, a considerable amount of the extraordinary properties (high surface areas and small pore sizes) of unfired gels are retained following calcination, offering the possibility of using the gel as a substrate for chemical reactions. These properties, characteristic of inorganic gels as a result of low-temperature processing, are unattainable by conventional sorbent preparation techniques and, to the best knowledge of the authors, have not been exploited in hot gas desulfurization applications. One important consideration is to maintain the necessary properties after heat treatment, and in fact, the uniqueness of sol-gel derived materials diminishes as the heat treatment is increased.

In the sol-gel approach of Method III, a stable sol is first prepared from a titania precursor (alkoxide and/or powder). The required amount of a zinc precursor (zinc nitrate hexahydrate) is then added to bring the zinc oxide content to the desired level. The resulting solution is then well mixed to disperse the reactive oxide, thickened, dried, and finally calcined at the desired temperature for a predetermined period.

Eleven (11) sorbent formulations were prepared using the sol-gel approach. The nominal zinc oxide content of the sorbents prepared ranged from 10 to $40 \mathrm{wt} . \%$. The calcination temperature ranged from 450 to $725^{\circ} \mathrm{C}$. Granules from each of the above sorbents were then produced in the desired size range of $425-600 \mu \mathrm{m}$ and $45-180 \mu \mathrm{m}$ for testing in the packed-bed and fluidized-bed reactors, respectively.

\section{EXPERIMENTAL APPROACH AND PROCEDURES}

\section{Preliminary Screening of Prepared Sorbents}

A single-hole attrition unit was used to make a preliminary determination of the relative physical strength of the sorbents prepared. A schematic diagram of this unit is shown in Figure 10. To determine the attrition resistance of the sorbents, a small quantity of each prepared sorbent, ranging in size from 125 to $300 \mu \mathrm{m}$, was fluidized in the attrition unit using a high velocity central jet to create a strong shearing effect and turbulence, thus providing measurable attrition between sorbent particles. After a specified period of time (30 minutes) the test was terminated and the fraction of the sorbent particles below a pre-determined size $(105 \mu \mathrm{m})$ was determined.

A commercial zinc titanate sorbent manufactured by United Catalyst, Inc. and designated as UCI-4169 was used as a basis to evaluate granular sorbent performance in 
attrition tests. This sorbent has already been extensively tested using IGT's highpressure high temperature fluid-bed reactor as well as Enviropower's pilot-scale desulfurization unit in Finland. ${ }^{27,37,67-69}$ The attrition resistance of the UCI-4169 formulation, as determined in the single-hole unit, was considered as a minimum mechanical strength requirement that each prepared sorbent must meet to qualify for further evaluation tests in packed-bed and/or thermogravimetric analysis (TGA) reactors. The attrition resistance of the baseline UCI-4169 zinc titanate sorbent is in Figure 11. All sorbents that met minimum mechanical strength requirement were evaluated for $\mathrm{H}_{2} \mathrm{~S}$ removal efficiency and effective sulfur capacity.

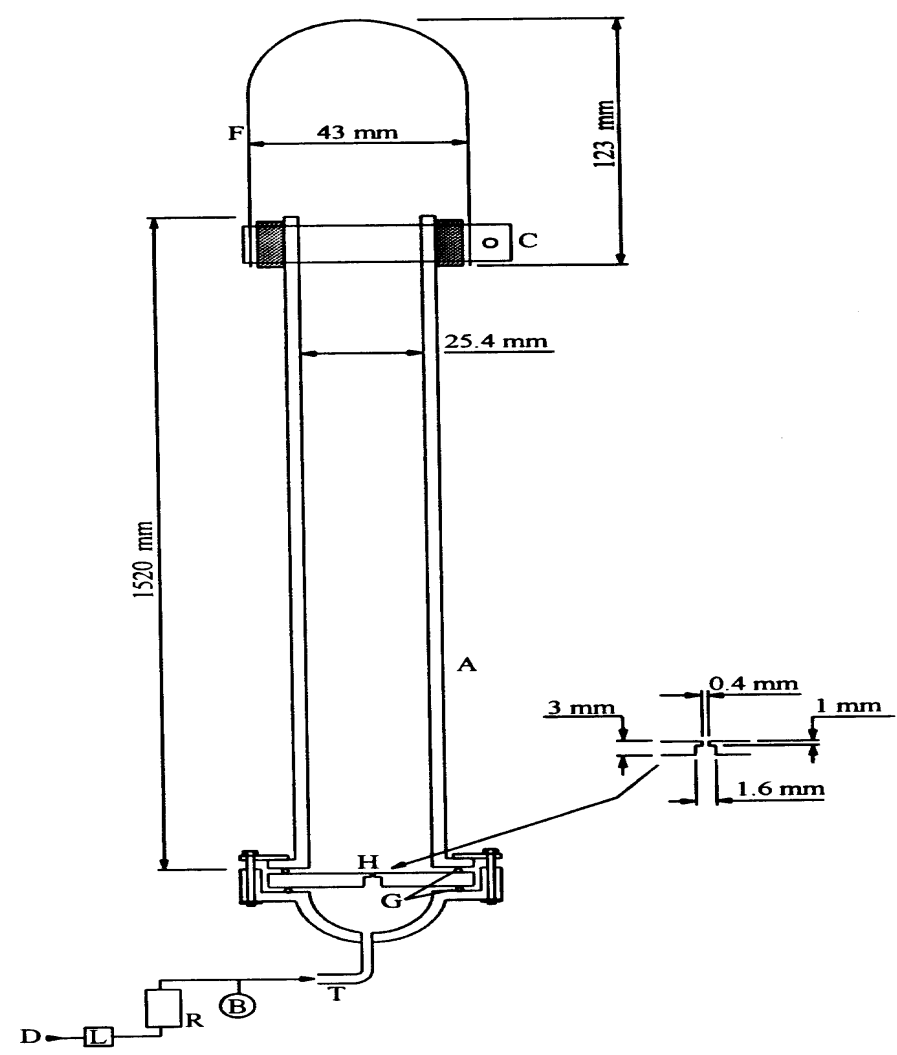

Figure 10. Experimental Arrangement for Preliminary Attrition Resistance Evaluation of Sorbents

\section{Chemical Analysis and Physical Characterization}

Fresh as well as reacted samples from selected sorbents were subjected to wet chemical analysis and standard physical characterization, including BET surface area, mercury porosimetry and pore size distribution, particle density, and X-ray Diffraction (XRD) analysis. This work was carried out at IGT's Chemical Research Services department.

Wet chemical analysis either by Atomic Absorption (AA) or Ion Coupled Plasma (ICP) can measure the loss of sorbent phases after testing in a $\mathrm{H}_{2} \mathrm{~S}$ removal reactor. 
Samples for metal analysis were prepared using acid digestions and/or sodium tetraborate fusion and were analyzed using a Thermo Jarrell Ash Atomscan 25 inductively coupled plasma atomic emission spectrophotometer (ICP/AES), equipped with a 95-place autosampler for multi-element analyses of aqueous and nonaqueous samples. Samples for sulfide sulfur and sulfate sulfur analyses were acid digested, and in the case of the sulfide analysis, a closed system was used where the evolved gases were collected in an alkaline peroxide sorbent. The resulting solutions were analyzed by ICP for sulfur.

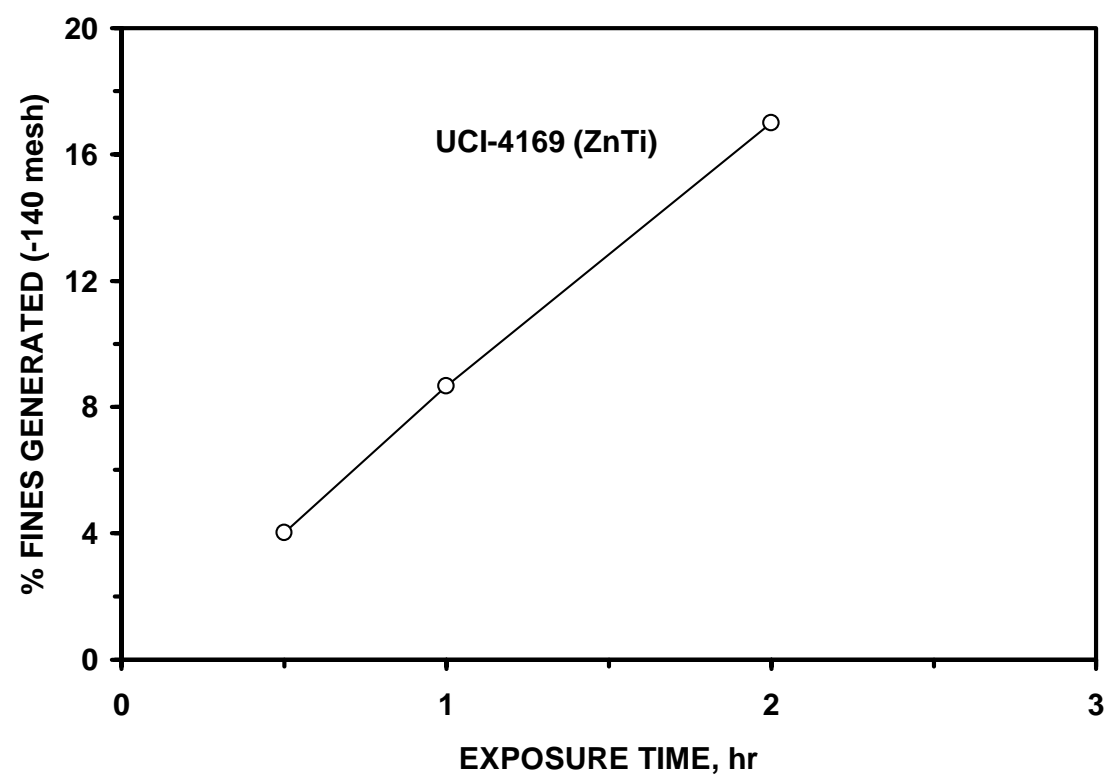

\section{Figure 11. Preliminary Attrition Resistance of Baseline Sorbent (UCI-4169 Zinc Titanate)}

BET surface area measurements are commonly used for correlating the activity and reactivity of solids on a surface area basis. BET techniques can be extended to include pore size and pore size distribution. A computer-controlled Micrometrics Model 9310, 30,000-psia mercury porosimeter was used for semiautomated measurements of pore size distribution, pore volume, and internal pore surface area. A Micromeritics Model 2100D surface-area analyzer, equipped with chemisorption accessory, was used for surface area measurement, chemisorption study, and micropore distribution. A Beckman pycnometer was used for helium (true) density measurement. A 16-channel Model TA-II Coulter counter, with an electronic interference-free sample stand, was used for subsieve particle size analysis.

X-ray Diffraction is important to the study of sorbents because it measures the bulk phases. Performing XRD before and after sorption/regeneration cycles can give important information regarding the breakdown of phases in the sorbent material. A Ranger Scientific Model MS-900 Mosbauer spectrometer, equipped with a ${ }^{57} \mathrm{Co}$ source 
and high-temperature vacuum furnace, was used to provide information about the oxidation state of sorbent materials.

\section{ASTM Attrition Resistance Procedure}

D 5757-95 is a standard ASTM test method for the determination of the relative attrition characteristics of powdered catalysts by air jets. ${ }^{70}$ This test method is capable of providing reliable information concerning the ability of a powdered material to resist particle size reduction (i.e., attrition) during use in a fluidized environment. Strictly speaking, this method is applicable to spherically or irregularly shaped particles ranging in size between 10 and $180 \mu \mathrm{m}$ and having skeletal densities between 2.4 and $3.0 \mathrm{~g} / \mathrm{cm}^{3}$ Nevertheless, the information it provides can be particularly valuable for research and development efforts in the area of sorbent development for fluidized-bed as well as transport reactor applications, where sorbent durability during multi-cycling is crucial.

An air jet attrition unit has been constructed at IGT according to the ASTM method specifications. As indicated on the schematic diagram shown in Figure 12, this apparatus consists of an attrition tube, a settling chamber, a fines collection assembly, and a circular orifice plate containing 3 holes and attached to the bottom of the vertical attrition tube within an air delivery manifold. During a typical test, a representative dry sample of the granular material (approximately 50 grams) is subjected to attrition by means of three high-velocity jets of air. The fines generated during this process are continuously removed from the attrition zone by elutriation into the collection assembly. The percent attrition loss after five (5) hours is defined as the Air Jet Index (AJI), and is calculated from the elutriated fines to give a relative estimate of the attrition resistance of the granular material.

During a typical test, the system is first reassembled without the fines collection assembly. Air supply is turned on and the flow adjusted to $10.00 \mathrm{~L} / \mathrm{min}$ at standard temperature and pressure $(273.15 \mathrm{~K}$ and $101.325 \mathrm{kPa})$, resulting in a back pressure in the range of 179 to $203 \mathrm{kPa}$. This is an indication that the air jet nozzles are clean and that there are no leaks in the apparatus connections.

Two fines collection assemblies are then prepared and weighed. With the air flowing at $10 \mathrm{~L} / \mathrm{min}$ and the fines collection assembly off, $50 \mathrm{~g}$ of the material to be tested is charged through the top of the settling chamber. The first fines collection assembly is then quickly secured to the apparatus and the timekeeping started. After exactly 1 hour from the start, the first fines collection assembly is replaced with the second one. After exactly 5 hours from the start, the second fines collection assembly is removed, the attrition unit disassembled, and the sample from the attriting tube and settling chamber recovered and weighed. 


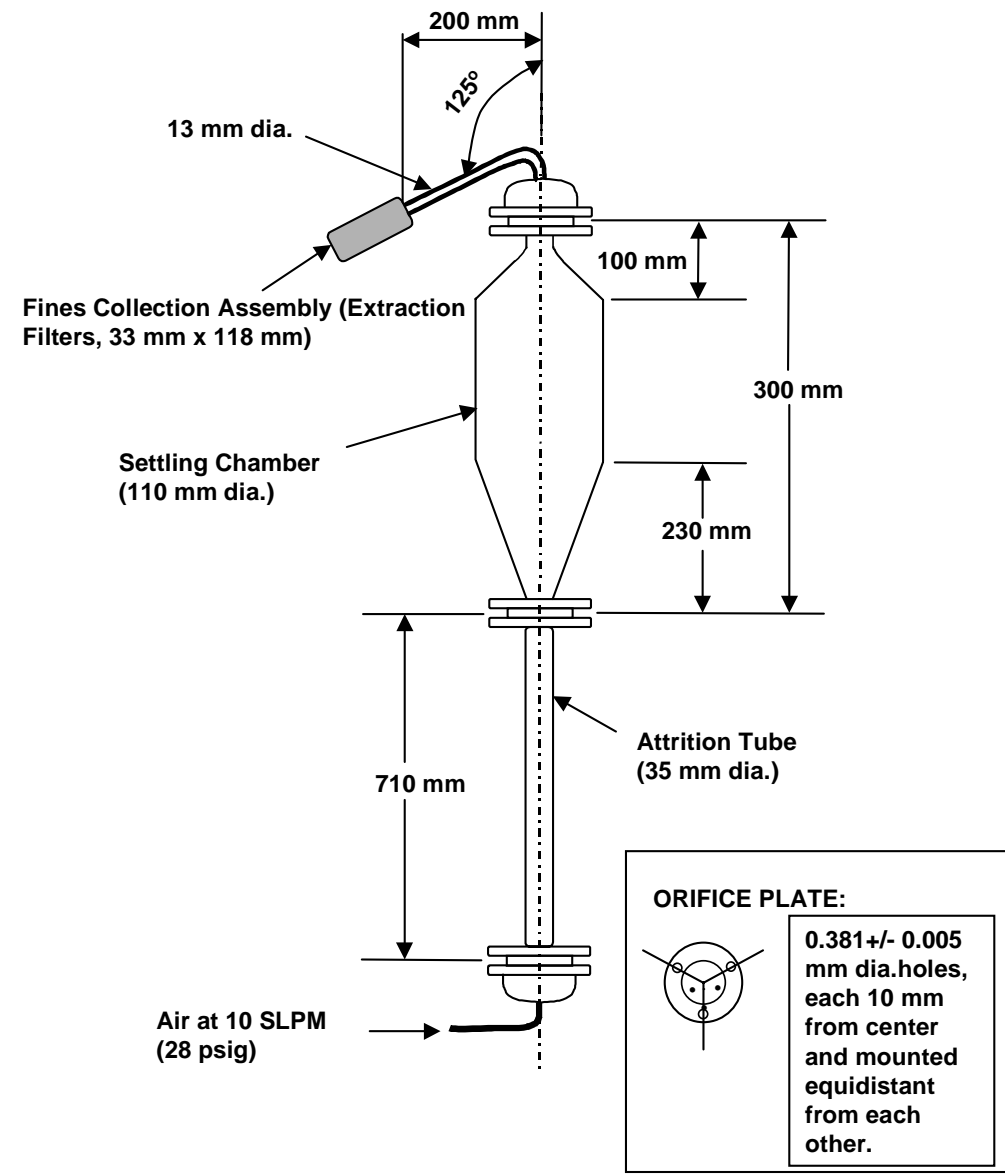

Figure 12. Schematic Diagram of the Three-Hole Attrition Resistance Measurement Unit

\section{Attrition Unit Performance Verification}

The results of an inter-laboratory study conducted by Akzo Nobel Research Facility (ANRF) in Pasadena, Texas, on the measurement of AJI of a fresh FCC catalyst in 3 separate tests conducted at 4 different laboratories are presented in Figure 13, to demonstrate the expected variation in the values of AJI of a selected material. ANRF is one of the laboratories that participated in establishing the ASTM procedure. These results indicate an average five-hour loss due to attrition of $20.36 \%$ with a standard deviation of $3.6 \%$.

The performance of IGT's attrition unit was then verified, using four different materials, in collaboration with ANRF. The materials tested included FCC catalyst, dolomite 245, limestone 246, and the UCI-4169 zinc titanate. The FCC material is widely used in the petroleum industry and may be considered as a suitable standard against which sorbent performance in attrition tests can be compared. The results obtained are presented in Figure 14, indicating that the results obtained using the IGT attrition unit are well within the experimental error of the test method. A striking result is the one obtained with the UCI-4169 zinc titanate sorbent, showing an air jet index greater than $75 \%$. 


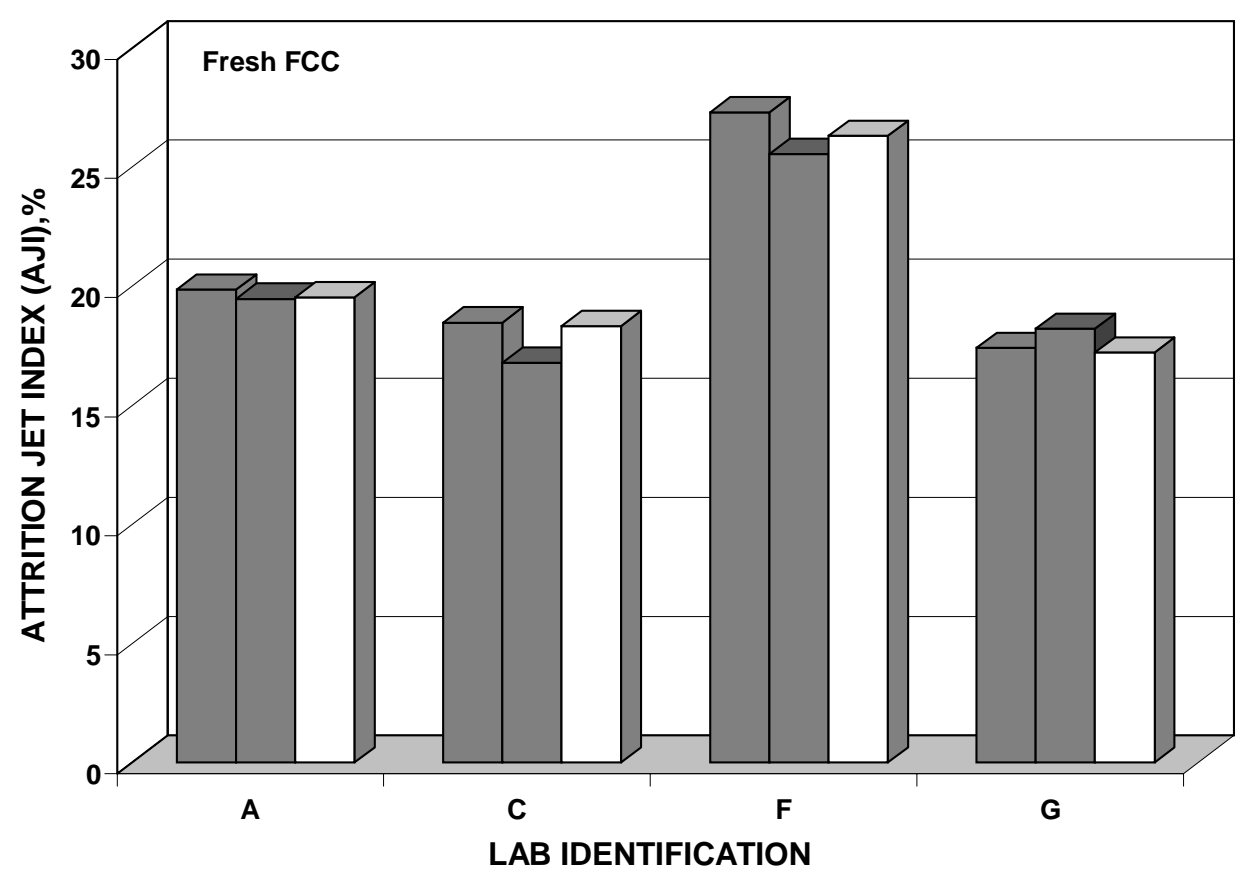

Figure 13. Comparison of AJI Results of FCC Catalyst at Different Facilities

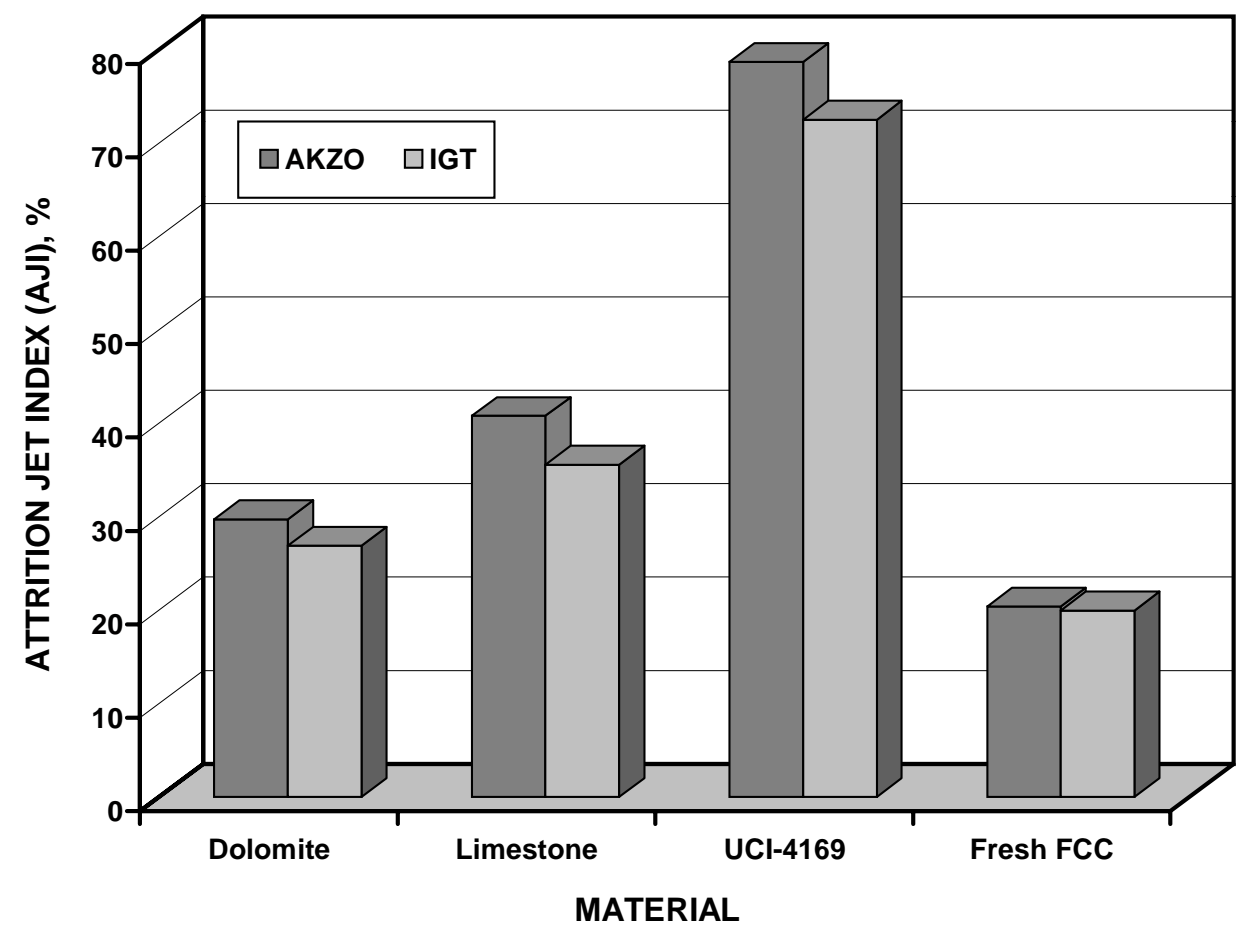

Figure 14. Comparison of Attrition Results of Different Materials at IGT and ANRF 


\section{HPTGA System Description and Testing Procedures}

A high-pressure/high-temperature thermogravimetric analyzer (HPTGA) unit was used to determine the initial reactivities of various sorbents during the initial screening process. This unit is capable of continuously weighing a sample that is undergoing reaction in a gaseous environment at constant pressure and constant or varying temperature. The gas flow rates used with this system are sufficiently large such that changes in gas composition due to reaction products are virtually eliminated and gas composition is essentially constant. This reactor unit is designed based on balanced pressure concept and is capable of operation at temperatures up to $1000^{\circ} \mathrm{C}$ and pressures up to 100 bar, using very small quantities of solids and very high gas flow rates, thus eliminating the "starvation condition" and "gas film diffusion" that are of concern in high pressure thermogravimetric experiments. All the hot wetted parts of the unit are made of quartz to prevent reaction with corrosive and reactive gases. This provision is especially important when conducting gas/solid reaction tests involving very low concentrations of reactant gases (i.e., $<1 \mathrm{vol} \%$ ).

A schematic diagram of the overall arrangement of the HPTGA unit is provided in Figure 15. It consists of a high-pressure microbalance, a gas supply and preheating system, a steam generator, a pressure control system, a reaction chamber with a watercooled sample lock for the protection of sensitive electrical parts and the microbalance from excessive heating by rising gases, off-gas filtering and cooling systems to protect the sensitive pressure expansion valves, a mechanism for lowering and raising the sample into and from the reaction zone, and a gas switching mechanism allowing the direction of the gas to the reactor or to a by-pass line.

The pressure control system consists of a pressure sensor installed in the purging gas line, pressure expansion valves, and a back-pressure regulator. The pressure in the reactor is measured using an electrical pressure transducer. Each gas supply line consists of a pressure controller, a pressure gauge, and a mass flow controller. The steam generator consists of a high-pressure pump, which supplies the steam generator with water via a stainless steel capillary. The switching facility is extremely important when operating with steam. Since the steam generator has a minimum start-up time of $30 \mathrm{~min}$, it is only possible to achieve a switch-over to steam with immediate flow through the reactor with the help of steam switch-over 3-way valve/by-pass line.

The high-pressure microbalance consists of a symmetrical balance beam, a system board, an amplifier, and a display unit. During operation this microbalance is continuously purged with helium to protect it from corrosive gases and other impurities. In addition to the water-cooled sample lock, the balance is protected against thermal radiation by a cone holding the chain. This microbalance works according to the compensation principle: Any deflection of the balance beam from the position of equilibrium, caused by a change in sample weight, is sensed by a linear differential transformer on the "sample" arm of the balance. A restoring force that is proportional to the change in weight is supplied to the "opposite" arm with an electromagnet. The 
recording balance control unit senses the force required to maintain a null and converts this into a signal proportional to the weight of the sample.

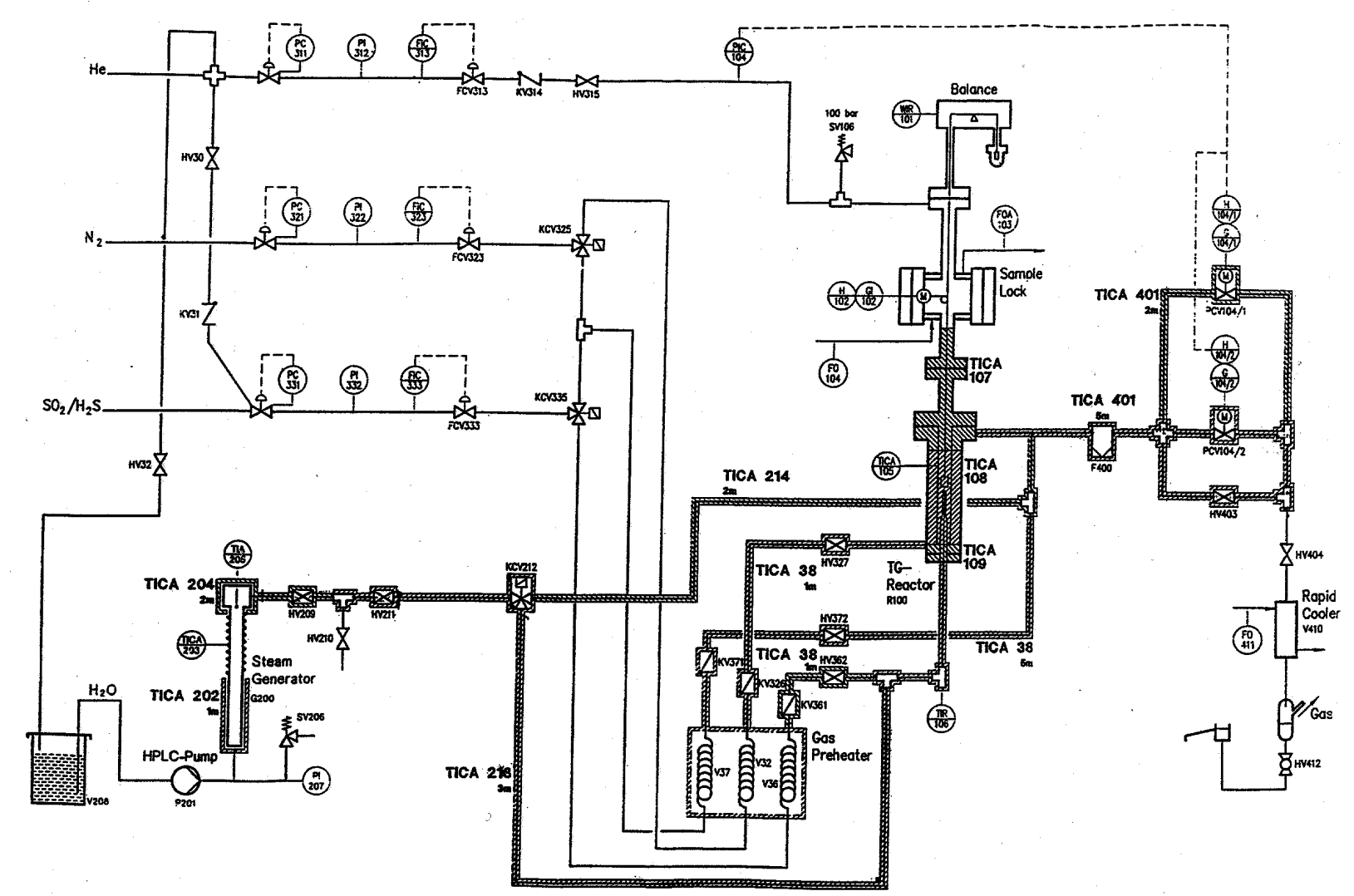

\section{Figure 15. Schematic Diagram of the Overall Arrangement of the High-Pressure Thermogravimetric Analyzer (HPTGA)}

Details about the reactor are provided in Figure 16. This reactor is constructed specifically for the investigation of gas/solid reactions involving sulfur-containing gases, such as $\mathrm{H}_{2} \mathrm{~S}, \mathrm{SO}_{2}, \mathrm{COS}$, or other corrosive gases, such as $\mathrm{HCl}$ or $\mathrm{NO}_{\mathrm{x}}$. The reactor is equipped with a quartz tube, which protects the heating tube from corrosive gases. It is sealed at the top end of the quartz tube using a graphite gasket. The penetration of corrosive gases into the space between the quartz tube and the reaction tube is prevented by a flow of nitrogen, which flows the same way as the corrosive gas and is added as a second reaction gas to the reactive gas mixture. In addition, the reactor tube is equipped with a special bottom flange holding another quartz tube (lance), which serves as supply line for the corrosive gas mixture as well as a protective tube for the thermocouple measuring the sample temperature. The sample temperature is measured approximately 5 $\mathrm{mm}$ underneath the sample basket by means of a NiCr-Ni thermocouple. As mentioned earlier, another added advantage of conveying the corrosive gases in quartz tubes is that any change in gas composition due to reactions with metals or other catalytic action is prevented. However, the stream of corrosive gases cannot be pre-heated outside the 
reactor to reaction temperature because of the potential corrosion, requiring further control of sample temperature. This control is largely accomplished by the non-corrosive reactor gas, which is diverted several times and preheated to the desired reaction temperature prior to mixing with the reactive gas mixture, thus minimizing the shift of the temperature profile in the reaction chamber.

In a typical HPTGA test, a sample weighing approximately 5-100 mg is contained in a platinum wire-mesh basket, which is then attached to the platinum chain in the upper section of the reactor. The wire-mesh basket allows the use of powders with particle diameters $>100 \mu \mathrm{m}$. The weight of the empty basket and the weight of the sample plus basket are determined on an analyzing balance with an accuracy of $0.001 \mathrm{mg}$. The sample is then lowered into the reaction chamber and allowed to stabilize before the flow of gases is started. These gases include a downward flow of helium (He) flowing at about 5 slpm to protect the balance zone from corrosive gases, main nitrogen, and nitrogen through the lance. During ambient pressure tests, the total flow rate of nitrogen through the system is about $3 \mathrm{slpm}$. Data acquisition is then initiated and the heating cycle started. When the set point temperature is reached, the temperature controller is placed on manual control and the set point temperature is adjusted until the desired sample temperature is achieved. Few minutes are then allowed before a baseline is measured under stable conditions of gas flow and temperature. The average relative reading of the HPTGA during this period is taken to correspond to the actual weight of the fresh unreacted sample.

The test is initiated following establishment of the baseline condition by switching the nitrogen flow through the lance to the reactive gas mixture and allowing the sample to react with $\mathrm{H}_{2} \mathrm{~S}$. The flow rate of individual streams is adjusted to provide the desired sulfidation gas composition. The flowrate of nitrogen is always maintained higher than that of the reactive gas mixture to prevent back-flow of corrosive gases into the exterior reactor chamber. This procedure was determined to minimize temperature changes as gases through the lance are switched between $\mathrm{N}_{2}$ and a reactive gas mixture. Exposure of the fresh sample to the reactive gas mixture is usually allowed for a period of one hour during which time the sample weight is continuously monitored and recorded as it reacts with the gas. The test is terminated when the sample weight reaches a constant value (no weight loss or gain). At this point, the reactive gas mixture is switched back to $\mathrm{N}_{2}$ and a second baseline is established for the reacted or sulfided sample, when conditions of flow and sample temperature become stable. During a typical test, experimental data including the sample weight, the rate of weight change, reactor pressure, flow rates in different streams, and the temperature of the furnace in close proximity to the sorbent being tested, are collected by a computerized data acquisition system and stored on diskettes for further analysis. The weight gain-versus-time curve produced in these tests is used as a measure of reactivity and capacity of the sorbent tested. 


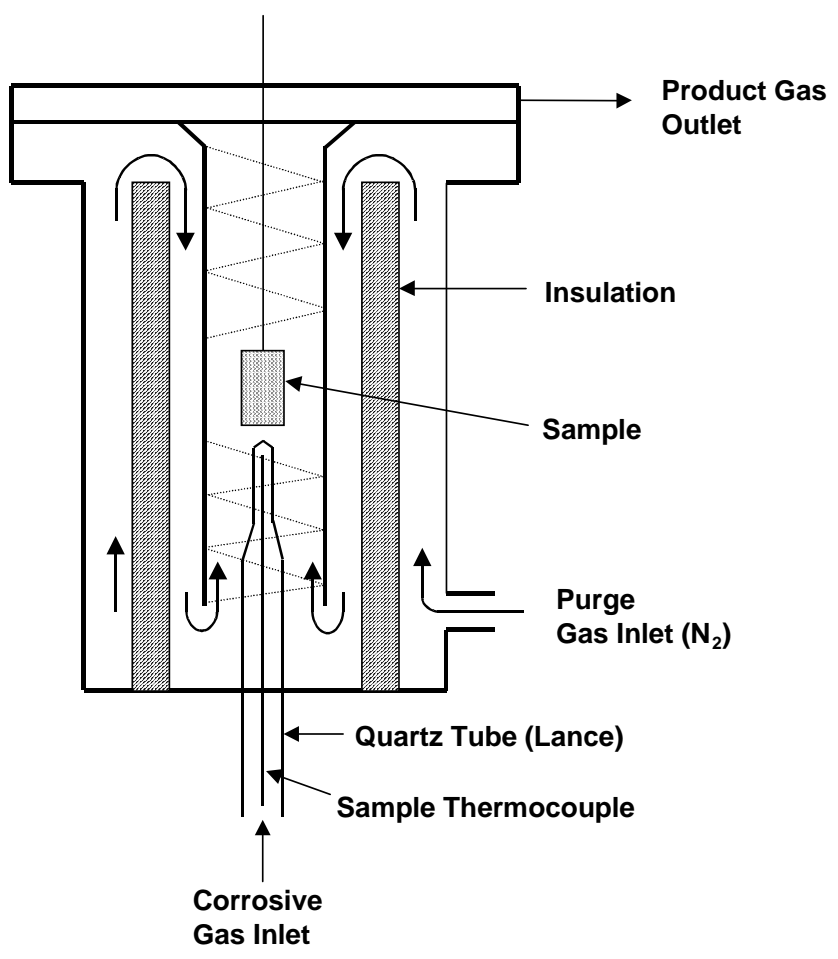

Figure 16. Schematic Diagram of HPTGA Reaction Chamber Details

\section{Ambient Pressure Packed-/Fluidized-Bed Reactor}

The schematic diagram of the packed-bed reactor used in this study is shown in Figure 17. The unit essentially consists of a quartz reactor that is externally heated by two electric furnaces, equipment for feeding and measuring the flow rate of the gases, measuring and controlling the bed temperature, and monitoring the reactor pressure.

This reactor can be configured both for flowing gas downwards or upwards for sulfidation and regeneration tests. A coarse porous quartz frit near the middle of the reactor is used to support the sorbent bed. Several quartz reactors with diameters ranging from 1.2 to $7.5 \mathrm{~cm} \mathrm{ID} \mathrm{can} \mathrm{be} \mathrm{used} \mathrm{with} \mathrm{this} \mathrm{reactor} \mathrm{system.} \mathrm{A} \mathrm{thermocouple,} \mathrm{sheathed} \mathrm{with} \mathrm{a} \mathrm{3-mm}$ closed-end quartz tube and positioned in the middle of the sorbent bed, is used to measure temperature. Temperature is recorded as a function of time using a computerized data acquisition system. Teflon ${ }^{\mathrm{R}}$ tubing is used to convey $\mathrm{SO}_{2} / \mathrm{H}_{2} \mathrm{~S}$-containing exit gas at temperatures lower than $200^{\circ} \mathrm{C}$.

The dry reactant gases required for sulfidation and regeneration of the sorbent are obtained from a commercial supplier in compressed gas cylinders. The gases are passed through pre-calibrated electronic mass flow controllers, which are set to give the desired mixture flow rate prior to entering the reactor. A syringe pump was used to introduce water into the reactor through capillary tubing. 


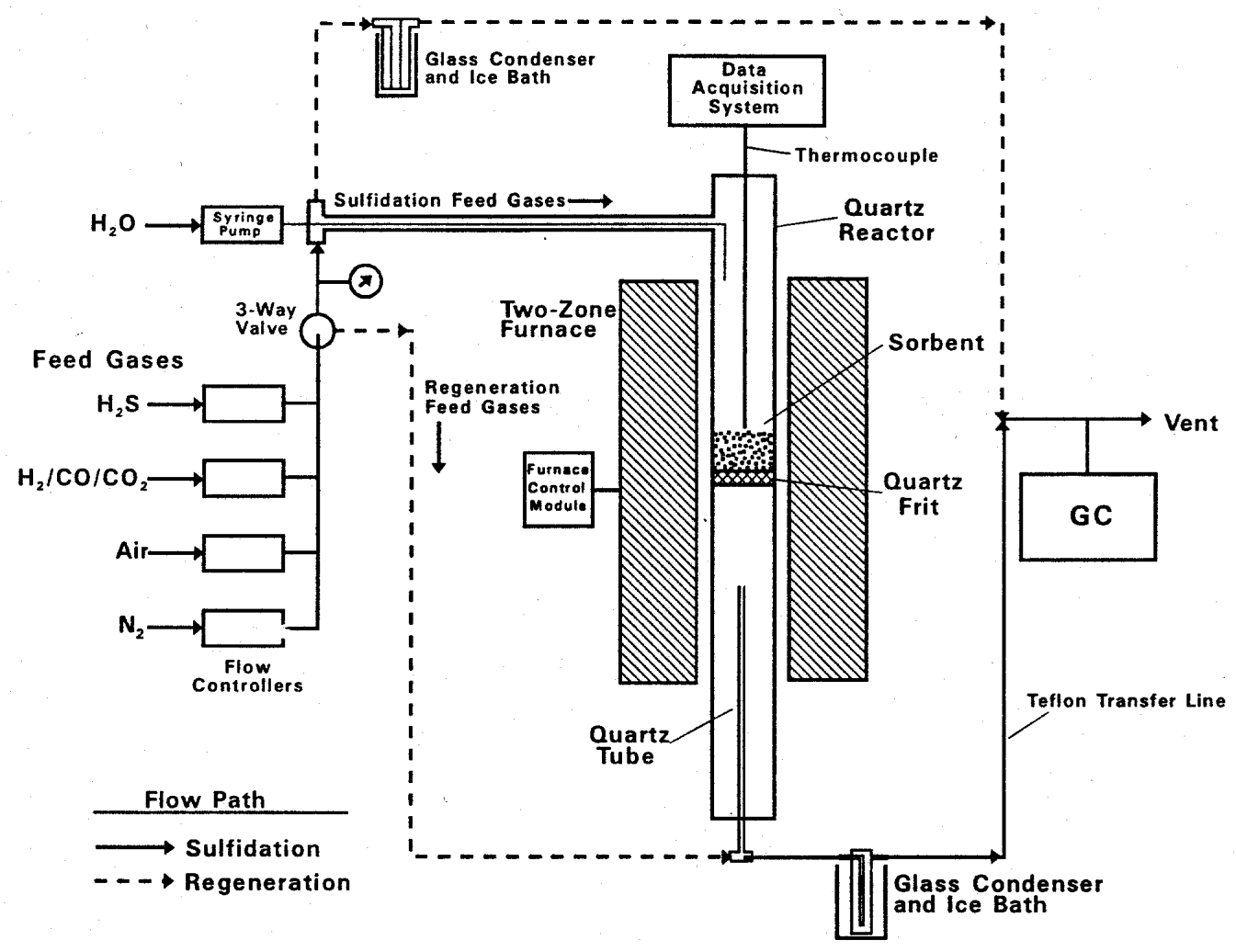

Figure 17. Schematic Diagram of the Packed-Bed Reactor Unit

In a typical test, a predetermined quantity of a fresh sorbent granules (approximately 20-40 grams in the size range of 50 to $850 \mu \mathrm{m}$ ) is loaded into the reactor prior to heating to the desired temperature in flowing nitrogen. The reactant gas mixture is then initiated and the $\mathrm{H}_{2} \mathrm{~S}$ (and $\mathrm{SO}_{2}$ ) concentration in the reactor effluent is determined by on-line dedicated gas chromatographs. The composition of the simulated coal gas used for sulfidation tests is reported in Table 4. This composition represents a slight modification of the U-GAS simplified composition, as reported previously in Table 1. The $\mathrm{H}_{2} \mathrm{~S}$ concentration was artificially increased to $2 \mathrm{vol} \%$ to reduce the time necessary for sorbent evaluation. The sulfidation test is terminated by stopping the flow of reactant gas when the $\mathrm{H}_{2} \mathrm{~S}$ concentration reaches an arbitrary breakthrough value (i.e., 200-500 ppmv). At the conclusion of the sulfidation test the furnace is set to provide the desired regeneration temperature while the sorbent bed is being flushed with nitrogen to purge remaining combustible gases. A regeneration gas mixture consisting of air and $\mathrm{N}_{2}$ is initiated with the product gas being periodically analyzed for $\mathrm{SO}_{2}$ using the on-line gas chromatograph. Regeneration is terminated when $\mathrm{SO}_{2}$ concentration is measured below 50 ppmv.

During each sulfidation/regeneration test a slipstream of the gas from the reactor is diverted to the gas chromatograph for measurement of $\mathrm{H}_{2} \mathrm{~S}$ and $\mathrm{SO}_{2}$ concentrations. Gas sampling of the effluent gas is conducted with a sulfur-dedicated Hewlett-Packard Model No. 5890A Gas Chromatograph. The system includes a flame photometric detector 
(FPD) and a thermoconductivity detector (TCD) to detect $\mathrm{H}_{2} \mathrm{~S}$ and $\mathrm{SO}_{2}$. Prior to each test, the gas chromatograph is calibrated using calibration standard gas samples. Hydrogen sulfide passing through the sorbent bed during the sulfidation reaction is monitored to determine the correct extent of conversion or effective sulfur capacity of the sorbent. Sulfur dioxide is monitored to determine regenerability of the sorbent and also to provide a mass balance on the sulfur loaded on the sulfided sorbent.

Table 4. Simulated Fuel Gas Composition for Sorbent Evaluation

\begin{tabular}{|c|c|}
\hline Component & Vol. \% \\
\hline $\mathrm{H}_{2}$ & 10 \\
$\mathrm{CO}$ & 20 \\
$\mathrm{CO}_{2}$ & 10 \\
$\mathrm{H}_{2} \mathrm{O}$ & 10 \\
$\mathrm{~N}_{2}$ & 48 \\
$\mathrm{H}_{2} \mathrm{~S}$ & 2 \\
\hline
\end{tabular}

\section{Bench-Scale High-Temperature/High-Pressure Reactor (HPTR)}

An existing state-of-the-art bench-scale high-pressure/high-temperature batch fluidized-bed/fixed-bed reactor (HPTR) was used to carry out bench-scale of selected sorbents. A schematic diagram of the test unit is shown in Figure 18. The test unit includes simulated hot coal-derived gas feed systems, an absorption/regeneration reactor, and associated process instrumentation and control devices.

This is a flexible reactor system that is capable of operating either in a fluidizedbed reactor mode or in a fixed-bed reactor mode. This unit can be operated as a 2 -inch or 3 -inch batch fluidized-bed/fixed-bed reactor at conditions that are expected in the hot gas desulfurization process. The design of the reactor is based on a double-shell balanced pressure system. All the $\mathrm{H}_{2} \mathrm{~S}$ wetted parts of the reactor are constructed of quartz or ceramic material to prevent corrosion and loss of sulfur.

The gas feed system is capable of delivering simulated gas mixtures containing $\mathrm{CO}, \mathrm{CO}_{2}, \mathrm{H}_{2}, \mathrm{H}_{2} \mathrm{O}, \mathrm{H}_{2} \mathrm{~S}, \mathrm{~N}_{2}$, and $\mathrm{CH}_{4}$ with different compositions representing various gasifiers. The gas feed system has been set up to deliver the desired simulated fuel gas compositions through six independently controlled gas streams, as well as a liquid (water) stream to deliver gas mixtures with widely different compositions.

Some important design aspects of this system are as follows:

- $\quad$ The HPTR vessel is a pressure-balanced system. A nitrogen purge prevents the $\mathrm{H}_{2} \mathrm{~S}$ and other corrosive gases from contacting metal surfaces such as the pressure-retaining vessel wall, reactor heater assembly, and insulation. 
- Reactor materials that contact $\mathrm{H}_{2} \mathrm{~S}$ containing gases are constructed of quartz or ceramic material to prevent corrosion and loss of $\mathrm{H}_{2} \mathrm{~S}$. This is crucial to accurate measurement of the sorbent performance.

- $\quad$ The exit gas is sampled in the disengaging zone of the fluidized-bed reactor using a ceramic probe.

- $\quad$ Feed gases (dry gas and the steam feed) are preheated within the reaction vessel. $\mathrm{H}_{2} \mathrm{~S}$ and other corrosive gases are fed directly to the bottom of the quartz HPTR where it mixes with the wet hot gases before entering the fluidized-bed/fixed-bed reactor.

- $\quad$ The HPTR unit is internally heated using a diffusion-type heater divided into four temperature-control zones.

- $\quad$ Thermocouples used to measure heater, fluidized-bed/fixed-bed (five thermocouples) and preheat zone temperatures are protected by quartz/ceramic thermowells.

The pressure-retaining vessel houses the 2- or 3-inch O.D. quartz reactor insert, the reactor heater assembly, metal liners, ceramic tubes, and thermowells. Dry feed gases enter at the bottom of the reactor vessel through a distribution ring. De-ionized water is pumped to the bottom of the reactor vessel and into a stainless steel coil wrapped around the lower section of the outer liner. The water is vaporized in the coil and superheated. The steam produced mixes with the dry feed gases at the exit of the coil in the bottom of the reactor vessel. The annular space between the two metal liners is used as an annular heat exchanger to preheat the feed gases and super heat the steam. The hydrogen sulfide and other corrosive gases enter at the bottom of the reactor vessel and flow up through a small quartz tube.

The bulk of the exit gas leaves the reactor top through a ceramic tube. A separate gas stream that is used for gas sampling leaves through a second, smaller ceramic tube. A ceramic thermowell, extending down from the top of the reactor vessel, contains five thermocouples to monitor the fluidized-bed/fixed-bed temperatures at various levels in the reactor and the exit gas temperature.

A quartz reactor insert is used to contain the sorbent. The quartz insert consists of a flange, disengaging section, reactor bed, gas inlet sections, and a fritted ceramic gas distribution plate. The quartz reactor insert was fabricated with a flange at the top of the reactor for ease of removal and replacement.

The exit gas is sampled in the disengaging zone of the quartz reactor insert using a ceramic probe. The sampling gas stream is cooled immediately after leaving the reactor. The gas is sent directly to a dual-column gas chromatograph for analysis. The composition of the reactor exit gas is measured with a dual column gas chromatograph that is currently equipped with a flame photometric detector (FPD), a thermal 
conductivity detector (TCD) and auto-samplers. The FPD is used to detect low levels (0-100 ppm) of $\mathrm{H}_{2} \mathrm{~S}$ and COS while the TCD can be used to detect the sulfur dioxide $\left(\mathrm{SO}_{2}\right)$ in the exit gas.

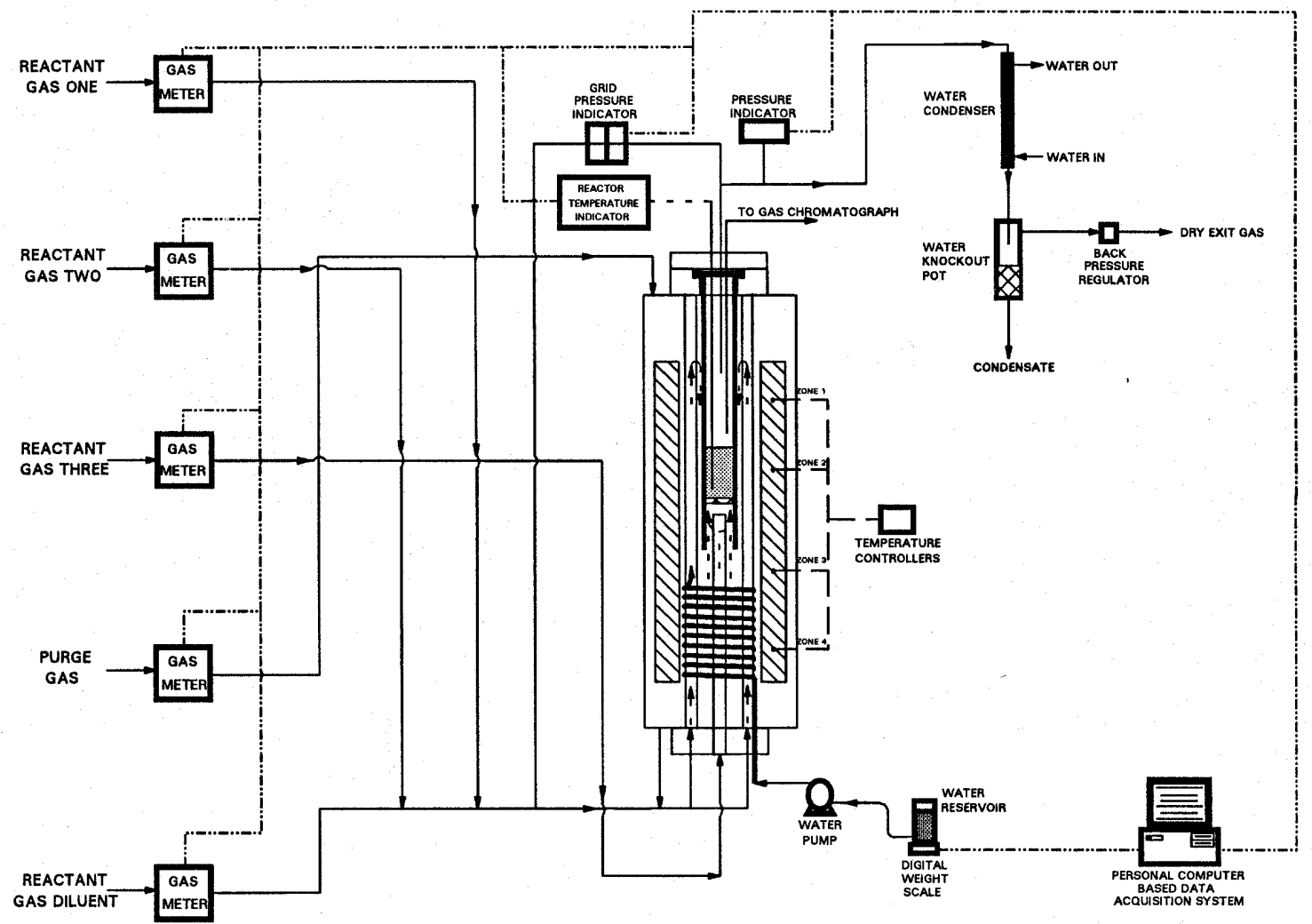

Figure 18. Schematic Diagram of the High-Pressure/High-Temperature Reactor (HPTR) Unit 


\section{RESULTS AND DISCUSSION}

\section{Sorbents Prepared with Method I}

To establish a baseline for evaluation of the sorbents developed in this program, a commercial zinc titanate sorbent manufactured by United Catalyst, Inc. and designated as UCI-4169 was used as the baseline sorbent. As indicated earlier, this sorbent was extensively tested using IGT's high-pressure high temperature fluid-bed reactor as well as Enviropower's pilot-scale desulfurization unit in Finland, ${ }^{27,37,67-69}$ and was shown to have acceptable reactivity for desulfurization of coal gases at the temperature of $550^{\circ} \mathrm{C}$.

The $\mathrm{H}_{2} \mathrm{~S}$ pre-breakthrough levels for the UCI-4169 sorbent in the temperature range of 425 to $500 \mathrm{C}$ in a packed-bed reactor, as shown in Figure 19. The results indicate that the overall effective capacity of this sorbent is very sensitive to sulfidation temperature, decreasing rapidly with decreasing temperature to unacceptable levels in the range investigated.

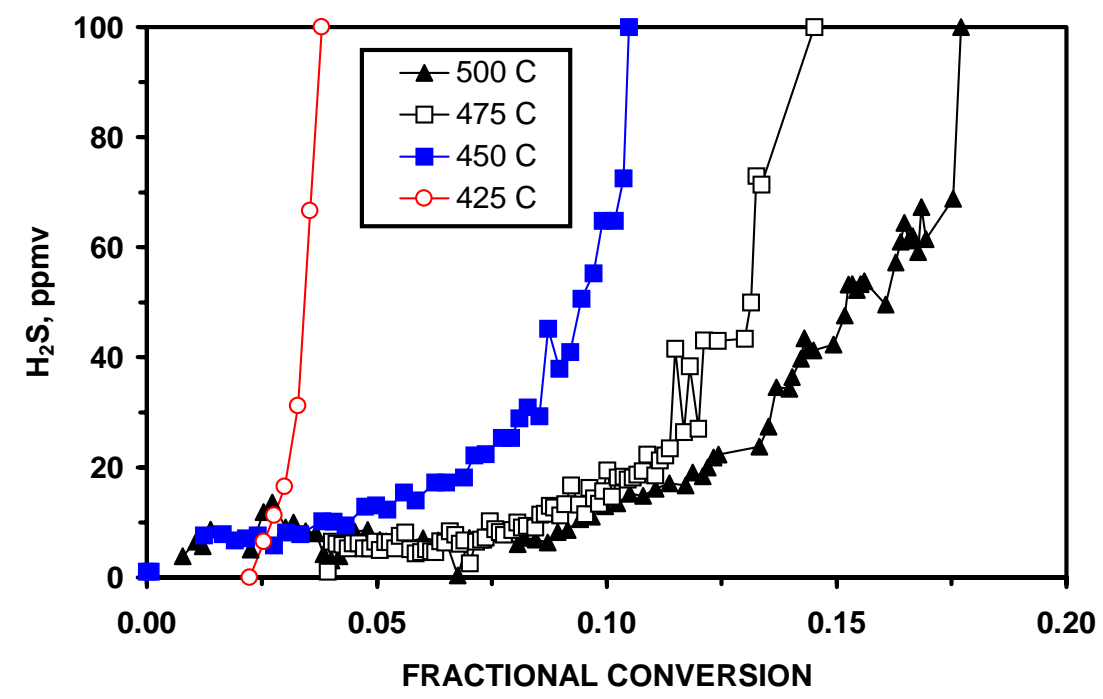

Figure 19. $\mathrm{H}_{2} \mathrm{~S}$ Breakthrough Curves for UCI-4169 Zinc Titanate Sorbent

Following evaluation of the baseline UCI-4169 sorbent, initial testing included two bulk copper-chromite sorbents $(\mathrm{CuCr}-1$ and $\mathrm{CuCr}-2)$ which were tested at IGT and were shown (in earlier programs supported by the Illinois Clean Coal Institute) ${ }^{27,29}$ to be highly efficient desulfurization sorbents at higher temperatures $\left(550-850^{\circ} \mathrm{C}\right)$. The $\mathrm{CuCr}-$ 1 and $\mathrm{CuCr}-2$ sorbents were previously prepared at IGT using a general method for synthesizing highly porous bulk mixed oxides. $\mathrm{CuCr}-1$, a chromium-rich and $\mathrm{CuCr}-2$, a copper-rich copper chromite, contain about $10 \%$ and $25 \%$ copper, respectively. 
The $\mathrm{H}_{2} \mathrm{~S}$ breakthrough curves for the $\mathrm{CuCr}-1$ and $\mathrm{CuCr}-2$ sorbents are shown in Figures 20 and 21, respectively. Sorbent conversion is based on the assumption that the active sulfide phase produced during sulfidation is the most thermodynamically stable (i.e., $\mathrm{Cu}_{2} \mathrm{~S}$ or $\mathrm{ZnS}$ ). Conversions greater than a value of one indicate the presence of other sulfided species. The desulfurization data for $\mathrm{CuCr}-1$ and $\mathrm{CuCr}-2$ at $750^{\circ} \mathrm{C}$, obtained in a previous program, ${ }^{29}$ were included in these figures to extend the temperature range for comparison purposes. The pre-breakthrough $\mathrm{H}_{2} \mathrm{~S}$ exit gas concentrations range from less than 1 to about $5 \mathrm{ppmv}$, and are significantly lower than those predicted for the elemental $\mathrm{Cu}-\mathrm{H}_{2} \mathrm{~S}$ equilibrium. These lower levels generally correspond to the copper oxide- $\mathrm{H}_{2} \mathrm{~S}$ equilibrium, suggesting that copper oxide in the compound was not completely reduced to elemental copper by the fuel gas during the sulfidation stage. It is believed that this is probably due to either chemical and/or physical mechanisms, whereby compound formation, such as surface spinels or surface adsorption, may retard the complete reduction to metallic copper.

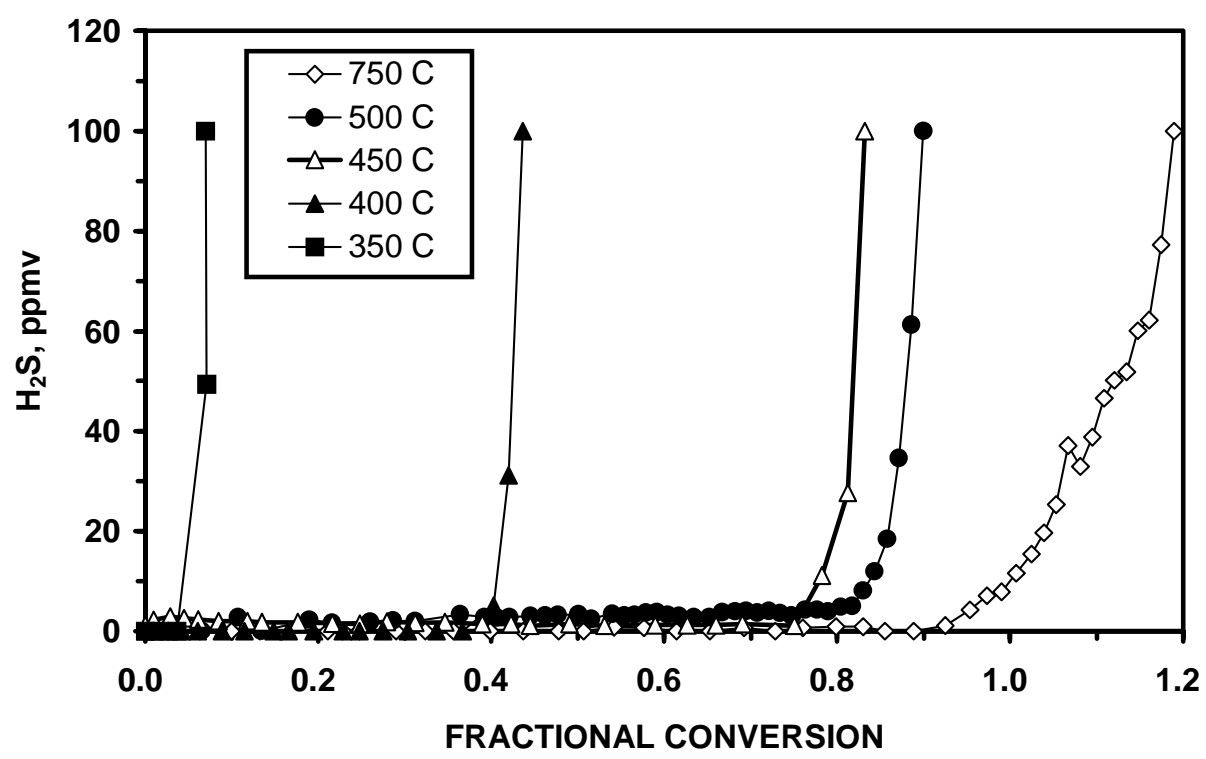

Figure 20. $\mathrm{H}_{2} \mathrm{~S}$ Breakthrough Curves for $\mathrm{CuCr}-1$ Sorbent

The rate of sulfidation of sorbents in the form of compounds, such as the copper chromite spinels shown here, is generally expected to be lower compared to the rate of sulfidation of pure metal oxides. However, the sharp rise in the $\mathrm{H}_{2} \mathrm{~S}$ breakthrough curves and the high sorbent conversions observed in these tests indicate that the overall reaction rate involving copper chromite compound is sufficiently high at temperatures above $450^{\circ} \mathrm{C}$.

The maximum effective conversion as a function of temperature for the $\mathrm{CuCr}-1$, $\mathrm{CuCr}-2$, and UCI-4169 sorbents is summarized in Figure 22. The effective maximum conversion of the $\mathrm{CuCr}-2$ sorbent is lower than that of the $\mathrm{CuCr}-1$ sorbent throughout the entire temperature range studied, clearly indicating the beneficial effects of dispersion on 
enhancing chemical reactivity $(\mathrm{CuCr}-1$ contains $10 \% \mathrm{Cu}$, whereas $\mathrm{CuCr}-2$ contains $25 \%$ $\mathrm{Cu}$ ). The effective conversion of the zinc titanate sorbent is lower than that of the copper chromite sorbents and decreases with decreasing temperature at about the same rate as that of the $\mathrm{CuCr}-2$ sorbent.

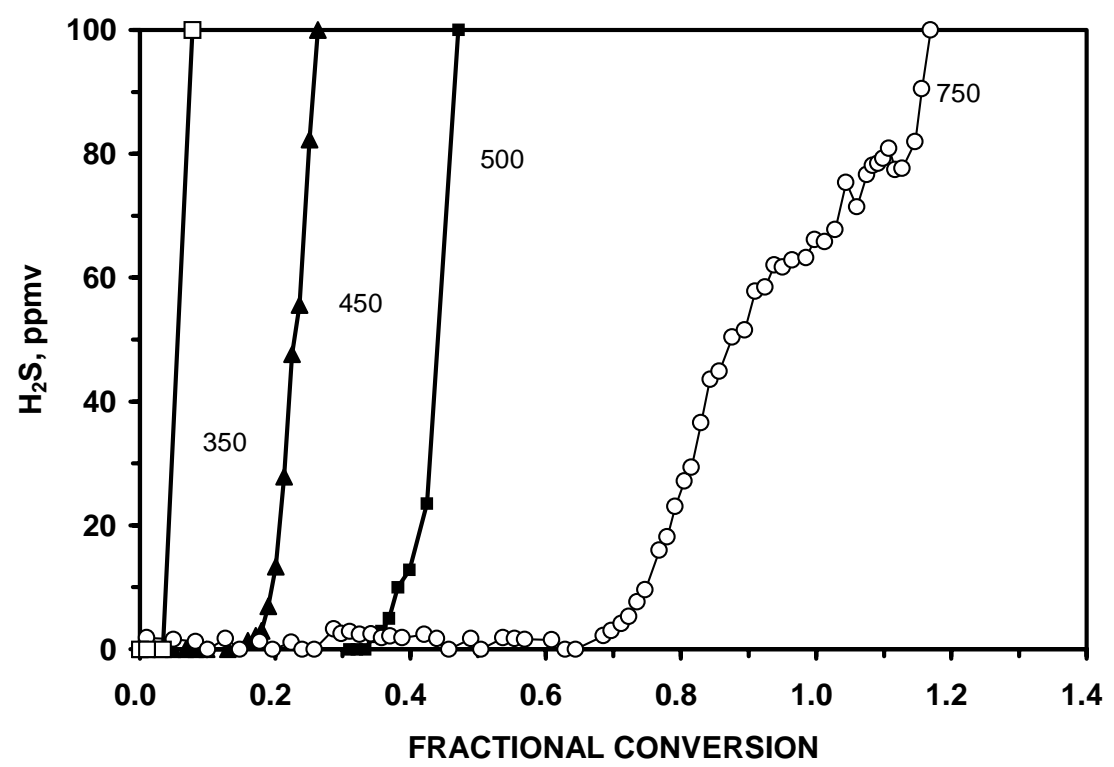

Figure 21. $\mathrm{H}_{2} \mathrm{~S}$ Breakthrough Curves for $\mathrm{CuCr}-2$ Sorbent

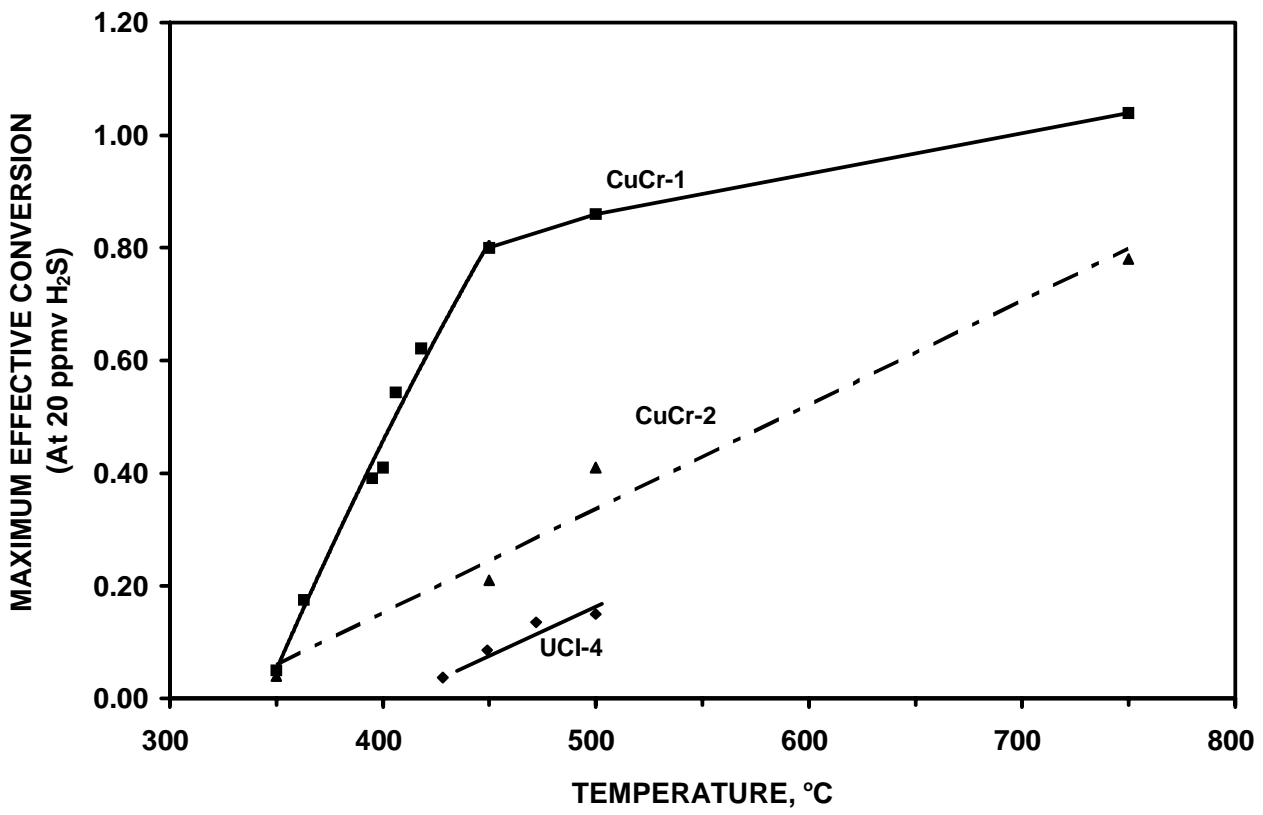

Figure 22. Effect of Temperature on Effective Sorbent Conversion 
Another indication of the higher reactivity of the highly dispersed copper chromite sorbent is shown in Figure 23, which shows the effect of temperature on the maximum space velocity. At $500^{\circ} \mathrm{C}$, the $\mathrm{CuCr}-1$ sorbent is capable of reducing the $\mathrm{H}_{2} \mathrm{~S}$ content of the fuel gas to below $20 \mathrm{ppmv}$ at space velocities as high as $15,000 \mathrm{hr}^{-1}$, which is significantly higher than the maximum space velocity for the $\mathrm{CuCr}-2$ and UCI-4169 sorbents.

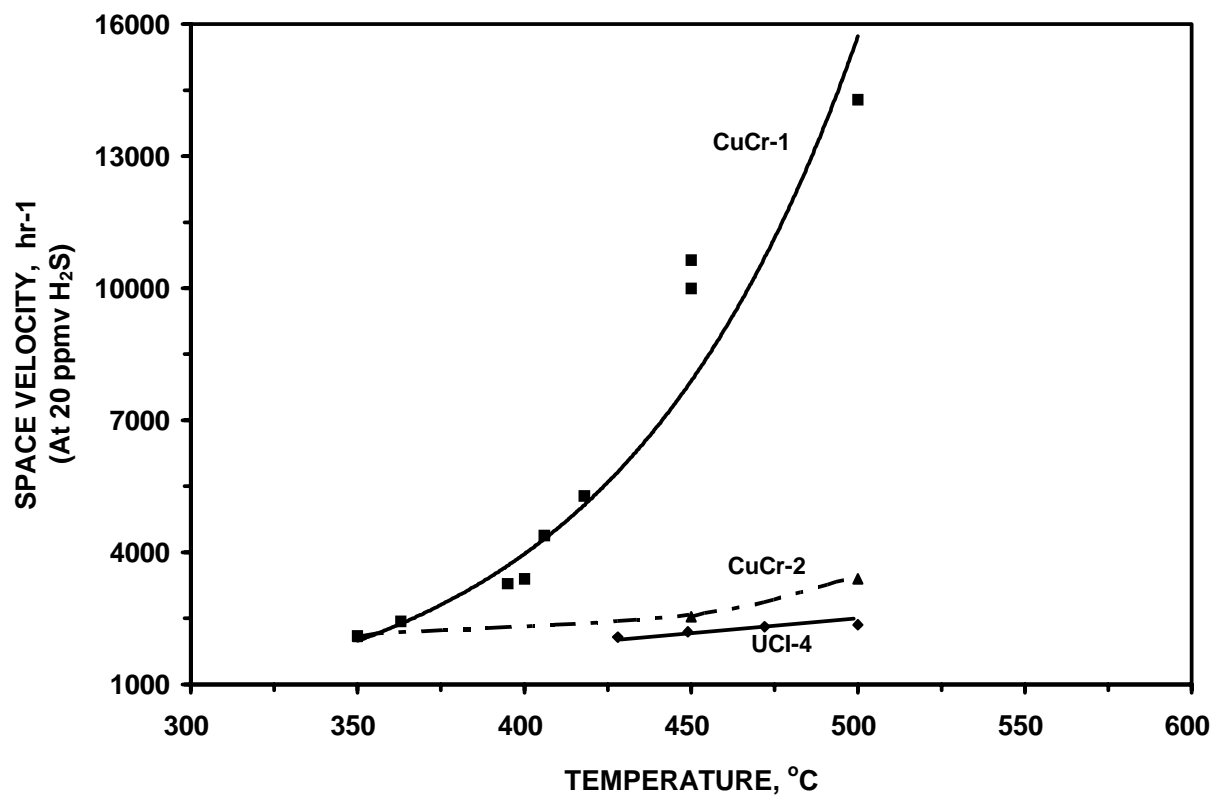

Figure 23. Effect of Temperature on Maximum Space Velocity

Figure 24, which shows the effect of temperature on the maximum effective sulfur capacity, indicates that, although the chromium-rich copper chromite sorbent has a much lower theoretical sulfur capacity than that of the CuCr-2 or UCI-4169 zinc titanate sorbents, it has comparable effective sulfur capacities at temperatures around $450^{\circ} \mathrm{C}$. However, neither of the copper chromite sorbents had sufficient mechanical durability for fluidized-bed application. Therefore, no further testing of these sorbents was undertaken.

The results obtained with the above three sorbents indicate that although high theoretical sorbent capacity and high initial reactivity are desired, both of these factors are not required in developing a sorbent that would have acceptable long-term physical and chemical durability, as well as sufficient effective sulfur capacity. Therefore, if the higher reactivity of a sorbent with a lower theoretical capacity can be maintained or stabilized over a very large number of cycles, then the fresh sorbent makeup rate in an actual desulfurization process can be reduced, thereby reducing the overall cost of hot gas cleanup.

Given the above considerations, a total of 66 sorbent formulations were prepared and evaluated early in this investigation using Method I, which focused on the 
preparation of highly dispersed metal oxide sorbent formulations using refractory supports/dispersants which are themselves highly resistant to sintering and deterioration.

Of the 66 sorbent formulations prepared by Method I, those formulations that exhibited higher attrition resistance than the baseline UCI-4169 sorbent (see Figure 11) were evaluated for their sulfidation reactivity in the packed-bed reactor. These sorbent formulations generally had low sulfur capacity (about 2-3\%), but they all had good mechanical strength. The regenerability of those sorbent formulations that achieved high levels of conversion during the first cycle were each evaluated in a $1 \frac{1 / 2}{2}$ cycle test. The sorbent formulations that exhibited good reactivity and regenerability in the moderate temperature range of 350 to $538^{\circ} \mathrm{C}$ were further evaluation in multi-cycle testing. The results obtained with a selected number of sorbents, that were subjected to multi-cycle testing, are described below.

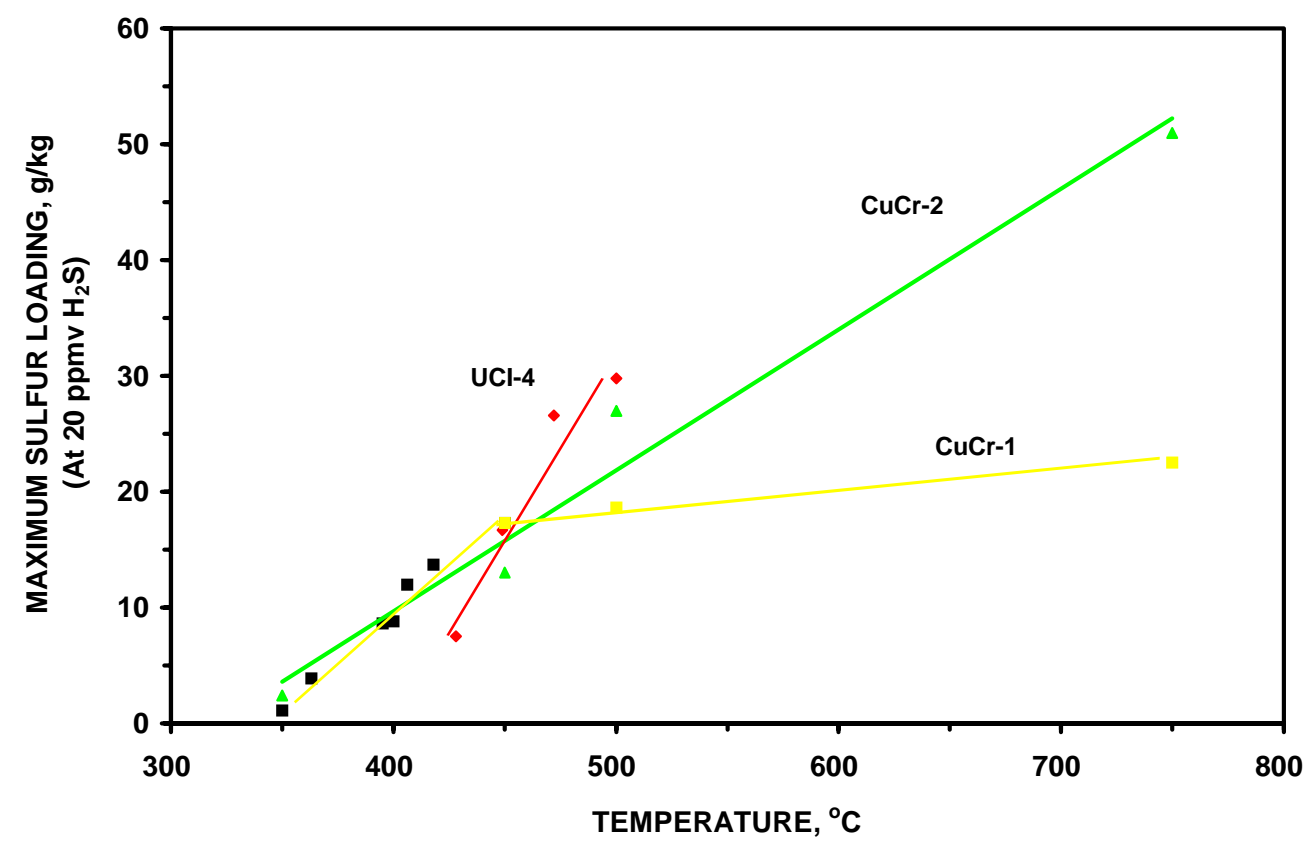

Figure 24. Effect of Temperature on Maximum Effective Sulfur Capacity

Among the initial sorbent formulations prepared in this program, the IGTSS-1 appeared to have the highest reactivity toward $\mathrm{H}_{2} \mathrm{~S}$ at $350^{\circ} \mathrm{C}$. Therefore, a series of 15cycle test was conducted with the IGTSS -1 at $350^{\circ} \mathrm{C}$. As indicated in Figure 25, high levels of sorbent conversion were obtained at $350^{\circ} \mathrm{C}$ in the first 10 cycles for sorbent IGTSS-1. The $\mathrm{H}_{2} \mathrm{~S}$ breakthrough profiles for this sorbent (Figure 26) also indicate very high levels of desulfurization $\left(<10 \mathrm{ppmv} \mathrm{H}_{2} \mathrm{~S}\right)$. The very sharp rise in the $\mathrm{H}_{2} \mathrm{~S}$ breakthrough curves at high levels of sorbent utilization indicates that the reactivity of this sorbent towards $\mathrm{H}_{2} \mathrm{~S}$ is very high. However, reactivity of the sorbent significantly decreased after the $10^{\text {th }}$ cycle. An examination of the sorbent after the 15th cycle revealed that it had disintegrated, which may explain the rapid decline in its reactivity. 


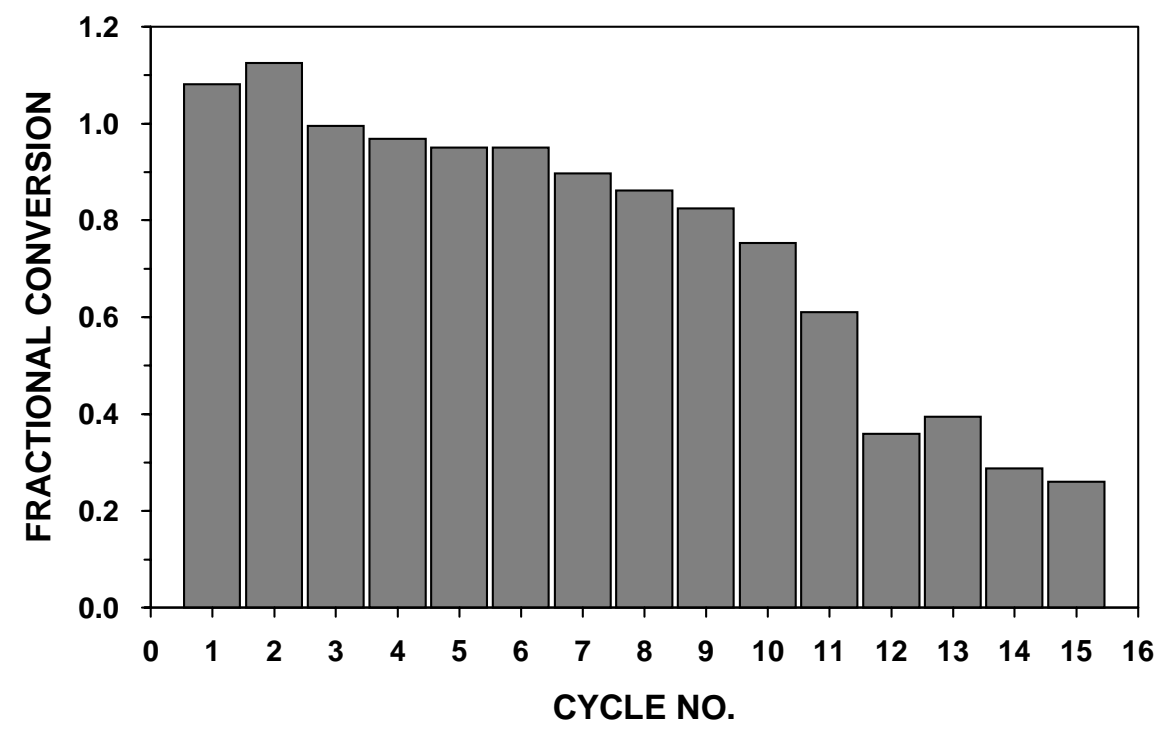

Figure 25. Conversions for Sorbent IGTSS-1 at $350^{\circ} \mathrm{C}$

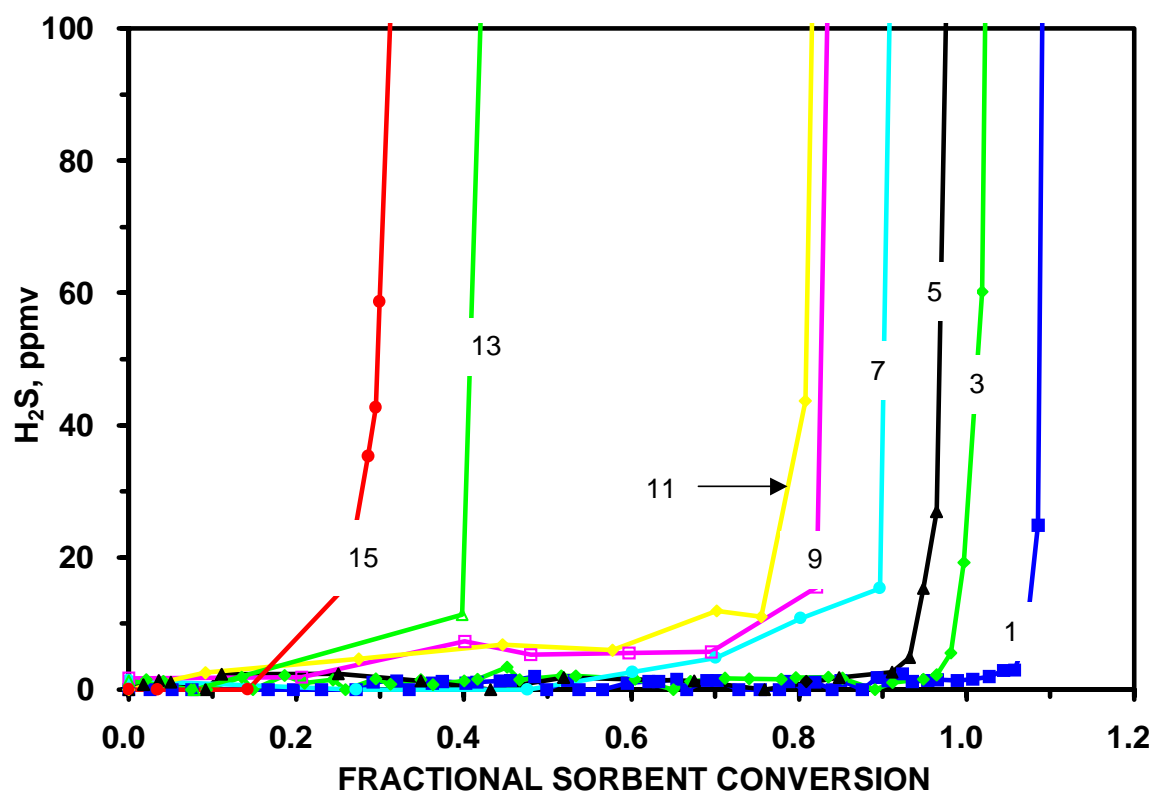

Figure 26. $\mathrm{H}_{2} \mathrm{~S}$ Breakthrough Curves for Sorbent IGTSS-1 at $350^{\circ} \mathrm{C}$

Based on the performance of IGTSS-1 during the initial 10 cycles, a stronger version of this sorbent, IGTSS-11, was prepared and evaluated. The sorbent conversions 
are relatively high and constant over the 13 cycles tested at $450^{\circ} \mathrm{C}$, as shown in Figure 27. The $\mathrm{H}_{2} \mathrm{~S}$ breakthrough curves (Figure 28) indicate that this sorbent can reduce $\mathrm{H}_{2} \mathrm{~S}$ to below 10 ppmv. No loss of strength was observed after 13 cycles.

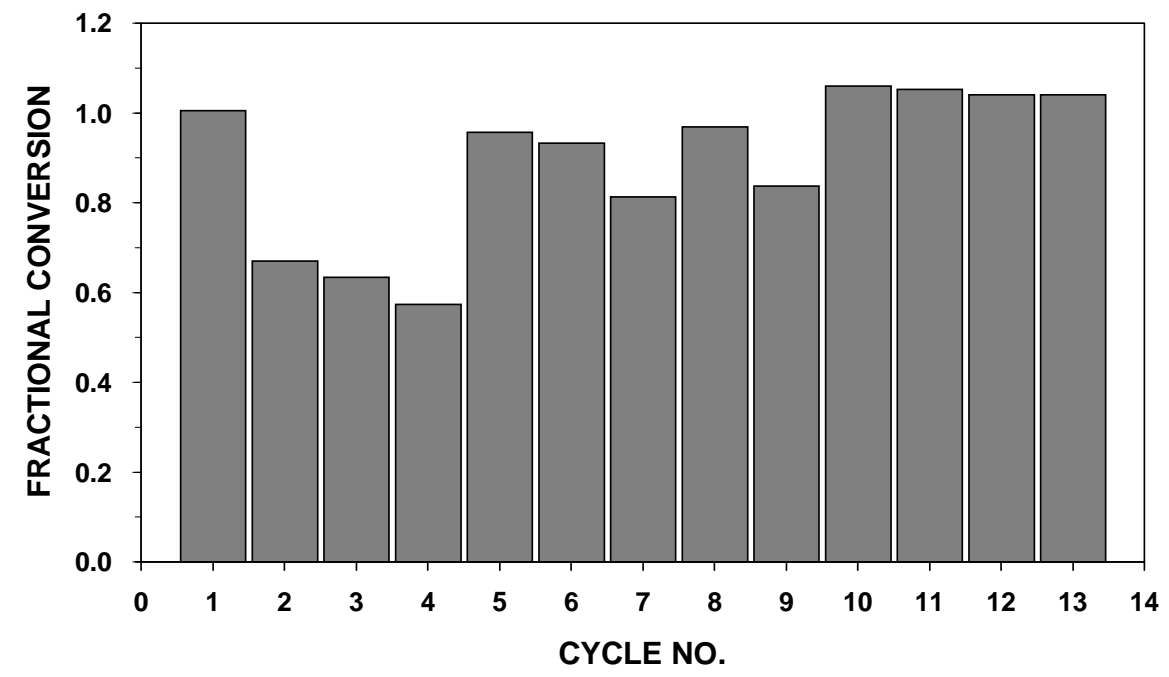

Figure 27. Conversions for Sorbent IGTSS-11 at $450^{\circ} \mathrm{C}$

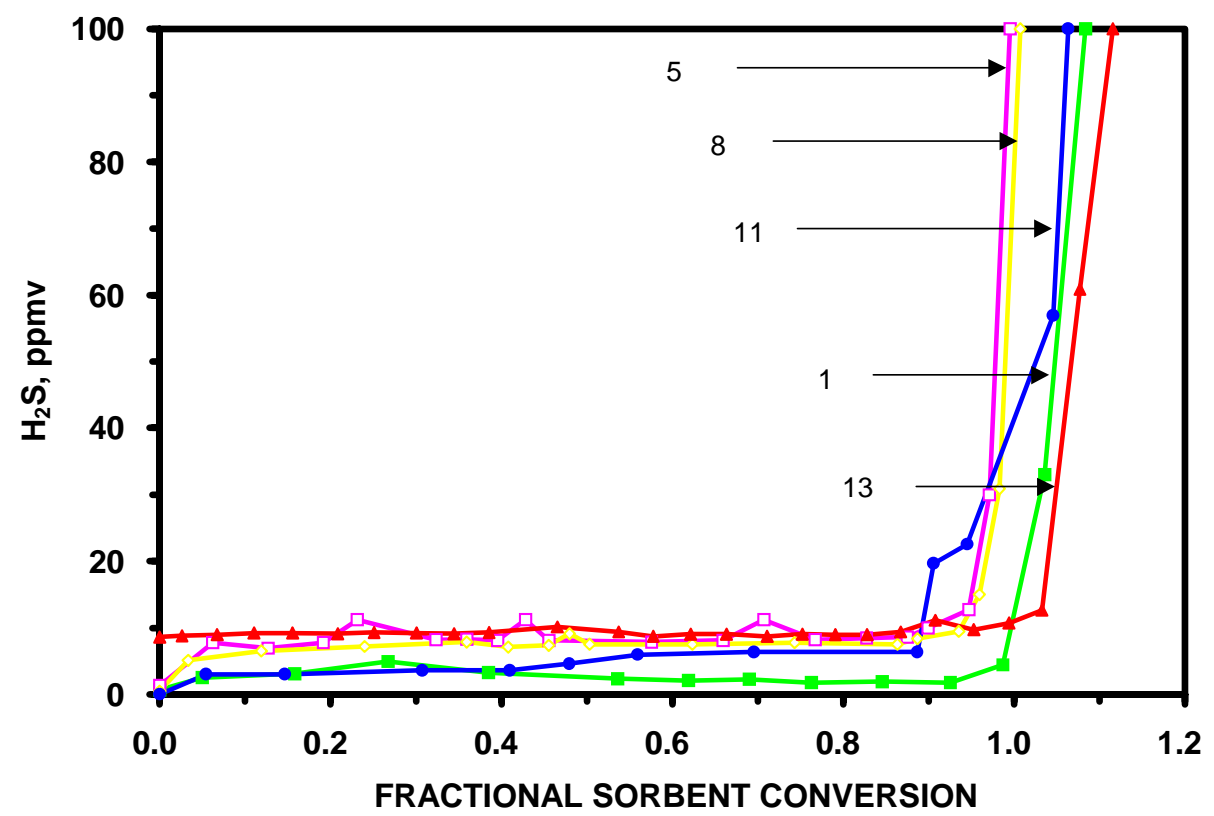

Figure 28. $\mathrm{H}_{2} \mathrm{~S}$ Breakthrough Curves for Sorbent IGTSS-11 at $450^{\circ} \mathrm{C}$ 
The results of 16 sulfidation/regeneration cycles conducted with the IGTSS-6 sorbent are shown in Figures 29 and 30, indicating that the reactivity of this sorbent did not decrease during the 16 cycles tested. This series of tests was conducted at $350^{\circ} \mathrm{C}$, at a space velocity of $2000 \mathrm{hr}^{-1}$. In cycle 16, the sorbent was exposed to a reducing gas for an extended period before $\mathrm{H}_{2} \mathrm{~S}$ was added to the fuel gas. As shown in Figures 29 and 30, the results indicate that possible sorbent pre-reduction did not adversely affect the performance of the sorbent. The high level of fractional conversions obtained in this series of tests indicates that this sorbent is highly reactive toward $\mathrm{H}_{2} \mathrm{~S}$ and that the high level of reactivity of the results is maintained during the first 16 cycles.

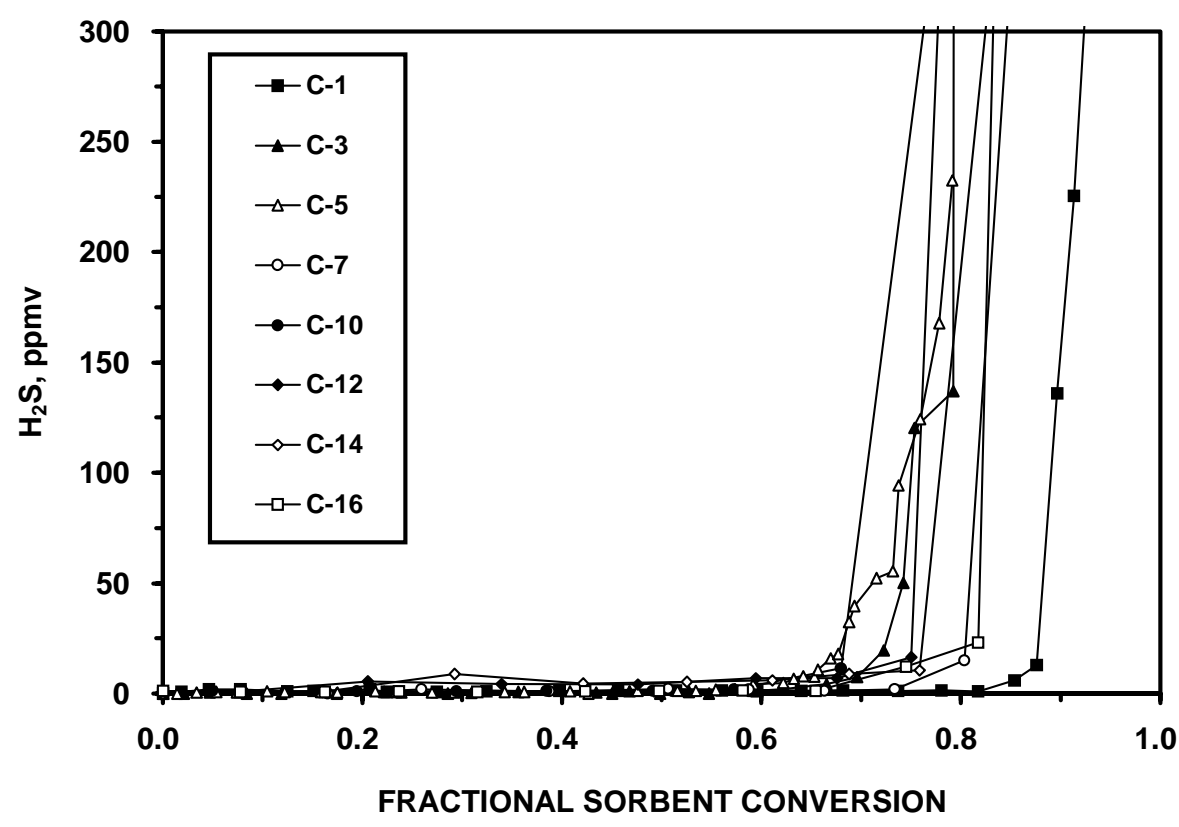

Figure 29. $\mathrm{H}_{2} \mathrm{~S}$ Breakthrough Curves for IGTSS-6 Sorbent at $350^{\circ} \mathrm{C}$

Although the IGTSS-6 and IGTSS-11 exhibited excellent reactivity and mechanical strength, because of low concentrations of active metal oxide, their effective sulfur capacity was low. The IGTSS-6 sorbent was based on copper/titania containing $8.6 \%$ copper oxide, while IGTSS-11 was based on copper/zirconia with a copper content of $10.9 \%$. Based on these copper contents and the sorbent conversions shown in Figures 27 and 30, the effective sulfur capacity of both sorbents was still below 2\%. Although, as indicated earlier, high mechanical strength combined with stable reactivity over and extended number of sulfidation/regeneration cycles will lead to a low fresh sorbent makeup rate, the low effective capacity will necessitate larger reactors and/or much higher sorbent circulation rate between the sulfidation and regeneration reactors. Therefore, it is desirable to increase the effective capacity of the sorbent while maintaining strong mechanical strength and stability in multi-cycling. 


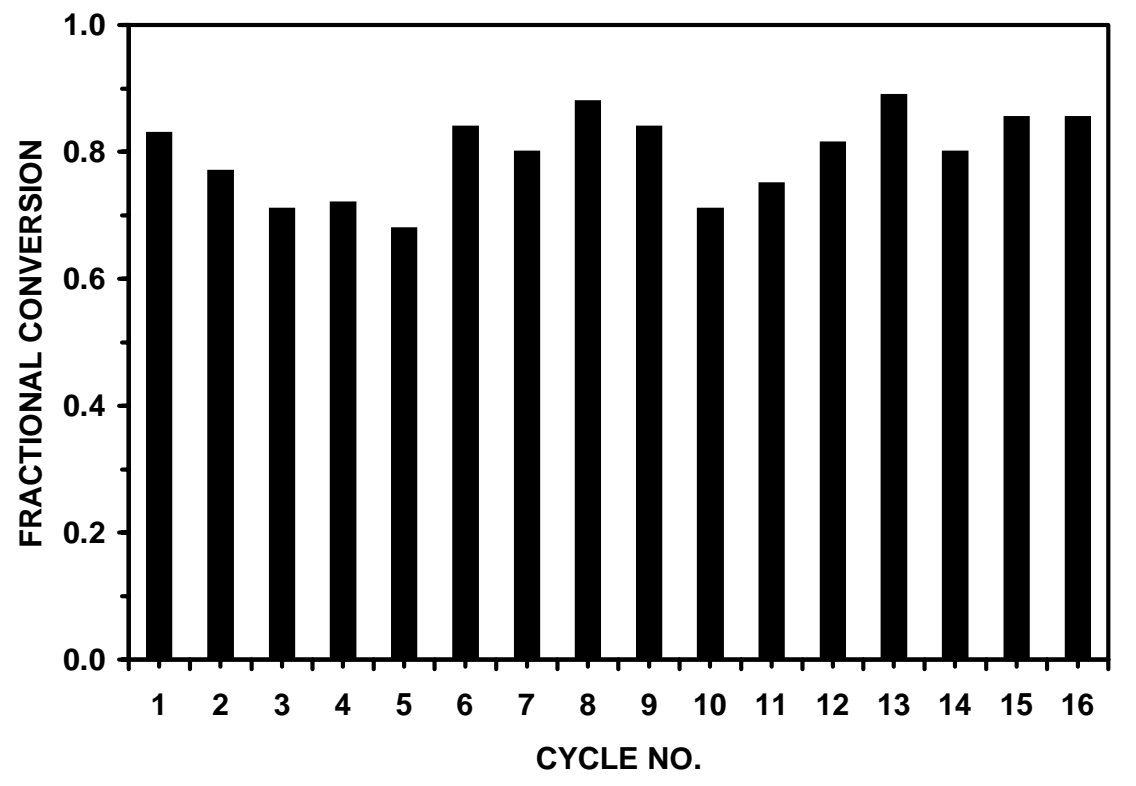

Figure 30. Fractional Conversion of IGTSS-6 Sorbent in Successive Cycles at $350^{\circ} \mathrm{C}$

Following the favorable results of the low capacity sorbents, attempts were made to improve the sulfur capacity of the sorbents, using the same sorbent preparation technique (i.e., Method I). However, most of the sorbent formulations prepared with this approach lacked sufficient strength and/or reactivity toward $\mathrm{H}_{2} \mathrm{~S}$. Among the higher capacity sorbents evaluated in this program, two sorbent formulations (IGTSS-5 and IGTSS-55) appeared to have sufficient mechanical strength and sulfur capacity. The results of packed bed tests conducted with these sorbents are shown in Figure 31. IGTSS-5, which was tested at $450^{\circ} \mathrm{C}$, showed a marked reduction in conversion after the first cycle, reducing the effective capacity to an unacceptable level. The IGTSS-55 did not exhibit sufficient reactivity at $450^{\circ} \mathrm{C}$ and a conversion of about $35 \%$ was achieved with this sorbent after 3 cycles at a temperature of $538^{\circ} \mathrm{C}$.

Because none of the sorbents prepared by the initial sorbent preparation technique (i.e., Method I) exhibited acceptable characteristics in all the required attributes (i.e., mechanical strength, sulfur reactivity, regenerability, and long term durability), further testing of these sorbents was not pursued. 


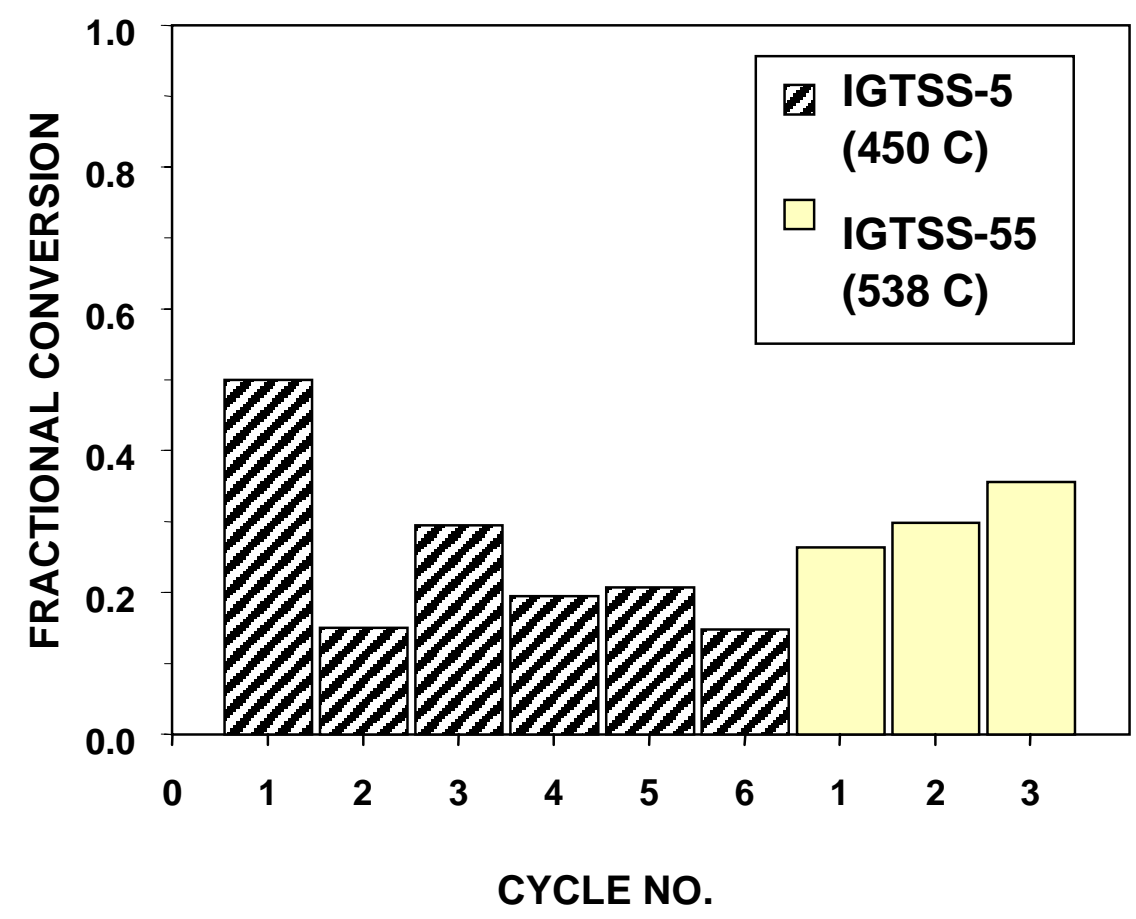

Figure 31. Conversions for Sorbents with Higher Theoretical Sulfur Capacities 


\section{Sorbents Prepared with Method II}

In order to achieve sorbent stability at the highest possible effective sorbent capacity, secondary efforts were devoted to the preparation of sorbents having higher sulfur capacity and mechanical strength. This was accomplished by extending the application of a pelletization technique previously developed for the formulation of spherical pellets $(\text { dia. }=3-5 \mathrm{~mm})^{60,61}$ to the preparation of highly attrition resistant granular (dia. $=50$ to $850 \mu \mathrm{m})$ sorbents. This sorbent manufacturing technique (i.e., Method II) has been applied to prepare over 113 formulations of copper-, iron-, manganese-, and zinc-based sorbents suitable for fluidized-bed applications at lower temperatures, i.e., $\mathrm{T} \leq$ $550^{\circ} \mathrm{C}$. A number of these formulations had mechanical strength equal to or better than that of the UCI-4169 zinc titanate sorbent (see Figure 11).

All sorbents that met minimum mechanical strength requirement were evaluated for $\mathrm{H}_{2} \mathrm{~S}$ removal efficiency and effective sulfur capacity. Testing was undertaken to determine the sulfidation reactivity and effective sulfur capacity of prepared sorbents to identify potential candidates for further evaluation in the bench-scale high pressure fluidized-bed reactor unit. The chemical analysis results of a select group of fresh sorbents and their physical characteristics are reported in Table 5 and Table 6, respectively.

Table 5. Chemical Analysis Results of Fresh Sorbents (Method II)

\begin{tabular}{|c|c|c|c|c|c|c|c|c|c|}
\hline & \multicolumn{9}{|c|}{ Chemical Analysis, wt. $\%$} \\
\hline $\begin{array}{c}\text { Sorbent } \\
\text { Designation }\end{array}$ & $\mathrm{Zn}$ & $\mathrm{Mn}$ & $\mathrm{Cu}$ & $\mathrm{Fe}$ & $\mathrm{Ti}$ & $\mathrm{Al}$ & $\mathrm{Mg}$ & Mo & $\mathrm{Ni}$ \\
\hline IGTSS-057 & & 72.5 & & & & 2.3 & & & \\
\hline IGTSS-122 & 37.6 & & & & 27.5 & & & 1.3 & 1.6 \\
\hline IGTSS-135 & 26.0 & & & & 36.7 & & & & \\
\hline IGTSS-139 & 36.1 & & & & 27.1 & & & 1.3 & 1.6 \\
\hline IGTSS-149 & & & & 38.6 & 1.2 & 20.0 & & & \\
\hline IGTSS-179 & & 11.3 & 35.8 & & & 17.9 & & & \\
\hline IGTSS-189 & 36.8 & & & 3.3 & 26.5 & & & 1.1 & \\
\hline IGTSS-314B & 27.7 & & & & 38.9 & & & & \\
\hline IGTSS-325A & 36.9 & & & 2.99 & 28.1 & & & & \\
\hline UCI-4169 & 43.8 & & & & 23.5 & & & & \\
\hline
\end{tabular}

Preliminary sorbent testing included determination of the sulfidation reactivity and effective sulfur capacity of pre-screened sorbents. Sorbent evaluation was carried out in a $2.5-\mathrm{cm}$ diameter quartz packed-bed reactor system (Figure 17) at ambient pressure and at temperatures in the range of 350 to $550^{\circ} \mathrm{C}$, using a fuel gas mixture simulating the U-Gas composition, as indicated in Table 4, at a space velocity of usually $2000 \mathrm{hr}^{-1}$. The particle size of the sorbents tested is in the range of 180 to $425 \mu \mathrm{m}$. 
Sulfided sorbents were regenerated using nitrogen-air mixtures at temperatures of 550 to $750^{\circ} \mathrm{C}$ (750 to $800^{\circ} \mathrm{C}$ for Mn-based sorbents). The extent of desulfurization and regeneration was determined by analyzing the reactor exit gas for $\mathrm{H}_{2} \mathrm{~S}$ and $\mathrm{SO}_{2}$, respectively, with a dedicated gas chromatograph, as previously explained.

Table 6. Physical Characteristics of Selected Sorbents (Method II)

\begin{tabular}{lcccccc}
\hline & $\begin{array}{c}\text { Particle } \\
(\mathrm{Hg}) \\
\text { Density }\left(\rho_{\mathrm{b}}\right) \\
\left(\mathrm{g} / \mathrm{cm}^{3}\right)\end{array}$ & $\begin{array}{c}\text { Skeletal }(\mathrm{He}) \\
\text { Density }\left(\rho_{\mathrm{a}}\right) \\
\left(\mathrm{g} / \mathrm{cm}^{3}\right)\end{array}$ & $\begin{array}{c}\text { Hg Pore } \\
\text { Volume* } \\
\left(\mathrm{cm}^{3} / \mathrm{g}\right)\end{array}$ & $\begin{array}{c}\text { Porosity } \\
(\%)\end{array}$ & $\begin{array}{c}\text { Surface } \\
\text { Area } \\
\left(\mathrm{m}^{2} / \mathrm{g}\right)\end{array}$ & $\begin{array}{c}\text { Median Pore } \\
\text { Diameter } \\
(\mu \mathrm{m})\end{array}$ \\
\hline IGTSS-057 & 2.39 & 4.69 & 0.206 & 49.1 & 9.19 & 0.19 \\
IGTSS-122 & 2.75 & 4.54 & 0.143 & 39.4 & 3.91 & 1.81 \\
IGTSS-135 & 2.07 & 2.69 & 0.111 & 22.9 & 0.33 & 1.22 \\
IGTSS-139 & 2.43 & 4.69 & 0.198 & 48.2 & 1.60 & 1.64 \\
IGTSS-179 & 3.65 & 4.17 & 0.034 & 12.5 & 5.21 & 0.51 \\
IGTSS-189 & 2.75 & 4.91 & 0.161 & 44.1 & 2.07 & 1.20 \\
IGTSS-314B & 2.85 & 4.48 & 0.127 & 36.3 & 3.33 & 0.82 \\
IGTSS-325A & 2.31 & 4.55 & 0.212 & 49.1 & 2.59 & 1.20 \\
UCI-4169 & 2.19 & 3.14 & 0.138 & 30.3 & 0.71 & 0.82 \\
\hline
\end{tabular}

Corrected for inter-particle void.

Calculated based on corrected values as $\left(1-\rho_{\mathrm{b}} / \rho_{\mathrm{a}}\right) * 100$

During this study, it was determined that, because of the high temperatures employed during the thermal treatment procedure of prepared sorbents, most of these sorbents (especially those based on $\mathrm{ZnO}$ ) required an "activation" or conditioning step to improve their reactivities in the moderate temperature range. A series of tests was conducted in the high-pressure/high temperature thermogravimetric analyzer (HPTGA) to determine the optimum activation method, which essentially consisted of a series of sulfidation/regeneration cycles. Sulfidation during the activation step was carried out at a temperature high enough to result in high sorbent conversion. Parametric testing showed that the extent of sorbent conversion during the activation step is the main reason for the measured improvement in sorbent reactivity. As shown by the typical examples in Figures 32 and 33, the results obtained indicate that the sorbent activation technique significantly affects the reactivity of the sorbent toward $\mathrm{H}_{2} \mathrm{~S}$, and therefore, its effective capacity for sulfur.

These results also suggest that sorbent activation may be necessary in the development of attrition-resistant sorbents for the moderate temperature range. Sorbent activation, if required, may be carried out on-line at a commercial IGCC plant; however, if that cannot be accommodated, activation can be incorporated into the sorbent manufacturing process. The latter would require the use of an alternative to $\mathrm{H}_{2} \mathrm{~S}$ as a sulfur source. Swisher reported some success in sorbent activation using a liquid chemical that was used to presulfide fresh sorbents twice at $620^{\circ} \mathrm{C}$ for achieving good reactivity in $\mathrm{H}_{2} \mathrm{~S}$ at $427^{\circ} \mathrm{C} .{ }^{52}$ 


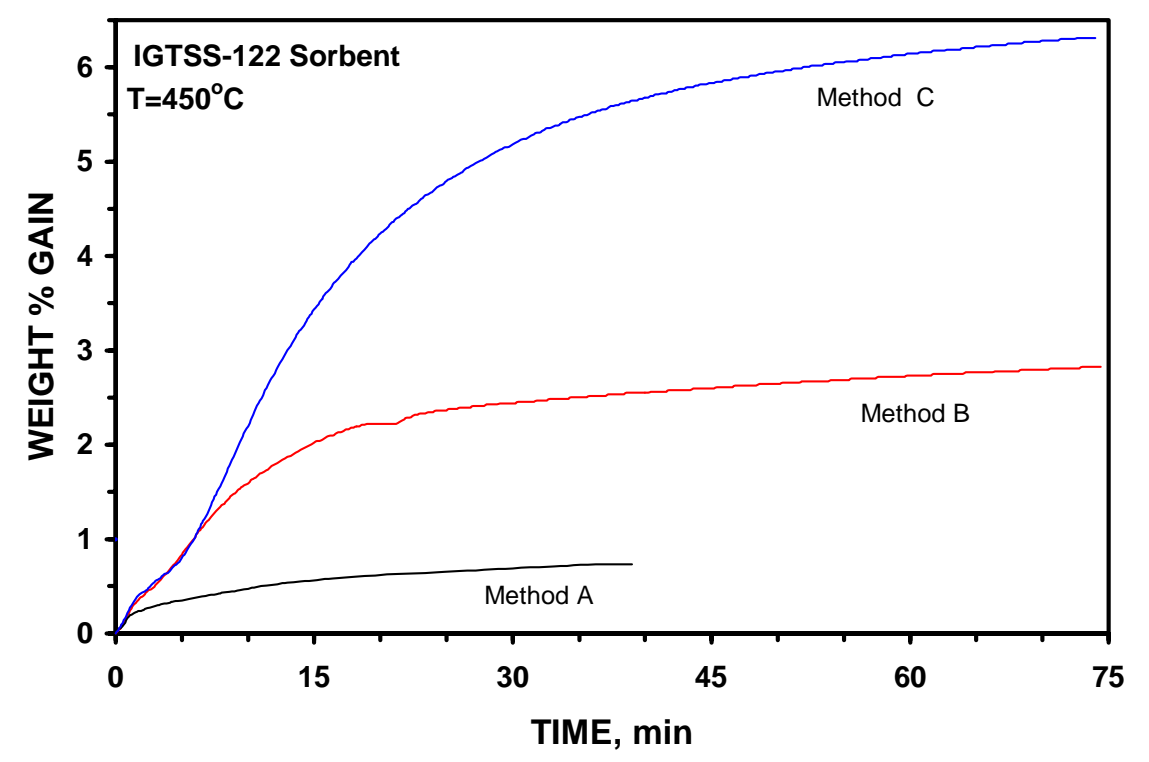

Figure 32. Effect of Fresh Sorbent Activation Method on Sulfidation Performance of IGTSS-122 Sorbent at $450^{\circ} \mathrm{C}$

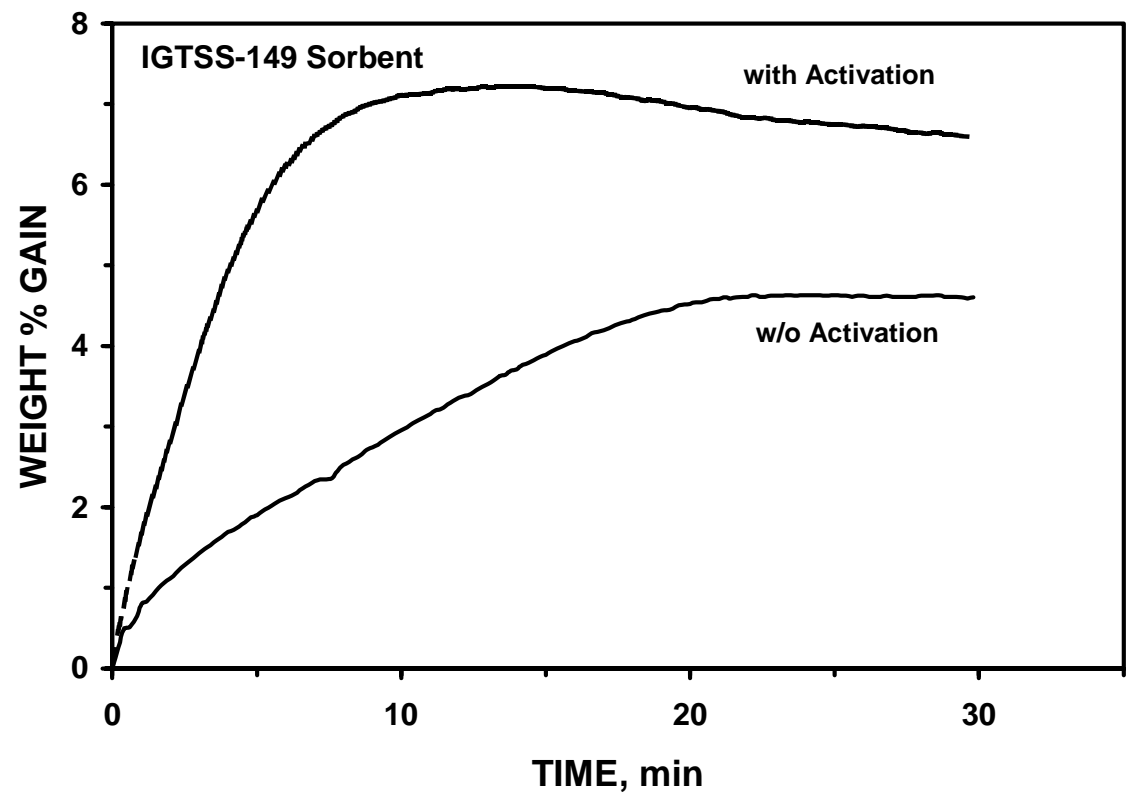

Figure 33. Effect of Sorbent Activation on Reactivity and Effective Sulfur Capacity

To establish a baseline for evaluation of the high capacity sorbents developed in this program by Method II, the commercial UCI-4169 zinc titanate sorbent was used as the baseline sorbent. The results of three cycles of packed bed testing with the UCI-4169 sorbent at the baseline condition, after sorbent activation, are presented in Figure 34, indicating that this sorbent could achieve an effective sulfur capacity in the range of 5 to 
$6 \mathrm{~g} \mathrm{~S} / 100 \mathrm{~g}$ sorbent at $450^{\circ} \mathrm{C}$. The effective sulfur capacity of zinc-based IGTSS-122 sorbent at $450^{\circ} \mathrm{C}$, after activation, is presented in Figure 35, reaching a level of $6 \mathrm{~g} \mathrm{~S} / 100$ g sorbent. Other selected zinc-based formulations, such as the IGTSS-135, IGTSS-139, and IGTSS-189 sorbents, achieved effective sulfur capacities of less than $4 \mathrm{~g}$ S/100 $\mathrm{g}$ sorbent, after activation, indicating lower reactivities compared to the UCI-4169 sorbent. Less favorable results were obtained with selected iron-based formulations.

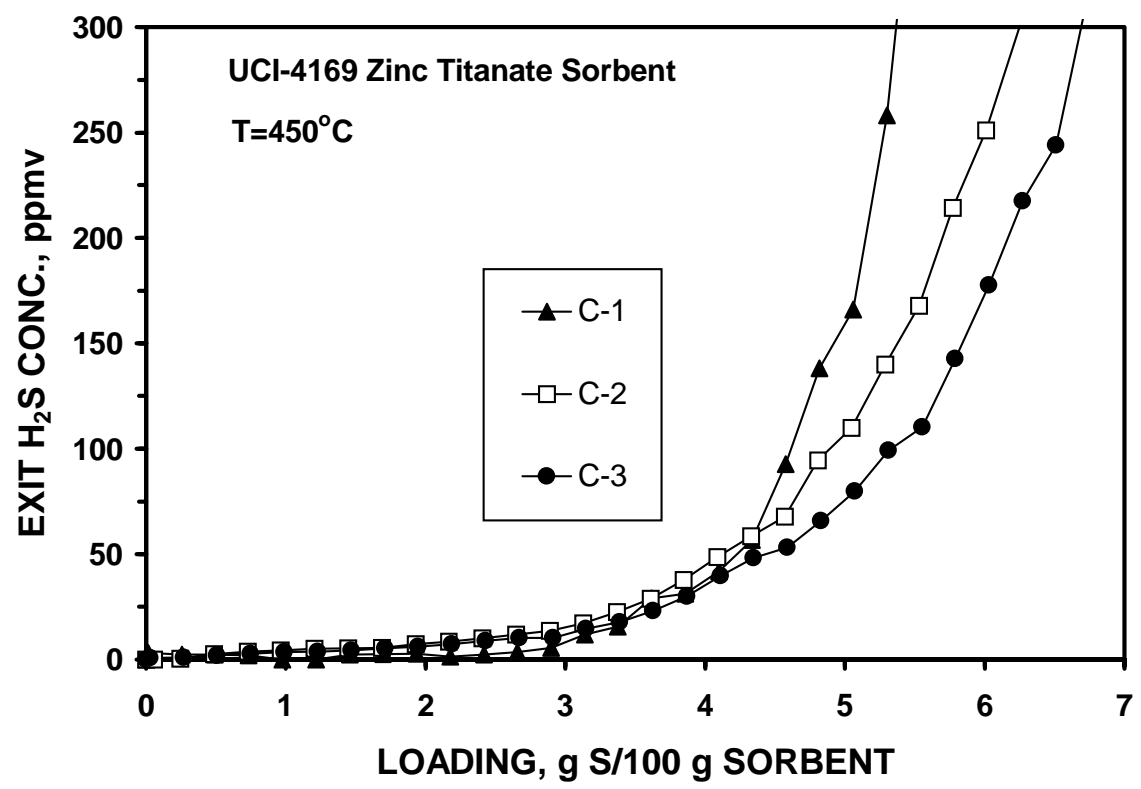

Figure 34. $\mathrm{H}_{2} \mathrm{~S}$ Breakthrough Curves for the Baseline UCI-4169 Zinc Titanate Sorbent

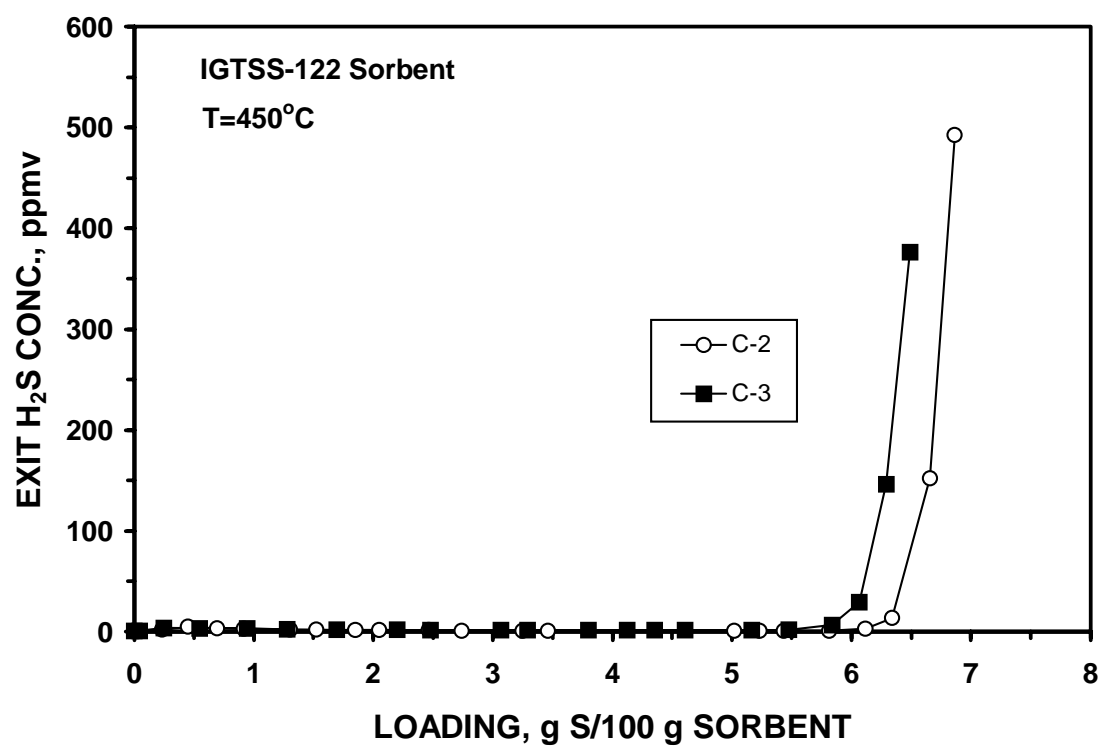

Figure 35. $\mathrm{H}_{2} \mathrm{~S}$ Breakthrough Curves for the IGTSS-122 Sorbent 
All above sorbents contained minor amounts of the inorganic bentonite binder and they were indurated at temperatures higher than $900^{\circ} \mathrm{C}$. Using the results obtained, a second family of sorbents was developed based on the elimination of the inorganic binder and thermal treatment at slightly higher temperatures to compensate for the loss of mechanical strength incurred by the absence of bentonite. Selected formulations from this second family of zinc-based sorbents include IGTSS-314B and IGTSS-325A.

The effective sulfur capacities for the IGTSS-314B in four (4) successive cycles, without activation, are shown in Figure 36, indicating that the reactivity of this sorbent gradually improved in the cyclic process. The effective sulfur capacity of this sorbent during the first cycle is more than twice that of the IGTSS-122 sorbent. Although the $6 \mathrm{~g}$ S/100 g sorbent effective sulfur capacity for the IGTSS-314B is similar to that of the UCI-4169, the very low $\mathrm{H}_{2} \mathrm{~S}$ pre-breakthrough level and the sharp breakthrough curve are indicative of higher reactivity for the IGTSS-314B sorbent. The results obtained with the IGTSS-325A sorbent in three successive cycles are presented in Figure 37, indicating that a much higher effective sulfur capacity of 10-12 g S/100 g sorbent was achieved with this sorbent, which is twice the effective sulfur capacity achieved with the baseline UCI-4169 zinc titanate sorbent.

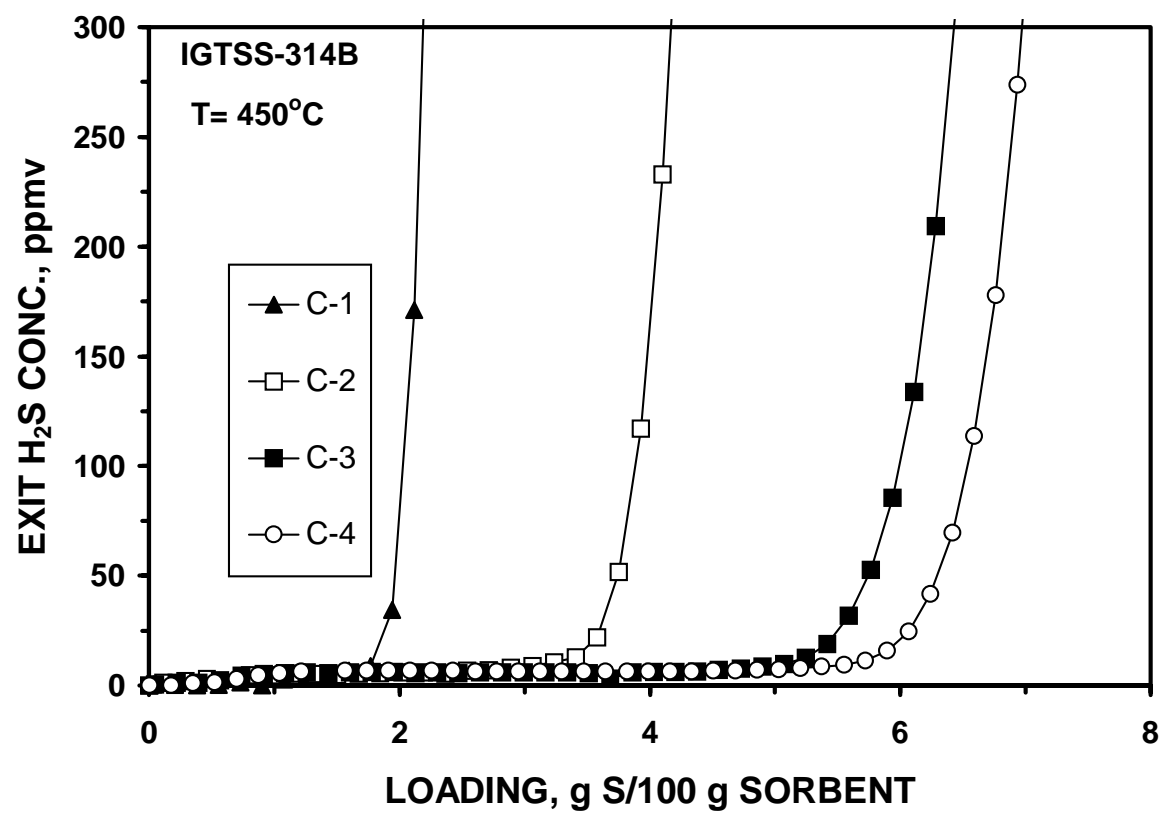

Figure 36. $\mathrm{H}_{2} \mathrm{~S}$ Breakthrough Curves for the IGTSS-314B Sorbent

As indicated earlier in Table 3, sorbents based on manganese oxide received the least attention among the four oxides investigated in this program. One of the manganese-based sorbent formulations, designated as IGTSS-057, achieved a total prebreakthrough time of about six (6) hours in a second sulfidation cycle at $450^{\circ} \mathrm{C}$, as shown in Figure 38. This time corresponds to a total sorbent conversion of nearly $47 \%$, at a $\mathrm{H}_{2} \mathrm{~S}$ breakthrough level of $20 \mathrm{ppmv}$, and to an effective sulfur capacity of approximately $20 \mathrm{~g}$ 
$\mathrm{S} / 100 \mathrm{~g}$ sorbent. This increase in capacity over that seen in the first cycle is likely due to structural changes during sulfidation-regeneration, leading to improved sorbent performance. Also, as shown in Figure 38, IGTSS-057 sorbent, in its fresh condition, performed comparably well at $350^{\circ} \mathrm{C}$. To reduce the cycle time during testing of IGTSS057 sorbent, the sulfidation gas space velocity was increased to $6000 \mathrm{hr}^{-1}$. The results from several cycles are reported in Figure 39. As indicated in this figure, IGTSS-057 performed consistently well even at this higher sulfidation gas space velocity, achieving effective sulfur capacities ranging from 10 to $12 \mathrm{~g} \mathrm{~S} / 100 \mathrm{~g}$ sorbent. The regeneration tests were carried out at $800^{\circ} \mathrm{C}$.

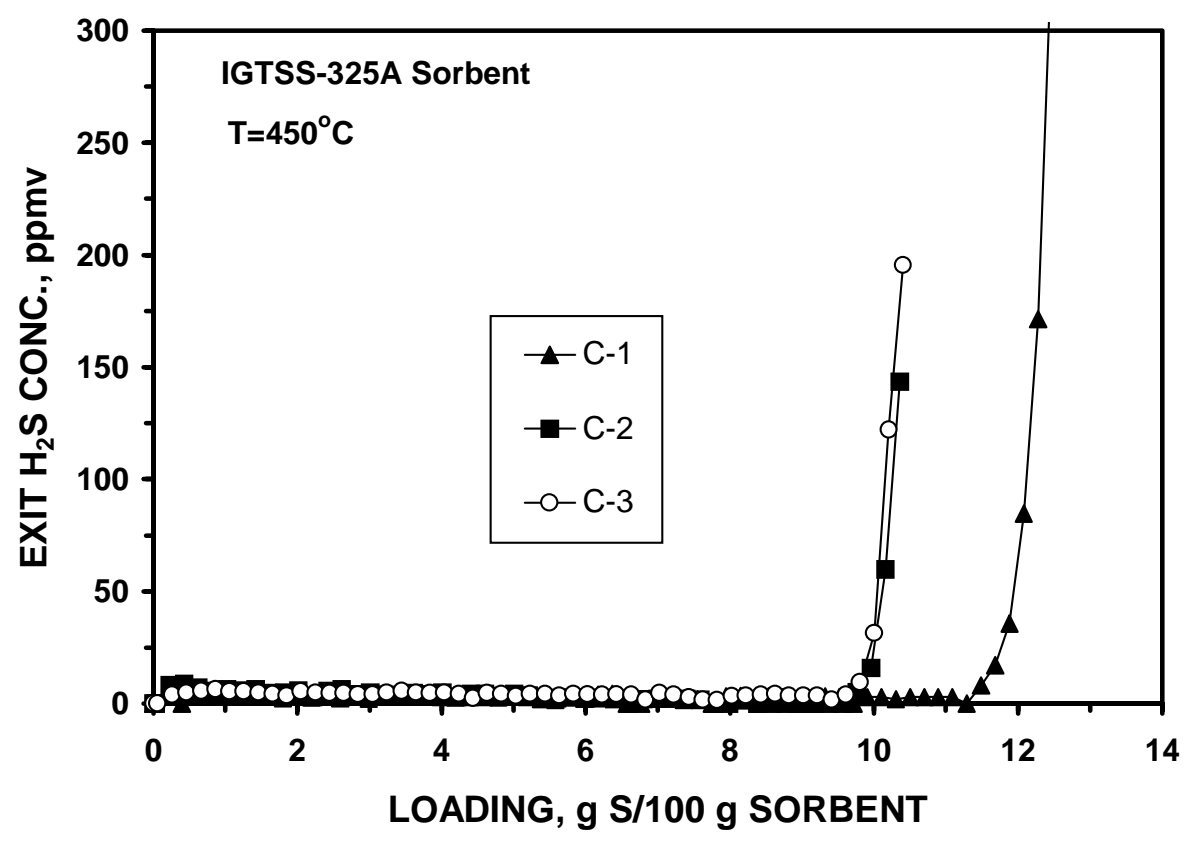

Figure 37. $\mathrm{H}_{2} \mathrm{~S}$ Breakthrough Curves for the IGTSS-325A Sorbent

The IGTSS-057 sorbent combines the advantages of high sulfur capacity and high reactivity in the moderate temperature range, without any requirement for sorbent preconditioning or activation. However, its high $\mathrm{MnO}: \mathrm{Al}_{2} \mathrm{O}_{3}$ mole ratio (see Table 5) raises concerns that it may eventually degrade since the amount of support material may not be sufficient to allow for sulfur movement in and out of the sorbent during multiple sulfidation/regeneration cycles. In addition, a temperature of at least $750^{\circ} \mathrm{C}$ is required for oxidative regeneration of this manganese-based formulation. This may not be readily accommodated by current desulfurization systems requiring regeneration ignition temperatures of about $550^{\circ} \mathrm{C}$. Therefore, considerable efforts in another investigation ${ }^{71}$ sponsored by the Illinois Clean Coal Institute focused on the determination of the optimum mole ratio of $\mathrm{MnO}$ to $\mathrm{Al}_{2} \mathrm{O}_{3}$ (or $\mathrm{TiO}_{2}$ ) to strike a balance among attrition resistance, sufficient reactivity at 350 to $550^{\circ} \mathrm{C}$, and long-term durability. However, further research is still needed on alternative regeneration approaches to reduce the 
disparity between temperatures for sulfidation and regeneration of manganese-based sorbents.

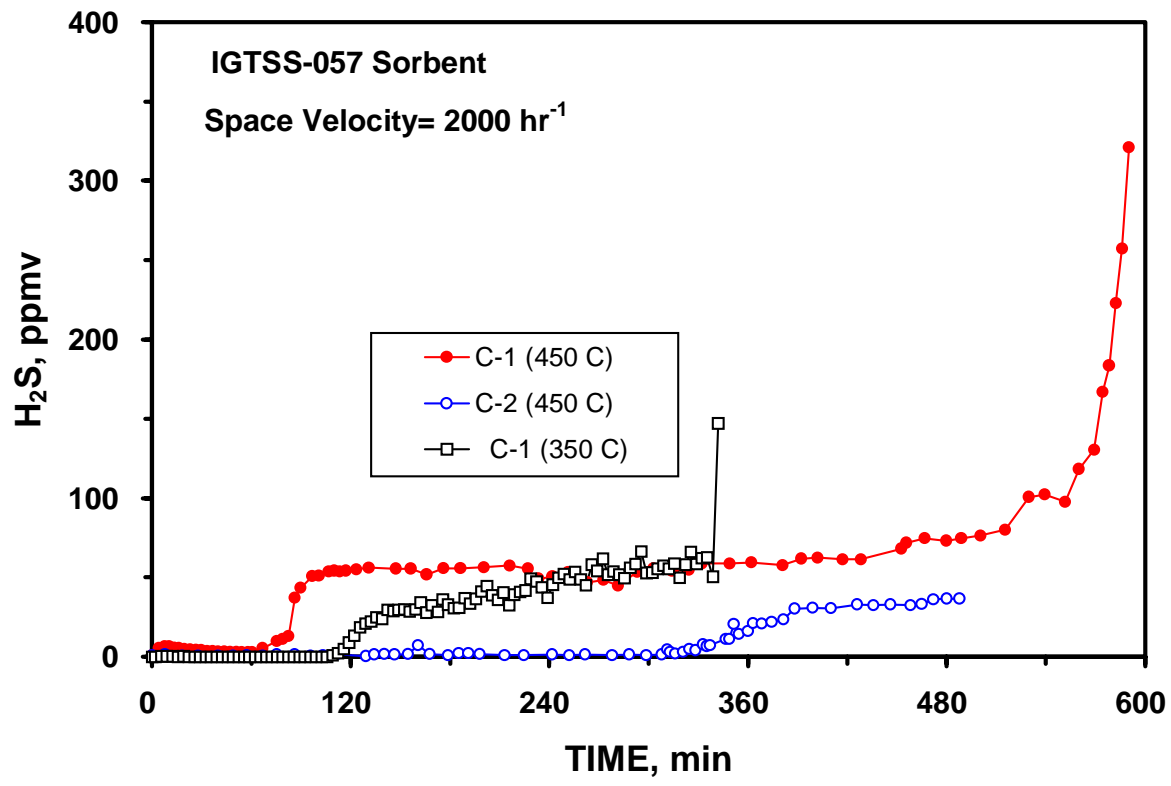

Figure 38. Comparison of Sulfidation Performance of IGTSS-057 Sorbent at $450^{\circ} \mathrm{C}$ and $350^{\circ} \mathrm{C}$

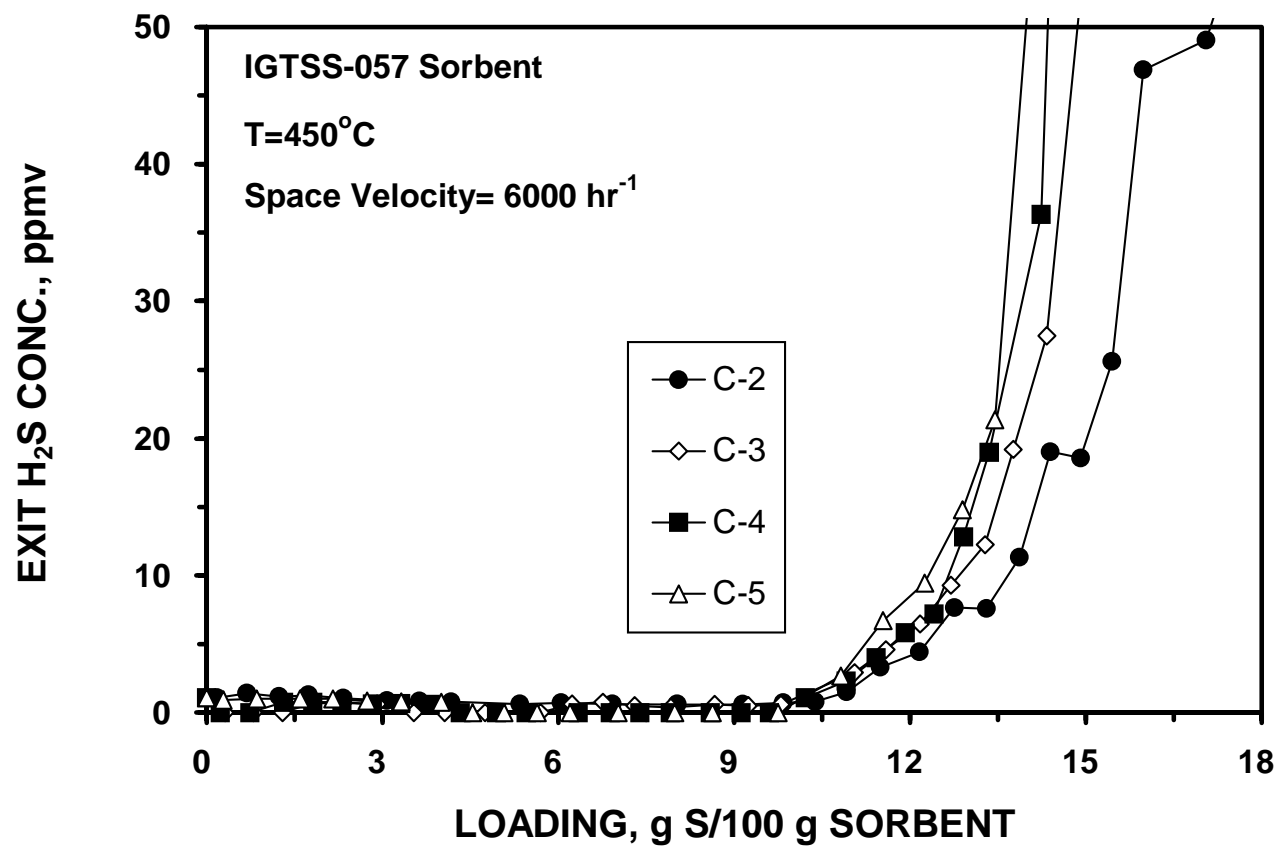

Figure 39. $\mathrm{H}_{2} \mathrm{~S}$ Breakthrough Curves for the IGTSS-057 Sorbent 
In a concurrent research program sponsored by the Illinois Clean Coal Institute, ${ }^{72}$ a new class of copper-based sorbents were developed that combined good attrition resistance and chemical reactivity in the temperature range of 350 to $550^{\circ} \mathrm{C}$. The IGTSS179 , one of the leading copper-based sorbents from this class of sorbents showed much higher reactivity and attrition resistance compared to leading commercial zinc titanate sorbents. As shown in Figure 40, the results from three cycles conducted with the IGTSS-179 sorbent in the packed-bed reactor at $450^{\circ} \mathrm{C}$ indicated that this sorbent has excellent $\mathrm{H}_{2} \mathrm{~S}$ removal efficiency and an effective sulfur capacity approximating $7 \mathrm{~g}$ $\mathrm{S} / 100 \mathrm{~g}$ sorbent, which corresponds to a sorbent conversion of $70 \%$. It must also be pointed out that despite its significantly higher attrition resistance (i.e., two times higher than FCC and 8 times higher than UCI-4169 zinc titanate sorbent according to ASTM D5757-95 method, as discussed later), the IGTSS-179 copper-based sorbent did not require an activation step to enhance its reactivity in the moderate temperature range. Furthermore, as shown in Figure 41, the sulfidation performance of IGTSS-179 sorbent at $350^{\circ} \mathrm{C}$ is essentially comparable to that at $450^{\circ} \mathrm{C}$. Sulfidation tests conducted at $350^{\circ} \mathrm{C}$ with the commercial UCI-4169 zinc titanate sorbent at identical operating conditions resulted in immediate $\mathrm{H}_{2} \mathrm{~S}$ breakthrough, indicating a complete lack of reactivity at $350^{\circ} \mathrm{C}$ for this sorbent, as reported in Figure 42.

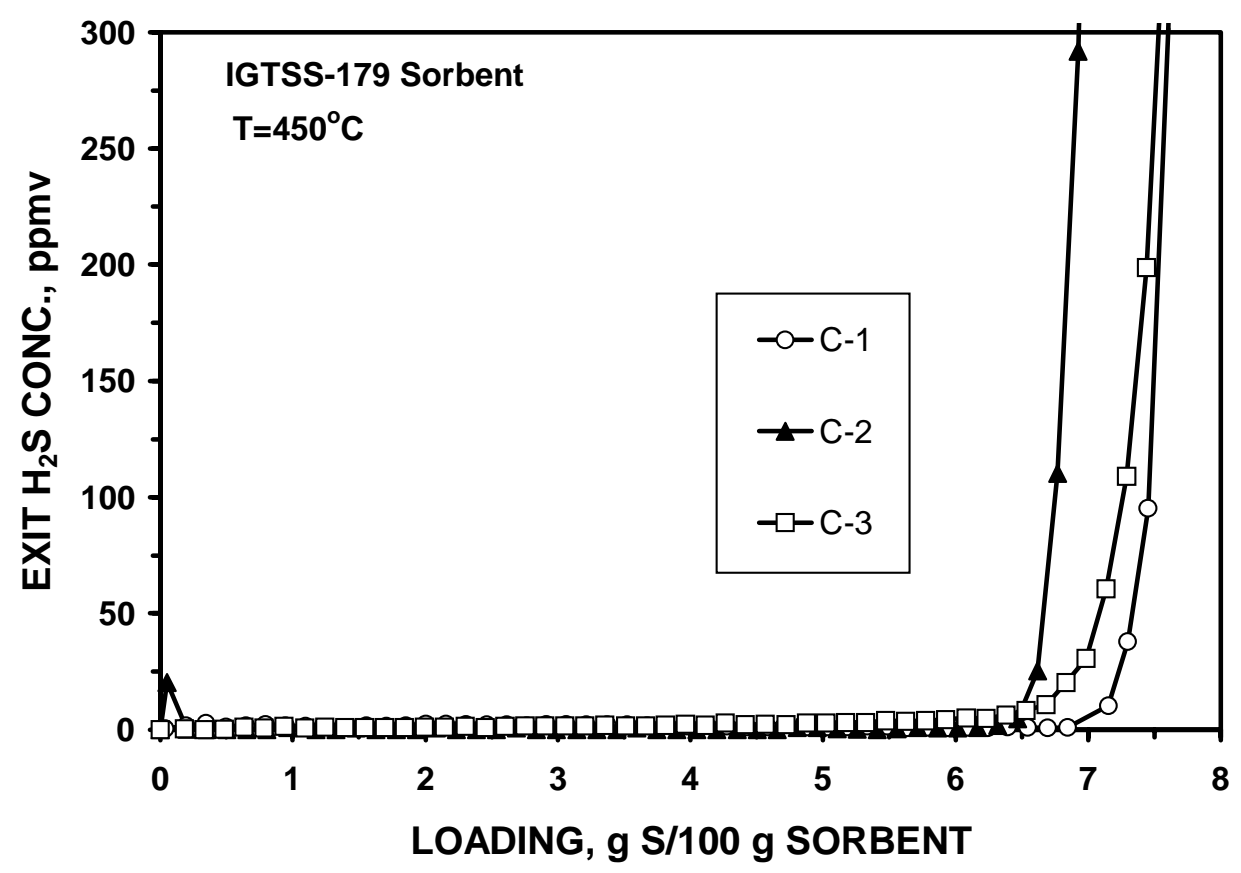

Figure 40. $\mathrm{H}_{2} \mathrm{~S}$ Breakthrough Curves for the IGTSS-179 Sorbent at $450^{\circ} \mathrm{C}$ 


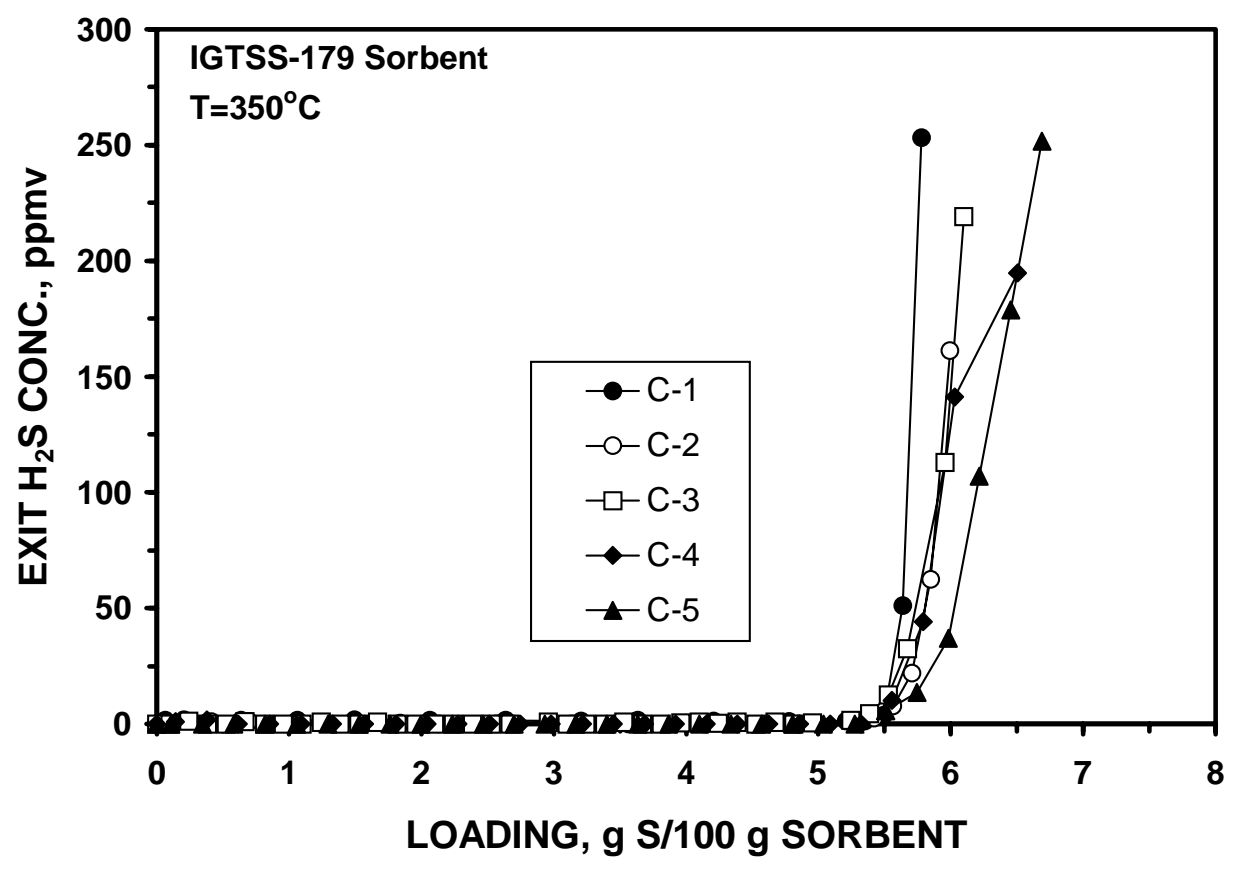

Figure 41. $\mathrm{H}_{2} \mathrm{~S}$ Breakthrough Curves for the IGTSS-179 Sorbent at $350^{\circ} \mathrm{C}$

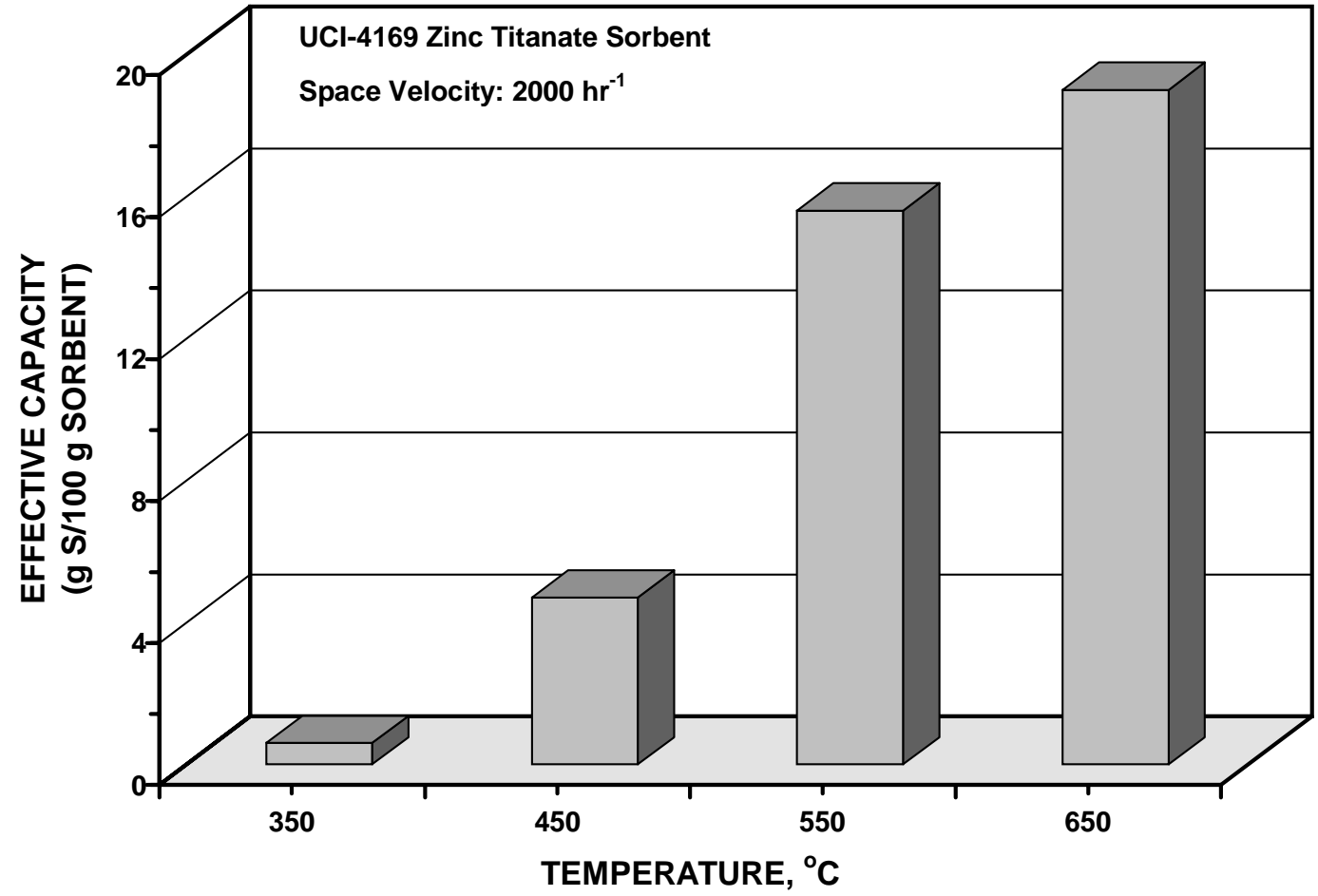

Figure 42. Effective Capacity for Sulfur of a Commercial Zinc Titanate Sorbent (UCI-4169) as a Function of Desulfurization Temperature 
The IGTSS-179 copper-based formulation was used as a baseline sorbent in a recent investigation, sponsored by the Illinois Clean Coal Institute, ${ }^{78}$ to further improve this sorbent for desulfurization applications at moderate temperatures. These efforts led to the development of IGTSS-326A sorbent. The results from five sulfidation/regeneration cycles conducted with this sorbent are shown in Figure 43, indicating excellent $\mathrm{H}_{2} \mathrm{~S}$ removal efficiency and effective sulfur capacity in the range of 6 to $7 \mathrm{~g} \mathrm{~S} / 100 \mathrm{~g}$ of this sorbent at $450^{\circ} \mathrm{C}$. The IGTSS-326A sorbent exhibited comparable effective sulfur capacity to the IGTSS-179 sorbent. Moreover, it was shown to possess attrition resistance $2 \frac{1}{2}$ times higher than that of the IGTSS-179 sorbent, as determined according to the ASTM D5757-95 method. The physical and chemical durability of the IGTSS-326A sorbent formulation was also assessed over 50 sulfidation/regeneration cycles completed in the packed-bed reactor. Results from these tests indicated excellent long-term durability of this sorbent. The various characteristics for the leading copperbased sorbents are summarized in Table 7.

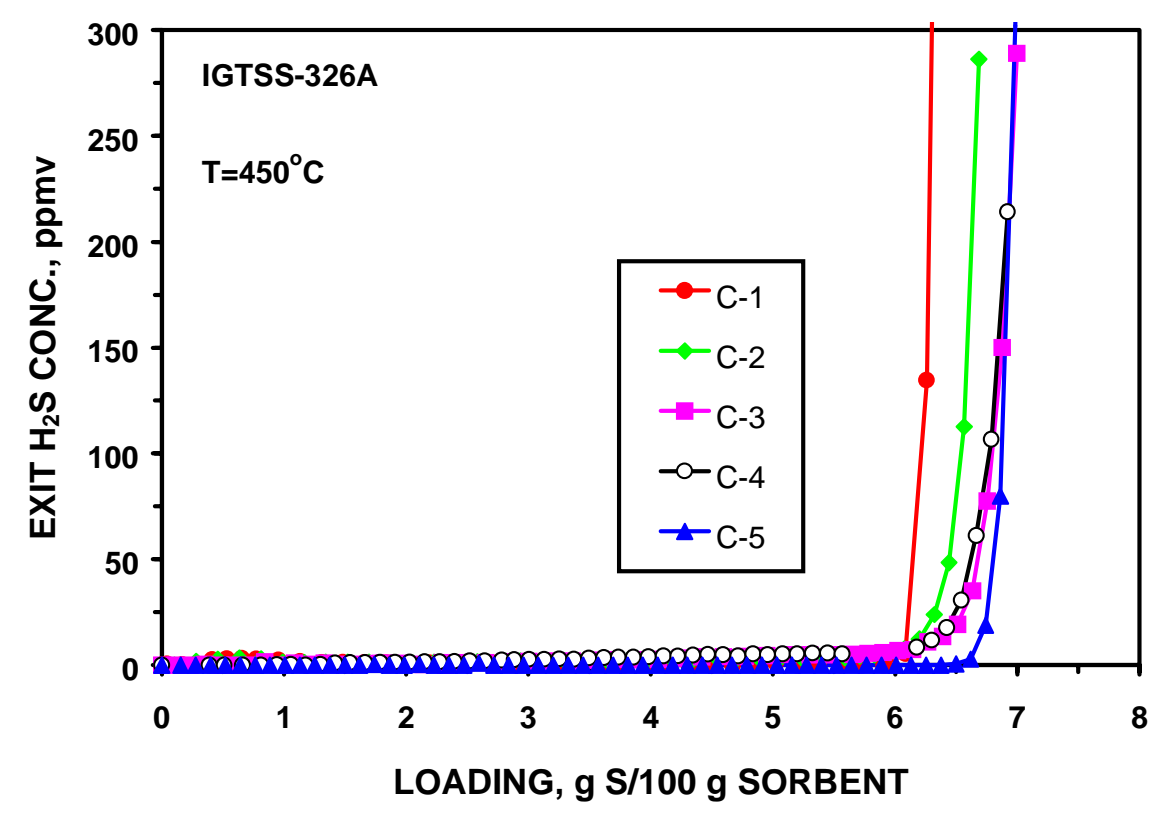

Figure 43. $\mathrm{H}_{2} \mathrm{~S}$ Breakthrough Curves for the IGTSS-326A Sorbent at $450^{\circ} \mathrm{C}$

\section{Comparison of Attrition Resistance}

The attrition resistance of selected sorbents was determined by the ASTM D575795 method. The results of the ASTM attrition tests are shown in Figure 44, indicating that the expected attrition loss of the zinc-based sorbents is about four times higher than the FCC catalyst. The attrition losses of the IGTSS-057 and IGTSS-179 were 39\% and $10 \%$, respectively, corresponding to approximately $1 / 2$ and $1 / 7$ of the commercial zinc titanate sorbent evaluated. 
Table 7. Data Summary for IGT's Leading Copper-Based Sorbents (Method II)

\begin{tabular}{|l|l|}
\hline \multicolumn{1}{|c|}{ Parameter } & \multicolumn{1}{c|}{ Value } \\
\hline Sulfur capacity & $10 \mathrm{~g} \mathrm{~S} / 100 \mathrm{~g}$ sorbent \\
\hline Temperature range of desulfurization operation & 300 to $538^{\circ} \mathrm{C}\left(572\right.$ to $\left.1000^{\circ} \mathrm{F}\right)$ \\
\hline Pre-breakthrough $\mathrm{H}_{2} \mathrm{~S}$ concentration & $<1 \mathrm{ppmv}$ \\
\hline Temperature range and method of regeneration & $600^{\circ}$ to $650^{\circ} \mathrm{C}$ \\
\hline $\begin{array}{l}\text { Space velocity for desulfurization and regeneration (volume } \\
\text { flow of gas at } 25^{\circ} \mathrm{C} \text { and } 1 \text { atm/volume of sorbent) }\end{array}$ & $2000 \mathrm{hr}^{-1}$ \\
\hline Regeneration gas composition & 2 to $6 \% \mathrm{O}_{2}$ in $\mathrm{N}_{2}$ \\
\hline Maximum number of cycles that the sorbent has been tested & 50 \\
\hline Attrition rate and method of testing & $\begin{array}{l}4 \% 5 \text {-hour loss (ASTM } \\
\text { D5757-95) }\end{array}$ \\
& $\begin{array}{l}0.7 \% \text { Average loss per hour } \\
\text { (AI per DOE's definition) }\end{array}$ \\
\hline Stability of sorbent as a function of cycle & $\begin{array}{l}\text { Very stable in 50 packed-bed } \\
\text { cycles }\end{array}$ \\
\hline Activation requirements of sorbent & None \\
\hline Sorbent density & $2.0 \mathrm{~g} / \mathrm{cm}^{3}$ \\
\hline
\end{tabular}

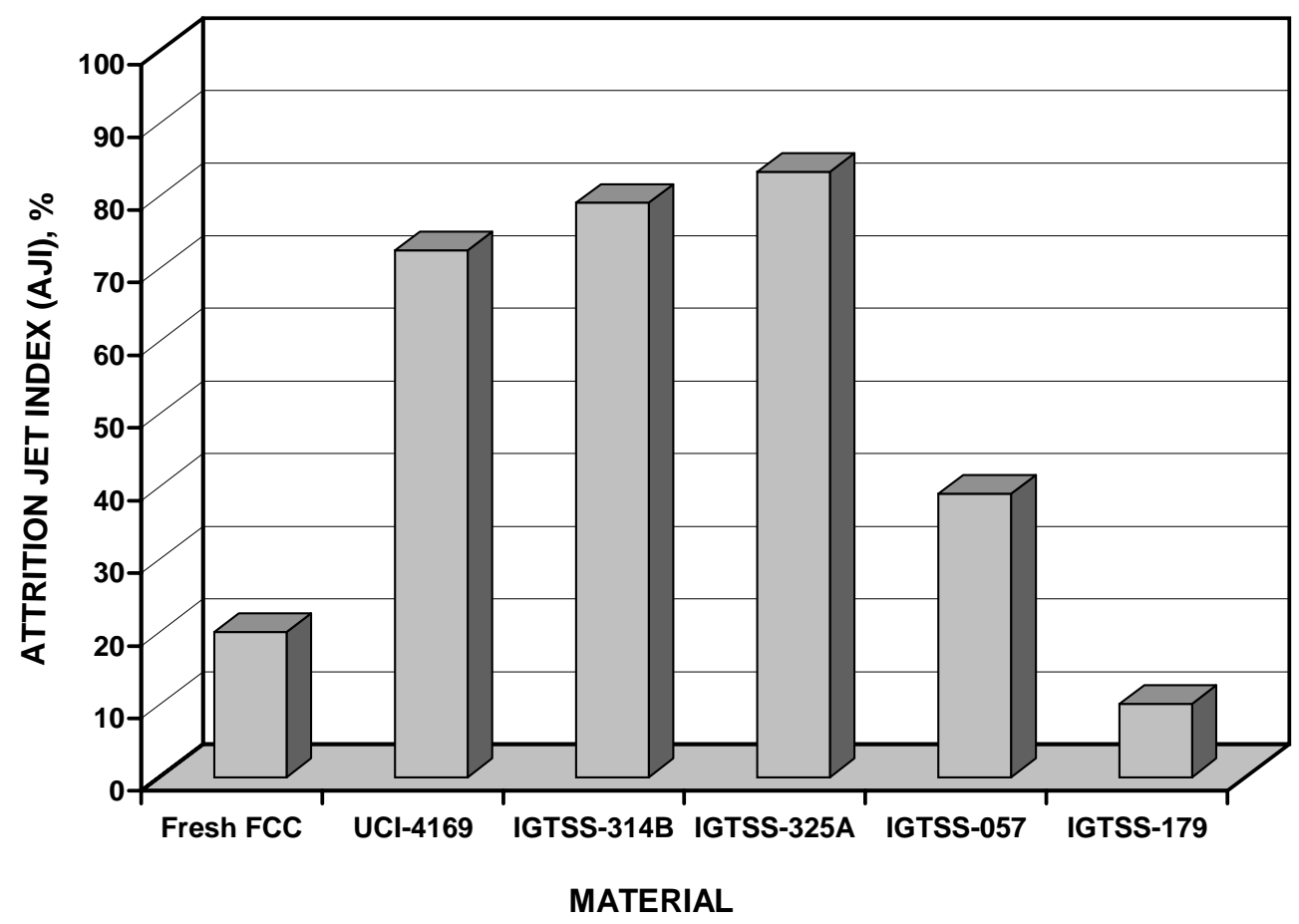

Figure 44. Comparison of Attrition Results of Different Sorbents

The improvement in sorbent reactivity realized with the second family of zincbased sorbents evidently came at the expense of lower attrition resistance, as exhibited by the performance of the IGTSS-314B and IGTSS-325A sorbents in the attrition unit. 
In summary, based on the results of evaluation of sorbents prepared by the traditional Method II, the following conclusions are drawn:

- Fe-based sorbents: No sorbent based on iron oxide was found to have sufficient reactivity in the moderate temperature range.

- Mn-based sorbents: Encouraging results were obtained with sorbents based on manganese oxide; however, their regeneration necessitates very high temperatures that cannot be accommodated by current desulfurization systems requiring regeneration ignition temperatures of about $550^{\circ} \mathrm{C}$.

- Zn-based sorbents: The results obtained with zinc-based sorbents prepared using Method II suggest that although excellent effective sulfur capacity and $\mathrm{H}_{2} \mathrm{~S}$ removal efficiency can be achieved in the moderate temperature range of 350 to $550^{\circ} \mathrm{C}$, using traditional sorbent preparation techniques such as solid oxide mixing, coprecipitation, etc., may not be suitable for development of effective sorbents with sufficient attrition resistance required for a demanding commercial application, such as the Piñon Pine transport reactor.

- Cu-based sorbents: Only sorbents based on copper oxide were found to possess the best combination of high attrition resistance and sulfidation reactivity, sulfur removal efficiency, and pre-breakthrough conversion in the moderate temperature range of 350 to $550^{\circ} \mathrm{C}$.

Because sorbents based on zinc oxide have undergone significant development and are best suited for desulfurization, especially in the moderate temperature range of current interest (i.e., 350 to $550^{\circ} \mathrm{C}$ ), an alternative sorbent preparation approach was deemed necessary. For these reasons, during the latter part of the program, efforts were directed towards employing alternative sorbent preparation techniques that have been shown to produce mechanically strong, porous solids with median pore diameters in the range of interest. Review of the literature identified sol-gel processing as a promising method, as described later in this report.

Given the results obtained, two zinc-based sorbents (IGTSS-314B, IGTSS-325A), one manganese-based sorbent (IGTSS-057), and one copper-based sorbent (IGTSS-179) were selected for the bench-scale fluidized-bed tests in the high-pressure reactor, as described below.

\section{Bench-Scale Testing in the High-Pressure Reactor}

As indicated earlier in this report, based on the results obtained, two zinc-based sorbents (IGTSS-314B and IGTSS-325A), one manganese-based sorbent (IGTSS-057), and one copper-based sorbent (IGTSS-179) were selected for the bench-scale fluidizedbed tests in the high-pressure reactor. The operating conditions for evaluation of the selected sorbents are provided in Table 8. The simulated coal gas composition used in these tests was similar to that reported in Table 4, except that the $\mathrm{H}_{2} \mathrm{~S}$ content of the feed 
gas was reduced to $0.15 \%(1500 \mathrm{ppmv})$. The sulfided sorbents were regenerated with a $\mathrm{N}_{2} / \mathrm{O}_{2}$ mixture containing $2-3 \%$ oxygen.

\section{Table 8. Operating Conditions for Evaluation of Selected Sorbents in the Bench- Scale High-Pressure Reactor}

\begin{tabular}{|l|l|}
\hline \multicolumn{1}{|c|}{ Parameter } & \multicolumn{1}{|c|}{ Condition } \\
\hline Sorbent Formulations & 4 \\
Mode of Operation & Bubbling fluidized-bed \\
Sulfidation Temperature & $450^{\circ} \mathrm{C}$ \\
Regeneration Temperature & $650^{\circ} \mathrm{C}\left(750-850^{\circ} \mathrm{C}\right.$ for IGTSS-057) \\
Pressure & $10 \mathrm{~atm}$ \\
Particle Size & $180-425 \mu \mathrm{m}$ \\
Bed Height & $5 \mathrm{~cm}$ \\
L/D ratio & 1 \\
Superficial Gas Velocity & $20 \mathrm{~cm} / \mathrm{s}$ \\
\hline
\end{tabular}

It should be noted that the operating conditions used correspond to a very shallow bubbling fluidized-bed with a very short gas residence time of about 0.25 second. Therefore, the sulfur loading obtained with the sorbents in these tests is much lower than the expected loadings in commercial reactors, where the fluidized-bed height and gas residence time are significantly higher. To provide a basis for comparison of the sorbents, prior to testing of the four selected sorbents, one sulfidation test was conducted with the UCI-4169 zinc titanate sorbent at the same operating conditions.

The $\mathrm{H}_{2} \mathrm{~S}$ breakthrough curve for the UCI-4169 is presented in Figure 45, indicating a sulfur loading of about $0.5 \%$ at the test conditions. The $\mathrm{H}_{2} \mathrm{~S}$ breakthrough curve for the two zinc-based sorbents developed in this program (i.e., IGTSS-314B and IGTSS-325A) are presented in Figures 46 and 47, indicating that their effective sulfur loading are generally similar to the UCI-4169 sorbent.

Significantly higher sulfur loading was achieved with the IGTSS-057 sorbent, as shown in Figure 48. Although, the manganese-based IGTSS-057 sorbent achieved a very high sulfur loading, the relatively high $\mathrm{H}_{2} \mathrm{~S}$ pre-breakthrough concentration, and a much higher temperature of $800^{\circ} \mathrm{C}$ required for successful regeneration of this sorbent are undesirable characteristics of this sorbent.

A sulfur loading of 4-6\% was achieved with the copper-based IGTSS-179 sorbents in cycles 2 through 5, as shown in Figure 49. Fluidization of this sorbent alone in the reducing environment at elevated temperature (i.e., above $450^{\circ} \mathrm{C}$ ) proved to be difficult because of relatively strong attractive inter-particle forces, leading to defluidization of the bed. To improve the fluidization behavior of the IGTSS-179 sorbent, this sorbent was mixed with the IGTSS-135 (which has been shown to have very low reactivity toward $\mathrm{H}_{2} \mathrm{~S}$ ). As shown in Figure 49, the reactivity of the IGTSS-179 sorbent appears to be improving with the cyclic process, and the $\mathrm{H}_{2} \mathrm{~S}$ pre-breakthrough concentration is well below 20 ppmv. The high reactivity of the IGTSS-179 sorbent, 
coupled with the very high attrition resistance, indicates that the IGTSS-179 is the best sorbent formulation evaluated in this program, using Method II sorbent preparation technique.

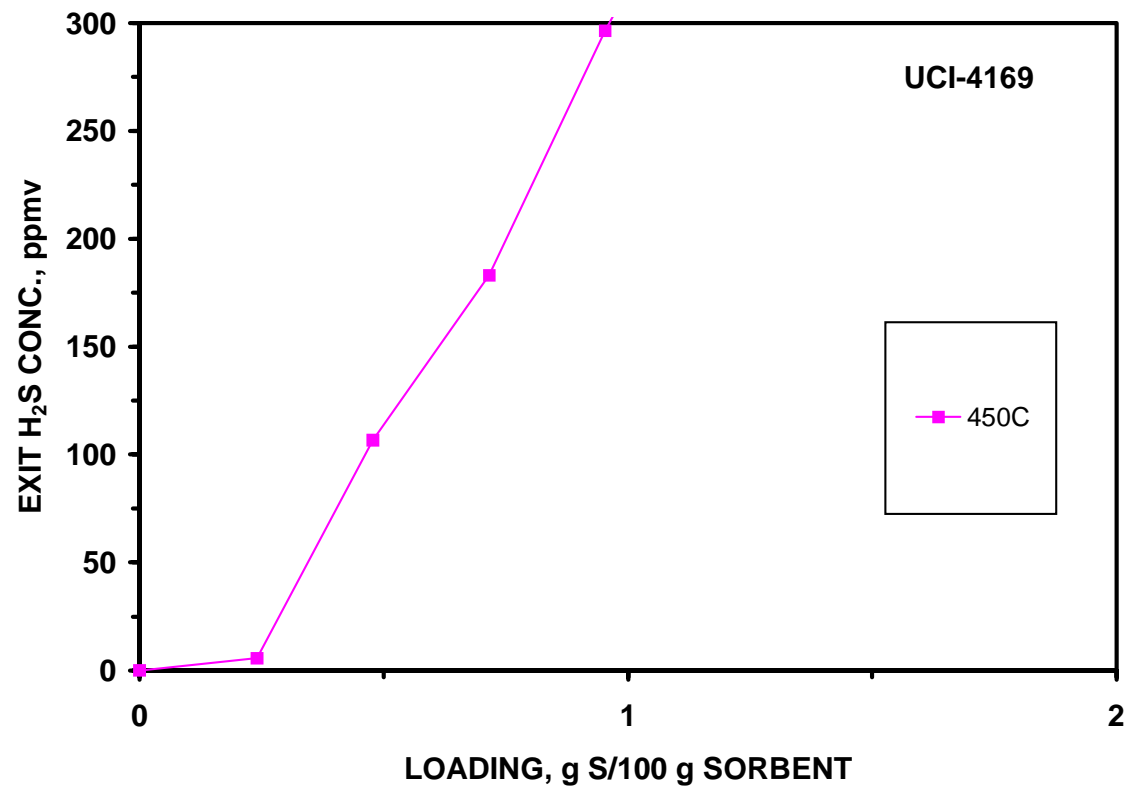

Figure 45. $\mathrm{H}_{2} \mathrm{~S}$ Breakthrough Curves for the UCI-4169 Sorbent in High-Pressure Bench-Scale Fluidized-Bed Reactor

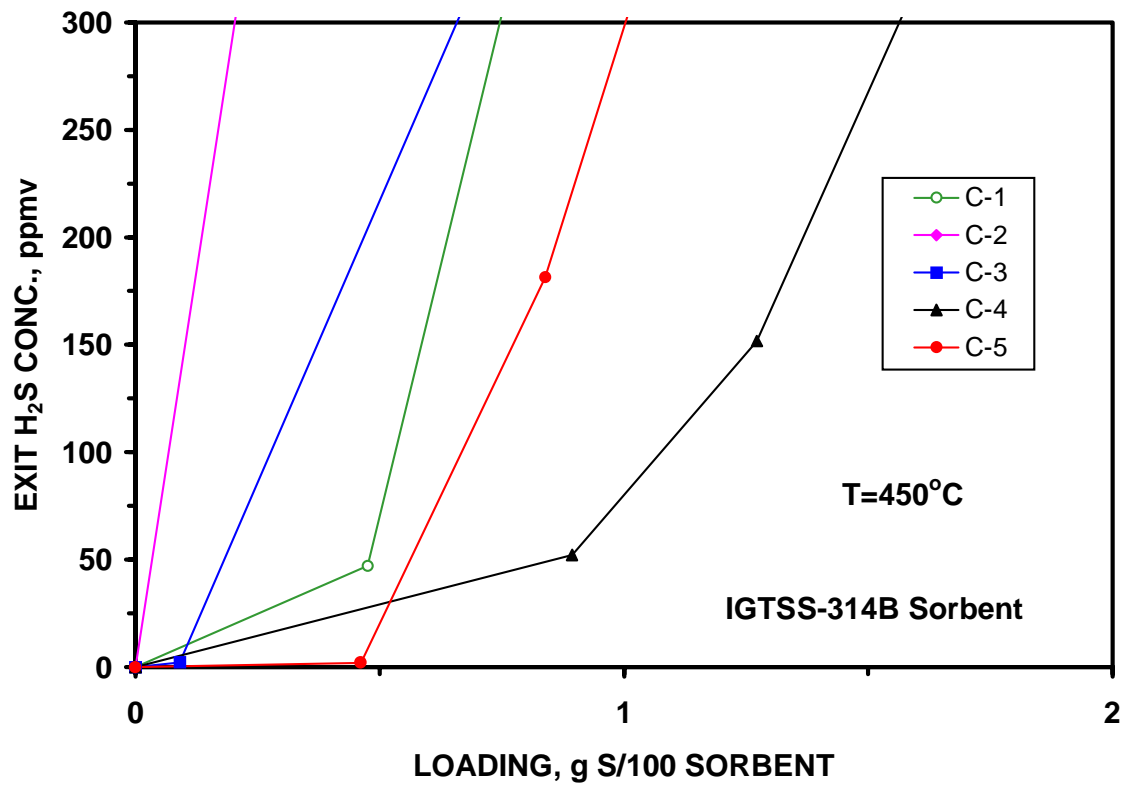

Figure 46. $\mathrm{H}_{2} \mathrm{~S}$ Breakthrough Curves for the IGTSS-314B Sorbent in HighPressure Bench-Scale Fluidized-Bed Reactor 


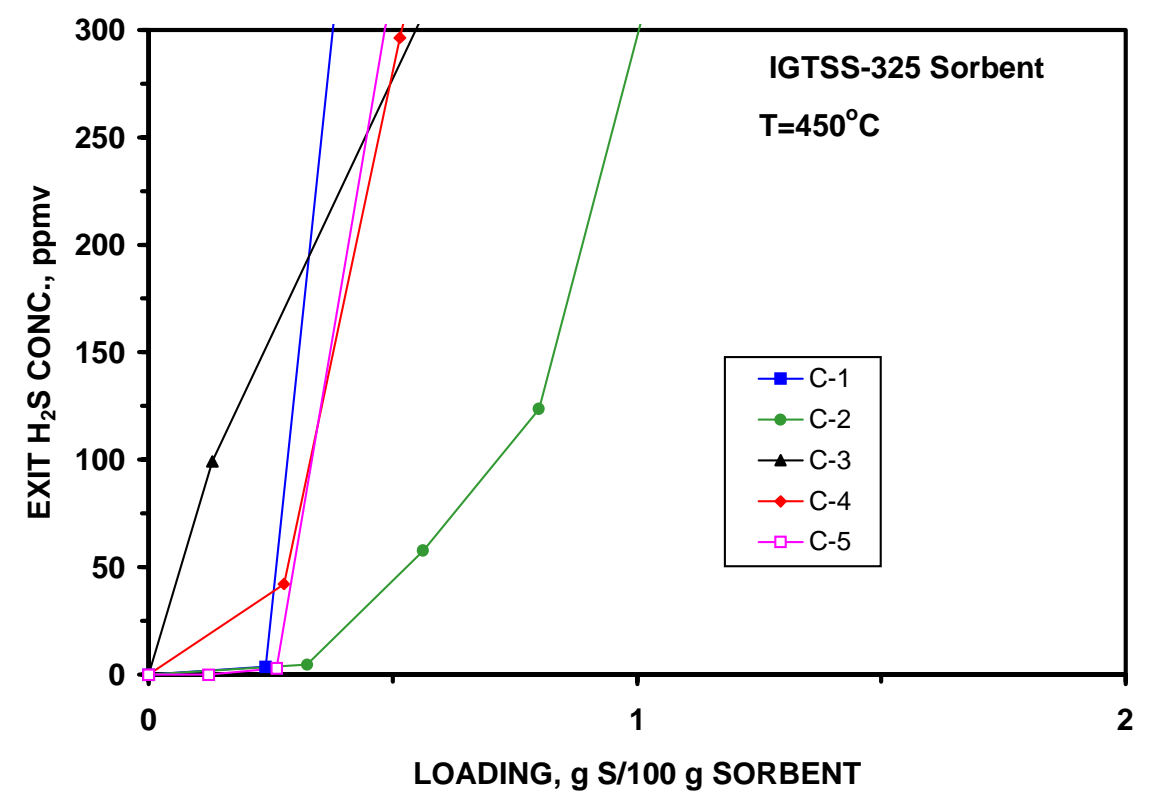

Figure 47. $\mathrm{H}_{2} \mathrm{~S}$ Breakthrough Curves for the IGTSS-325A Sorbent in HighPressure Bench-Scale Fluidized-Bed Reactor

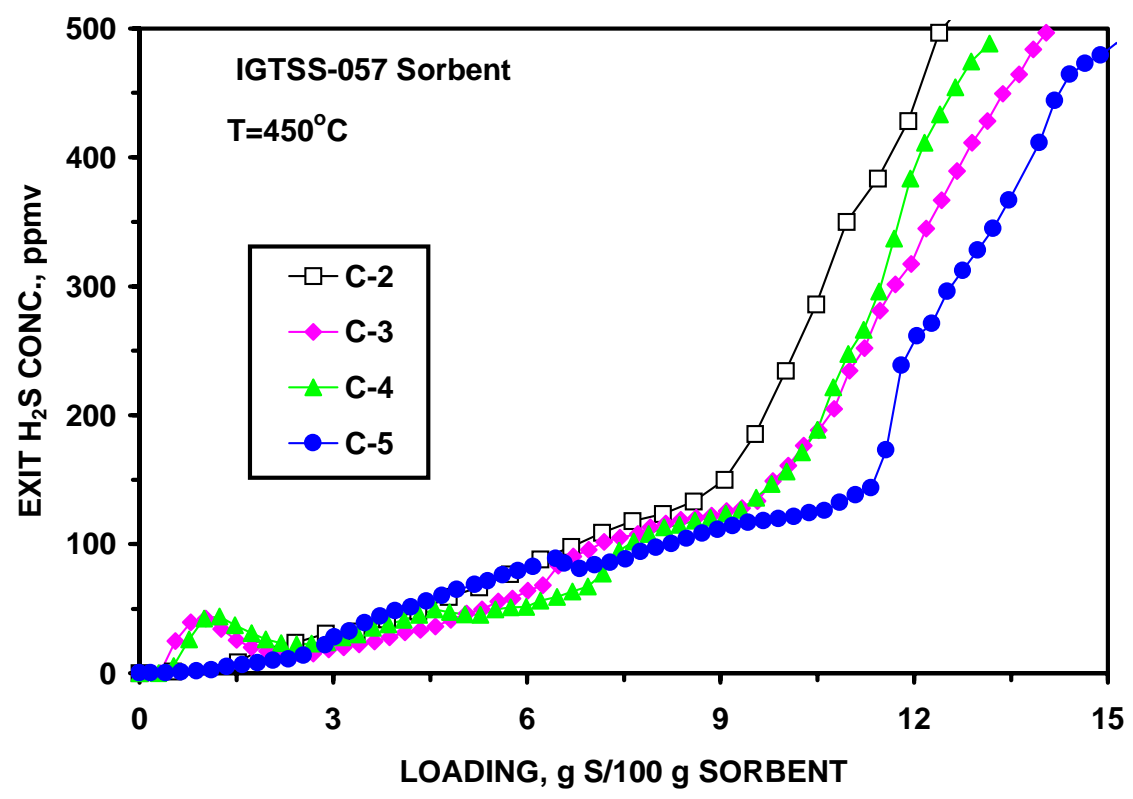

Figure 48. $\mathrm{H}_{2} \mathrm{~S}$ Breakthrough Curves for the IGTSS-057 Sorbent in High-Pressure Bench-Scale Fluidized-Bed Reactor 


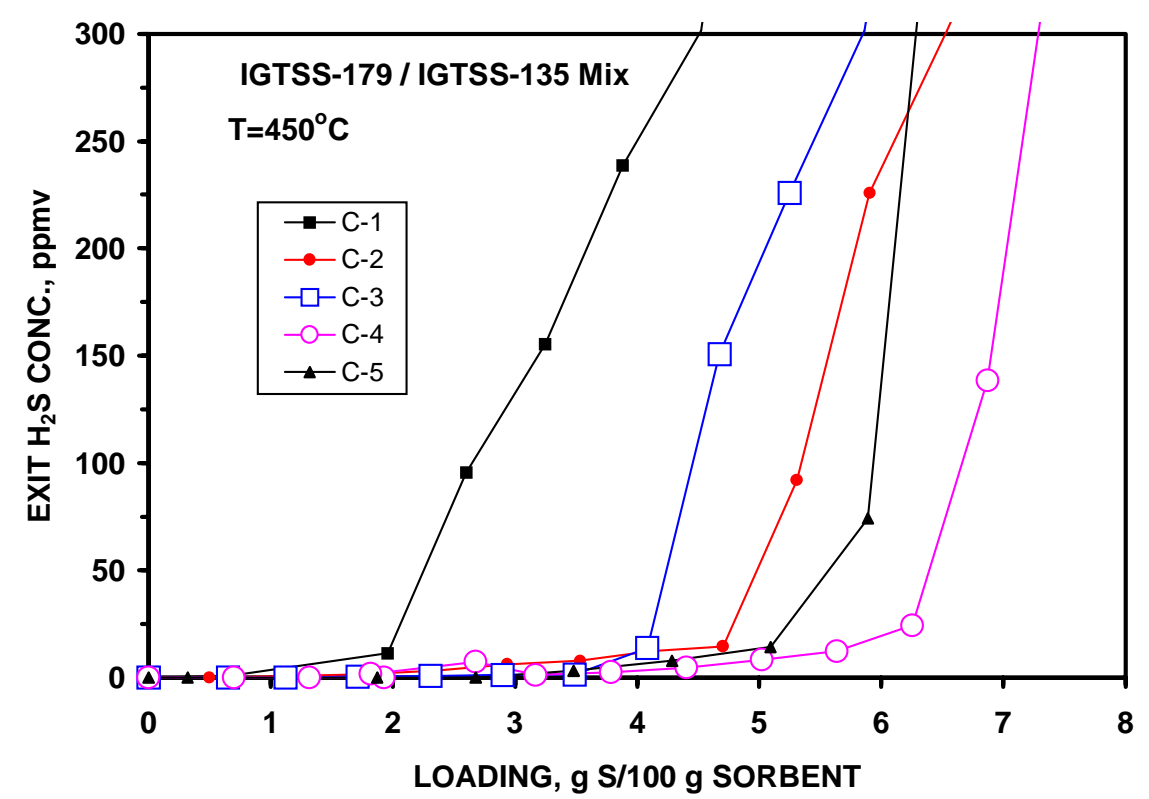

\section{Figure 49. $\mathrm{H}_{2} \mathrm{~S}$ Breakthrough Curves for the IGTSS-179 Sorbent in High-Pressure Bench-Scale Fluidized-Bed Reactor}

Given the emergence of the transport reactor as the only demonstration scale technology for hot fuel gas desulfurization, efforts were directed specifically toward development of sorbents that would meet the significantly more stringent requirement for the transport reactor application.

As discussed above, copper-based sorbents were the only sorbents that could satisfy the attrition resistance requirement of and that the requirement for attrition resistance of the sorbents for transport reactor is significantly more stringent than the bubbling fluidized-bed, attrition resistance became a deciding criterion for selection of suitable sorbents. However, because fluidization of the copper-based sorbents in the reducing fuel gas environment appeared to be problematic, additional efforts were directed toward further evaluation of copper-based sorbents in fluidized-bed reactors.

\section{Further Efforts with Copper-Based Sorbents}

Although high reactivity, superior attrition resistance, and excellent durability of the leading copper-based sorbents were demonstrated, in order to move the sorbent towards the IGCC demonstration stage at the Piñon Pine facility, the U.S. DOE, the M. W. Kellogg (MWK), and the Sierra Pacific Power Company (SPPC) require that the sorbent be produced by a commercial sorbent manufacturer and its effectiveness evaluated according to a precise test protocol developed by USDOE/NETL. ${ }^{73}$

As a first step towards the demonstration of the suitability of these sorbents for the transport reactor application, the leading copper-based sorbents (i.e., IGTSS-179 and IGTSS-326A) were evaluated in the fluidized-bed mode. These tests were conducted in 
1-inch and 2-inch diameter fluidized-bed reactors, both at ambient pressure. Sulfidation was carried out at a temperature in the range of 300 to $450^{\circ} \mathrm{C}$ in a simulated $\mathrm{KRW}$ fuel gas composition, as shown in Table 9. To simulate the regeneration process in continuous reactors, the sulfided sorbent was successfully regenerated, using 2 to $6 \% \mathrm{O}_{2^{-}}$ $\mathrm{N}_{2}$ mixtures at controlled temperatures between 600 and $650^{\circ} \mathrm{C}$, by controlled feeding to a pre-heated reactor containing a regenerated sorbent. The results of these tests indicate that the leading copper-based sorbents are highly reactive at the moderate sulfidation temperatures, achieving effective sulfur capacities of over $2 \mathrm{~g} \mathrm{~S} / 100 \mathrm{~g}$ sorbent, at very short gas residence times of 0.1 to 0.15 second.

\section{Table 9. Simplified Composition of KRW Fuel Gas, Vol\%}

\begin{tabular}{|c|c|}
\hline Component & Vol. \% \\
\hline $\mathrm{H}_{2}$ & 14.5 \\
$\mathrm{CO}$ & 23.9 \\
$\mathrm{CO}_{2}$ & 5.5 \\
$\mathrm{H}_{2} \mathrm{O}$ & 5.5 \\
$\mathrm{~N}_{2}$ & 48.6 \\
$\mathrm{H}_{2} \mathrm{~S}$ & 2 \\
\hline
\end{tabular}

Careful monitoring of the sorbent bed during the fluidized-bed tests conducted with IGTSS-179 and IGTSS-326 indicated that achieving uniform fluidization with these sorbents at low fluidization velocity (i.e., $20 \mathrm{~cm} / \mathrm{s}$ ), in the reducing environment at elevated temperature (i.e., above $450^{\circ} \mathrm{C}$ ) would to be difficult, because of relatively strong attractive interparticle forces, leading to defluidization of the bed. To overcome this limitation, sulfidation gas velocities were gradually increased during the tests and ranged from 20 to $32 \mathrm{~cm} / \mathrm{s}$. As expected, the fluidization behavior of the leading copperbased sorbents improves with increasing gas velocity. However, because of the limitation of the batch reactors employed, higher gas velocities cannot be used. Therefore, it is not feasible to determine the gas velocity beyond which good sorbent fluidization can be maintained during sulfidation.

Although, the undesirable fluidization behavior observed in the small batch unit is not expected to be encountered during the actual use of these sorbents in the transport reactor facility, to obtain reproducible and reliable experimental data during the evaluation of the sorbent in the high pressure bench scale unit, efforts have been devoted to further modify the sorbent composition, and/or manufacturing technique to improve the fluidization properties of the sorbent.

The initial efforts focused on determination of the parameters contributing to the agglomeration tendencies of copper-based sorbents. In this regard, IGTSS-179, IGTSS$326 \mathrm{~A}$, as well as few commercially produced copper-based sorbents were evaluated in this program. The commercial copper-based sorbents currently being studied include a supported copper based sorbent produced by ALCOA and a bulk sorbent produced by UCI. One additional copper chromite sorbent (i.e., IGTSS-068) ${ }^{41}$ developed earlier at 
IGT was also included in this investigation. The relevant physical and chemical properties of these sorbents are presented in Table 10.

Table 10. Physical and Chemical Properties of Copper-Based Sorbents Investigated

\begin{tabular}{|l|c|c|c|c|c|}
\hline $\begin{array}{l}\text { Sorbent } \\
\text { Designation }\end{array}$ & $\begin{array}{c}\text { Sorbent } \\
\text { Type }\end{array}$ & $\begin{array}{c}\text { Cu Content } \\
(\%)\end{array}$ & $\begin{array}{c}\text { Hg Surface* } \\
\text { Area }\left(\mathrm{m}^{2} / \mathrm{g}\right)\end{array}$ & $\begin{array}{c}\text { Hg Pore* } \\
\text { Volume, } \\
\text { cc/g }\end{array}$ & $\begin{array}{c}\text { Median Pore* } \\
\text { Dia. }\left(\mathrm{A}^{\circ}\right)\end{array}$ \\
\hline ALCOA & Supported & 7.0 & 24.541 & 0.2644 & 5,400 \\
IGTSS-068 & Bulk & 46.2 & 0.868 & 0.081 & 17,000 \\
IGTSS-179 & Bulk & 35.8 & 5.210 & 0.0343 & 5,100 \\
IGTSS-326A & Bulk & 36.6 & 2.731 & 0.0252 & 2,400 \\
UCI-4489 & Bulk & 40.8 & 4.49 & 0.0540 & 8,500 \\
\hline
\end{tabular}

* Corrected for inter-particle void

The experimental approach was geared towards correlating the fluidization characteristics and the sulfidation reactivities of the sorbents with the physical and chemical properties of the sorbents shown in the above table. The goal was to obtain the information necessary to determine the most effective approach for modification of the sorbent prior to commercial production. Fluidization tests were conducted in the 1-inch reactor with all the sorbents under identical operating conditions and consisted of a series of oxidation/reduction tests, over several cycles.

In a typical test the oxidized sorbent is exposed to a reducing gas at superficial gas velocities in the range of $20-45 \mathrm{~cm} / \mathrm{s}$ at temperatures in range of $300-500^{\circ} \mathrm{C}$ until the sorbent is fully reduced. The effects of superficial gas velocity and the reactor temperature on the fluidization behavior of the sorbent is visually observed and recorded. Following the completion of the reduction period, the sorbent is oxidized and the cycle is repeated few time to determine effect of cycling on the fluidization behavior of the sorbent. Based on visual observation and pressure drop across the sorbent bed, the fluidization behavior is generally recorded in one of three categories; Uniform Fluidization, Slugging, or Defluidization.

The fluidization behavior of the selected sorbents was also determined in a series of sulfidation/regeneration test under operating conditions similar to those described above. The goal was to compare the fluidization behavior in the two series of tests, and obtain useful information regarding the nature of the attractive interparticle forces, leading to undesirable fluidization behavior at lower velocities.

The sulfidation reactivities of new sorbents were determined under identical operating condition as those previously obtained with IGTSS-179 and IGTSS-326 sorbents. The sulfidation reactivity and regenerability of the ALCOA supported sorbents were determined over two series of $2 \frac{1}{2}$ cycle tests. The results indicate that the sorbent 
can be successfully regenerated. However, because of the lower copper content of this sorbent, its effective sulfur capacity is significantly lower than those of the bulk copper sorbents.

Similar to the IGTSS-179 and IGTSS-326A sorbents, both bulk copper-based IGTSS-068 and UCI-4489 exhibited slugging fluidization behavior at $450^{\circ} \mathrm{C}$, leading to defluidization of the bed. The results obtained clearly indicated that achieving uniform fluidization with bulk copper-based sorbents containing over $40 \%$ copper was difficult in the reducing environment at fluidization velocities up to $45 \mathrm{~cm} / \mathrm{s}$ and elevated temperature (i.e., above $450^{\circ} \mathrm{C}$ ). In contrast, uniform fluidization can be achieved at the same operating condition with the supported ALCOA sorbent that contains about $10 \%$ copper.

A comparison of the physical properties of the sorbents tested during this part of the investigation is given in Table 10, indicating that while the copper content of the ALCOA sorbent is significantly lower than those of bulk copper sorbents, the specific surface area and pore volume are higher and the median pore diameters are generally similar.

Given the favorable fluidization behavior of the supported ALCOA sorbent, sorbent preparation efforts focused on lowering the copper content of bulk sorbents, while maintaining their relatively high sulfur capacity. This was accomplished by replacing a portion of copper oxide in the sorbent with another reactive metal oxide (i.e., zinc oxide). This approach consisted of first taking one of the leading bulk copper-based sorbents (IGTSS-179 or IGTSS-326A), grinding it down to a very fine size, regranulating it, and indurating (hardening) the results pellets/granules at the same temperature as the original formulation. The physical strength of resulting granules was then evaluated and was determined to be similar to that of the original formulation. One of our zinc-based formulations was also subjected to the same procedure and its physical strength was also found to be similar to the original formulation. Once reproducibility of reprocessed sorbent materials was established, powders of one copper-based sorbent and another zinc-based sorbent were well mixed in the desired proportions, granulated, dried, and then indurated at the appropriate temperature that would impart the required physical strength. The initial starting materials consisted of reprocessed indurated formulations to make sure copper oxide and zinc oxide existed in their "compounded" condition.

A sorbent formulation was prepared according to the above procedure, based on copper-based sorbent IGTSS-179 and zinc-based sorbent IGTSS-135. This sorbent was designated as IGTSS-344 and consisted of 50 wt.\% IGTSS-179, 50 wt.\% IGTSS-135. This sorbent was extremely strong, suggesting the possibility of obtaining the required strength with lower induration temperatures. This sorbent was evaluated for its sulfidation reactivity and fluidization behavior in the fluid-bed reactor. Unfortunately, sorbent de-fluidization occurred under our operating conditions and no further work was done on this sorbent. 
De-fluidization of the IGTSS-344 sorbent was attributed mainly to its high copper oxide content and possibly to the high titania content of the IGTSS-135 zinc titanate sorbent. To address these issues a second formulation was prepared based on IGTSS-179 copper-based sorbent and a different zinc-based sorbent (i.e., IGTSS-189). The proportions of these sorbents were adjusted in the original formulation to result in a sorbent containing approximately $12 \% \mathrm{CuO}$ and $35 \% \mathrm{ZnO}$. This sorbent formulation was designated as IGTSS-345B. The fluidization behavior of this latter sorbent formulation was evaluated in the fluid-bed reactor in 5 cycles of sulfidation/regeneration under operating conditions similar to those outlined above. Good sorbent fluidization was maintained during these cycles using gas velocities in the range of 25 to $35 \mathrm{~cm} / \mathrm{s}$. Given the encouraging results in the fluidized-bed tests, the effective sulfur capacity of the IGTSS-345B sorbent formulation was also determined in packed-bed tests. Results from testing of a fresh batch of this sorbent indicated effective sulfur capacity of $11.3 \mathrm{~g}$ $\mathrm{S} / 100 \mathrm{~g}$ sorbent at $450^{\circ} \mathrm{C}$, following sorbent activation.

The attrition resistance of IGTSS-345B, IGTSS-189, IGTSS-179, and IGTSS326A sorbents were also determined according to a modified version of the ASTM D 5757-95 method, which is calculated by dividing the difference between the 5-hr and 1-hr loss by 4 . The results obtained are given in Table 11 .

Table 11. Attrition Resistance Indices for Various Sorbents

\begin{tabular}{|c|c|c|c|c|}
\hline Sorbent & $\begin{array}{l}\text { Size Range } \\
\qquad(\mu \mathrm{m})\end{array}$ & $\begin{array}{c}1-\mathrm{hr} \text { loss, } \\
\%\end{array}$ & 5-hr loss, $\%$ & $\begin{array}{c}\left(5^{\mathrm{th}} \mathrm{hr}-1^{\mathrm{st}} \mathrm{hr}\right) / 4 \\
\%\end{array}$ \\
\hline FCC Catalyst & $45-180$ & 3.7 & 20.0 & 4.1 \\
\hline IGTSS-179 & $75-150$ & 2.2 & 6.4 & 1.0 \\
\hline IGTSS-326A & $75-150$ & 3.4 & 7.9 & 1.1 \\
\hline IGTSS-189 & $75-106$ & 50.2 & 82.8 & 8.05 \\
\hline IGTSS-345B & $45-180$ & 13.2 & 34.5 & 5.3 \\
\hline EX-SO3 (RTI) & APS : 90 & N/A & $\mathrm{N} / \mathrm{A}$ & 4.0 \\
\hline
\end{tabular}

A larger batch of the IGTSS-345B sorbent was prepared for additional testing in the 2-inch fluidized-bed reactor. The fluidized-bed test was conducted at $538^{\circ} \mathrm{C}$ at a fluidization velocity of $20 \mathrm{~cm} / \mathrm{s}$, resulting in an effective sulfur capacity of over $6 \%$ at a very low gas residence time of 0.4 seconds. This results indicate that the reactivity and/or effective sorbent capacity of this sorbent is considerably higher than the EX-SO3 sorbent, while its attrition index is slightly higher (i.e., 5.3\% compared to 4\%) of that of the EX-SO3 sorbent. Therefore, based on the results obtained with IGTSS-345B, this sorbent was selected as a suitable candidate for further evaluation.

\section{Sorbents Prepared by Sol-Gel Technique (Method III)}

The main focus of this part of the research program was to explore the possibility of preparing zinc-based sorbents using a modified sol-gel approach (i.e., Method III) that has been shown to require only a moderate temperature for calcination, while resulting in 
significantly more attrition-resistant sorbents. Eleven (11) sorbent formulations were prepared using a sol-gel approach, where a stable sol is first prepared from a titania precursor (alkoxide and/or powder). The required amount of a zinc precursor (zinc nitrate) is then added to bring the zinc oxide content to the desired level. The resulting solution is then well mixed to disperse the reactive oxide, thickened, dried, and finally calcined at the desired temperature for a predetermined period. The nominal zinc oxide content of the sorbents prepared during the reporting period ranged from 10 to $40 \%$. The calcination temperature ranged from 450 to $725^{\circ} \mathrm{C}$. The designations for the sorbents prepared and their nominal $\mathrm{ZnO}$ content are summarized in Table 12.

Table 12. Zinc-Based Sorbents Prepared using Sol-Gel Approach (Method III)

\begin{tabular}{|l|c|}
\hline $\begin{array}{l}\text { Sorbent } \\
\text { Designation }\end{array}$ & $\begin{array}{c}\text { ZnO } \\
\text { wt\% }\end{array}$ (nominal) \\
\hline IGTSS-349 & 10 \\
IGTSS-350 & 40 \\
IGTSS-351 & 20 \\
IGTSS-353 & 30 \\
IGTSS-354 & 30 \\
IGTSS-355 & 30 \\
IGTSS-356 & 30 \\
IGTSS-357* & 30 \\
IGTSS-358* & 30 \\
IGTSS-359 & 30 \\
IGTSS-360 & 40 \\
\hline
\end{tabular}

* Sorbent does not contain any titania

Granules from each of the above sorbents were then produced in the desired size range of $425-600 \mu \mathrm{m}$ and $45-180 \mu \mathrm{m}$ for testing in the packed-bed and fluidized-bed reactors, respectively. The granular sorbents were then evaluated for their $\mathrm{H}_{2} \mathrm{~S}$ removal efficiency and effective sulfur capacity (i.e., $\mathrm{H}_{2} \mathrm{~S}$ concentration prior to breakthrough and the total amount of sulfur loaded at breakthrough time). Sulfidation tests was carried out in the temperature range of 350 to $550^{\circ} \mathrm{C}$ and a gas space velocity of $2000 \mathrm{hr}-1$ for packed-bed and $5000 \mathrm{hr}-1$ for fluid-bed tests. Two sulfidation gas compositions have been used: The first one consisted of $10 \% \mathrm{H} 2 \mathrm{O}, 10 \% \mathrm{H} 2,20 \% \mathrm{CO}, 10 \% \mathrm{CO}_{2}, 2 \% \mathrm{H}_{2} \mathrm{~S}$, and $48 \% \mathrm{~N} 2$ and the second one consisted of $10 \% \mathrm{H} 2 \mathrm{O}, 40 \% \mathrm{H} 2,2 \% \mathrm{H} 2 \mathrm{~S}$, and $48 \% \mathrm{~N} 2$. Reacted sorbent regeneration was investigated in the temperature range of 480 to $650^{\circ} \mathrm{C}$ (900 to $1200^{\circ} \mathrm{F}$ ) using a gas mixture containing $2-7 \% \mathrm{O} 2,0-10 \% \mathrm{H} 2 \mathrm{O}$, and balance $\mathrm{N} 2$. Fresh as well as reacted samples from selected sorbents were subjected to chemical analysis and physical characterization, including BET surface area, porosity and pore size distribution, particle density, and XRD analysis. Four selected sorbent formulations (i.e., IGTSS-353, -354, -357, and -359) were also evaluated for their attrition resistance properties in accordance with the ASTM D5757-95 method. Their performance was compared against those of selected sorbents previously developed in this program and that of a leading candidate zinc titanate sorbent (i.e., EX-SO3) for the $\mathrm{Pi}^{\mathrm{TM}}$ on Pine 
Demonstration Project. The results of extensive evaluation of the sorbents prepared by sol-gel techniques are presented and discussed below.

\section{Sorbent Characterization.}

The results of physical characterization of two selected sol-gel-derived sorbents (i.e., IGTSS-353 and -354) as well as those of selected sorbents previously prepared by conventional techniques are summarized in Table 13. Comparison of the sorbents presented in Table 13 indicates that although all these sorbents have similar densities and porosities, the mercury pore surface areas of the sol-gel derived sorbents are one to two orders of magnitude higher than those prepared by other techniques. The high surface areas of the sol-gel-derived sorbents should be attributed to significantly smaller pore diameters in these sorbents. This desirable combination of high porosity, high surface area, and small pore diameters resulted in higher reactivity and much higher attrition resistance, as will be discussed later.

Table 13. Physical Characteristics of Selected Sorbents

\begin{tabular}{|l|cccccc|}
\hline $\begin{array}{l}\text { Sorbent } \\
\text { Designation }\end{array}$ & $\begin{array}{c}\text { Main } \\
\text { Reactive } \\
\text { Metal }\end{array}$ & $\begin{array}{c}\text { Bulk } \\
\text { Density } \\
\left(\mathrm{g} / \mathrm{cm}^{3}\right)\end{array}$ & $\begin{array}{c}\mathrm{Hg} \text { Particle } \\
\text { Density } \rho_{\mathrm{b}}, \\
\left(\mathrm{g} / \mathrm{cm}^{3}\right)\end{array}$ & $\begin{array}{c}\text { Skeletal } \\
\text { Density, } \\
\rho_{\mathrm{a}}\left(\mathrm{g} / \mathrm{cm}^{3}\right)\end{array}$ & $\begin{array}{c}\text { Porosity } \\
(\%)\end{array}$ & $\begin{array}{c}\text { Total Hg } \\
\text { Pore Surface } \\
\text { Area }\left(\mathrm{m}^{2} / \mathrm{g}\right)\end{array}$ \\
\hline IGTSS-353(sol-gel) & $\mathrm{Zn}$ & 1.55 & 2.43 & 3.66 & 33.6 & 39.23 \\
IGTSS-354(sol-gel) & $\mathrm{Zn}$ & 1.55 & 2.13 & 4.12 & 48.1 & 56.92 \\
IGTSS-314B & $\mathrm{Zn}$ & 1.35 & 2.27 & 4.48 & 49.4 & 3.34 \\
IGTSS-325A & $\mathrm{Zn}$ & 1.32 & 1.93 & 4.55 & 57.5 & 2.59 \\
UCI-4169 & $\mathrm{Zn}$ & 1.37 & 1.38 & 3.14 & 56.1 & 0.72 \\
IGTSS-057 & $\mathrm{Mn}$ & 1.75 & 1.62 & 4.69 & 65.6 & 9.21 \\
IGTSS-179 & $\mathrm{Cu}$ & 2.05 & 3.06 & 4.17 & 26.7 & 5.23 \\
\hline
\end{tabular}

\section{Comparison of Attrition Resistance}

Figure 50 reports the results from attrition tests carried out on the IGTSS-353 and IGTSS-354 sorbents. These results are also compared against those obtained previously with the commercial UCI-4169 zinc titanate sorbent and two selected bulk zinc-based sorbents developed earlier in this program. Also shown in Figure 50 are the results from the baseline FCC material. The results reported in Figure 50 are in terms of the attrition jet index (AJI), as defined by the ASTM D5757-95 procedure, which corresponds to the 5-hour loss. As shown in this figure, the new sol-gel derived zinc-based sorbents achieved attrition losses that are about half that of the FCC material and about 1/10 those of the conventional bulk zinc-based sorbents.

Figure 51 reports the attrition losses obtained with the IGTSS-353 and IGTSS354 sorbents during the second hour only of the 5-hour attrition test. This modified procedure of the ASTM D5757-95 method has been reported to provide adequate assessment of the relative attrition resistance of sorbent materials for the purpose of 
screening effective sorbents for the Piñon Pine application. Also shown in Figure 51 are the results obtained with other leading regenerable sorbents developed at IGT (i.e., IGTSS-179 and IGTSS-345B) and the results reported for EX-SO3 zinc titanate sorbent. This latter is currently the leading sorbent being considered for the $\mathrm{Pi}^{\mathrm{TM}}$ on Pine Clean Coal Demonstration Project. As shown, Both IGTSS-353 and IGTSS-354 exhibit significantly lower attrition losses that are 3 to 4 times better than the leading EX-SO3 sorbent.

Figure 52 compares the performance of IGTSS-353 and IGTSS-354 sorbents with those of other selected copper-based (IGTSS-179), manganese-based (IGTSS-057), zincbased (UCI-4169), and mixed-oxide (IGTSS-345B) sorbents in the attrition unit. Attrition resistance in this figure is reported in accordance with DOE/FETC's definition of $\left(5^{\text {th }} \mathrm{hr}-1^{\text {st }} \mathrm{hr}\right) / 4$, i.e., the average per hour loss due to attrition with the first hour loss not taken into consideration. As shown, IGTSS-353 and IGTSS-354 demonstrated significantly lower attrition losses among all the sorbents.

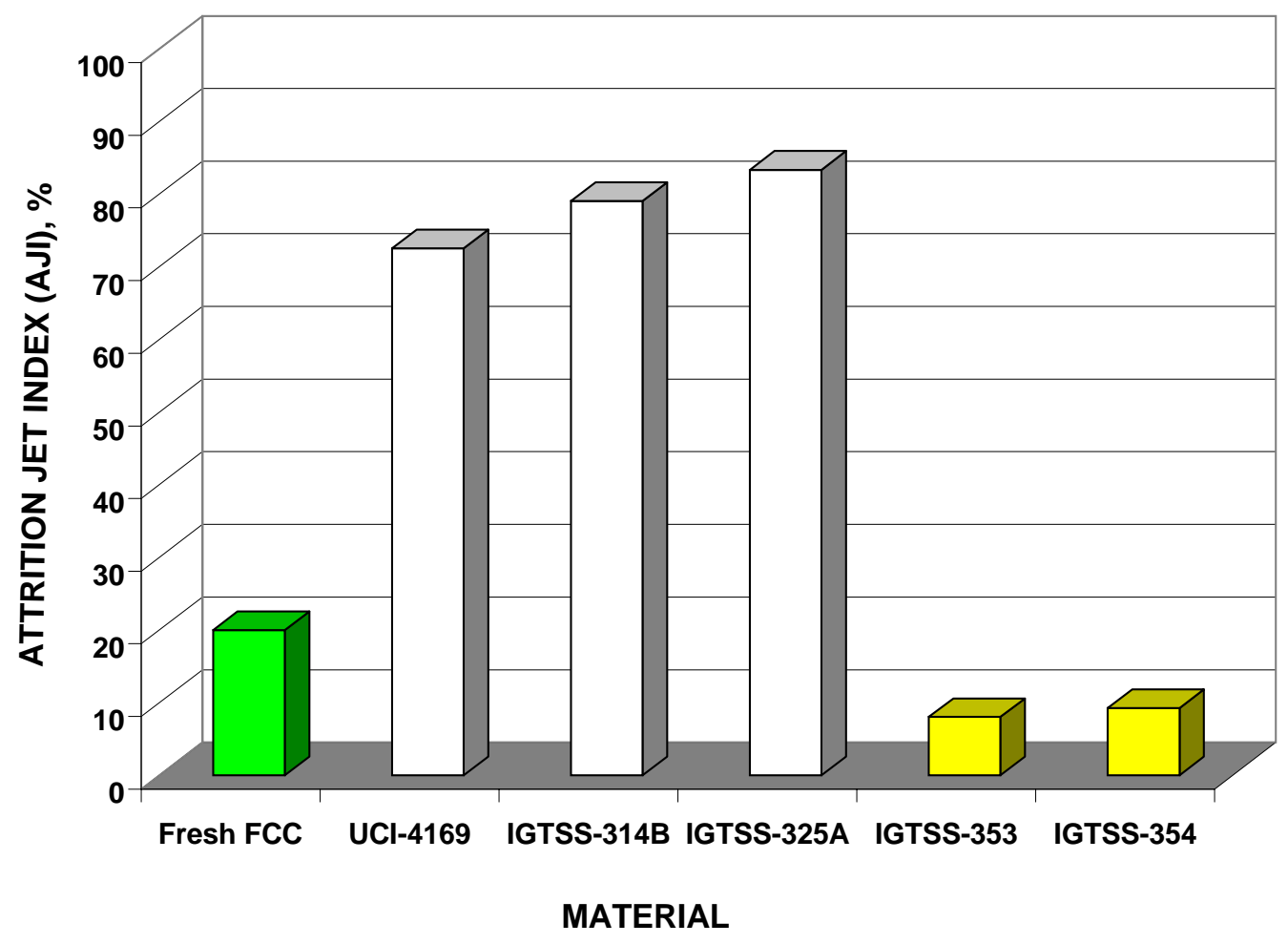

Figure 50. Attrition Resistance of New and Conventional ZnO-Based Sorbents (5-hr Loss) 


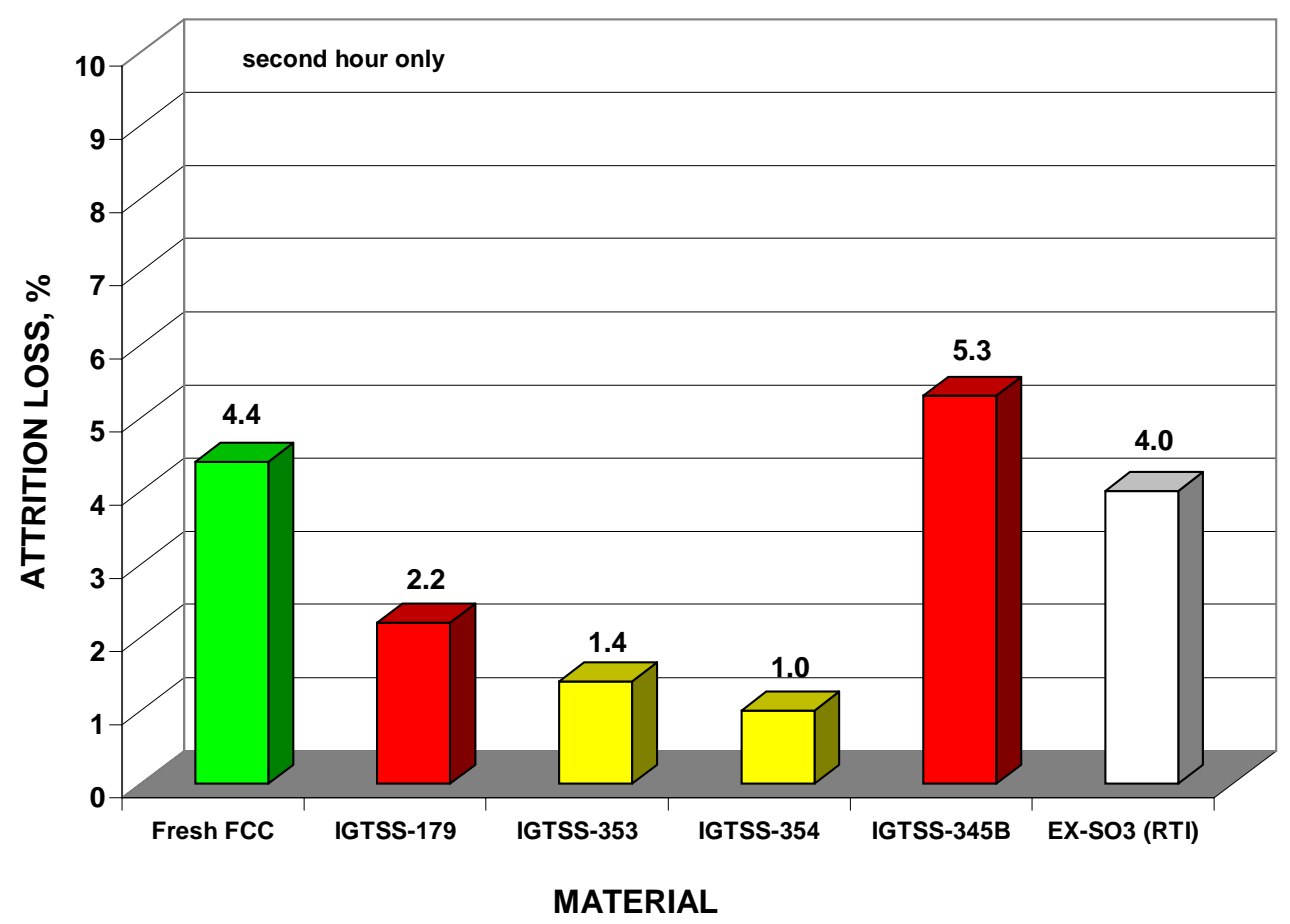

Figure 51. Attrition Resistance of Selected Sorbents $\left(2^{\text {nd }} \mathrm{hr}\right.$ Only $)$

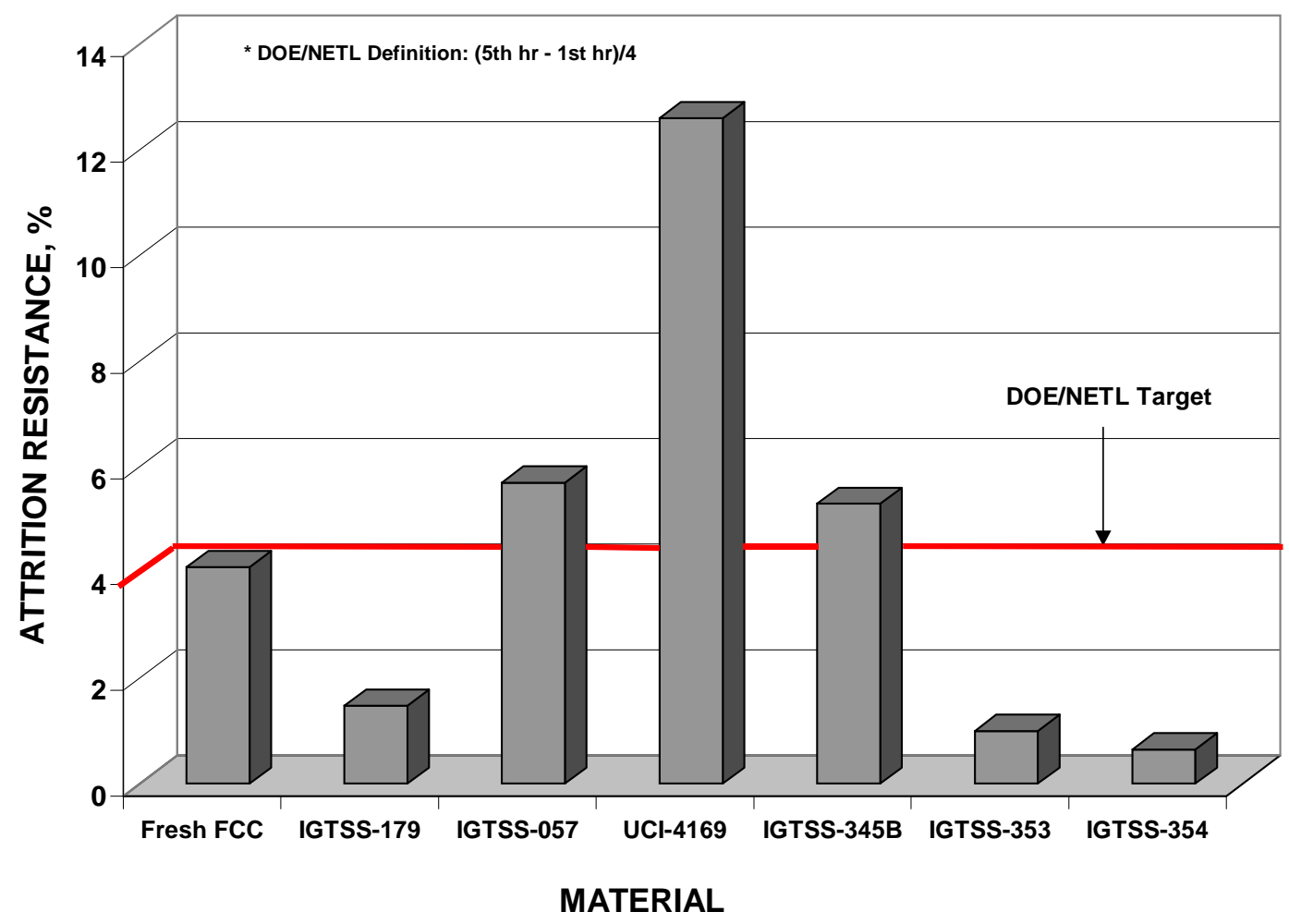

Figure 52. Attrition Resistance of Selected Sorbents 


\section{Evaluation of Chemical Reactivity, Regenerability, and Durability}

All eleven (11) sol-gel-derived sorbents prepared in this program (see Table 12) were evaluated for their reactivity towards $\mathrm{H}_{2} \mathrm{~S}$ in the packed-bed reactor. The extent of evaluation of each sorbent (i.e., number of cycles, parametric studies, etc.) depended on the performance of the sorbent. The most promising sorbents were also evaluated in the fluidized-bed reactor. The ranges of operating conditions used during sorbent evaluation are presented in Table 14. The results of evaluation of the sorbents are discussed below.

Table 14. Ranges of Operating Parameters

\begin{tabular}{ll}
\hline Operating Parameters & Ranges of Operating Parameters \\
\hline Sorbent Size, $\mu \mathrm{m}$ & $425-600$ (Packed-Bed) \\
& $45-180$ (Fluid-Bed) \\
Sulfidation Temperature, ${ }^{\circ} \mathrm{C}$ & $350-550$ \\
Sulfidation Space Velocity, $\mathrm{hr}^{-1}$ & $2000-5000$ \\
Sulfidation Gas Composition, Vol\% & \\
$\mathrm{CO}_{2}$ & $0-10$ \\
$\mathrm{CO}$ & $0-20$ \\
$\mathrm{H}_{2}$ & $10-40$ \\
$\mathrm{H}_{2} \mathrm{O}$ & $10-11$ \\
$\mathrm{H}_{2} \mathrm{~S}$ & $1-2$ \\
$\mathrm{~N}_{2}$ & Balance \\
Regeneration Temperature, ${ }^{\circ} \mathrm{C}$ & $480-650$ \\
Regeneration Space Velocity, hr ${ }^{-1}$ & $2000-5000$ \\
Regeneration Gas Composition, Vol\% & \\
$\mathrm{O}_{2}$ & $2-9$ \\
$\mathrm{H}_{2} \mathrm{O}$ & $0-10$ \\
$\mathrm{~N}_{2}$ & balance \\
\hline
\end{tabular}

\section{IGTSS-349}

The results obtained from packed-bed testing of the first sol-gel-derived sorbent prepared in this program (i.e., IGTSS-349) is shown in Figure 53. This sorbent has a nominal $\mathrm{ZnO}$ content of about $10 \mathrm{wt} \%$, which corresponds to a theoretical sulfur capacity of $3.95 \%$. As shown in Figure 53, this sorbent achieved near complete conversion of $\mathrm{ZnO}$ in the packed-bed, which is indicative of very high sulfidation reactivity. This sorbent was regenerated at $650^{\circ} \mathrm{C}$ using a dry $\mathrm{O}_{2}-\mathrm{N}_{2}$ mixture; however, because of the heat generated by the exothermic regeneration reaction and the exposure of this sorbent to temperatures higher than $750^{\circ} \mathrm{C}$, the effectiveness of this sorbent in subsequent sulfidation tests was reduced by about 50\%. Given its low $\mathrm{ZnO}$ content, no further evaluation was performed with this sorbent and the efforts were directed towards preparation of higher capacity sorbents. 


\section{IGTSS-350}

Following the encouraging results obtained with the low-capacity IGTSS-349 sorbent, IGTSS-350 was prepared containing $40 \% \mathrm{ZnO}$. However, this sorbent exhibited very low reactivity during the first cycle and no further testing was performed on this sorbent. Initially, the unexpected low reactivity observed with this sorbent was attributed to its high $\mathrm{ZnO}$ content. Consequently, efforts were directed towards determination of the optimum $\mathrm{ZnO}$ content for sol-gel-derived sorbents.

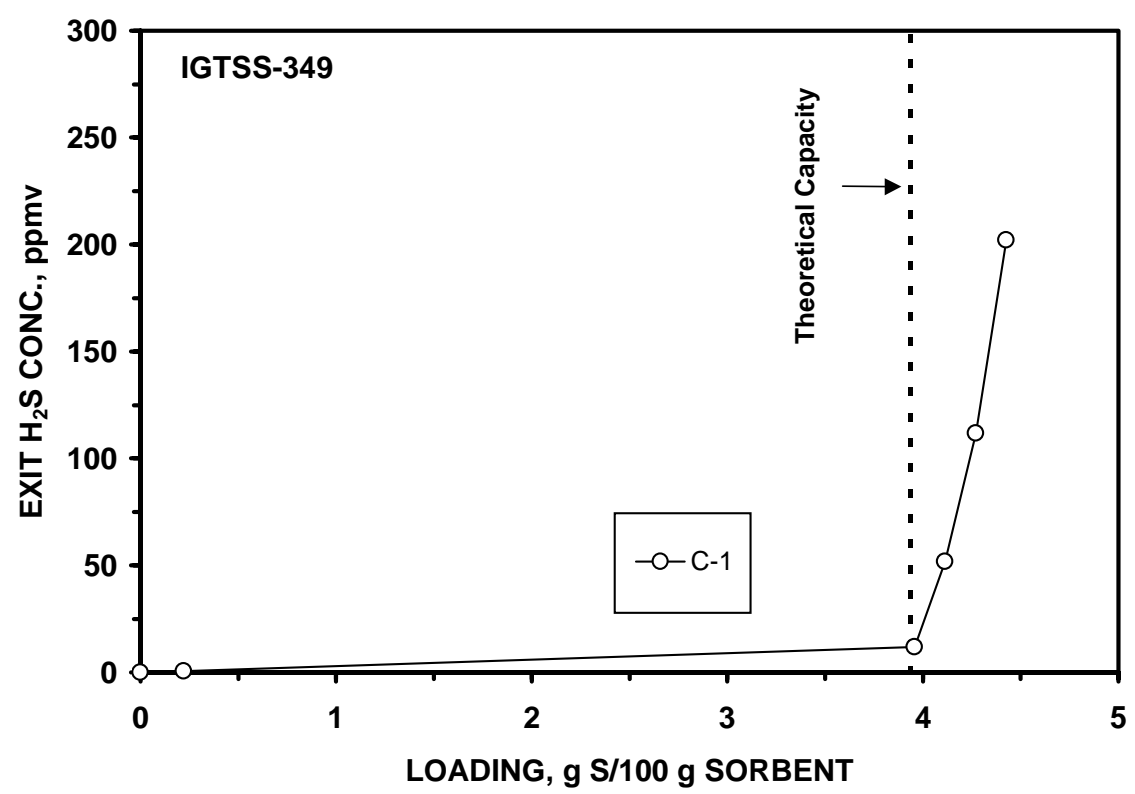

Figure 53. Sulfidation Performance of IGTSS-349 Sorbent

\section{IGTSS-351}

This sorbent which contains about $20 \% \mathrm{ZnO}$ also exhibited very high reactivity, achieving complete conversion at $450^{\circ} \mathrm{C}$ during the first sulfidation. However, the reactivity of this sorbent declined by about $25 \%$ following regeneration at $650^{\circ} \mathrm{C}$. This result further confirmed that regeneration of this sorbent at an initial temperature of $650^{\circ} \mathrm{C}$ (peak temperature above $750^{\circ} \mathrm{C}$ ) will have an adverse effect on the effectiveness of the sorbent. Based on the results obtained with this sorbent, it was decided to increase the $\mathrm{ZnO}$ content of the sorbents to $30 \%$ while limiting the regeneration temperature to $600^{\circ} \mathrm{C}$.

\section{IGTSS-353}

The results of six (6) cycles of sulfidation/regeneration performed with this sorbent, which contains $30 \% \mathrm{ZnO}$, are presented in Figure 54. This sorbent was regenerated at $593^{\circ} \mathrm{C}\left(1100^{\circ} \mathrm{F}\right)$ using a $\mathrm{O}_{2}-\mathrm{N}_{2}$ gas mixture, achieving a peak temperature below $650^{\circ} \mathrm{C}$ during regeneration. As shown in Figure 54, this sorbent exhibited excellent reactivity towards $\mathrm{H}_{2} \mathrm{~S}$, achieving a sulfur loading of 6-7\% over the six cycles completed without any loss of reactivity. 
A second series of tests consisting of four cycles was conducted with this sorbent to investigate the effect of regeneration condition on the performance of the sorbent. The parameters investigated included the effect of temperature $\left(538\right.$ versus $\left.593^{\circ} \mathrm{C}\right)$ as well as the effect of addition of steam (10\%) to the regeneration gas. Figure 55 shows that the regeneration temperature in the range of $538-593^{\circ} \mathrm{C}$ does not affect the performance of the sorbent. The $\mathrm{SO}_{2}$ released during these regeneration tests are presented in Figure 11, indicating that the theoretical (i.e., based on stoichiometry) concentration of $\mathrm{SO}_{2}$ can be achieved in this temperature range.

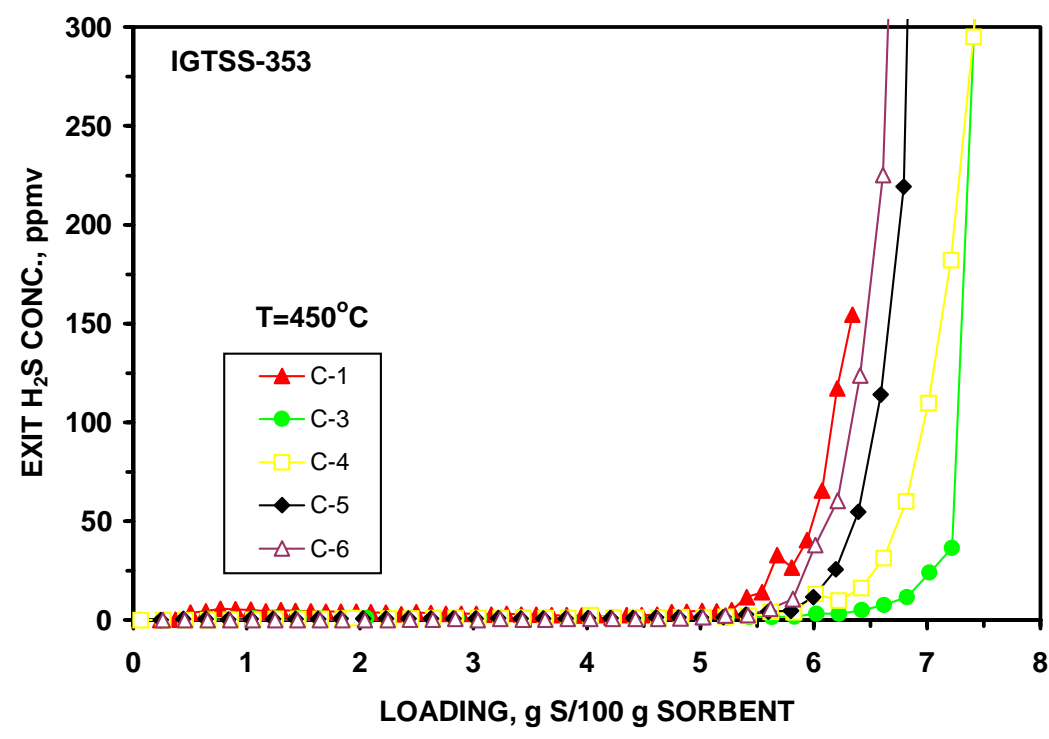

Figure 54. Performance of IGTSS-353 Sorbent

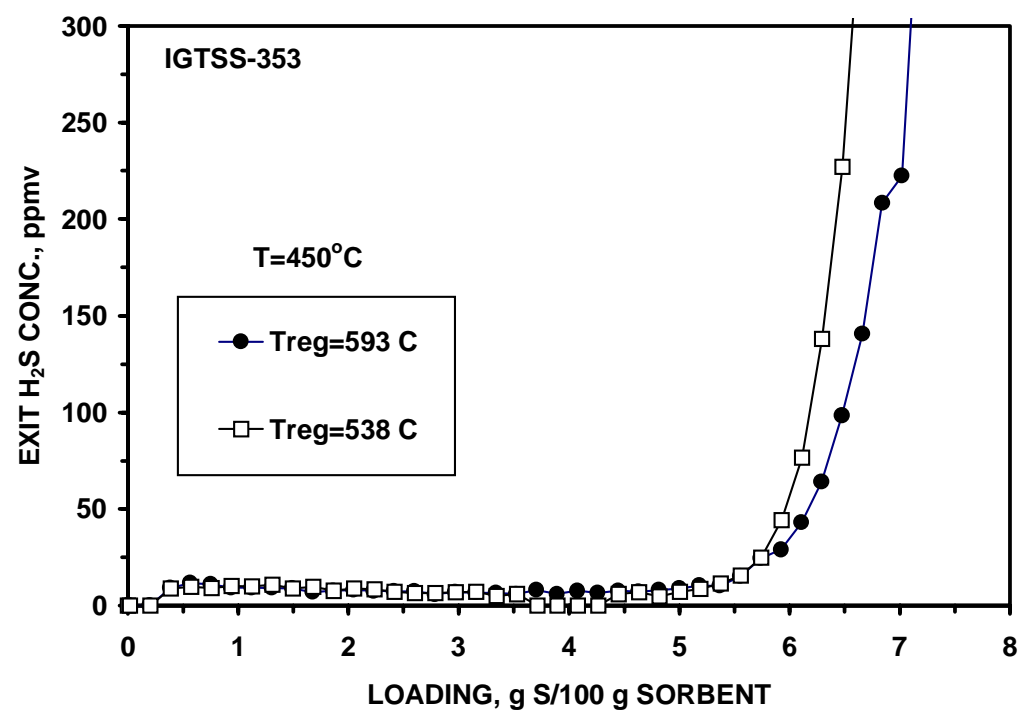

Figure 55. Performance of IGTSS-353 Following Different Regeneration Temperatures 


\section{IGTSS-354}

To improve the tolerance of the sorbent for exposure to high temperature, the IGTSS-354 was prepared by modifying the IGTSS-353 formulation through addition of a non-titania material to the sorbent. The results of ten (10) cycles completed with this sorbent at $450^{\circ} \mathrm{C}$ are presented in Figure 57, indicating that the effective sulfur capacity of this sorbent was maintained in the cyclic process. The lower effective capacity in cycle 9 is the result of incomplete regeneration in the preceding cycle, which was carried out at $538^{\circ} \mathrm{C}$ with a dry $\mathrm{O}_{2}-\mathrm{N}_{2}$ gas mixture. Although the effective sulfur capacity improved in the subsequent cycle (i.e., S-10), which followed a regeneration at $593^{\circ} \mathrm{C}$, because of possible sulfate formation during regeneration at the lower temperature, the effective sulfur capacity was not fully restored.

The $\mathrm{H}_{2} \mathrm{~S}$ and $\mathrm{SO}_{2}$ concentrations in the reactor effluent during a typical sulfidation/regeneration cycle are presented in Figure 58. The feed gas during the sulfidation test contained $2 \% \mathrm{H}_{2} \mathrm{~S}$. The results indicate excellent sulfur balance achieved in these tests, confirming the observed sulfur loading during sulfidation. The results of chemical analysis indicated a sulfur loading of $9 \%$ (sulfide S) at the reactor entrance after sulfidation and $0.2 \%$ (sulfate $\mathrm{S}$ ) after regeneration, which are also consistent with the experimental results, which indicate an average sulfur loading of about $7 \%$ and complete regeneration.

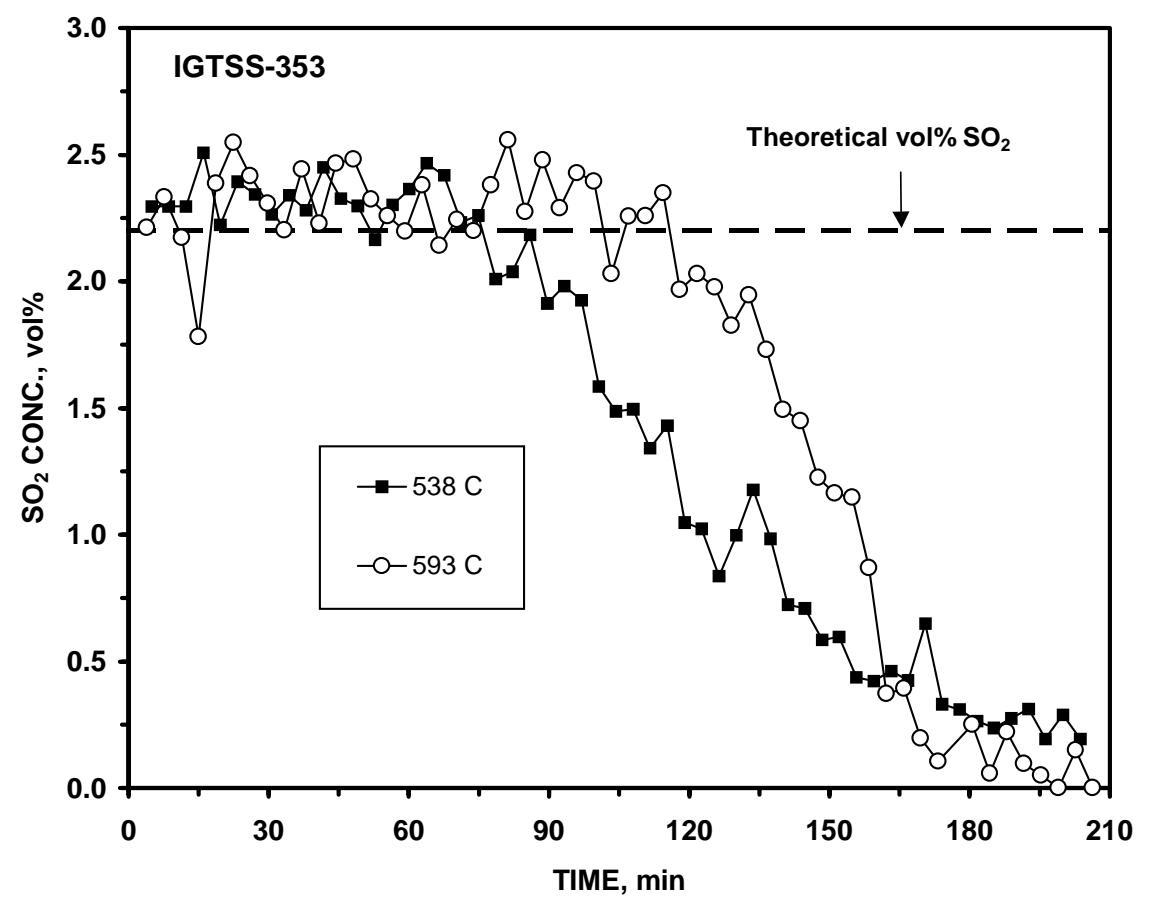

Figure 56. Regeneration of IGTSS-353 at Different Temperatures 


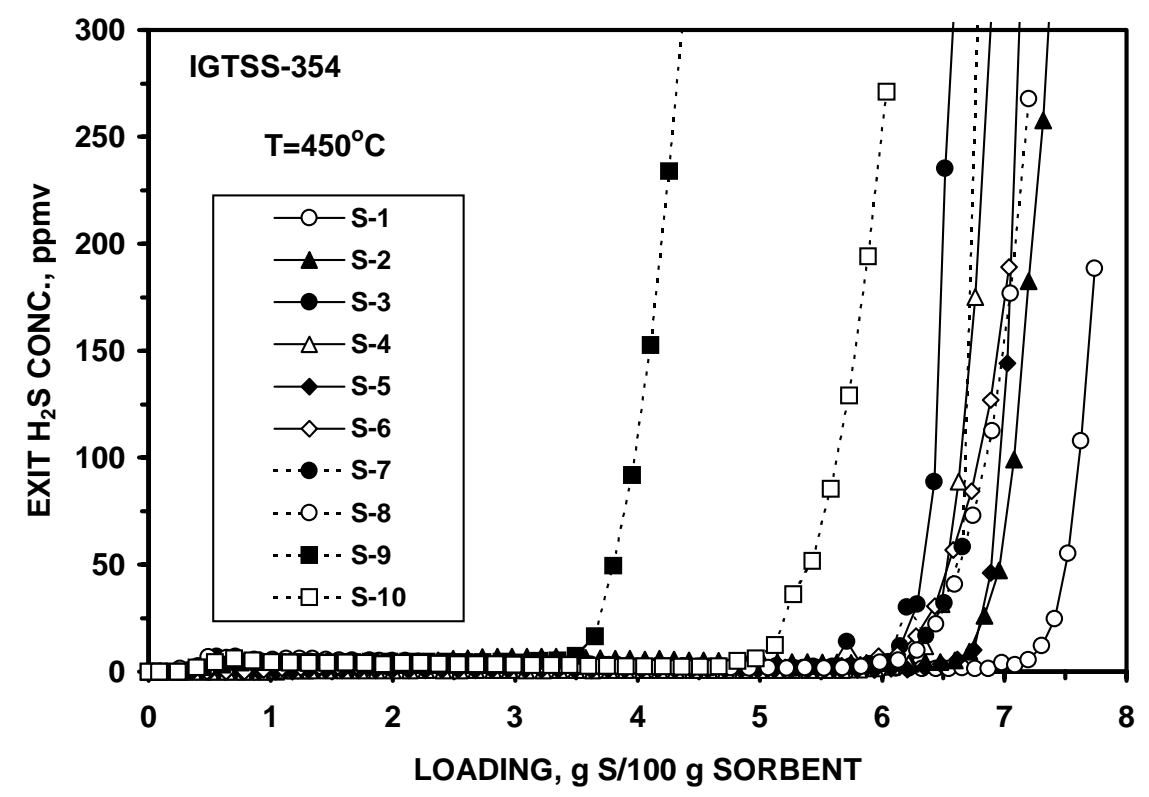

Figure 57. Performance of IGTSS-354 Sorbent

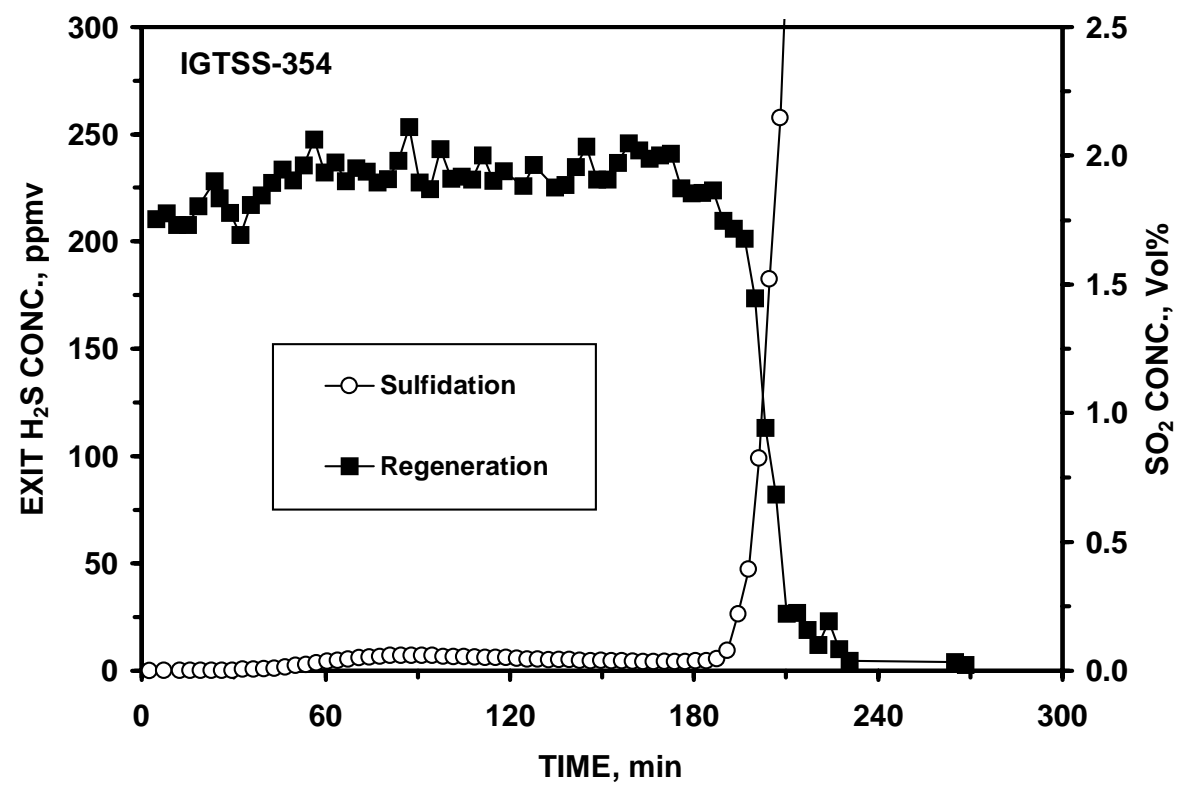

Figure 58. Sulfur Balance in a Typical Sulfidation/Regeneration Cycle

The effects of temperature and steam content of the regeneration gas on the regenerability of the IGTSS-354 sorbent are shown in Figures 59 and 60. The results indicate that the sorbent can be fully regenerated at $593^{\circ} \mathrm{C}$ with or without steam; however, to fully regenerate the sorbent at $538^{\circ} \mathrm{C}$, the presence of steam in the regeneration gas is required. 
To ensure reproducibility of the sorbent preparation procedure, a second batch of the IGTSS-354 sorbent was prepared and evaluated over two cycles. The results of these tests are presented in Figure 61, which are similar to those obtained with the first batch of IGTSS-354 sorbent presented earlier in Figure 57.

The performance of the IGTSS-354 sorbent in the fluidized-bed reactor was also determined over four cycles. The results of these tests are shown in Figure 62, indicating that the sorbent achieved an effective sulfur loading of about $6 \%$ at $450^{\circ} \mathrm{C}$ in the fluidized-bed reactor, where the gas residence time was less than one second.

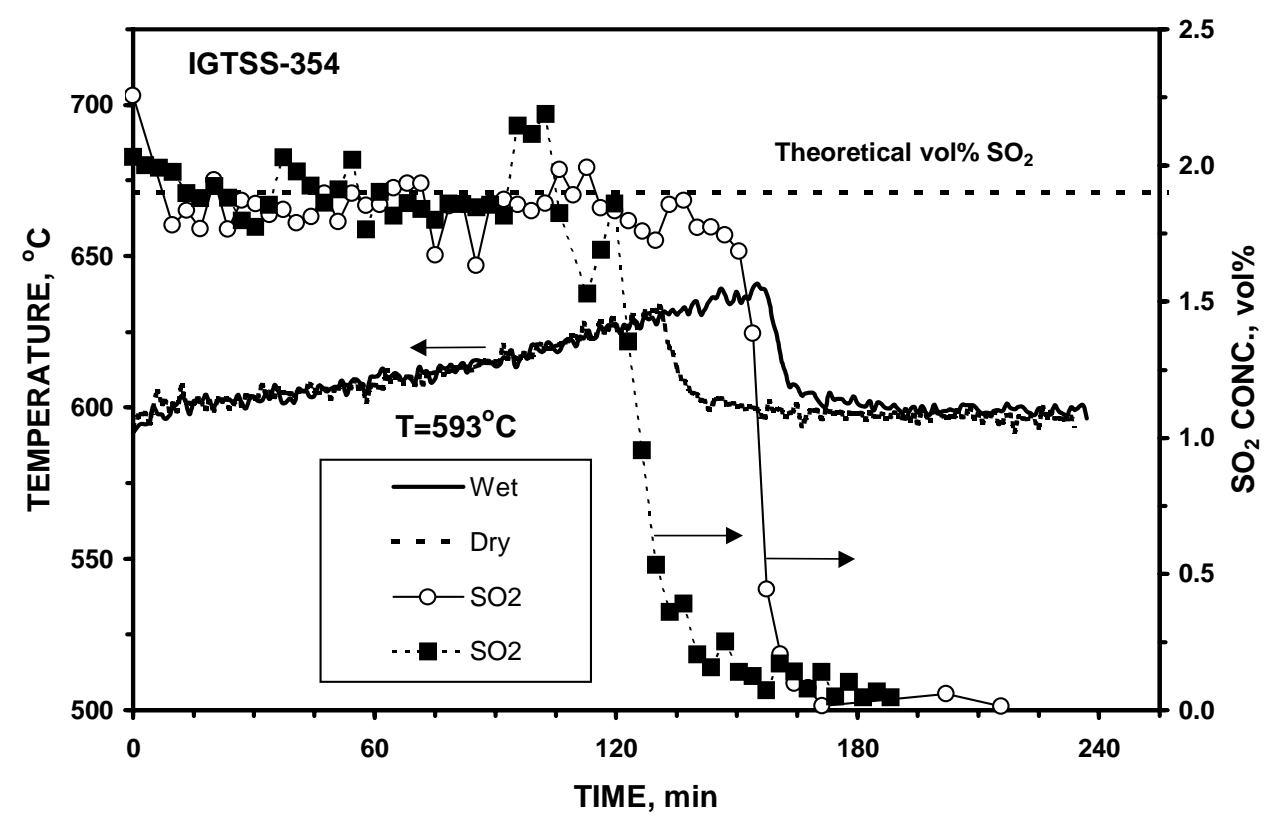

Figure 59. Effect of Steam on Regenerability of IGTSS-354 Sorbent

\section{IGTSS-355}

The effect of exposure to high temperature on the performance of these sol-gelderived sorbents was investigated by preparing the IGTSS-355 sorbent, which is similar to the IGTSS-353 sorbent, except that it was exposed to a calcination temperature of $750^{\circ} \mathrm{C}$ during sorbent preparation. Evaluation of sulfidation reactivity of this sorbent in the packed-bed reactor resulted in an effective sulfur capacity of less than $2 \%$, confirming the detrimental effect of exposure to temperatures above $750^{\circ} \mathrm{C}$. Analysis of the physical properties of this sorbent indicated that its mercury surface area is about 2 orders of magnitude lower than that of the IGTSS-353 sorbent.

\section{IGTSS-356}

The effect of calcination temperature on the sorbent performance was further investigated by preparing the IGTSS-356 sorbent, which is also similar to the IGTSS353 , except that this sorbent was calcined at $650^{\circ} \mathrm{C}$, which is the highest temperature expected during sorbent regeneration. The effective sulfur capacity of this sorbent was determined in the packed-bed at $450^{\circ} \mathrm{C}$ and was found to be similar to that of IGTSS-353. 
The results obtained with IGTSS-355 and IGTSS-356 indicate that the sorbent can maintain its high effective sulfur capacity as long as the sorbent is exposed to temperatures below $650^{\circ} \mathrm{C}$.

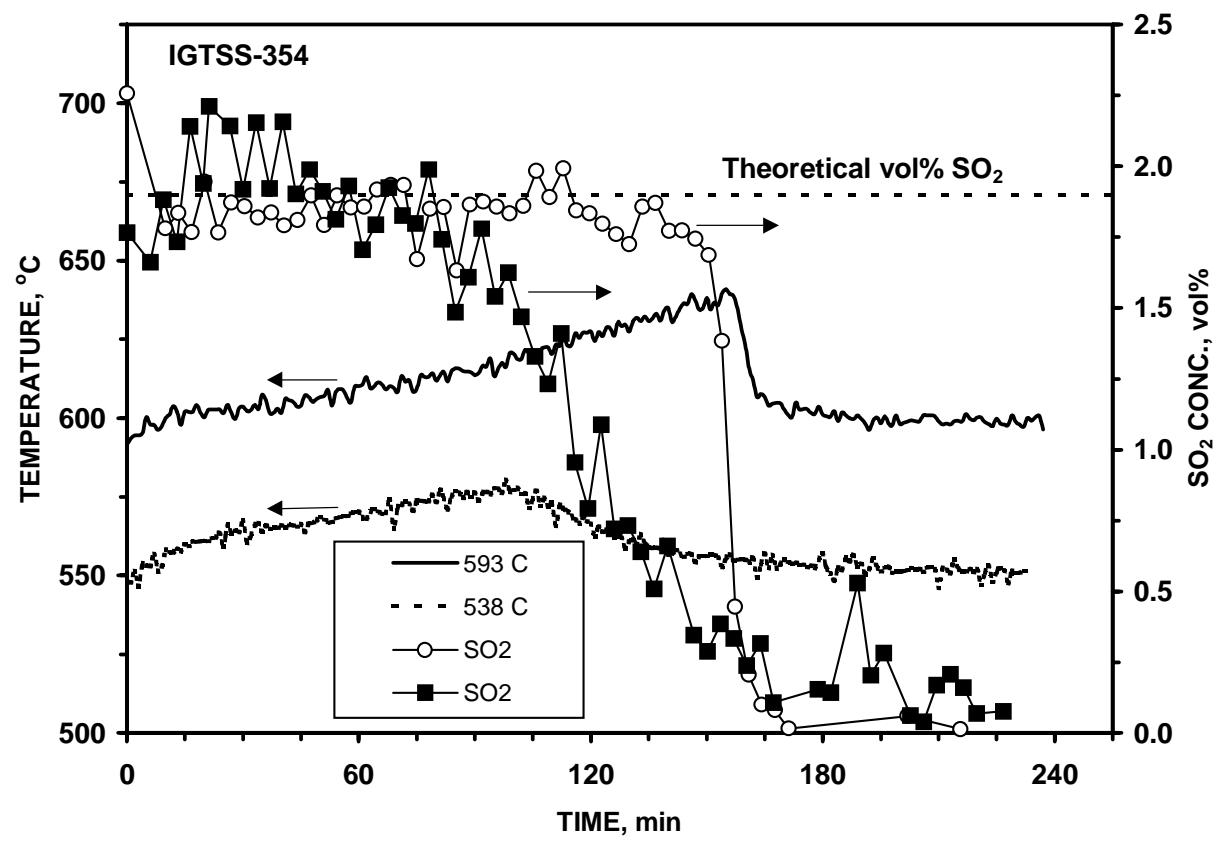

Figure 60. Effect of Temperature on Regenerability of IGTSS-354 Sorbent

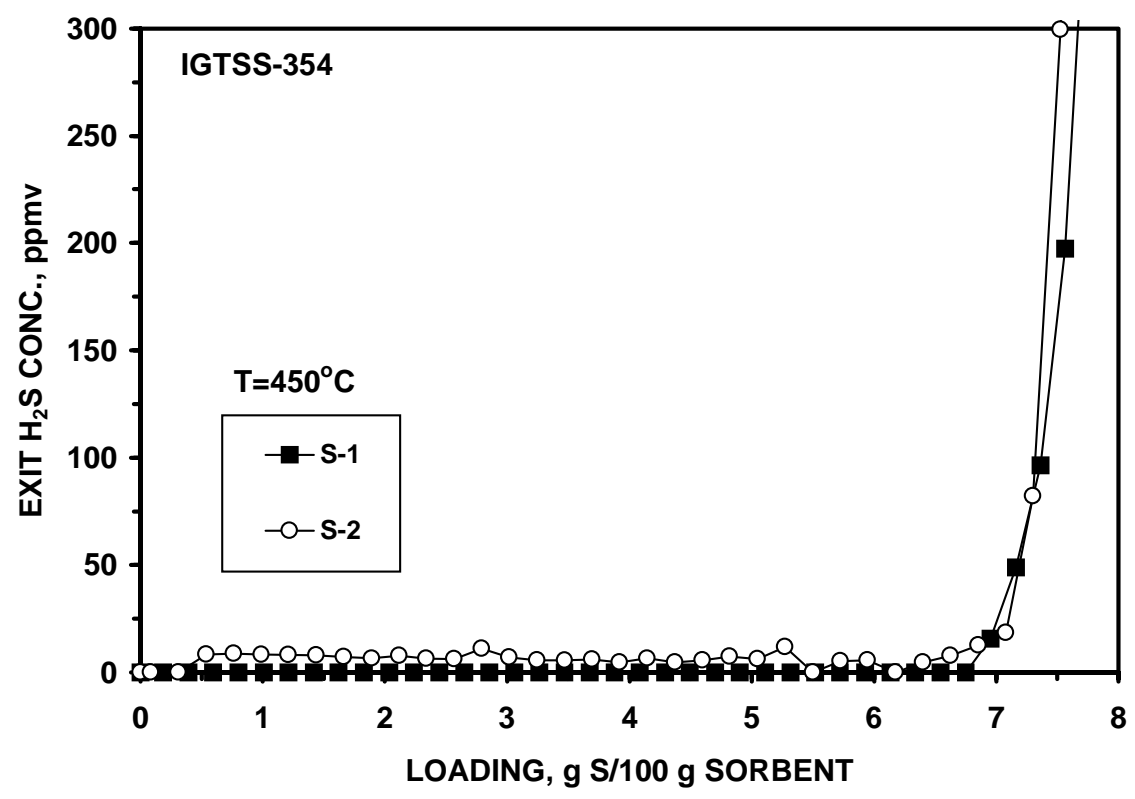

Figure 61. Performance of IGTSS-354 Sorbent ( $2^{\text {nd }}$ Batch) 


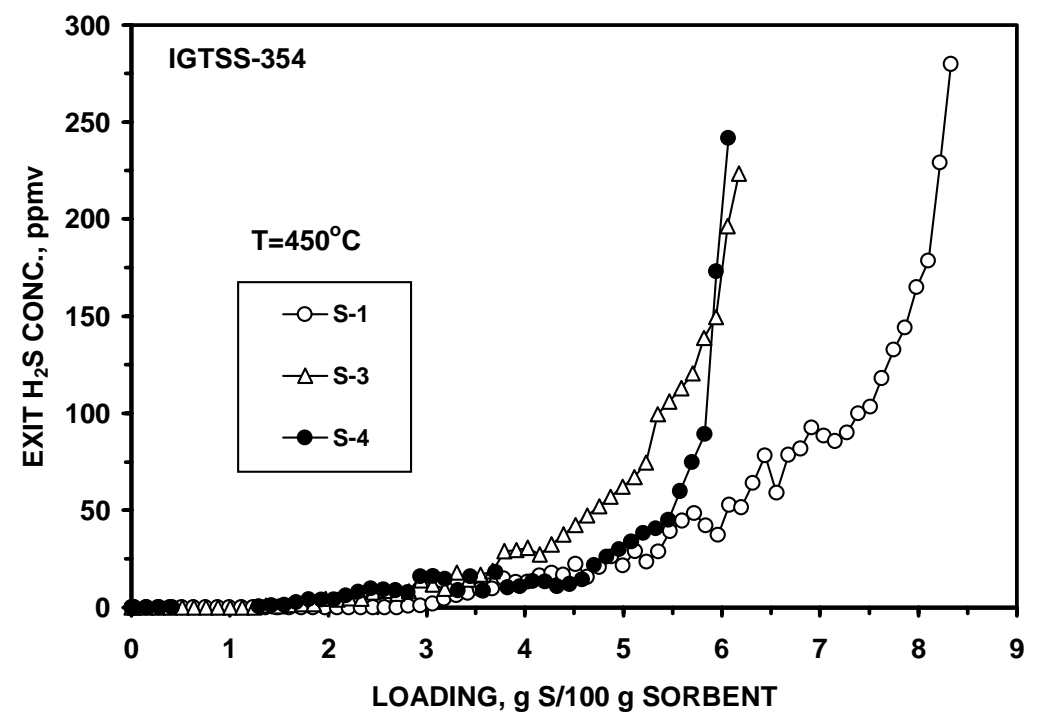

Figure 62. Performance of IGTSS-354 Sorbent in Fluidized-Bed Reactor

\section{IGTSS-357}

This sorbent which contains about $30 \% \mathrm{ZnO}$ and a non-titania support, was prepared to investigate the suitability of alternative support materials. The performance of this sorbent over four cycles at $450^{\circ} \mathrm{C}$ is presented in Figure 63. These results indicate that although the effective sulfur capacity of this sorbent during the first cycle is comparable to that of the IGTSS-353 sorbent, the effective sulfur capacity decreases in subsequent cycles to about $4 \%$. This decline in the performance of the sorbent is probably due to changes in the physical and chemical properties of the sorbent in the cyclic process.

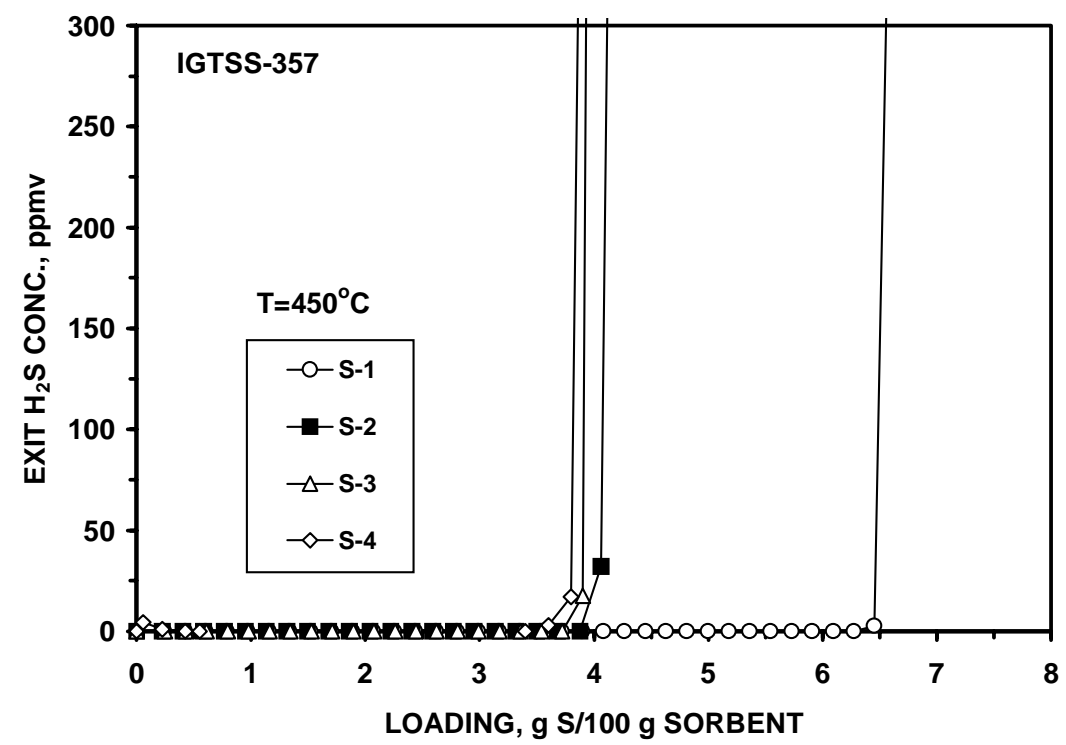

Figure 63. Performance of IGTSS-357 Sorbent 


\section{$\underline{\text { IGTSS-358 }}$}

This sorbent also contained $30 \% \mathrm{ZnO}$ and another non-titania support. However, evaluation of this sorbent in the packed-bed reactor resulted in immediate breakthrough, indicating the reactivity of this sorbent towards $\mathrm{H}_{2} \mathrm{~S}$ is very low.

\section{IGTSS-359}

Given the excellent results obtained with the IGTSS-354 sorbent, the preparation procedure was simplified to reduce the number of steps to lower the sorbent preparation costs. These efforts resulted in the IGTSS-359 sorbent, which was shown to have similar attrition resistance and effective sulfur capacity compared to the IGTSS-354 sorbent. The performance of the IGTSS-359 sorbent in the temperature range of 350 to $550^{\circ} \mathrm{C}$ is shown in Figure 64, indicating that the sorbent can maintain its high sulfur capacity even at $350^{\circ} \mathrm{C}$. The $\mathrm{SO}_{2}$ concentration and the reactor temperature during regeneration are presented in Figure 65, indicating improved regenerability for IGTSS-359 (sharper $\mathrm{SO}_{2}$ concentration profile) compared to the IGTSS-354 sorbent.

\section{$\underline{\text { IGTSS-360 }}$}

Given the unexpectedly low effective sulfur capacity observed with IGTSS-350 and the adverse effect of exposure to high temperature on the performance of the sorbents, it was postulated that the low reactivity of IGTSS-350 might have been due to exposure to high temperature during the preparation step. Consequently, IGTSS-360 was prepared containing $40 \% \mathrm{ZnO}$, while the calcination temperature was closely controlled below $650^{\circ} \mathrm{C}$. The results of three sulfidation cycles carried out at $450^{\circ} \mathrm{C}$ with this sorbent formulation are presented in Figure 66, indicating that the effective sulfur capacity of this sorbent is generally higher than those of IGTSS-353 and IGTSS-354, which should be attributed to the higher $\mathrm{ZnO}$ content of the IGTSS-360 sorbent.

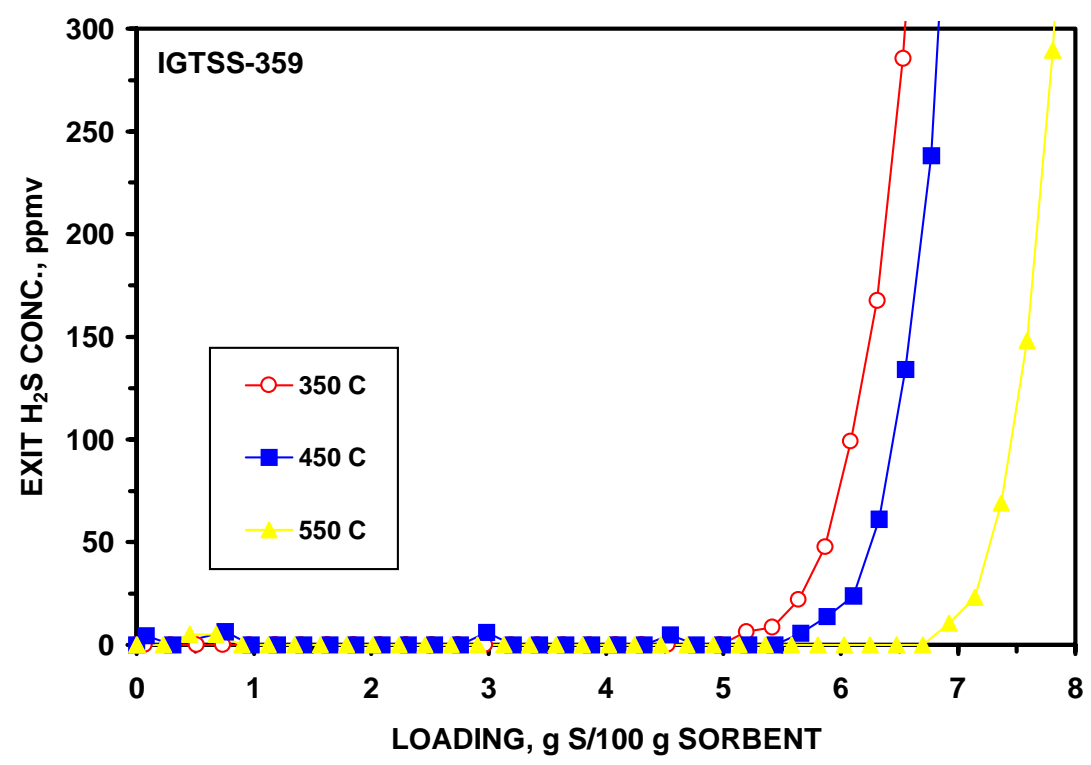

Figure 64. Performance of IGTSS-359 Sorbent 


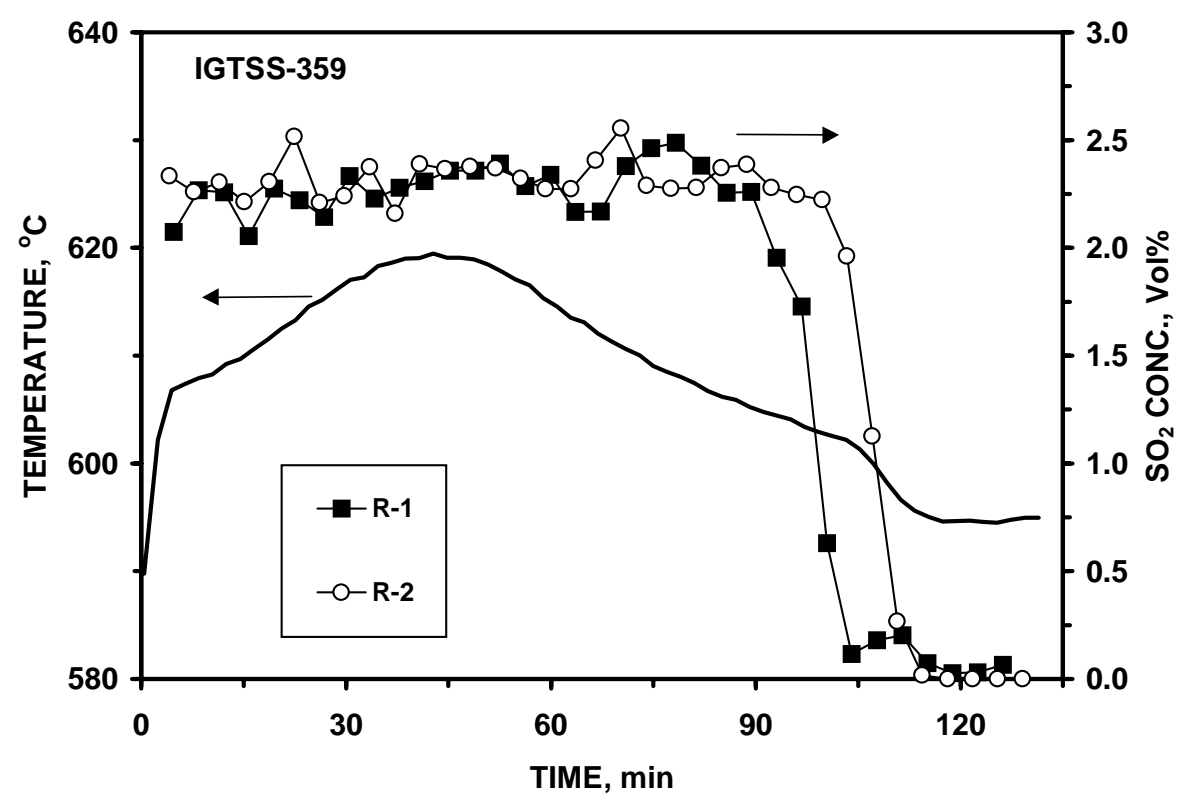

Figure 65. Temperature and $\mathrm{SO}_{2}$ Profiles during Regeneration of IGTSS-359 Sorbent

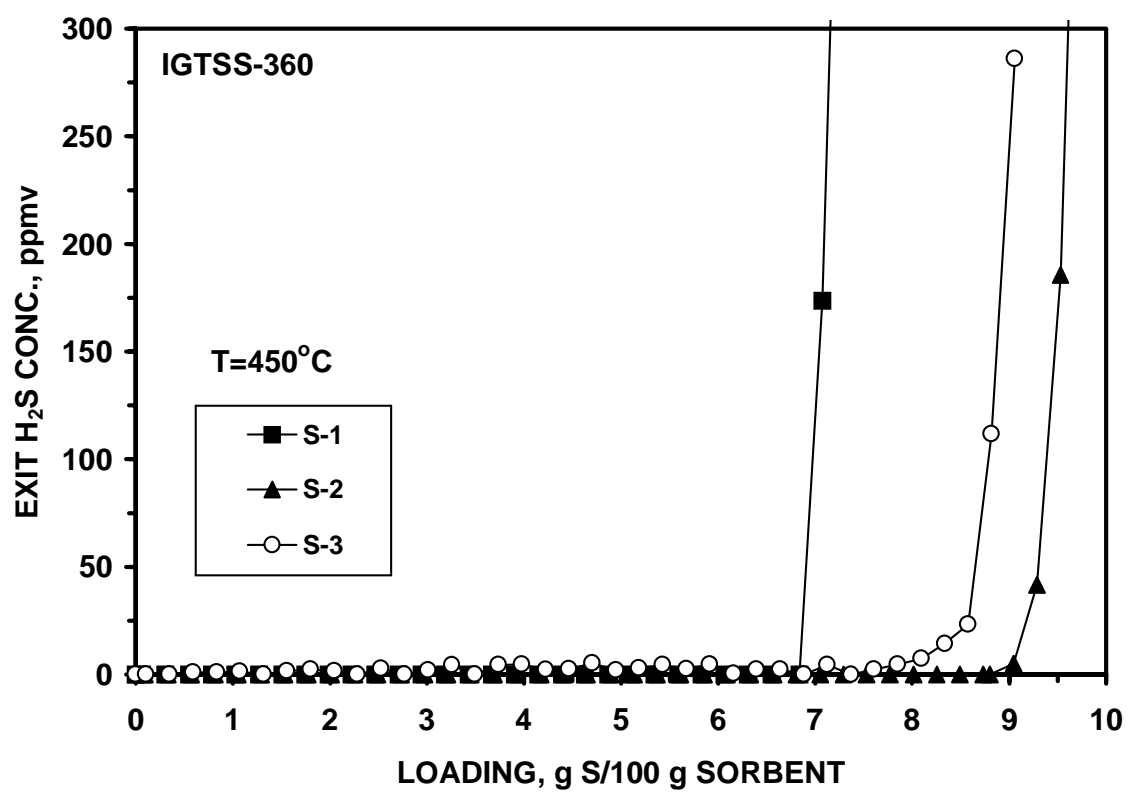

Figure 66. Performance of IGTSS-360 Sorbent 


\section{SORBENT PRODUCTION BY COMMERCIAL MANUFACTURERS}

As indicated earlier in this report, work in the early part of this project was directed towards the development of regenerable sorbents for the fluidized-bed application in general. However, because the only remaining Clean Coal Technology Demonstration Program utilizes transport reactor technology for hot fuel gas desulfurization, work in the latter part of this program was directed toward development of sorbents for the specific desulfurization application in the transport reactor system.

Although high reactivity, superior attrition resistance, and excellent durability were demonstrated for a number of sorbents, in order to move these leading sorbents towards the IGCC demonstration stage at the Piñon Pine facility, the U.S. DOE, the M. W. Kellogg (MWK), and the Sierra Pacific Power Company (SPPC) require that the sorbent be produced by a commercial sorbent manufacturer and its effectiveness evaluated according to a precise test protocol developed by USDOE/NETL. ${ }^{73}$

Based on the results obtained in this program, three sorbent formulations were selected as potentially-suitable candidates for the transport reactor application. These sorbents included IGTSS-326A, IGTSS-345B, and IGTSS-354. IGTSS-326A is a copper-based sorbent, while IGTSS-345B is a mixed copper- and zinc-oxide based sorbent, both produced by Method II.

The IGTSS-354 is a zinc-based sorbent produced by a modified sol-gel technique (i.e., Method III). Among these three sorbents, the IGTSS-354 had the best combination of attrition resistance, chemical reactivity, and fluidization behavior. However, it requires a special manufacturing technique.

The IGTSS-345B exhibited good fluidization behavior and chemical reactivity, however, the attrition loss of the sample prepared at IGT was slightly above that required in the test protocol. However, because this sorbent was to be produced by a spray-drying technique (rather than the granulation technique used at IGT laboratories), it was anticipated that the sorbent produced commercially would have improved attrition resistance to meet the requirement for the transport reactor application.

Although the IGTSS-326A sorbent produced at IGT exhibited undesirable fluidization behavior in the small batch unit, it was believed that spray-drying would improve the fluidization behavior of the sorbent. This stems from the fact that shorter sorbent induration time during spray-drying in the commercial unit will reduce copper migration and accumulation at the surface of the sorbent, and consequently will reduce the attractive inter-particle forces, leading to improved fluidization behavior of the sorbent. In addition, as indicated earlier, the fluidization behavior of this sorbent improves with increasing gas velocity. Therefore, it is logical to assume that this sorbent may be quite suitable for transport reactor application provided that the operating conditions for evaluation of the sorbent closely simulate those prevailing in the transport reactor. 
Arrangements were made, under a confidentiality agreement, with United Catalyst, Inc. (UCI) to prepare 10 pounds of each of IGTSS-326A and IGTSS-345B according to IGT's preparation procedure, but using a spray-drying technique. A similar arrangement was also made with Contract Materials Processing, Inc. (CMP) to produce 20 pounds of IGTSS-354 sorbent. The commercially-produced sorbents were evaluated for their attrition resistance, chemical reactivity, and fluidization behavior.

A comparison of the attrition resistance properties of the IGTSS-326A and IGTSS-345B produced at IGT and UCI is provided in Figure 67. As shown in this figure, the spray-dried sorbents produced by UCI have significantly higher attrition resistance than those produced at IGT, both significantly exceeding the requirement for the transport reactor application. However, particle size analysis of the commerciallyproduced IGTSS-354 sorbent (produced by CMP) indicated that $100 \%$ of its particles are smaller than 45 microns. The attrition resistance of this commercially produced material could not be determined by the ASTM 5757-95 technique because essentially all the materials are elutriated from the unit.

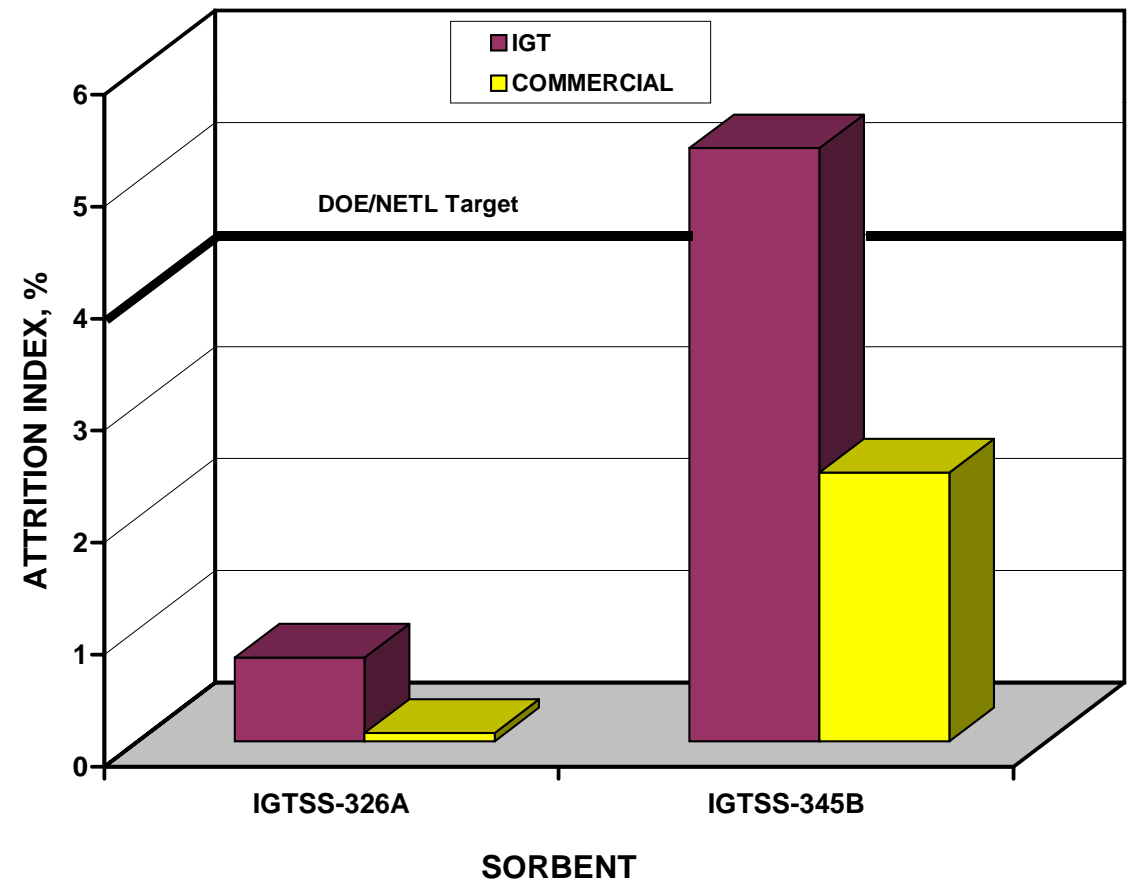

Figure 67. Comparison of Attrition Resistance of Sorbents Produced by IGT and Commercial Manufacturer

The effective sulfur capacities of the commercially-produced sorbents were also determined in the packed-bed reactor for comparison with those produced at IGT. The results are presented in Figure 68, indicating that the effective sulfur capacities of all commercially-produced sorbents are lower than those produced at IGT. In the case of IGTSS-326A and IGTSS-345B sorbents the effective sulfur capacities of the sorbents produced by UCI are only slightly lower than those produced at IGT. As indicated 
earlier, for the sorbent formulations produced by conventional preparation techniques, there is a trade-off between chemical reactivity and mechanical strength. The lower reactivity and higher attrition resistance exhibited by the commercially-produced sorbents (compared to those produced at IGT) are an indication of this trade-off between these sorbent properties. Despite the small particle size of the commercially-produced IGTSS354 (produced by CMP), this sorbent exhibited significantly lower reactivity and sulfur capacity, compared to those obtained with the sorbent produced at IGT, which should be attributed to the production technique used by CMP.

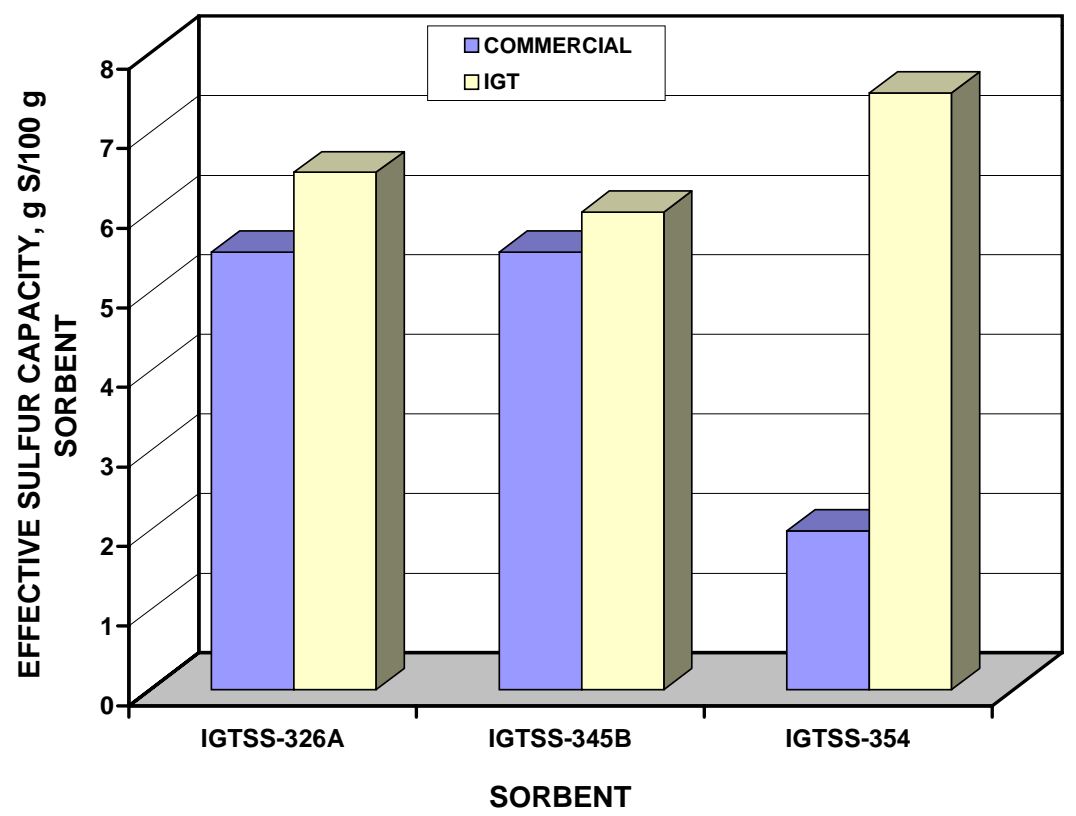

Figure 68. Comparison of Effective Sulfur Capacities of Sorbents Produced by IGT and Commercial Manufacturers

The commercially-produced IGTSS-326A and IGTSS-345B sorbents were evaluated for their fluidization behavior. However, fluidization of both of these spray-dried sorbents under bubbling fluidized-bed conditions appeared to be difficult. Efforts were directed toward determination of the ranges of operating conditions under which acceptable fluidization behavior can be maintained. In general, these efforts were similar to those previously attempted with the IGTSS-326A and IGTSS-345B formulations produced at IGT, which emphasized the development of further understanding of the agglomeration tendency of copper-based sorbents in reducing environments. Reduction/oxidation and sulfidation/regeneration tests were carried out in a fluidized-bed reactor involving both commercially-produced spray-dried sorbents in the 90-125 $\mu \mathrm{m}$ size range. Several parameters were investigated, including reduction/sulfidation temperature (300 to $550^{\circ} \mathrm{C}$ ), composition of reduction/sulfidation gas, and superficial gas velocity (20 to $45 \mathrm{~cm} / \mathrm{s})$. The results obtained and observations made suggest the following: 
(a) The commercially-produced copper-based IGTSS-326A and IGTSS-345B sorbents were found to be highly reactive in fluid-bed tests with a simulated KRW fuel gas, even at the low temperature of $300^{\circ} \mathrm{C}$, achieving an effective sulfur capacity of about $2 \mathrm{~g} \mathrm{~S} / 100 \mathrm{~g}$ sorbent at gas velocities corresponding to very short gas residence times of 0.1 to 0.15 second.

(b) In the range of gas velocities employed, achieving desirable fluidization behavior with the commercially-produced copper-based IGTSS-326A and IGTSS-345B sorbents alone, after undergoing reduction or simultaneous reduction/sulfidation, is also problematic. The fluidization behavior of the sorbents improved with increasing gas velocities, and may be expected to be problem-free at the much higher gas velocities prevailing in the transport reactor. However, because of the limitation of the batch reactor used in this project, higher gas velocities could not be used and it was not possible to determine the gas velocity beyond which good sorbent fluidization can be maintained during sulfidation.

(c) Although higher gas velocities generally improved the fluidization behavior of these sorbents, repeated cycling of the sorbent appears to have an adverse effect, requiring higher and higher gas velocities to prevent defluidization of the sorbent bed. This may be the result of metallic copper migration to the surface.

(d) Desirable fluidization behavior in the range of gas velocities investigated can be achieved by using the spray-dried IGTSS-326A and IGTSS-345B sorbents in combination with another material, such as a zinc-based sorbent or an inert (and cheaper) material (i.e., sand). However, there appeared to be a minimum amount of this secondary material that was required to ensure good fluidization of the physical mixture. Because it was desirable to maximize the fraction of the reactive sorbent in the mixture, it may not be feasible to achieve this while still meeting the minimum requirement of effective sulfur capacity.

(e) Similar to what was observed previously, because of its tendency to agglomerate, the sorbent bed de-fluidized during heat up to the regeneration temperature of 600 to $650^{\circ} \mathrm{C}$. To remedy this problem and closely simulate the sorbent transfer between the sulfider and the regenerator in Kellogg's transport reactor system, a fluid-bed reactor system was assembled that allowed addition of the sulfided sorbent to a preheated regeneration reactor. The gradual addition in small quantities of the sulfided sorbent to a preheated bed of fresh (or regenerated) sorbent maintained at the regeneration temperature proved successful. Also, this approach provided for better simulation of the much higher heatup rate of the sulfided sorbent as well as mixing of the sulfided and regenerated sorbents in the regeneration vessel of the transport reactor.

Based on the above results, although high reactivity and superior attrition resistance were demonstrated for the commercially-produced IGTSS-326A and IGTSS345B sorbents, it did not appear feasible to evaluate this sorbent under the experimental conditions specified in the DOE/NETL test protocol. This protocol was established for the screening of candidate sorbents prior to their demonstration at the IGCC Piñon Pine 
facility of the Sierra Pacific Power Company (SPPC). To a large extent, this protocol is tailored to zinc-based sorbents, which require lower fluidization velocities than copperbased sorbents. 


\section{CONCLUSIONS AND RECOMMENDATIONS}

During the course of this program, three different sorbent preparation approaches were investigated. These research approaches were designated as Method I, Method II, and Method III.

Method I concentrated on the preparation of highly dispersed metal oxide sorbent formulations using refractory supports/dispersants which are themselves highly resistant to sintering and deterioration. The rationale was that these low-capacity sorbents would have a high probability of maintaining good chemical reactivity and physical stability with cycling. A total of 66 sorbent formulations were prepared using Method I. The sorbents prepared using Method I were found to exhibit high reactivity toward $\mathrm{H}_{2} \mathrm{~S}$ along with acceptable durability in multi-cycle testing. Attempts were then made to improve the sulfur capacity of the prepared sorbents, using the same sorbent preparation technique. However, most of the sorbent formulations prepared with this approach lacked sufficient strength and/or reactivity toward $\mathrm{H}_{2} \mathrm{~S}$, necessitating an alternative sorbent preparation technique to be utilized.

In order to achieve sorbent stability at the highest possible effective sulfur capacity, secondary efforts were devoted to the preparation of sorbents having higher sulfur capacity and mechanical strength. This was accomplished by extending the application of a pelletization technique previously developed for the formulation of spherical pellets (dia. $=3-10 \mathrm{~mm}$ ) to the preparation of highly attrition-resistant granular sorbents (dia. $=50$ to $850 \mu \mathrm{m})$. This sorbent manufacturing technique was applied to prepare 113 formulations of $\mathrm{Cu}-, \mathrm{Fe}-, \mathrm{Mn}-$, and $\mathrm{Zn}$-based sorbents suitable for fluidizedbed application.

Based on the results of evaluation of sorbents prepared by the traditional Method II, the following conclusions are drawn:

- Fe-based sorbents: No sorbent based on iron oxide was found to have sufficient reactivity in the moderate temperature range.

- Mn-based sorbents: Encouraging results were obtained with sorbents based on manganese oxide; however, their regeneration necessitates very high temperatures that cannot be accommodated by current desulfurization systems requiring regeneration ignition temperatures of about $550^{\circ} \mathrm{C}$.

- Zn-based sorbents: The results obtained with zinc-based sorbents prepared using Method II suggest that although excellent effective sulfur capacity and $\mathrm{H}_{2} \mathrm{~S}$ removal efficiency can be achieved in the moderate temperature range of 350 to $550^{\circ} \mathrm{C}$, using traditional sorbent preparation techniques such as solid oxide mixing, coprecipitation, etc., may not be suitable for development of effective sorbents with 
sufficient attrition resistance required for a demanding commercial application, such as the Piñon Pine transport reactor.

- Cu-based sorbents: Only sorbents based on copper oxide were found to possess the best combination of high attrition resistance and sulfidation reactivity, sulfur removal efficiency, and pre-breakthrough conversion in the moderate temperature range of 350 to $550^{\circ} \mathrm{C}$.

Given the results obtained, two zinc-based sorbents (IGTSS-314B, IGTSS-325A), one manganese-based sorbent (IGTSS-057), and one copper-based sorbent (IGTSS-179) were selected for the bench-scale fluidized-bed tests in the high-pressure reactor. The results of these tests indicated that the copper-based IGTSS-179 was the only sorbent that could satisfy both the high attrition resistance and the high reactivity requirements for the transport reactor application. However, because fluidization of copper-based sorbents in the reducing fuel gas environment at low superficial velocities of bubbling fluidized-bed appeared to be problematic, additional efforts were directed toward further evaluation of copper-based sorbents in fluidized-bed reactors. These efforts resulted in the development of IGTSS-326A and IGTSS-345B sorbents, which exhibited improved fluidization behavior compared to the IGTSS-179 sorbent.

Given the results obtained with the sorbents prepared by the conventional Method II, there was a need for an alternative sorbent preparation approach that have been shown to produce mechanically strong, porous solids with median pore diameters in the range of interest. Review of the literature identified sol-gel processing as a promising technique for development of more effective sorbents.

Eleven (11) $\mathrm{ZnO}$-based sorbent formulations were prepared using a modified solgel approach (Method III). These sorbents exhibited unique properties that are unattainable by conventional sorbent preparation methods. This method eliminates the need for excessively high thermal treatment temperatures to impart the required physical strength and has made possible the achievement of the challenging combination of high reactivity (desirable pore size distribution and high surface area), high attrition resistance, and regenerability at lower temperature.

Based on the results obtained with this sorbent preparation technique, three zincbased sorbents (i.e., IGTSS-353, IGTSS-354, and IGTSS-360) demonstrated high chemical reactivity, regenerability at lower temperatures, and attrition resistance properties far exceeding the stringent requirement of the transport reactor application. The results of ASTM D5757-95 attrition tests indicate that the new sol-gel derived zincbased sorbents achieved attrition losses that are about 1/2 that of the FCC material, 1/10 those of the conventional bulk zinc-based sorbents, and 1/3 of the leading EX-SO3 sorbent.

Based on the results obtained in this program, three sorbent formulations were selected as potentially-suitable candidates for the transport reactor application. These 
sorbents included the copper-based IGTSS-326A, the mixed copper-and zinc-based IGTSS-345B, and the zinc-based IGTSS-354.

Although high reactivity, superior attrition resistance, and excellent durability were demonstrated for a number of sorbents, in order to move these leading sorbents towards the IGCC demonstration stage at the Piñon Pine facility, the U.S. DOE, the M. W. Kellogg (MWK), and the Sierra Pacific Power Company (SPPC) require that the sorbent be produced by a commercial sorbent manufacturer and its effectiveness evaluated according to a precise test protocol developed by USDOE/NETL.

Arrangements were made, under a confidentiality agreement, with United Catalyst, Inc. (UCI) to prepare 10 pounds of each of IGTSS-326A and IGTSS-345B according to IGT's preparation procedure, but using a spray-drying technique. A similar arrangement was also made with Contract Materials Processing, Inc. (CMP) to produce 20 pounds of IGTSS-354 sorbent. The commercially-produced sorbents were evaluated for their attrition resistance, chemical reactivity, and fluidization behavior.

Comparison of the attrition resistance properties of the IGTSS-326A and IGTSS345B produced at IGT and UCI indicated that the spray-dried sorbents produced by UCI have significantly higher attrition resistance than those produced at IGT, both significantly exceeding the requirement for the transport reactor application. However, particle size analysis of the commercially-produced IGTSS-354 sorbent (produced by CMP) indicated that $100 \%$ of its particles are smaller than 45 microns. The attrition resistance of this commercially produced material could not be determined by the ASTM 5757-95 technique because essentially all the materials are elutriated from the unit.

The effective sulfur capacities of the commercially-produced sorbents were also determined in the packed-bed reactor for comparison with those produced at IGT. The results indicated that the effective sulfur capacities of all commercially-produced sorbents are lower than those produced at IGT. In the case of IGTSS-326A and IGTSS-345B sorbents the effective sulfur capacities of the sorbents produced by UCI are only slightly lower than those produced at IGT. Despite the small particle size of the commerciallyproduced IGTSS-354 (produced by CMP), this sorbent exhibited significantly lower reactivity and sulfur capacity, compared to those obtained with the sorbent produced at IGT, which should be attributed to the production technique used by CMP.

The commercially-produced IGTSS-326A and IGTSS-345B sorbents were also evaluated for their fluidization behavior. However, fluidization of both of these spraydried sorbents under bubbling fluidized-bed conditions continued to be problematic. Efforts were directed toward determination of the ranges of operating conditions under which acceptable fluidization behavior can be maintained. The parameters investigated included reduction/sulfidation temperature $\left(300\right.$ to $\left.550^{\circ} \mathrm{C}\right)$, composition of reduction/sulfidation gas, and superficial gas velocity $(20$ to $45 \mathrm{~cm} / \mathrm{s}$ ). The results obtained and observations made suggest that in the range of gas velocities employed, achieving desirable fluidization behavior with the commercially-produced copper-based IGTSS-326A and IGTSS-345B sorbents alone, after undergoing reduction or simultaneous reduction/sulfidation, is also problematic. The fluidization behavior of the 
sorbents improved with increasing gas velocities, and may be expected to be problemfree at the much higher gas velocities prevailing in the transport reactor. However, because of the limitation of the batch reactor used in this project, higher gas velocities could not be used and it was not possible to determine the gas velocity beyond which good sorbent fluidization can be maintained during sulfidation.

Based on all the results obtained in this program, the $\mathrm{ZnO}$-based sorbents produced by sol-gel technique developed in this program exhibited the best attrition resistance that significantly exceeds the requirement for the transport reactor application. Furthermore, this class of sorbents showed excellent reactivity, regenerability at lower temperatures, and long-term durability.

To ensure successful commercialization of this class of sorbents, the preparation technique should be modified to make it readily adaptable to a large-scale production. Therefore, at the completion of this program, these efforts are continuing under the sponsorship of the Illinois Clean Coal Institute in coordination with DOE/NETL. 


\section{REFERENCES}

1. "MERC - Hot Gas Cleanup Process," Final Report, MERC/SP-78/2, Morgantown, W.V., 1978.

2. Joshi, D., Olson, T. H., Hayes, M. L. and Shah, "Hot Low-Btu Producer Gas Desulfurization in Fixed-Bed of Iron Oxide-Fly Ash," APCI Final Report to DOE, Contr. No. FE-77-2757-3, 1979.

3. Tamhankar, S. S., Hasatani, M. and Wen, C. Y., Chem. Eng. Sci. 6ㅜ, 1181-1191 (1981).

4. Grindley, T. and Steinfeld, G., "Development and Testing of Regenerable Hot Coal Gas Desulfurization Sorbents,” Final Report No. DOE/MC/16545-1125, 1981.

5. Jalan, V. and Wu, D., "High Temperature Desulfurization of Fuel Gases for Molten Carbonate Fuel Cell Power Plants," Paper presented at the National Fuel Cell Seminar, San Diego, CA, July 14-16, 1980.

6. Lew, S., "High-Temperature Regenerative $\mathrm{H}_{2} \mathrm{~S}$ Removal by $\mathrm{ZnO}-\mathrm{TiO}_{2}$ Systems," M.S. Thesis, Massachusetts Institute of Technology, January 1987.

7. Flytzani-Stephanopoulos, M. et al., Final Report to DOE, DOE/MC22193-2582, October 1987.

8. Lew, S., Jothimurugesan, K. and Flytzani-Stephanopoulos, M., Ind. Eng. Chem. Res. $\underline{28}, 535$ (1989).

9. Westmoreland, P. R.; Gibson, J. B.; Harrison, D. P. "Comparative Kinetics of HighTemperature Reaction Between $\mathrm{H}_{2} \mathrm{~S}$ and Selected Metal Oxides". Environ. Sci. Technol. 1977, 11, 488-491.

10. Grindley, T. and Steinfeld, G., "Zinc Ferrite as Hydrogen Sulfide Absorbent," 3rd Ann. Contr. Mtg. on Contaminant Control in Coal-Derived Gas Streams, Rp. No. DOE/METC/84-6, 1983.

11. Anderson, G. L. et al., "Development of Hot Gas Cleanup System for Integrated Coal Gasification/Molten Carbonate Fuel Cell Plants," Final Report, No. DOE/MC/194031816, 1985.

12. Jalan, V. (Giner, Inc.), Final Report, DOE/MC/16021-1486, 1983.

13. Flytzani-Stephanopoulos, M., Tamhankar, S. S., Sharma, P. K. and Gavalas, G. R., "Novel Sorbents for High-Temperature Regenerative $\mathrm{H}_{2} \mathrm{~S}$ Removal," Jet Propulsion Laboratory Final Report No. DOE/MC/20417-1898, October 1985. 
14. Tamhankar, S. S., Bagajewicz, M., Gavalas, G. R., Sharma, P. K. and FlytzaniStephanopoulos, M., Ind. Eng. Chem. Proc. Des. Dev. 25, 429-437 (1986).

15. Flytzani-Stephanopoulos, M. et al., "High-Temperature Regenerative Removal of $\mathrm{H}_{2} \mathrm{~S}$ by Porous Mixed Oxide Sorbents," ACS Div. Fuel Chem. Preprints $\underline{30}$, 16-25 (1985).

16. Focht, G. D., Ranade, P. V., Harrison, D. P., "High-Temperature Desulfurization Using Zinc Ferrite: Reduction and Sulfidation Kinetics," Chemical Engineering

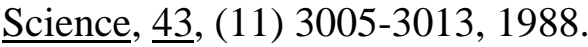

17. Smith, K. J., Haldipur, G. B. and Lucas, J. L., "KRW Process Development Coal Gasification/Hot Gas Cleanup," Proceedings, 7th Ann. Gasification and Gas Stream Cleanup Systems Contr. Rev. Mtg. DOE/METC-87/6079, 2, 668, June 1987.

18. Wu, T. C., Kassman, J. S. and Robin, A. M., "Integration and Testing of Hot Desulfurization and Entrained Flow Gasification for Power Generation Systems," Proceedings of 9th Ann. Gasification and Gas Stream Cleanup Systems Contr. Rev. Mtg., Morgantown, WV, June 1989, DOE/METC-89/6107, 1, 25-36.

19. Grindley, T. and Goldsmith, H., "Development of the Ferrite Desulfurization Sorbents for Large-Scale Testing," AIChE 1987 Annual Meeting, New York, November 15-20, 1987; Session 114D: Control of Hydrogen Sulfide From Hot CoalDerived Gases.

20. Gavalas, G. R., Patrick, U., Jothimurugeson, Kandaswami, Flytzani-Stephanopoulas, Maria, "High-Temperature Sulfidation-Regeneration of $\mathrm{CuO}-\mathrm{Al}_{2} \mathrm{O}_{3}$ Sorbents," Ind. Eng. Chem. Res., 28, 931-940 (1989).

21. Flytzani-Stephanopoulas, Maria, Gavalas, George, R., Tamhankar, Statish, S., Sharma, Pramod, "Novel Sorbents for High-Temperature Regenerable $\mathrm{H}_{2} \mathrm{~S}$ Removal," METC, 1985.

22. Gangwal, S. K., Harkins, W. M., Stronger, J. M., Bossart, S. J., "Testing of Novel Sorbents for $\mathrm{H}_{2} \mathrm{~S}$ Removal From Coal Gas," Environmental Progress, $\underline{8}$, (1) 26 (1989).

23. Gangwal, Santosh, K., Dorchak, Thomas, P., "Direct Sulfur Recovery Process for Elemental Sulfur Recovery from Gas,” Research Triangle Institute.

24. Flytzani-Stephanopoulos, M., Lew, S. and Sarofim, A. F., "Mechanistic and Kinetic Studies of High-Temperature Coal Gas Desulfurization Sorbents," Quarterly Report to DOE/PETC, DOE/PC88927-1, December 1988. 
25. Flytzani-Stephanopoulos, M., Lew, S. and Sarofim, A. F., "Hot Gas Desulfurization by Zinc Oxide-Titanium Dioxide Regenerable Sorbents," ACS - Division of Fuel Chemistry Preprints of Papers. Presented at 199th ACS Nat'l Mtg., Boston, MA, Vol. $\underline{35}$ (1), p. 77, April 1990.

26. Patrick, V., Gavalas, G. R., Flytzani-Stephanopoulos, M. and Jothimurugesan, K., Ind. Eng. Chem. Res. 28, 931-940, 1989.

27. Mojtahedi, W., Salo, K. and Abbasian, J. "Desulfurization of Hot Coal Gas in Fluidized-Bed With Regenerable Zinc Titanate Sorbents," Fuel Processing Technology 1994, 37, 53-65.

28. W. Mojtahedi, K. Salo, J. Abbasian, J. R. Wangerow and F. S. Lau "High Temperature Fuel Gas Desulfurization in Fluidized-Bed With Zinc Titanate," Paper presented at the AIChE Annual Meeting, St. Louis, 1993.

29. Abbasian, J., Hill, A. H., and Wangerow, J. R., "Development of Novel Copper Based Sorbent for Hot Gas Cleanup," Final Technical Report, September 1, 19909August 31, 1992, prepared by Institute of Gas Technology for Center for Research on Sulfur in Coal.

30. Abbasian, J., Rehmat, A., Stephanopoulous, M.F., and Hu, Z., "Development of Novel Copper-Based Sorbent for Hot Gas Cleanup." Paper presented at the 1992 AIChE Spring National Meeting, New Orleans, LA.

31. Abbasian, J., Hill, A. H., and Stephanopoulous, M.F., "Development of Novel Copper-Based Sorbent for Hot Gas Desulfurization." Paper presented at the AIChE 1993 Annual Meeting, St. Louis, Mo.

32. Anderson, G. A., et. al., "Development of a Hot Gas Cleanup System for Integrated Coal Gasification/Molten Carbonate Fuel Cell Power Plant," Final Report Prepared by Institute of Gas Technology for U.S. DOE/METC

33. NOVEM. 1991. "System Study High Temperature Gas Cleaning at IGCC Systems." Netherlands Agency for Energy and the Environment.

34. Craig, K.R. and Koch, R.W. "Hot Gas Cleanup Systems Analysis," Proceedings of the $7^{\text {th }}$ Annual Gasification and Gas Stream Cleanup Systems Contractors' Review Meeting, DOE/METC-87/6079, Vol. 1.

35. Thibeault, P.R. and Gibson, C.R. "Combustion Engineering IGCC Repowering Project," Proceedings of the $12^{\text {th }}$ Annual Gasification and Gas Stream Cleanup Systems Contractors' Review Meeting, DOE/METC-92/6128, Vol. 1.

36. Moorehead, E.L., Henningsen, G.B., Katta, S., and O’Donnell, J.J. "Hot Gas Desulfurization Using Transport Reactors," Proceedings of the Advanced Coal Fired 
Power Systems Review Meeting, Morgantown Energy Technology Center, July 16-18, 1996.

37. Notestein, J.E. "Commercial Gasifier for IGCC Applications Study Report," U.S. DOE/METC, June 1990, p.163.

38. Konttinen, J., Mojtahedi, W., and Abbasian, J. "Coal Gas Desulfurization at the 15 $\mathrm{MW}_{\text {th }}$ Pressurized Gasification Pilot Plant," 3rd International Symposium and Exhibition : Gas Cleaning at High Temperatures, 18-20 September, 1996, University of Karlsruhe, Karlsruhe, Germany, pp. 756-766.

39. Westmoreland, P. R.; Harrison, D. P. "Evaluation of Candidate Solids for HighTemperature Desulfurization for Low-Btu Gases”. Environ. Sci. Technol. 1976, 10, 659-661.

40. Elseviers, W.F. and Verelst, H. "Transition metal oxides for hot gas desulphurization," FUEL 78 (1999) 601-612.

41. Abbasian, J. and Slimane, R.B. "A Regenerable Copper-Based Sorbent for $\mathrm{H}_{2} \mathrm{~S}$ Removal from Coal Gases,” Ind. Eng. Chem. Res., Vol. 37, No.7, 1998.

42. Slimane, R.B. and Abbasian, J. "Copper-Based Sorbents for Coal Gas Desulfurization at Moderate Temperatures," Accepted for Publication in Industrial \& Engineering Chemistry Research, February 2000.

43. Focht, G.D., Ranade, P.V., and Harrison, D.P. "High-Temperature Desulfurization using Zinc Ferrite: Reduction and Sulfidation Kinetics," Chemical Engineering Science 1988, 43 (11), 3005-3013.

44. Kawasaki Heavy Industries, Ltd., "Present Stage and Recent Development of Moving Bed Gas Clean-up System," ANRE/DOE-METC Joint Technical Meeting in Surface Coal Gasification, Tokyo, Japan, October 1993.

45. Sasaoka, E., Ichio, T., and Kasaoka, S. "High-Temperature $\mathrm{H}_{2} \mathrm{~S}$ Removal from CoalDerived Gas by Iron Ore,” Energy \& Fuels, Vol. 6, No. 5, 1992, 603-608.

46. Hasatani, M., Matsuda, H., and Kataoka, A. "Desulfurization of low-calorie gas produced by the gasification of a solid fuel in a packed bed of iron oxide pellets," International Chemical Engineering, Vol. 28, No. 3, July 1988, 497-503.

47. Fuda, K., Palmer, A.D., Sears, P., Blais, D., and Furimsky, E. "Chemical changes occurring during sulfidation and regeneration of iron-containing sorbents," FUEL, 1991, Vol. 70, 100-106.

48. Van der Wal, W.J.J. "Desulfurization of Process Gas by Means of Iron-Oxide-onSilica Sorbents," Ph.D. Thesis, University of Utrecht, The Netherlands, 1987. 
49. De Wild, P.J., Kiel, J.H.A., and Schenk, E. "Iron Oxide/Molybdenum Oxide Sorbents for High Temperature Fuel Gas Desulfurization," Proceedings of the 13th Annual International Pittsburgh Coal Conference, Volume 1, pp.608-613.

50. Patrick, V., Gavalas, G.R., and Sharma, P.K. "Reduction, Sulfidation, and Regeneration of Mixed Iron-Aluminum Oxide Sorbents," Ind. Eng. Chem. Res. 1993, 32, 519-532.

51. Wakker, J. P., Gerritsen, A. W., and Moulijn, J. A. "High Temperature $\mathrm{H}_{2} \mathrm{~S}$ and COS Removal with $\mathrm{MnO}$ and $\mathrm{FeO}$ on $\gamma-\mathrm{Al}_{2} \mathrm{O}_{3}$ Acceptors," Ind. Eng. Chem. Res., 1993, 32, 139-149.

52. Swisher, J.H. "Development of a New Sulfur Sorbent for the 600 to $1000^{\circ} \mathrm{F}$ Temperature Range," Final Technical Report, Sept. 1, 1997 - Aug. 31, 1998, Illinois Clean Coal Institute (ICCI).

53. Gupta, R.P., at al. 1996 "Hot-Gas Desulfurization in Fluidized-bed Reactors Using Zinc Titanate Sorbents," In High-Temperature Gas Cleaning, published by Institut fur Mechanische Verfahrenstechnik und Mechanik der Universitat Karlsruhe (TH), pp. 543-556.

54. Gupta, R.P., Turk, B.S., and Vierheilig, A.A. "Desulfurization Sorbents for Transport-Bed Applications," Proceedings of the Advanced Coal-Based and Environmental Systems '97 Conference, Pittsburgh, PA, July 22-24, 1997.

55. Turkdogan, E.T. Physical Chemistry of High Temperature Technology; Academic Press: New York, 1980, p.5-24.

56. Mu, J.; Perlmutter, D.D.; Thermal Decomposition of Inorganic Sulfates and Their Hydrates, Ind. Eng. Chem. Process Des. Dev. 1981, 20, 640-646.

57. Habashi, F.; Shaheer, A.M.; Vo Van, K. Reduction of sulfates by hydrogen, Can. J. Chem. Vol. 54, 1976, 3646-3650.

58. Roine, E. HSC Chemistry 4.0, Outokumpu Research Oy, June 30, 1999.

59. Hill, A.H. "Tentative Secret Method for Preparing Metal Oxide Sorbents," Private Communication, June 1995.

60. R.B. Slimane "Desulfurization of Hot Coal-Derived Fuel Gases with Manganese-Based Regenerable Sorbents," PhD Dissertation, University of Minnesota, Aug. 1994.

61. R.B. Slimane, R.W. Stuart, and M.T. Hepworth "Preparation and Testing of ValueAdded Sulfur Sorbent Pellets from In Situ Mined Minnesota Manganese Deposits," Energy \& Fuels 1996, 10, 1250-1256. 
62. Swisher, J.H., Yang, J., and Gupta, R.P. “Attrition-Resistant Zinc Titanate Sorbent for Sulfur,” Ind. Eng. Chem. Res. 1995, 34, 4463-4471.

63. Moorehead, E.L., Hennigsen, G.B., Katta, S., and O’Donnell, J.J. "Hot Gas Desulfurization Using Transport Reactors," Proceedings of Advanced Coal-Fired Power Systems '96 Contractors' Review Meeting, Federal Energy Technology Center, Morgantown, WV, July 16-18, 1996.

64. Slimane, R.B. and Abbasian, J. "Regenerable Mixed Metal Oxide Sorbents for Coal Gas Desulfurization at Moderate Temperatures," Submitted to Advances in Environmental Research, December 1999.

65. Fraenkel, D., Levitan, R., and Levy, M. "A Solar Thermochemical Pipe Based on the $\mathrm{CO}_{2}-\mathrm{CH}_{4}$ (1:1) System," Int. J. Hydrogen Energy, Vol. 11, No. 4, pp. 267-277, 1986.

66. Brinker, C.J. and Scherer, G.W. Sol-Gel Science: The Physics and Chemistry of SolGel Processing, Academic Press, Inc, 1990.

67. Mojtahedi, W. and Abbasian, J. " $\mathrm{H}_{2} \mathrm{~S}$ Removal from Coal Gas at Elevated Temperature and Pressure in Fluidized Bed with Zinc Titanate Sorbents. 1. Cyclic Tests," Energy \& Fuels, 1995, Vol. 9, No 3, p. 429-434.

68. Mojtahedi, W. and Abbasian, J. " $\mathrm{H}_{2} \mathrm{~S}$ Removal from Coal Gas at Elevated Temperature and Pressure in Fluidized Bed with Zinc Titanate Sorbents. 2. Sorbent Durability," Energy \& Fuels, 1995, Vol. 9, No 5, p. 782-787.

69. Abbasian, J., Bachta, R., Wangerow, J. and W. Mojtahedi, "An Advanced High Pressure Bench-Scale Reactor for Testing of Hot Corrosive Gases," Ind. Eng. Chem. Res., Vol. 33, No. 1, 1994.

70. "Determination of Attrition and Abrasion of Powdered Catalysts by Air Jets," 1985 Annual Book of ASTM Standards, Petroleum Products and Lubricants (III): D-2981latest; Catalysts, Vol. 05.03

71. Slimane, R.B., Abbasian, J., Zarnegar, M.K., and Wangerow, J.R. "Highly Attrition Resistant Sorbents for Desulfurization of Hot Coal Gases" The Proceedings of the $23^{\text {rd }}$ International Technical Conference on Coal Utilization \& Fuel Systems, March 9-13, 1998, Clearwater, Florida, 795-806.

72. J. Abbasian, R.B. Slimane, J.R. Wangerow, and M.K. Zarnegar "Development of Novel Sorbents for Hot Gas Desulfurization in IGCC," Final Technical Report for IGT Project No. 40391, Sept. 1, 1997 - Aug. 31, 1998, Prepared by IGT for the Illinois Clean Coal Institute, Aug. 1998. 
73. D. Cicero, "Test Protocol: Testing of Fluid-Bed Desulfurization Sorbents in a BenchScale Research Facility", Private Communication, Federal Energy Technology Center, March 1999. 